\title{
STACKED CONJUGATED OLIGOMERS AS MOLECULAR MODELS TO EXAMINE INTERCHAIN INTERACTIONS IN \\ CONJUGATED MATERIALS
}

\author{
A Dissertation \\ Presented to \\ The Academic Faculty \\ by \\ Kurt M. Knoblock \\ In Partial Fulfillment \\ of the Requirements for the Degree \\ Doctor of Philosophy in the \\ School of School of Chemistry and Biochemistry
}

Georgia Institute of Technology

December 2006

COPYRIGHT @ KURT KNOBLOCK 2006 


\section{STACKED CONJUGATED OLIGOMERS AS MOLECULAR MODELS TO EXAMINE INTERCHAIN INTERACTIONS IN CONJUGATED MATERIALS}

Approved by:

Dr. David Collard, Advisor

School of Chemistry and biochemistry

Georgia Institute of Technology

Dr. Uwe Bunz

School of Chemistry and Biochemistry

Georgia Institute of Technology

Dr. Mohan Srinivasarao

Polymer, Textile, and Fiber Engineering

Georgia Institute of Technology
Dr. Marcus Weck

School of Chemistry and

Biochemistry

Georgia Institute of Technology

Dr. Mostafa El-Sayed

School of Chemistry and

Biochemistry

Georgia Institute of Technology

Date Approved: November 2006 
To my wife, Dawson 


\section{ACKNOWLEDGEMENTS}

I would like to thank my advisor, Dr. David M. Collard, for his guidance in my graduate studies and his patience in helping me grow as a scientist. His devotion to science is greatly appreciated and mentoring will be missed. I also would like to thank my committee members Drs. Marcus Weck, Uwe Bunz. Mostafa El-Sayed, and Mohan Srinivasarao for their support at Georgia Tech.

I wish to thank my parents for supporting me throughout my life and encouraging me to pursue my dreams and aspirations, helping me realize that education is paramount.

I would like to thank Dr. Leslie Gelbaum for variable temperature NMR experiments, Dr. Robert Braga for learning how to use the ESR instrument, and David Bostwick for running mass spectrophotometer samples.

Special thanks to Dr. Glen Brizius for his helpful discussions and overall knowledge as a synthetic chemist. I would like to thank all Dr. Collard's lab group members, current and past for their willingness to work together in everyday lab activities. I would like to thank my undergraduate student, Catherine Silvestri, for her efforts in being attentive and willingness to take on new tasks.

I would like to thank my wife, Dawson, for her love and support especially when I felt overwhelmed in my studies. Her friendship has made me appreciate the little things in life so much more. 


\section{TABLE OF CONTENTS}

$\begin{array}{lr} & \text { Page } \\ \text { ACKNOWLEDGEMENTS } & \text { iv } \\ \text { LIST OF TABLES } & \text { ix } \\ \text { LIST OF FIGURES } & \mathrm{x} \\ \text { LIST OF SYMBOLS AND ABBREVIATIONS } & \text { xxi } \\ \text { SUMMARY } & \text { xxiii }\end{array}$

\section{CHAPTER}

1 INTRODUCTION TO CONJUGATED POLYMERS

1.1. $\pi$-Conjugated Materials 25

1.2. Charge Carriers in Conductive Materials 26

1.3. Fates of Radical Cations in Doped $\pi$-Conjugated Oligomers 28

1.4. Two-Dimensional Compounds: $\pi$-Stacking Interactions 32

1.5. Scope of Work 34

$\begin{array}{ll}\text { 1.6. References } & 37\end{array}$

2 SYNTHESIS AND STRUCTURAL CHARACTERIZATION OF DITHIENOFUSED BICYCLO[4.4.1] UNDECANE

2.1. Introduction 46

2.2. Experimental $\quad 50$

$\begin{array}{ll}\text { 2.2.1. General Procedures } & 50\end{array}$

2.2.2. Synthetic Procedures $\quad 51$

$\begin{array}{ll}\text { 2.3. Results and Discussion } & 67\end{array}$

2.3.1. Synthetic Approaches for a Key Intermediate: 3,4- 
2.3.2. Synthesis of Dithieno-Fused Bicyclo[4.4.1]undecanone

2.3.3. Ketalization of Dithieno-Fused Bicyclo[4.4.1]undecanone

2.3.4. Synthesis of Tetramethylated $\pi$-Stacked Analog

2.3.5. Synthesis of Unstacked Linear Model Tetramethythiophene

2.3.6. Structural Characterization: Variable Temperature ${ }^{1} \mathrm{H}$ NMR and ${ }^{13} \mathrm{C}$ NMR Spectroscopy

2.3.7. X-ray Structural Analysis EXTENDED DITHIENO-FUSED BICYCLO[4.4.1] UNDECANES

3.1. Introduction

4 PHOTOPHYSICAL AND ELECTROCHEMICAL CHARACTERIZATION OF $\pi$-STACKED OLIGOTHIOPHENES 
$\begin{array}{ll}\text { 4.3. Results and Discussion } & 136\end{array}$

4.3.1. UV-vis spectroscopy of Neutral Compounds 136

$\begin{array}{ll}\text { 4.3.2. Electrochemistry } & 148\end{array}$

4.3.3. Chemical Oxidation of Neutral Oligothiophenes to Radical Cations

4.3.4. Formation of Dications and $\pi$-Dimers

4.3.5. ESR Spectroscopy: Formation of $\pi$-Dimers 164

4.3.6. Electronic Structure 166

$\begin{array}{lr}\text { 4.4. Conclusion } & 172\end{array}$

4.5. References

5 PHENYL-CAPPED OLIGOTHIOPHENES SYNTHESIS, CHARACTERIZATION, AND PHOTOPHYSICAL/ ELECTROCHEMICAL PROPERTIES

5.1. Introduction

5.2. Experimental

5.3.2. Structural Characterization: ${ }^{1} \mathrm{H}$ and ${ }^{13} \mathrm{C}$ NMR Spectroscopy

5.3.3. Structural Characterization: Molecular Modeling 
6 FERROCENE-CAPPED OLIGOTHIOPHENE: SYNTHESIS AND PHYSICAL PROPERTIES

6.1. Introduction

6.3. Results and Discussion

7 FUTURE WORK 


\section{LIST OF TABLES}

Page

Table 3.1. NMR Chemical Shifts $(\delta)$ for Aromatic and Methyl Protons of Stacked and Unstacked Compounds in $\mathrm{CDCl}_{3}$

Table 4.1. Electronic Spectral Data of Models and Stacked Oligothiophenes

Table 4.2. Oxidation Potentials of Unstacked and Stacked Oligothiophenes

Table 4.3. UV- Vis-NIR Data for Charged Species

Table 4.4. Cyclic Voltammetry and UV-vis Absorption Data

Table 5.1. ${ }^{1} \mathrm{H}$ NMR Chemical Shifts $(\delta)$ for Aromatic Protons of Phenyl-capped Model and $\pi$-Stacked Compounds.

Table 5.2. Electronic Spectral Data ${ }^{a}$ of Models and Stacked Oligothiophenes

Table 5.3. Oxidation Potentials of Unstacked and Stacked Oligothiophenes

Table 5.4. Cyclic Voltammetry and UV-vis Absorption Data 


\section{LIST OF FIGURES}

Page

Figure 1.1. Examples of some $\pi$-conjugated oligomeric polymers.

Figure 1.2. Schematic diagram for Peierl's distortion.

Figure 1.3. Doping of a $\pi$-conjugated polyene.

Figure 1.4. Schematic representation of the fates of radical cations.

Figure 1.5. $\pi$-Dimer formation by aggregation of radical cations.

Figure 1.6. X-ray structural analysis of radical cation salt (from reference 33).

Figure 1.7. Unstacked linear analog (left) and $\pi$-stacked analog (right).

Figure 1.8. REdox states arising from oxidation of $\pi$-stacked oligomers.

Figure 1.9. Synthesis of dithieno-fused $\pi$-stacked orthocyclophane with ethylene glycol

Figure 2.1. Conformational benzo-annelated bicylo[4.4.1] undecanes (from reference 8).

Figure 2.2. Possible dynamic conformations (from reference 8).

Figure 2.3. Orthocyclophanes with benzene and naphthalene (from reference 9). $\mathrm{B}$ and $\mathrm{N}$ indicate benzo and 2,3-naphtho annelation.

Figure 2.4. Triple-Deckered Orthocyclophane (from reference 3).

Figure 2.5. Quadruple Decker Orthocyclophane (from reference 6). 
Figure 2.6. Synthetic approach to make thiophene-3,4-dialdehyde.

Figure 2.7. Attempt to prepare 3,4-bis(hydroxymethyl)thiophene by reductive dechlorination of 3,4-bis(hydroxymethyl)-2,5-dichlorothiophene.

Figure 2.8. Attempted $\mathrm{Zn} / \mathrm{AcOH}$ dechlorination of 3,4-bis(hydroxymethyl)-2,5dichlorothiophene to synthesize 3,4-bis(hydroxymethyl)thiophene.

Figure 2.9. Successful, albeit low yielding, synthesis of 3,4-bis(bromomethyl)thiophene.

Figure 2.10. Approach to prepare 3,4-dimethylthiophene on a larger scale by McMurry reaction.

Figure 2.11. Efficient route to synthesize 3,4-dimethylthiophene from 3,4dibromothiophene.

Figure 2.12. Successful radical bromination of 3,4-dimethylthiophene to 3,4bis(bromomethyl)-thiophene.

Figure 2.13. Synthesis of bisthieno-fused bicyclo[4.4.1] undecanone.

Figure 2.14. Ketalization of the dithieno-fused ketone, 2.3.

Figure 2.15. Synthesis of methylated $\pi$-stacked analog, 2.8 .

Figure 2.16. Attempt to alkylate with 3,4-bis(bromomethyl)2,5-dichlorothiophene. 77

Figure 2.17. Attempt to alkylate with 3,4-bis(bromomethyl)2,5-dibromothiophene. 77

Figure 2.18. Synthesis of 2,3,4,5-tetramethylthiophene.

Figure 2.19. ${ }^{1} \mathrm{H} \mathrm{NMR}\left(300 \mathrm{MHz}, \mathrm{CDCl}_{3}\right)$ of diester 2.1 at room temperature.

Figure 2.20. ${ }^{1} \mathrm{H} \mathrm{NMR}\left(400 \mathrm{MHz}, \mathrm{CDCl}_{3}\right)$ of diester 2.1 at $-60{ }^{\circ} \mathrm{C}$. 
Figure 2.21. ${ }^{1} \mathrm{H} \mathrm{NMR}\left(400 \mathrm{MHz}, \mathrm{CDCl}_{3}\right)$ of 2.5 at $\mathrm{RT}$ (top) and $-40{ }^{\circ} \mathrm{C}$ (bottom).

Figure 2.22. ${ }^{1} \mathrm{H} \mathrm{NMR}\left(300 \mathrm{MHz}, \mathrm{CDCl}_{3}\right)$ of ketone 2.3 at room temperature.

Figure 2.23. ${ }^{1} \mathrm{H}$ NMR $\left(400 \mathrm{MHz}, \mathrm{CDCl}_{3}\right)$ of 2.3 at $-60{ }^{\circ} \mathrm{C}$.

Figure 2.24. ${ }^{1} \mathrm{H} \mathrm{NMR}\left(300 \mathrm{MHz}, \mathrm{CDCl}_{3}\right)$ of ketone 2.7 at room temperature.

Figure 2.25. ${ }^{1} \mathrm{H}$ NMR $\left(300 \mathrm{MHz}, \mathrm{CDCl}_{3}\right)$ of ketal 2.4 at room temperature.

Figure 2.26. ${ }^{1} \mathrm{H} \mathrm{NMR}\left(300 \mathrm{MHz}, \mathrm{CDCl}_{3}\right)$ of ketal 2.8 at room temperature.

Figure 2.27. ${ }^{13} \mathrm{C} \mathrm{NMR}\left(75 \mathrm{MHz}, \mathrm{CDCl}_{3}\right)$ of diester 2.3 at room temperature.

Figure 2.28. ${ }^{13} \mathrm{C} \mathrm{NMR}\left(75 \mathrm{MHz}, \mathrm{CDCl}_{3}\right)$ of ketone 2.3 at room temperature.

Figure 2.29. ${ }^{13} \mathrm{C} \mathrm{NMR}\left(75 \mathrm{MHz}, \mathrm{CDCl}_{3}\right)$ of ketal 2.4 at room temperature.

Figure 2.30. ${ }^{13} \mathrm{C} \mathrm{NMR}\left(75 \mathrm{MHz}, \mathrm{CDCl}_{3}\right)$ of ketone 2.7 (top) and ketal (bottom) at RT.

Figure 2.31. Heteronuclear Multiple Bond Correlation (HMBC) for diacid 2.2.

Figure 2.32. ${ }^{1} \mathrm{H}-{ }^{1} \mathrm{H}$ NMR correlation (COSY) of $\pi$-stacked compound 2.4 .

Figure 2.33. ${ }^{1} \mathrm{H}-{ }^{13} \mathrm{C}$ NMR correlation (HETCOR) of $\pi$-stacked compound 2.4 .

Figure 2.34. X-ray structural analysis of $\mathbf{2 . 4}$ (sideview).

Figure 2.35. X-ray structural analysis of $\mathbf{2 . 4}$ (sideview).

Figure 2.36. Packing diagram of $\pi$-stacked compound 2.4.

Figure 2.37. HOMO (left) and LUMO (right) of $\mathbf{2 . 4}$. 
Figure 3.1. Synthesis of 3.1 and attempts to synthesize 3.2 via Suzuki coupling.

Figure 3.2. Synthesis of ketone 3.3 and $\pi$-stacked ketal 3.4.

Figure 3.3. Synthesis of ketone 3.5 and $\pi$-stacked ketal 3.6.

Figure 3.4. Synthesis of linear model terthiophene 3.6.

Figure 3.5. Synthesis of linear, methyl-capped model terthiophene 3.7.

Figure 3.6. Synthesis of intermediate 2-methyl-5:2'-bithiophene, 3.8.

Figure 3.7. Synthesis of quinquethiophene ketone 3.9 and ketal 3.10.

Figure 3.8. Synthesis of linear model quinquethiophene 3.11.

Figure 3.9. Aromatic region of ${ }^{1} \mathrm{H} \mathrm{NMR}$ spectrum $\left(300 \mathrm{MHz}, \mathrm{CDCl}_{3}\right)$ of model terthiophene 3.6.

Figure 3.10. Aromatic region of ${ }^{1} \mathrm{H}$ NMR spectrum $\left(300 \mathrm{MHz}, \mathrm{CDCl}_{3}\right)$ of $\pi$-stacked terthiophene 3.3.

Figure 3.11. ${ }^{1} \mathrm{H} \mathrm{NMR}\left(300 \mathrm{MHz}, \mathrm{CDCl}_{3}\right)$ of ketone 3.2.

Figure 3.12. ${ }^{1} \mathrm{H} \mathrm{NMR}\left(300 \mathrm{MHz}, \mathrm{CDCl}_{3}\right)$ of methyl-capped model terthiophene, 3.7 (top), ketone 3.4 (middle), ketal 3.5 (bottom).

Figure 3.13. ${ }^{1} \mathrm{H} \mathrm{NMR}\left(300 \mathrm{MHz}, \mathrm{CDCl}_{3}\right.$ ) of model quinquethiophene $\mathbf{3 . 1 1}$ (top), ketone 3.9 (middle), and ketal 3.10 (bottom).

Figure 3.14. ORTEP diagrams of 3.4 illustrating chair-boat conformatio.

Figure 3.15. ORTEP diagrams of $\pi$-stacked terthiophene 3.3.

Figure 3.16. Packing diagram of 3.3. Hydrogen atoms excluded. 
Figure 3.18. Crystal packing diagram of 3.5 .

Figure 4.1. Absorbance fluorescence spectrum of $s t-\left[\mathbf{H}-\mathbf{T h} \mathbf{h}_{\mathbf{1}}-\mathbf{H}\right]_{\mathbf{2}}$ (top). Absorbance and fluorescence spectrum of $\boldsymbol{s t}$-[Me-Th $\mathbf{1}-\mathbf{M e}]_{2}$ (bottom). Models not shown.

Figure 4.2. Absorbance and fluorescence spectrum of $\mathbf{H}-\mathbf{T h} \mathbf{h}_{\mathbf{3}}-\mathbf{H}$.

Figure 4.3. Fluorescence spectrum of $\mathbf{H}-\mathbf{T h}_{\mathbf{3}}-\mathbf{H}$ at variable excitations.

Figure 4.4. Absorbance and fluorescence spectrum of $s t-\left[\mathbf{H}-\mathbf{T h}_{3}-\mathbf{H}\right]_{2}$.

Figure 4.5. Fluorescence spectrum of $s t-\left[\mathbf{H}-\mathbf{T h}_{3}-\mathbf{H}\right]_{2}$ at variable excitations.

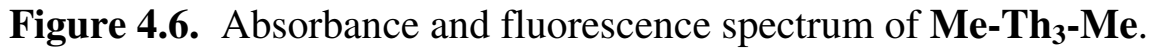

Figure 4.7. Absorbance and fluorescence spectrum of $s t-\left[\mathbf{M e}-\mathbf{T h}_{3}-\mathbf{M e}\right]_{2}$.

Figure 4.8. Fluorescence spectrum of $\mathbf{M e}-\mathbf{T h} \mathbf{h}_{3}-\mathbf{M e}$ at variable excitations.

Figure 4.9. Fluorescence spectrum of $s t-\left[\mathbf{M e}-\mathbf{T h}_{3}-\mathbf{M e}\right]_{2}$ at variable excitations.

Figure 4.10. Absorbance and fluorescence spectrum of Me-Th5-Me.

Figure 4.11. Absorbance and fluorescence spectrum of $s t-\left[\mathrm{Me}-\mathbf{T h}_{5}-\mathbf{M e}\right]_{2}$.

Figure 4.12. Fluorescence spectrum of $\mathbf{M e}-\mathbf{T h}_{5}-\mathbf{M e}$ at variable excitations.

Figure 4.13. Fluorescence spectrum of $s t-\left[\mathbf{M e}-\mathbf{T h}_{5}-\mathbf{M e}\right]_{2}$ at variable excitations.

Figure 4.14. Stokes shifts of model and stacked oligothiophenes versus the number of aromatic rings. 
Figure 4.15. $\mathrm{CV}$ of Me-Th -Me. $c=2 \mathrm{mM}$ in $\mathrm{CH}_{2} \mathrm{Cl}_{2} ; 0.1 \mathrm{M} n-\mathrm{BuNPF}_{6} / \mathrm{CH}_{2} \mathrm{Cl}_{2}$;

$\mathrm{Au}$ working electrode; $\mathrm{Pt}$ auxillary, $\mathrm{Ag} / \mathrm{Ag}^{+}$reference electrode;

$v=100 \mathrm{mV} / \mathrm{s}$.

Figure 4.16. $\mathrm{CV}$ of $s t$-[Me-Th $-\mathrm{Me}]_{2} . c=2 \mathrm{mM}$ in $\mathrm{CH}_{2} \mathrm{Cl}_{2} ; 0.1 \mathrm{M} n-\mathrm{BuNPF}_{6} / \mathrm{CH}_{2} \mathrm{Cl}_{2}$;

$\mathrm{Au}$ working electrode; $\mathrm{Pt}$ auxillary, $\mathrm{Ag} / \mathrm{Ag}^{+}$reference electrode;

$v=100 \mathrm{mV} / \mathrm{s}$.

Figure 4.17. DPV of Me-Th $-\mathrm{Me}$ and $s t$-[Me-Th $-\mathrm{Me}]_{2} . \quad c=2 \mathrm{mM}$ in $\mathrm{CH}_{2} \mathrm{Cl}_{2} ; 0.1 \mathrm{M}$ $n$-BuNPF $6 / \mathrm{CH}_{2} \mathrm{Cl}_{2}$; Au working electrode; Pt auxillary, $\mathrm{Ag} / \mathrm{Ag}^{+}$reference electrode; $v=100 \mathrm{mV} / \mathrm{s}$.

Figure 4.18. $\mathrm{CV}$ of Me-Th-Me. $c=2 \mathrm{mM}$ in $\mathrm{CH}_{2} \mathrm{Cl}_{2} ; 0.1 \mathrm{M} n-\mathrm{BuNPF}_{6} / \mathrm{CH}_{2} \mathrm{Cl}_{2}$; $\mathrm{Au}$ working electrode; $\mathrm{Pt}$ auxillary, $\mathrm{Ag} / \mathrm{Ag}^{+}$reference electrode; $v=100 \mathrm{mV} / \mathrm{s}$.

Figure 4.19. $\mathrm{CV}$ of $\mathbf{s t}-\left[\mathrm{Me}-\mathrm{Th}_{3}-\mathrm{Me}\right]_{2} . \quad c=2 \mathrm{mM}$ in $\mathrm{CH}_{2} \mathrm{Cl}_{2} ; 0.1 \mathrm{M} n-\mathrm{BuNPF}_{6} / \mathrm{CH}_{2} \mathrm{Cl}_{2}$; $\mathrm{Au}$ working electrode; $\mathrm{Pt}$ auxillary, $\mathrm{Ag} / \mathrm{Ag}^{+}$reference electrode; $v=100 \mathrm{mV} / \mathrm{s}$.

Figure 4.20. DPV of Me-Th $\mathbf{H}_{\mathbf{3}}$-Me (dotted line) and st-[Me-Th $\left.\mathbf{H}_{\mathbf{3}}-\mathbf{M e}\right]_{2}$ (solid line). $c=2$ $\mathrm{mM}$ in $\mathrm{CH}_{2} \mathrm{Cl}_{2} ; 0.1 \mathrm{M} n$ - $\mathrm{BuNPF}_{6} / \mathrm{CH}_{2} \mathrm{Cl}_{2} ; \mathrm{Au}$ working electrode; $\mathrm{Pt}$ auxillary, $\mathrm{Ag} / \mathrm{Ag}^{+}$reference electrode; $v=100 \mathrm{mV} / \mathrm{s}$.

Figure 4.21. $\mathrm{CV}$ of Me-Th-Me. $c=2 \mathrm{mM}$ in $\mathrm{CH}_{2} \mathrm{Cl}_{2} ; 0.1 \mathrm{M} n$ - $\mathrm{BuNPF} / \mathrm{CH}_{2} \mathrm{Cl}_{2}$; $\mathrm{Au}$ working electrode; $\mathrm{Pt}$ auxillary, $\mathrm{Ag} / \mathrm{Ag}^{+}$reference electrode; $v=100 \mathrm{mV} / \mathrm{s}$.

Figure 4.22. $\mathrm{CV}$ of $s t$-[Me-Th5-Me $]_{2} . \quad c=2 \mathrm{mM}$ in $\mathrm{CH}_{2} \mathrm{Cl}_{2} ; 0.1 \mathrm{M} n-\mathrm{BuNPF}_{6} / \mathrm{CH}_{2} \mathrm{Cl}_{2}$; $\mathrm{Au}$ working electrode; $\mathrm{Pt}$ auxillary, $\mathrm{Ag} / \mathrm{Ag}^{+}$reference electrode; $v=100 \mathrm{mV} / \mathrm{s}$.

Figure 4.23. DPV of Me-Th $-\mathbf{M e}$ (dotted line) and $s t-\left[\mathbf{M e}-\mathbf{T h}_{\mathbf{5}}-\mathbf{M e}_{\mathbf{2}}\right.$ (solid line). $c=2$ $\mathrm{mM}$ in $\mathrm{CH}_{2} \mathrm{Cl}_{2} ; 0.1 \mathrm{M} n$-BuNPF$/ \mathrm{CH}_{2} \mathrm{Cl}_{2} ; \mathrm{Au}$ working electrode; $\mathrm{Pt}$ auxillary, $\mathrm{Ag} / \mathrm{Ag}^{+}$reference electrode; $v=100 \mathrm{mV} / \mathrm{s}$.

Figure 4.24. Oxidation potentials of oligothiophenes.

Figure 4.25. UV-vis-NIR spectrum of $\mathbf{M e -} \mathbf{T h}_{\mathbf{3}}-\mathbf{M e}$ doped with $\mathrm{FeCl}_{3}$ (0-2 eq.). 


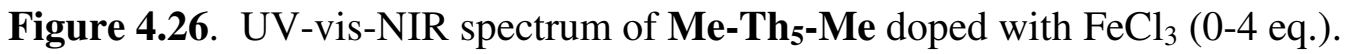

Figure 4.27. UV-vis-NIR spectrum radical cations of $\mathbf{M e -} \mathbf{T h}_{\mathbf{3}}-\mathbf{M e}$ (dashed) and Me-Th5-Me (solid).

Figure 4.28. UV-vis-NIR spectrum of mono(radical cation) species of $s t$-[Me-Th $-\mathbf{M e}_{2}$ (dashed line), st-[Me-Th/ $\left.-\mathbf{M e}\right]_{2}$ (solid line).

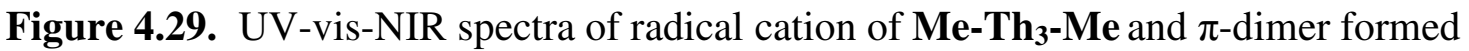
upon cooling radical cation to $-30{ }^{\circ} \mathrm{C}$ (top). UV-vis-NIR spectra of radical cation of Me-Th $\mathbf{5}$-Me and $\pi$-dimer of formed upon cooling radical cation to $-30{ }^{\circ} \mathrm{C}$ (bottom).

Figure 4.30. Absorbance spectra of dication ( $\pi$-dimer) species of $s t-\left[\mathbf{M e}-\mathbf{T h}_{\mathbf{3}}-\mathbf{M e}\right]_{2}$ (dashed line), st-[Me-Th5-Me $]_{2}$ (solid line).

Figure 4.31. Absorbance spectra of neutral, radical dication, and $\pi$-dimer species of Me-Th5-Me (top). Absorbance spectra of neutral, radical dication, and $\pi$ dimer species of $s t$-[Me-Th $\mathbf{5}-\mathbf{M e}]_{2}$ (bottom).

Figure 4.32. ESR spectra of $\mathbf{M e}-\mathbf{T h}_{\mathbf{5}}$-Me radical cation formed upon addition of 2 equivalents of $\mathrm{FeCl}_{3}$ then cooling down gradually to form the $\pi$-dimer in acetonitrile.

Figure 4.33. ESR spectra of $s t-\left[\mathrm{Me}-\mathbf{T h}_{\mathbf{5}}-\mathrm{Me}_{2}\right.$ radical cation formed upon addition of 2 equivalents of $\mathrm{FeCl}_{3}$ and continued titration up to 4 equivalents total) to form the dicationic $\pi$-dimer.

Figure 4.34. Schematic diagram of various redox states of a single chain (A) and two $\pi$-stacked oligomers (B).

Figure 4.35. HOMO-LUMO energy levels determined by cyclic voltammetry and UV absorption.

Figure 5.1. Synthesis of 2-phenyl-5-tri- $n$-butylstannylthiophene, 5.2.

Figure 5.2. Synthesis of model 2,5-diphenyl-3,4-dimethylthiophene, 5.3.

Figure 5.3. Synthesis of model 2,5"-diphenyl-3',4'-dimethyl-5,2':5',2"-terthiophene, 5.4 . 
Figure 5.4. Synthesis of phenyl-capped, $\pi$-stacked oligothiophenes, 5.6, and 5.8.

Figure 5.5. ${ }^{1} \mathrm{H} \mathrm{NMR}\left(300 \mathrm{MHz}, \mathrm{CDCl}_{3}\right)$ of model $\mathbf{5 . 3}$ at room temperature.

Figure 5.6. ${ }^{13} \mathrm{C} \mathrm{NMR}\left(300 \mathrm{MHz}, \mathrm{CDCl}_{3}\right)$ of model $\mathbf{5 . 3}$ at room temperature.

Figure 5.7. Variable temperature ${ }^{1} \mathrm{H}$ NMR ( $300 \mathrm{MHz}$, Pyridine-d6) of 5.6. Room temperature (black), $40{ }^{\circ} \mathrm{C}$ (red), $60{ }^{\circ} \mathrm{C}$ (blue), $80{ }^{\circ} \mathrm{C}$ (green), and $100{ }^{\circ} \mathrm{C}$ (purple).

Figure 5.8. ${ }^{13} \mathrm{C} \mathrm{NMR}\left(300 \mathrm{MHz}, \mathrm{CDCl}_{3}\right)$ of $\mathbf{5 . 6}$ at room temperature.

Figure 5.9. ${ }^{1} \mathrm{H} \mathrm{NMR}\left(300 \mathrm{MHz}, \mathrm{CDCl}_{3}\right)$ of $\mathbf{5 . 4}$ at room temperature.

Figure 5.10. ${ }^{13} \mathrm{C} \mathrm{NMR}\left(300 \mathrm{MHz}, \mathrm{CDCl}_{3}\right)$ of $\mathbf{5 . 4}$ at room temperature.

Figure 5.11. ${ }^{1} \mathrm{H}$ NMR $\left(300 \mathrm{MHz}, \mathrm{CDCl}_{3}\right)$ of $\mathbf{5 . 8}$ (top). ${ }^{13} \mathrm{C} \mathrm{NMR}\left(300 \mathrm{MHz}, \mathrm{CDCl}_{3}\right)$ of 5.8 (bottom).

Figure 5.12. Optimized geometry for $\mathbf{5 . 1}$ performed at the B3LYP-6-31G* level.

Figure 5.13. HOMO (left) and LUMO (right) levels of 5.6.

Figure 5.14. Absorbance/Emission Spectra of model 5.3 (black); extended model 5.4 (green); $\boldsymbol{\pi}$-stacked compound $\mathbf{5 . 6}$ (red); extended $\pi$-stacked compound 5.8 (blue).

Figure 5.15. Emission spectra of 5.4 (left) and $\mathbf{5 . 8}$ (right).

Figure 5.16. Stokes shifts of model and stacked oligothiophenes versus \# aromatic rings.

Figure 5.17. $\mathrm{CV}$ of model, 5.3, (red line) and $\pi$-stacked compound, 5.6, (black line). $c=2 \mathrm{mM}$ in $\mathrm{CH}_{2} \mathrm{Cl}_{2} ; 0.1 \mathrm{M} n-\mathrm{Bu}_{4} \mathrm{NPF}_{6} / \mathrm{CH}_{2} \mathrm{Cl}_{2} ; \mathrm{Au}$ working electrode auxillary, $\mathrm{Ag} / \mathrm{Ag}^{+}$reference electrode; $v=100 \mathrm{mV} / \mathrm{s}$. 
Figure 5.18. DPV of model compound, 5.3, (red dotted line) and $\pi$-stacked compound 5.6 (solid line). $c=2 \mathrm{mM}$ in $\mathrm{CH}_{2} \mathrm{Cl}_{2} ; 0.1 \mathrm{M} n-\mathrm{BuN}_{4} \mathrm{PF}_{6} / \mathrm{CH}_{2} \mathrm{Cl}_{2} ; \mathrm{Au}$ working electrode; $\mathrm{Pt}$ auxillary, $\mathrm{Ag} / \mathrm{Ag}^{+}$reference electrode; $v=100 \mathrm{mV} / \mathrm{s}$.

Figure 5.19. $\mathrm{CV}$ of model, 5.4, (red line) and $\pi$-stacked compound, 5.8, (black line). $c=2 \mathrm{mM}$ in $\mathrm{CH}_{2} \mathrm{Cl}_{2} ; 0.1 \mathrm{M} n-\mathrm{BuN}_{4} \mathrm{PF}_{6} / \mathrm{CH}_{2} \mathrm{Cl}_{2} ; \mathrm{Au}$ working electrode; Pt auxillary, $\mathrm{Ag} / \mathrm{Ag}^{+}$reference electrode; $v=100 \mathrm{mV} / \mathrm{s}$.

Figure 5.20. DPV of model, 5.4, (red dotted line) and $\pi$-stacked compound, 5.8, (black line). $c=2 \mathrm{mM}$ in $\mathrm{CH}_{2} \mathrm{Cl}_{2} ; 0.1 \mathrm{M} n-\mathrm{BuN}_{4} \mathrm{PF}_{6} / \mathrm{CH}_{2} \mathrm{Cl}_{2}$; $\mathrm{Au}$ working electrode; Pt auxillary, $\mathrm{Ag} / \mathrm{Ag}^{+}$reference electrode; $v=100 \mathrm{mV} / \mathrm{s} . \quad 204$

Figure 5.21. DPV of model, 5.4, (blue dotted line) and $\pi$-stacked compound, 5.8, (black line). $c=2 \mathrm{mM}$ in $\mathrm{CH}_{2} \mathrm{Cl}_{2} ; 0.1 \mathrm{M}\left[n-\mathrm{Bu}_{4} \mathrm{~N}\right]\left[\mathrm{B}\left(\mathrm{C}_{6} \mathrm{~F}_{5}\right)_{4}\right] / \mathrm{CH}_{2} \mathrm{Cl}_{2} ; \mathrm{Au}$ working electrode; $\mathrm{Pt}$ auxillary, $\mathrm{Ag} / \mathrm{Ag}^{+}$reference electrode; $v=100 \mathrm{mV} / \mathrm{s}$.

Figure 5.22. Absorbance spectrum of 5.4. Neutral (black line), addition of 2eq. $\mathrm{FeCl}_{3}$ (red line), cooling solution to $-30{ }^{\circ} \mathrm{C}$ (blue line) in acetonitrile.

Figure 5.23. Absorbance spectrum of 5.4. Neutral (black line), addition of 2eq. $\mathrm{FeCl}_{3}$ (red line), addition of 4 eq. $\mathrm{FeCl}_{3}$ (blue line) in dichloromethane at room temperature.

Figure 5.24. ESR spectra of $\mathbf{5 . 4}$ (bottom) and $\mathbf{5 . 8}$ (top).

Figure 5.25. HOMO-LUMO energy levels deduced from cyclic voltammetry and UV absorption.

Figure 6.1. Synthesis of model 2,5-diferrocennyl-3,4-dimethylthiophene, 6.1..

Figure 6.2. Synthesis of tetra-ferrocennyl-capped $\pi$-stacked compound 6.2.

Figure 6.3. ${ }^{1} \mathrm{H} \mathrm{NMR}\left(300 \mathrm{MHz}, \mathrm{CDCl}_{3}\right)$ of model 6.1 at room temperature.

Figure 6.4. ${ }^{13} \mathrm{C}$ NMR $\left(300 \mathrm{MHz}, \mathrm{CDCl}_{3}\right)$ of model 6.1 at room termperature. 
Figure 6.5. ${ }^{1} \mathrm{H} \mathrm{NMR}\left(300 \mathrm{MHz}, \mathrm{CDCl}_{3}\right)$ of $\pi$-stacked compound 6.2 at room temperature.

Figure 6.6. ${ }^{13} \mathrm{C} \mathrm{NMR}\left(300 \mathrm{MHz}, \mathrm{CDCl}_{3}\right)$ of 6.2 .

Figure 6.7. UV-vis spectrum of model compound 6.1.

Figure 6.8. UV-vis spectrum of $\pi$-stacked compound 6.2.

Figure 6.9. $\mathrm{CV}$ of model compound 6.1 (solid line) and ferrocene (dashed line). $c=1$ $\mathrm{mM}$ in $\mathrm{CH}_{2} \mathrm{Cl}_{2} ; 0.1 \mathrm{M} n$-BuNPF$/ \mathrm{CH}_{2} \mathrm{Cl}_{2} ; \mathrm{Au}$ working electrode; $\mathrm{Pt}$ auxillary, $\mathrm{Ag} / \mathrm{Ag}^{+}$reference electrode; $v=100 \mathrm{mV} / \mathrm{s}$.

Figure 6.10. $\mathrm{DPV}$ of model compound 6.1. $c=1 \mathrm{mM}$ in $\mathrm{CH}_{2} \mathrm{Cl}_{2} ; 0.1 \mathrm{M} n-\mathrm{BuNPF}_{6} /$ $\mathrm{CH}_{2} \mathrm{Cl}_{2}$; $\mathrm{Au}$ working electrode; $\mathrm{Pt}$ auxiliary, $\mathrm{Ag} / \mathrm{Ag}^{+}$reference electrode; $v=100 \mathrm{mV} / \mathrm{s}$.

Figure 6.11. $\mathrm{CV}$ of model compound, 6.1. $c=1 \mathrm{mM}$ in $\mathrm{CH}_{2} \mathrm{Cl}_{2}$; bulky electrolyte: $0.1 \mathrm{M}[n-\mathrm{BuN}]\left[\mathrm{B}\left(\mathrm{C}_{6} \mathrm{~F}_{5}\right)_{4}\right] / \mathrm{CH}_{2} \mathrm{Cl}_{2} ;$ Au working electrode; Pt auxiliary, $\mathrm{Ag} / \mathrm{Ag}^{+}$reference electrode; $v=25-350 \mathrm{mV} / \mathrm{s}$.

Figure 6.12. $\mathrm{CV}$ of model compound, 6.1. $c=1 \mathrm{mM}$ in $\mathrm{CH}_{2} \mathrm{Cl}_{2}$; bulky electrolyte: $0.1 \mathrm{M}[n-\mathrm{BuN}]\left[\mathrm{B}\left(\mathrm{C}_{6} \mathrm{~F}_{5}\right)_{4}\right] / \mathrm{CH}_{2} \mathrm{Cl}_{2} ; \mathrm{Au}$ working electrode; $\mathrm{Pt}$ auxiliary, $\mathrm{Ag} / \mathrm{Ag}^{+}$reference electrode; $v=100 \mathrm{mV} / \mathrm{s}$.

Figure 6.13. $\mathrm{CV}$ of $\pi$-stacked compound, 6.2. $c=1 \mathrm{mM}$ in $\mathrm{CH}_{2} \mathrm{Cl}_{2}$; bulky electrolyte: $0.1 \mathrm{M}[n-\mathrm{BuN}]\left[\mathrm{B}\left(\mathrm{C}_{6} \mathrm{~F}_{5}\right)_{4}\right] / \mathrm{CH}_{2} \mathrm{Cl}_{2} ; \mathrm{Au}$ working electrode; $\mathrm{Pt}$ auxiliary, $\mathrm{Ag} / \mathrm{Ag}^{+}$reference electrode; $v=100 \mathrm{mV} / \mathrm{s}$.

Figure 6.14. DPV of $\pi$-stacked compound, 6.2. $c=1 \mathrm{mM}$ in $\mathrm{CH}_{2} \mathrm{Cl}_{2}$; bulky electrolyte: $0.1 \mathrm{M}[n-\mathrm{BuN}]\left[\mathrm{B}\left(\mathrm{C}_{6} \mathrm{~F}_{5}\right)_{4}\right] / \mathrm{CH}_{2} \mathrm{Cl}_{2} ;$ Au working electrode; $\mathrm{Pt}$ auxiliary, $\mathrm{Ag} / \mathrm{Ag}^{+}$reference electrode; $v=100 \mathrm{mV} / \mathrm{s}$.

Figure 7.1. Synthesis of terthiophene $\pi$-stacked compounds 7.1 and 7.2.

Figure 7.2. Synthesis of model terthiophene 7.3.

Figure 7.3. Synthesis of model methyl-capped terthiophene 7.4.

Figure 7.4. Synthesis of alkyne spacer in terthiophene $\pi$-stacked compound 7.5. 238 
Figure 7.5. Synthesis of alkyne substituted model compound 7.6.

Figure 7.6. Ethylenedioxy-substituted terthiophene 7.7 and quinquethiophene 7.8. 240

Figure 7.7. Thiazole-substituted $\pi$-stacked compounds 7.9 and 7.10. 


\section{LIST OF SYMBOLS AND ABBREVIATIONS}

$\delta$

$\lambda$

$\varepsilon$

$J$

$\mathrm{Hz}$

ppm

d

dd

$\mathrm{t}$

b s

MP

BP

dppp

RT

CV

DPV

IR

NMR

ESR

OLED

OFET
Chemical shift

Wavelength

Molar absorptivity

Coupling constant

Hertz

Parts per million

Doublet

Doublet of doublets

Triplet

Singlet

Broad singlet

Melting point

Boiling point

diphenylphosphinopropane

Room temperature

Cyclic Voltammetry

Differential Pulse Voltammetry

Infrared

Nuclear Magnetic resonance

Electron Spin Resonace

Organic light emitting diode

Organic field effect transistor 


\begin{tabular}{ll} 
NIR & Near infrared \\
DMF & Dimethyl foramide \\
THF & Tetrahydrofuran \\
NBS & N-bromosuccinimide \\
BPO & Benzoyl peroxide \\
TMEDA & N,N,N,N-Tetramethyl ethylene diamine \\
HOMO & Highest Occupied Molecular Orbital \\
LUMO & Lowest Occupied Molecular Orbital \\
SOMO & Singly Occupied Molecular Orbital \\
CT & Charge transfer \\
HRMS & High resolution mass spectrometry \\
p-TSA & Para-toluene sulfonic acid \\
Bz & Benzene \\
EI & Electron Ionization \\
Th & Thiophene \\
EA & Elemental Anaylsis \\
RC & Radical cation \\
DC & Dication \\
D1 & Dimer \\
BME & Oxidation potential \\
B & Dimethoxyethane \\
\hline
\end{tabular}




\section{SUMMARY}

Conjugated oligomers and polymers have attracted attention for their potential use in organic field effect transistors and light emitting diodes by virtue of their semiconducting properties. However, the movement of delocalized charge carriers along individual conjugated chains (i.e., a one dimensional pathway) does not provide for a complete understanding of conduction in the solid state. The importance of interchain hopping in conjugated materials led us to propose an extension of one-dimensional models into the second dimension by preparation and analysis of well-defined oligomers held in permanent cofacial arrangements. Thieno-fused bicyclo[4.4.1]undecanes provide a convenient scaffold to prepare oligomers that are held in a covalent $\pi$-stack, affording control of the distance and orientation of the conjugated segments and the study of the nature of charge transport by UV-vis-NIR spectroscopy and electrochemical measurements.

We have substituted the bis(thieno)fused bicyclo[4.4.1] undecane core to prepare a series of stacked oligothiophenes including terthiophene and a quinquethiophene, along with their linear (unstacked) analogs. Preparation of this first series of compounds provided insights into synthetic methodology as well as preliminary understanding of the $\pi$-stacking effects the electronic structure of radical cations and dication. With this series

we were able to determine trends in the spectroscopic and electrochemical behavior of conjugated molecules and relate the influence of $\pi$-stacking to the stability of delocalized radical cations, and the potential role for $\pi$-dimers in charge transport. 
Expanding this synthetic methodology, we were able to devise compounds that were covalently stacked with phenyl-capped oligothiophenes and a stacked ferrocene hybrid compound. Although less electron rich and with slightly higher oxidation potentials, the phenyl-capped series allowed us to examine the formation of $\pi$-dimers of conjugated radical cations. The stacked ferrocene compound and its unstacked model also demonstrated effective stacking by through space charge delocalization illustrated in electrochemistry measurements.

With this bis(thieno)fused bicyclo[4.4.1] undecane core, numerous other types of $\pi$-stacked derivatives may be synthesized to provide further insight into organic semiconducting materials (i.e. alkyne substituted oligomers, 3,4-ethylenedioxythiophenes, and n-dopable substituents). Varying the degree of $\pi$-overlap of terthiophene also may allow us to examine the stability of radical cations held in different orientations by use of the bis(thieno)fused bicyclo[4.4.1]undecane core. 


\section{CHAPTER 1}

\section{INTRODUCTION}

\section{1. $\pi$-Conjugated Materials}

The electronic properties of $\pi$-conjugated materials are important in many aspects of chemistry. Over the last 25 years new classes of $\pi$-conjugated polymers such as oligothiophenes, ${ }^{1,2}$ oligo(phenylene vinylene)s, ${ }^{3} \quad$ oligo(isothianaphthene)s ${ }^{4}$ and oligo(phenylene ethynylene) $\mathrm{s}^{5}$ have been synthesized and studied for their intrinsic abilities to conduct electricity, Figure 1.1. The appreciation for Heeger, MacDiarmid, and Shirakawa were honored with a Nobel Prize in Chemistry in 2000 for their work in the field originating with a published observation of conductivity of polyacetylene in the 1970s. ${ }^{6}$ The revolutionary discovery of the conductivity of polyacetylene provided a foundation for studying broad classes of organic conjugated polymers as "synthetic metals". 7,8 Among the incentives for the development of these conjugated materials are the potential for light, flexible, devices with characteristics that can be optimized by molecular design such as field effect transistors (FETs), ${ }^{9-13}$ light emitting diodes (LEDs), ${ }^{14}$ solar cells, ${ }^{15}$ and lasers, ${ }^{16,17}$ and other devices for energy storage such as supercapacitors ${ }^{18}$ and fuel cells. ${ }^{19}$ 

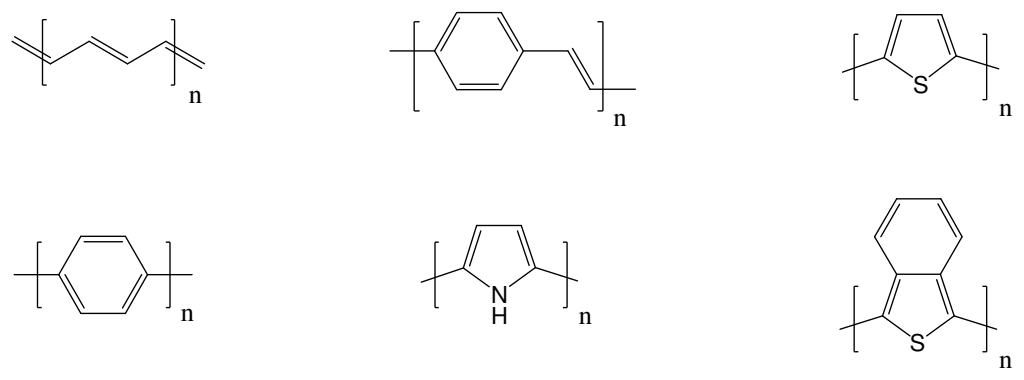

Figure 1.1. Examples of some $\pi$-conjugated oligomeric polymers.

\subsection{Charge Carriers in Conductive Materials}

As the conjugation length of a molecule is extended, a density of states develops leading to the formation of a band gap. Ideally, a $\pi$-conjugated system with equal bond lengths should produce a band gap that diminishes as conjugation length increases, causing the material to become more metallic. However, the coupling of electrons and lattice vibrations, known as Peierl's distortion, leads to the formation of a gap between valence and conducting bands, Figure 1.2. Extrapolation of the optical and electrochemical properties of model oligomers to an infinite length can be used to predict the intrinsic properties of conjugated polymers. 


\section{D ATOMIC CHAIN}

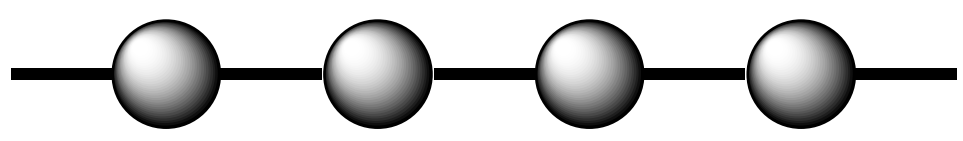

PEIERL'S DISTORTION

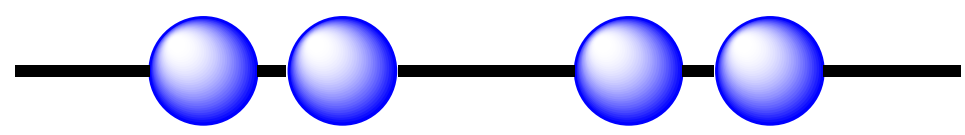

Figure 1.2. Schematic diagram for Peierl's distortion.

Longer conjugation lengths of $\pi$-conjugated polymers increases the ease of oxidation or reduction (processes known as doping), which greatly increases their conductivity. In the case of polymers with non-degenerate ground states, a low level of oxidation leads to polarons as charge carriers which give rise to new optical absorptions and an ESR signal. A positive polaron in polythiophene, for example, is created when an electron is removed by chemical doping with $\mathrm{FeCl}_{3}$. The charge (+1) and spin are localized over several thiophene rings with a geometrical change to a quinoid structure. A positive polaron corresponds to a radical cation in chemical terminology. Further oxidation leads to bipolarons which are spinless and ESR-silent. ${ }^{20-22}$ The positive charge (+2) localized on the polymer chain is known as a dication, Figure 1.3. 


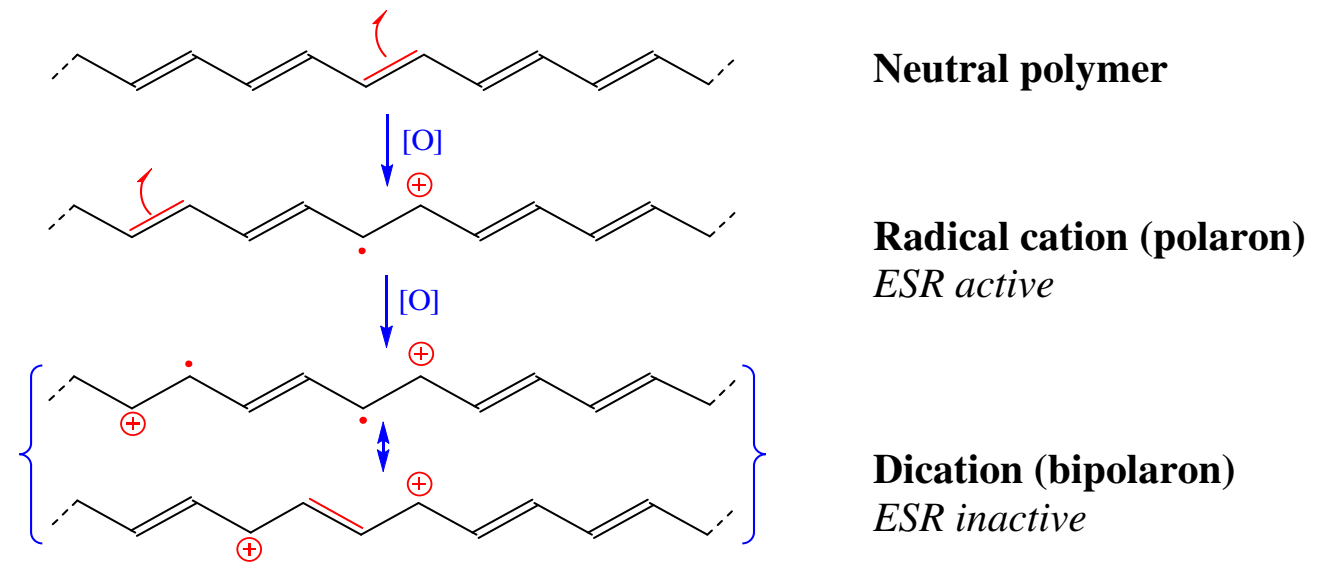

Figure 1.3. Doping of a $\pi$-conjugated polyene.

\subsection{Fates of Radical Cations in Doped $\pi$-Conjugated Oligomers}

A radical cation, formed upon one-electron oxidation, is delocalized along the $\pi$ conjugated chain. If we concentrate on the radical cation species only, it can interact in several ways, Figure 1.4. The first example illustrates radical cations located on two separated molecules (denoted ' $M$ ') where one becomes oxidized and the other reduced known as disproportionation. The process has been ovserved for rigid thienylene vinylene systems for which UV-vis-NIR and ESR analysis suggests gives rise to formed a neutral and dicationic species. ${ }^{23}$ 


\section{DISPROPORTIONATION}

$\mathrm{M}^{+\cdot}+\mathrm{M}^{+\cdot} \rightarrow \mathrm{M}^{2+}+\mathrm{M}^{0}$

\section{BIS(RADICAL CATION) COMBINATION \\ $\mathrm{M}^{2(+\cdot)} \rightarrow \mathrm{M}^{2+}$}

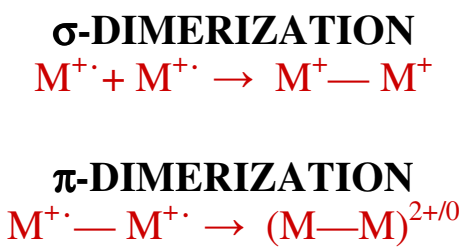

Figure 1.4. Schematic representation of the fates of radical cations.

Similarly, a secong $e$ - oxidation of a radical cation to form a bis(radical cation) on a single subunit may result in combination of the two radical cations form a dication, as depicted first in Figure 1.3 and in Figure 1.4. Orthogonally fused thiophene oligomers ${ }^{24}$ were probed electrochemically and exhibit this behavior.

Reversible $\sigma$-dimerization of two radical cations or anions is plausible where a $\sigma$ bond between two oligomers forms by alignment of the $s p^{2}$ orbitals. 1,3,5Tripyrrolidinobenzene has been shown to be a redox switch when two of these molecules join to form a sigma bond, ${ }^{25}$ and electroreduction of 9-fluoro-10-cyanoanthracene ${ }^{26}$ showed similar reversible dimerization. In another study of diphenylpolyene radical anions, ${ }^{27}$ argument against $\sigma$-bond dimerization was that such bond formation was energetically favored because of the relative orientation of the chains.

Analysis of alkylated oligothiophenes ${ }^{28}$ by Miller $^{29}$ and others ${ }^{30,31}$ indicates that the oligomeric radical cations associate in solution to form $\pi$-dimers, Figure 1.5. The dimers give rise to a new absorption band in the near IR and are ESR-silent, and serve as models for spinless bipolarons. These spectral characteristics are also noted for a polyester 
containing isolated tetrathiophene units. ${ }^{32}$ This four-ring system is too short for the formation of stable dications (bipolarons). However, one-electron oxidation of the conjugated units in the polyester (i.e., to the radical cation) leads to a strong optical absorption spectrum and a weak ESR signal consistent with dimerization of the polarons to form spinless charge carriers in aggregates of the arene units.

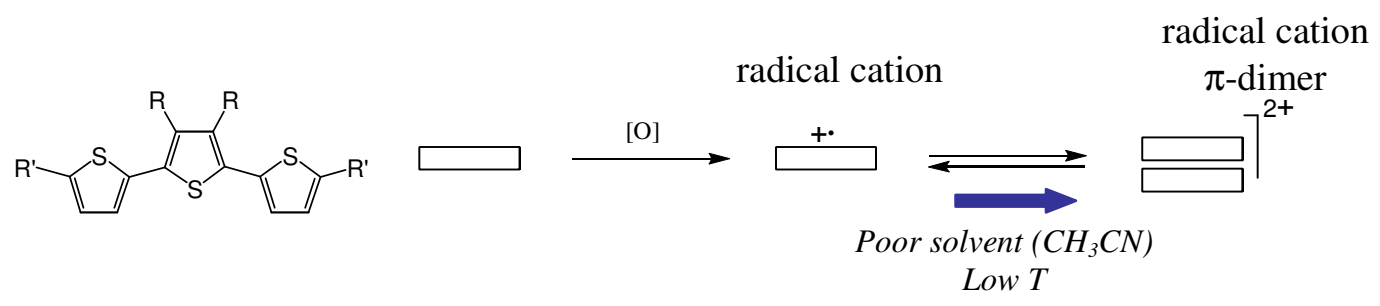

Figure 1.5. $\pi$-Dimer formation by aggregation of radical cations.

Whereas the structure of the $\pi$-dimers formed in solution or in the polyester are not well defined, the effects are observed in the crystalline state. Direct evidence for $\pi$-dimers comes from X-ray analysis of electro-crystallized oligothiophene radical cation salts ${ }^{33}$ which display a conductivity of $10^{-2} \mathrm{Scm}^{-1}$ in spite of their short conjugation length, Figure 1.6. 


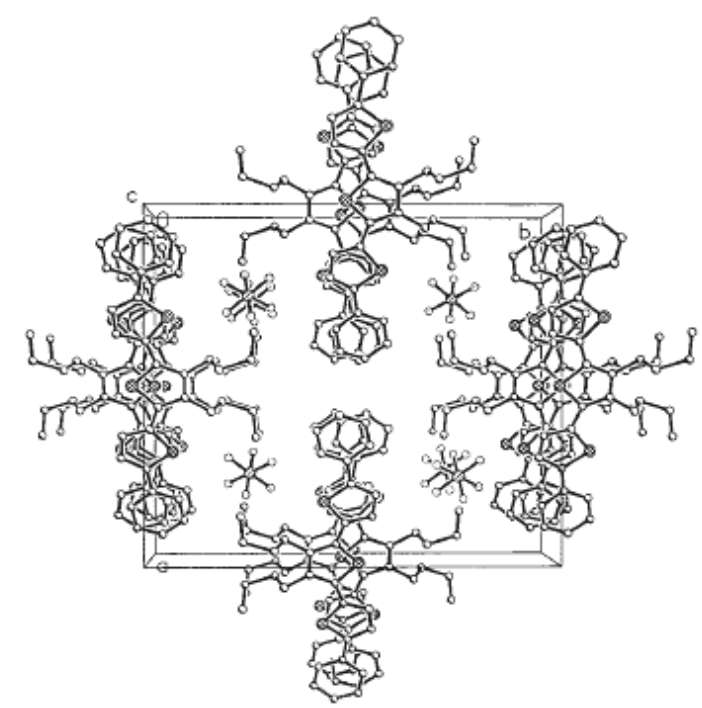

Figure 1.6. X-ray structural analysis of radical cation salt (from reference 33).

The concept of $\pi$-dimers is also illustrated by new UV-vis-NIR absorbances attributed to association of bis(radical cations of terthiophenes, quarterthiophenes, and $\beta$ methoxy- $\alpha$-methyl capped oligothiophenes. ${ }^{29,34-37}$ The solid-state structural analysis of 3',4'-dibutyl-2,5"-diphenyl-5,2':5',2"-terthiophene radical cation salt ${ }^{33}$ provided additional insight into the idea of that spinless charge carries can be models for polarons and bipolarons in polymer systems such as poly(p-phenylene)oligomers. ${ }^{38}$

Mimicking through-space delocalization of charge carriers in conjugated organic oligomers and polymers requires the ability to control the orientation and degree of interactions between adjacent chains. Studies of linear interchain electronic interactions in the development of new functional materials often ignore aggregation of oligomers in solution. $^{39-43}$ 


\subsection{Two-Dimensional Compounds: $\pi$-Stacking Interactions}

The movement of delocalized charge carriers along $\pi$-conjugated chains within a one dimensional unit does not provide complete understanding of conductivity in conjugated polymers. Conductivity over macroscopic distances in polymers requires interactions between chains, which are absent in the isolated linear oligomers in solution. The fact that organic semiconductor materials tend to be highly processable, flexible, and less costly favor the continued development of such materials.

The influence of $\pi$-stacking on the electronic structure of neutral arenes is apparent in the photophysical behavior resulting from their self-association as excimers and $\mathrm{J}$ aggregates. Monomolecular analogs of such assemblies have been studied extensively by the preparation of compounds in which two stilbene chromophores are held in a cofacial arrangement by a [2.2]paracyclophane unit. ${ }^{44,45}$ Others have used crystal engineering to examine the spectroscopy of neutral oligomers assembled into well-defined stacks in the solid state. ${ }^{46}$ In addition to investigations of stacked aggregates, other recent studies have addressed approaches to non-planar arrangements of oligomers (tetrahedral, ${ }^{47}$ dendritic ${ }^{48}$ ) to gain control over interchain interactions.

Cofacial stacking of oligomeric units into a permanent $\pi$-stack by covalent bonds would provide control of the distance and orientation of the conjugated systems, allowing us to study the nature of charge transport by spectroscopy and electrochemical measurements. Cyclophanes constitute an important class of organic molecules in which two or more arenes are fused on a single macrocycle. ${ }^{49,50}$ Small meta- and paracyclophanes adopt a face-to-face geometry in which the arenes are held at a short distance from one another. Orthocyclophanes are generally flexible and adopt non- 
stacked geometries. However, judicious choice of a bridging unit leads to the formation of stacked $\pi$-systems. ${ }^{51}$ This approach can also be used to prepare multi-layered orthocyclophanes $^{52}$ which are relatively simple to prepare relative to multilayered paracyclophanes. Thus, preparation of stacked orthocyclolphanes which hold $\pi$ conjugated oligomers in close proximity will allow for examination of the through space $\pi-\pi$ interactions and effect on stabilizing charged species which might serve as charge carriers in conjugated polymers. The through-space interaction of the $\pi$-systems has also been studied by substitution of the rings with various electroactive, electron-donating and electron-withdrawing substituents, ${ }^{53}$ and by UV-visible spectroscopy.

Approaches to compounds in which fused- or oligo- arenes are held in stacks include preparation of benzo-annelated bicyclo [4.4.1] undecanes, ${ }^{54-56}$ quadruple-layered orthonaphthophanes, ${ }^{52}$ and thieno[3.3]orthocyclophanes. ${ }^{57}$ Whereas benzene undergoes oxidation at a relatively high potential to form poorly defined polymers, ${ }^{58}$ these tripleand quadruple-decker analogs undergo oxidation to the radical cation and dication at relatively low potentials. Collard et. al. has previously synthesized oligothienylsubstituted [2.2]paracyclophanes illustrating the effect of through space delocalization of charges ${ }^{59,60}$ Other studies demonstrate the electronic communication of oligothiophenes through the paracyclophane subunit with shorter oligomer subunits. ${ }^{61-64}$ These studies have also been extrapolated to other classes of conjugated polymers such as polyfluorenes, ${ }^{65}$ where the anion radicals can be kinetically controlled by solvation. ${ }^{65}$

The electrochemistry and photophysics of conjugated oligomers continues to be an area of intense interest as models for conjugated polymers and for the development of new functional materials. Computational studies systematically compare effects such as orbital splitting, internal reorganization energies, and molecular packing motifs. ${ }^{66,67}$ 
Other studies provide a wealth of information to clues evolution of electronic structure of individual conjugated molecules as they are incorporated into a 3D molecular material. ${ }^{68-}$ 70 Other studies try to determine which theoretical theory is best for radical cation molecular geometry. ${ }^{71}$ There are few model systems to corroborate the output from these calculations. Ideally, a combination of experimental results and theoretical calculations should be used to examine the electronic structure of conjugated materials. ${ }^{72}$

\subsection{Scope of Work}

The importance of interchain hopping of charge carriers in doped conjugated polymers led us to propose an extension of one-dimensional models into the second dimension by synthesis of novel compounds and analysis of well-defined charged oligomers held in a permanent cofacial arrangement. We can exert control over the distance, orientation and overlap of conjugated units to determine the influence of molecular packing on the behavior of charge carriers, Figure 1.7.

\section{Stacked}
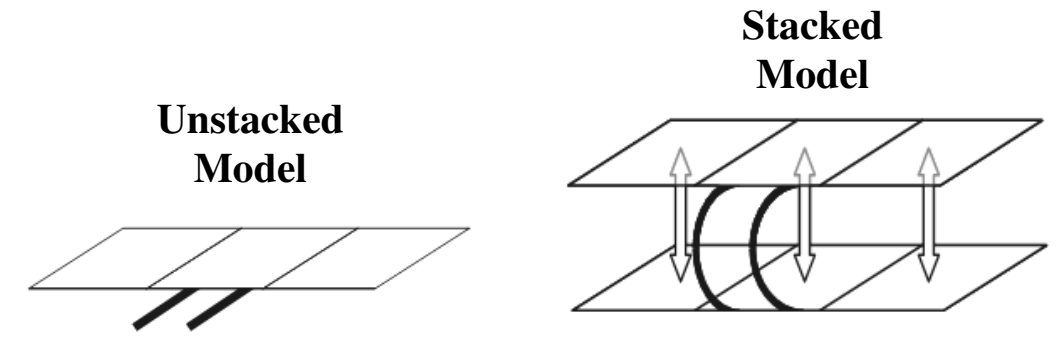

Figure 1.7. Unstacked linear analog (left) and $\pi$-stacked analog (right). Each box denotes a central thiophene unit attached at the $\alpha$-positions to another heterocycle or aromatic compound. 
To explore the effect of interacting conjugated systems on charged carriers in conjugated polymers we set out to vary the extent of interaction between conjugated oligothiophene by: (i) design of a framework to hold the oligomers in close proximity, (ii) variation of the length of the conjugated substituents, (iii) examination of the spectroscopy of different redox states by level of doping, and (iv) installation of substituents onto the oligomers. The design of models for polythiophene using this approach allows us to vary the extent of $\pi$-overlap and compare the properties of these $\pi$ dimers to unstacked model oligomers.

A combination of synthetic chemistry, electrochemistry, and spectroscopy will allow us to develop models for charge carriers in doped conjugated polymers, and to explore the evolution of electronic structure in materials consisting of close-packed $\pi$-electronrich molecules. In particular it allows us to examine the electronic structure of various states shown in Figure 1.8.

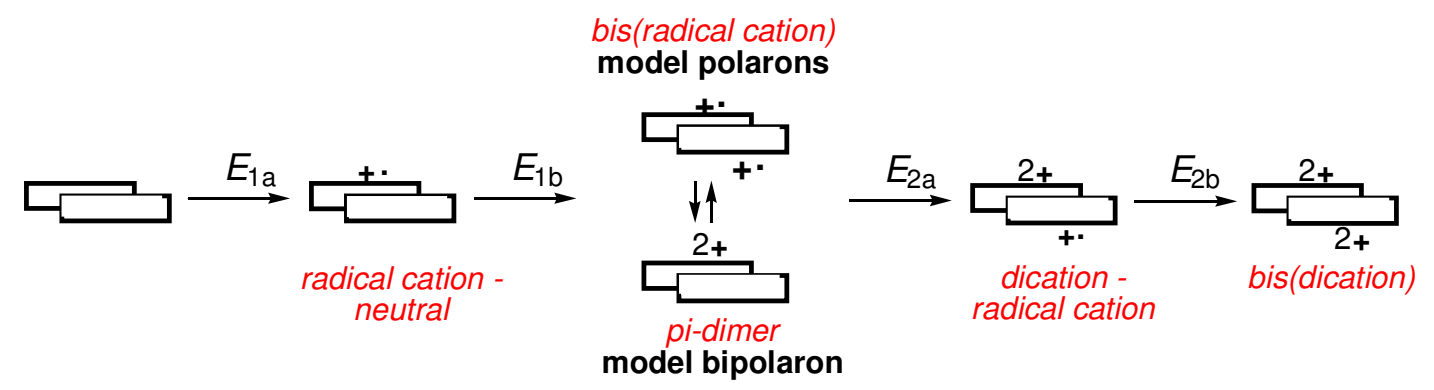

Figure 1.8. Redox states arising from oxidation of $\pi$-stacked oligomers.

Whereas, Otsubo recently reported a series of dimeric quinquethiophenes held together by bridges at the termini and examined them as $\pi$-dimers models of 
polythiophene, ${ }^{73-75}$ here, we prepare extended $\pi$-conjugated oligomers held together in the center. A divergent synthesis allows us to vary the length of the oligomers to explore the effect of chain length on charge delocalization. Extended conjugated oligomers based on a dithieno-fused bicyclo[4.4.1]undecone core show promise for further investigations to the nature of charge transport in organic materials.

The dithieno-fused bicyclo[4.4.1]undecane $\mathbf{1 . 4}$ can be prepared as a heteroarene analog of Mataka's work ${ }^{76}$ thereby providing us with access to stacked oligomers consisting entirely of thiophene rings. In analogy to the reaction of $\alpha, \alpha^{\prime}$-dibromo-oxylene, ${ }^{76}$ treatment of 3,4-Bis(bromomethyl)thiophene ${ }^{77} \mathbf{1 . 1}$ with dimethyl 1.3acetonedicarboxylate (dimethyl oxaglutarate, 1.2) under phase transfer conditions, followed by saponification, decarboxylation, and ketalization with ethylene glycol provides the dithieno-fused bicyclo[4.4.1]undecane $\mathbf{1 . 4}$ in which the arenas are held in a cofacial arrangement, Figure 1.9.

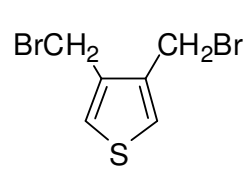

1.1

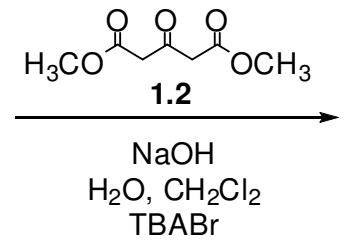

$\mathrm{TBABr}$

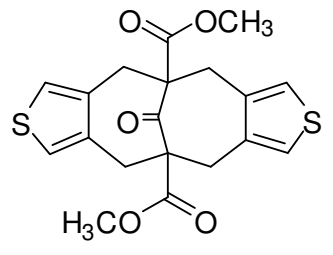

1.3
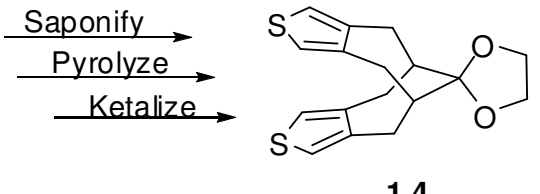

1.4

Figure 1.9. Synthesis of dithieno-fused $\pi$-stacked orthocyclophane with ethylene glycol.

Conjugated arms to be tethered to the framework core can be prepared by carboncarbon bond forming reactions (Stille, Negishi, or Suzuki reactions) at the unblocked $\alpha$ thienyl positions These arms include: (i)oligothiophenes, (ii) phenyl-terminated 
oligothiophene analogs, and (iii) ferrocene. This versatile framework is applicable to a wide variety of $\pi$-linear systems and allow us to demonstrate the infuence of permanent $\pi$-stacking on cofacial oligomers.

In Chapter 2, the synthesis of 3,4-bis(bromomethyl)thiophene, the dithieno-fused bicyclo[4.4.1] undecanone core, and $\pi$-stacked analogs is described. This is elaborated in Chapter 3 where the synthesis of extended terthiophene and quinquethiophene $\pi$-stacked compounds and their respective linear model compounds is discussed. In Chapter 4, the photophysical and electrochemical characterization of the $\pi$-stacked oligothiophenes and linear model is explored. Exploring other $\pi$-conjugated systems by varying the termini of oligothiophenes with phenyl-capped and ferrocene-capped substituents is synthesized and explored in Chapters 5 and 6 . Other $\pi$-conjugated compounds and varying the degree of overlap is mentioned in Chapter 7.

\subsection{References}

1. Ponomarenko, S.; Kirchmeyer, S., "Synthesis and thermal behaviour of $\alpha-\alpha^{\prime}-$ didecyloligothiophenes," J. Mater. Chem. 2003, 13, 197-202.

2. Frere, P.; Raimundo, J.-M.; Blanchard, P.; Delaunay, J.; Richomme, P.; Sauvajol, J.-L.; Orduna, J.; Garin, J.; Roncali, J., "Effect of local molecular structure on the chain-length dependence of the electronic properties of thiophene-based piconjugated systems," J. Org. Chem. 2003, 68, 7254-7265.

3. Cho, H.; Kim, E., "Highly fluorescent and photochromic diarylethene oligomer bridged by p-phenylenevinylene," Macromolecules 2002, 35, 8684-8687.

4. Meng, H.; Wudl, F., "A robust low band gap processable ntType conducting polymer based on poly(isothianaphthene)," Macromolecules 2001, 34, 1810-1816. 
5. Kukula, H.; Veit, S.; Godt, A., "Synthesis of monodisperse oligo(paraphenyleneethynylene)s using orthogonal protecting groups with different polarity for terminal acetylene units," Eur. J. Org. Chem. 1999, 277-286.

6. Shirakawa, H., "The discovery of polyacetylene film: The dawning of an era of conducting polymers (Nobel Lecture)," Angew. Chem. 2001, 40, 2575-2580.

7. Shirakawa, H.; Louis, E. J.; MacDiarmid, A. G.; Chiang, C. K.; Heeger, A. J., "Synthesis of electrically conducting organic polymers: halogen derivatives of polyacetylene, (CH)x," J. Chem. Soc., Chem. Commun. 1977, 578-80.

8. Stenger-Smith, J. D., "Intrinsically electrically conducting polymers. Synthesis, characterization, and their applications," Prog. Polym. Sci. 1998, 23, 57-79.

9. Drury, C. J.; Mutsaers, C. M. J.; Hart, C. M. M., M.; de Leeuw, D. M., "Low-cost all-polymer integrated circuits," Appl. Phys. Lett. 1998, 73, 108-110.

10. Katz, H. E.; Dodabalapur, A.; Z., B.; Fichou, D., "Oligo- and PolythiopheneBased Field-Effect Transistors," 1998.

11. Tsumura, A.; Koezuka, H.; Ando, T., "Macromolecular electronic device: Fieldeffect transistor with a polythiophene thin film," Appl. Phys. Lett. 1986, 49, 12101212.

12. Garnier, F.; Horowitz, G.; Peng, X. Z.; Fichou, D., "An all-organic soft, thin-film transistor with very high carrier mobility," Adv. Mater. 1990, 2, 592-594.

13. Garnier, F.; Hajlaoui, R.; Yassar, A.; Srivastava, P., "All Polymer Field Effect Transistor $r=$ Realized by Printing Techniques," Science 1994, 265, 1684-1686.

14. Burroughes, J. H.; Bradley, D. D. C.; Brown, A. R.; Marks, R. N.; Mackay, K.; Friend, R. H.; Burns, P. L.; Holmes, A. B., "Light-emitting diodes based on conjugated polymers," Nature (London, United Kingdom) 1990, 347, 539-41.

15. Liu, J.; Tanaka, T.; Sivula, K.; Alivisatos, A. P.; Frechet, J. M., "Employing EndFunctional Polythiophene To Control the Morphology of Nanocrystal-Polymer Composites in Hybrid Solar Cells," J. Am. Chem. Soc. 2004, 126, 6550-6551. 
16. McGehee, M. D.; Heeger, A. J., "Semiconducting (conjugated) polymers as materials for solid-state lasers," Adv. Mater. 2000, 12, 1655-1668.

17. Tessler, N.; Denton, G. J.; Friend, R. H., "Lasing from conjugated-polymer microcavities," Nature 1996, 382, 695-697.

18. Kumar, C. Z. a. S.; Tour, C. D. D. a. J. M., "Functionalized Single Wall Carbon Nanotubes Treated with Pyrrole for Electrochemical Supercapacitor Membranes," Chem. Mater. 2005, 17, 1997-2002.

19. Haji, S.; Erkey, C., "Removal of Dibenzothiophene from Model Diesel by Adsorption on Carbon Aerogels for Fuel Cell Applications," Ind. Eng. Chem. Res. 2003, 42, 6933-6937.

20. Kaufman, J. H.; Colaneri, N. S., J.C.; Street, G. B., "Evolution of polaron states into bipolarons in polypyrrole," Phys. Rev. Lett. 1984, 53, 1005-1008.

21. Bredas, J. L.; Street, G. B., "Polarons, bipolarons, and solitons in conducting polymers," Acc. Chem. Res. 1985, 18, 309-315.

22. Cornil, J.; Calbert, J. P.; Beljonne, D.; Silbey, R.; Bredas, J. L., "Interchain interactions in p-conjugated oligomers and polymers: a primer," Synth. Met. 2001, 119, 1-6.

23. Frere, P.; Allain, M.; Elandaloussi, E. H.; Levillain, E.; Sauvage, F.-X.; Riou, A.; Roncali, J., "Effects of structural factors on the p-dimerization and/or disproportionation of the cation radical of extended TTF containing thiophenebased p-conjugated spacers," Chem. Eur. J. 2002, 8, 784-792.

24. Guay, J.; Diaz, A.; Wu, R.; Tour, J. M., "Electrochemical and electronic properties of neutral and oxidized soluble orthogonally fused thiophene oligomers," J. Am. Chem. Soc. 1993, 115, 1869-74.

25. Heinze, J.; Willmann, C.; Bäuerle, P., "Evidence for s Dimerization During Anodic Redox Switching of 1,3,5-Tripyrrolidinobenzene: A New Molecular Switch," Angewandte Chemie International Edition 2001, 40, 2861-2864.

26. Heinze, J.; Rasche, A., "Electroreduction of 9-fluoro-10-cyanoanthracene," Electrochem. Commun. 2003, 5, 776-781. 
27. Smie, A.; Heinze, J., "Reversible dimerization of diphenylpolyene radical cations: an alternative to the bipolaron model," Angew. Chem., Int. Ed. Engl. 1997, 36, 363-367.

28. Ten Hoeve, W.; Wynberg, H.; Havinga, E. E.; Meijer, E. W., "Substituted 2,

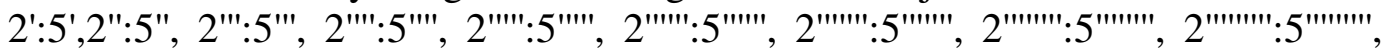
2 "'"'"'--undecithiophenes, the longest characterized oligothiophenes," J. Am. Chem. Soc. 1991, 113, 5887-5889.

29. Miller, L. L.; Mann, K. R., "p-Dimers and p-Stacks in Solution and in Conducting Polymers," Acc. Chem. Res. 1996, 29, 417-423.

30. Nessakh, B.; Horowitz, G.; Garnier, F.; Deloffre, F.; Srivastava, P.; Yassar, A., "Cyclic voltammetry and differential cyclic voltabsorptometry of soluble oligothiophenes: evidence for a four-fold charged p-dimer in duodecithiophene," J. Electroanal. Chem. 1995, 399, 97-103.

31. Zotti, G.; Schiavon, G.; Berlin, A.; Pagani, G., "Electrochemistry of end-capped oligothienyls. New insights into the polymerization mechanism and the charge storage, conduction and capacitive properties of polythiophene," Synth. Met. 1993, 61, 81-87.

32. Hong, Y.; Yu, Y.; Miller, L. L., "An oxidized oligothiophene that forms pstacks," Synth. Met. 1995, 74, 133-135.

33. Graf, D. D.; Campbell, J. P.; Miller, L. L.; Mann, K. R., "Single-Crystal X-ray Structure of the Cation Radical of 3',4'-Dibutyl-2,5"-diphenyl-2,2':5',2"terthiophene: Definitive Evidence for p-Stacked Oxidized Oligothiophenes," $J$. Am. Chem. Soc. 1996, 118, 5480-5481.

34. Apperloo, J. J.; Raimundo, J.-M.; Frere, P.; Roncali, J.; Janssen, R. A. J., "Redox states and associated interchain processes of thienylenevinylene oligomers," Chem. Eur. J. 2000, 6, 1698-1707.

35. Zinger, B.; Mann, K. R.; Hill, M. G.; Miller, L. L., "Photochemical formation of oligothiophene cation radicals in acidic solution and Nafion," Chem. Mater. 1992, 4, 1113-1118.

36. Miller, L. L.; Yu, Y., "Synthesis of b-Methoxy, Methyl-Capped aOligothiophenes," J. Org. Chem. 1995, 60, 6813-6819. 
37. Apperloo, J. J.; Janssen, R. A. J., "Solvent effects on the p-dimerization of cation radicals of conjugated oligomers," Synth. Met. 1999, 101, 373-374.

38. Khann, R. K.; Jiang, Y. M.; Srinivas, B.; Smithhart, C. B.; Wertz, D. L., "Electronic Transitions in Polarons and Bipolarons of Poly(p-phenylene) Oligomers," Chem. Mater. 1993, 5, 1792-1798.

39. Guay, J.; Kasai, P.; Diaz, A.; Wu, R.; Tour, J. M.; Dao, L. H., "Chain-length dependence of electrochemical and electronic properties of neutral and oxidized soluble a,a-coupled thiophene oligomers," Chem. Mater. 1992, 4, 1097-105.

40. Bauerle, P.; Segelbacher, U.; Maier, A.; Mehring, M., "Electronic Structure of Mono- and Dimeric Cation Radicals in End-Capped Oligothiophenes," J. Am. Chem. Soc. 1993, 115, 10217-110223.

41. Hoeve, W.; Wynberg, H.; Havinga, E. E.; Meijer, E. W., "Substituted Undecithiophenes," J. Am. Chem. Soc. 1991, 113, 5887-5889.

42. Tour, J. M.; Wu, R., "Synthesis and UV-visible properties of soluble a-thiophene oligomers. Monomer to octamer," Macromolecules 1992, 25, 1901-1907.

43. Hotta, S.; Waragai, K., "Solid-State Absorbance Spectropy of Alkyl-Substituted Oligothiophenes," J. Phys. Chem. 1993, 97, 7427-7434.

44. Bartholomew, G. P.; Bazan, G. C., "Synthesis, Characterization, and Spectroscopy of 4,7,12,15-[2.2]Paracyclophane Containing Donor and Acceptor Groups: Impact of Substitution Patterns on Through-Space Charge Transfer," $J$. Am. Chem. Soc. 2002, 124, 5183-5196.

45. Bartholomew, G. P.; Bazan, G. C., "Bichromophoric Paracyclophanes: Models for Interchromophore Delocalization," Acc. Chem. Res. 2001, 34, 30-39.

46. Koren, A. B.; Curtis, M. D.; Francis, A. H.; J.W., K., "Intermolecular Interactions in pi-stacked conjugated molecules. Synthesis, structure, and spectral characterization of alkyl bithiazole oligomers," J. Am. Chem. Soc. 2003, 125, 5040-5041. 
47. Summers, M. A.; Robinson, M. R.; Bazan, G. C.; Buratto, S. K., "Single molecule spectroscopy of tetrahedral oligophenylenevinylene molecules," Chem. Phys. Lett. 2002, 364, 542-549.

48. Xia, C.; Fan, X.; Locklin, J.; Advincula, R. C., "A first synthesis of fhiophene dendrimers," Org. Lett. 2002, 4, 2067-2070.

49. Keehn, P. M.; Rosenfeld, S. M., "Cyclophanes," Academic Press, New York 1983.

50. Vögtle, F., "Cycophane chemistry - Synthesis, structures and reactions," Wiley, Chichester 1993.

51. Grimme, W.; Kaemmerling, H. T.; Lex, J.; Gleiter, R.; Heinze, J.; Dietrich, M., "syn-Sesqui- and sesterbenzobicyclo[2.2.2]octenes. Molecules with stacked benzene rings," Angew. Chem. Int. Ed. Engl. 1991, 30, 205-207.

52. Mataka, S.; Shigaki, K.; Sawada, T.; Mitoma, Y.; Taniguchi, M.; Thiemann, T.; Ohga, K.; Egashira, N., "Quadruple decker [3.3][3.3][3.3]orthocyclophane acetal - an orthocyclophane ladder," Angew. Chem. Int. Ed. 1998, 37, 2532-2534.

53. Cram, D. J.; Bauer, R. H., "Macro rings. XX. Transannular effects in pi-picomplexes," J. Am. Chem. Soc. 1959, 81, 5971-5977.

54. Mataka, S.; Mitoma, Y.; Sawada, T.; Thiemann, T.; Taniguchi, M.; Tashiro, M., "Benzo[3.3]benzo[3.3]benzo- and naphtho[3.3]benzo[3.3]naphthoortho-cyclophane bis(alcohols): Preparations and structures," Tetrahedron 1998, 54, 51715186.

55. Mataka, S.; Takahashi, K.; Hirota, T.; Takuma, K.; Kobayashi, H.; Tashiro, M., "[3.3] Orthocyclophanes having vis-a-vis benzene rings," J. Chem. Soc., Chem. Commun. 1985, 973.

56. Mataka, S.; Takahashi, K.; Mimura, T.; Hirota, T.; Takuma, K.; Kobayashi, H.; Tashiro, M.; Imada, K.; Kuniyoshi, M., "[3.3]Orthocyclophanes with facing benzene and naphthalene rings," J. Org. Chem. 1987, 52, 2653-6.

57. Thiemann, T.; Ohira, D.; Li, Y.; Sawada, T.; Taniguchi, M.; Tashiro, M.; Mataka, S., "Thieno[3.3] orthocyclophanes: preparations and structures," New J. Chem. 1999, 23, 675-678. 
58. Dietrich, M.; Mortensen, J.; Heinze, J., "Electropolymerization of benzene to a poly(p-phenylene) film for use as a rechargeable battery electrode," J. Chem. Soc., Chem. Commun. 1986, 1131.

59. Salhi, F.; Lee, B.; Metz, C.; Bottomley, L. A.; Collard, D. M., "Influence of pStacking on the Redox Properties of Oligothiophenes: (a-Alkyloligothienyl)para[2.2]cyclophanes," Org. Lett. 2002, 4, 3195-3198.

60. Salhi, F.; Collard, D. M., "p-Stacked conjugated polymers: the influence of paracyclophane p-stacks on the redox and optical properties of a new class of broken conjugated polythiophenes," Adv. Mater. 2003, 15, 81-85.

61. Guyard, L.; Dumas, C.; Miomandre, F.; Pansu, R.; Renault-Meallet, R.; Audebert, P., "Synthesis and the electrochemical and fluorescence properties of new cyclophane-derivatized oligothiophenes," New J. Chem. 2003, 27, 1000-1006.

62. Guyard, L.; Audebert, P.; Dolbier, W. R.; Duan, J.-X., "Synthesis and electrochemical polymerization of new oligothiophene functionalized fluorocyclophanes," J. Electroanal. Chem. 2002, 537, 189-193.

63. Guyard, L.; Audebert, P., "Synthesis and electrochemical polymerization of bisdithienyl cyclophane," Electrochem. Commun. 2001, 3, 164-167.

64. Guyard, L.; Nguyen Dinh An, M.; Audebert, P., "Synthesis and electrochemical polymerization of new oligothiophene functionalized cyclophanes," Adv. Mater. 2001, 13, 133-136.

65. Rathore, R.; Abdelwahed, S. H.; Kiesewetter, M. K.; Reiter, R. C.; Stevenson, C. D., "Intramolecular Electron Transfer in Cofacially Pi-Stacked Fluorenes: Evidence of Tunneling," J. Phys. Chem. 2006, 110, 1536-1540.

66. Hutchison, G. R.; Ratner, M. A.; Marks, T. J., "Intermolecular Charge Transfer between Heterocyclic Oligomers. Effects of Heteroatom and Molecular Packing on Hopping Transport in Organic Semiconductors," J. Am. Chem. Soc. 2005, 127, 16866-16881.

67. Hutchison, G. R.; Ratner, M. A.; Marks, T. J., "Hopping Transport in Conductive Heterocyclic Oligomers: Reorganization Energies and Substituent Effects," J. Am. Chem. Soc. 2005, 127, 2339-2350. 
68. Beljonne, D.; Cornil, J.; Bredas, J. L.; Friend, R. H., "Theoretical investigation of the lowest singlet and triplet excited states in oligo(phenylene vinylene)s and oligothiophenes," Synth. Met. 1996, 76, 61-5.

69. Cornil, J.; Beljonne, D.; Bredas, J. L., "Nature of optical transitions in conjugated oligomers. II. Theoretical characterization of neutral and doped oligothiophenes," J. Chem. Phys. 1995, 103, 842-9.

70. Beljonne, D.; Cornil, J.; Friend, R. H.; Janssen, R. A. J.; Bredas, J. L., "Influence of Chain Length and Derivatization on the Lowest Singlet and Triplet States and Intersystem Crossing in Oligothiophenes," J. Am. Chem. Soc. 1996, 118, 64536461.

71. Geskin, V. M.; Grozema, F. C.; Siebbeles, L. D. A.; Beljonne, D.; Bredas, J. L.; Cornil, J., "Impact of the Computational Method on the Geometric and Electronic Properties of Oligo(phenylene vinylene) Radical Cations," Journal of Physical Chemistry B 2005, 109, 20237-20243.

72. Beljonne, D.; Langeveld-Voss, B. M. W.; Shuai, Z.; Janssen, R. A. J.; Meskers, S. C. J.; Meijer, E. W.; Bredas, J. L., "Exciton coupling in oligothiophenes: a combined experimental/theoretical study," Synth. Met. 1999, 102, 912-913.

73. Sakai, T.; Satou, T.; Kaikawa, T.; Takimiya, K.; Otsubo, T.; Aso, Y., "Syntheses, Structures, Spectroscopic Properties, and Pi-Dimeric Interactions of [n. n]Quinquethiophenophanes," J. Am. Chem. Soc. 2005, 127, 8082-8089.

74. Satou, T.; Sakai, T.; Kaikawa, T.; Takimiya, K.; Otsubo, T.; Aso, Y., "r,öBis(quinquethienyl)alkanes as a ð-Dimer Model of Polythiophene," Org. Lett. 2004, 6, 997-1000.

75. Kaikawa, T.; Takimiya, K.; Aso, Y.; Otsubo, T., "Synthesis and Spectroscopic Properties of [2.2]Quinquethiophenophane as an Ideal ð-Dimer Model," Org. Lett. 2000, 2, 4197-4199.

76. Mataka, S.; Takahashi, K.; Hirota, T.; Takuma, K.; Kobayashi, H.; Tashiro, M., "On the Conformation of Benzo-Annelated Bicyclo[4.4.1]undecanes, Bicyclo[5.5.1]tridecanes, and a Bicyclo[5.4.1]dodecane," J. Org. Chem. 1986, 51, 4618-4622. 
77. Von Helmers, R., "2-Amino-indene und deren heterologe. II Sterische hinderung der enolform bei heterologen alkoxycarbonyl-indanon-(2)derivaten," J. Prakt. Chemie 1972, 314, 334. 


\section{CHAPTER 2}

\section{SYNTHESIS AND STRUCTURAL CHARACTERIZATION OF DITHIENO-FUSED BICYCLO[4.4.1]UNDECANES}

\subsection{Introduction}

In covalently linking two $\pi$-conjugated oligomers together in a stacked arrangement, we chose a rigid dithieno-fused bicyclo[4.4.1] undecane framework. Such fused-arene bicycles were previously prepared by Shuntaro Mataka at Kyushu University from 1986-2000. ${ }^{1-10}$ Incorporation of fused-dithieno rings according to the methodology of Mataka would provide control over the orientation of the two thiophenes stacked on top one another to allow charged carriers (i.e. radical cations, dications) to hop through space when oxidized chemically or electrochemically.

Early work by Mataka ${ }^{8}$ examined the synthesis and conformational rigidity of a series of bicyclic compounds. Symmetrical fused dibenzo[3,4;8,9]bicyclo[4.4.1] undeca3,8-dienes, dinaphtho-[3,4- $\left.b ; 8,9-b^{\prime}\right]$ bicyclo[4.4.1]undeca-3,8-dienes and dinaphtho[3,4,5$\left.d e ;-9,10,11-d^{\prime} e^{\prime}\right]$ bicyclo[5.5.1]trideca-3,9-dienes, and asymmetrically fused naphtha[3,4,5-de]benzo[9,10]bicyclo[ 5.4.1] dodeca-3,9-dien-12-one compounds, 2.1-2.4, exist in different conformations depending on the temperature, as shown by ${ }^{1} \mathrm{H}$ and ${ }^{13} \mathrm{C} \mathrm{NMR}$ spectroscopy, Figure 2.1. The methylene groups of 2.1c give a coalesced signal in the ${ }^{1} \mathrm{H}$ NMR spectrum and one signal in the ${ }^{13} \mathrm{C}$ NMR spectrum at room temperature. Upon 
cooling to $-40{ }^{\circ} \mathrm{C}$, the ${ }^{13} \mathrm{C}$ NMR exhibits two types of methylene peaks and two sets of aromatic signals ( 3 carbons each). ${ }^{8}$

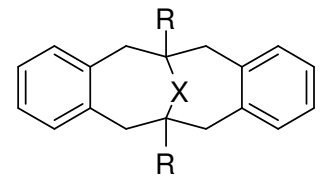

2.1a, $\mathrm{R}=\mathrm{CO}_{2} \mathrm{Me} ; \mathrm{X}=\mathrm{CO}$

2.1b, $\mathrm{R}=\mathrm{CO}_{2} \mathrm{H} ; \mathrm{X}=\mathrm{CO}$

2.1c, $\mathrm{R}=\mathrm{H} ; \mathrm{X}=\mathrm{CO}$

2.1d, $\mathrm{R}=\mathrm{CO}_{2} \mathrm{Me} ; \mathrm{X}=\mathrm{CHOH}$

2.1e, $\mathrm{R}=\mathrm{H} ; \mathrm{X}=\mathrm{CHOH}$

2.1f, $\mathrm{R}=\mathrm{H} ; \mathrm{X}=\mathrm{CH}_{2}$

2.1g, $\mathrm{R}=\mathrm{CO}_{2} \mathrm{Me} ; \mathrm{X}=\mathrm{CHOCH}_{3}$

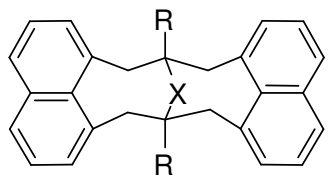

2.3a, $\mathrm{R}=\mathrm{CO}_{2} \mathrm{Me} ; \mathrm{X}=\mathrm{CO}$

2.3b, $\mathrm{R}=\mathrm{CO}_{2} \mathrm{H} ; \mathrm{X}=\mathrm{CO}$

2.3c, $\mathrm{R}=\mathrm{H} ; \mathrm{X}=\mathrm{CO}$

2.3e, $\mathrm{R}=\mathrm{H} ; \mathrm{X}=\mathrm{CHOH}$

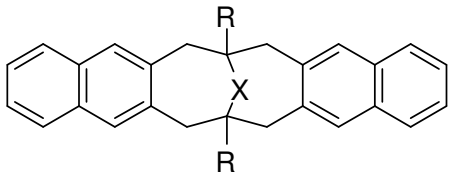

2.2a, $\mathrm{R}=\mathrm{CO}_{2} \mathrm{Me} ; \mathrm{X}=\mathrm{CO}$

2.2b, $\mathrm{R}=\mathrm{CO}_{2} \mathrm{H} ; \mathrm{X}=\mathrm{CO}$

2.2c, $\mathrm{R}=\mathrm{H} ; \mathrm{X}=\mathrm{CO}$

2.2e, $\mathrm{R}=\mathrm{H} ; \mathrm{X}=\mathrm{CHOH}$

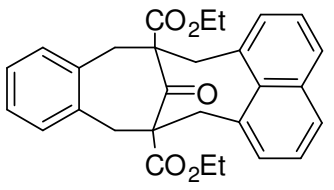

2.4

Figure 2.1. Conformational benzo-annelated bicylo[4.4.1] undecanes (from reference 8).

The plausible conformations for these compounds are illustrated in Figure 2.2. The boat-boat form $\left(\mathbf{B}_{1}\right)$ and chair-chair $\left(\mathbf{C}_{\mathbf{1}}\right)$ conformations are not formed according to the NMR characterization for 2.1c, 2.1f, 2.2a, and 2.2c. The $\mathbf{A}_{1} / \mathbf{A}_{1}{ }^{*}$ chair-boat conformations exist in equilibrium at room temperature, and one conformation is preferred at low temperature. One single crystal structure analysis of $\mathbf{2 . 1 a}$ confirmed the chair-boat conformation in the solid state. Comparisons of $\Delta G$ values calculated from dynamic ${ }^{13} \mathrm{C}$ NMR spectra (kinetic data from ring inversions calculated by signal widths 
and activation energies calculated from Eyring plots ${ }^{11}$ ) indicate that the conversion between chair-boat conformations (i.e. $\mathrm{A}_{1}$ and $\mathrm{A}_{1}{ }^{*}$ ) is stepwise.
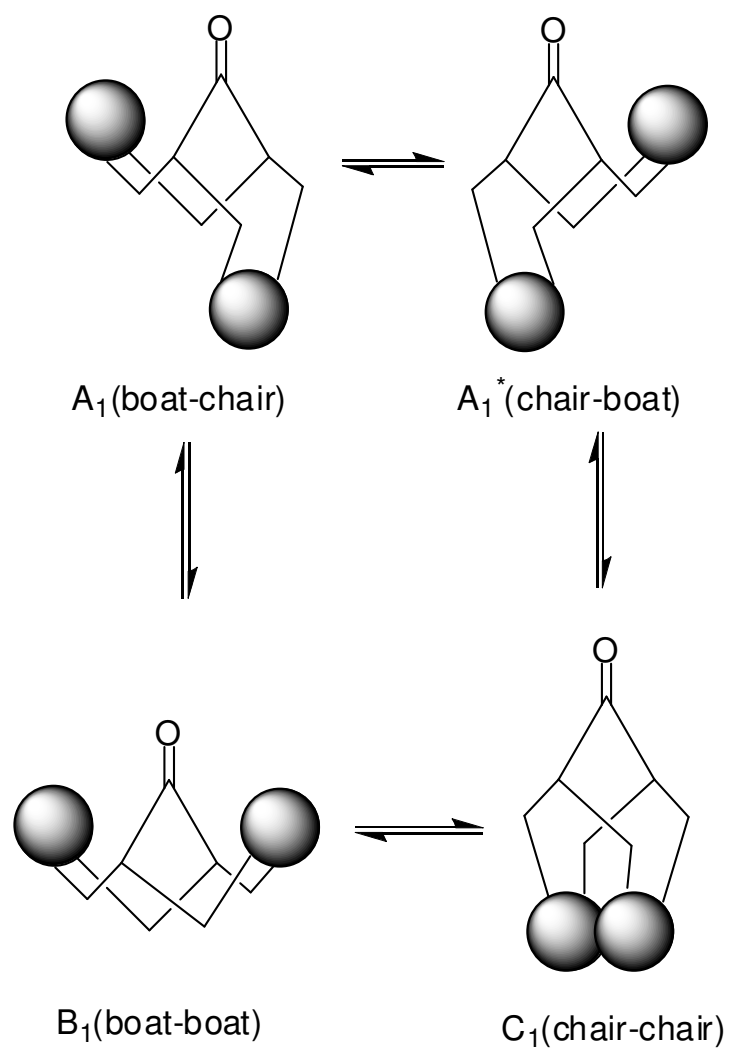

Figure 2.2. Possible dynamic conformations (from reference 8).

Expanding on his previous work, Mataka showed that the arenes fused to the bicyclo[4.4.1] undecane core could be forced into a stacked orientation, i.e. $\mathbf{C}_{\mathbf{1}}$ (chairchair) conformation, by ketalizing the ketones $\mathbf{2 . 1 - 2 . 3 c} .^{9}$ Several ketalizing groups were used: ethylene glycol, neopentyl glycol, and dithioketal to afford compounds $\mathbf{2 . 5}$ and $\mathbf{2 . 6}$, Figure 2.3. Face-to-face stacking was shown by an upfield shift for the aromatic signals in ${ }^{1} \mathrm{H}$ NMR spectra of ketals by $0.3-0.5$ ppm compared to the ketone precursors. In addition, the methylene protons exhibited geminal and vicinal splitting (i.e., a pair of 
doublet of doublets for the ketal). The X-ray crystal structures of some of the compounds showed close arene-arene contact of 3.03 to $4.1 \AA$.

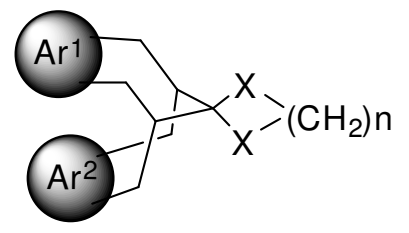

$$
2.5(X=O) \quad 2.6(X=S, n=2)
$$

2.5a: $A r^{1}=B, A r^{2}=B, n=2, Y=79 \%$

2.6a: $A r^{1}=B, A r^{2}=B, Y=96 \%$

2.5b: $A r^{1}=B, A r^{2}=B, n=3, Y=89 \%$

2.6b: $A r^{1}=N, A r^{2}=N, Y=96 \%$

2.5c: $A r^{1}=N, A r^{2}=N, n=2, Y=70 \%$

2.6c: $A r^{1}=B, A r^{2}=N, Y=62 \%$

2.5d: $A r^{1}=B, A r^{2}=N, n=2, Y=24 \%$

Figure 2.3. Orthocyclophanes with benzene and naphthalene (from reference 9). B and $\mathrm{N}$ indicate benzo and 2,3-naphtho annelation.

Mataka expanded his previous synthetic methodology to prepare arene-fused multi-decker orthocyclophanes to study the electronic properties of such compounds. One such compound was a triple-layered orthocyclophane ${ }^{3}$ in which Mataka demonstrated $\pi$ - $\pi$-communication from one naphthalene unit through the benzene core, to the other naphthalene unit by electrochemical investigations, Figure 2.4. Upfield shifts were apparent for this compound as well as the coupling of methylene protons consistent with a chair-chair conformation.

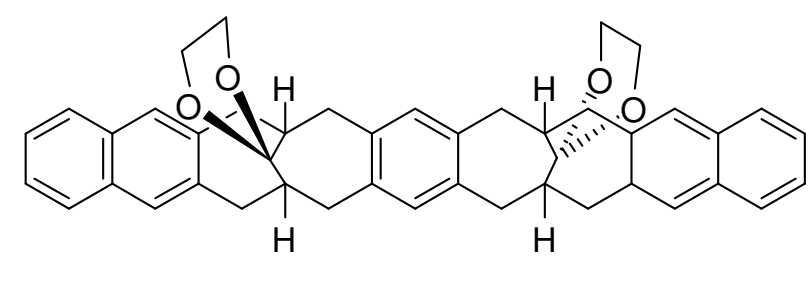

7 (anti acetals)

Figure 2.4. Triple-Deckered Orthocyclophane (from reference 3). 
The $\pi$-stacking effect were also apparent in a quadruple decker ${ }^{6}$ reported by Mataka in 1998, Figure 2.5. There was an pronounced upfield proton shift for the two inner benzene units $(\delta 5.77 \mathrm{ppm})$ and a less dramatic upfield shift for the outer benzene units $(\delta$ 6.4-6.62 ppm).

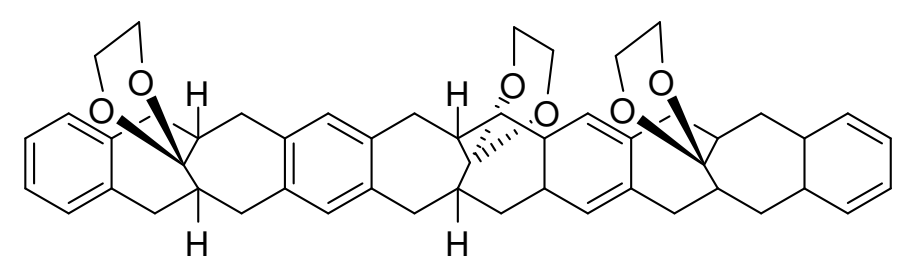

Figure 2.5. Quadruple Decker Orthocyclophane (from reference 6).

Here we report a roadmap to the efficient synthesis of a dithieno-fused bicyclo[4.4.1] undecane scaffold, and the ketalization of this core to provide a $\pi$-stacked core for $\pi$-conjugated oligomers to examine charge distribution in doped $\pi$-conjugated materials. Structural characterization was performed by variable temperature NMR and X-ray crystallography.

\subsection{Experimental}

\subsubsection{General Procedures}

All reagents and catalysts were purchased from Aldrich, TCI, or Strem Chemicals and used without further purification. THF and diethyl ether were distilled from benzophenone-sodium ketyl. Dichloromethane was distilled from calcium hydride and anhydrous DMF was purchased from Aldrich. ${ }^{1} \mathrm{H}$ and ${ }^{13} \mathrm{C}$ NMR spectra were recorded from a 300 or $400 \mathrm{MHz}$ Varian Mercury spectrophotometer. Infrared spectra were 
recorded on a Nicolet 4700 FTIR. Mass spectra were collected on a VG-70SE instrument. Elemental analyses were obtained from Atlantic Microlabs, Inc. Gravity and flash column chromatographies were carried out with silica gel (32-63 mesh, $60 \AA$ from Sorbent Technologies). TLC plates were visualized by a UV lamp or iodine vapor.

\subsubsection{Synthetic Procedures}

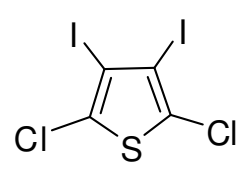

2,5-Dichloro-3,4-diiodothiophene. ${ }^{12}$ Iodine $(41 \mathrm{~g}, 0.16 \mathrm{~mol})$ was added to a solution of 2,5-dichlorothiophene (30 g, $0.2 \mathrm{~mol})$, periodic acid (20 g, $0.09 \mathrm{~mol})$, acetic acid (110 $\mathrm{mL}), \mathrm{H}_{2} \mathrm{O}(22 \mathrm{~mL})$, and $\mathrm{H}_{2} \mathrm{SO}_{4}(3.4 \mathrm{~mL})$, and the mixture was heated at $90{ }^{\circ} \mathrm{C}$ for $18 \mathrm{~h}$. The reaction mixture was cooled and a saturated aq. solution of $\mathrm{Na}_{2} \mathrm{SO}_{3}(300 \mathrm{~mL})$ was added, and the mixture was stirred for $10 \mathrm{~min} . \mathrm{CHCl}_{3}(100 \mathrm{~mL})$ was added, and the organic layer was separated. The aqueous layer was extracted with $\mathrm{CHCl}_{3}(2 \times 75 \mathrm{~mL})$ and the organic layers were combined, washed with $\mathrm{H}_{2} \mathrm{O}(5 \times 100 \mathrm{~mL}), 0.2 \mathrm{M} \mathrm{NaOH}(2 \times$ $50 \mathrm{~mL}$ ), $\mathrm{H}_{2} \mathrm{O}$ again $\left(2 \times 50 \mathrm{~mL}\right.$ ), dried over $\mathrm{MgSO}_{4}$, and the solvent was removed under reduced pressure. The crude product was recrystallized in ethanol $(300 \mathrm{~mL})$ to afford 2,5dichloro-3,4-diiodothiophene as a white crystalline solid (30 g, 80\%). MP $=78-80{ }^{\circ} \mathrm{C}$ (Lit. $\left.\mathrm{MP}=80-81{ }^{\circ} \mathrm{C}\right) .{ }^{13} \mathrm{C} \mathrm{NMR}\left(75 \mathrm{MHz}, \mathrm{CDCl}_{3}\right): \delta 128.3(\mathrm{Th}-3,4), 94.7(\mathrm{Th}-2,5) . \mathrm{MS}$ (EI): $m / z(\%) 403.7\left(\mathrm{M}^{+}, 100\right), 276\left(\mathrm{M}^{+}-\mathrm{I}, 24\right), 149\left(\mathrm{M}^{+}-2 \mathrm{I}, 30\right)$. 


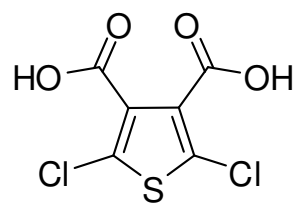

2,5-Dichloro-thiophene-3,4-dicarboxylic acid. ${ }^{12}$ A $2.5 \mathrm{M}$ solution of $n$-BuLi in hexanes $(0.28 \mathrm{~mol}, 110 \mathrm{~mL})$ was added dropwise to a cooled solution of 2,5-dichloro-3,4diiodothiophene $(50 \mathrm{~g}, 0.12 \mathrm{~mol})$ in dry ether $(200 \mathrm{~mL})$ at $-78{ }^{\circ} \mathrm{C}$. The mixture was allowed to stir for $1 \mathrm{~h}$ and then $\mathrm{CO}_{2}$ gas was bubbled through the reaction for $12 \mathrm{~h}$. Crushed ice (200 g) was added, and the aqueous layer was separated. The organic layer was washed with $10 \%$ aqueous $\mathrm{NaOH}(3 \times 50 \mathrm{~mL})$, and the combined aqueous layers were acidified with $12 \mathrm{M} \mathrm{HCl}$ to $\mathrm{pH}=1$. The aqueous layer was then slowly cooled to 4 ${ }^{\circ} \mathrm{C}$ overnight, and the precipitated needles were filtered and washed with cold water to afford 2,5-dichlorothiophene-3,4-dicarboxylic acid (14 g, 46\%) MP $=204-206{ }^{\circ} \mathrm{C}$ (Lit. $\left.\mathrm{MP}=205-206{ }^{\circ} \mathrm{C}\right) .{ }^{13} \mathrm{C} \mathrm{NMR}\left(75 \mathrm{MHz}, \mathrm{CDCl}_{3}\right): \delta 161.9(\mathrm{C}=\mathrm{O}), 131.7(\mathrm{Th}-2,5), 127.8$ (Th-3,4).

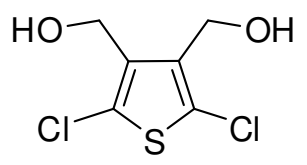

2,5-Dichloro-3,4-bis(hydroxymethyl)thiophene. ${ }^{13} \mathrm{LiAlH}_{4}(8.3 \mathrm{~g}, 0.2 \mathrm{~mol})$ was added to a solution of 2,5-dichlorothiophene-3,4-dicarboxylic acid (13 g, $50 \mathrm{mmol})$ in dry $\mathrm{Et}_{2} \mathrm{O}$ (300 $\mathrm{mL}$ ) at $0{ }^{\circ} \mathrm{C}$, warmed slowly to reflux, and stirred for $18 \mathrm{~h}$. The reaction was quenched with $\mathrm{H}_{2} \mathrm{O}$, and the product collected in ether. The solvent was removed under reduced pressure. Recrystallization from ethanol provided the title compound as a white solid 
$(10.2 \mathrm{~g}, 89 \%) . \mathrm{MP}=132-134{ }^{\circ} \mathrm{C}\left(\right.$ Lit. $\left.\mathrm{MP}=134-135^{\circ} \mathrm{C}\right) .{ }^{1} \mathrm{H}$ NMR $\left(300 \mathrm{MHz} \mathrm{CDCl}_{3}\right)$ : $\delta 4.80$ (b s, $2 \mathrm{H},-\mathrm{OH}), 4.61$ (s, $\left.4 \mathrm{H},-\mathrm{CH}_{2}-\right) .{ }^{13} \mathrm{C} \mathrm{NMR}\left(75 \mathrm{MHz}, \mathrm{CDCl}_{3}\right): \delta 136.6$ (Th3,4), 124.5 (Th-2,5), 56.7 (methylene). IR (KBr) 3470 (-OH), 2900, 1045, $825 \mathrm{~cm}^{-1}$. MS (EI): $m / z(\%) 211.9\left(\mathrm{M}^{+}, 100\right)$.

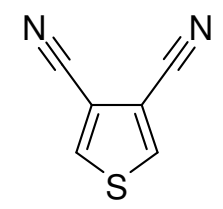

3,4-Dicyanothiophene. . $^{14,15}$ 3,4-Dibromothiophene (10 g, $\left.41 \mathrm{mmol}\right)$ was added to a suspension of copper cyanide $(10.7 \mathrm{~g}, 120 \mathrm{mmol})$ in DMF $(15 \mathrm{~mL})$ and refluxed for $4 \mathrm{~h}$. The mixture was cooled and poured into a solution of ferric chloride $(42 \mathrm{~g})$ in $1.7 \mathrm{M} \mathrm{HCl}$ $(100 \mathrm{~mL})$. The mixture was stirred for $30 \mathrm{~min}$ at $60{ }^{\circ} \mathrm{C}$, cooled and extracted with $\mathrm{CH}_{2} \mathrm{Cl}_{2}(3 \times 100 \mathrm{~mL})$. The organic layers were combined, washed with $2 \mathrm{M} \mathrm{HCl}, \mathrm{H}_{2} \mathrm{O}$ (200 mL), aqueous $\mathrm{Na}_{2} \mathrm{CO}_{3}(3 \times 50 \mathrm{~mL})$, and dried over $\mathrm{MgSO}_{4}$. The solvent was removed under reduced pressure, and the residue was sublimed and the residue then recrystallized from acetonitrile to afford 3,4-dicyanothiophene as a yellow solid (700 mg, 12\% $) . \mathrm{MP}=168-169{ }^{\circ} \mathrm{C}\left(\mathrm{Lit} . \mathrm{MP}=169-171^{\circ} \mathrm{C}\right) . \quad{ }^{1} \mathrm{H}$ NMR $\left(300 \mathrm{MHz}, \mathrm{CDCl}_{3}\right): \delta 8.1$ (s, 2H, Th-2,5). IR (KBr) 3018, 2235, $2230 \mathrm{~cm}^{-1}$. 


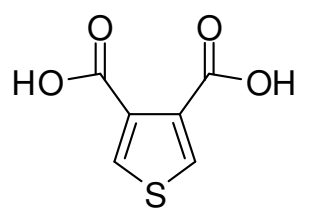

Thiophene-3,4-dicarboxylic acid. ${ }^{14,16}$ A solution of 3,4-dicyanothiophene $(1.4 \mathrm{~g}, 10$ mmol) and $\mathrm{NaOH}(2.7 \mathrm{~g}, 68 \mathrm{mmol})$ in ethylene glycol $(15 \mathrm{~mL})$ was heated to reflux, and the mixture was stirred for $18 \mathrm{~h}$, cooled, and poured onto ice (100 g). The solution was washed with $\mathrm{Et}_{2} \mathrm{O}(50 \mathrm{~mL})$, and the organic layer discarded. The aqueous layer was acidified with $12 \mathrm{M} \mathrm{HCl}$ to $\mathrm{pH}=1$. The round bottom was placed in the freezer overnight, and the precipitated crystals were separated by filtration and washed with cold $\mathrm{H}_{2} \mathrm{O}$ to afford thiophene-3,4-dicarboxylic acid as colorless needles (340 mg, 19\%). MP = 226-228 ${ }^{\circ} \mathrm{C}\left(\right.$ Lit. MP $\left.=227-229{ }^{\circ} \mathrm{C}\right) . \quad{ }^{1} \mathrm{H}$ NMR $\left(300 \mathrm{MHz}, \mathrm{CDCl}_{3}\right): \delta 8.10(\mathrm{~s}, 2 \mathrm{H}$, Th2,5), $10.90(-\mathrm{OH}) .{ }^{13} \mathrm{C}$ NMR (75 MHz, $\left.\mathrm{CDCl}_{3}\right): \delta 163.9(\mathrm{C}=\mathrm{O}), 137.4(\mathrm{Th}-3,4), 125.1$ (Th-2,5). IR (KBr) 3320, 3018, 1203, 1040, $976 \mathrm{~cm}^{-1}$.

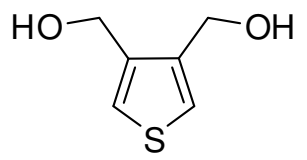

3,4-Bis(hydroxymethyl)thiophene. ${ }^{13,17} \mathrm{LiAlH}_{4}(3.15 \mathrm{~g}, 0.09 \mathrm{~mol})$ was added to a solution of thiophene-3,4-dicarboxylic acid $(1.5 \mathrm{~g}, 8.7 \mathrm{mmol})$ in dry THF $(150 \mathrm{~mL})$ and heated at reflux for $18 \mathrm{~h}$. The reaction was cooled to $0{ }^{\circ} \mathrm{C}$ and a saturated $\mathrm{NH}_{4} \mathrm{Cl}$ solution $(100$ $\mathrm{mL}$ ) was added dropwise over $45 \mathrm{~min}$. The solution was vigorously stirred and acidified with $12 \mathrm{M} \mathrm{HCl}$ to $\mathrm{pH}=1$. The organic layer was separated and the aqueous extracted with $\mathrm{CH}_{2} \mathrm{Cl}_{2}(3 \times 50 \mathrm{~mL})$. The combined organic layers were washed with $\mathrm{H}_{2} \mathrm{O}$ (100 $\mathrm{mL}$ ), and the solvent removed under reduced pressure to afford 3,4- 
bis(hydroxymethyl)thiophene as an white solid $(1.1 \mathrm{~g}, 88 \%)$. MP $=64-65^{\circ} \mathrm{C}(\mathrm{Lit} \mathrm{MP}=$ 65-66 $\left.{ }^{\circ} \mathrm{C}\right) .{ }^{1} \mathrm{H}$ NMR $\left(300 \mathrm{MHz}, \mathrm{CDCl}_{3}\right): \delta 7.1(\mathrm{~s}, 2 \mathrm{H}, \mathrm{Th}-2,5), 4.5\left(\mathrm{~s}, 4 \mathrm{H},-\mathrm{CH}_{2}-\right), 4.2$ (b s , 2H, -OH). ${ }^{13} \mathrm{C}$ NMR (75 MHz, $\mathrm{CDCl}_{3}$ ): $\delta 140.2$ (Th-3,4), 124.8 (Th-2,5), 59.3 (methylene). IR (KBr) 3295 (-OH), 3098, 2966, 2910, 1050, $1000 \mathrm{~cm}^{-1}$.

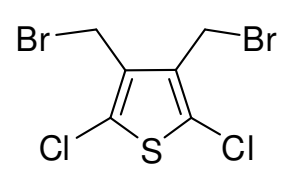

3,4-Bis(bromomethyl)-2,5-dichlorothiophene. ${ }^{13}$ 2,5-dichlorothiophene (5.1 g, $33 \mathrm{mmol}$ ) was added to a solution of $48 \%$ aq. $\mathrm{HBr}(100 \mathrm{~mL})$ and $36.8 \%$ aqueous formaldehyde (27.5 mL). The mixture was stirred at room temperature for $24 \mathrm{~h}, \mathrm{H}_{2} \mathrm{O}(100 \mathrm{~mL})$ was added, and the aqueous layer was extracted with $\mathrm{CH}_{2} \mathrm{Cl}_{2}(2 \times 50 \mathrm{~mL})$. The combined organic layers were washed with $10 \%$ aq. $\mathrm{NaHCO}_{3}(2 \times 100 \mathrm{~mL})$, and $\mathrm{H}_{2} \mathrm{O}(3 \times 100 \mathrm{~mL})$, and dried over $\mathrm{MgSO}_{4}$. The solvent was removed under reduced pressure to afford 3,4bis(bromomethyl)-2,5-dichlorothiophene as a white crystalline solid $(8.3 \mathrm{~g}, 73 \%) .{ }^{1} \mathrm{H}$ NMR (300 MHz, $\left.\mathrm{CDCl}_{3}\right): \delta 4.5$ (s, 4H, $\left.-\mathrm{CH}_{2}-\right) .{ }^{13} \mathrm{C} \mathrm{NMR}\left(75 \mathrm{MHz}, \mathrm{CDCl}_{3}\right): \delta 132.8$ (Th-3,4), 126.8 (Th-2,5), 21.9 (-CH $\left.2^{-}\right) . \quad$ IR (KBr) 2970, 2904, 1411, $975 \mathrm{~cm}^{-1}$. MS (EI): m/z (\%) $337.8\left(\mathrm{M}^{+}, 15\right), 259$ (100), 178 (80), 143 (15). HRMS (EI): m/z Calcd. for $\mathrm{C}_{6} \mathrm{H}_{4} \mathrm{Cl}_{2} \mathrm{Br}_{2} \mathrm{~S}, 337.77570$; found, 337.77593, $\Delta=0.6 \mathrm{ppm}$.<smiles>CC(=O)CSCC(C)=O</smiles>

1,1'-Thiodipropan-2-one. ${ }^{18}$ A solution of $\mathrm{Na}_{2} \mathrm{~S} \cdot 9 \mathrm{H}_{2} \mathrm{O}(52 \mathrm{~g}, 0.22 \mathrm{~mol})$ in $\mathrm{H}_{2} \mathrm{O}(200 \mathrm{~mL})$ was added dropwise to a solution of chloroacetone ( $40 \mathrm{~g}, 34 \mathrm{~mL}, 0.43 \mathrm{~mol})$ in acetone $(400 \mathrm{~mL})$ at room temperature over a period of $1 \mathrm{~h}$. The yellow solution was allowed to 
stir for an additional $1 \mathrm{~h}$, after which the acetone was removed under reduced pressure. The residue solution was extracted with methylene chloride $(10 \mathrm{~mL})$, and the aqueous layer was extracted with methylene chloride $(2 \times 50 \mathrm{~mL})$. The combined organic layers were washed with $10 \% \mathrm{Na}_{2} \mathrm{CO}_{3}(2 \times 50 \mathrm{~mL}), \mathrm{H}_{2} \mathrm{O}(2 \times 50 \mathrm{~mL})$, and dried over $\mathrm{MgSO}_{4}$. Evaporation of the solvent under reduced pressure afforded 1,1'-thiodipropan-2-one as orange crystals $(25 \mathrm{~g}, 80 \%) . \mathrm{MP}=43-45^{\circ} \mathrm{C}$. IR (neat) 2932, 1690, 1436, 1200, 1106 $\mathrm{cm}^{-1} .{ }^{1} \mathrm{H}$ NMR $\left(300 \mathrm{MHz}, \mathrm{CDCl}_{3}\right): \delta 2.26\left(\mathrm{~s}, 6 \mathrm{H},-\mathrm{CH}_{3}\right), 3.29\left(\mathrm{~s}, 4 \mathrm{H},-\mathrm{CH}_{2}-\right)$.

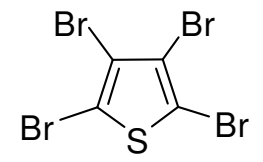

2,3,4,5-Tetrabromothiophene. ${ }^{19} \mathrm{Br}_{2}(220 \mathrm{~mL}, 4.0 \mathrm{~mol})$ was added dropwise to solution of thiophene $(84.0 \mathrm{~g}, 1.0$ mole $)$ in $\mathrm{CHCl}_{3}(35 \mathrm{~mL})$ at $0{ }^{\circ} \mathrm{C}$ over $3 \mathrm{~h}$. The last $50 \mathrm{~mL}$ of $\mathrm{Br}_{2}$ were added without external cooling. The mixture was heated for an additional 4 h. $2 \mathrm{M}$ $\mathrm{NaOH}(150 \mathrm{~mL})$ was cautiously added and the mixture was heated at reflux for an additional $1 \mathrm{~h}$. The mixture was transferred to a large evaporating dish and allowed to cool to room temperature. The large crystalline mass was filtered and washed with $\mathrm{H}_{2} \mathrm{O}$ (1 L). Recrystallization from $\mathrm{CHCl}_{3}$ afforded 2,3,4,5-tetrabromothiophene as a white crystalline solid $(315 \mathrm{~g}, 80 \%) . \mathrm{MP}=113-115{ }^{\circ} \mathrm{C}\left(\mathrm{Lit} . \mathrm{MP}=112-114{ }^{\circ} \mathrm{C}\right) .{ }^{13} \mathrm{C} \mathrm{NMR}(75$ $\mathrm{MHz}, \mathrm{CDCl}_{3}$ ): $\delta 116.9$ (Th-C-3,4), 110.3 (Th-C-2,5). IR (KBr) 1491, 1406, 1291, 866, $761 \mathrm{~cm}^{-1}$. 


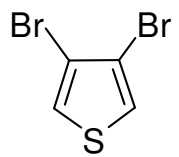

3,4-Dibromothiophene. ${ }^{19,20}$ A $2.5 \mathrm{M}$ solution of $n$-butyllithium in hexanes $(100 \mathrm{~mL}, 0.25$ mol) was added to a solution of tetrabromothiophene ( $50.0 \mathrm{~g}, 0.13 \mathrm{~mol})$ in dry $\mathrm{Et}_{2} \mathrm{O}$ (200 $\mathrm{mL}$ ) at $0{ }^{\circ} \mathrm{C}$. The resulting suspension was stirred for $2 \mathrm{~h}$ at $0{ }^{\circ} \mathrm{C}$, poured onto crushed ice $(350 \mathrm{~g})$, and extracted with $\mathrm{Et}_{2} \mathrm{O}(3 \times 50 \mathrm{~mL})$. The combined organic layers were washed with water ( $3 \times 150 \mathrm{~mL})$, dried over $\mathrm{MgSO}_{4}$, and the solvent was removed under reduced pressure. The residue was distilled to provide 3,4-dibromothiophene as a colorless liquid $(25 \mathrm{~g}, 81 \%) . \mathrm{BP}=96-99^{\circ} \mathrm{C} / 11 \mathrm{mmHg}$. (Lit. $\mathrm{BP}=220{ }^{\circ} \mathrm{C} / 760$ torr. $){ }^{1} \mathrm{H}$ NMR $(300 \mathrm{MHz}$, $\left.\mathrm{CDCl}_{3}\right): \delta 7.41(\mathrm{~s}, 2 \mathrm{H}, \mathrm{Th}-\mathrm{H}) .{ }^{13} \mathrm{C}$ NMR $\left(75 \mathrm{MHz}, \mathrm{CDCl}_{3}\right): \delta 123.6$ (Th-H), 113.8 (ThBr). IR (neat) 3112, 1415, 1394, 1208, 1155, 900, $702 \mathrm{~cm}^{-1}$.

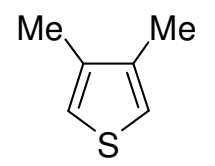

3,4-Dimethylthiophene. ${ }^{19,21}$ A $2.5 \mathrm{M}$ solution of methylmagnesium bromide $(200 \mathrm{~mL})$ in hexanes was cannulated into a solution of 3,4-dibromothiophene (50 g, $0.21 \mathrm{~mol})$ and $\mathrm{Ni}(\mathrm{dppp}) \mathrm{Cl}_{2}(5.6 \mathrm{~g}, 11 \mathrm{mmol})$ in $\operatorname{dry~}_{\mathrm{Et}} \mathrm{O}(250 \mathrm{~mL})$ at $0{ }^{\circ} \mathrm{C}$ under $\mathrm{N}_{2}$. After $30 \mathrm{~min}$, the mixture was heated to reflux and stirred for $24 \mathrm{~h}$. The flask was cooled to $0{ }^{\circ} \mathrm{C}$ and carefully poured onto crushed ice $(300 \mathrm{~g})$, and a $2 \mathrm{M} \mathrm{HCl}(50 \mathrm{~mL})$ solution was added. The organic layer was separated, and the aqueous phase was extracted with $\mathrm{Et}_{2} \mathrm{O}(4 \times 100$ $\mathrm{mL})$. The combined organic layers were washed with saturated aq. $\mathrm{NaHCO}_{3}(2 \times 150$ $\mathrm{mL}), \mathrm{H}_{2} \mathrm{O}(3 \times 100 \mathrm{~mL})$, and dried over $\mathrm{MgSO}_{4}$. The solvent was removed under reduced pressure, and the residue was distilled to afford 3,4-dimethylthiophene as a 
colorless liquid $(20 \mathrm{~g}, 87 \%) . \mathrm{BP}=142-144{ }^{\circ} \mathrm{C} / 760$ torr. ${ }^{1} \mathrm{H}$ NMR $\left(300 \mathrm{MHz}, \mathrm{CDCl}_{3}\right): \delta$ $6.88(\mathrm{~s}, 2 \mathrm{H}, \mathrm{Th}-2,5), 2.21\left(\mathrm{~s}, 6 \mathrm{H},-\mathrm{CH}_{3}\right) .{ }^{13} \mathrm{C} \mathrm{NMR}\left(75 \mathrm{MHz}, \mathrm{CDCl}_{3}\right): \delta 137.6$, (Th-C3,4), 127.6 (Th-C-2,5), $14.6\left(-\mathrm{CH}_{2}-\right)$. IR (neat) 3110, 2948, 2875, 1413, 1394, 1228, 1155, 900, $750 \mathrm{~cm}^{-1}$. HRMS (EI): $\mathrm{m} / z$ Calcd. for $\mathrm{C}_{6} \mathrm{H}_{8} \mathrm{~S}, 112.01498$; found, 112.01532, $\Delta=3.1 \mathrm{ppm}$

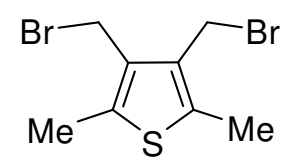

3,4-Bis(bromomethyl)-2,5-dimethylthiophene. ${ }^{22}$ 2,5-dimethylthiophene (5.0 g, $\left.45 \mathrm{mmol}\right)$ was added to a solution of $48 \%$ aq. $\mathrm{HBr}(100 \mathrm{~mL})$ and $37 \%$ aqueous formaldehyde $(27.5$ $\mathrm{mL})$. The mixture was stirred at room temperature for $24 \mathrm{~h}, \mathrm{H}_{2} \mathrm{O}(100 \mathrm{~mL})$ was added, and the aqueous layer was extracted with $\mathrm{CH}_{2} \mathrm{Cl}_{2}(2 \times 50 \mathrm{~mL})$. The combined organic layers were washed with $10 \%$ aq. $\mathrm{NaHCO}_{3}(2 \times 100 \mathrm{~mL}), \mathrm{H}_{2} \mathrm{O}(3 \times 100 \mathrm{~mL})$, and dried over $\mathrm{MgSO}_{4}$. The solvent was removed under reduced pressure to afford 3,4bis(bromomethyl)-2,5-dimethylthiophene as a pale green crystalline solid (11.02 g, 83\%). $\mathrm{MP}=76-78{ }^{\circ} \mathrm{C} .{ }^{1} \mathrm{H}$ NMR $\left(300 \mathrm{MHz}, \mathrm{CDCl}_{3}\right): \delta 4.52\left(\mathrm{~s}, 4 \mathrm{H},-\mathrm{CH}_{2}-\right), 2.37\left(\mathrm{~s}, 6 \mathrm{H},-\mathrm{CH}_{3}\right)$. ${ }^{13} \mathrm{C}$ NMR (75 MHz, $\left.\mathrm{CDCl}_{3}\right): \delta 135.9(\mathrm{Th}-\mathrm{C}-3,4), 131.7(\mathrm{Th}-\mathrm{C}-2,5), 24.6\left(-\mathrm{CH}_{2}-\right), 13.0(-$ $\left.\mathrm{CH}_{3}\right) . \mathrm{IR}(\mathrm{KBr}) 3113,2914,2880,1412,1380,1201,1145,905,750 \mathrm{~cm}^{-1} . \mathrm{MS}(\mathrm{EI}): \mathrm{m} / z$ (\%) $297.9\left(\mathrm{M}^{+}\right.$, 9), $219\left(\mathrm{M}^{+}-\mathrm{Br}, 45\right), 138\left(\mathrm{M}^{+}-2 \mathrm{Br}, 100\right)$. HRMS (EI): $m / z$ Calcd. for $\mathrm{C}_{6} \mathrm{H}_{10} \mathrm{Br}_{2} \mathrm{~S}, 297.88495$; found, 297.88461, $\Delta=1.1 \mathrm{ppm}$. 


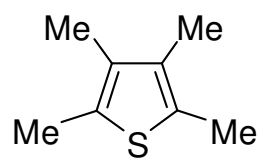

Tetramethylthiophene. ${ }^{23} \mathrm{LiAlH}_{4}(3.5 \mathrm{~g}, 93 \mathrm{mmol})$ was added to a solution of 3,4bis(bromomethyl)-2,5-dimethy-thiophene $(11.0 \mathrm{~g}, 37 \mathrm{mmol})$ in dry THF $(150 \mathrm{~mL})$ at 0 ${ }^{\circ} \mathrm{C}$ under $\mathrm{N}_{2}$. The mixture was heated to reflux for $18 \mathrm{~h}$, cooled to $0{ }^{\circ} \mathrm{C}$, and saturated aq. $\mathrm{NH}_{4} \mathrm{Cl}(100 \mathrm{~mL})$ was added. The aqueous layer was extracted with hexanes $(3 \times 50 \mathrm{~mL})$. The combined organic layers were washed with $\mathrm{H}_{2} \mathrm{O}(150 \mathrm{~mL})$, dried over $\mathrm{MgSO}_{4}$, and the solvent was removed under reduced pressure. The residue was vacuum distilled to afford tetramethylthiophene as a colorless liquid $(3.2 \mathrm{~g}, 60 \%) . \mathrm{BP}=80-85^{\circ} \mathrm{C} / 20 \mathrm{~mm}$ (Lit. $\left.\mathrm{BP}=74-79^{\circ} \mathrm{C} / 15 \mathrm{~mm}\right) . \quad{ }^{1} \mathrm{H}$ NMR $\left(300 \mathrm{MHz}, \mathrm{CDCl}_{3}\right): \delta 2.37\left(\mathrm{~s}, 6 \mathrm{H}, \mathrm{Th}-2,5-\mathrm{CH}_{3}\right)$, 2.08 (s, 6H, Th-3,4-CH 3 ). ${ }^{13} \mathrm{C}$ NMR (75 MHz, $\mathrm{CDCl}_{3}$ ): $\delta 132.8$ (Th-C-3,4), 127.6 (Th-C2,5), $13.0\left(-\mathrm{CH}_{3}\right), 12.7\left(-\mathrm{CH}_{3}\right)$. IR (neat) 2911, 2858, 1438, 1383, 1156, 1043, 954.

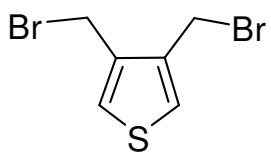

3,4-bis(bromomethyl)-thiophene. ${ }^{17} \mathrm{~N}$-bromosuccinimide $(6.4 \mathrm{~g}, 36 \mathrm{mmol})$ and benzoyl peroxide (200 mg, $0.8 \mathrm{mmol})$ were added to a solution of 3,4-dimethylthiophene ( $2.0 \mathrm{~g}$, $18 \mathrm{mmol})$ in $\mathrm{CCl}_{4}(100 \mathrm{~mL})$. The solution was slowly warmed to reflux at which time a W lamp was placed against the flask for $30 \mathrm{~min}$. After $2 \mathrm{~h}$ the solution was cooled to 0 ${ }^{\circ} \mathrm{C}$, and the succinimide was removed by filtration. The solvent was removed under reduced pressure to produce an orange oil which was subjected to column chromatography (100\% hexanes) to afford 3,4-bis(bromomethyl)thiophene as a colorless solid $(1.9 \mathrm{~g}, 40 \%) . \mathrm{MP}=81-82{ }^{\circ} \mathrm{C} .{ }^{1} \mathrm{H}$ NMR $\left(300 \mathrm{MHz}, \mathrm{CDCl}_{3}\right): \delta 7.4(\mathrm{~s}, 2 \mathrm{H}, \mathrm{Th}-2,5)$, 4.6 (s, 4H, - $\left.\mathrm{CH}_{2}-\right) .{ }^{13} \mathrm{C}$ NMR (75 MHz, $\mathrm{CDCl}_{3}$ ): $\delta 136.4$ (Th-C-3,4), 127.0 (Th-C-2,5), 
$25.7\left(-\mathrm{CH}_{2}-\right) . \quad \mathrm{IR}(\mathrm{KBr}) 3100,2950,1412,1200,610 \mathrm{~cm}^{-1} . \mathrm{MS}(\mathrm{EI}): \mathrm{m} / z(\%) 269.9\left(\mathrm{M}^{+}\right.$, 17). HRMS (EI): $\mathrm{m} / z$ Calcd. for $\mathrm{C}_{6} \mathrm{H}_{6} \mathrm{Br}_{2} \mathrm{~S}, 267.85569$; found, 267.85354, $\Delta=8 \mathrm{ppm}$.

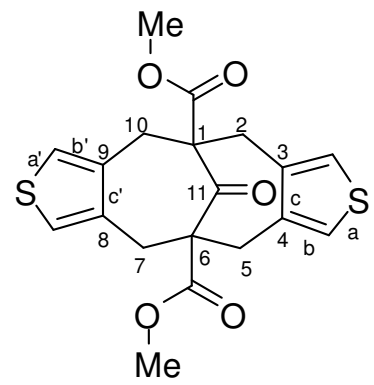

Dimethyl 11-oxo-dithieno[3,4-c:8,9-c']bicyclo[4.4.1]undeca-3,8-diene-1,6-dicarboxylate. Tetra- $n$-butylammonium bromide $(1.05 \mathrm{~g}, 3.2 \mathrm{mmol})$ was added to a solution of 3,4bis(bromomethyl)thiophene $(3.1 \mathrm{~g}, 11 \mathrm{mmol})$ in $\mathrm{CH}_{2} \mathrm{Cl}_{2}(30 \mathrm{~mL})$ analogous to literature procedures. ${ }^{4-7,9}$ A $25 \%$ aq. $\mathrm{NaOH}$ solution $(25 \mathrm{~mL})$ was added, and the resulting biphasic mixture was vigorously stirred at room temperature. A solution of dimethyl 1,3acetonedicarboxylate $(1.13 \mathrm{~g}, 6.50 \mathrm{mmol})$ in $\mathrm{CH}_{2} \mathrm{Cl}_{2}(30 \mathrm{~mL})$ was added dropwise over 1 h. After stirring for $24 \mathrm{~h}, \mathrm{H}_{2} \mathrm{O}(50 \mathrm{~mL})$ was added and the organic layer was separated. The aqueous layer was extracted with $\mathrm{CH}_{2} \mathrm{Cl}_{2}(3 \times 50 \mathrm{~mL})$. The combined organic layers were washed with a $5 \%$ aqueous $\mathrm{HCl}$ solution $(2 \times 50 \mathrm{~mL})$ and $\mathrm{H}_{2} \mathrm{O}(3 \times 75 \mathrm{~mL})$, and dried over $\mathrm{MgSO}_{4}$. Removal of solvent under reduced pressure afforded a yellow oil, which was purified by flash chromatography (30\% ethyl acetate/70\% hexanes) to give the title compound as a white solid $(1.9 \mathrm{~g}, 74 \%) . \mathrm{MP}=162-164{ }^{\circ} \mathrm{C} .{ }^{1} \mathrm{H}$ NMR $(300 \mathrm{MHz}$, $\left.\mathrm{CDCl}_{3}\right): \delta$ 7.01-7.1 (b s, $\left.4 \mathrm{H}, \mathrm{Th}-\mathrm{H}\right), 3.71\left(\mathrm{~s}, 6 \mathrm{H},-\mathrm{OCH}_{3}\right), 2.65-3.32\left(\mathrm{~m}, 8 \mathrm{H},-\mathrm{CH}_{2}-\right) .{ }^{1} \mathrm{H}$ NMR $\left(\mathrm{CDCl}_{3},-60{ }^{\circ} \mathrm{C}\right): \delta 7.0(\mathrm{~s}, 2 \mathrm{H}, \mathrm{Th}), 7.2(\mathrm{~s}, 2 \mathrm{H}, \mathrm{Th}) 3.61\left(\mathrm{~s}, 6 \mathrm{H},-\mathrm{OCH}_{3}\right), 3.70(\mathrm{~d}$, $\left.2 \mathrm{H}, J=15.4 \mathrm{~Hz},-\mathrm{CH}_{2}-\right), 3.40\left(\mathrm{~d}, 2 \mathrm{H}, J=15.4 \mathrm{~Hz},-\mathrm{CH}_{2}-\right), 3.01(\mathrm{~d}, 2 \mathrm{H}, J=14.8 \mathrm{~Hz},-$ $\left.\mathrm{CH}_{2}-\right), 2.45\left(\mathrm{~d}, 2 \mathrm{H}, J=14.8 \mathrm{~Hz},-\mathrm{CH}_{2}-\right) .{ }^{13} \mathrm{C}$ NMR $\left(75 \mathrm{MHz}, \mathrm{CDCl}_{3}\right) \delta 209.6$ (ketone 
$\mathrm{C}=\mathrm{O}$ ), 172.4 (ester $\mathrm{C}=\mathrm{O}), 136.6$ (Th-C-3,4), 124.0 (Th-C-2,5), 64.5 (-CH-), 52.3 ($\left.\mathrm{OCH}_{3}\right), 31.02\left(-\mathrm{CH}_{2}-\right)$. IR (KBr) 3158, 3098, 3006, 2960, 2848, 1738, 1697, 1433, 1275, 1235, 1104, 1071, 919, 748, $694 \mathrm{~cm}^{-1}$. MS (EI): $\mathrm{m} / z(\%) 390.2\left(\mathrm{M}^{+}, 100\right) . \quad$ HRMS (EI): $\mathrm{m} / 2$ Calcd. for $\mathrm{C}_{19} \mathrm{H}_{18} \mathrm{O}_{5} \mathrm{~S}_{2}, 390.05957$; found, 390.06095, $\Delta=3.5 \mathrm{ppm}$.

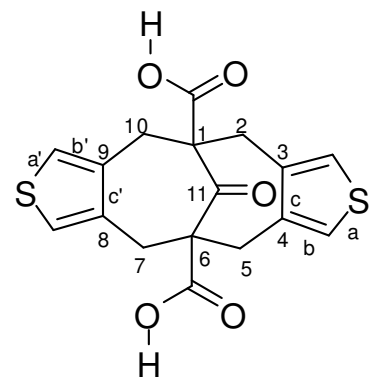

11-Oxo-dithieno[3,4-c:8,9-c']bicyclo[4.4.1]undeca-3,8-diene-1,6-dicarboxylic acid. ${ }^{4-7,9}$ A solution of the dimethyl-11-oxo-dithieno[3,4-c:8,9-c']bicyclo[4.4.1]undeca-3,8-diene1,6-dicarboxylate $(2.0 \mathrm{~g}, 5.5 \mathrm{mmol})$ and $\mathrm{KOH}(3.1 \mathrm{~g}, 54 \mathrm{mmol})$ in ethanol/ $\mathrm{H}_{2} \mathrm{O}(30 \mathrm{~mL} / 5$ $\mathrm{mL})$ was heated at reflux for $18 \mathrm{~h}$. The solvent was evaporated, and water $(25 \mathrm{~mL})$ was added. The mixture was acidified to $\mathrm{pH}=1$ with concentrated $\mathrm{HCl}$, and the precipitated white solid was collected by filtration and recrystallized from ethanol to give the title compound as colorless needles $(1.5 \mathrm{~g}, 80 \%) . \quad \mathrm{MP}=>300{ }^{\circ} \mathrm{C}($ decomp$) . \quad{ }^{1} \mathrm{H}$ NMR $(300$ MHz, DMSO- $\left.d_{6}\right): \delta 7.2(\mathrm{~s}, 4 \mathrm{H}, \mathrm{Th}-2,5), 3.2(\mathrm{~b} \mathrm{~s}, 1 \mathrm{H},-\mathrm{OH}), 2.71-3.02\left(\mathrm{~m}, 8 \mathrm{H},-\mathrm{CH}_{2}-\right.$ ). ${ }^{13} \mathrm{C}$ NMR (75MHz, DMSO- $\left.d_{6}\right): \delta 207.3$ (ketone $\left.\mathrm{C}=\mathrm{O}\right), 173.0$ (diacid C=O), 137.3 (Th-C3,4), 124.1 (Th-C-2,5), 63.7 (-CH-), 32.0 (- $\left.\mathrm{CH}_{2}-\right) . \quad$ IR (KBr) 3420, 3011, 2952, 1702, 1695, 1241, 1040, 918, 830, $715 \mathrm{~cm}^{-1}$. MS (EI): $\mathrm{m} / z(\%) 362.0\left(\mathrm{M}^{+}, 100\right) . \quad$ HRMS (EI): $\mathrm{m} / \mathrm{z}$ Calcd. for $\mathrm{C}_{15} \mathrm{H}_{14} \mathrm{OS}_{2}, 362.02827$; found, 362.02908, $\Delta=2.2 \mathrm{ppm}$. 


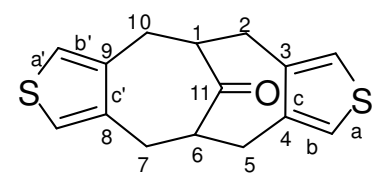

Dithieno[3,4-c:8,9-c']bicyclo[4.4.1] undeca-3,8-diene-11-one. ${ }^{4-7,9}$ 11-Oxo-dithieno[3,4c:8,9-c']bicyclo[4.4.1]undeca-3,8-diene-1,6-dicarboxylic acid (200 mg, $550 \mu \mathrm{mol})$ was heated at $300{ }^{\circ} \mathrm{C}$ in a pyrex tube under $\mathrm{N}_{2}$ until the evolution of gas ceased (approx. 5-10 min). After the reaction was complete, $\mathrm{CH}_{2} \mathrm{Cl}_{2}(25 \mathrm{~mL})$ and a $10 \%$ aq. $\mathrm{NaOH}$ solution (10 $\mathrm{mL})$ were added. The organic layer was separated, dried over $\mathrm{MgSO}_{4}$, and the solvent was removed under reduced pressure. The aqueous layer was reacidified with 12 $\mathrm{M} \mathrm{HCl}$ to $\mathrm{pH}=1$, extracted with $\mathrm{Et}_{2} \mathrm{O}$, dried over $\mathrm{MgSO}_{4}$, and resubjected to pyrolysis. The residue was extracted with $\mathrm{CH}_{2} \mathrm{Cl}_{2}(30 \mathrm{~mL})$, and the solvent was removed. The combined residues were subjected to column chromatography on silica gel (30\% ethyl acetate/70\% hexanes) to give a white solid $(115 \mathrm{mg}, 76 \%) . \mathrm{MP}=180-181{ }^{\circ} \mathrm{C} .{ }^{1} \mathrm{H}$ NMR (300 MHz, $\mathrm{CDCl}_{3}$ ): $\delta$ 6.99-7.01 (br s, 4H, Th-H), 3.00-3.25 (m, 2H, -CH-), 2.70-2.90 (m, 8H, $-\mathrm{CH}_{2-}$ ). ${ }^{13} \mathrm{C}$ NMR $\left(75 \mathrm{MHz}, \mathrm{CDCl}_{3}\right.$ ): $\delta 215.4$ (ketone $\left.\mathrm{C}=\mathrm{O}\right), 138.3$ (Th-C-3,4), 123.0 (Th-C-2,5), 53.7 (-CH-), 30.2 (- $\left.\mathrm{CH}_{2}-\right)$. IR (KBr) 3151, 3098, 2934, 2848, 1690, 1216, 1104, 908, $740 \mathrm{~cm}^{-1}$. MS (EI): $m / z(\%) 274.0\left(\mathrm{M}^{+}, 100\right), 163$ (59), 135 (15), 111 (46). HRMS (EI): $m / z$ Calcd. for $\mathrm{C}_{15} \mathrm{H}_{14} \mathrm{OS}_{2}, 274.04861$; found, 274.04744, $\Delta=4.2 \mathrm{ppm}$.

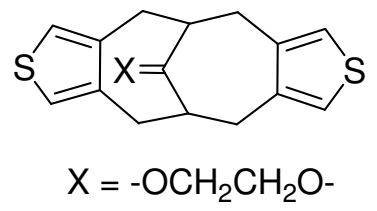

Ethylene acetal of dithieno[3,4-c:8,9-c']bicyclo[4.4.1]undeca-3,8-diene-11-one. ${ }^{4-7,9} \mathrm{~A}$ solution of the dithieno[3,4-c:8,9-c']bicyclo[4.4.1]undeca-3,8-diene-11-one (50 mg, 0.18 mmol), ethylene glycol (113 mg, $1.82 \mathrm{mmol})$, and $p$-toluenesulfonic acid (2 mg) in 
benzene $(10 \mathrm{~mL})$ was heated at reflux for $18 \mathrm{~h}$ with a Dean-Stark trap. The solvent was evaporated under reduce pressure, and the residue was subjected to column chromatography on silica gel (10\% ethyl acetate/90\% hexanes) to give the title compound as colorless crystalline solid $(55 \mathrm{mg}, 95 \%) . \mathrm{MP}=214-215{ }^{\circ} \mathrm{C}(\mathrm{decomp}) .{ }^{1} \mathrm{H}$ NMR (300 $\left.\mathrm{MHz}, \mathrm{CDCl}_{3}\right): \delta 6.51$ (s, 4H, Th-H), $4.06\left(\mathrm{~s}, 4 \mathrm{H},-\mathrm{OCH}_{2} \mathrm{CH}_{2} \mathrm{O}-\right), 3.17$ (dd, $4 \mathrm{H}, J=3.3,15$ $\left.\mathrm{Hz},-\mathrm{CH}_{2^{-}}\right), 2.80\left(\mathrm{dd}, 4 \mathrm{H}, J=5,15 \mathrm{~Hz},-\mathrm{CH}_{2}-\right), 2.16-2.25$ (m, $\left.2 \mathrm{H},-\mathrm{CH}-\right) .{ }^{13} \mathrm{C}$ NMR (75 $\mathrm{MHz}, \mathrm{CDCl}_{3}$ ): $\delta 140.2$ (Th-C-3,4), 121.5 (Th-C-2,5), 113.8 (ketal), $64.7\left(-\mathrm{OCH}_{2} \mathrm{CH}_{2} \mathrm{O}-\right.$ ), 42.5 (bridgehead), $31.2\left(-\mathrm{CH}_{2}-\right)$. IR (KBr) 3125, 2920, 1430, 1250, 1170, 100, 990, 945 $\mathrm{cm}^{-1}$. MS (EI): m/z (\%) $318.1\left(\mathrm{M}^{+}, 100\right), 273$ (5), 232 (10), 207 (84), 163 (21), 135 (16), 110 (12). HRMS (EI): $m / z$ Calcd. for $\mathrm{C}_{17} \mathrm{H}_{18} \mathrm{O}_{2} \mathrm{~S}_{2}, 318.07482$; found, 318.07665, $\Delta=5.7$ ppm. Anal. calcd. for $\mathrm{C}_{17} \mathrm{H}_{18} \mathrm{O}_{2} \mathrm{~S}_{2}$ : C, 64.11; H, 5.78; S, 20.14. Found: C, 64.10; H, 5.69; S, 20.08 .

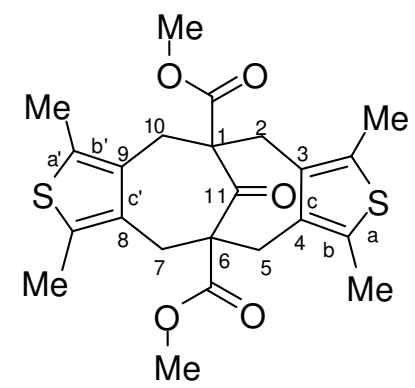

Dimethyl 11-oxo-(2,2',5,5'-tetramethyl)dithieno[3,4-c:8,9-c']bicyclo[4.4.1]undeca-3,8diene-1,6-dicarboxylate. ${ }^{24}$ Tetra- $n$-butylammonium bromide $(3.09 \mathrm{~g}, 9.6 \mathrm{mmol})$ was added to a solution of 3,4-bis(bromomethyl)-2-5-dimethylthiophene (10 g, $34 \mathrm{mmol}$ ) in $\mathrm{CH}_{2} \mathrm{Cl}_{2}(50 \mathrm{~mL})$. A $25 \%$ aq. $\mathrm{NaOH}$ solution $(50 \mathrm{~mL})$ was added, and the resulting biphasic mixture was vigorously stirred at room temperature. A solution of dimethyl 1,3acetonedicarboxylate $(3.36 \mathrm{~g}, 19 \mathrm{mmol})$ in $\mathrm{CH}_{2} \mathrm{Cl}_{2}(50 \mathrm{~mL})$ was added dropwise over $1 \mathrm{~h}$. After stirring for $24 \mathrm{~h}, \mathrm{H}_{2} \mathrm{O}(50 \mathrm{~mL})$ was added and the organic layer was separated. The 
aqueous layer was extracted with $\mathrm{CH}_{2} \mathrm{Cl}_{2}(3 \times 50 \mathrm{~mL})$. The combined organic layers were washed with a $5 \%$ aqueous $\mathrm{HCl}$ solution $(2 \times 50 \mathrm{~mL})$ and $\mathrm{H}_{2} \mathrm{O}(2 \times 25 \mathrm{~mL})$, and dried over $\mathrm{MgSO}_{4}$. Removal of solvent under reduced pressure afforded a yellow oil, which was purified by flash chromatography (20\% ethyl acetate/ $80 \%$ hexanes) to give the title compound as a white solid $(3.8 \mathrm{~g}, 50 \%) . \mathrm{MP}=221-222{ }^{\circ} \mathrm{C}\left(\mathrm{Lit} . \mathrm{MP}=215-216^{\circ} \mathrm{C}\right) .{ }^{1} \mathrm{H}$ NMR (300 MHz, $\left.\mathrm{CDCl}_{3}\right): 3.75$ (s, 6H, $\left.-\mathrm{OCH}_{3}\right), 2.70-3.32\left(\mathrm{~m}, 8 \mathrm{H},-\mathrm{CH}_{2}-\right), 2.32(\mathrm{~s}, 12 \mathrm{H}$, methyl). ${ }^{13} \mathrm{C}$ NMR $\left(75 \mathrm{MHz}, \mathrm{CDCl}_{3}\right) \delta 207.0$ (ketone $\mathrm{C}=\mathrm{O}$ ), 172.9 (ester $\mathrm{C}=\mathrm{O}$ ), 132.5 (Th-C-3,4), 124.0 (Th-C-2,5), 64.6 (bridgehead), $52.6\left(-\mathrm{OCH}_{3}\right), 29.0$ (methylene), 13.1 (methyl). IR (KBr) 2953, 2914, 2839, 1736, 1446, 1229, 1235, 1071, 913, 742, $657 \mathrm{~cm}^{-1}$. MS (EI): $m / z(\%) 446.1\left(\mathrm{M}^{+}, 52\right), 428.2(25), 369.1$ (14), 138.3 (100). HRMS (EI): $\mathrm{m} / \mathrm{z}$ Calcd. for $\mathrm{C}_{23} \mathrm{H}_{26} \mathrm{O}_{5} \mathrm{~S}_{2}$, 446.12217; found, 446.12406, $\Delta=4.2 \mathrm{ppm}$.

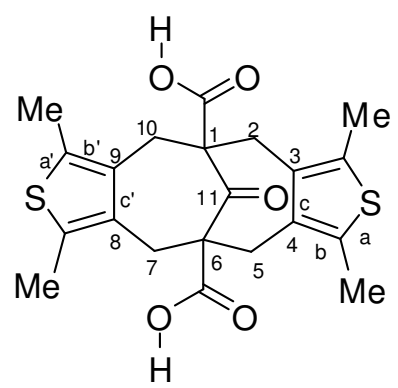

11-Oxo-(2,2',5,5'-tetramethyl)dithieno[3,4-c:8,9-c']bicyclo[4.4.1]undeca-3,8-diene-1,6dicarboxylic acid. $^{24}$ A solution of the dimethyl 11-oxo-dithieno[3,4-c:8,9c']bicyclo[4.4.1]undeca-3,8-diene-1,6-dicarboxylate $(1.6 \mathrm{~g}, 3.6 \mathrm{mmol})$ and $\mathrm{KOH}(2.5 \mathrm{~g}$, $63 \mathrm{mmol})$ in ethanol/ $\mathrm{H}_{2} \mathrm{O}(40 \mathrm{~mL} / 10 \mathrm{~mL})$ was heated at reflux for $18 \mathrm{~h}$. The solvent was evaporated, and $\mathrm{H}_{2} \mathrm{O}(25 \mathrm{~mL})$ was added. The mixture was acidified to $\mathrm{pH}=1$ with concentrated $\mathrm{HCl}$, and the precipitated white solid was collected by filtration and recrystallized from ethanol to give the title compound as colorless needles $(1.4 \mathrm{~g}, 93 \%)$. 
$\mathrm{MP}=315-316{ }^{\circ} \mathrm{C}($ decomp$)\left(\right.$ Lit. $\left.\mathrm{MP}=322-324{ }^{\circ} \mathrm{C}\right) .{ }^{1} \mathrm{H}$ NMR $\left(300 \mathrm{MHz}\right.$, DMSO- $\left.d_{6}\right): \delta$ 2.5-2.65 (m, 8H, methylene), 3.02 (m, 2H, bridgehead), 2.21 (s, 12H, methyl). ${ }^{13} \mathrm{C}$ NMR (75MHz, DMSO- $\left.d_{6}\right): \delta 215.3$ (ketone C=O), $173.0($ diacid C=O), $133.3($ Th-C-3,4), 130.1 (Th-C-2,5), 63.5 (bridgehead), 27.0 (methylene), 12.8 (methyl). IR (KBr) 3420, 2852, $1680,1415,1241,1130,1040,924,850,715 \mathrm{~cm}^{-1}$.

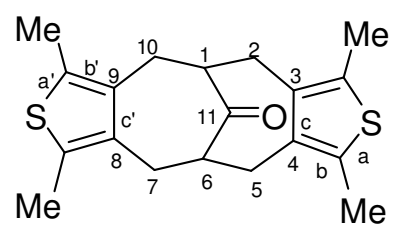

2,2',5,5'-Tetramethyl-dithieno[3,4-c:8,9-c']bicyclo[4.4.1]undeca-3,8-diene-11-one. ${ }^{24} 11$ Oxo-(2,2',5,5'-tetramethyl)dithieno[3,4-c:8,9-c']bicyclo[4.4.1]undeca-3,8-diene-1,6-dicarboxylic acid $(1.4 \mathrm{~g}, 3.3 \mathrm{mmol})$ was heated at $300{ }^{\circ} \mathrm{C}$ in a pyrex tube under $\mathrm{N}_{2}$ until the evolution of gas ceased (approx. 5-10 min). After the reaction was complete, $\mathrm{CH}_{2} \mathrm{Cl}_{2}$ (25 $\mathrm{mL})$ and a $10 \%$ aq. $\mathrm{NaOH}$ solution $(10 \mathrm{~mL})$ were added. The organic layer was separated, dried over $\mathrm{MgSO}_{4}$, and the solvent was removed under reduced pressure. The aqueous layer was reacidified with $12 \mathrm{M} \mathrm{HCl}$ to $\mathrm{pH}=1$, extracted with $\mathrm{Et}_{2} \mathrm{O}$, dried over $\mathrm{MgSO}_{4}$, and resubjected to pyrolysis. The residue was extracted with $\mathrm{CH}_{2} \mathrm{Cl}_{2}(30 \mathrm{~mL})$ and the solvent was removed. The combined residues were subjected to column chromatography on silica gel (30\% ethyl acetate/70\% hexanes) to give a white solid (960 mg, 81\%). $\mathrm{MP}=255-256{ }^{\circ} \mathrm{C}\left(\right.$ Lit. $\left.\mathrm{MP}=252-253{ }^{\circ} \mathrm{C}\right) .{ }^{1} \mathrm{H} \mathrm{NMR}\left(300 \mathrm{MHz}, \mathrm{CDCl}_{3}\right): \delta$ 3.0 (m, 2H, bridgehead), 2.40-2.70 (m, 8H, methylene), 2.20 (s, 12H, methyl). ${ }^{13} \mathrm{C}$ NMR $\left(75 \mathrm{MHz}, \mathrm{CDCl}_{3}\right): \delta 215.9$ (ketone $\left.\mathrm{C}=\mathrm{O}\right), 133.9$ (Th-C-3,4), 129.8 (Th-C-2,5), 53.3 (bridgehead), 27.4 (methylene), 13.0 (methyl). IR (KBr) 2954, 2920, 2855, 1690, 1459, 
1388, 1144, 1098, 908, $657 \mathrm{~cm}^{-1}$. MS (EI): $\mathrm{m} / z$ (\%) $330.2\left(\mathrm{M}^{+}, 100\right), 191.1(58), 138.1$ (68). HRMS (EI): $\mathrm{m} / z$ Calcd. for $\mathrm{C}_{19} \mathrm{H}_{22} \mathrm{OS}_{2}, 330.11121$; found, 330.11016, $\Delta=3.2 \mathrm{ppm}$.

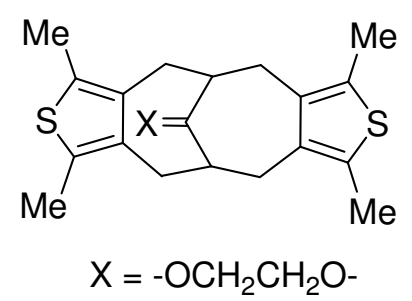

Ethylene acetal of 2,5,2',5'-tetramethyl-dithieno[3,4-c:8,9-c']bicyclo[4.4.1]undeca-3,8diene-11-one. $^{24} \quad \mathrm{~A}$ solution of the 2,5,2'5'-tetramethyldithieno[3,4-c:8,9c']bicyclo[4.4.1]undeca-3,8-diene-11-one (270 mg, $0.81 \mathrm{mmol})$, ethylene glycol (300 mg, $5.2 \mathrm{mmol})$, and $p$-toluenesulfonic acid $(2 \mathrm{mg})$ in benzene $(10 \mathrm{~mL})$ was heated at reflux for $18 \mathrm{~h}$ with a Dean-Stark trap. The solvent was evaporated under reduce pressure, and the residue was subjected to column chromatography on silica gel (10\% ethyl acetate/90\% hexanes) to give the title compound as colorless crystalline solid (260 mg, $85 \%) . \mathrm{MP}=275-276{ }^{\circ} \mathrm{C}$, decomp. $\left(\right.$ Lit. $\left.\mathrm{MP}=273{ }^{\circ} \mathrm{C}\right) .{ }^{1} \mathrm{H}$ NMR $\left(300 \mathrm{MHz}, \mathrm{CDCl}_{3}\right): \delta$ $4.01\left(\mathrm{~s}, 4 \mathrm{H},-\mathrm{OCH}_{2} \mathrm{CH}_{2} \mathrm{O}-\right), 2.80-2.90\left(\mathrm{dd}, 4 \mathrm{H}, J=3 \mathrm{~Hz}, J=15 \mathrm{~Hz},-\mathrm{CH}_{2}-\right), 2.65-2.75$ $\left(\mathrm{dd}, 4 \mathrm{H}, J=5 \mathrm{~Hz}, J=15 \mathrm{~Hz},-\mathrm{CH}_{2}-\right), 2.19-2.23\left(\mathrm{~m}, 14 \mathrm{H},-\mathrm{CH}-+-\mathrm{CH}_{3}\right) .{ }^{13} \mathrm{C}$ NMR $(75$ $\left.\mathrm{MHz}, \mathrm{CDCl}_{3}\right): \delta 135.8$ (Th-C-3,4), 126.8 (Th-C-2,5), 114.2 (ketal), $64.6\left(-\mathrm{OCH}_{2} \mathrm{CH}_{2} \mathrm{O}-\right)$, 42.6 (bridgehead), $28.1\left(-\mathrm{CH}_{2}-\right), 13.3\left(-\mathrm{CH}_{3}\right)$. IR (KBr) 2961, 2917, 1448, 1257, 1109, 1048, 1000, 913, 787, $730 \mathrm{~cm}^{-1}$. MS (EI): m/z (\%) $374.1\left(\mathrm{M}^{+}, 100\right), 312(30), 235$ (40), 138 (36). HRMS (EI): $m / z$ Calcd. for $\mathrm{C}_{21} \mathrm{H}_{26} \mathrm{O}_{2} \mathrm{~S}_{2}, 374.13742$; found, 374.13597, $\Delta=3.9$ ppm. 


\subsection{Results and Discussion}

\subsubsection{Synthetic Approaches for a Key Intermediate: 3,4-bis(bromomethyl)thiophene}

3,4-Bis(bromomethyl)thiophene is a intermediate in out multi-step synthesis of $\pi$ stacked oligothiophenes. According to the literature, it was first prepared in the early 1970's from the reaction of $\mathrm{PBr}_{3}$ in dry ether with 3,4-bis(hydroxymethyl)-thiophene. ${ }^{17}$ The bis(hydroxy)thiophene compound was prepared by reduction of 3,4-thiophene dicarboxylate (for which a convenient synthesis is not reported). Consequently, our first attempt to prepare 3,4-bis(bromomethyl)thiophene made use of 2,5-dichlorothiophene (Aldrich) as a starting material. It was envisioned that carboxylic and aldehyde functional groups could be installed at the 3-and 4- positions and that the ring could then be dechlorinated to afford thiophene-3,4-dialdehyde. The iodination of 2,5dichlorothiophene ${ }^{12}$ with molecular iodine in strong oxidizing conditions (potassium periodate, sulfuric acid) provided 2,5-dichloro-3,4-diiodo-thiophene in reasonable yields after isolation and recrystallization from ethanol, Figure 2.6. However, subsequent lithiation with $n$-butyllithium followed by reaction with dimethyl formamide did not produce the desired product dialdehyde in reasonable or reproducible yields. ${ }^{12}$

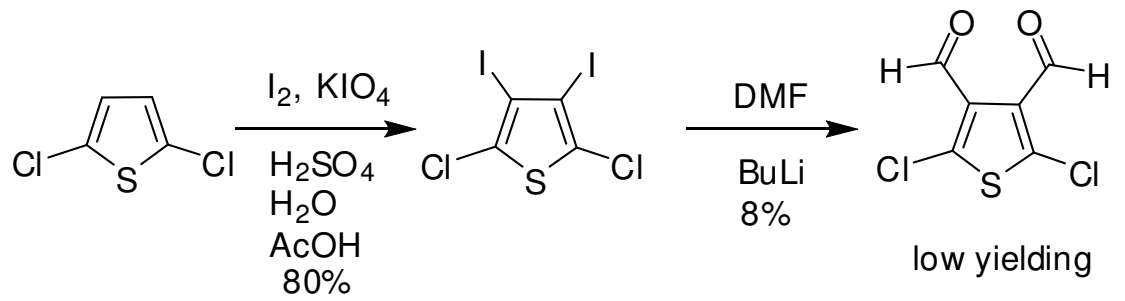

Figure 2.6. Synthetic approach to make thiophene-3,4-dialdehyde.

Modification to the above procedure by quenching the lithiated intermediate with carbon dioxide instead of DMF followed by acidification with $12 \mathrm{M} \mathrm{HCl}$ produced the desired 2,5-dichlorothiophene-3,4-dicarboxylic acid $^{12}$ in moderate yields (45-60\%), 
Figure 2.7. Reduction of the dicarboxylic acid with $\mathrm{LiAlH}_{4}$ in dry THF afforded 2,5dichloro-3,4-bis(hydroxymethyl)thiophene in good yields (85-95\%). However, attempted dehalogenation of the 2- and 5- positions following a known literature procedure, ${ }^{13}$ proved to be irreproducible and decomposition of the starting material was evident by NMR analysis (poisoning of the catalyst with sulfur). While attempts were made to optimize reaction conditions (Pt catalyst, reaction time, reaction pressure, solvent) none of these were particularly successful this route was terminated.
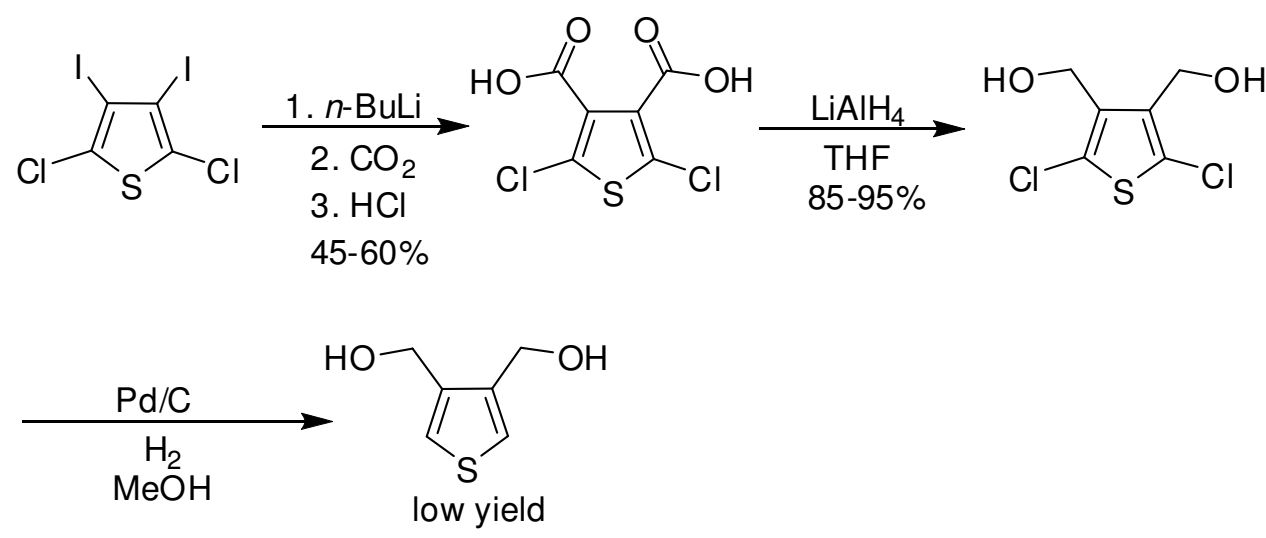

Figure 2.7. Attempt to prepare 3,4-bis(hydroxymethyl)thiophene by reductive dechlorination of 3,4-bis(hydroxymethyl)-2,5-dichlorothiophene.

Attempts to dehalogenate with and zinc metal in acetic acid following a literature procedure $^{13}$ gave he desired product in milligram amounts. Byproducts including monochlorinated thiophenes and acetate esters of the bis(hydroxymethyl) starting material, Figure 2.8. Thus, this route again proved to be inefficient for the synthesis of suitable substituted thiophenes. 


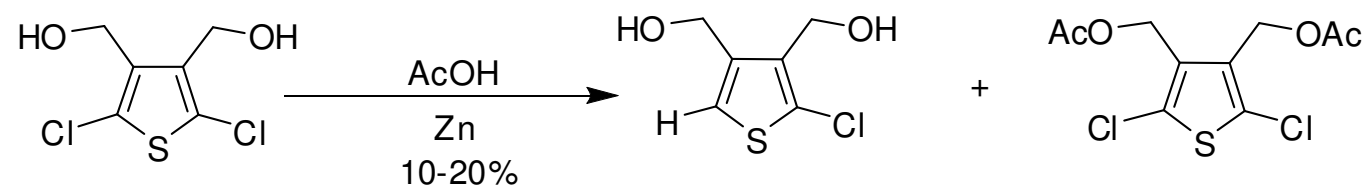

Figure 2.8. Attempted $\mathrm{Zn} / \mathrm{AcOH}$ dechlorination of 3,4-bis(hydroxymethyl)-2,5dichlorothiophene to synthesize 3,4-bis(hydroxymethyl)thiophene.

Another attempted route for the synthesis of 3,4-bis(hydroxymethyl)thiophene is shown in Figure 2.9. Tetrabromination of thiophene with molecular bromine in chloroform under gentle reflux afforded tetrabromothiophene ${ }^{19}$ in good yield after recrystallization from chloroform in an evaporating dish and washing the crystals with a copious amount of $\mathrm{H}_{2} \mathrm{O}(1-2 \mathrm{~L})$, Figure 2.9. Lithiation of the 2,5- positions with 2 equivalents of $n$-butyllithium in diethyl ether at $0{ }^{\circ} \mathrm{C}$ provided 3,4-dibromothiophene ${ }^{19,20}$ as a colorless liquid after vacuum distillation. The conversion of 3,4-dibromothiophene to 3,4-dicyanothiophene was best accomplished by modification of a literature procedure. $^{14}$ However, this only low yields of product due to losses during the exhaustive extraction with aqueous $\mathrm{HCl}$, water washings, sublimation, and recrystallization from acetonitrile (yield 12\%). The subsequent hydrolysis of the cyano groups with hydroxide in ethylene glycol followed by acidification provided thiophene3,4-dicarboxylic acid in another low yielding step (19\%). Reduction of the dicarboxylic acid (LAH, dry THF at reflux) provided 3,4-bis(hydroxymethyl)thiophene in satisfactory yield $(74 \%)$. The last step in this synthetic route was bromination with phosphorus tribromide in dry ether which produced 3,4-bis(bromomethyl)thiophene in a reasonable yield after column chromatography and recrystallization from methanol (yield, 80\%). This overall scheme proved to be cumbersome, with two low yielding steps which did not provide an adequate supply of 3,4-bis(bromomethyl)thiophene. 

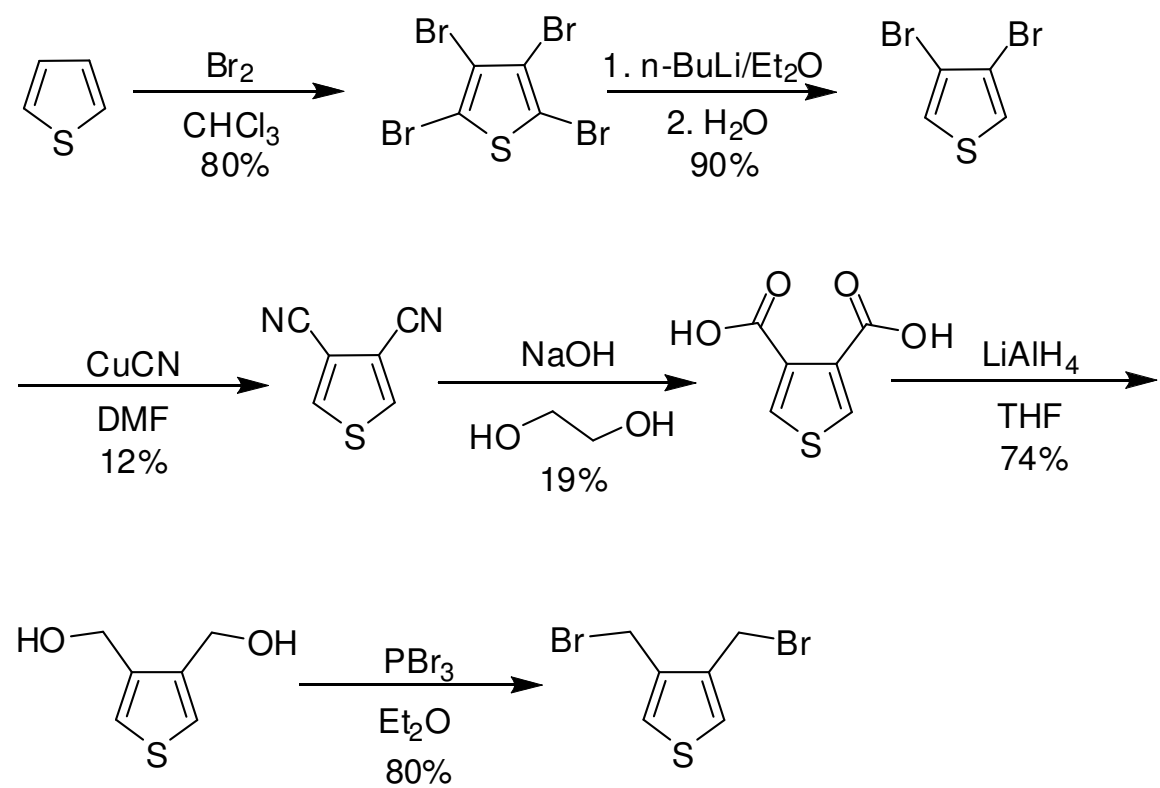

Figure 2.9. Successful, albeit low yielding, synthesis of 3,4-bis(bromomethyl)thiophene.

Another possible precursor for the synthesis of 3,4-bis(bromomethyl)thiophene could be 3,4-dimethylthiophene. A large scale synthesis to provide ample 3,4dimethylthiophene was attempted on a modified literature procedure which contained neopentyl groups on thiophene instead of methyl groups. ${ }^{25}$ The reaction of 1chloropropan-2-one with sodium sulfide in acetone gave 1,1'-thiodipropan-2-one in good yields $(80-90 \%)$. However, cyclization by a the McMurry reaction ${ }^{26}$ was problematic and pure product could not be obtained after many attempts with various conditions (temperature, concentration, metal reducing agent), Figure 2.10. 


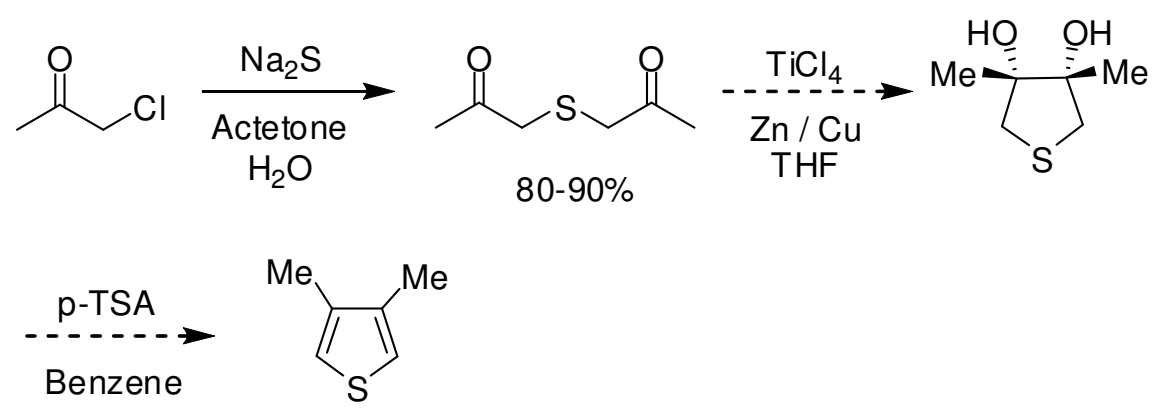

Figure 2.10. Approach to prepare 3,4-dimethylthiophene on a larger scale by McMurry reaction.

Our favored route to synthesize 3,4-dimethylthiophene from thiophene in three steps is illustrated in Figure 2.11. This involved the Kumada coupling of 3,4dibromothiophene with $\operatorname{MeMgX},(X=\mathrm{Br}$ or $\mathrm{Cl})$ in the presence of 1,3bis(diphenylphosphino) propane dichloronickel (II) in dry ether and distillation to produce 3,4-dimethylthiophene in a yield of $96 \%$.

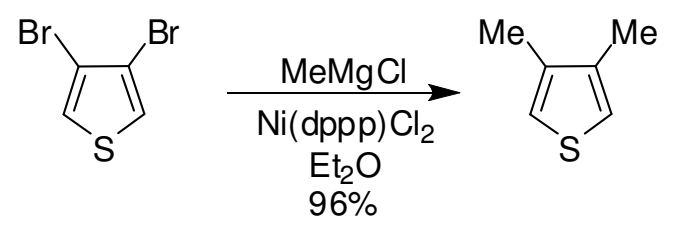

Figure 2.11. Efficient route to synthesize 3,4-dimethylthiophene from 3,4dibromothiophene.

Several attempts to perform radical bromination of 3,4-dimethyl-thiophene with $N$-bromosuccinimide and catalytic azobisisobutyronitrile (AIBN) in benzene were unsuccessful. The major products of this reaction were the monobrominated material and products resulting from the mono and dibromination of the 2,5-positions of the thiophene ring. Various parameters were modified (concentration, mode of addition, stoichiometry, and reaction times) with no success. 
The use of different solvents and catalyst i.e., benzoyl peroxide (BPO) are reported in the literature for the radical bromination of 3-methylthiophene in $\mathrm{CCl}_{4}$ with NBS. $^{27}$ Optimization of these conditions led us to the use of BPO added to solutions of 2-g of 3,4-dimethylthiophene with 2.0 equivalents of $\mathrm{NBS}$ in $\mathrm{CCl}_{4}(100 \mathrm{~mL})$, Figure 2.12 . However, one equivalent of NBS was added initially then another equivalent added 10 min later while the reaction mixture was at reflux. The mixture was irradiated with a mercury lamp at the start of the reaction and removed when the reaction mixture become faint orange. After stirring the mixture until the orange color turned light yellow $(<1 \mathrm{~h})$, the reaction mixture was cooled in an ice bath, and succinimide was removed by filtertration and washed with cold $\mathrm{CCl}_{4}$. The solvent was removed by rotary evaporation. The crude product from other batches was combined at this stage. Recrystallization from various solvents (cyclohexane, hexanes) were moderately successful, removing starting material $\left(R_{f}=0.85\right)$ in hexanes and mono-reacted material $\left(R_{f}=0.7\right)$. Flash chromatography used immediately after workup to prevent hydrolysis of the unstable product. After careful fractionation, the desired product was obtained as a white crystalline solid $\left(\mathrm{R}_{\mathrm{f}}=0.2\right.$ in hexanes) with yields ranging from 20-40\%. Almost immediately above this spot on TLC is residual BPO which becomes discolored on silica plates, and was discarded.

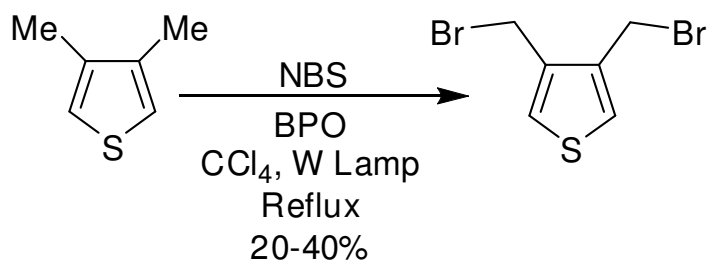

Figure 2.12. Successful radical bromination of 3,4-dimethylthiophene to 3,4bis(bromomethyl)thiophene. 


\subsubsection{Synthesis of Dithieno-Fused Bicyclo[4.4.1]undecanone}

Once an adequate supply of 3,4-bis(bromomethyl)thiophene was obtained, we used to used it to alkylate dimethyl 1,3-acetonedicarboxylate under phase transfer condition. Tetrabutylammonium bromide was used as the phase transfer reagent in the presence of hydroxide anion in a vigorously stirred solution of dichloromethane and aq. $\mathrm{NaOH}$. Dimethyl 1,3-acetonedicarboxylate in dichloromethane was added dropwise to a solution of 3,4-bis(bromomethyl)thiophene over $20 \mathrm{~min}$, Figure 2.13. The reaction was performed at room temperature and stirred fro $18 \mathrm{~h}$. After workup and purification by column chromatography (30\% ethyl acetate/70\% hexanes) gave the resulting bicyclic diester, 2.1.
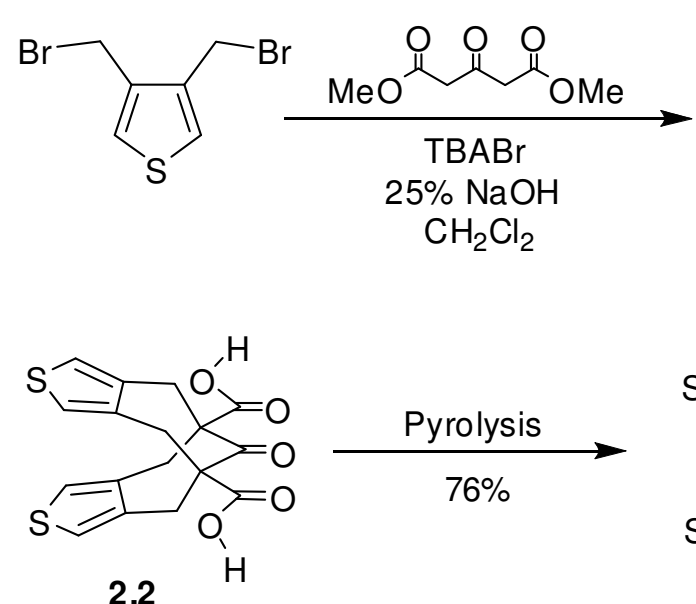

2.2

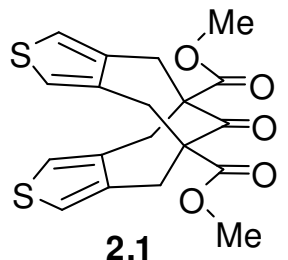

2.1

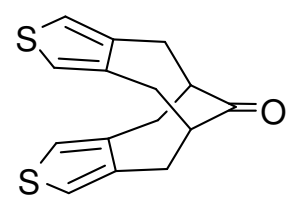

2.3

Figure 2.13. Synthesis of bisthieno-fused bicyclo[4.4.1] undecanone.

The saponification of the diester was performed by reaction with excess base $(\mathrm{KOH}$ or $\mathrm{NaOH})$ in refluxing aqueous ethanol, Figure 2.13. Careful workup included removal of ethanol prior to acidification with $12 \mathrm{M} \mathrm{HCl}$ to $\mathrm{pH}=1$. The resulting aqueous solution was placed in the freezer overnight. The resulting crystalline solid was 
recrystallized from $\mathrm{H}_{2} \mathrm{O}$, filtered, and dried in under reduced pressure to afford the diacid 2.2 in good yield (90\%). In 10-30\% ethyl acetate/hexanes, the $\mathrm{R}_{\mathrm{f}}$ value of the $\mathbf{2 . 2}$ was zero, so it was easily distinguished from the starting material. The dithieno-fused bicyclo[4.4.1] undecanone core $\mathbf{2 . 3}$ was synthesized by decarboxylation of $\mathbf{2 . 2}$ at elevated temperatures. Large scale pyrolysis resulted in a large amount of char and only low yields of product due to poor heat transfer. Accordingly, this process was performed on a small scale. The small scale reaction of diacid $2.2(>250 \mathrm{mg})$ provided best results upon heating to temperatures of $250-300{ }^{\circ} \mathrm{C}$. The major byproduct in the reaction was the mono-decarboxylated material. While this byproduct was present in most reaction mixtures the material could be recovered and re-pyrolyzed. A simple base wash (5-10\% aqueous $\mathrm{NaOH}$ ) removed the monoacid after it was taken back up in $\mathrm{CH}_{2} \mathrm{Cl}_{2}$. Reacidification of the basic extract to $\mathrm{pH}=1$, extraction into $\mathrm{Et}_{2} \mathrm{O}$, removal of the solvent under reduced pressure, and resubjecting the residue to decarboxylation provided more desired crude product. Purification was performed by passing a solution (10\% ethyl acetate/90\% hexanes) of crude product through a short silica plug with to afford the desired ketone $\mathbf{2 . 3}$ as a white solid in good yields (65-76\%).

\subsubsection{Ketalization of the Dithieno-Fused Bicyclo[4.4.1]undecanone}

The ketalization of the dithieno-fused ketone $\mathbf{2 . 3}$ provides a suitable scaffold to examine through-space interactions between adjacent thiophenes stacked on top one another. Initial attempts to ketalize with neopentyl glycol were unsuccessful; the predominant material obtained was the hemiacetal. Reaction of ketone 2.3 in a small 
round bottom flask with excess ethylene glycol, benzene, and para-toluenesulfonic acid (p-TSA) afforded the ethylene ketal 2.4, Figure 2.14.

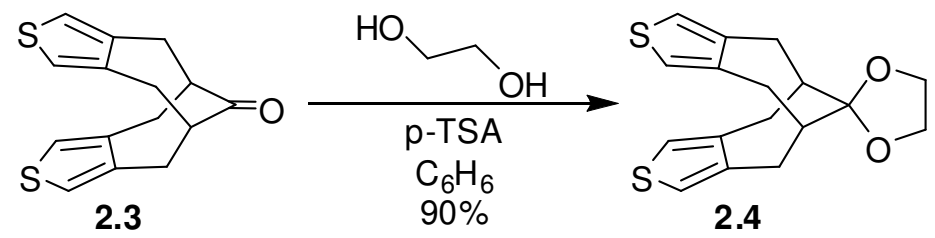

Figure 2.14. Ketalization of the dithieno-fused ketone, 2.3.

Careful precautions were taken to avoid decomposition of the acid sensitive product. The solvent was evaporated to less than $15 \%$ of the original volume and the residual solution was immediately placed on a column for flash chromatography. NMR analysis of the ketal was performed in deuterated chloroform that had been distilled onto molecular sieves and sodium bicarbonate. Typical yields for the ketalization step were $>90 \%$.

\subsubsection{Synthesis of the Tetramethylated $\pi$-Stacked Analog}

The tetramethylated $\pi$-stacked analog 2.8 was synthesized in an analogous route. ${ }^{24}$ This analog was important in our study for charge migration of doped $\pi$-stacked oligothiophenes. 2,5-Dimethyl-3,4-bis(bromomethyl)thiophene was synthesized in one step from 2,5-dimethylthiophene, aqueous formaldehyde, and aqueous $\mathrm{HBr}$, Figure 2.15. Reaction with dimethyl 1,3-acetonedicarboxylate followed by saponification, decarboxylation, and ketalization with ethylene glycol gave the $\pi$-stacked tetramethylated analog 2.8 in good yield, Figure 2.14. The two dithieno-fused bicyclo[4.4.1] undecanes 
provide suitable scaffolds to elucidate the properties of conjugated oligomers arising from $\pi$-stacking interactions.

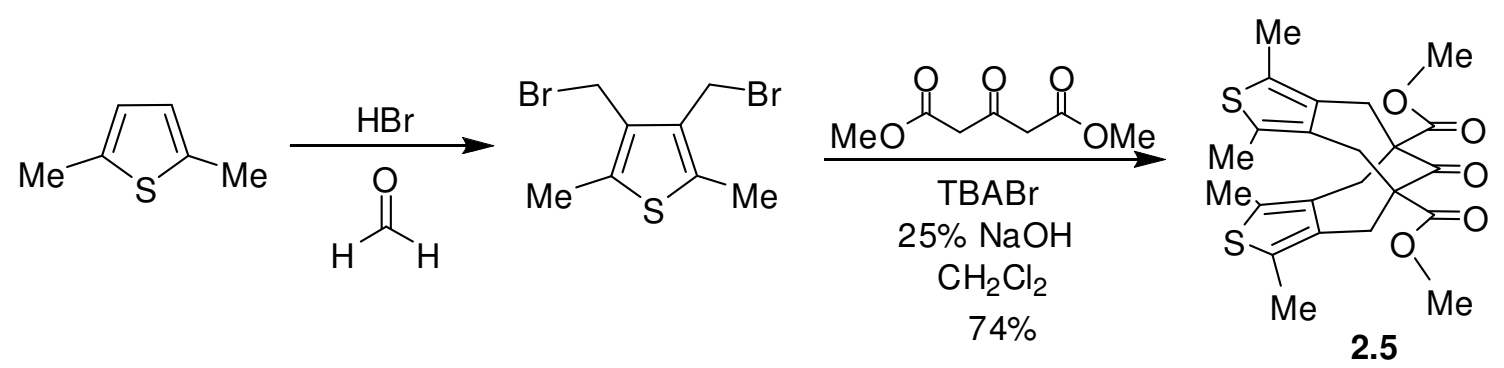
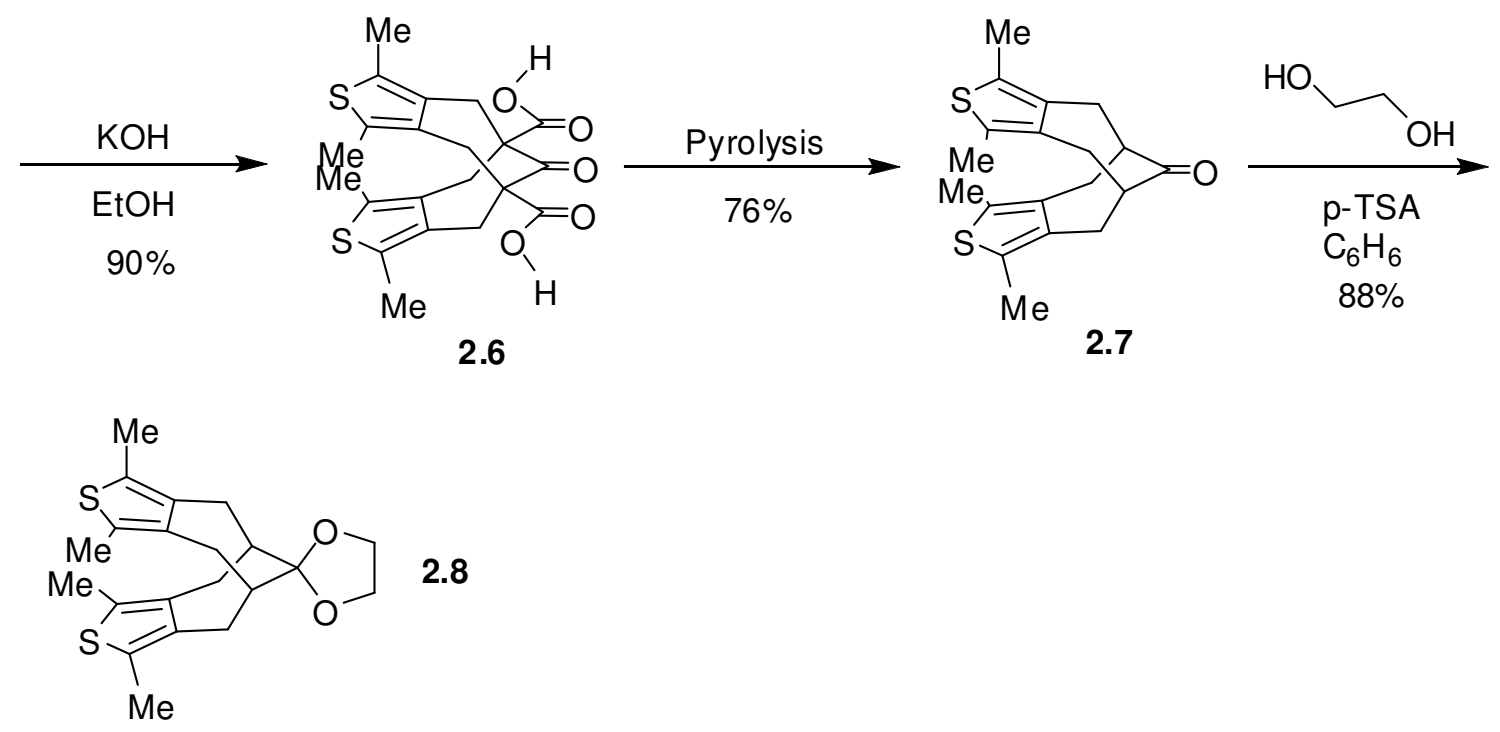

Figure 2.15. Synthesis of methylated $\pi$-stacked analog, 2.8.

The dithieno-fused bicycle[4.4.1]undecanone $\mathbf{2 . 3}$ as a core in the development of extended oligomers for studies of charge migration in doped conjugated materials. To prepare analogous stacked oligomers, we explored the synthesis of a bisthieno-diester halogens installed in the thiophene 2,5- positions. This would allow us to install aromatic units on the central thiophenes to prepare conjugated chains. Reaction of 2,5dichlorothiophene with aqueous formaldehyde and aqueous $\mathrm{HBr}$ produced 2,5-dichloro3,4-bis(chloromethyl)thiophene, Figure 2.16. However, this material failed to undergo 
reaction with dimethyl 1,3-acetonedicarboxylate under phase transfer conditions, and it decomposes readily.

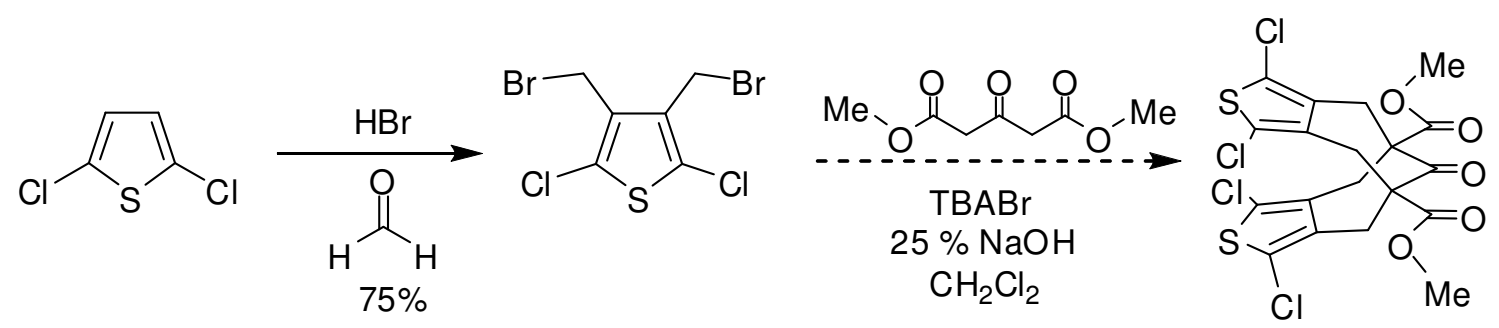

Figure 2.16. Attempt to alkylate with 3,4-bis(bromomethyl)2,5-dichlorothiophene.

Similarly, the alklylation of dimethyl 1,3-acetonedicarboxylate with 2,5-dibromo3,4-bis(bromomethyl)thiophene was not successful under various reaction condition modifications, Figure 2.17. Variation of the reaction with temperature, mode of addition, and concentration also did not provide any desired product. The majority of the starting material was recovered in this reaction with no desired product.

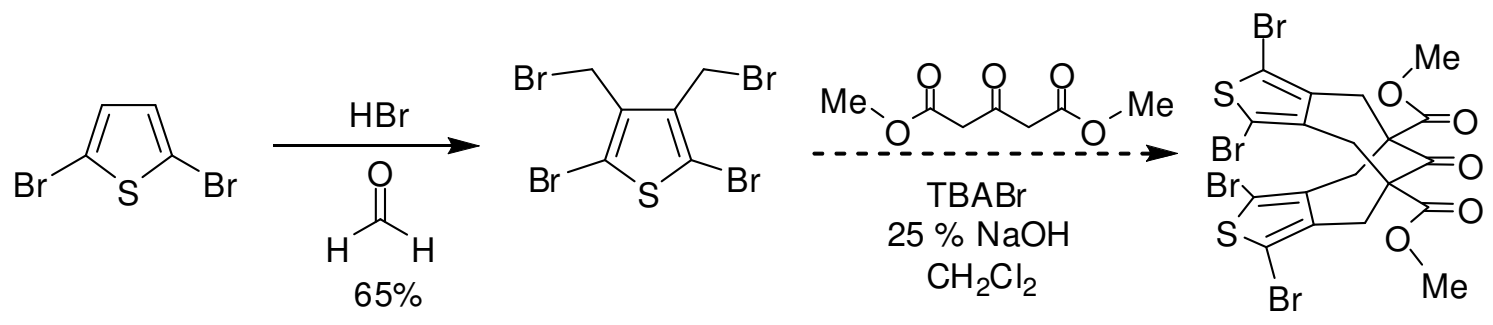

Figure 2.17. Attempt to alkylate with 3,4-bis(bromomethyl)2,5-dibromothiophene.

\subsubsection{Synthesis of Unstacked Linear Model 2,3,4,5-Tetramethylthiophene}

In order to determine the effect of stacking on the electronic structure of conjugated oligomeric polythiophene it was important to have analogous unstacked model linear analogs. The electrophilic aromatic substitution at the 3- and 4- positions of 2,5-dimethylthiophene with aqueous $\mathrm{HBr}$ and aqueous formaldehyde provided 3,4- 
bis(bromomethyl)2,5-dimethylthiophene. Reduction of 3,4-bis(bromomethyl)2,5dimethylthiophene with $\mathrm{LiAlH}_{4}$ in dry THF provided the model linear compound 2,3,4,5tetramethylthiophene as a colorless liquid after distillation $\left(\mathrm{BP}=80-85{ }^{\circ} \mathrm{C} / 20 \mathrm{~mm}\right)$ in good yield (90\%), Figure 2.18.

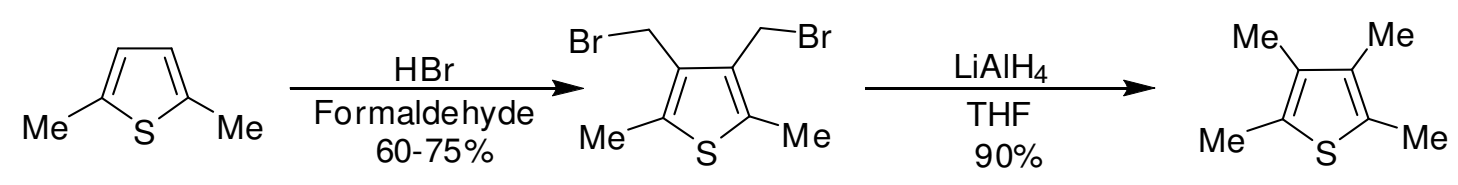

Figure 2.18. Synthesis of 2,3,4,5-tetramethylthiophene.

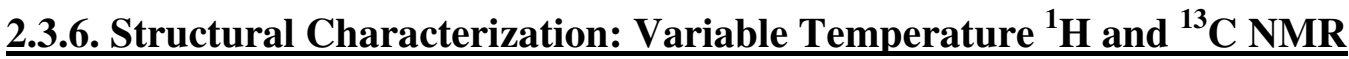 Spectroscopy}

The successful synthesis of $\pi$-stacked ethylene acetals 2.4 and 2.8 are conformational rigid compared to their respective ketone/diester precursors which was

confirmed by variable temperature ${ }^{1} \mathrm{H}$ NMR. The ${ }^{1} \mathrm{H}$ NMR spectrum of the diester $\mathbf{2 . 1}$ at room temperature is illustrated in Figure 2.19. The conformational flexibility between chair-boat, chair-chair, and boat-boat conformations exhibits a broadened, coalesced multiplet (2.6-3.4 ppm) for the methylene protons. A broadened singlet $(7.0 \mathrm{ppm})$ for the aromatic protons is representative of coalesced signals for the different conformations. The methyl ester protons are not affected by the conformation flexibility, therefore are equivalent (singlet at $\delta 3.7 \mathrm{ppm}$ ). 


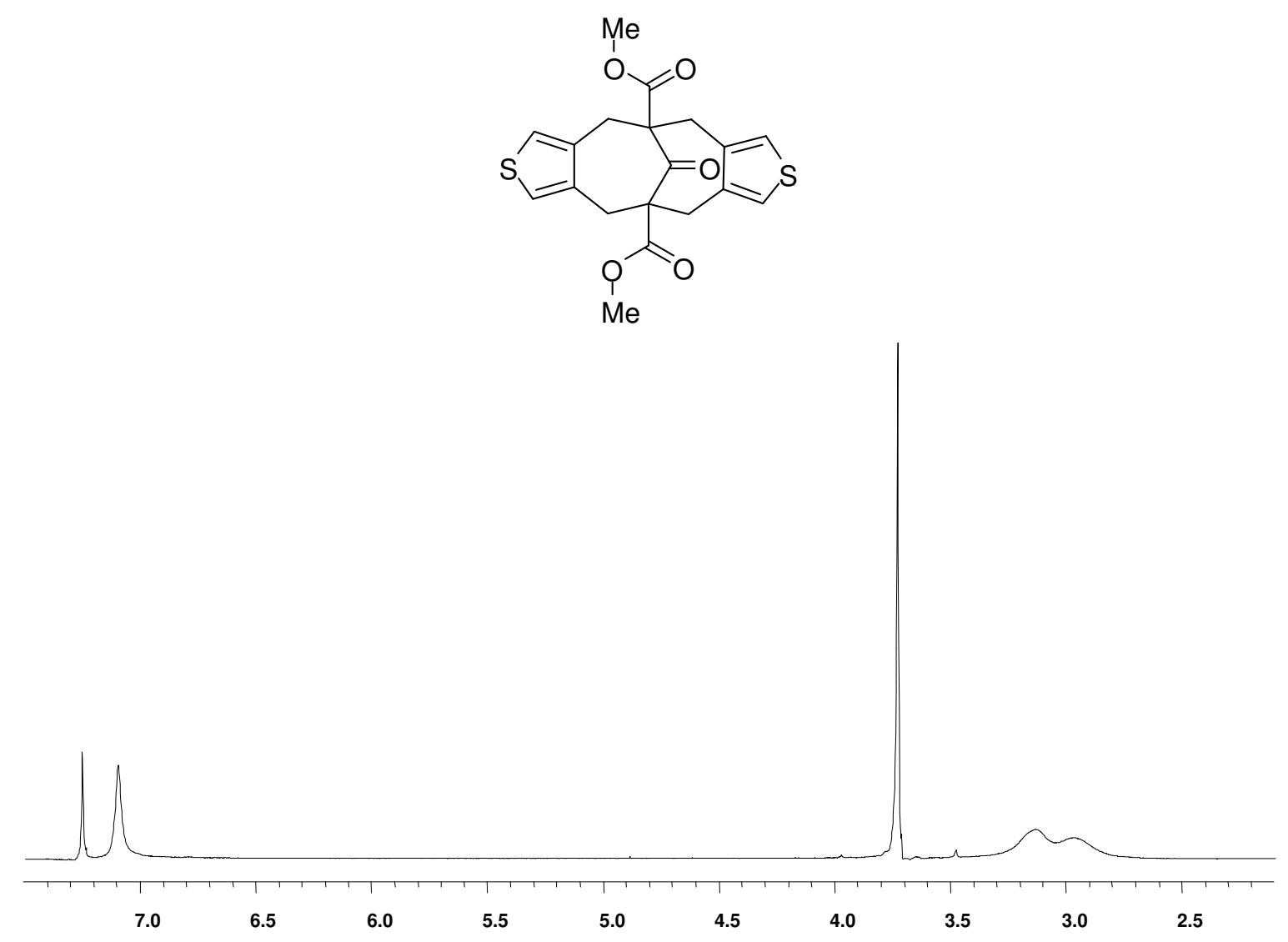

Figure 2.19. ${ }^{1} \mathrm{H} \mathrm{NMR}\left(300 \mathrm{MHz}, \mathrm{CDCl}_{3}\right)$ of diester 2.1 at room temperature.

Upon cooling to $-60{ }^{\circ} \mathrm{C}, \mathbf{2 . 1}$ adopts one chair-boat conformation, Figure 2.20. This conformation is thermodynamically favored at lower temperature with methylene protons being decoalesced into four doublets $(2.70,2.95,3.15,3.30 \mathrm{ppm} ; J=15 \mathrm{~Hz})$. Two sharp singlets for the four aromatic protons (7.0, $7.2 \mathrm{ppm})$ confirm the chair-boat conformation (the two thiophene protons closest to the ketone give a different signal from the other thiophene ring further away from the ketone). 

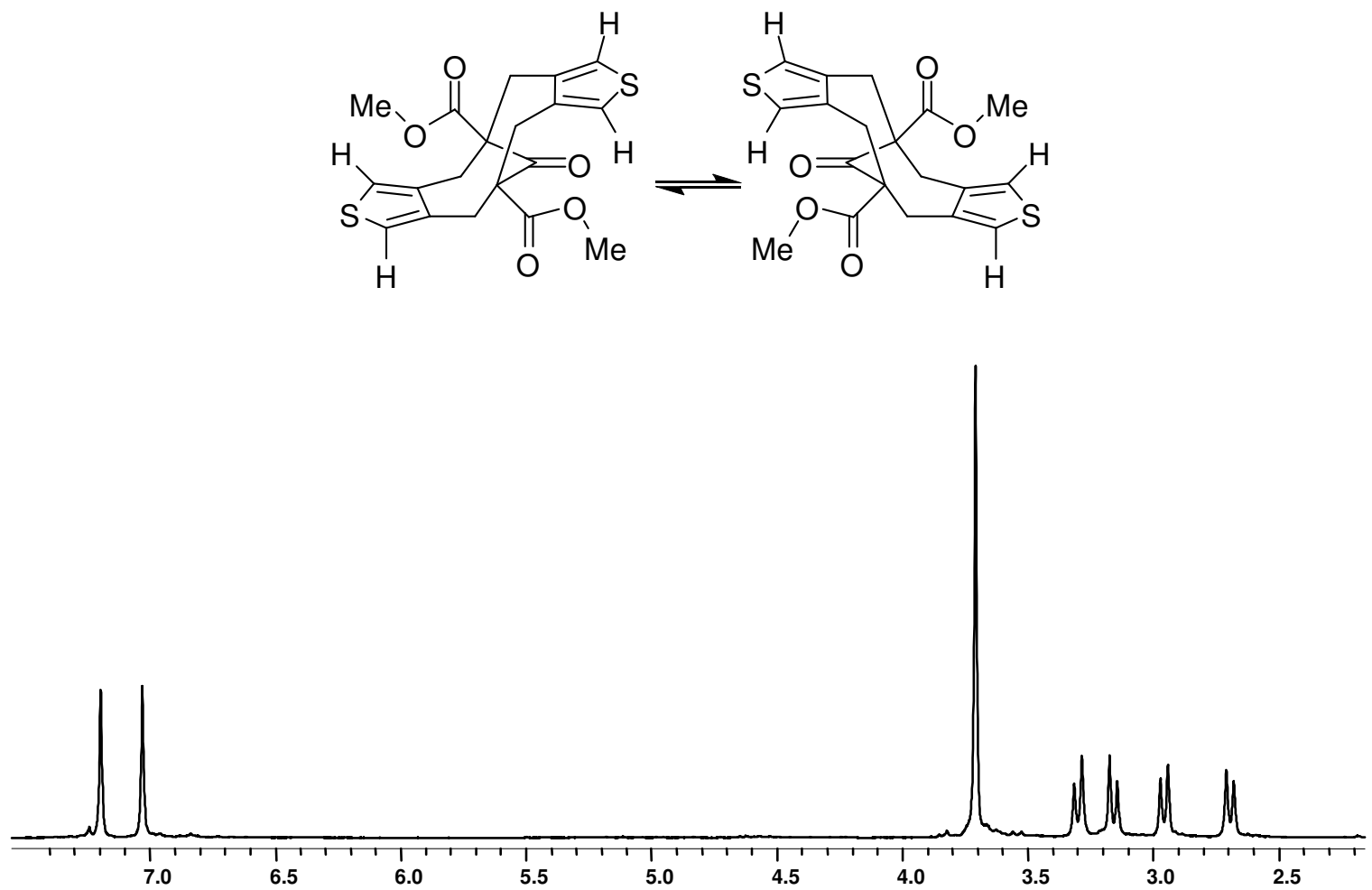

Figure 2.20. ${ }^{1} \mathrm{H}$ NMR $\left(400 \mathrm{MHz}, \mathrm{CDCl}_{3}\right)$ of diester 2.1 at $-60{ }^{\circ} \mathrm{C}$.

Similarly, the room temperature ${ }^{1} \mathrm{H}$ NMR spectrum of the tetramethylated diester 2.5 exhibits a coalesced signal for the methylene protons (2.8-3.2 ppm) and a broad singlet for the twelve methyl protons $(2.3 \mathrm{ppm})$, Figure 2.21 . Upon cooling $-40{ }^{\circ} \mathrm{C}$, the methylene protons decoalesced to four distinct doublets $(2.51,2.90,3.10,3.15 \mathrm{ppm}, J=$ $15 \mathrm{~Hz}$ ), and the methyl protons decoalesced into two singlets (2.3-2.4 ppm) confirming conformation rigidity at low temperature and conformational flexibility at room temperature. 


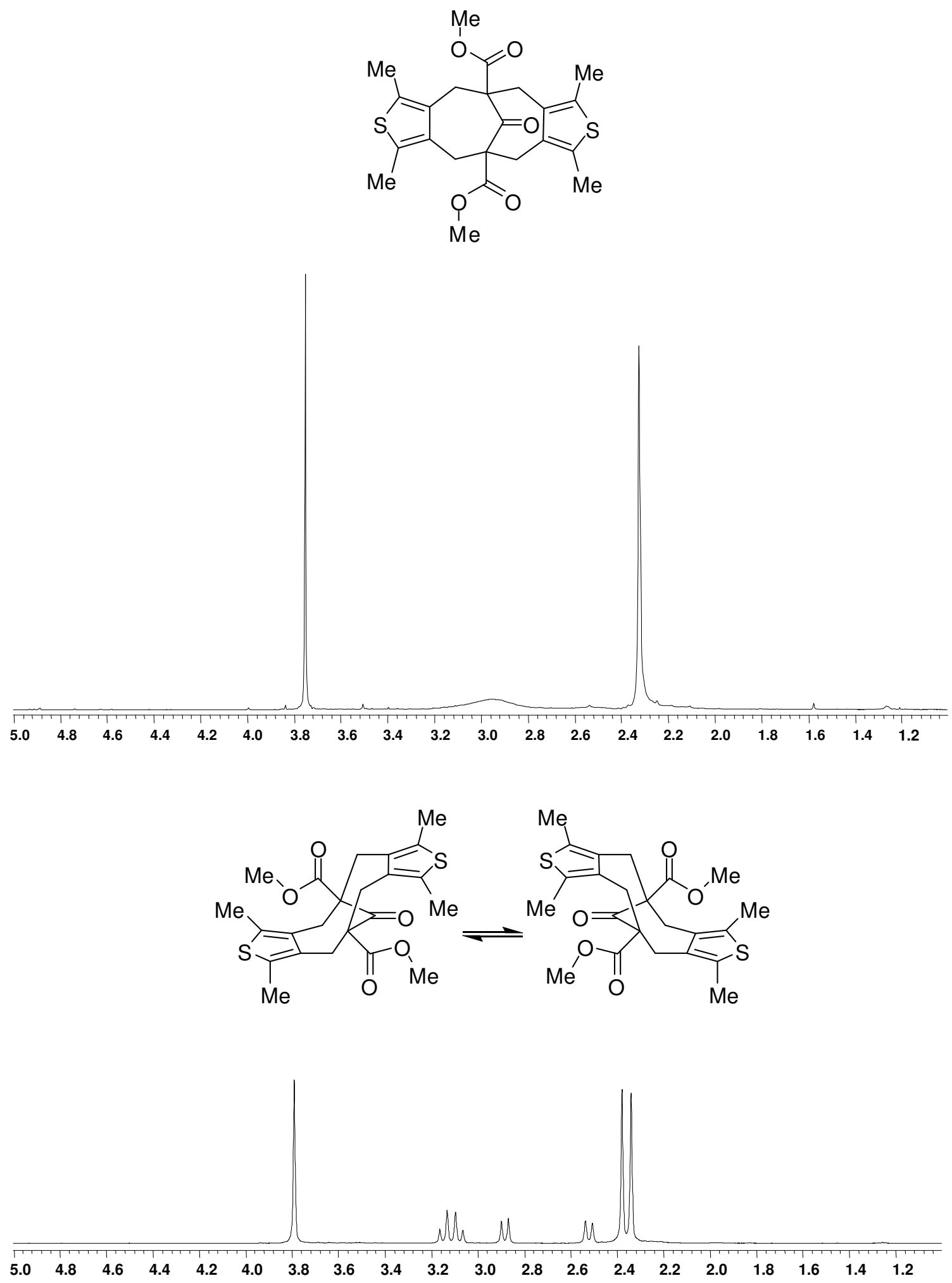

Figure 2.21. ${ }^{1} \mathrm{H} \mathrm{NMR}\left(400 \mathrm{MHz}, \mathrm{CDCl}_{3}\right.$ ) of 2.5 at $\mathrm{RT}$ (top) and $-40{ }^{\circ} \mathrm{C}$ (bottom). 
The ${ }^{1} \mathrm{H}$ NMR spectrum of ketone $\mathbf{2 . 3}$ exhibits similar conformational flexibility at room temperature. The eight methylene protons are coalesced into a broad multiplet (2.7-2.9 ppm) at room temperature due to the signal averaging from different conformations, Figure 2.22. The two bridgehead protons appear as a multiplet (3.1 ppm), and the four aromatic protons appear as a broad singlet at $7.0 \mathrm{ppm}$. Upon cooling to -60 ${ }^{\circ} \mathrm{C}$, the chair-boat conformation is thermodynamically favored at displaying four distinct multiplets $(2.5,2.7,2.8,3.1 \mathrm{ppm})$ for the methylene protons (one set coincidental with the bridgehead protons at $3.1 \mathrm{ppm})$, as well two singlets for the aromatic protons (6.9 and $7.2 \mathrm{ppm})$, Figure 2.23.

Similarly, the ${ }^{1} \mathrm{H}$ NMR spectrum of tetramethylated ketone 2.5 exhibited a coalesced signal for the eight methlyne protons (2.51-2.78 ppm), Figure 2.24. The two bridgehead protons gave a signal at $3.0 \mathrm{ppm}$, and the twelve methyl protons gave a sharp singlet at $2.3 \mathrm{ppm}$. Upon cooling to $-60{ }^{\circ} \mathrm{C}$, the ${ }^{1} \mathrm{H}$ NMR spectrum exhibited decoalesced signals for the methylene protons, and two singlets for the methyl protons.
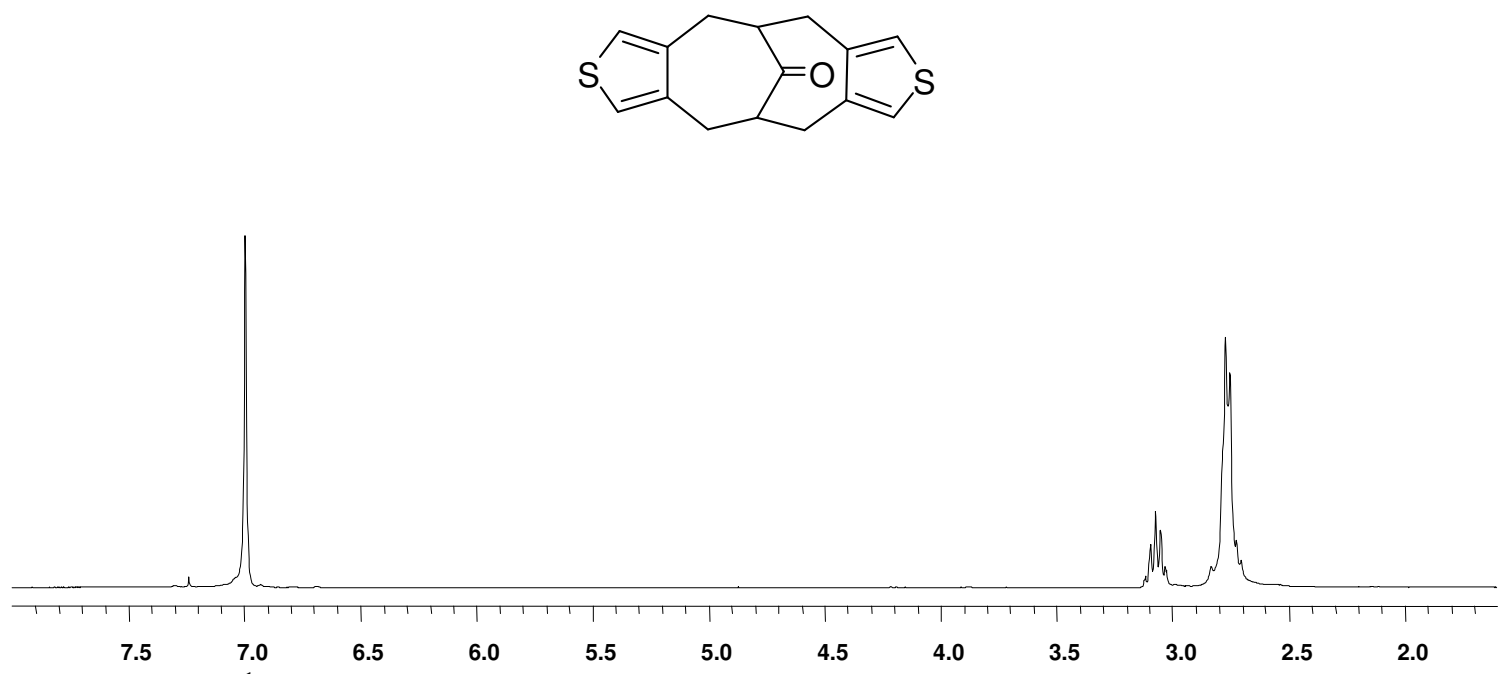

Figure 2.22. ${ }^{1} \mathrm{H} \mathrm{NMR}\left(300 \mathrm{MHz}, \mathrm{CDCl}_{3}\right)$ of ketone $\mathbf{2 . 3}$ at room temperature. 

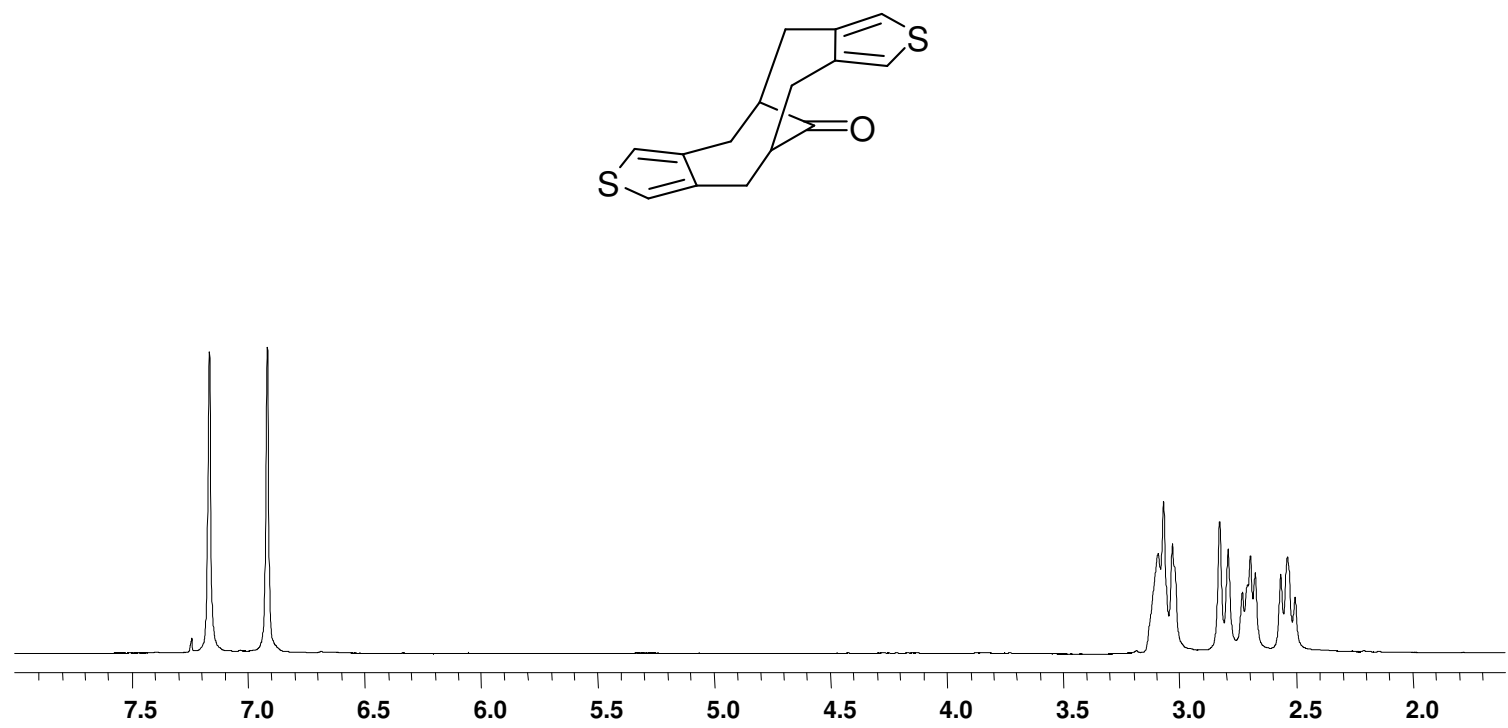

Figure 2.23. ${ }^{1} \mathrm{H}$ NMR $\left(400 \mathrm{MHz}, \mathrm{CDCl}_{3}\right)$ of 2.3 at $-60{ }^{\circ} \mathrm{C}$.

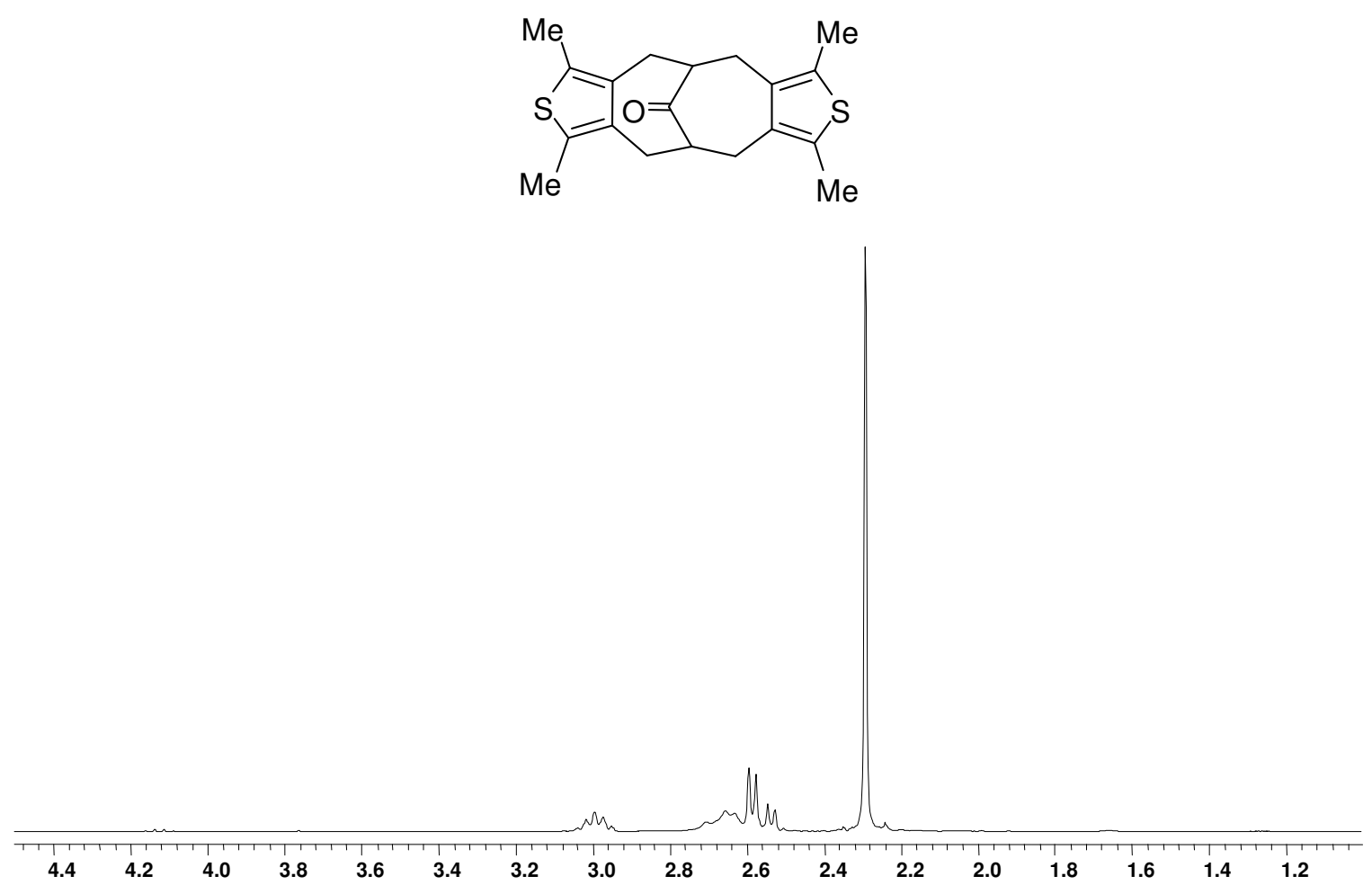

Figure 2.24. ${ }^{1} \mathrm{H} \mathrm{NMR}\left(300 \mathrm{MHz}, \mathrm{CDCl}_{3}\right)$ of ketone 2.7 at room temperature. 
The ${ }^{1} \mathrm{H}$ NMR spectrum of $\pi$-stacked compound $\mathbf{2 . 4}$ at room temperature warmed to $100{ }^{\circ} \mathrm{C}$ was unchanged and consistent with the compound existing in a single chairchair conformation. There is an upfield shift for the aromatic protons (6.51 ppm) compared to 3,4-dimethylthiophene $(6.88 \mathrm{ppm})$, and the methylene protons are a pair of doublet of doublets $(2.8 \mathrm{ppm}, J=3,15 \mathrm{~Hz} ; 3.15 \mathrm{ppm}, J=5,15 \mathrm{~Hz}$ ), Figure 2.25. The two bridgehead protons give a multiplet and are shifted upfield (2.2 ppm) compared to that of the bridgehead protons of the ketone 2.3 (3.1 ppm). Similarly, the methylated $\pi$ stacked compound $\mathbf{2 . 8}$ exhibited similar splitting for the methylene protons, and an upfield shift for the bridgehead protons $(2.2 \mathrm{ppm})$ coincidental with the twelve methyl protons, Figure 2.26.

The upfield shift due to $\pi$-stacking can be ascribed to the relationship of the protons in the circulating magnetic field of the thiophene rings (induced field) to the external magnetic field, commonly known as anisotropy. In this case, the positions where the aromatic protons and bridgehead protons are located actually oppose the magnetic external field and are shielded (upfield). Similarly, the coupling constants for the methylene protons can be approximated by the Karplus Equation: ${ }^{28}$

$$
\mathrm{J}_{\mathrm{HH}}=\mathrm{A}+\mathrm{B} \cos \theta+\cos 2 \theta
$$

where $\mathrm{A}, \mathrm{B}$, and $\mathrm{C}$ are approximately constant for an $\mathrm{sp}^{3}$ hybridized carbon bond and $\theta$ is the angle between the two protons measured. These theoretical values are in good agreement with the experimental results observed for $\pi$-stacked compounds $\mathbf{2 . 4}$ and $\mathbf{2 . 8}$. 

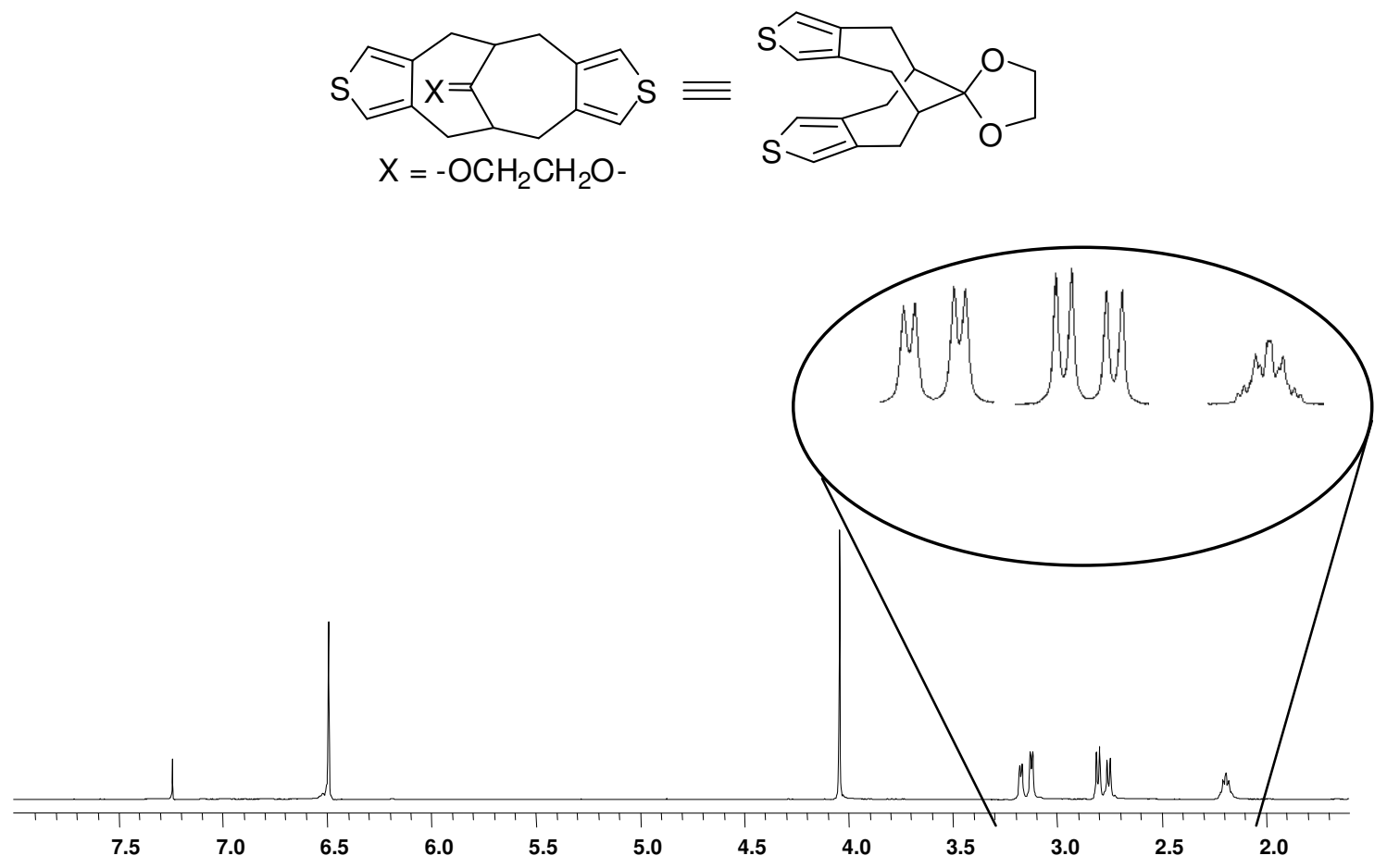

Figure 2.25. ${ }^{1} \mathrm{H} \mathrm{NMR}\left(300 \mathrm{MHz}, \mathrm{CDCl}_{3}\right)$ of ketal 2.4 at room temperature.
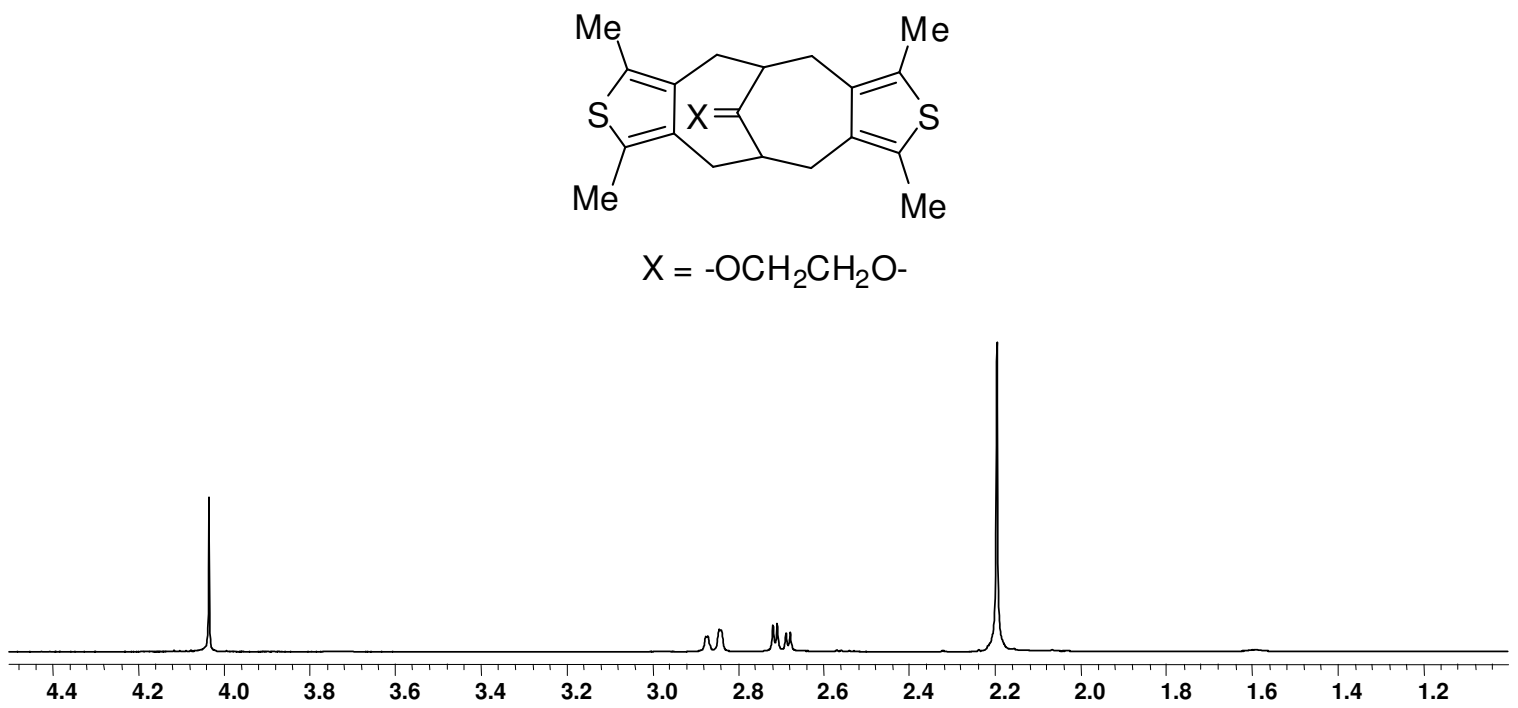

Figure 2.26. ${ }^{1} \mathrm{H} \mathrm{NMR}\left(300 \mathrm{MHz}, \mathrm{CDCl}_{3}\right)$ of ketal 2.8 at room temperature.

The ${ }^{13} \mathrm{C}$ NMR spectrum of the diester 2.1 exhibits conformational flexibility in the aromatic carbon signal (125 ppm, Th-C-2,5) and methylene carbons (30 ppm). These 
carbon signals are broadened, because they are influenced by the conversion between different conformations at room temperature, Figure 2.27. In the case of the ${ }^{13} \mathrm{C} N M R$ spectrum of ketone $\mathbf{2 . 3}$, these carbon signals are sharpened but are still broadened more than other carbon signals in the spectrum, Figure 2.28. The bridgehead carbon signals in the diester $\mathbf{2 . 1}$ and ketone $\mathbf{2 . 3}$ both appear at 52 and 55 ppm, respectively.
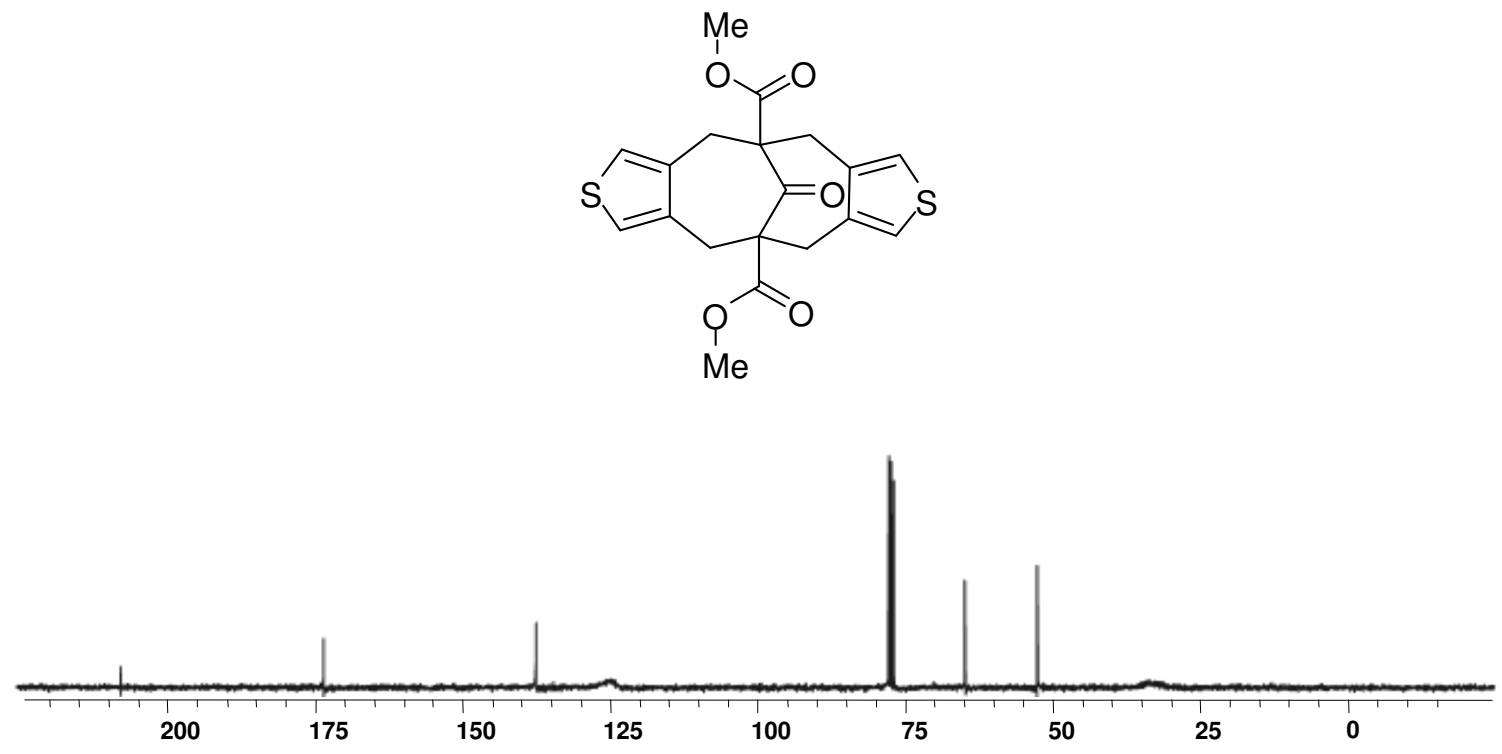

Figure 2.27. ${ }^{13} \mathrm{C} \mathrm{NMR}\left(75 \mathrm{MHz}, \mathrm{CDCl}_{3}\right)$ of diester 2.3 at room temperature.

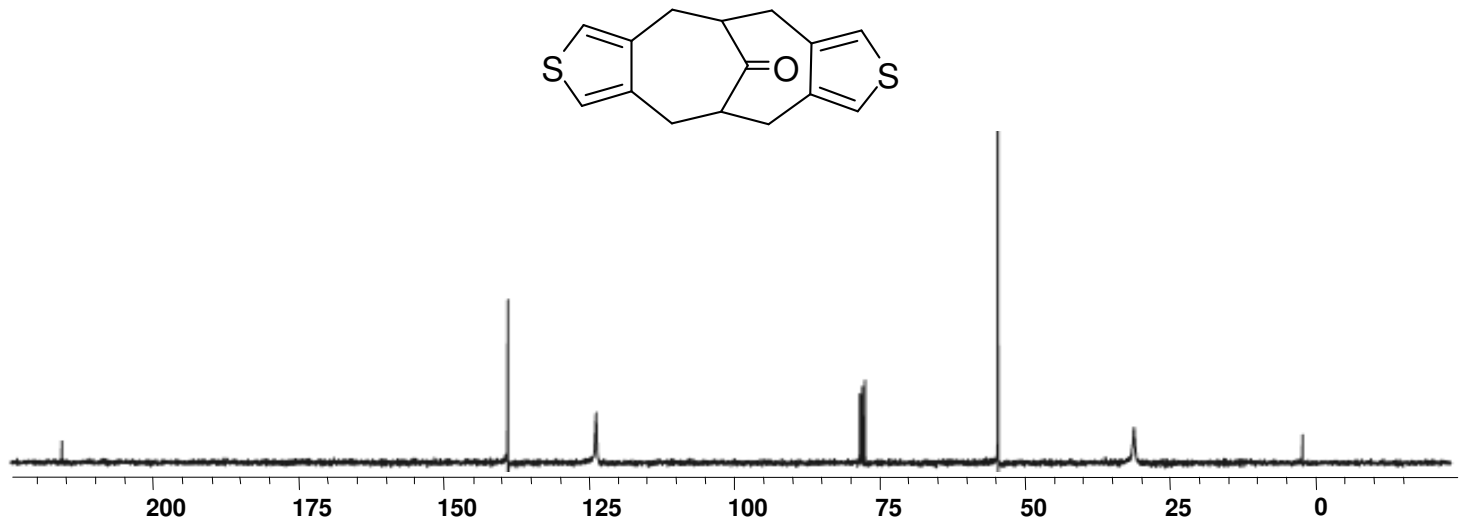

Figure 2.28. ${ }^{13} \mathrm{C}$ NMR $\left(75 \mathrm{MHz}, \mathrm{CDCl}_{3}\right)$ of ketone 2.3 at room temperature. 
Upon ketalization with ethylene glycol, the ${ }^{13} \mathrm{C}$ NMR spectrum of $\pi$-stacked compound 2.4 at room temperature exhibits sharp signals for all carbon signals consistent with one conformation, Figure 2.29. The ketone signal (215 ppm) disappears as the ethylene glycol peak (65 ppm) replaces it upon ketalization, and a ketal peak (tertiary carbon) appears at $155 \mathrm{ppm}$. The bridgehead carbon signal shifts upfield (44 ppm) due to $\pi$-stacking the thiophene rings together and forcing the compound in a chair-chair conformation.
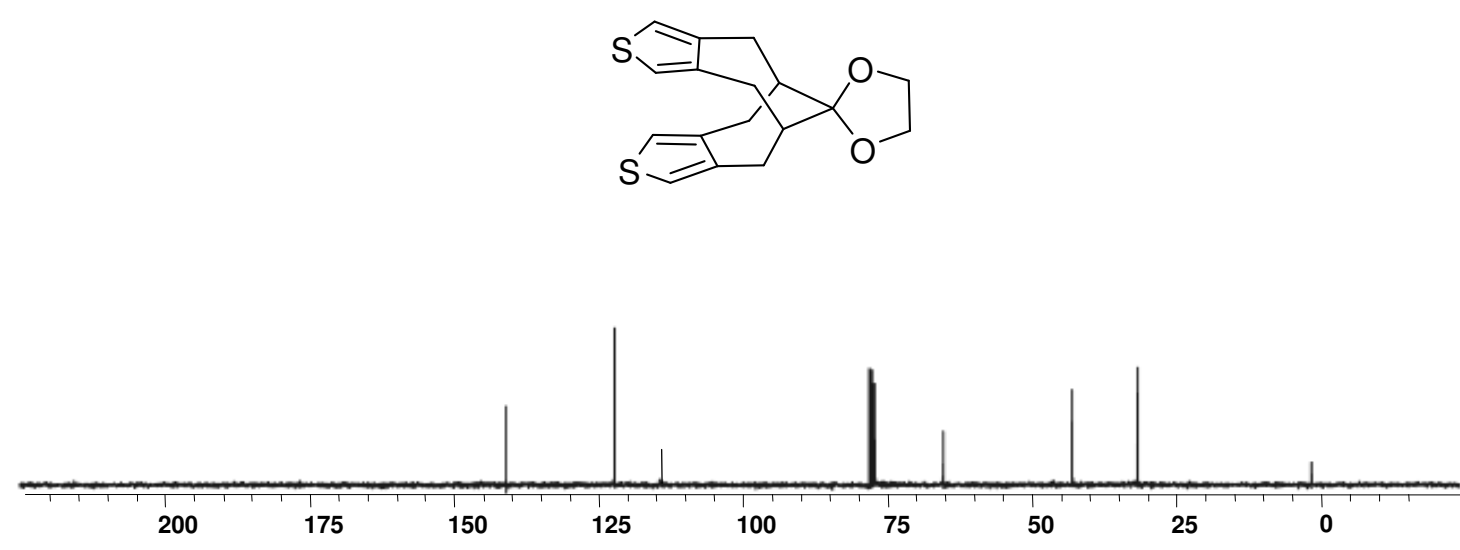

Figure 2.29. ${ }^{13} \mathrm{C} \mathrm{NMR}\left(75 \mathrm{MHz}, \mathrm{CDCl}_{3}\right)$ of ketal 2.4 at room temperature.

The ${ }^{13} \mathrm{C}$ NMR spectrum of tetramethylated ketone $\mathbf{2 . 7}$ and ketalization to the $\pi$ stacked compound 2.8 exhibited similar behavior, Figure 2.30. 

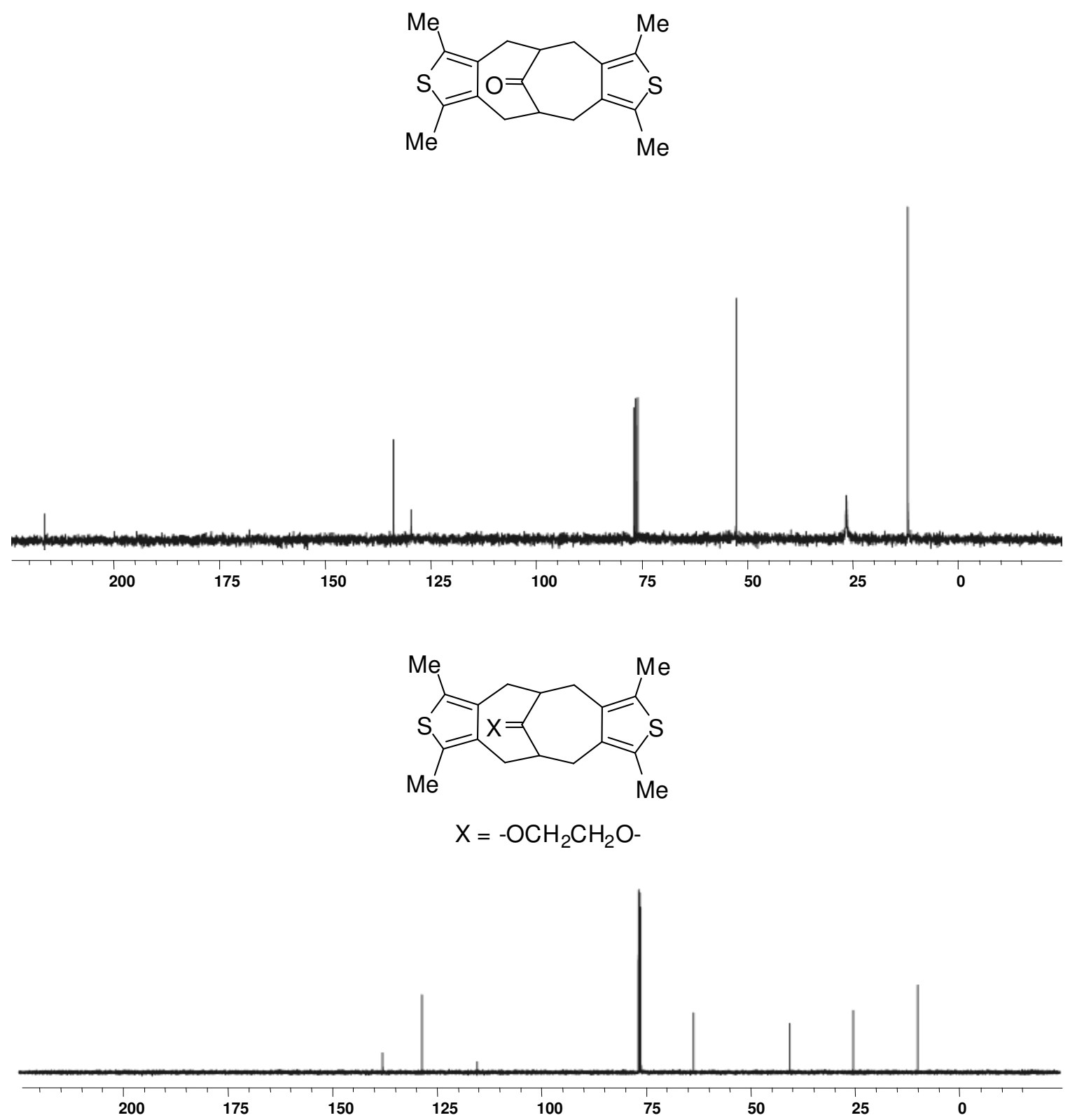

Figure 2.30. ${ }^{13} \mathrm{C} \mathrm{NMR}\left(75 \mathrm{MHz}, \mathrm{CDCl}_{3}\right)$ of ketone 2.7 (top) and ketal (bottom) at RT.

Heteronuclear Multiple Bond Correlation (HMBC) was used to identify proton nuclei with carbon nuclei that are separated by more than one bond. The connectivity in the bicyclo[4.4.1] undecane framework was demonstrated with the diacid 2.2, Figure 2.31. Selective excitation at $\delta 3.0 \mathrm{ppm}$ on the methylene protons shows that the carbonyl 
ketone, carbonyl ester, bridgehead, and thiophene 3,4- carbons are all connected to one another.
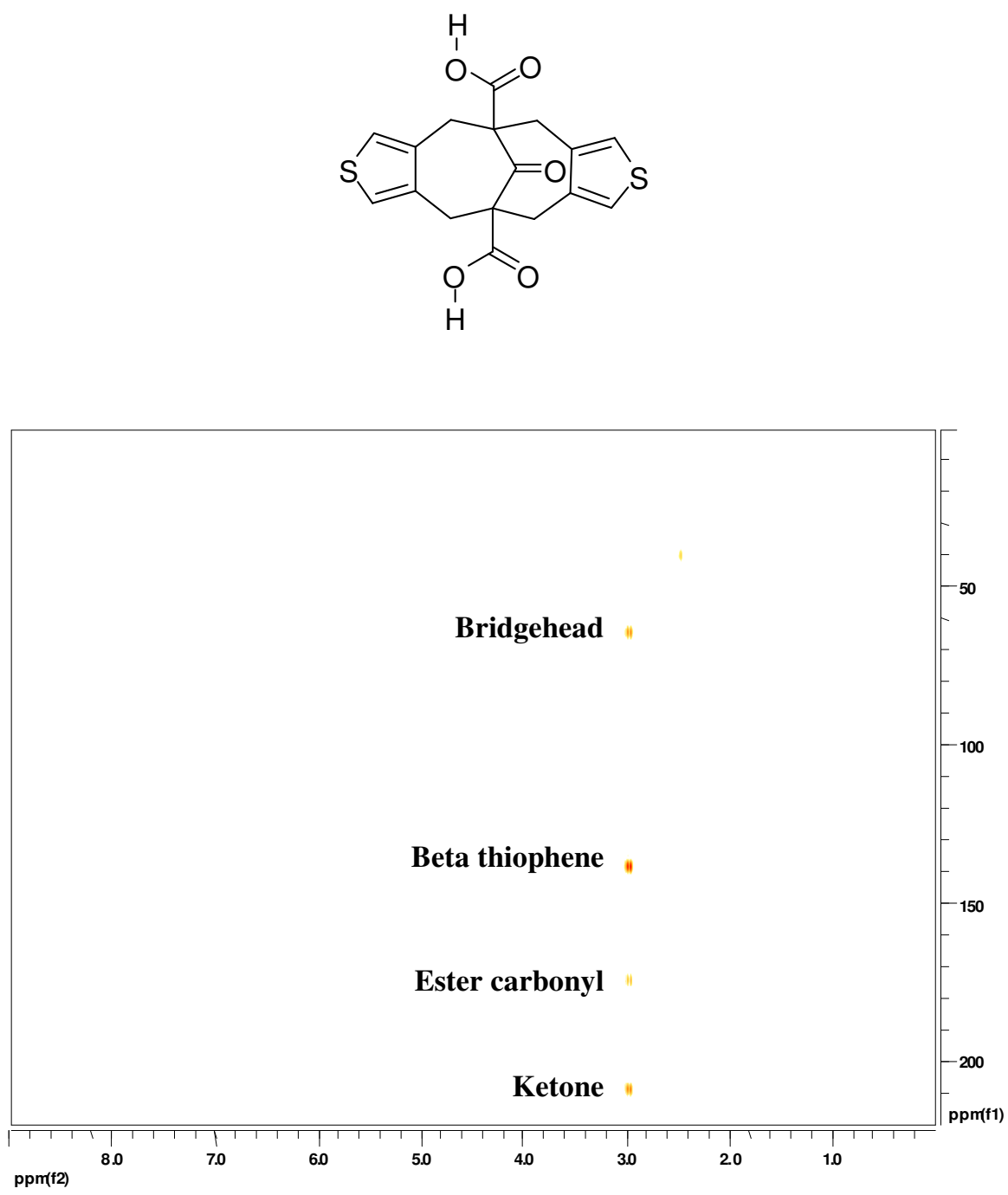

Figure 2.31. Heteronuclear Multiple Bond Correlation (HMBC) for diacid 2.2.

${ }^{1} \mathrm{H}-{ }^{1} \mathrm{H}$ correlation (COSY) experiment were used to confirm the coupled protons in the $\pi$-stacked compound 2.4. Protons labeled C, D, and B correspond to the methylene and bridgehead protons and all are coupled to each other according to the COSY 
spectrum, Figure 2.32. There are no other coupled protons in the compound. The $\pi$ stacked compound $\mathbf{2 . 8}$ exhibited similar behavior in its COSY spectrum.

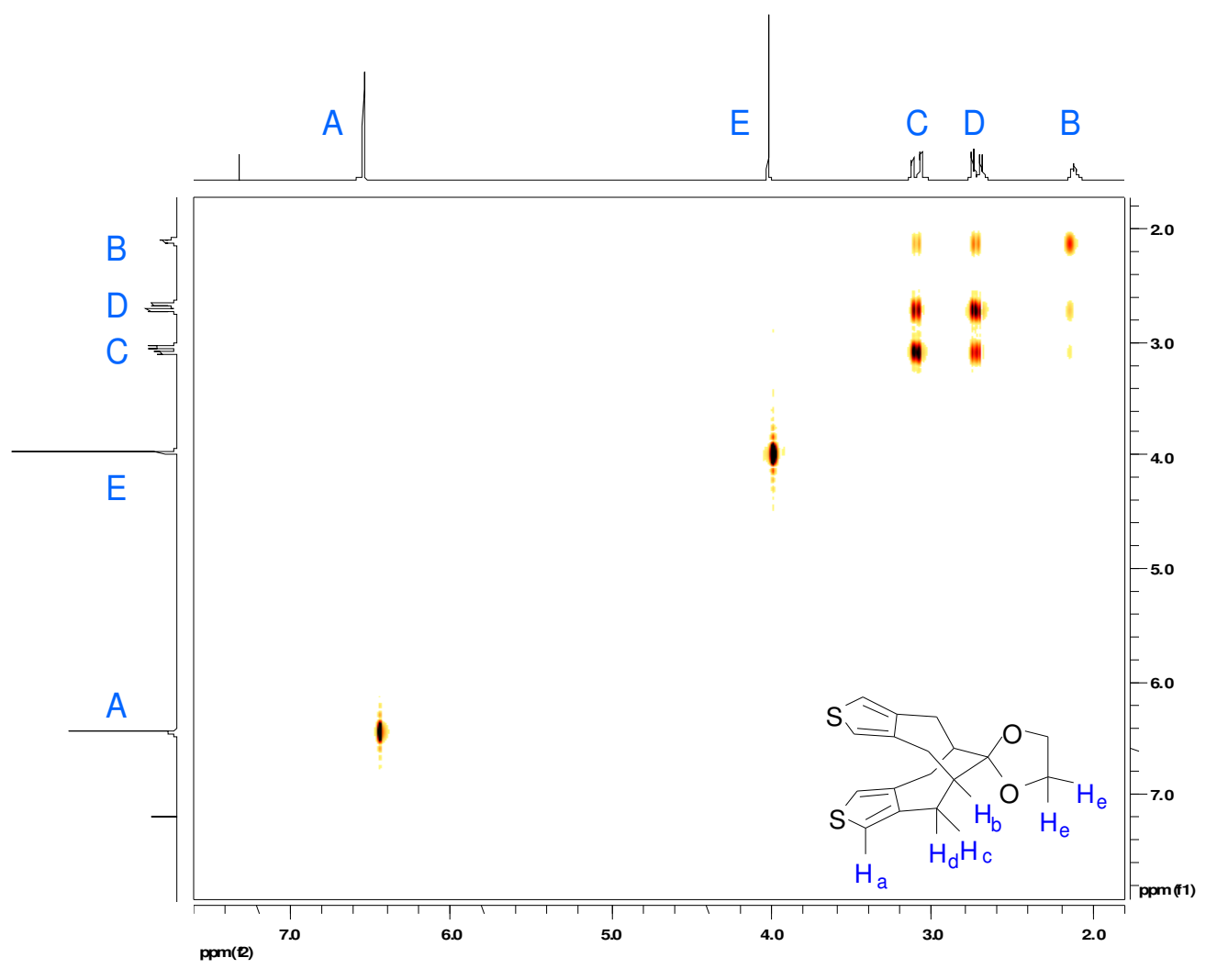

Figure 2.32. ${ }^{1} \mathrm{H}-{ }^{-1} \mathrm{H}$ NMR correlation (COSY) of $\pi$-stacked compound 2.4.

Signals arising in a ${ }^{1} \mathrm{H}-{ }^{13} \mathrm{C}$ NMR correlation (HETCOR) spectrum determined which proton signal was associated with each carbon signal. This shows conclusive evidence for the assigned ${ }^{1} \mathrm{H}$ NMR signals, Figure 2.33 . 


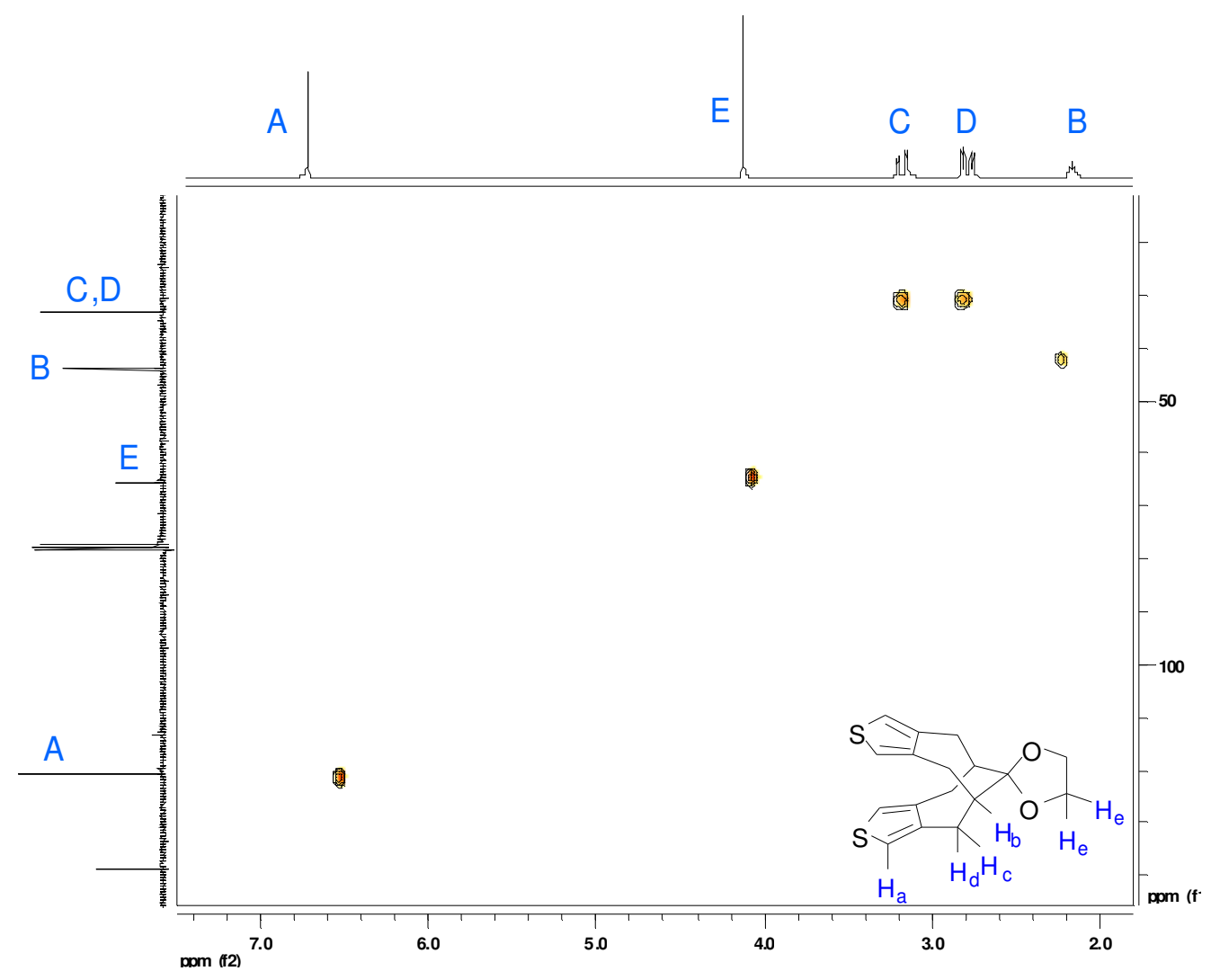

Figure 2.33. ${ }^{1} \mathrm{H}-{ }^{13} \mathrm{C}$ NMR correlation (HETCOR) of $\pi$-stacked compound 2.4 .

\subsubsection{X-ray Structural Analysis}

The X-ray structural analysis of $\pi$-stacked compound $\mathbf{2 . 4}$ confirms a rigid cofacial chair-chair arrangement. The distance between the centroid positions of each thiophene ring is $359 \mathrm{pm}$ apart, Figure 2.34. The furthest distance for the two thiophene rings is $429 \mathrm{ppm}$ between the two sulfur atoms of each ring. The angle of coplanarity between the two thiophene units is $28^{\circ}$, comparable to that of the methyl-capped analog 2.8 with angle deviation of $28.9^{\circ} .^{24}$ Another ORTEP view of 2.4 is illustrated in Figure 2.35. The packing diagram in the unit cell for $\mathbf{2 . 4}$ is illustrated in Figure 2.36. 

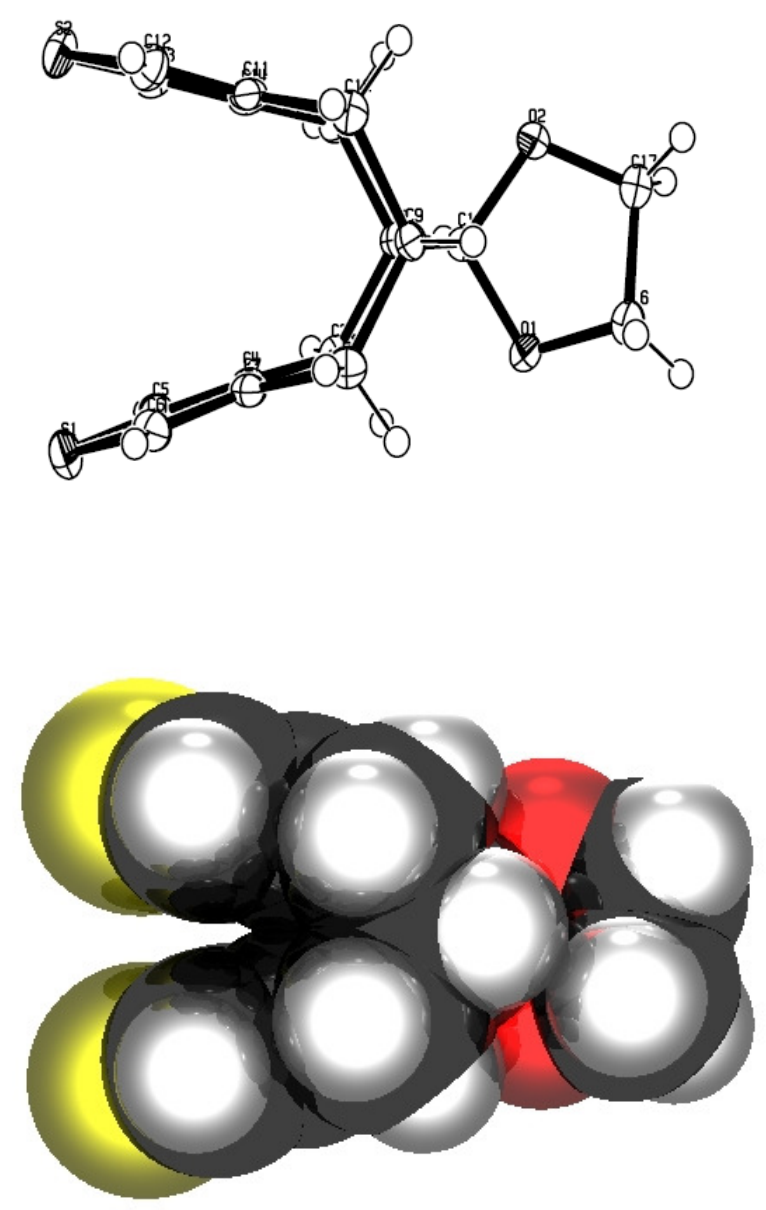

Figure 2.34. X-ray structural analysis of $\mathbf{2 . 4}$ (sideview). 

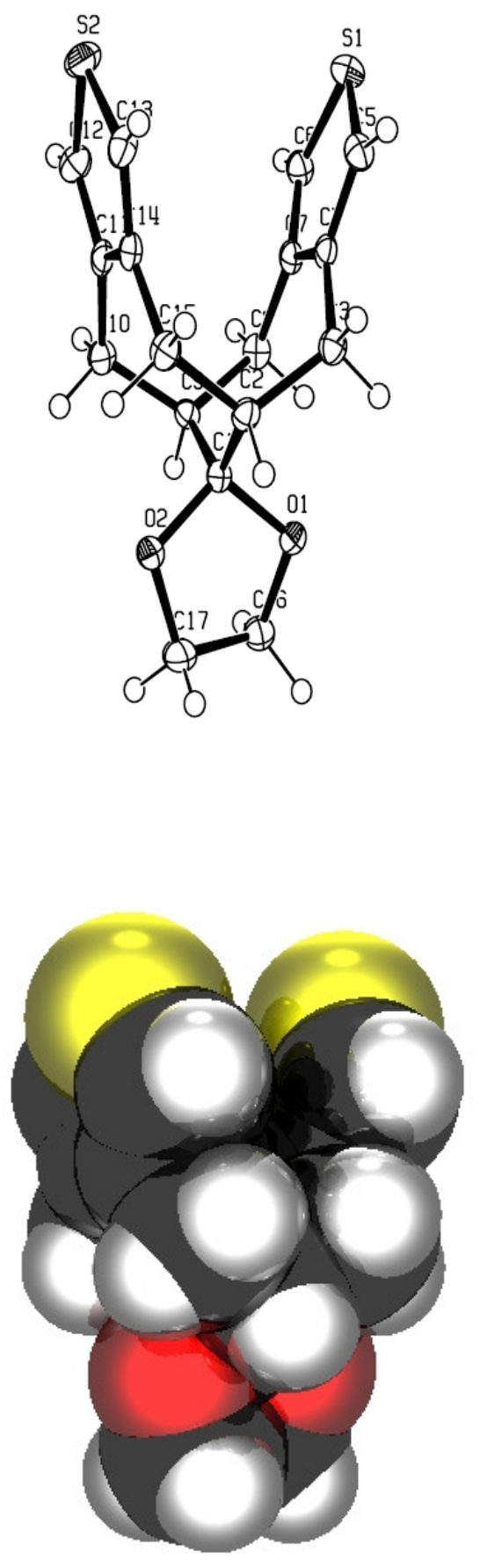

Figure 2.35. X-ray structural analysis of $\mathbf{2 . 4}$ (sideview). 


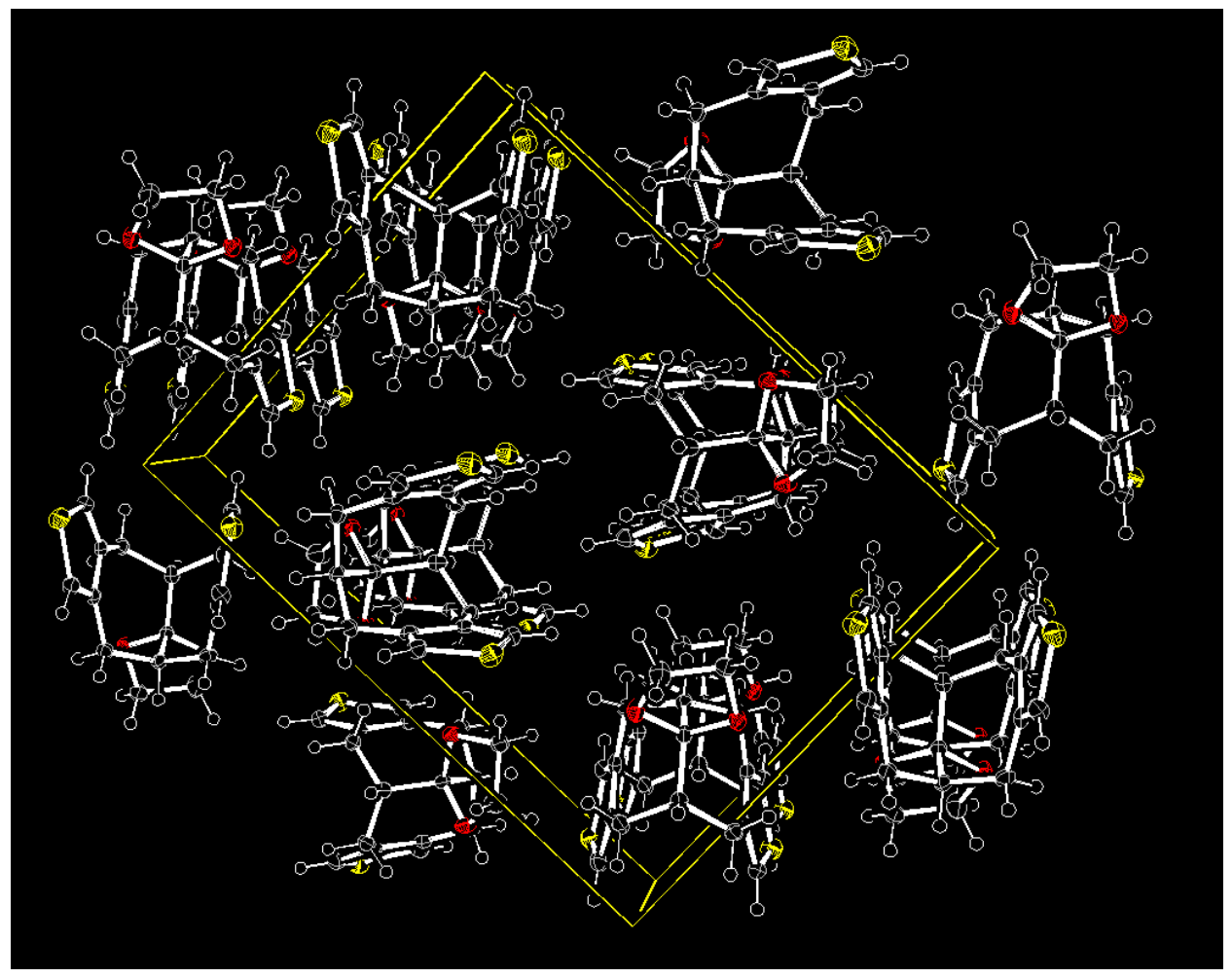

Figure 2.36. Packing diagram of $\pi$-stacked compound 2.4.

The calculated HOMO and LUMO orbitals ${ }^{29}$ illustrate the electron densities for the $\pi$-stacked compound, Figure 2.37. The 2,5-positions of each thiophene contain the larger proportion of electron density, similar to that of thiophene for the HOMO level. A large portion of electron density resides on the sulfur atoms in the LUMO model. The proximity of the orbitals demonstrates that this framework will be ideal for through-space electronic communication of other oligothiophene compounds with this bicyclo[4.4.1] undecanone core. 


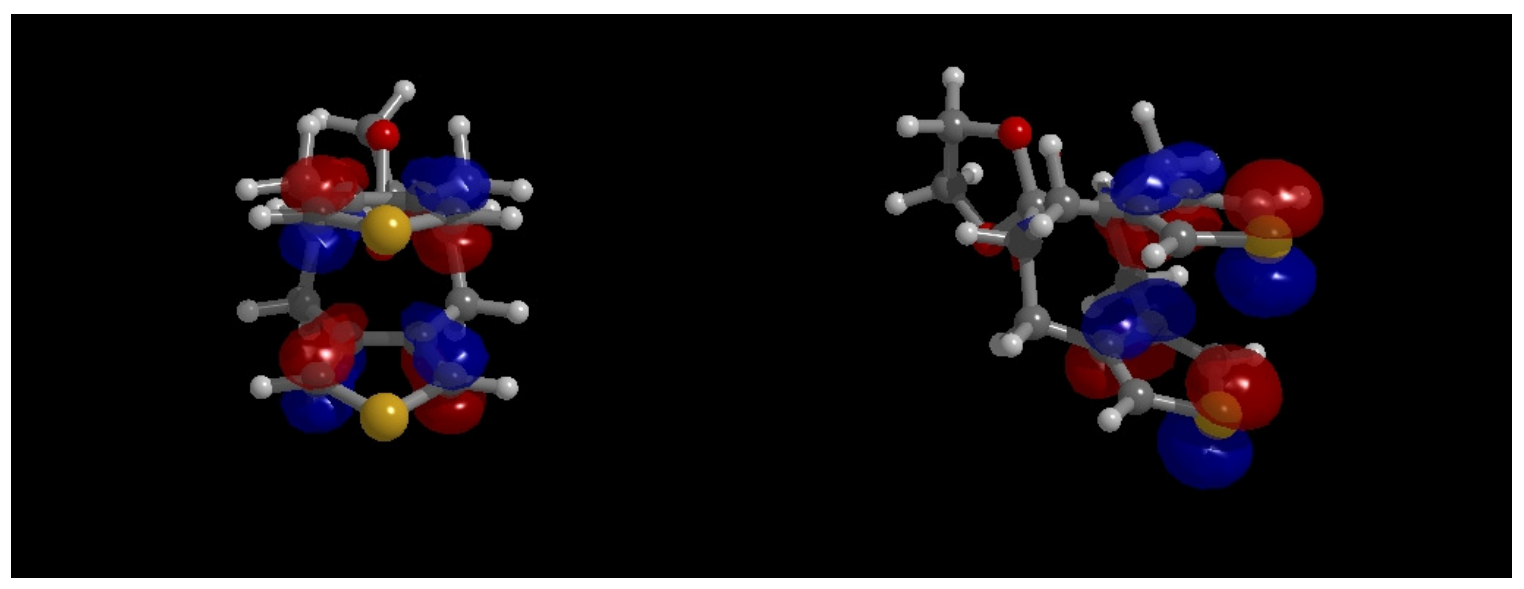

Figure 2.37. HOMO (left) and LUMO (right) of 2.4.

\subsection{Conclusion}

In conclusion, this chapter explored various synthetic routes to produce the key starting material 3,4-bis(bromomethyl)thiophene, the continued synthesis to the dithienofused bicyclo[4.4.1] undecane $\pi$-stacked compounds, and the structural characterization of these compounds. Variable temperature ${ }^{1} \mathrm{H}$ NMR spectroscopy demonstrated the tendencies compounds to exist in flexible conformations at room temperature and rigid conformations at low temperature. The X-ray structural analysis, COSY, and HETCOR all chair-chair conformation of the dithieno-fused bicyclo[4.4.1] undecanone framework upon ketalization with ethylene glycol. The dithieno-fused bicyclo[4.4.1]undecanone core will allow us to the further explore of other $\pi$-stacked compounds by expansion at the available unblocked $\alpha$-thiophene positions. 


\subsection{References}

1. Mataka, S.; Ma, J.; Thiemann, T.; Rudzinski, J. M.; Sawada, T.; Tashiro, M., "Aromatic rin-System Controls Pi-Facial Selectivity in diels-Alder Reactions of [3.3] Orthoantracenophanes," Tetrahedron Lett. 1995, 36, 6105-6108.

2. Mataka, S.; Mimura, T.; Lee, S. T.; Kobayashi, H.; Takahashi, K.; Tashiro, M., "NMR Spectroscopic Evidence for a Twin-Chair Conformer in QuinoxalineAnnelated Bicyclo[4.4.1]undecanones," J. Org. Chem. 1989, 54, 5237-5241.

3. $\quad$ Mataka, S.; Mitoma, Y.; Sawada, T.; Tashiro, M., "Triple-Layered Orhonaphho[3.3] orthobenzeno[3.3]orthonapthophane," Tetrahedron Lett. 1996, $37,65-68$.

4. Mataka, S.; Mitoma, Y.; Sawada, T.; Thiemann, T.; Taniguchi, M.; Tashiro, M., "Benzo[3.3]benzo[3.3]benzo- and naphtho[3.3]benzo[3.3]naphthoortho-cyclophane bis(alcohols): Preparations and structures," Tetrahedron 1998, 54, 51715186.

5. Mataka, S.; Mitoma, Y.; Thiemann, T.; Sawada, T.; Taniguchi, M.; Kobuchi, M.; Tashiro, M., "Bisacetals of aromatic ring-annelated benzo[a,d]bis\{bicyclo[4.4.1] undeca-3,8-diene-11-one \}. [3.3][3.3] Orthocyclophanes with triple-layered benzo/benzo/benzo and naphtho/benzo/naphtho system," Tetrahedron 1997, 53, 3015-3026.

6. Mataka, S.; Shigaki, K.; Sawada, T.; Mitoma, Y.; Taniguchi, M.; Thiemann, T.; Ohga, K.; Egashira, N., "Quadruple decker [3.3][3.3][3.3]orthocyclophane acetal - an orthocyclophane ladder," Angew. Chem. Int. Ed. 1998, 37, 2532-2534.

7. Mataka, S.; Takahashi, K.; Hirota, T.; Takuma, K.; Kobayashi, H.; Tashiro, M., "[3.3] Orthocyclophanes having vis-a-vis benzene rings," J. Chem. Soc., Chem. Commun. 1985, 973.

8. Mataka, S.; Takahashi, K.; Hirota, T.; Takuma, K.; Kobayashi, H.; Tashiro, M., "On the Conformation of Benzo-Annelated Bicyclo[4.4.1] undecanes, Bicyclo[5.5.1]tridecanes, and a Bicyclo[5.4.1]dodecane," J. Org. Chem. 1986, 51, 4618-4622.

9. Mataka, S.; Takahashi, K.; Mimura, T.; Hirota, T.; Takuma, K.; Kobayashi, H.; Tashiro, M.; Imada, K.; Kuniyoshi, M., "[3.3]Orthocyclophanes with facing benzene and naphthalene rings," J. Org. Chem. 1987, 52, 2653-6. 
10. Mataka, S.; Thiemann, T.; Taniguchi, M.; Sawada, T., "Layered [3.3] orthocyclophanes - interesting study objects in p-p interaction," Synlett 2000, 1211-1227.

11. Tichy, M., Advances in Organic Chemistry. Methods and Results. Wynberg H., Ed.; Interscience Publishers New York/London/Syndney: 1965; Vol. 5, p 155.

12. Steinkopf, W.; Kohler, W., "Thiophene series. XXXVIII. Chlorine derivatives of thiophene and the limited usefulness of mixed melting points with the isomeric thiophene derivatives," Ann. 1937, 532, 250-82.

13. Zwanenburg, D. J.; Wynberg, H., "Steric inhibition of intramolecular cyclizations by ortho substituents. Synthesis of 1H,3H-thieno[3,4-c]thiophene, its 2,2-dioxide, and 5-ethyl-5,6-dihydro-4H-thieno[3,4-c]pyrrole," J. Org. Chem. 1969, 34, 33340 .

14. MacDowell, D. W. H.; Wisowaty, J. C., "Thiophene Analogs of Anthraquinone," J. Org. Chem. 1972, 37, 1712-1717.

15. Crayston, J. A.; Iraqi, A.; Mallon, P.; Walton, J. C., "Preparation and characterization of thienonaphthoquinones and their radical ions," Journal of the Chemical Society, Perkin Transactions 2: Physical Organic Chemistry (19721999) 1993, 9, 1589-95.

16. Galvez, C.; Garcia, F.; Garcia, J.; Soldevila, J., "Synthesis of thiophenedicarbonyl diazides and di-tert-butyl thiophendicarbamates," J. Heterocycl. Chem. 1986, 23, 1103-8.

17. Helmers, R., "Sterische Hinderung der Enolform bei heterologen Alkoxycarbonyl-indanon-(2)-Derivaten," Journal fur praktische Chemie 1972, 314, 334-352.

18. Usol'tsev, A. A.; Karaulov, E. S.; Kostin, V. G.; Tilichenko, M. N. Diacetonyl sulfide. 80-2968397910612, 1982.

19. Agarwal, N.; Mishra, S. P.; Kumar, A.; Ravikanth, M., "Synthesis of b-thiophenesubstituted 21,23-dithiaporphyrins," Chem. Lett. 2003, 32, 744-745. 
20. D'Auria, M.; De Mico, A.; D'Onofrio, F.; Piancatelli, G., "Photochemical synthesis of bithienyl derivatives," Journal of the Chemical Society, Perkin

Transactions 1: Organic and Bio-Organic Chemistry (1972-1999) 1987, 1777-80.

21. Frisch, A. C.; Shaikh, N.; Zapf, A.; Beller, M., "Palladium-catalyzed coupling of alkyl chlorides and Grignard reagents," Angew. Chem. Int. Ed. 2002, 41, 40564059.

22. Snyder, C. A.; Selegue, J. P.; Dosunmu, E.; Tice, N. C.; Parkin, S., "C,ODialkylation of Meldrum's Acid: Synthesis and Reactivity of 1,3,7,7-Tetramethyl4H,10H-6,8,9-trioxa-2-thiabenz[f]azulen-5-one," J. Org. Chem. 2003, 68, 74557459.

23. Davies, A. G.; Julia, L.; Yazdi, S. N., "An electron spin resonance study of the radical cations of pyrroles, furans, and thiophenes in liquid solution," Journal of the Chemical Society, Perkin Transactions 2: Physical Organic Chemistry (19721999) 1989, 239-44.

24. Thiemann, T.; Ohira, D.; Li, Y.; Sawada, T.; Taniguchi, M.; Tashiro, M.; Mataka, S., "Thieno[3.3] orthocyclophanes: preparations and structures," New J. Chem. 1999, 23, 675-678.

25. Nakayama, J.; Yoshimura, K., "A General Synthesis of Aromatic Compounds Carrying Two Neopentyl Groups on Adjacent Positions," Tetrahedron Lett. 1994, 35, 2709-2712.

26. McMurry, J. E.; Fleming, M. P., "New method for the reductive coupling of carbonyls to olefins. Synthesis of $\beta$-carotene," J. Am. Chem. Soc. 1974, 96, 47084709.

27. Campaigne, E.; LeSuer, W. M., J. Am. Chem. Soc. 1948, 70, 1555-1559.

28. Karplus, M., "Vicinal Proton Coupling in Nuclear Magnetic Resonance," J. Am. Chem. Soc. 1963, 85, 2870-2871.

29. Thompson, M. A., ArgusLab 4.0.1, http://www.arguslab.com. 


\section{CHAPTER 3}

\section{SYNTHESIS AND STRUCTURAL CHARACTERIZATION OF EXTENDED DITHIENO-FUSED BICYCLO[4.4.1]UNDECANES}

\subsection{Introduction}

The dithieno-fused bicyclo[4.4.1] undecane scaffold described in Chapter 2 provides a $\pi$-stacked orientation of the thiophene rings. In this chapter, the stacked thiophene core is elaborated to provide $\pi$-stacked terthiophene and quinquethiophene oligomers by installation of arenes. There are numerous studies of linear oligothiophenes that provide insight into the electronic structure of conjugated radical cations and dications.

Detailed studies of radical ions look at the preparation, optical, and electrochemical properties of 3,4-ethylenedioxythiophene oligomers (EDOTn, $\mathrm{n}=1-4)^{1}$. Solutions of radical cations were cooled down and formed a new species which was reversible and called a $\pi$-dimer. An FT-Raman study of a chemical doped methyl-capped quinquethiophenes $^{2}$ offered an useful technique to explain these charged species formed in solution. Furukawa demonstrated that polarons are the major species existing in doped polythiophene ${ }^{3}$. New oligothiophenes recently characterized with cyano- and hexylterminated ends of quarterthiophene and terthiophene have been studied as thin films of oligothiophenes fabricated by vacuum deposition. ${ }^{4}$ Recent work also on $\alpha, \alpha^{\prime}-$ 
bis(diphenylamino)-capped oligothiophenes in situ spectroelectrochem ${ }^{5}$ has been explored for their oxidized species which strongly depend on the number of thiophene units. The new idea that quarterthiophene potassium salt may serve as models for polaron aggregation (ie. $\pi$-dimers) ${ }^{6}$ between two oligomers opened the idea up that carefully designed systems can be synthesized and studied for the inherent electrocnic conduction capabilities.

The continued interest on linear $\pi$-conjugated oligomers is important for developing an understanding of how charged species within a conjugated chain migrate (i.e. intramolecularly), and also how intermolecular interactions between aggregated chains effect charge carriers. The identity and role of radical cations, dications, and $\pi$ dimers on charge migration can be explored by the methodology outlined here.

\subsection{Experimental}

\subsubsection{General Procedures}

All reagents and catalysts were purchased from Aldrich, TCI, or Strem Chemicals and used without further purification. NBS was recrystallized from $\mathrm{H}_{2} \mathrm{O}$. THF and diethyl ether were distilled from benzophenone-sodium ketyl. Dichloromethane was distilled from calcium hydride and anhydrous DMF was purchased from Aldrich. ${ }^{1} \mathrm{H}$ and ${ }^{13} \mathrm{C}$ NMR spectra were recorded from a 300 or $400 \mathrm{MHz}$ Varian Mercury spectrophotometer. Infrared spectra were recorded on a Nicolet 4700 FTIR. Mass spectra were collected on a VG-70SE instrument. Elemental analyses were obtained from Atlantic Microlabs, Inc. Gravity and flash column chromatographies were carried out with silica gel (32-63 mesh, $60 \AA ̊$ from Sorbent Technologies). 


\subsubsection{Synthetic Procedures}

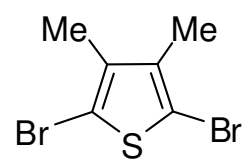

2,5-Dibromo-3,4-dimethylthiophene. $N$-Bromosuccinimide $(6.4 \mathrm{~g}, 36 \mathrm{mmol})$ was added to a solution of 3,4-dimethylthiophene $(2.0 \mathrm{~g}, 18 \mathrm{mmol})$ in $\mathrm{CHCl}_{3}(20 \mathrm{~mL})$ at $0{ }^{\circ} \mathrm{C}$ under $\mathrm{N}_{2}$. The flask was covered in foil, warmed to room temperature, and the mixture was stirred for $18 \mathrm{~h}$. The mixture was cooled to $0{ }^{\circ} \mathrm{C}$, succinimide was removed by filtration, and the organic layer was washed with $5 \%$ aq. $\mathrm{NaOH}(2 \times 50 \mathrm{~mL})$. The aqueous layer was extracted with $\mathrm{CH}_{2} \mathrm{Cl}_{2}(3 \times 50 \mathrm{~mL})$ and the combined organic layers were dried over $\mathrm{MgSO}_{4}$. The solvent was removed under reduced pressure to afford 2,5-dibromo-3,4dimethylthiophene as a colorless liquid (4.70 g, 99\%). ${ }^{1} \mathrm{H} \mathrm{NMR}\left(300 \mathrm{MHz}, \mathrm{CDCl}_{3}\right): \delta$ $2.10\left(\mathrm{~s}, 6 \mathrm{H},-\mathrm{CH}_{3}\right) .{ }^{13} \mathrm{C}$ NMR $\left(75 \mathrm{MHz}, \mathrm{CDCl}_{3}\right.$ ): $\delta 136.9$ (Th-C-3,4), 107.3 (Th-C-2,5), $14.9\left(-\mathrm{CH}_{3}\right)$. MS (EI): $m / z(\%) 269.9\left(\mathrm{M}^{+}, 100\right), 191.0\left(\mathrm{M}^{+}-\mathrm{Br}, 45\right), 110.1\left(\mathrm{M}^{+}-2 \mathrm{Br}, 36\right)$. HRMS (EI): $m / z$ Calcd. for $\mathrm{C}_{6} \mathrm{H}_{6} \mathrm{SBr}_{2}, 267.85569$; found, 267.85525, $\Delta=1.6 \mathrm{ppm}$.

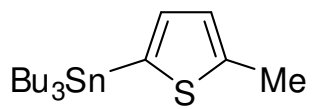

5-Methyl-2-tri-n-butylstannylthiophene. ${ }^{7,8}$ A $2.5 \mathrm{M}$ solution of $n$-BuLi in hexanes (140 $\mathrm{mL}, 56 \mathrm{mmol})$ was added dropwise to solution of 2-methylthiophene $(5.0 \mathrm{~g}, 51 \mathrm{mmol})$ in dry $\mathrm{Et}_{2} \mathrm{O}(80 \mathrm{~mL})$ at $0{ }^{\circ} \mathrm{C}$, and the mixture was stirred for $1 \mathrm{~h}$. A solution of tri- $n$-butyltin chloride $(17 \mathrm{~g}, 53 \mathrm{mmol})$ in $\mathrm{Et}_{2} \mathrm{O}(20 \mathrm{~mL})$ was added dropwise over $10 \mathrm{~min}$, and the mixture was stirred for and additional $12 \mathrm{~h}$. A saturated aq. solution of $\mathrm{NaHCO}_{3}(80 \mathrm{~mL})$ was added and the mixture was stirred for $30 \mathrm{~min}$. The aqueous layer was separated, 
extracted with $\mathrm{Et}_{2} \mathrm{O}(2 \times 100 \mathrm{~mL})$, and the combined organic layers were washed with $\mathrm{H}_{2} \mathrm{O}(3 \times 100 \mathrm{~mL})$ and dried over $\mathrm{MgSO}_{4}$. The solvent was removed under reduce pressure to afford 5-methyl-2-tri- $n$-butylstannyl-thiophene as an orange oil (19.0 g, 96\%) that was used without further purification. ${ }^{1} \mathrm{H}$ NMR $\left(300 \mathrm{MHz}, \mathrm{CDCl}_{3}\right): \delta 7.01(\mathrm{~d}, 1 \mathrm{H}, J$ $=2 \mathrm{~Hz}, \mathrm{Th}-3), 6.90(\mathrm{dq}, 1 \mathrm{H}, J=1 \mathrm{~Hz}, \mathrm{Th}-4), 2.6\left(\mathrm{~d}, 3 \mathrm{H}, J=1 \mathrm{~Hz},-\mathrm{CH}_{3}\right), 1.53-1.65(\mathrm{~m}$, $\left.6 \mathrm{H},-\mathrm{CH}_{2} \mathrm{CH}_{2} \mathrm{CH}_{2} \mathrm{CH}_{3}\right), 1.25-1.40\left(\mathrm{~m}, 6 \mathrm{H},-\mathrm{CH}_{2} \mathrm{CH}_{2} \mathrm{CH}_{2} \mathrm{CH}_{3}\right), 1.13-1.17(\mathrm{~m}, 6 \mathrm{H},-$ $\mathrm{CH}_{2} \mathrm{CH}_{2} \mathrm{CH}_{2} \mathrm{CH}_{3}$ ), 0.89-0.95 (m, 9H, $-\mathrm{CH}_{2} \mathrm{CH}_{2} \mathrm{CH}_{2} \mathrm{CH}_{3}$ ). ${ }^{13} \mathrm{C} \mathrm{NMR} \mathrm{(75} \mathrm{MHz,} \mathrm{CDCl}_{3}$ ): $\delta$ 145.1, 135.3, 134.1, 126.53 (aromatic), $29.4 \quad\left(-\mathrm{CH}_{2} \mathrm{CH}_{2} \mathrm{CH}_{2} \mathrm{CH}_{3}\right), \quad 29.1 \quad$ ($\left.\mathrm{CH}_{2} \mathrm{CH}_{2} \mathrm{CH}_{2} \mathrm{CH}_{3}\right), 15.1\left(-\mathrm{CH}_{3}\right), 10.8\left(-\mathrm{CH}_{2} \mathrm{CH}_{2} \mathrm{CH}_{2} \mathrm{CH}_{3}\right), 8.9\left(-\mathrm{CH}_{2} \mathrm{CH}_{2} \mathrm{CH}_{2}-\mathrm{CH}_{3}\right)$.

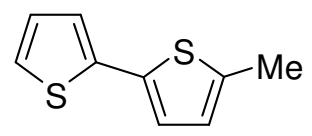

5-Methyl-2,2'-bithiophene. ${ }^{9}$ 2-Tri- $n$-butylstannylthiophene (16 g, $\left.42 \mathrm{mmol}\right)$ was added to a solution of 2-bromo-5-methylthiophene (5.0 g, $28 \mathrm{mmol}), \mathrm{Pd}\left(\mathrm{PPh}_{3}\right)_{4}(330 \mathrm{mg}, 300$ $\mu \mathrm{mol})$, and $\mathrm{LiCl}(3.6 \mathrm{~g}, 85 \mathrm{mmol})$ in dry $\operatorname{DMF}(25 \mathrm{~mL})$ and the mixture heated at $65{ }^{\circ} \mathrm{C}$ for $18 \mathrm{~h}$. The mixture was cooled and a saturated aq. solution of KF $(10 \mathrm{~mL})$ was added and stirred for $2 \mathrm{~h}$ at room temperature. The aq. layer was discarded and the organic solution was passed through celite and a silica plug and the solvent was removed under reduced pressure. The residue was subjected to column chromatography (100\% hexanes) to afford 5-methyl-2,2'-bithiophene as a colorless liquid (2.8 g, 55\%). ${ }^{1} \mathrm{H}$ NMR (300 $\left.\mathrm{MHz}, \mathrm{CDCl}_{3}\right): \delta$ 7.10-7.20 (m, 2H, Th), 7.00-7.10 (m, 2H, Th), 6.67-6.70 (m, 1H, Th), $2.50\left(\mathrm{~s}, 3 \mathrm{H},-\mathrm{CH}_{3}\right) .{ }^{13} \mathrm{C} \mathrm{NMR}\left(75 \mathrm{MHz}, \mathrm{CDCl}_{3}\right): \delta 138.8,137.7,134.9,127.5,125.7$, 123.5, 123.4, 122.8 (aromatic), $15.3\left(-\mathrm{CH}_{3}\right) . \mathrm{IR}(\mathrm{KBr}) 2974,2944,2917,2865,1439$, 
1108, 1102, 983, 909, 857, $778 \mathrm{~cm}^{-1}$. MS (EI): $\mathrm{m} / z(\%) 180.0\left(\mathrm{M}^{+}, 100\right)$. HRMS (EI): $\mathrm{m} / z$ Calcd. for $\mathrm{C}_{9} \mathrm{H}_{8} \mathrm{~S}_{2}, 180.00674$; found, $180.00615, \Delta=3.3 \mathrm{ppm}$.

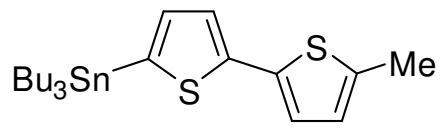

2-Methyl-5'-tri-n-butylstannyl-5,2'-bithiophene. ${ }^{10}$ A $1.6 \mathrm{M}$ solution of $n$-BuLi in hexanes (26 mL, $16 \mathrm{mmol})$ was added dropwise to solution of 5-methyl-2,2'-bithiophene (2.6 g, $15 \mathrm{mmol})$ in dry $\mathrm{Et}_{2} \mathrm{O}(50 \mathrm{~mL})$ at $0{ }^{\circ} \mathrm{C}$ and the mixture was stirred for $2 \mathrm{~h}$. A solution of tri- $n$-butyltin chloride $(5.7 \mathrm{~g}, 53 \mathrm{mmol})$ in $\mathrm{Et}_{2} \mathrm{O}(20 \mathrm{~mL})$ was added dropwise over 20 min., and the mixture was stirred for an additional $18 \mathrm{~h}$. A saturated aq. solution of $\mathrm{NaHCO}_{3}(50 \mathrm{~mL})$ was added and the mixture was stirred for $30 \mathrm{~min}$. The aqueous layer was separated, extracted with $\mathrm{Et}_{2} \mathrm{O}(2 \times 50 \mathrm{~mL})$, and the combined organic layers were washed with saturated aq. $\mathrm{NaHCO}_{3}(50 \mathrm{~mL})$ and dried over $\mathrm{MgSO}_{4}$. The solvent was removed under reduce pressure to afford 2-methyl-5'-tri- $n$-butylstannyl-5,2'-bithiophene as an orange oil $(6.8 \mathrm{~g}, 99 \%)$ without further purification. ${ }^{1} \mathrm{H} \mathrm{NMR}\left(300 \mathrm{MHz}, \mathrm{CDCl}_{3}\right)$ : $\delta 7.19(\mathrm{~d}, 1 \mathrm{H}, J=3.3 \mathrm{~Hz}, \mathrm{Th}), 7.04(\mathrm{~d}, 1 \mathrm{H}, J=3.3 \mathrm{~Hz}, \mathrm{Th}), 6.9(\mathrm{~d}, 1 \mathrm{H}, J=3.5 \mathrm{~Hz}, \mathrm{Th})$, $6.63(\mathrm{dq}, 1 \mathrm{H}, J=3.5 \mathrm{~Hz}, 1.1 \mathrm{~Hz}, \mathrm{Th}), 2.5\left(\mathrm{~d}, 3 \mathrm{H}, J=1 \mathrm{~Hz},-\mathrm{CH}_{3}\right), 1.53-1.62(\mathrm{~m}, 6 \mathrm{H},-$ $\left.\mathrm{CH}_{2} \mathrm{CH}_{2} \mathrm{CH}_{2} \mathrm{CH}_{3}\right), \quad 1.26-1.41 \quad\left(\mathrm{~m}, \quad 6 \mathrm{H}, \quad-\mathrm{CH}_{2} \mathrm{CH}_{2} \mathrm{CH}_{2} \mathrm{CH}_{3}\right), \quad 1.12-1.18 \quad(\mathrm{~m}, \quad 6 \mathrm{H}, \quad-$ $\mathrm{CH}_{2} \mathrm{CH}_{2} \mathrm{CH}_{2} \mathrm{CH}_{3}$ ), 0.88-0.94 (m, 9H, $\left.-\mathrm{CH}_{2} \mathrm{CH}_{2} \mathrm{CH}_{2} \mathrm{CH}_{3}\right) .{ }^{13} \mathrm{C} \mathrm{NMR}\left(75 \mathrm{MHz}, \mathrm{CDCl}_{3}\right.$ ): $\delta$ $143.1, \quad 138.5, \quad 135.8, \quad 135.6, \quad 135.3, \quad 125.7, \quad 124.1,123.2 \quad$ (aromatic), $29.5 \quad$ ($\left.\mathrm{CH}_{2} \mathrm{CH}_{2} \mathrm{CH}_{2} \mathrm{CH}_{3}\right), 27.4\left(-\mathrm{CH}_{2} \mathrm{CH}_{2} \mathrm{CH}_{2} \mathrm{CH}_{3}\right), 15.6\left(-\mathrm{CH}_{3}\right), 13.9\left(-\mathrm{CH}_{2} \mathrm{CH}_{2} \mathrm{CH}_{2} \mathrm{CH}_{3}\right), 11.1$ (- $\left.\mathrm{CH}_{2} \mathrm{CH}_{2} \mathrm{CH}_{2}-\mathrm{CH}_{3}\right)$. IR (neat) 2953, 2922, 2870, 2852, 1517, 1461, 1413, 1370, 1070, $948,865,796,687,670,596,474 \mathrm{~cm}^{-1}$. 


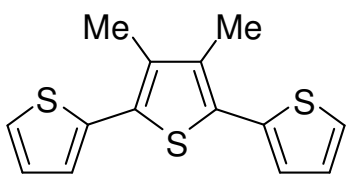

3',4'-Dimethyl-2,2':5'2"-terthiophene. ${ }^{11-13} \quad$ 2-Tri-n-butylstannylthiophene $(1.2 \mathrm{~g}, 7.4$ mmol) was added to a solution of 2,5-dibromo-3,4-dimethylthiophene (0.5 g, $2 \mathrm{mmol})$, $\operatorname{Pd}\left(\mathrm{PPh}_{3}\right)_{4}(100 \mathrm{mg}, 100 \mu \mathrm{mol})$, and $\mathrm{LiCl}(30 \mathrm{mg}, 0.7 \mathrm{mmol})$ in dry DMF $(5 \mathrm{~mL})$, and the mixture was heated at $75{ }^{\circ} \mathrm{C}$ for $18 \mathrm{~h}$. The mixture was cooled and a saturated aq. solution of KF (10mL) was added and the mixture was stirred for $1 \mathrm{~h}$. The aqueous layer was discarded, and the organic solution was passed through celite and silica, and the solvent was removed under reduced pressure. The residue was subjected to column chromatography (10\% ethyl acetate/90\% hexanes) followed by recrystallization from hexanes to afford $3^{\prime}, 4^{\prime}$-dimethyl-2,2':5'2"-terthiophene as a yellow crystalline solid (330 $\mathrm{mg}, 63 \%) . \mathrm{MP}=116-118{ }^{\circ} \mathrm{C} .{ }^{1} \mathrm{H} \mathrm{NMR}\left(300 \mathrm{MHz}, \mathrm{CDCl}_{3}\right): \delta 7.30(\mathrm{dd}, 2 \mathrm{H}, J=5 \mathrm{~Hz}, 1$ Hz, Th-5), 7.13 (dd, 2H, $J=1 \mathrm{~Hz}, 3.3 \mathrm{~Hz}, \mathrm{Th}-3$ ), 7.07 (dd, 2H, $J=5 \mathrm{~Hz}, 3.3 \mathrm{~Hz}$, Th-4), $2.30\left(\mathrm{~s}, 6 \mathrm{H},-\mathrm{CH}_{3}\right) .{ }^{13} \mathrm{C} \mathrm{NMR}\left(75 \mathrm{MHz}, \mathrm{CDCl}_{3}\right): \delta 136.2,135.0,129.4,127.3,125.9$, 125.2, (aromatic), $14.4\left(-\mathrm{CH}_{3}\right) . \mathrm{IR}(\mathrm{KBr}) 3157,2987,2900,1530,1439,1378,1213$, 1156, 1091, $735 \mathrm{~cm}^{-1}$. MS (EI): $\mathrm{m} / z$ (\%) $276.0\left(\mathrm{M}^{+}, 100\right)$. HRMS (EI): $\mathrm{m} / \mathrm{z}$ Calcd. for $\mathrm{C}_{14} \mathrm{H}_{12} \mathrm{~S}_{3}, 276.01012$; found, 276.01300, $\Delta=10 \mathrm{ppm}$. Anal. calcd. for $\mathrm{C}_{14} \mathrm{H}_{12} \mathrm{~S}_{3}$ : C, 60.82; H, 4.38; S, 34.80. Found: C, 60.79; H, 4.36; S, 34.59. 


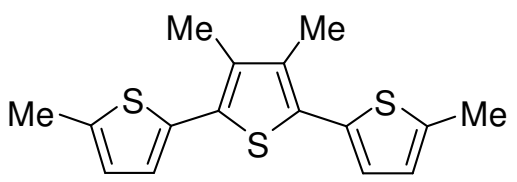

2,3', $4^{\prime}, 5^{\prime \prime}$-Tetramethyl-5, $2^{\prime}: 5^{\prime}, 2^{\prime \prime}$-terthiophene. ${ }^{11-13} \quad$ 5-Methyl-2-tri- $n$-butylstannyl thiophene (4.3 g, $11 \mathrm{mmol})$ was added to a solution of 2,5-dibromo-3,4dimethylthiophene (1.0 g, $2.7 \mathrm{mmol}), \mathrm{Pd}\left(\mathrm{PPh}_{3}\right)_{4}(260 \mathrm{mg}, 0.16 \mathrm{mmol})$, and $\mathrm{LiCl}$ (48 mg, $1.1 \mathrm{mmol})$ in dry DMF $(5 \mathrm{~mL})$, and the mixture was heated at $70{ }^{\circ} \mathrm{C}$ for $18 \mathrm{~h}$. The mixture was cooled and a saturated aq. solution of $\mathrm{KF}(10 \mathrm{~mL})$ was added, and the mixture was stirred for $1 \mathrm{~h}$. The aqueous layer was discarded and the organic solution was passed through celite and a silica plug, and the solvent was removed under reduced pressure. The residue was subjected to column chromatography (10\% ethyl acetate/ $0 \%$ hexanes) followed by recrystallization from hexane to afford the product as yellow crystalline solid $(750 \mathrm{mg}, 66 \%) . \mathrm{MP}=80-82{ }^{\circ} \mathrm{C} .{ }^{1} \mathrm{H} \mathrm{NMR}\left(300 \mathrm{MHz}, \mathrm{CDCl}_{3}\right): \delta 6.89$ (d, 2H, $J=3 \mathrm{~Hz}, \mathrm{Th}-3), 6.70$ (dd, 2H, $J=1 \mathrm{~Hz}, 3 \mathrm{~Hz}, \mathrm{Th}-4), 2.49$ (d, 6H, $J=1 \mathrm{~Hz}, 2,5 "$ $\left.\mathrm{CH}_{3}\right), 2.26\left(\mathrm{~s}, 6 \mathrm{H}, 3^{\prime}, 4^{\prime}-\mathrm{CH}_{3}\right) .{ }^{13} \mathrm{C} \mathrm{NMR}\left(75 \mathrm{MHz}, \mathrm{CDCl}_{3}\right): \delta 139.8,134.4,133.9,129.4$, 125.7, 125.5 (aromatic), $15.4\left(-\mathrm{CH}_{3}\right), 14.4\left(-\mathrm{CH}_{3}\right) . \mathrm{IR}(\mathrm{KBr}) 3070,2978,2913,2852$, 1530, 1439, 1378, 1213, 1044, $787 \mathrm{~cm}^{-1} . \mathrm{MS}(\mathrm{EI}): \mathrm{m} / z(\%) 304.1\left(\mathrm{M}^{+}, 100\right), 289(5)$, 152 (10), 59 (3). HRMS (EI): $\mathrm{m} / z$ Calcd. for $\mathrm{C}_{16} \mathrm{H}_{16} \mathrm{~S}_{3}, 304.04142$; found, 304.04137, $\Delta$ $=0.2$ ppm. Anal. calcd. for $\mathrm{C}_{16} \mathrm{H}_{16} \mathrm{~S}_{3}=\mathrm{C}, 63.19 ; \mathrm{H}, 5.30 ; \mathrm{S}, 31.63$. Found: $\mathrm{C}, 62.39 ; \mathrm{H}$, $5.31 ; \mathrm{S}, 31.28$. 


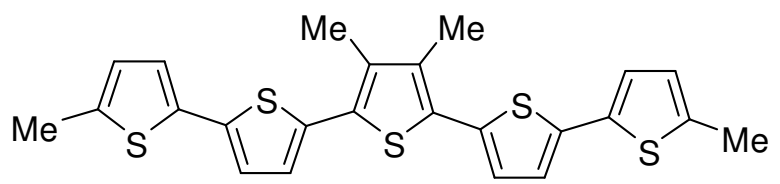

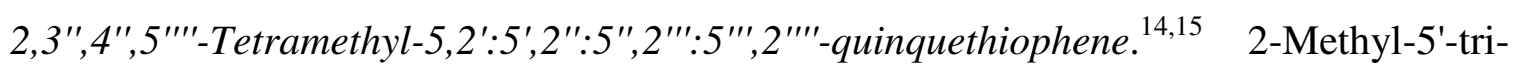
$n$-butylstannyl-5,2'-bithiophene $(3.7 \mathrm{~g}, 8.0 \mathrm{mmol})$ was added to a solution of 2,5dibromo-3,4-dimethyl-thiophene (0.5 g, $1.9 \mathrm{mmol}), \mathrm{Pd}\left(\mathrm{PPh}_{3}\right)_{4}(215 \mathrm{mg}, 0.19 \mathrm{mmol})$. $\mathrm{LiCl}(42 \mathrm{mg}, 1.0 \mathrm{mmol})$ in dry DMF $(10 \mathrm{~mL})$ was added and the mixture was heated at 70 ${ }^{\circ} \mathrm{C}$ for $18 \mathrm{~h}$. The mixture was cooled, a saturated aq. solution of $\mathrm{KF}(10 \mathrm{~mL})$ was added and the mixture was stirred for $1 \mathrm{~h}$. The aqueous layer was discarded, the organic solution was passed through celite and a silica plug, and the solvent was removed under reduced pressure. The residue was subjected to column chromatography (20\% dichloromethane/ $80 \%$ hexanes) followed by recrystallization from toluene to afford 2,3",4",5"'-tetramethyl-5,2':5',2":5",2"':5"',2"'-quinquethiophene as an orange solid (600 $\mathrm{mg}, 69 \%) . \quad \mathrm{MP}=165-166{ }^{\circ} \mathrm{C} .{ }^{1} \mathrm{H} \mathrm{NMR}\left(300 \mathrm{MHz}, \mathrm{CDCl}_{3}\right): \delta 7.03(\mathrm{~d}, 2 \mathrm{H}, J=3.8 \mathrm{~Hz}$, Th-4'), 7.00 (d, 2H, $J=3.8 \mathrm{~Hz}$, Th-3'), 6.97 (d, 2H, $J=3.3 \mathrm{~Hz}, \mathrm{Th}-4), 6.64-6.68(\mathrm{~m}, 2 \mathrm{H}$, Th-3), $2.48\left(\mathrm{~d}, 6 \mathrm{H}, J=1.0 \mathrm{~Hz},-\mathrm{CH}_{3}\right), 2.32\left(\mathrm{~s}, 6 \mathrm{H},-\mathrm{CH}_{3}\right) .{ }^{13} \mathrm{C} \mathrm{NMR}\left(75 \mathrm{MHz}, \mathrm{CDCl}_{3}\right): \delta$ $139.2,137.5,135.1,134.7,134.5,129.3,126.3,125.9,123.5,123.2$ (aromatic), 15.5 ($\left.\mathrm{CH}_{3}\right), 14.6\left(-\mathrm{CH}_{3}\right) . \mathrm{IR}(\mathrm{KBr}) 3065,2904,2852,1504,1430,1069,796 \mathrm{~cm}^{-1} . \mathrm{MS}(\mathrm{EI})$ : $m / z(\%) 468.1\left(\mathrm{M}^{+}, 100\right), 454$ (4), 234 (15), 217 (3), 141 (3), 45 (3). HRMS (EI): $m / z$ Calcd. for $\mathrm{C}_{24} \mathrm{H}_{20} \mathrm{~S}_{5}, 468.01686$; found, 468.01416, $\Delta=5.8 \mathrm{ppm}$. Anal. calcd. for $\mathrm{C}_{24} \mathrm{H}_{20} \mathrm{~S}_{5}=\mathrm{C}, 61.58 ; \mathrm{H}, 4.31 ; \mathrm{S}, 34.24$. Found: C, 61.32; H, 4.32; S, 34.08. 


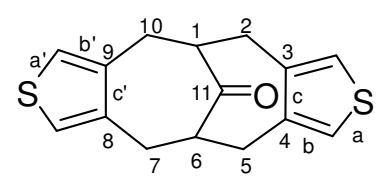

Dithieno[3,4-c:8,9-c']bicyclo[4.4.1]undeca-3,8-diene-11-one. 11-Oxo-dithieno[3,4c:8,9-c']bicyclo[4.4.1]undeca-3,8-diene-1,6-dicarboxylic acid (200 mg, $550 \mu \mathrm{mol})$ was heated at $300{ }^{\circ} \mathrm{C}$ in a pyrex tube under $\mathrm{N}_{2}$ until the evolution of gas ceased (approx. 5-10 min). After the reaction was complete, $\mathrm{CH}_{2} \mathrm{Cl}_{2}(25 \mathrm{~mL})$ and $10 \%$ aq. $\mathrm{NaOH}$ solution (10 $\mathrm{mL}$ ) were added. The organic layer was separated, dried over $\mathrm{MgSO}_{4}$, and the solvent was removed under reduced pressure. The aqueous layer was acidified with $12 \mathrm{M} \mathrm{HCl}$ to $\mathrm{pH}=1$, extracted with $\mathrm{Et}_{2} \mathrm{O}(3 \times 25 \mathrm{~mL})$, dried over $\mathrm{MgSO}_{4}$, and resubjected to pyrolysis. The residue was extracted with $\mathrm{CH}_{2} \mathrm{Cl}_{2}(30 \mathrm{~mL})$ and the solvent was removed. The combined residues were subjected to column chromatography on silica gel (30\% ethyl acetate/70\% hexanes) to give the title compound as a white solid (115 mg, $76 \%$ ). $\mathrm{MP}=180-181{ }^{\circ} \mathrm{C} .{ }^{1} \mathrm{H}$ NMR $\left(300 \mathrm{MHz}, \mathrm{CDCl}_{3}\right): \delta 6.99-7.01$ (br s, $\left.4 \mathrm{H}, \mathrm{Th}-\mathrm{H}\right), 3.00-3.25$ (m, 2H, -CH-), 2.70-2.90 (m, 8H, - $\left.\mathrm{CH}_{2}-\right) .{ }^{13} \mathrm{C}$ NMR $\left(75 \mathrm{MHz}, \mathrm{CDCl}_{3}\right): \delta 215.4$ (ketone $\mathrm{C}=\mathrm{O}$ ), 138.3 (Th-C-3,4), 123.0 (Th-C-2,5), 53.7 (-CH-), 30.2 (- $\left.\mathrm{CH}_{2}-\right)$. IR (KBr) 3151, 3098, 2934, 2848, 1690, 1216, 1104, 908, $740 \mathrm{~cm}^{-1}$. MS (EI): $\mathrm{m} / z$ (\%) $274.0\left(\mathrm{M}^{+}, 100\right)$, 163 (59), 135 (15), 111 (46). HRMS (EI): $m / z$ Calcd. for $\mathrm{C}_{15} \mathrm{H}_{14} \mathrm{OS}_{2}, 274.04861$; found, $274.04744, \Delta=4.2 \mathrm{ppm}$. 


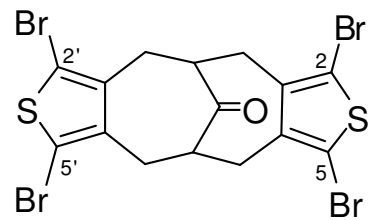

Tetrabromodithieno[3,4-c:8,9-c']bicyclo[4.4.1]undeca-3,8-diene-11-one. N-Bromosuccinimide (1.33 g, $7.5 \mathrm{mmol})$ was added to a solution of dithieno[3,4-c:8,9c']bicyclo[4.4.1]undeca-3,8-diene-11-one (500 $\mathrm{mg}, 1.8 \mathrm{mmol})$ in DMF $(10 \mathrm{~mL})$ at $0{ }^{\circ} \mathrm{C}$ in the dark, and the mixture was stirred for $18 \mathrm{~h}$. A solution of $10 \%$ aq. $\mathrm{HCl}(25 \mathrm{~mL})$ was added and the mixture was extracted with $\mathrm{CH}_{2} \mathrm{Cl}_{2}(3 \times 100 \mathrm{~mL})$. The combined organic layers were washed with $0.1 \mathrm{M} \mathrm{HCl}(4 \times 100 \mathrm{~mL}), 0.1 \mathrm{M} \mathrm{NaOH}(4 \times 100 \mathrm{~mL}), \mathrm{H}_{2} \mathrm{O}(3 \mathrm{x}$ $100 \mathrm{~mL}$ ), and dried over $\mathrm{MgSO}_{4}$. The solvent was removed under reduced pressure, and the residue was triturated with methanol to afford the title compound as a white solid (1.0 $\mathrm{g}, 93 \%) . \mathrm{MP}=244-246{ }^{\circ} \mathrm{C}($ decomp$) . \quad{ }^{1} \mathrm{H}$ NMR $\left(300 \mathrm{MHz}\right.$, DMSO- $\left.d_{6}\right): \delta 3.12-3.17(\mathrm{~m}$, 2H, -CH-), 2.7-3.0 (m, 8H,-CH $\left.{ }_{2}-\right) .{ }^{13} \mathrm{C}$ NMR (75 MHz, DMSO- $\left.d_{6}\right): \delta 212.7(\mathrm{C}=\mathrm{O}), 137.4$ ( $\beta$-Th), 109.8 ( $\alpha$-Th), 52.2 (bridgehead), 29.6 (methylene). IR (KBr) 2929, 2849, 1704, 1434, 1259, 1105, 1031, $803 \mathrm{~cm}^{-1}$. MS (EI): $\mathrm{m} / z$ (\%) $589.7\left(\mathrm{M}^{+}, 100\right), 510.8\left(\mathrm{M}^{+}-\mathrm{Br}, 24\right)$. HRMS (EI): $\mathrm{m} / z$ Calcd. for $\mathrm{C}_{15} \mathrm{H}_{10} \mathrm{OBr}_{4} \mathrm{~S}_{2}, 585.69065$; found, 585.69360, $\Delta=5 \mathrm{ppm}$. 


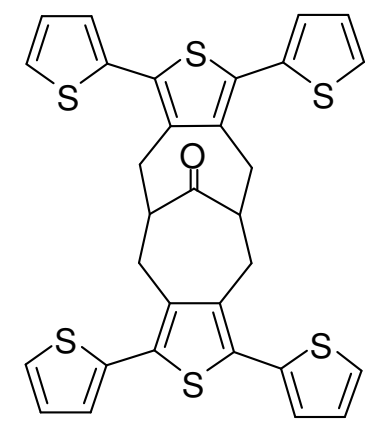

Tetra-(2-thienyl)-dithieno[3,4-c:8,9-c']bicyclo[4.4.1]undeca-3,8-diene-11-one. $\mathrm{Pd}\left(\mathrm{PPh}_{3}\right)_{4}$ (24 mg, $20 \mu \mathrm{mol}$ ) was added to a solution of 2,5,2',5'-tetrabromo-dithieno[3,4-c:8,9c']bicyclo[4.4.1]undeca-3,8-diene-11-one (200 mg, $0.34 \mathrm{mmol})$ and $\mathrm{LiCl}(25 \mathrm{mg}, 0.58$ mmol) in dry THF $(7 \mathrm{~mL})$, and the mixture was stirred at $0{ }^{\circ} \mathrm{C}$ for $10 \mathrm{~min}$. 2-Tri- $n$ butylstannylthiophene $(750 \mathrm{mg}, 2.01 \mathrm{mmol})$ was added dropwise, and the solution was heated at $65{ }^{\circ} \mathrm{C}$ for $3 \mathrm{~d}$. The resulting mixture was cooled, and the solvent was removed under reduced pressure. A saturated aq. solution of $\mathrm{KF}(10 \mathrm{~mL})$ was added and the mixture was extracted with $\mathrm{Et}_{2} \mathrm{O}(3 \times 50 \mathrm{~mL})$. The combined organic extracts were washed with $\mathrm{H}_{2} \mathrm{O}\left(2 \times 50 \mathrm{~mL}\right.$ ), dried over anhydrous $\mathrm{MgSO}_{4}$, and the solvent was removed under reduced pressure. The residue was subjected to column chromatography on silica gel (30\% ethyl acetate/70\% hexanes) followed by recrystallization from hexanes to provide the title compound as a pale yellow crystalline solid, $(112 \mathrm{mg}, 55 \%)$. MP = 263-265 ${ }^{\circ} \mathrm{C} . \quad{ }^{1} \mathrm{H}$ NMR $\left(300 \mathrm{MHz}, \mathrm{CDCl}_{3}\right): \delta 7.35$ (m, 4H, Th), 7.05 (m, 8H, Th), 2.8$3.25\left(\mathrm{~m}, 10 \mathrm{H},-\mathrm{CH}-\right.$ and $\left.-\mathrm{CH}_{2}-\right) .{ }^{13} \mathrm{C} \mathrm{NMR}\left(75 \mathrm{MHz}, \mathrm{CDCl}_{3}\right): \delta 214.5(\mathrm{C}=\mathrm{O}), 136.4$, 135.1, 134.7, 127.7, 127.1, 126.3 (aromatic), 53.6 (-CH-), $29.4\left(-\mathrm{CH}_{2}-\right) . \quad$ IR (KBr) 2934, 2862, 1697, 1453, 1098, 919, 841, $696 \mathrm{~cm}^{-1}$. MS (EI): $\mathrm{m} / z(\%) 602\left(\mathrm{M}^{+}, 100\right), 275\left(\mathrm{M}^{+}-\right.$ 4Th). HRMS (EI): $\mathrm{m} / \mathrm{z}$ Calcd. for $\mathrm{C}_{31} \mathrm{H}_{22} \mathrm{OS}_{6}, 601.99950$; found, 601.99752, $\Delta=3.3$ ppm. 


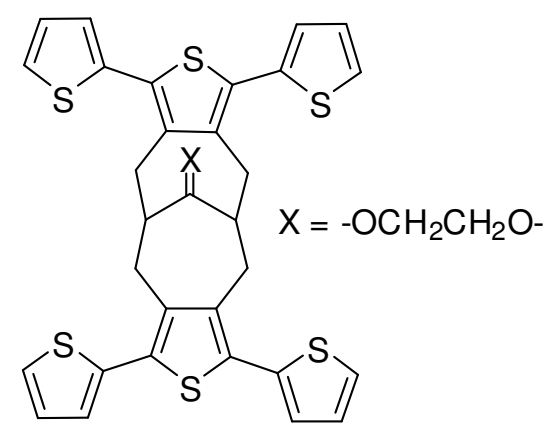

Ethylene acetal of tetra-(2-thienyl)-dithieno[3,4-c:8,9-c']bicyclo[4.4.1]undeca-3,8-diene11-one. A solution of the tetra-(2-thienyl)-dithieno[3,4-c:8,9-c']bicyclo[4.4.1]undeca-3,8diene-11-one $(100 \mathrm{mg}, 170 \mu \mathrm{mol})$, ethylene glycol $(100 \mathrm{mg}, 1.60 \mathrm{mmol})$, and $p$ toluenesulfonic acid $(1 \mathrm{mg}, 5 \mathrm{mmol})$ in benzene $(7 \mathrm{~mL})$ was heated at reflux for $18 \mathrm{~h}$ with a Dean-Stark trap. The solvent was evaporated under reduced pressure, and the residue was subjected to column chromatography on silica gel (10\% ethyl acetate/90\% hexanes) followed by recrystallization from $10 \%$ ethyl acetate/90\% hexanes to give the title compound $(105 \mathrm{mg}, 97 \%)$ as a yellow crystalline solid. $\mathrm{MP}=264-266{ }^{\circ} \mathrm{C} . \quad{ }^{1} \mathrm{H}$ NMR $\left(300 \mathrm{MHz}, \mathrm{CDCl}_{3}\right): \delta 7.11(\mathrm{dd}, 4 \mathrm{H}, J=1.1 \mathrm{~Hz}, J=5.1 \mathrm{~Hz}, \mathrm{Th}-5), 6.86(\mathrm{dd}, 4 \mathrm{H}, J=3.6$, $5.1 \mathrm{~Hz}, \mathrm{Th}-4), 6.80$ (dd, 4H, $J=1.1,3.5 \mathrm{~Hz}$, Th-3), 4.01 (s, 4H, - $\mathrm{OCH}_{2} \mathrm{CH}_{2} \mathrm{O}-$ ), 3.34 (dd, $\left.4 \mathrm{H}, J=5.6,15.5 \mathrm{~Hz},-\mathrm{CH}_{2}-\right), 3.10\left(\mathrm{dd}, 4 \mathrm{~h}, J=3.4,15.5 \mathrm{~Hz},-\mathrm{CH}_{2}-\right), 2.32(\mathrm{~m}, 2 \mathrm{H}$, bridgehead). ${ }^{13} \mathrm{C}$ NMR $\left(75 \mathrm{MHz}, \mathrm{CDCl}_{3}\right): \delta$ 138.0, 136.1, 129.6, 127.0, 126.1, 125.0 (aromatic), 113.4 (ketal), $64.7\left(-\mathrm{OCH}_{2} \mathrm{CH}_{2} \mathrm{O}-\right), 42.7$ (bridgehead), $28.6\left(-\mathrm{CH}_{2}-\right)$. IR (KBr) 2927, 2855, 1433, 1104, 1038, 906, 834, $703 \mathrm{~cm}^{-1} . \mathrm{MS}(\mathrm{EI}): \mathrm{m} / \mathrm{z}(\%) 646.1\left(\mathrm{M}^{+}\right.$, 100), $564\left(\mathrm{M}^{+}-\mathrm{Th}\right.$ ). HRMS (EI): $\mathrm{m} / \mathrm{z}$ Calcd. for $\mathrm{C}_{33} \mathrm{H}_{26} \mathrm{O}_{2} \mathrm{~S}_{6}, 646.02571$; found, 646.02561, $\Delta=0.2$ ppm. Anal. calcd. for $\mathrm{C}_{33} \mathrm{H}_{26} \mathrm{O}_{2} \mathrm{~S}_{6}=\mathrm{C}, 61.27 ; \mathrm{H}, 4.05 ; \mathrm{S}, 29.74$. Found: C, 61.04; H, 4.10; S, 29.57. 


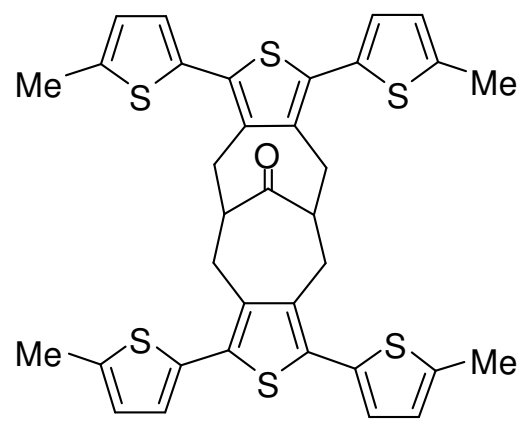

Tetra-(5-methyl-2-thienyl)-dithieno[3,4-c:8,9-c']bicyclo[4.4.1] undeca-3,8-diene-11-one. $\mathrm{Pd}\left(\mathrm{PPh}_{3}\right)_{4}(35 \mathrm{mg}, 30 \mu \mathrm{mol})$ was added to a solution of tetrabromo-dithieno[3,4-c:8,9c']bicyclo[4.4.1] undeca-3,8-diene-11-one (200 mg, $0.34 \mathrm{mmol})$ and $\mathrm{LiCl}$ (30 mg, 0.71 mmol) in dry THF (7 mL), and the mixture was stirred at $0{ }^{\circ} \mathrm{C}$ for $10 \mathrm{~min}$. 5-Methyl-2-tri$n$-butylstannylthiophene (1.1 g, $2.7 \mathrm{mmol})$ was added dropwise, and the solution was heated at $65{ }^{\circ} \mathrm{C}$ for $3 \mathrm{~d}$. The mixture was cooled, and the solvent was removed under reduced pressure. A saturated aq. solution of $\mathrm{KF}(10 \mathrm{~mL})$ was added, and the mixture was extracted with $\mathrm{Et}_{2} \mathrm{O}(3 \mathrm{x} 50 \mathrm{~mL})$. The combined organic extracts were washed with $\mathrm{H}_{2} \mathrm{O}(2 \times 75 \mathrm{~mL})$, dried over anhydrous $\mathrm{MgSO}_{4}$, and the solvent was removed under reduced pressure. The residue was subjected to column chromatography on silica gel (30\% ethyl acetate/70\% hexanes) followed by recrystallization from hexanes to provide the title compound as a pale yellow crystalline solid (105 mg, 47\%). MP $=257-259{ }^{\circ} \mathrm{C}$. ${ }^{1} \mathrm{H}$ NMR $\left(300 \mathrm{MHz}, \mathrm{CDCl}_{3}\right): \delta$ 6.6-6.8 (m, 8H, Th), 2.4-3.2 (m, 10H, -CH- and $-\mathrm{CH}_{2}-$ ), 2.2-2.4 (m, 12H, $\left.-\mathrm{CH}_{3}\right) .{ }^{13} \mathrm{C}$ NMR $\left(75 \mathrm{MHz}, \mathrm{CDCl}_{3}\right): \delta 215.0(\mathrm{C}=\mathrm{O}), 141.0,135.9$, 132.5, 126.9, 125.8, 122.8 (aromatic), 53.3 (bridgehead), 29.4 (methylene), 15.34 (methyl). IR (KBr) 3006, 2973, 2927, 1723, 1374, 1229, 1098, 913, 742, $650 \mathrm{~cm}^{-1}$. MS (EI): $m / z(\%) 658.1\left(\mathrm{M}^{+}, 100\right)$. HRMS (EI): $m / z=$ Calcd. for $\mathrm{C}_{35} \mathrm{H}_{30} \mathrm{OS}_{6}, 658.06210$; found, 658.05948, $\Delta=4.0 \mathrm{ppm}$. 


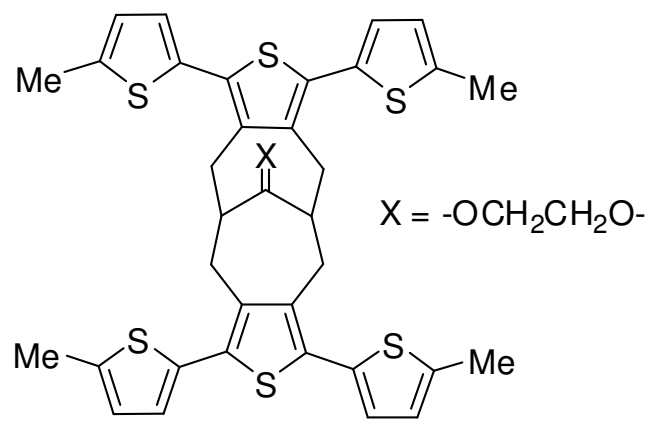

Ethylene acetal of tetra-(5-methyl-2-thienyl)-dithieno[3,4-c:8,9-c']bicyclo[4.4.1] undeca3,8-diene-11-one. A solution of 2,5,2'5'-tetra-(5-methyl-2-thienyl)-dithieno[3,4-c:8,9c']bicyclo[4.4.1]undeca-3,8-diene-11-one (105 mg, $160 \mu \mathrm{mol})$, ethylene glycol (317 mg, $5.11 \mathrm{mmol})$, and $p$-toluenesulfonic acid $(5 \mathrm{mg}, 30 \mathrm{mmol})$ in benzene $(7 \mathrm{~mL})$ was heated at reflux for $18 \mathrm{~h}$ with a Dean-Stark trap. The solvent was removed under reduced pressure, and the residue was subjected to column chromatography on silica gel (10\% ethyl acetate/90\% hexanes) followed by recrystallization from the eluent system to give the title compound as pale yellow crystalline solid $(100 \mathrm{mg}, 89 \%) . \mathrm{MP}=214-216{ }^{\circ} \mathrm{C} .{ }^{1} \mathrm{H}$ NMR (300 MHz, CDCl $): \delta 6.60(\mathrm{~d}, 4 \mathrm{H}, J=3.8 \mathrm{~Hz}, \mathrm{Th}), 6.50-6.54$ (m, 4H, Th), 4.03 (s, $\left.4 \mathrm{H},-\mathrm{OCH}_{2} \mathrm{CH}_{2} \mathrm{O}-\right), 3.29\left(\mathrm{dd}, 4 \mathrm{H}, J=5 \mathrm{~Hz}, \mathrm{~J}=15 \mathrm{~Hz},-\mathrm{CH}_{2}-\right), 3.02(\mathrm{dd}, 4 \mathrm{H}, J=3 \mathrm{~Hz}, J=$ $\left.15 \mathrm{~Hz},-\mathrm{CH}_{2}-\right), 2.38\left(\mathrm{~d}, 12 \mathrm{H}, J=1.0 \mathrm{~Hz},-\mathrm{CH}_{3}\right), 2.28-2.35(\mathrm{~m}, 2 \mathrm{H},-\mathrm{CH}-) .{ }^{13} \mathrm{C}$ NMR $(75$ $\left.\mathrm{MHz}, \mathrm{CDCl}_{3}\right): \delta 139.2,137.2,134.2,129.5,125.7,124.9$ (aromatic), $113.5(\mathrm{C}=\mathrm{O}), 64.6$ (- $\left.\mathrm{OCH}_{2} \mathrm{CH}_{2} \mathrm{O}-\right)$, 42.7 (bridgehead), $28.5\left(-\mathrm{CH}_{2}-\right), 15.2\left(-\mathrm{CH}_{3}\right)$. IR (KBr) 3074, 2961, 2913, 2887, 1435, 1252, 1100, 1039, 1000, 904, 783, $717 \mathrm{~cm}^{-1}$. MS (EI): $\mathrm{m} / z$ (\%) 702.1 $\left(\mathrm{M}^{+}\right), 640$ (4), 351 (5), 287 (6), 141 (7). HRMS (EI): $\mathrm{m} / \mathrm{z}$ Calcd. for $\mathrm{C}_{37} \mathrm{H}_{34} \mathrm{O}_{2} \mathrm{~S}_{6}$, 702.08831; found, 702.08240, $\Delta=8.4$ ppm. Anal. calcd. for $\mathrm{C}_{37} \mathrm{H}_{34} \mathrm{O}_{2} \mathrm{~S}_{6}: \mathrm{C}, 63.21 ; \mathrm{H}$, 4.88; S, 27.37. Found: C, 63.04; H, 4.86; S, 27.12. 


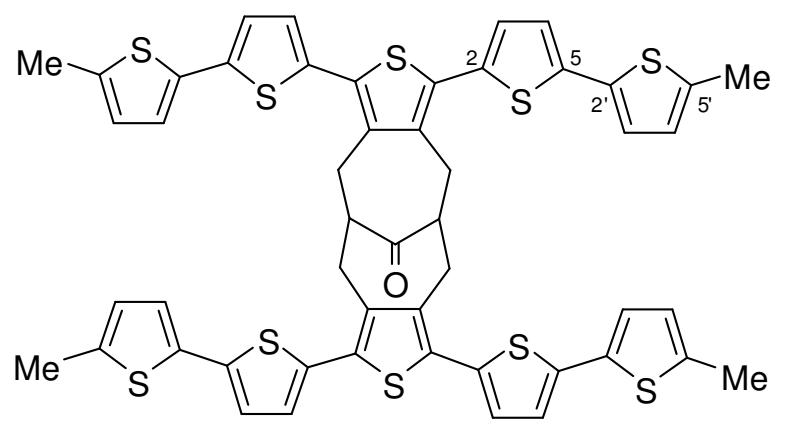

Tetra-[2-(5'-methyl-2',5-bithienyl)]-dithieno[3,4-c:8,9-c']bicyclo[4.4.1]undeca-3,8-

diene-11-one. 2-Methyl-5'-tributylstannyl-5,2'-bithiophene (1.60 g, $3.4 \mathrm{mmol})$ was added to a solution of tetrabromodithieno[3,4-c:8,9-c']bicyclo[4.4.1]undeca-3,8-diene-11-one (200 mg, $340 \mu \mathrm{mol}), \operatorname{Pd}\left(\mathrm{PPh}_{3}\right)_{4}(100 \mathrm{mg}, 80 \mu \mathrm{mol})$, and $\mathrm{LiCl}(45 \mathrm{mg}, 1.1 \mathrm{mmol})$ in dry DMF $(6 \mathrm{~mL})$, and the solution was heated at $65^{\circ} \mathrm{C}$ for $18 \mathrm{~h}$. The mixture was cooled and a saturated aq. solution of $\mathrm{KF}(15 \mathrm{~mL})$ was added, and the mixture was stirred for $1 \mathrm{~h}$. The aqueous layer was discarded and the organic solution was passed through celite and a silica plug, and the solvent was removed under reduced pressure. The residue was subjected to column chromatography ( $70 \% \mathrm{CHCl}_{3} / 30 \%$ hexanes) to afford the product as a golden brown solid $(180 \mathrm{mg}, 54 \%) . \mathrm{MP}=254-256{ }^{\circ} \mathrm{C} .{ }^{1} \mathrm{H} \mathrm{NMR}\left(300 \mathrm{MHz}, \mathrm{CDCl}_{3}\right): \delta$ 7.01 (d, 4H, $J=3 \mathrm{~Hz}$, Th-H), 6-94-6.97 (m, 8H, Th-H), 6.60-6.62 (m, 4H, Th-H), 2.80$3.20\left(\mathrm{~m}, 10 \mathrm{H}\right.$, methylene, bridgehead), 2.45-2.50 (bs, $\left.12 \mathrm{H},-\mathrm{CH}_{3}\right) .{ }^{13} \mathrm{C}$ NMR $(75 \mathrm{MHz}$, $\left.\mathrm{CDCl}_{3}\right): \delta 139.2,137.5,135.1,134.7,134.5,129.3,126.3,125.9,123.5,123.2$ (aromatic), 53.2 (bridgehead), $29.5\left(-\mathrm{CH}_{2}-\right), 15.5,\left(-\mathrm{CH}_{3}\right)$. IR (KBr) 3069, 2956, 2908, 2852, 1704, $1517,1434,1199,1055,781,473 \mathrm{~cm}^{-1}$. 


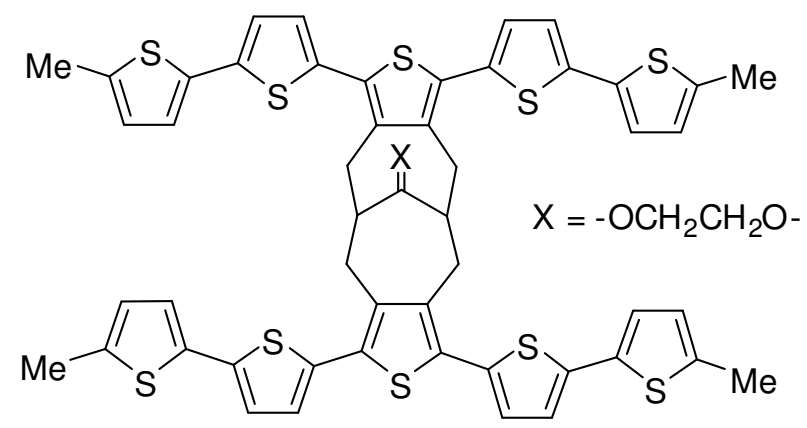

Ethylene acetal of Tetra-[2-(5'-methyl-2',5-bithienyl)]-dithieno[3,4-c:8,9c']bicyclo[4.4.1]undeca-3,8-diene-11-one. A solution of tetra-[2-(5'-methyl-2',5bithienyl)]-dithieno[3,4-c:8,9-c']bicyclo[4.4.1]undeca-3,8-diene-11-one (150 mg, 100 $\mu \mathrm{mol})$, ethylene glycol (100 mg, $1.61 \mathrm{mmol})$, and $p$-toluenesulfonic acid (2 mg, $10 \mathrm{mmol})$ in benzene $(7 \mathrm{~mL})$ was heated at reflux for $18 \mathrm{~h}$ with a Dean-Stark trap. The solvent was evaporated under reduced pressure, and the residue was subjected to column chromatography on silica gel $\left(70 \% \mathrm{CHCl}_{3} / 30 \%\right.$ hexanes) followed by recrystallization from toluene to give the title compound as an orange solid (70 mg, 45\%). MP $=260-261$ ${ }^{\circ} \mathrm{C}$ (decomp). ${ }^{1} \mathrm{H}$ NMR (300 MHz, $\left.\mathrm{CDCl}_{3}\right): \delta$ 6.65-6.78 (m, 12H, Ar), 6.48-6.53 (m, 4H, Ar), 4.10 (s, 4H, ethylene), 3.5 (dd, 4H, $J=5,15 \mathrm{~Hz}$, methylene), 3.09 (dd, 4H, $J=3,15$ $\mathrm{Hz}$, methylene), 2.30-2.50 (m, 14H, bridgehead, methyl). ${ }^{13} \mathrm{C} \mathrm{NMR}\left(75 \mathrm{MHz}, \mathrm{CDCl}_{3}\right): \delta$ $138.57,137.8,137.2,134.8,134.5,129.5,128.2,126.30,125.5,122.8$ (aromatic), 113.4 (ketal), 64.8 (-OCH$\left.{ }_{2} \mathrm{CH}_{2} \mathrm{O}-\right), 42.6$ (bridgehead), $28.72\left(-\mathrm{CH}_{2}-\right), 15.5\left(-\mathrm{CH}_{3}\right) . \quad \mathrm{IR}(\mathrm{KBr})$ $3065,2961,2917,1448,1257,1109,1048,1000,913,787,730 \mathrm{~cm}^{-1}$. MS (FAB): $\mathrm{m} / z$ (\%) $1029.8\left(\mathrm{M}^{+}, 100\right)$. HRMS (EI): $m / z=$ Calcd. for $\mathrm{C}_{53} \mathrm{H}_{42} \mathrm{O}_{2} \mathrm{~S}_{10}, 1030.03920$; found, 1030.03553, $\Delta=3.6$ ppm. Anal. calcd. for $\mathrm{C}_{53} \mathrm{H}_{42} \mathrm{O}_{2} \mathrm{~S}_{10}$ : C, 61.71; H, 4.10; S, 31.09. Found: C, 61.58; H, 3.94; S, 30.87. 


\subsection{Results and Discussion}

\subsubsection{Synthesis of $\pi$-Stacked Oligothiophenes}

$\pi$-Stacked Terthiophene. The successful synthesis and characterization of the dothieno-fused bicyclo[4.4.1[undecanone $\mathbf{2 . 3}$ provided a route to extended $\pi$-conjugated systems which are in close proximity to each other (3-4 $\AA$ ), typical for electronic communication in $\pi$-conjugated chains in sold state materials. Bromination of the reactive 2- and 5- positions on $\mathbf{2 . 3}$ with 4.1 eq. $N$-bromosuccinimide provided the tetrabromo derivative 3.1, Figure 3.1. Multiple attempts to couple 2-thiophene boronic acid under basic conditions with $\mathrm{Pd}\left(\mathrm{PPh}_{3}\right)_{4}$ in THF or DME were unsuccessful, Figure 3.1. Use of the neopentyl borate ester to increase solubility and reactivity also yielded no coupled product in THF or DME.

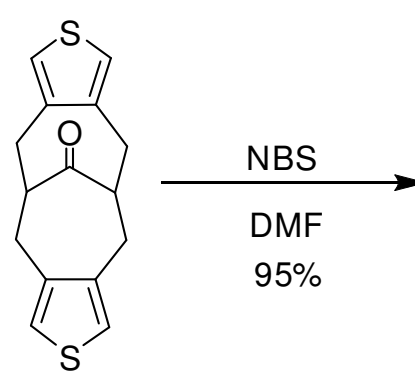

2.3

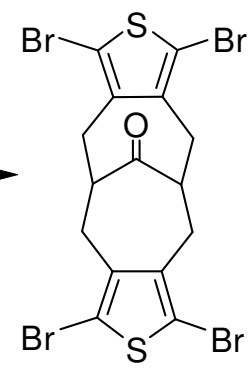

3.1

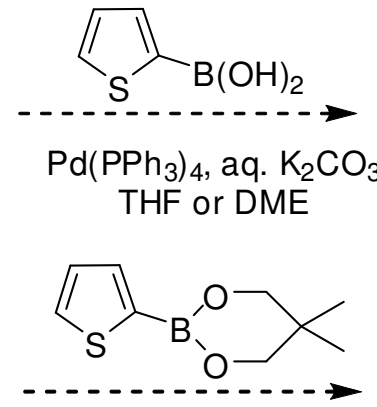

$\mathrm{Pd}\left(\mathrm{PPh}_{3}\right)_{4}$, aq. $\mathrm{K}_{2} \mathrm{CO}_{3}$ THF or DME

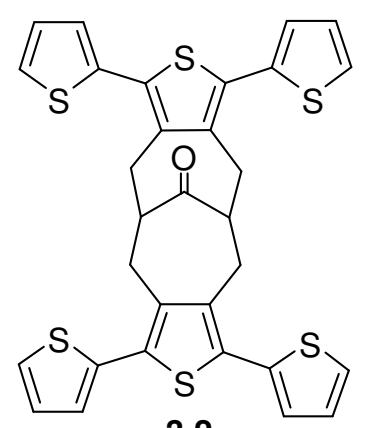

3.2

Figure 3.1. Synthesis of 3.1 and attempts to synthesize 3.2 via Suzuki coupling.

The Stille reaction was then attempted to install thienyl units on the dithienofused bicyclo[4.4.1] undecanone 3.1. Treatment of $\mathbf{3 . 1}$ with excess (6-8 eq.) commercially available 2-tri- $n$-butylstannylthiophene with $\mathrm{LiCl}$ (to aid in 
transmetallation), and $\mathrm{Pd}\left(\mathrm{PPh}_{3}\right)_{4}$ in anhydrous $\mathrm{DMF}$ at $65{ }^{\circ} \mathrm{C}$ for $3 \mathrm{~d}$ gave ketone 3.2 in good yield, 55\% (corresponding to $86 \%$ conversion of thienylic bromides), Figure 3.2. In order to lock the conformation on the bicyclo[4.4.1] undecanone into a chair-chair arrangement for $\pi-\pi$ communication between the terthiophene units, the ketalization was performed with ethylene glycol, benzene and p-toluenesulfonic acid fitted with a DeanStark trap Ketal $\mathbf{3 . 3}$ was obtained as a yellow crystalline solid after column chromatography (yield, 97\%), Figure 3.2.

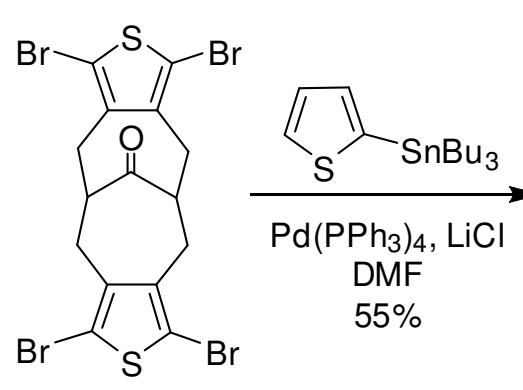

3.1

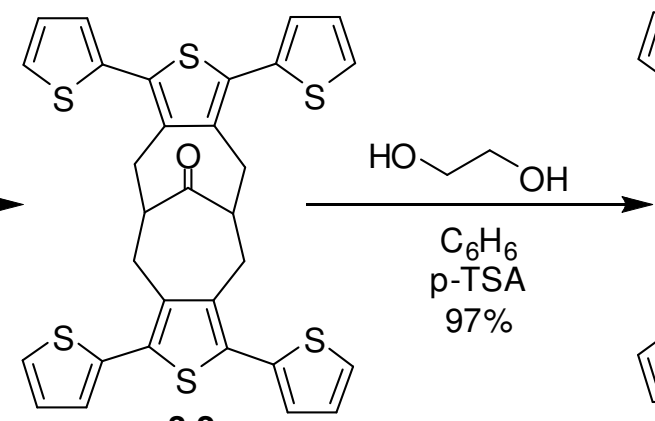

3.2

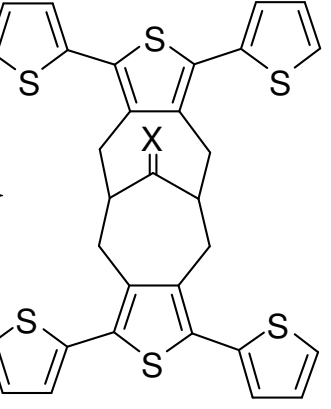

$\mathrm{X}=-\mathrm{OCH}_{2} \mathrm{CH}_{2} \mathrm{O}-$

3.3

Figure 3.2. Synthesis of ketone 3.3 and $\pi$-stacked ketal 3.4.

The methyl-capped terthiophene compound was syntheisized in a similar fashion. 2-Methyl-5-tri- $n$-butylstannylthiophene was prepared according to analogous literature procedures ${ }^{7,8}$ and was coupled to 3.1 in the presence of $\mathrm{Pd}\left(\mathrm{PPh}_{3}\right)_{4}$, and $\mathrm{LiCl}$ in anhydrous DMF. The ketone 3.4 was attained as a pale yellow crystalline solid a $47 \%$ yield (83\% conversion per thienylic bromide) after column chromatography and recrystallization from hexanes, Figure 3.3. Ketalization with ethylene glycol afforded the $\pi$-stacked compound 3.5 as a pale yellow crystalline solid (yield, 89\%), Figure 3.3. 


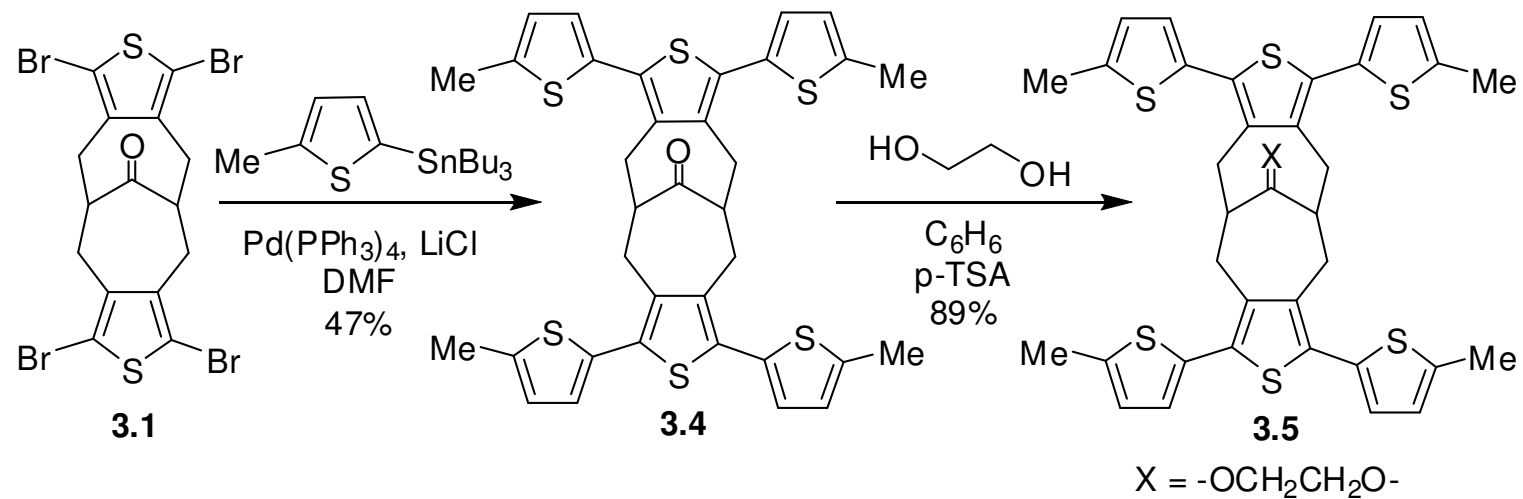

Figure 3.3. Synthesis of ketone 3.5 and $\pi$-stacked ketal 3.6.

Linear Model Terthiophenes. Model compound 3.6 was synthesized in two steps from 3,4-dimethylthiophene. Bromination with 2.1 eq. $\mathrm{N}$-bromosuccinimide in $\mathrm{CHCl}_{3}$ afforded 2.5-dibromo-3,4-dimethylthiophene in almost quantitative yield after aqueous workup and extraction with hexanes. The Suzuki reaction yielded some material on a small scale, but the Stille reaction conditions yielded more material on a larger scale. Column chromatography followed by recrystallization from hexanes afforded 3',4'dimethyl-2,2':5'2"-terthiophene, 3.6, as yellow crystalline solid, Figure 3.4.

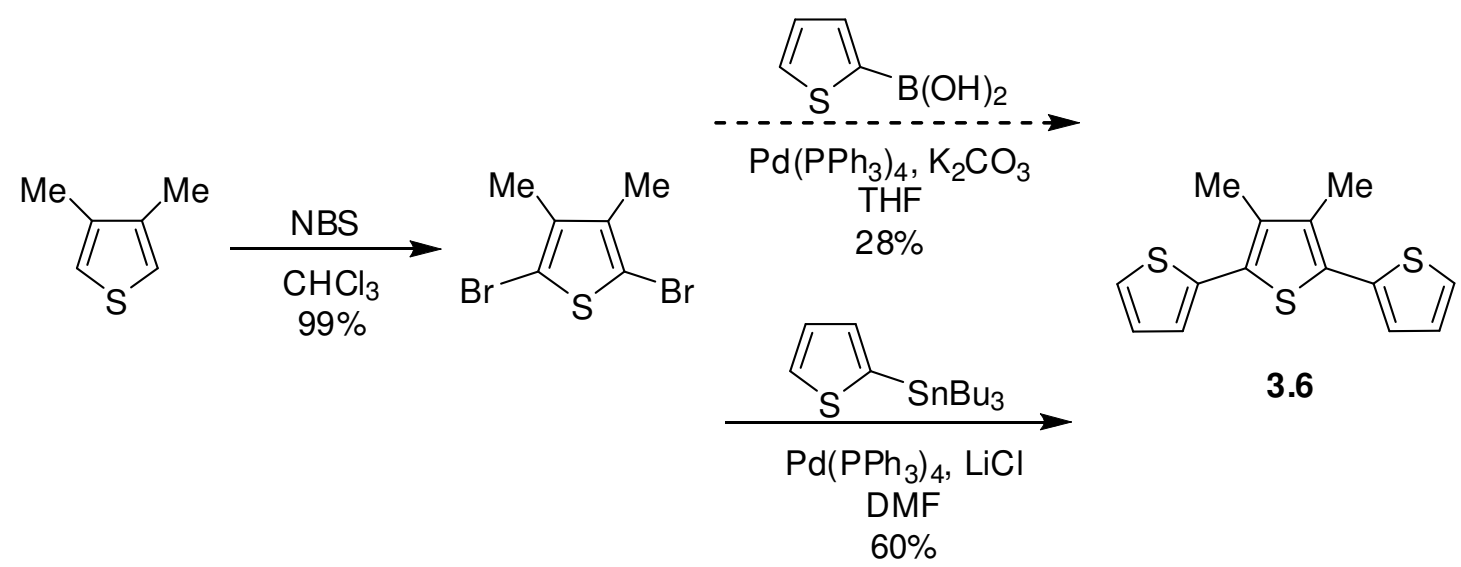

Figure 3.4. Synthesis of linear model terthiophene 3.6. 
The methyl-capped model terthiophene 3.7 was prepared in a similar fashion Reaction of 2,5-dibromo-3,4-dimethylthiophene with 2-methyl-5-tri- $n$-butylstannylthiophene in the presence of $\mathrm{Pd}\left(\mathrm{PPh}_{3}\right)_{4}$, and $\mathrm{LiCl}$ in anhydrous $\mathrm{DMF}$ at $60{ }^{\circ} \mathrm{C}$ provided 3.7 as yellow crystalline solid (yield, 66\%), Figure 3.5.

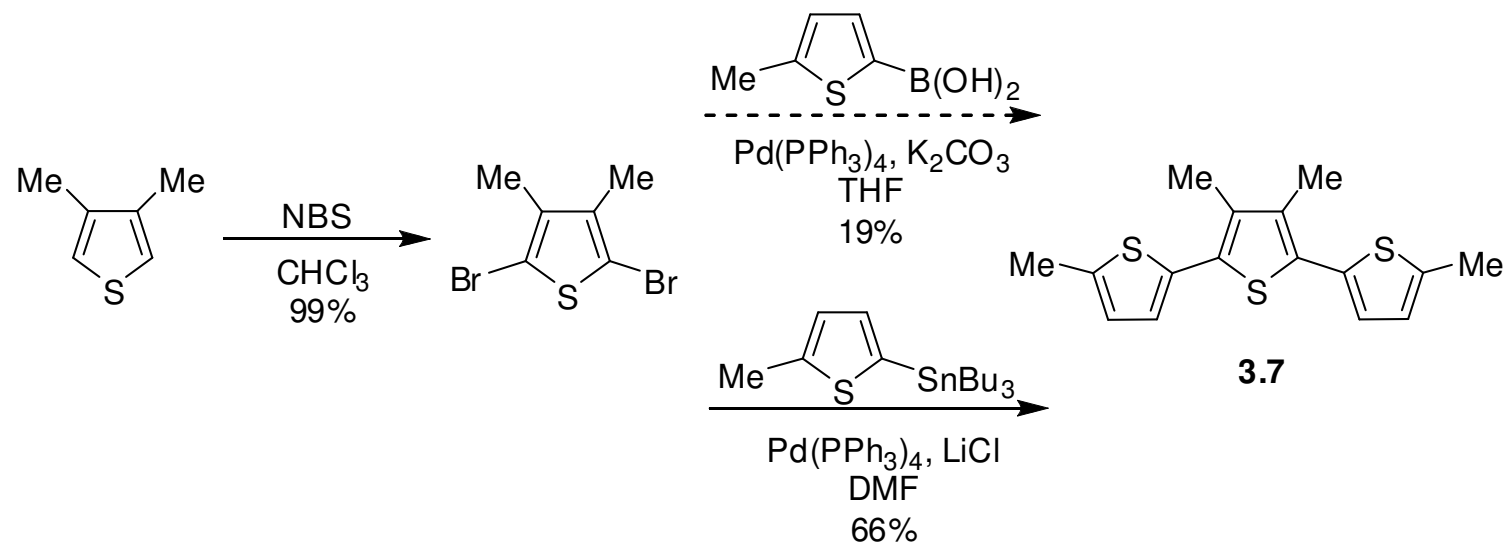

Figure 3.5. Synthesis of linear, methyl-capped model terthiophene 3.7.

Quinquethiophene $\pi$-Stacked and Linear Model Compounds. A key intermediate bithiophene 3.8 was synthesized to extend the conjugation length of the stacked oligomers and linear models up to the quinquethiophene. 2-Bromo-5-methylthiophene, was coupled to 2-tri- $n$-butylstannylthiophene in the presence of $\mathrm{Pd}\left(\mathrm{PPh}_{3}\right)_{4}$, and $\mathrm{LiCl}$ in dry DMF to provide 2-methyl-5:2'-bithiophene in good yield (55\%), Figure 3.6. ${ }^{9}$ Lithiation with $n$-butyllithium (1.1 eq.) in dry $\mathrm{Et}_{2} \mathrm{O}$ followed by addition of tri- $n$ butylstannyl chloride provided $\mathbf{3 . 8}$ as an orange oil in high yield (99\%) after workup. ${ }^{10}$

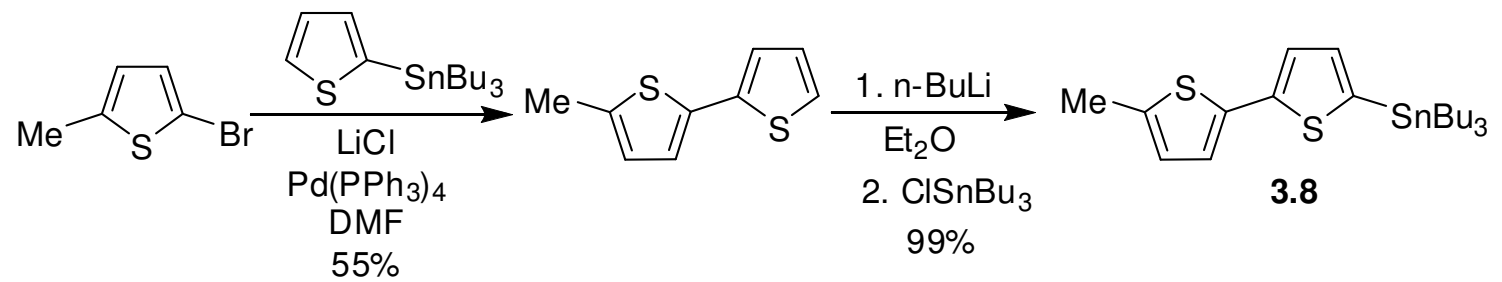

Figure 3.6. Synthesis of intermediate 2-methyl-5:2'-bithiophene, 3.8 . 
Synthesis of the quinquethiophene ketone 3.9 was accomplished by the Stille coupling of ketone 3.1 to bithiophene 3.8. Purification by column chromatography (afforded 3.9 as a golden brown solid (yield, 54\%), Figure 3.7. Ketalization of ketone 3.9 with ethylene glycol provided $\pi$-stacked ketal $\mathbf{3 . 1 0}$ as an orange solid, Figure 3.7. While the solubility of $\mathbf{3 . 1 0}$ was low in $\mathrm{CDCl}_{3}$ at room temperature, this did not present a problem for spectroscopic and electrochemical characterization.

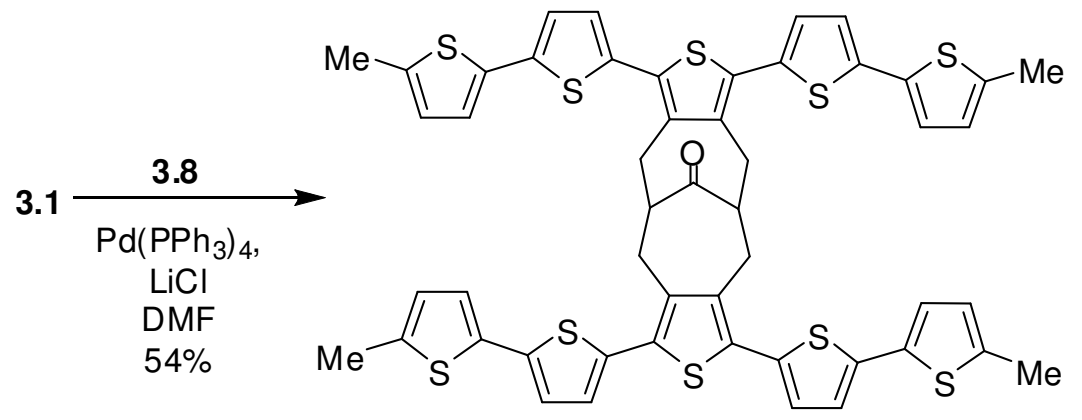

3.9

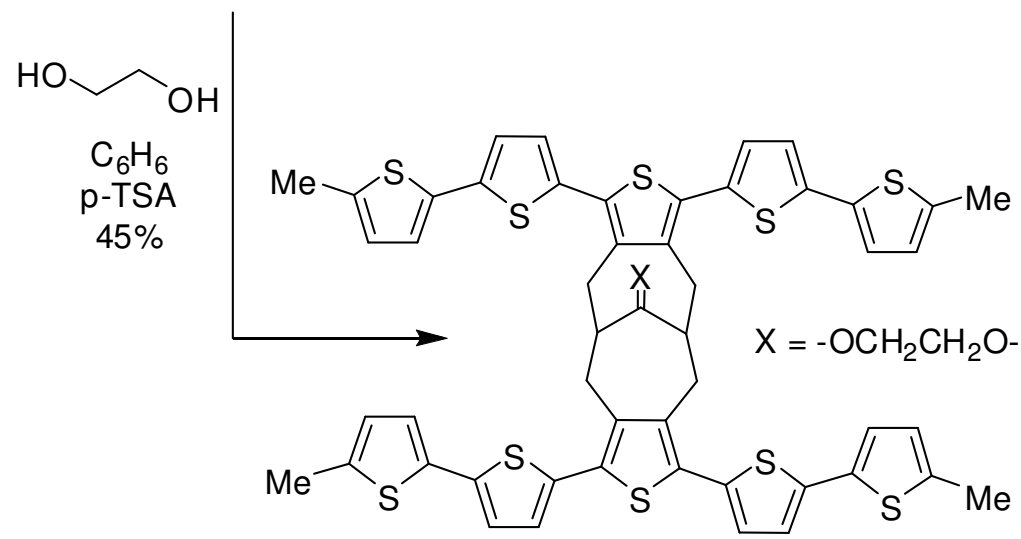

3.10

Figure 3.7. Synthesis of quinquethiophene ketone 3.9 and ketal 3.10.

The model quinquethiophene was synthesized by the Stille reaction of 2,5dibromo-3,4-dimethylthiophene with stannylated bithiophene 3.8. Purification by 
column chromatography followed by recrystallization from toluene afforded the desired quinquethiophene, 3.11, as an orange solid (yield, 69\%), Figure 3.8. The major byproduct isolated from this reaction was 2,5"'-dimethyl-5,2':5',2":5",2"'-quarterthiophene from the homocoupling of the stannane. The solubility of $\mathbf{3 . 1 1}$ was considerably higher than that of $\mathbf{3 . 1 0}$.

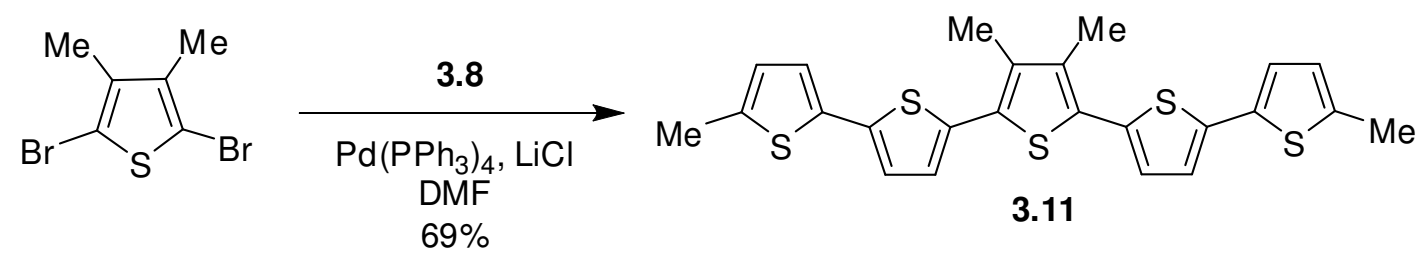

Figure 3.8. Synthesis of linear model quinquethiophene 3.11.

\subsubsection{Structural Characterization: ${ }^{1}$ H NMR Spectroscopy}

The influence of $\pi$-stacking of oligothiophenes can be observed by ${ }^{1} \mathrm{H}$ NMR spectroscopy as a change in the chemical shift of signals in the aromatic region of the spectrum. Model terthiophene 3.6 gives three distinct doublet of doublets (B, C, D) each representing two protons $(7.3,7.13$, and $7.07 \mathrm{ppm})$, Figure 3.9. The coupling constants for $\mathrm{D}$ are 1 and $5 \mathrm{~Hz} ; 1$ and $3 \mathrm{~Hz}$ for $\mathrm{B}$; and 3 and $5 \mathrm{~Hz}$ for $\mathrm{C}$ which are consistent with coupling of 2-thienyl substituents. The methyl signal at $\delta 2.30 \mathrm{ppm}$ is a singlet for six identical protons. ${ }^{\mathrm{i}}$ The signals for the aromatic protons of $\pi$-stacked terthiophene $\mathbf{3 . 3}$ are all shifted upfield in its aromatic protons compared to that of the model linear 3.6. The aromatic signals $(7.11,6.86$, and 6.80 ppm) each represents four protons (B, C, D) indicating an upfield shift due to shielding in the magnetic field from a $\pi$-stacked orientation, Figure 3.10.

\footnotetext{
${ }^{\mathrm{i}}$ The ${ }^{13} \mathrm{C}$ NMR spectrum (not shown) for $\mathbf{3 . 6}$ displayed six aromatic carbon signals and one methyl signal in $\mathrm{CDCl}_{3}$.
} 

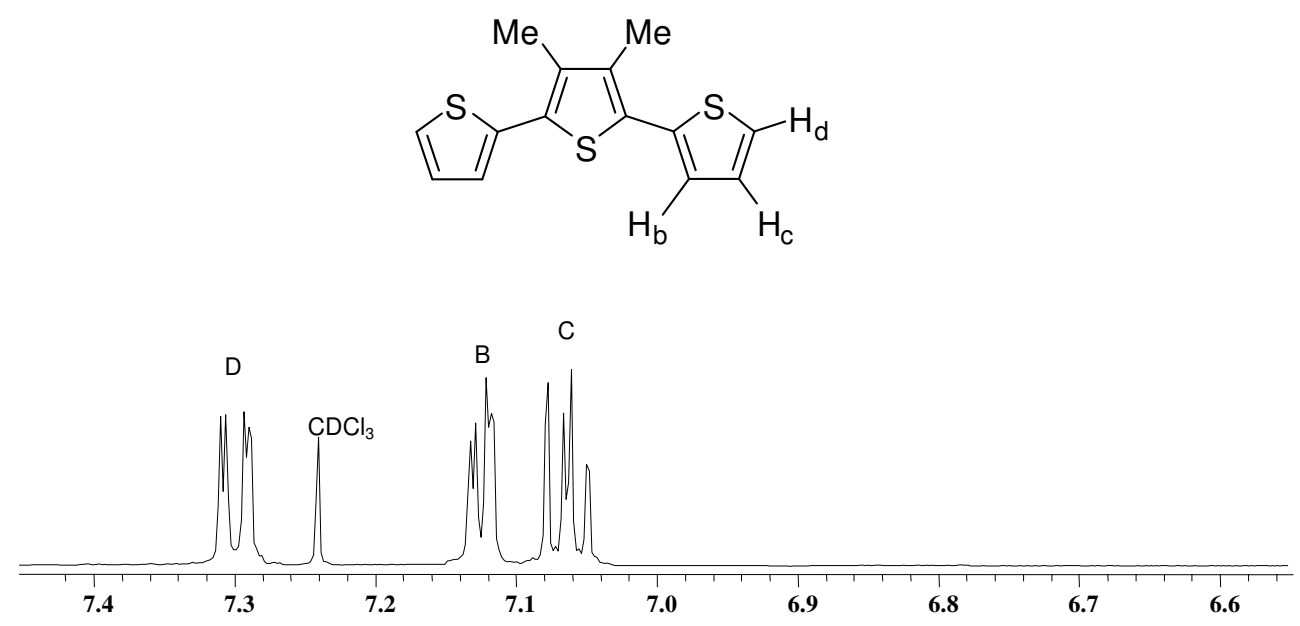

Figure 3.9. Aromatic region of ${ }^{1} \mathrm{H} \mathrm{NMR}$ spectrum $\left(300 \mathrm{MHz}, \mathrm{CDCl}_{3}\right)$ of model terthiophene 3.6.
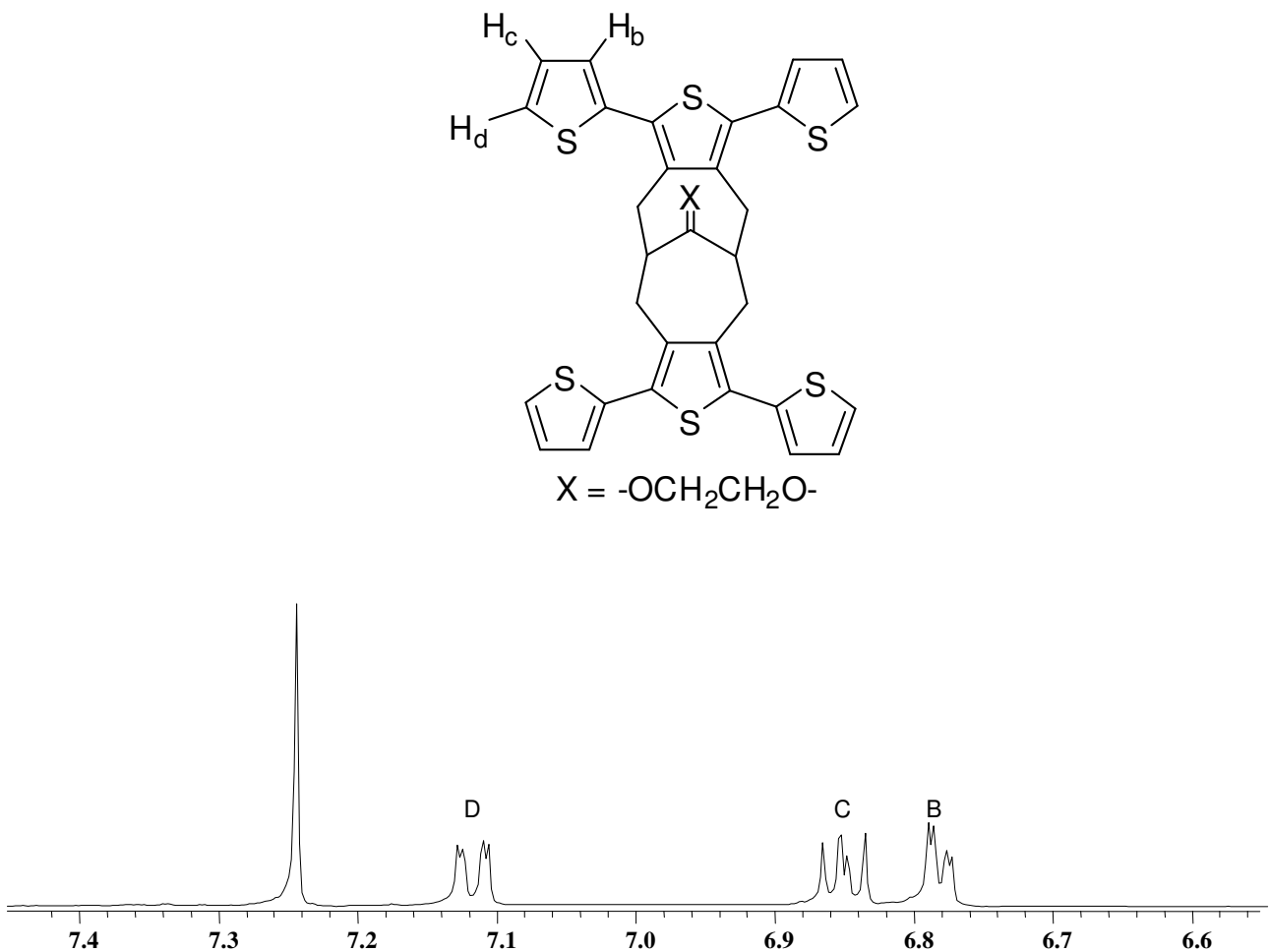

Figure 3.10. Aromatic region of ${ }^{1} \mathrm{H} \mathrm{NMR}$ spectrum $\left(300 \mathrm{MHz}, \mathrm{CDCl}_{3}\right)$ of $\pi$-stacked terthiophene 3.3. 
The methylene protons of $3.3(3.34,3.10 \mathrm{ppm})$ were each four proton doublet of doublets with coupling constants of 3 or 5 , and $15 \mathrm{~Hz}$. ${ }^{\text {ii }}$ These coupling constants are consistent with the formation of a chair-chair conformation demonstrating that the face to face packing of the central thiophene rings connected to the bicyclo[4.4.1] undecane framework with ethylene glycol is sufficient for $\pi$-stacking. The ketone precursor 3.2 displayed two multiplets in the aromatic region unlike the linear model and stacked compounds because of its conformational flexibility, Figure 3.11.
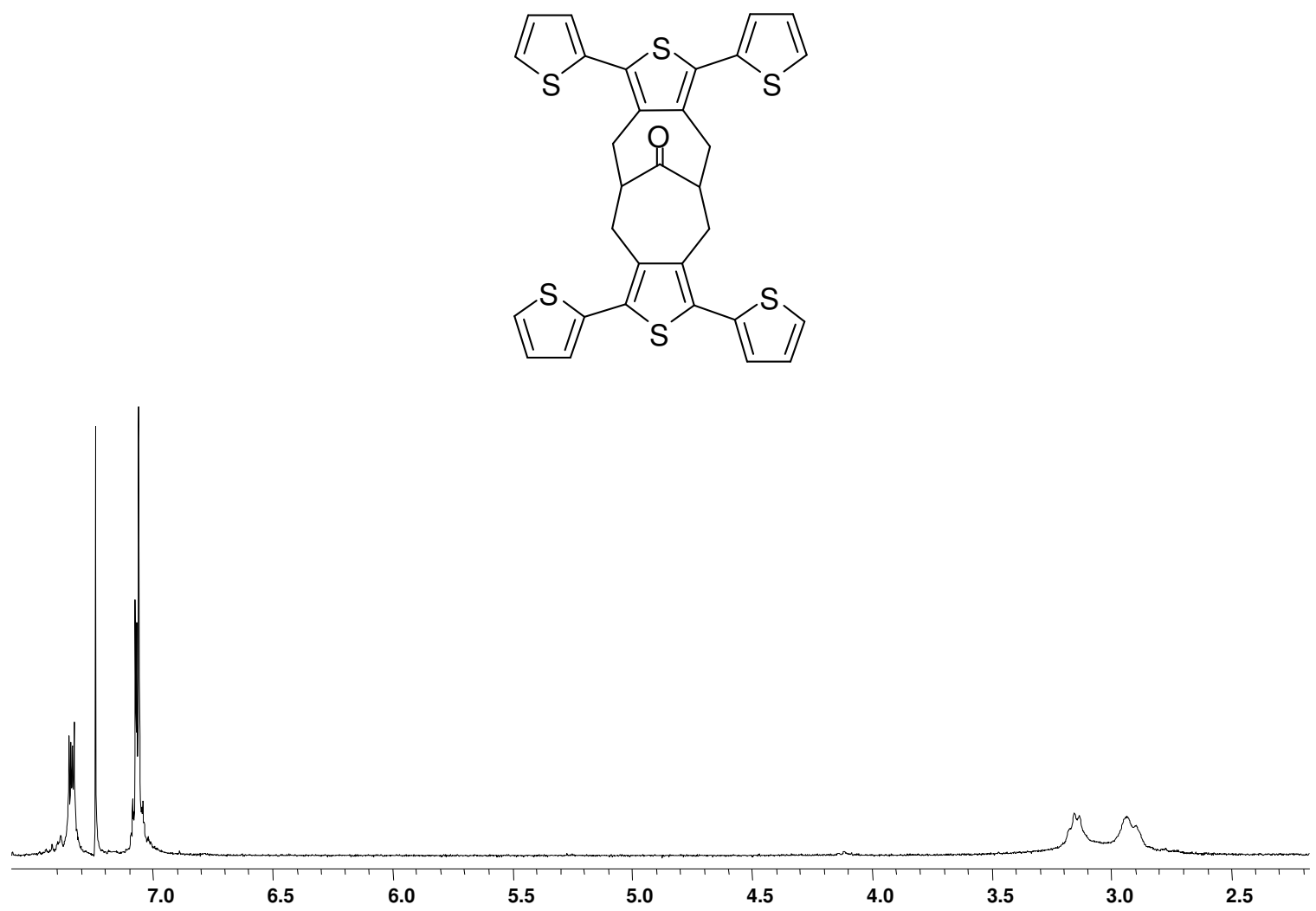

Figure 3.11. ${ }^{1} \mathrm{H} \mathrm{NMR}\left(300 \mathrm{MHz}, \mathrm{CDCl}_{3}\right)$ of ketone 3.2.

It should be noted that there is no slipping (thiophene rings are not offset with respect the ring opposite it) allowed for the thiophene subunits stacked atop one another

ii The ${ }^{13} \mathrm{C}$ NMR spectrum contains six aromatic protons and four signals for the methylene, ethylene, 
and anti/syn conformations may both give upfield shifts as seen in literature. ${ }^{16}$ The conformations are related to the energy of the oligomer where the thiophene rings can rotate accordingly to the lowest ground state energy level. In these examples, the upfield shifts in aromatic protons is due to $\pi$-stacking and are can coincidental when the oligomers are in different conformations.

The methyl-capped terthiophene model 3.7 exhibited two different types of aromatic protons at $\delta 6.89$ and $6.70 \mathrm{ppm}$, Figure 3.12 (top). Proton labeled B was a doublet $(J=3 \mathrm{~Hz})$ representing two identical protons from each thiophene unit. The other proton labeled $\mathrm{C}$ is a doublet of quartets $(J=1,3 \mathrm{~Hz})$, as it is split with the other $\beta$-proton and three protons of the methyl group by long-range coupling. One methyl signal at $\delta$ $2.49 \mathrm{ppm}$ is a doublet $(J=1 \mathrm{~Hz}){ }^{\text {iii }}$

The methylene protons and bridgehead of the intermediate ketone 3.4 are a coalesced multiplet between $\delta$ 2.8-3.2 ppm due to the flexibility of the compound, Figure 3.12 (middle). The chemical shifts of aromatic protons of $\mathbf{3 . 4}$ are similar to that of $\mathbf{3 . 7}$ consistent with an unstacked conformation. Upon ketalization with ethylene glycol, the two terthiophene units of $\mathbf{3 . 5}$ are forced over into a stacked conformation and the aromatic protons exhibit an upfield shift due to $\pi$-stacking (6.60 and $6.52 \mathrm{ppm})$. Both exhibited similar coupling constants. The methylene peaks (pair of doublet of doublets, $J$ $=3$ or $5,15 \mathrm{~Hz}$ ) of 3.5 confirm a chair-chair conformation which is stable to $100{ }^{\circ} \mathrm{C}$, and the bridgehead protons are shifted upfield and are nearly coincidental with the twelve methyl protons $(J=1 \mathrm{~Hz})$ at 2.4 ppm, Figure 3.12 (bottom). ${ }^{\text {iv }}$

bridgehead, and C-11 carbons (not shown).

iii The ${ }^{13} \mathrm{C}$ NMR spectrum of $\mathbf{3 . 7}$ has six aromatic signals and two different methyl signals.

${ }^{\text {iv }}$ The ${ }^{13} \mathrm{C}$ NMR spectrum for 3.5 displayed six aromatic, one methylene, one bridgehead, one ethylene glycol, and tertiary ketal carbon signals. 


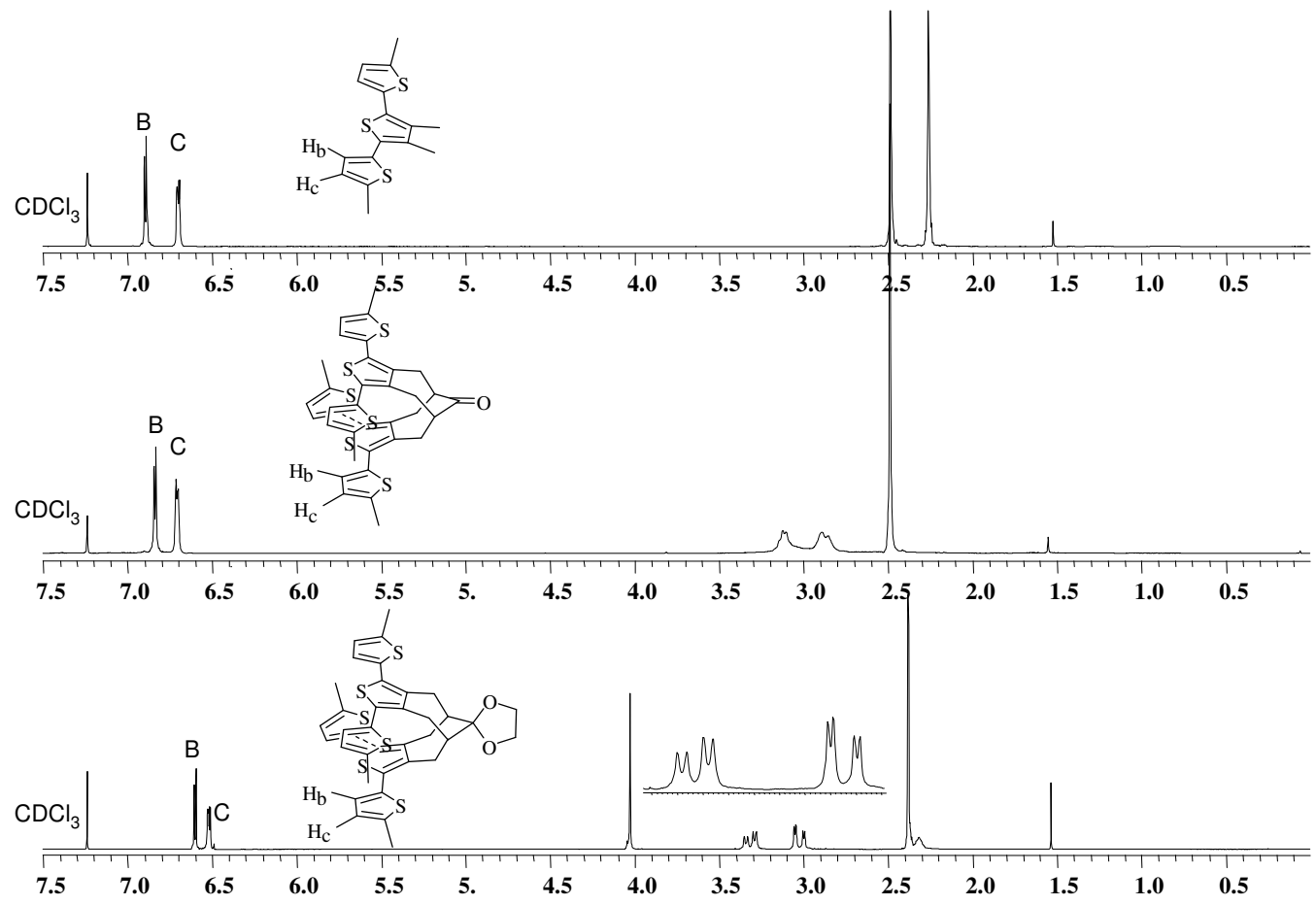

Figure 3.12. ${ }^{1} \mathrm{H}$ NMR $\left(300 \mathrm{MHz}, \mathrm{CDCl}_{3}\right)$ of methyl-capped model terthiophene, 3.7 (top), ketone 3.4 (middle), ketal 3.5 (bottom).

In the case of the linear model quinquethiophene compound, 3.11, the ${ }^{1} \mathrm{H}$ NMR spectrum displays four different aromatic signals for the $\beta$-thiophene protons $(\delta 7.03$, $7.00,6.97$, and $6.66 \mathrm{ppm}$ ) each of which each integrate to two signals each (eight protons total). Protons labeled $\mathrm{B}$, and $\mathrm{C}$ were coupled to each other with a coupling constant of 3 Hz. Protons labeled $\mathrm{E}$ and $\mathrm{F}$ had coupling constants of $3 \mathrm{~Hz}$, and 3 and $5 \mathrm{~Hz}$, respectively. The two different methyl signals appear at $\delta 2.48 \mathrm{ppm}$ (doublet, $J=1 \mathrm{~Hz}$ ) and $\delta 2.32 \mathrm{ppm}$ (singlet), Figure 3.13 (top). The spectrum of ketone $\mathbf{3 . 9}$ is similar to the linear model quinquethiophene $\mathbf{3 . 1 1}$ with very similar chemical shifts for the aromatic 
protons, Figure 3.13, (middle). The bridgehead and methylene proton signals are coincident in chemical shift, appearing as a broad multiplet at 2.8-3.2 ppm.

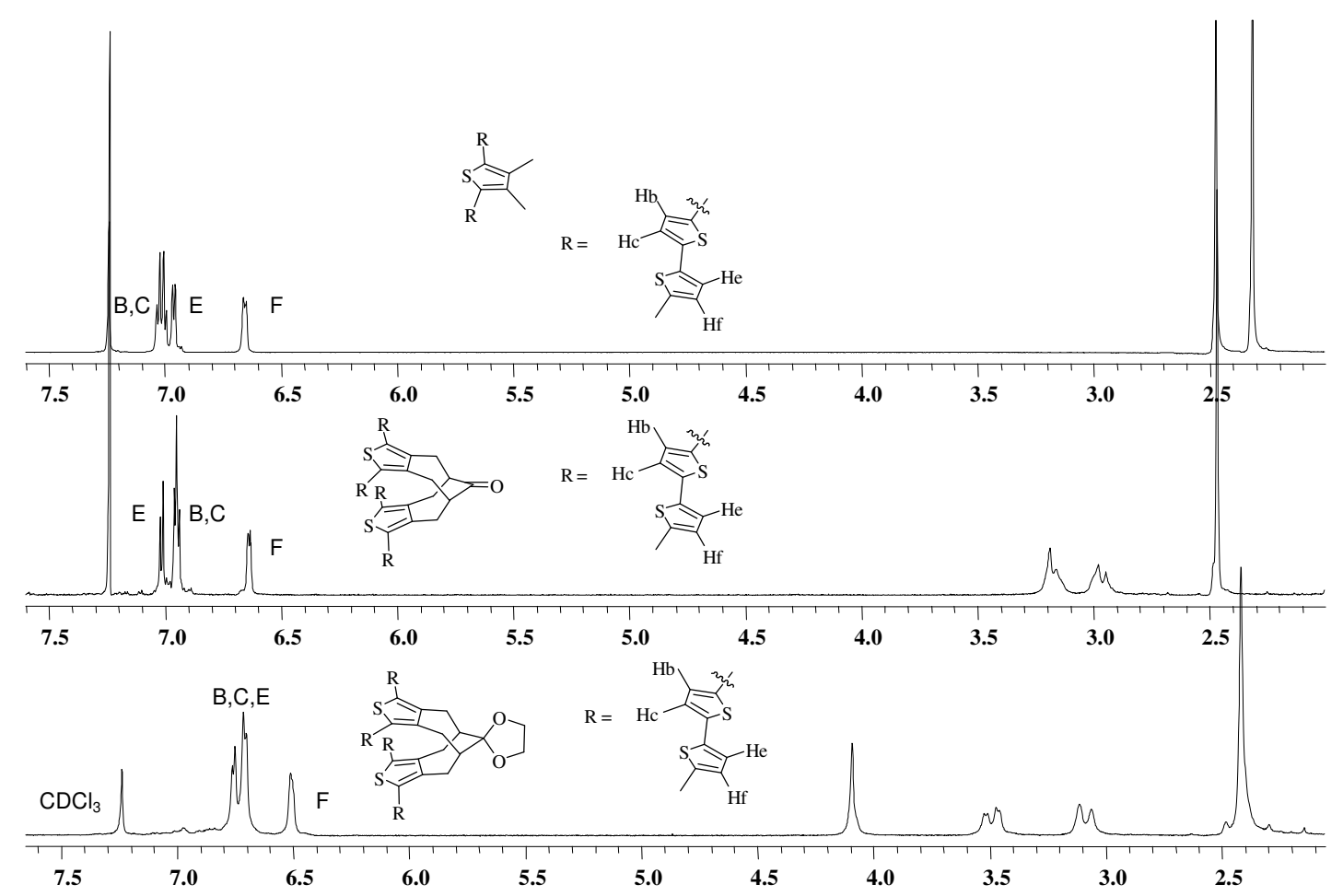

Figure 3.13. ${ }^{1} \mathrm{H} \mathrm{NMR}\left(300 \mathrm{MHz}, \mathrm{CDCl}_{3}\right.$ ) of model quinquethiophene $\mathbf{3 . 1 1}$ (top), ketone 3.9 (middle), and ketal 3.10 (bottom).

In the case of $\pi$-stacked compound 3.10, the aromatic protons are shifted upfield with three distinct multiplets $(6.77,6.70,6.51 \mathrm{ppm})$. The furthest downfield signal corresponds to the four protons labeled $\mathrm{B}$. The middle aromatic multiplet corresponds to two sets of coincidental proton signals labeled $\mathrm{C}$ and $\mathrm{E}$. The other signal at $\delta 6.51 \mathrm{ppm}$ corresponds to protons labeled F. The bridgehead protons are coincident with the methyl protons (2.3-2.5 ppm), showing coupling to the thienylic protons in the COSY spectrum. There is also a slight upfield shift of the methyl protons of $\mathbf{3 . 1 0}$ compared to model $\mathbf{3 . 1 1}$ 
$(0.1 \mathrm{ppm})$. The set of doublet of doublets $(\delta 3.50$ and $3.09 \mathrm{ppm})$ is consistent with the ethylene glycol clipping unit forcing the bicyclo[4.4.1] undecane framework into a chairchair conformation, Figure 3.13 (bottom). ${ }^{13} \mathrm{C}$ NMR spectrum of $\mathbf{3 . 1 0}$ shows ten aromatic signals, four signals for the undecane framework and one methyl signal consistent with a single conformation.

A summary of the aromatic and methyl end group protons of the model $\pi$ conjugated oligothiophenes and $\pi$-stacked analogs is illustrated in Table 3.1.

Table 3.1. NMR Chemical Shifts $(\delta)$ for aromatic and methyl protons of stacked and unstacked compounds in $\mathrm{CDCl}_{3}{ }^{a}$.

\begin{tabular}{|c|c|c|c|c|c|c|c|}
\hline Compound & $\mathrm{H}_{\mathrm{a}}$ & $\mathrm{H}_{\mathrm{b}}$ & $\mathrm{H}_{\mathrm{c}}$ & $\mathrm{H}_{\mathrm{d}}$ & $\mathrm{H}_{\mathrm{e}}$ & $\mathrm{H}_{\mathrm{f}}$ & $-\mathrm{CH}_{3}$ \\
\hline $\begin{array}{c}\text { tetramethylthiophene } \\
\text { stack } \mathbf{2 . 4}\end{array}$ & $\begin{array}{l}6.88 \\
6.51\end{array}$ & & & & & & \\
\hline $\begin{array}{c}\text { model 3.6 } \\
\text { stack 3.3 }\end{array}$ & & $\begin{array}{l}7.30 \\
7.12\end{array}$ & $\begin{array}{l}7.06 \\
6.86\end{array}$ & $\begin{array}{l}7.14 \\
6.79\end{array}$ & & & \\
\hline $\begin{array}{l}\text { model } 3.7 \\
\text { stack } 3.5\end{array}$ & & $\begin{array}{l}6.90 \\
6.62\end{array}$ & $\begin{array}{l}6.70 \\
6.51\end{array}$ & & & & $\begin{array}{l}2.50 \\
2.40\end{array}$ \\
\hline $\begin{array}{c}\text { model 3.11 } \\
\text { stack 3.10 }\end{array}$ & & $\begin{array}{l}7.03 \\
6.77\end{array}$ & $\begin{array}{l}7.01 \\
6.70\end{array}$ & & $\begin{array}{l}6.97 \\
6.70\end{array}$ & $\begin{array}{l}6.66 \\
6.51\end{array}$ & $\begin{array}{l}2.45 \\
2.40\end{array}$ \\
\hline
\end{tabular}

${ }^{a}$ Protons are labeled from inner thiophene unit to outer thiophene unit for each symmetrical oligomer.

\subsubsection{X-ray Structural Analysis}

A suitable single crystal of $\mathbf{3 . 4}$ was attained for X-ray structural analysis by slow evaporation of a 4:1 mixture of ethyl acetate/hexanes over two weeks. The X-ray structural analysis confirmed chair-boat conformation for the undecane framework, consistent with the low temperature ${ }^{1} \mathrm{H}$ NMR, Figure 3.14. The carbonyl at C-11 is not bulky enough to force the bicycle into a chair-chair conformation. 

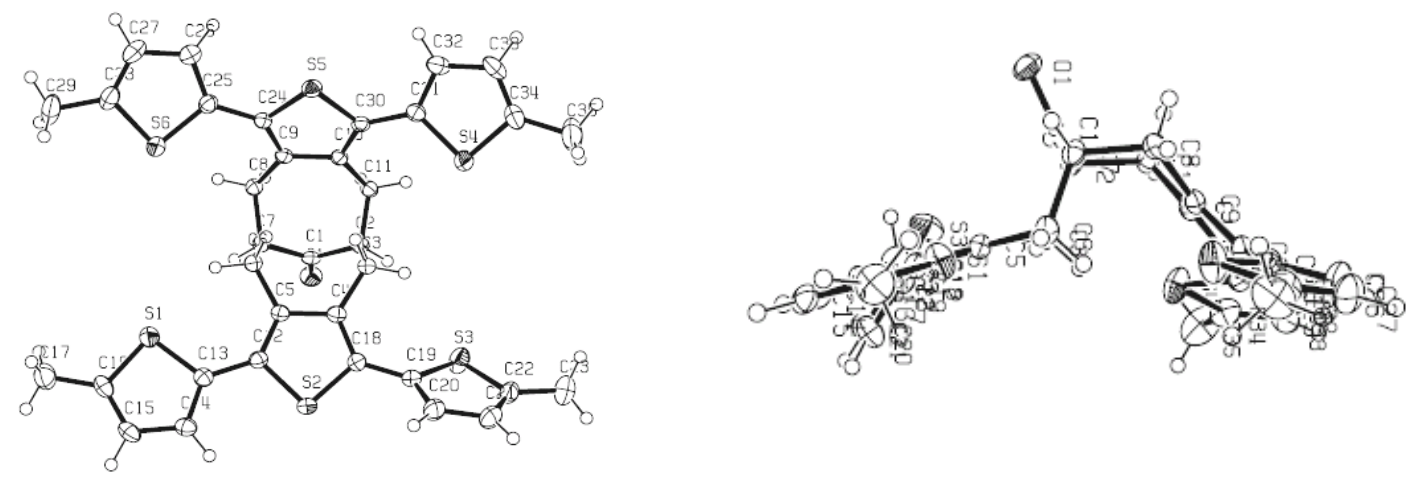

Figure 3.14. ORTEP diagrams of 3.4 illustrating chair-boat conformation (sideview).

Upon ketalization, the terthiophene oligomers stack on top one another in a rigid conformation. Compound $\mathbf{3 . 3}$ was dissolved in a 1:6 ethyl actetate/hexanes mixture and the solution was evaporated to obtain a suitable single crystal. The crystal structure of 3.3 shows one terthiophene oligomer in a transoid-cisoid conformation and the other terthiophene oligomer is in a cisoid-cisoid conformation. The stacked ketal $\mathbf{3 . 3}$ central core thienyl sulfur atoms are $414 \mathrm{pm}$ apart, Figure 3.15. The closest distance between the central thiophene core is $301 \mathrm{ppm}$ between C9-C13. The closest distance between these outer rings is $352 \mathrm{ppm}$ for C23-S5 and $363 \mathrm{ppm}$ for C31-S3. The terthiophenes are slightly twisted from planarity to facilitate $\pi$-stacking. The packing diagram of $\mathbf{3 . 3}$ illustrates the arrangement of the stacked compound in the solid state, Figure 3.16. 

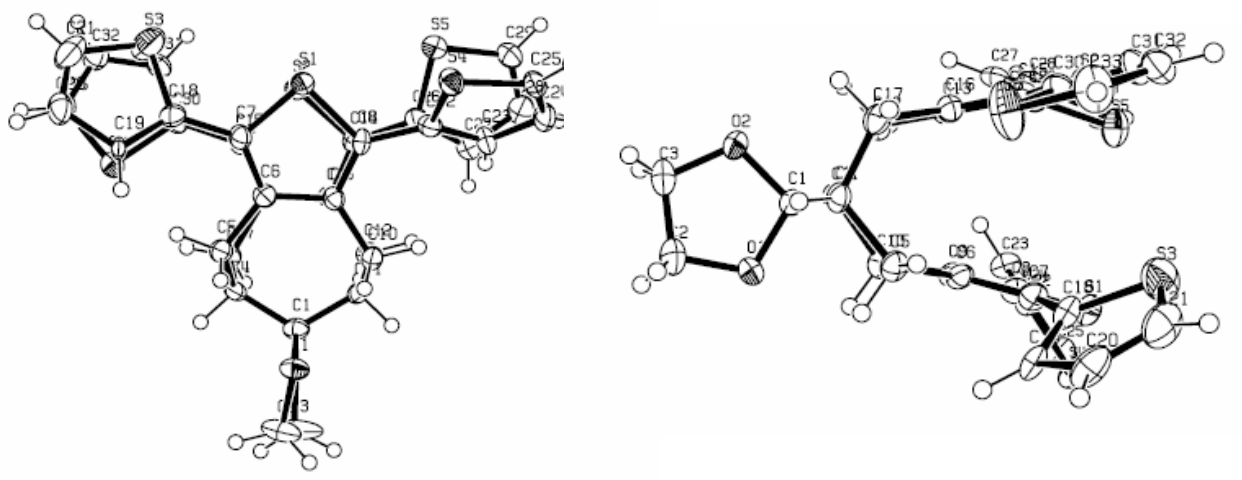

Figure 3.15. ORTEP diagrams of $\pi$-stacked terthiophene 3.3.

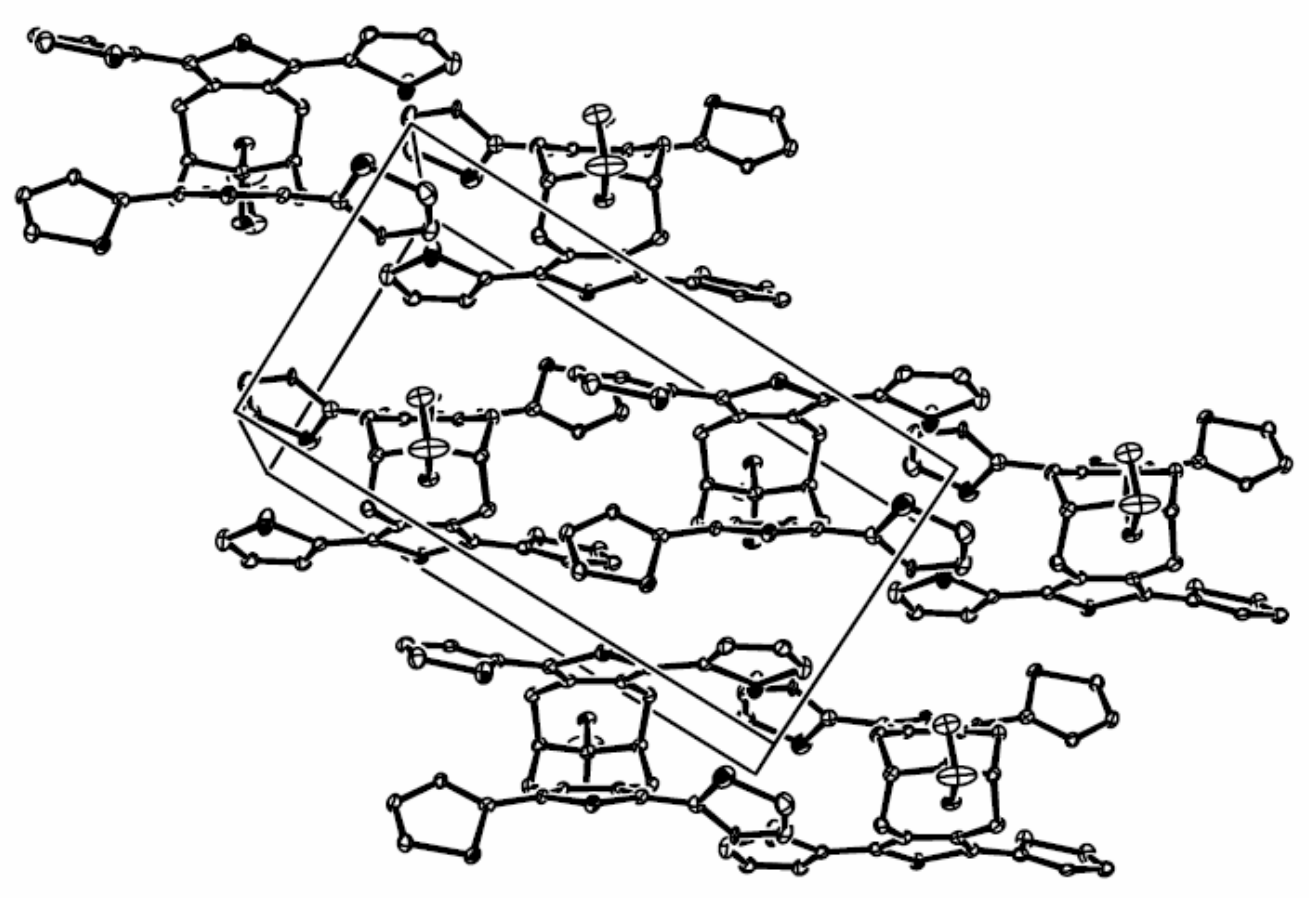

Figure 3.16. Packing diagram of 3.3. Hydrogen atoms excluded.

Methylated terthiophene $\pi$-stack 3.5 was slowly crystallized from a 1:9 mixture of ethyl acetate and hexanes over two weeks to obtain a suitable crystal. The sulfur-sulfur 
distance of the central thiophenes is $418 \mathrm{pm}$, and the distance between the $\beta$-carbons is 304 ppm (C6-C16), Figure 3.17. Similar to the case of the unmethylated analog 3.3, one terthiophene oligomer is in a cisoid-transoid conformation, while the other is a cisoidcisoid $\pi$-stacked terthiophene oligomer. Two thiophene rings stacked on top one another adjacent to the central thiophenes are closest at atoms S1-C27 with a distance of 374 ppm. On the opposite side of the molecule, the two thiophene rings $\pi$-stacked ontop one another are closest between atoms C23-C31 with a value of 327 ppm. The crystal structure analyses confirm the conformational rigidity in solid state, owing to the compounds existing in one conformation.
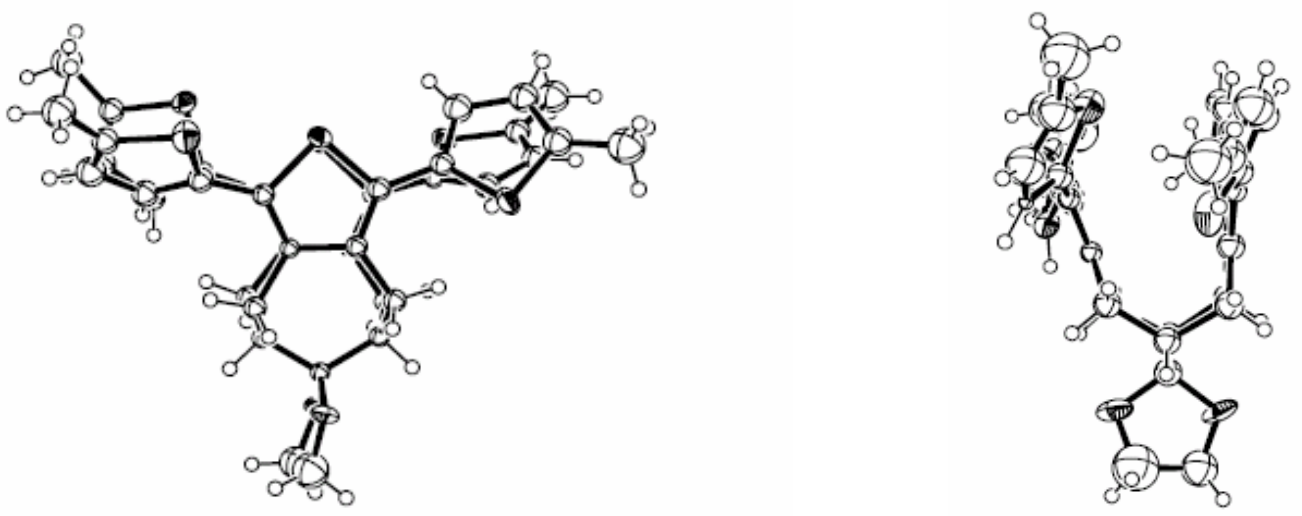

Figure 3.17. ORTEP diagrams of $\mathbf{3 . 5}$.

The crystal packing diagram of $\mathbf{3 . 5}$ illustrates how the rotations of the attached thiophenes to the undecane core are effected by neighboring rings, Figure 3.18. This compound adopts a partial herringbone motif with the sulfur of one thiophene ring oriented perpendicular to the ring of an adjacent molecule. The central thiophene units attached to the undecane core are still held in a $\pi$-stacked motif due to the ethylene glycol 
unit preventing conformational flexibility, but a contribution from both effects should be noted. The quinquethiophene $\pi$-stacked compound, 3.10 did not form X-ray quality crystals in multiple solvents.

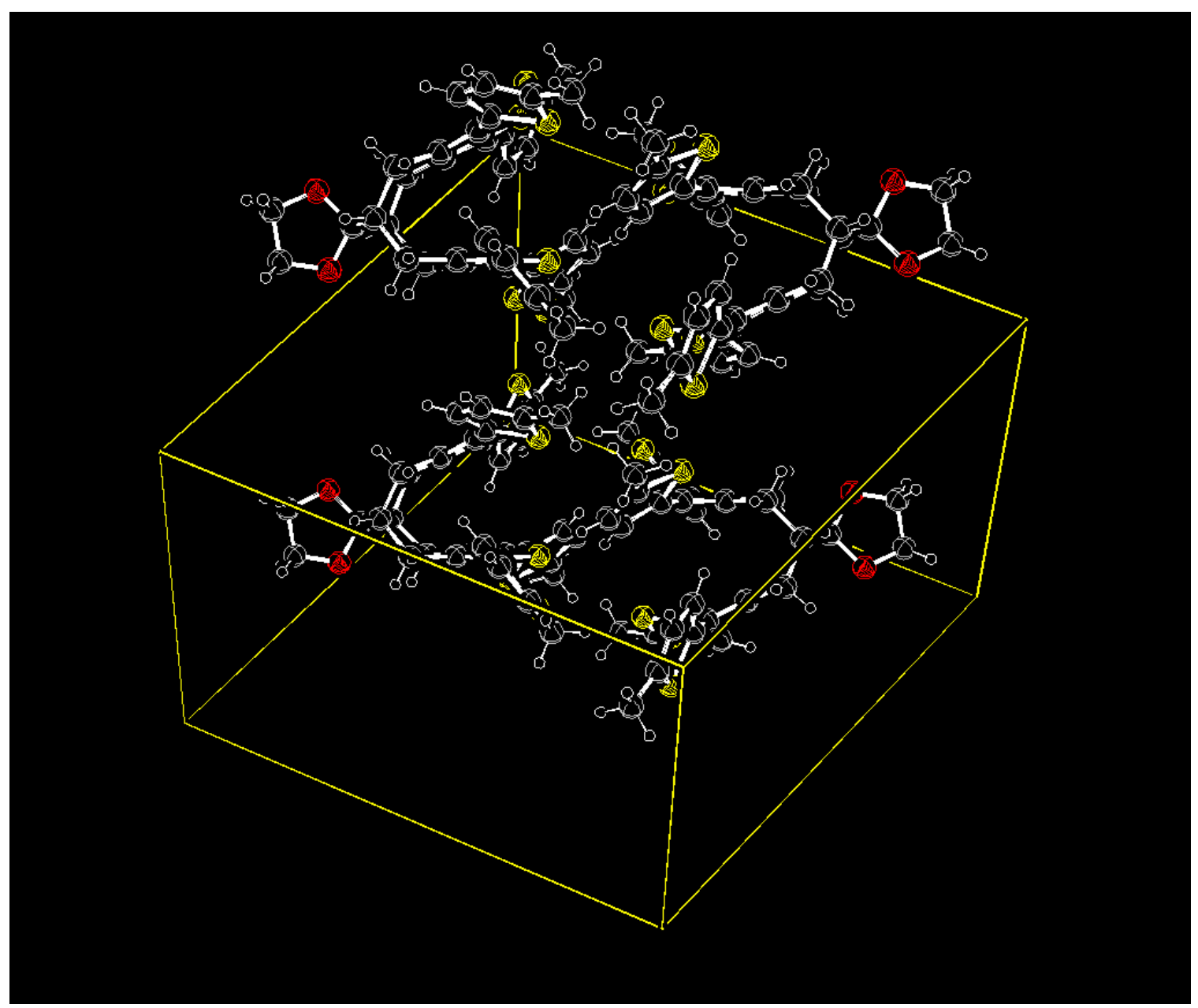

Figure 3.18. Crystal packing diagram of $\mathbf{3 . 5}$. 


\subsection{Conclusion}

The dithieno-fused bicyclo[4.4.1] undecanone core 2.3 is an ideal candidate to covalently link two $\pi$-conjugated oligomers together in a cofacial arrangement. Structural characterization supported the notion that the extended $\pi$-stacked oligomers are in close proximity of one another with the potential to influence one another's electronic structure. The influence of $\pi$-stacking on neutral and charge species (radical cation, dications) can further be studied through the use of spectroscopy (UV-vis-NIR), doping with chemical oxidants, and electrochemistry (Chapter 4).

\subsection{References}

1. Apperloo, J. J.; Groenendaal, L. B.; Verheyen, H.; Jayakannan, M.; Janssen, R. A. J.; Dkhissi, A.; Beljonne, D.; Lazzaroni, R.; Bredas, J.-L., "Optical and redox properties of a series of 3,4-ethylenedioxythiophene oligomers," Chem. Eur. J. 2002, 8, 2384-2396.

2. Casado, J.; Hernandez, V.; Hotta, S.; Navarrete, J. T., "FT-Raman Studies of Charged Defects Created on Methyl End-Capped Oligothiophene by Doping with $\mathrm{NOBF}_{4}, "$ Adv. Mater. (Weinheim, Fed. Repub. Ger.) 1998, 10, 1458-1461.

3. Yokonuma, N.; Furukawa, Y.; TAsumi, M.; Kurado, M.; Nakayama, J., "Electronic absorption and Raman studies of BF4--doped polythiophene based on the spectra of the radical cation and dication of $\alpha$-sexithiophene," Chem. Phys. Lett. 1996, 255, 431-436.

4. Wada, H.; Taguchi, T.; Goto, M.; Kambayashi, T.; Mori, T.; Ishikawa, K.; Takezoe, H., "Syntheses and properties of oligothiophenes with cyano and hexyl groups," Chem. Lett. 2006, 35, 280-281.

5. Rohde, D.; Dunsch, L.; Tabet, A.; Hartmann, H.; Fabian, J., "Radical Ions of a,a'Bis(diphenylamino)-capped Oligothiophenes: A Combined Spectroelectrochemical and Theoretical Study," Journal of Physical Chemistry B 2006, 110, 8223-8231. 
6. Miller, L. L.; Yu, Y.; Gunic, E.; Duan, R., "An oligothiophene cation radical that forms p-stacks. A model for polaron aggregation in conducting polymers," $A d v$. Mater. 1995, 7, 547-548.

7. Rossi, R.; Carpita, A.; Ciofalo, M.; Lippolis, V., "Selective and efficient syntheses of phototoxic 2,2':5',2"-terthiophene derivatives bearing a functional substituent in the 3'- or the 5-position," Tetrahedron 1991, 47, 8443-60.

8. Wigerinck, P.; Van Aerschot, A.; De Clercq, E.; Herdewijn, P., "5-(Thien-2-yl)2'-deoxyuridine: a new and potent inhibitor of herpes simplex virus type 1 replication," Nucleosides Nucleotides 1991, 10, 585-586.

9. Xia, G.-M.; Lu, P.; Xu, G.-B., "Synthesis, as well as linear and nonlinear fluorescence properties of 5,5'-bis(4-N-carbazolylstyryl)-2,2'-bithiophene," Journal of the Serbian Chemical Society 2004, 69, 335-341.

10. Kawano, S.-i.; Fujita, N.; Shinkai, S., "Quater-, quinque-, and sexithiophene organogelators: Unique thermochromism and heating-free sol-gel phase transition," Chem. Eur. J. 2005, 11, 4735-4742.

11. Rossi, R.; Carpita, A.; Ciofalo, M.; Houben, J. L., "Synthesis and characterization of 2,2':5',2\"-terthiophene derivatives of possible therapeutic use," Gazz. Chim. Ital. 1990, 120, 793-803.

12. Sone, T.; Sato, K., "Friedel-Crafts type reaction of chlorothiophenes with aromatic compounds and its application to the syntheses of aryl- and oligothiophenes," Yamagata Daigaku Kiyo, Kogaku 1999, 25, 69-85.

13. Yui, K.; Aso, Y.; Otsubo, T.; Ogura, F., "Novel electron acceptors bearing a heteroquinonoid system. I. Synthesis of conductive complexes of 5,5'bis(dicyanomethylene)-5,5'-dihydro-D2,2'-bithiophene and related compounds," Bull. Chem. Soc. Jpn. 1989, 62, 1539-1546.

14. Melucci, M.; Barbarella, G.; Zambianchi, M.; Di Pietro, P.; Bongini, A., "Solution-Phase Microwave-Assisted Synthesis of Unsubstituted and Modified aQuinque- and Sexithiophenes," J. Org. Chem. 2004, 69, 4821-4828.

15. Martinez, F.; Voelkel, R.; Naegele, D.; Naarmann, H., "Thiophene oligomers: synthesis and characterization," Mol. Cryst. Liq. Cryst. 1989, 167, 227-232. 
16. Miyahara, Y.; Inazu, T.; Yoshino, T., "Synthesis and properties of [3.3](2,5)furano(2,5)thiophenophane and [3.3](2,5)thiophenophane," Chem. Lett. 1980, 397-400. 


\section{CHAPTER 4}

\section{PHOTOPHYSICAL AND ELECTROCHEMICAL \\ CHARACTERIZATION OF \\ $\pi$-STACKED OLIGOTHIOPHENES}

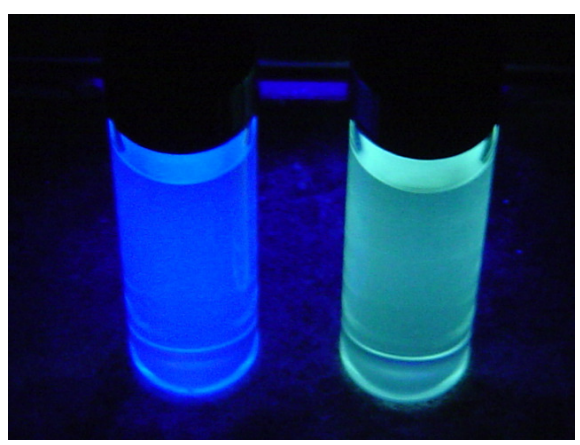

\subsection{Introduction}

To identify the nature of the charge carries in p-doped conducting polymers and explore interchain charge transfer of closely held oligomers, we designed twodimensional $\pi$-stacked oligothiophenes, Chapters 2 and 3. We focus now on determining the electronic structure of these compounds by UV-vis-NIR spectroscopy, electrochemistry, and ESR.

The electronic states of polarons and bipolarons have been discussed mainly in the framework of theories involving electron-lattice interactions which have been well studied extensively by Bredas ${ }^{1-4}$ and others. ${ }^{5,6}$ The polaron/bipolaron model for charge carriers in doped conjugated polymers serves to explain the observed paramagnetism at low levels of doping and diamagnetism at higher doping levels in materials with non- 
degenerate ground states. According to a theoretical study by Shimoi, ${ }^{7}$ a polaron gives rise to two absorption peaks, and a bipolaron gives rise to one peak. $\pi$-Dimers (formed at low temperature by aggregation of radical cations) show two subgap absorptions, which are characteristic to radical cations at room temperature but with new energy transitions in UV-vis-NIR. However, these $\pi$-dimers are ESR silent and establish a possible role for another charge transport mechanism of doped conjugated polymers.

Here we report the physical properties of both $\pi$-stacked and linear oligomers model. Comparison of the UV-vis absorbance and fluorescence spectra of the neutral compounds demonstrate the effects of $\pi$-stacking two conjugated oligomers together using the bicyclo[4.4.1] undecane framework. Oxidation with $\mathrm{FeCl}_{3}$ along with electrochemistry allow us to determine how stacking facilitates $\pi$-dimer formation and thereby effects the stability of cjarge carriers in doped conjugated polymers. The characterization of these $\pi$-dimers provide further understanding of the nature of charge carriers in doped $\pi$-conjugated polymers.

\subsection{Experimental}

Absorbance and fluorescence spectra were recorded on a Shimadzu 2401PC UVvis spectrophotometer and RF5301PC spectrofluorophotometer. UV-vis-NIR spectra were recorded on a Perkin Elmer Lambda 19 spectrophotometer. Specially designed four sided quartz cuvettes fitted with a 14/20 female joint sealed with a rubber septum were used in order to titrate stock solutions of $\mathrm{FeCl}_{3} / \mathrm{CH}_{2} \mathrm{Cl}_{2}$ via syringe into known concentrations of analyte (1-2 mM). Spectra were typically recorded upon addition of every 0.25 equivalents analyte. $\mathrm{FeCl}_{3}$ was dried at $100{ }^{\circ} \mathrm{C}$ under vacuum for $4 \mathrm{~h}$ prior to 
dissolution in $\mathrm{CH}_{2} \mathrm{Cl}_{2}$ (1-2 mM). $\mathrm{CH}_{2} \mathrm{Cl}_{2}$ was distilled from $\mathrm{CaH}_{2}$ onto molecular sieves prior to use.

Electrochemical measurements were carried out under nitrogen and recorded on a BAS 100B Electrochemical Analyzer with a three electrode cell equipped with a $2 \mathrm{~mm}$ gold working electrode, a platinum counter electrode, and a $\mathrm{Ag} / \mathrm{Ag}^{+}$reference electrode with $3 \mathrm{M} \mathrm{NaCl}$ solution end capped with a vycor tip. Substrates (1-2 mM) were dissolved in $\mathrm{CH}_{2} \mathrm{Cl}_{2}$ containing $0.1 \mathrm{M} n-\mathrm{Bu}_{4} \mathrm{NPF}_{6}$ which was purchased from Fluka. The ferrocene/ferrocenium couple is $+0.45 \mathrm{~V}$ under these conditions. Bulk electrolysis was performed in a specially designed cell enclosing a carbon mesh wire as the working electrode. The auxiliary electrode was enclosed in a fritted tube to prevent decomposition of material over typically extended run times.

ESR measurements were recorded on a Bruker EMX EPR with a 4131VT nitrogen temperature controller. ESR tubes were purchased from Wilmad. Typical analyte concentrations were $10^{-3}$ to $10^{-4} \mathrm{M}$ and a stock solution of $\mathrm{FeCl}_{3} / \mathrm{CH}_{2} \mathrm{Cl}_{2}$ (1-2.5 $\mathrm{mM}$ ) was titrated into the tube and measured. Typical power was $0.6 \mathrm{~mW}-1 \mathrm{~mW}$ and center fields were $3480-3520$ Gauss. The modulation phase was set to 260 degrees in all experiments.

\subsection{Results and Discussion}

\subsubsection{UV-vis Spectroscopy of Neutral Compounds}

The model linear $\pi$-conjugated oligothiophenes described in Chapters 2 and 3 are denoted as $\mathbf{R}-\mathbf{T h} \mathbf{h}_{\mathbf{n}}-\mathbf{R}(\mathrm{R}=\mathrm{H}$ or Me, $\mathrm{n}=1,3,5)$, and the stacked analogs as $\boldsymbol{s t}-[\mathbf{R}-\mathbf{T h} \mathbf{n}-\mathbf{R}]_{\mathbf{2}}$ $(\mathrm{R}=\mathrm{H}$ or $\mathrm{Me}, \mathrm{n}=1,3,5)$. The electronic spectra of model neutral oligothiophenes and 
$\pi$-stacked oligothiophene series show $\pi-\pi^{*}$ absorption bands and vibronic emission bands in the visible region. The comparison between the linear and stacked analog is a good starting point to illustrate how oligothiophenes affect the electronic structure of conjugated systems. The stacked compound $\boldsymbol{s t}-\left[\mathbf{H}-\mathbf{T} \mathbf{h}_{\mathbf{1}}-\mathbf{H}\right]_{\mathbf{2}}\left(\lambda_{\max }=238 \mathrm{~nm}\right)$ shows a small hypsochromic shift ( $2 \mathrm{~nm})$ in absorbance upon stacking compared to its model 3,4 dimethylthiophene, $\mathbf{H}-\mathbf{T h}_{\mathbf{1}}-\mathbf{H},\left(\lambda_{\max }=240 \mathrm{~nm}\right)$, Figure 4.1 (top). A small bathochromic shift in fluorescence $\left(\lambda_{\max }=308 \mathrm{~nm}, 1 \mathrm{~nm}\right)$ for $\boldsymbol{s t}-\left[\mathbf{H}-\mathbf{T h} \mathbf{h}_{\mathbf{1}}-\mathbf{H}\right]_{\mathbf{2}}$ compared to $3,4-$ dimethylthiophene, H-Th $\mathbf{1}-\mathbf{H},\left(\lambda_{\max }=307 \mathrm{~nm}\right)$ suggests that stacking does not have a dramatic effect on the electronic structure of arenas, Figure 4.1 (bottom). The Stokes shift is $67 \mathrm{~nm}$ for the model and $70 \mathrm{~nm}$ for the $\pi$-stacked compound.

Similarly, the methyl terminated $\pi$-stacked compound $s t$-[Me-Th $\mathbf{1}-\mathbf{M e}]_{2}\left(\lambda_{\max }=\right.$ $241 \mathrm{~nm})$ shows a small hypsochromic shift $(1 \mathrm{~nm})$ in absorbance compared to tetramethylthiophene, Me-Th $\mathbf{1}-\mathbf{M e},\left(\lambda_{\max }=242 \mathrm{~nm}\right)$, Figure 4.1 (bottom). Again, there is only a small bathochromic shift in fluorescence $\left(\lambda_{\max }=310 \mathrm{~nm}, 2 \mathrm{~nm}\right)$ for $\boldsymbol{s t}$-[Me-Th $\mathbf{M}_{\mathbf{1}}$ $\mathbf{M e}_{\mathbf{2}}$ compared to tetramethylthiophene, Me-Th $\mathbf{-}-\mathbf{M e},\left(\lambda_{\max }=308 \mathrm{~nm}\right)$. The Stokes shift for the model compound is $66 \mathrm{~nm}$ and for the $\pi$-stacked compound is $69 \mathrm{~nm}$. 

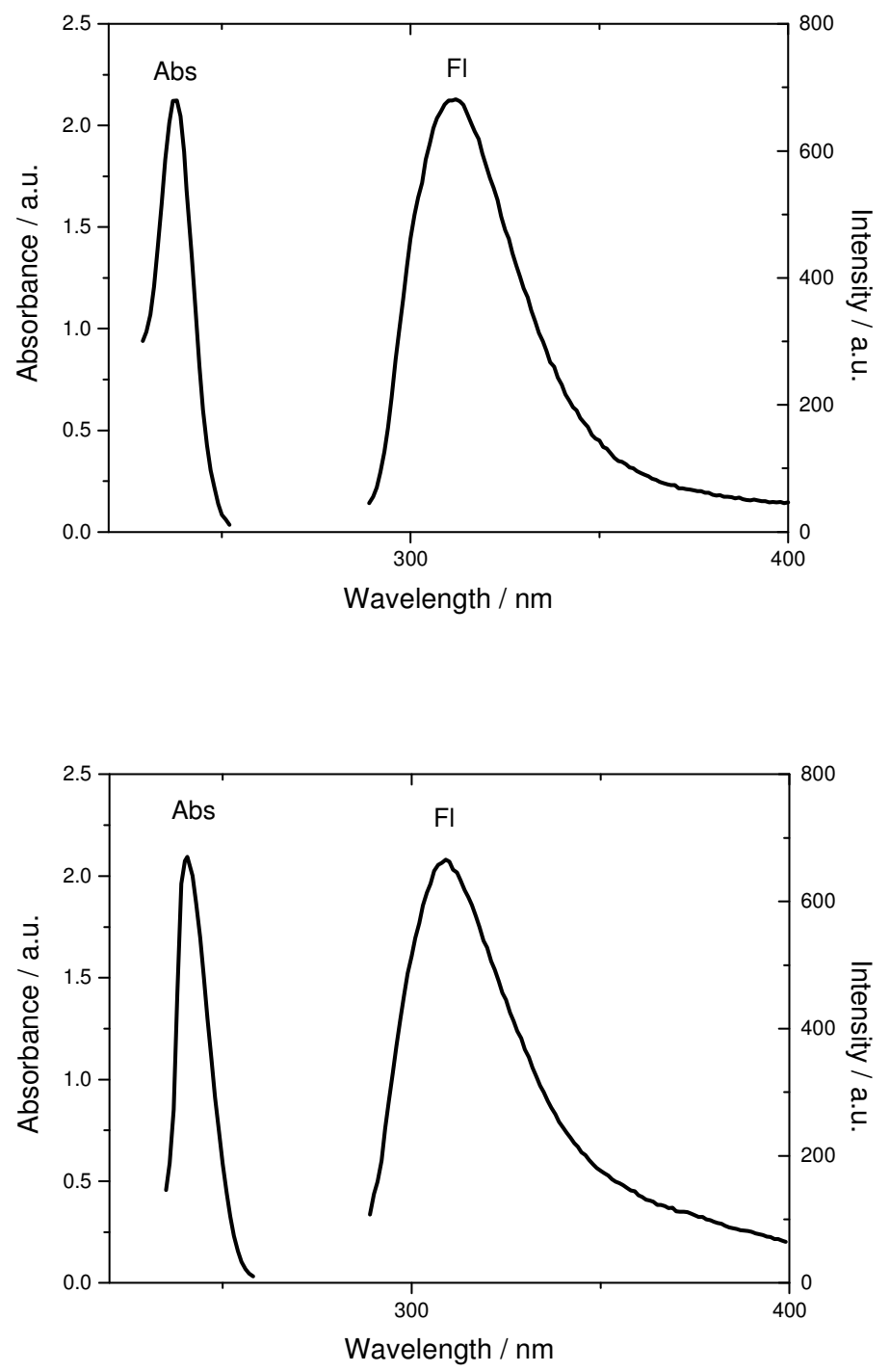

Figure 4.1. Absorbance fluorescence spectrum of $s t-\left[\mathbf{H}-\mathbf{T h} \mathbf{h}_{\mathbf{1}}-\mathbf{H}\right]_{\mathbf{2}}$ (top). Absorbance and fluorescence spectrum of $s t$-[Me-Th $\mathbf{T}-\mathbf{M e}]_{2}$ (bottom). Models not shown.

The absorbance band of model terthiophene $\mathbf{H}-\mathbf{T h}_{\mathbf{3}} \mathbf{- H}$ appears at $\lambda_{\max }=333 \mathrm{~nm}$. Upon excitation at this wavelength the emission band appears at $\lambda_{\max }=431 \mathrm{~nm}$ with a small higher energy peak at $\lambda=412 \mathrm{~nm}$, Figure 4.2. The Stokes shift for the model compound is $98 \mathrm{~nm}$. The effect of varying the excitation wavelength is illustrated in Figure 4.3. 


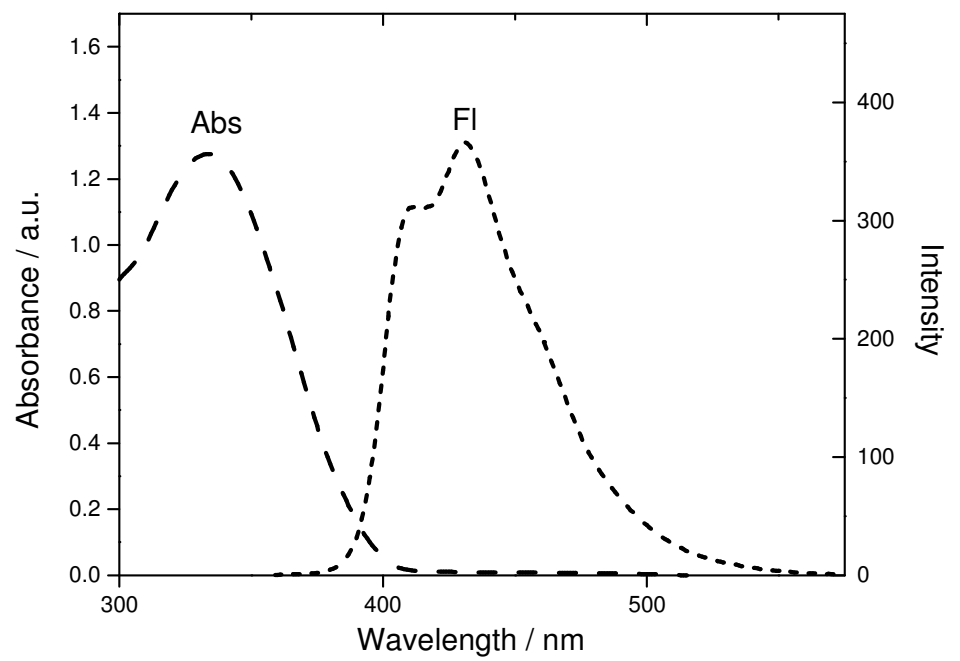

Figure 4.2. Absorbance and fluorescence spectrum of $\mathbf{H}-\mathbf{T h} \mathbf{h}_{\mathbf{3}}-\mathbf{H}$.

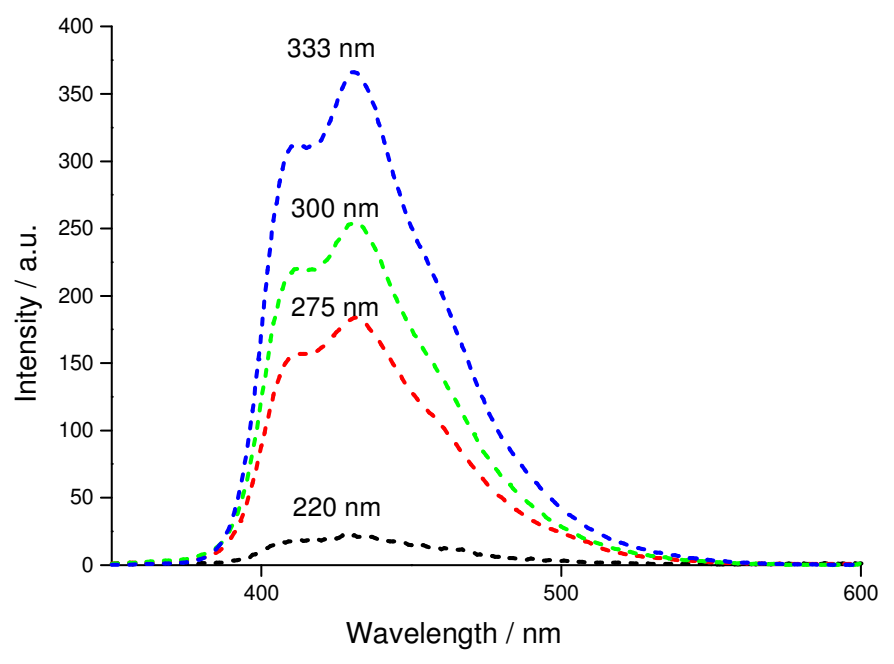

Figure 4.3. Fluorescence spectrum of $\mathbf{H}-\mathbf{T h} \mathbf{h}_{3}-\mathbf{H}$ at variable excitations.

For $\boldsymbol{s t}$ - $\left[\mathbf{H}-\mathbf{T h}_{\mathbf{3}}-\mathbf{H}\right]_{\mathbf{2}}$, the absorbance band at $\lambda_{\max }=324 \mathrm{~nm}$ is blue shifted by $9 \mathrm{~nm}$ compared to the model $\mathbf{H}-\mathbf{T h} \mathbf{h}_{\mathbf{3}} \mathbf{- H}\left(\lambda_{\max }=333 \mathrm{~nm}\right)$. Conversely, the fluorescence of $\boldsymbol{s t}-[\mathbf{H}-$ $\left.\mathbf{T h}_{\mathbf{3}}-\mathbf{H}\right]_{\mathbf{2}}$ is red shifted by $9 \mathrm{~nm}\left(\lambda_{\max }=421 \mathrm{~nm}\right)$ to that of $\mathbf{H}-\mathbf{T h}_{\mathbf{3}}-\mathbf{H}\left(\boldsymbol{\lambda}_{\max }=412 \mathrm{~nm}, 431\right.$ 
$\mathrm{nm}$ ), and there is a broad shoulder at $500 \mathrm{~nm}$, Figure 4.4. Excitation wavelengths of $\boldsymbol{s t}$ $\left[\mathbf{H}-\mathbf{T h}_{\mathbf{3}}-\mathbf{H}\right]_{\mathbf{2}}$ at wavelengths from $220-350 \mathrm{~nm}$ is illustrated in Figure 4.5.

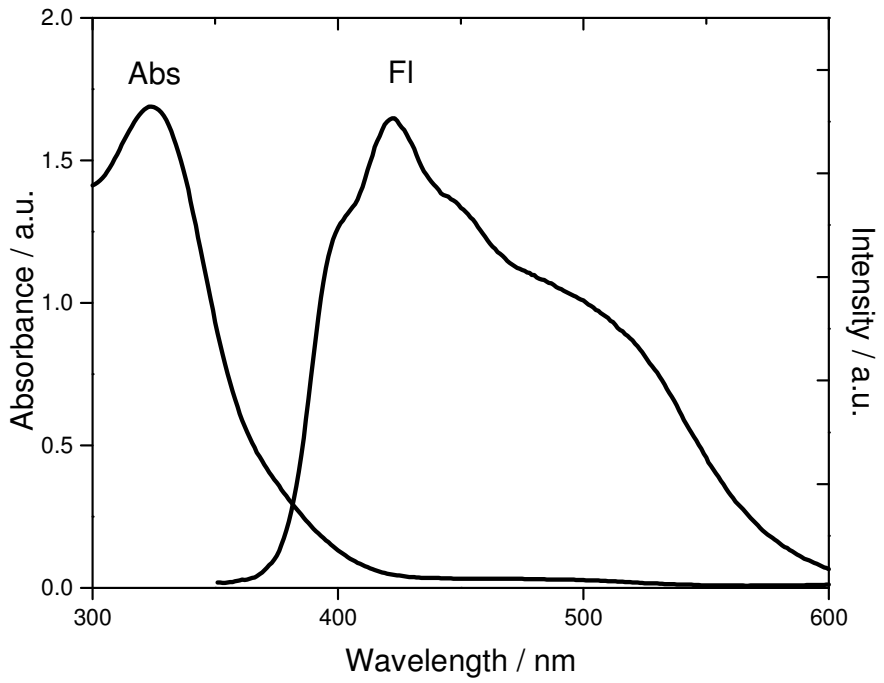

Figure 4.4. Absorbance and fluorescence spectrum of $s t-\left[\mathbf{H}-\mathbf{T h} \mathbf{h}_{3}-\mathbf{H}\right]_{2}$.

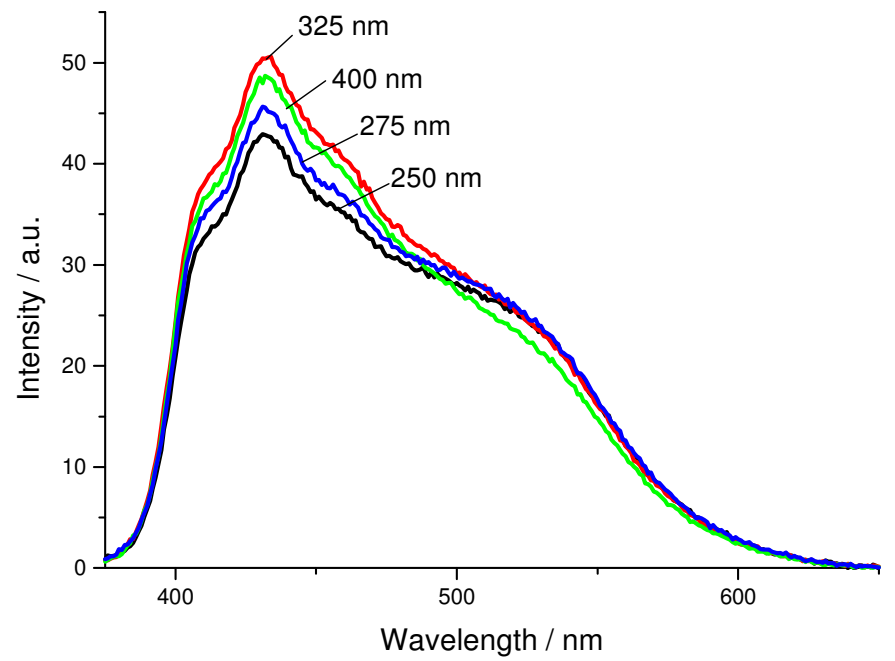

Figure 4.5. Fluorescence spectrum of $s t-\left[\mathbf{H}-\mathbf{T h} \mathbf{h}_{3}-\mathbf{H}\right]_{2}$ at variable excitations. 
As for the methyl-capped terthiophene $\pi$-stacked compound $s t-\left[\mathbf{M e}-\mathbf{T h}_{\mathbf{3}}-\mathbf{M e}\right]_{2}$, it shows a ref shift in fluorescence and a blue shift in absorbance compared to model compound Me-Th $\mathbf{T}-\mathbf{M e}$. The absorbance band of $s t-\left[\mathbf{M e}-\mathbf{T h}_{\mathbf{3}}-\mathbf{M e}\right]_{2}$ is blue shifted by 10 $\mathrm{nm}$ to $\lambda_{\max }=335 \mathrm{~nm}$ and the emission band is red shifted by $21 \mathrm{~nm}\left(\lambda_{\max }=444 \mathrm{~nm}, 505\right.$ shoulder), compared to $\mathbf{M e}-\mathbf{T h}_{\mathbf{3}}-\mathbf{M e}\left(\lambda_{\max }=345 \mathrm{~nm}, \mathrm{Fl}=423\right.$ shoulder, $\left.442 \mathrm{~nm}\right)$, Figures 4.6 and Figure 4.7.

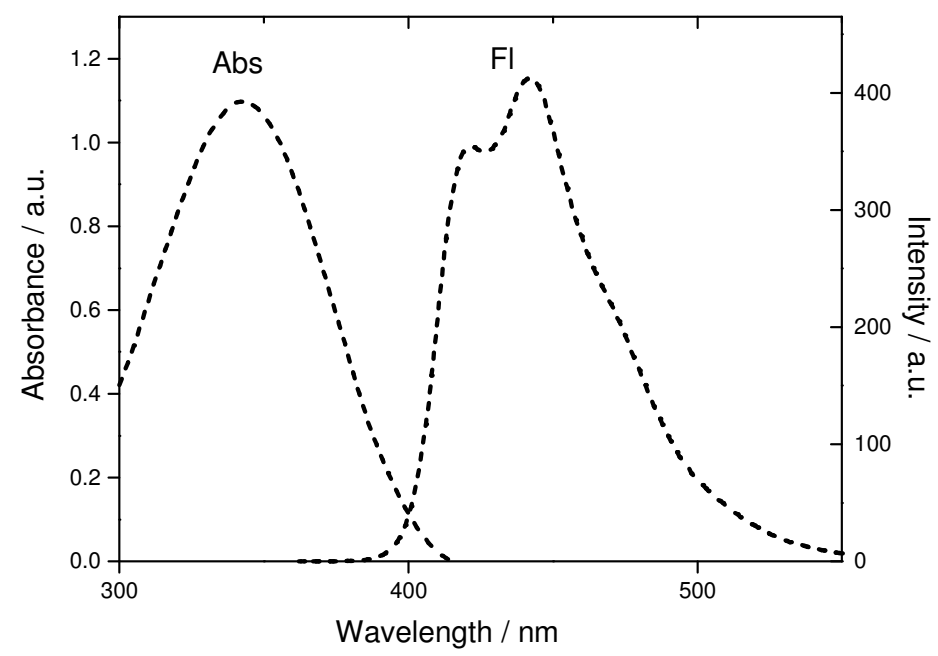

Figure 4.6. Absorbance and fluorescence spectrum of Me-Th/-Me.

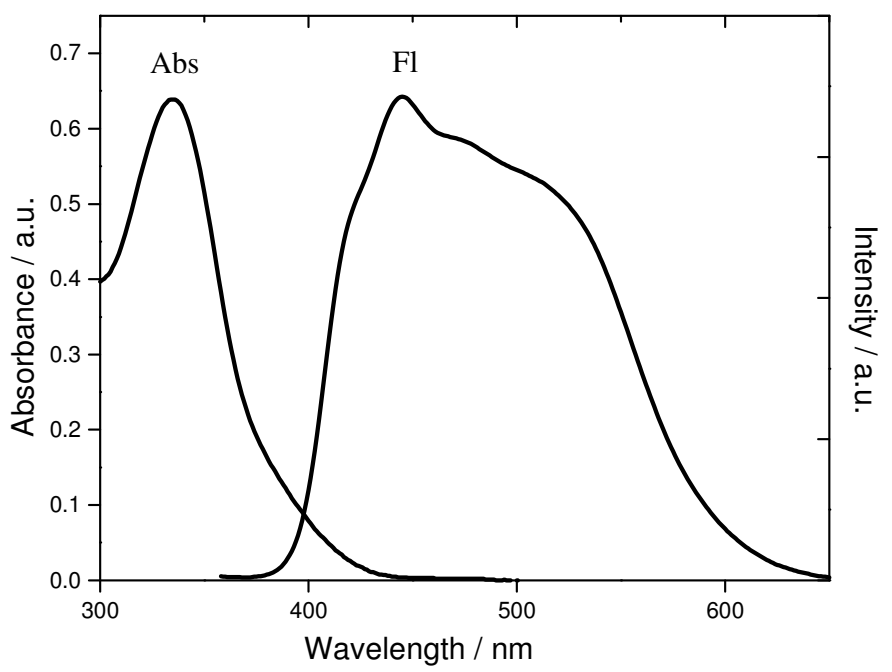

Figure 4.7. Absorbance and fluorescence spectrum of $s t-\left[\mathrm{Me}-\mathrm{Th}_{\mathbf{3}}-\mathrm{Me}\right]_{2}$. 


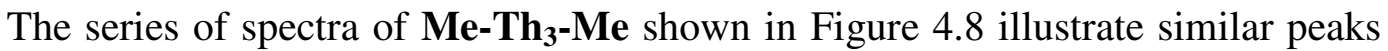
with weakened intensity at wavelengths other than the $\lambda_{\max }$ due to one absorbing species contributing to the emission spectra. St-[Me-Th $3-\mathbf{M e}]_{2}$ exhibits similar behavior with broadened peaks at weaker intensities upon excitation at different wavelengths, Figure 4.9. The Stokes shift increases from $97 \mathrm{~nm}$ to $170 \mathrm{~nm}$ upon $\pi$-stacking the two terthiophene oligomers together.

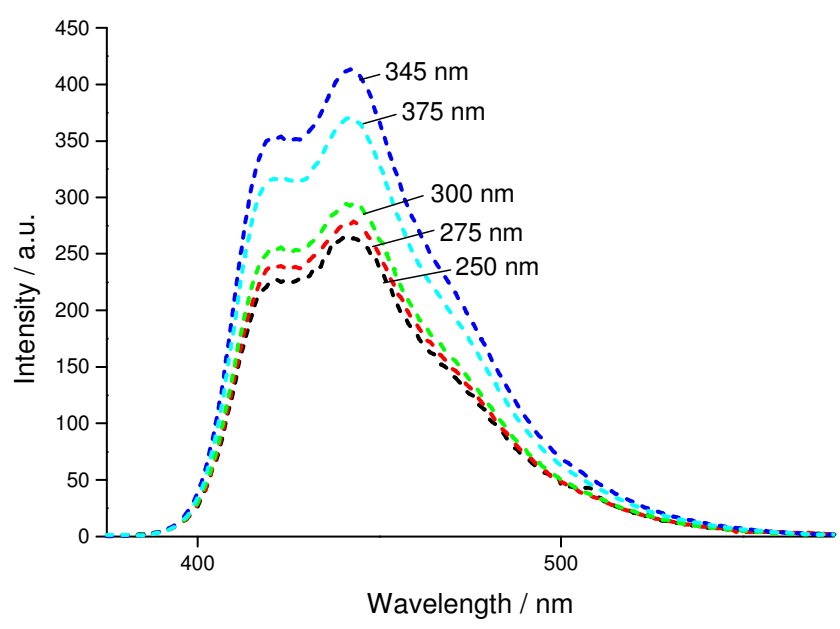

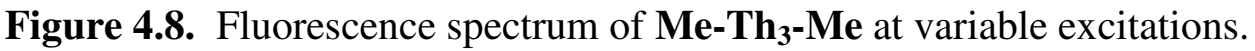

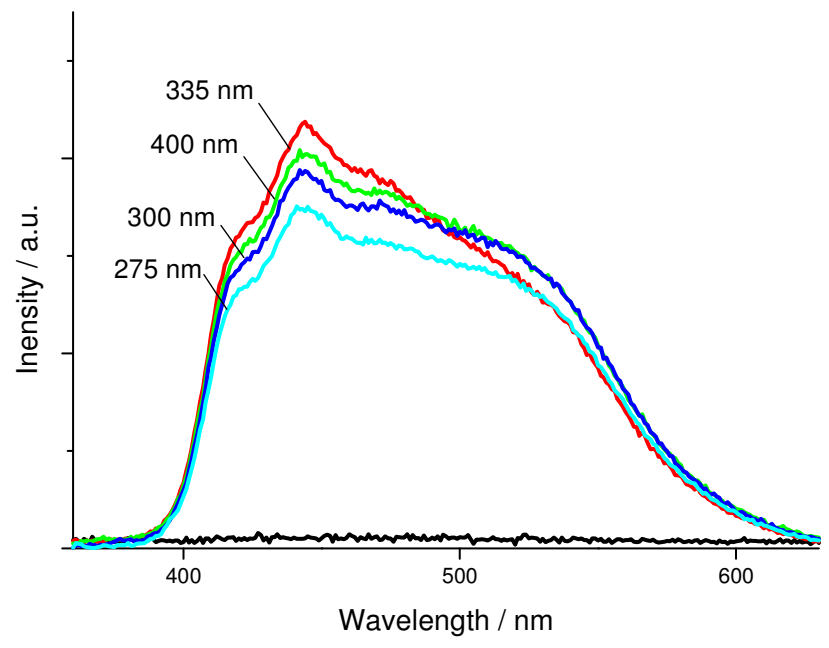

Figure 4.9. Fluorescence spectrum of $s t-\left[\mathrm{Me}-\mathrm{Th}_{3}-\mathrm{Me}\right]_{2}$ at variable excitations. 
The quinquethiophene model compound Me-Th5-Me absorbs at a longer wavelength due to its greater conjugation length $\left(\lambda_{\max }=400 \mathrm{~nm}\right)$. Excitation at $400 \mathrm{~nm}$ gives a maximum at $\lambda_{\max }=492 \mathrm{~nm}$ with shoulder at $\lambda=520 \mathrm{~nm}$, Figure 4.10 . The Stokes shift for this compound is $23 \mathrm{~nm}$ larger than the model terthiophene Me-Th/3-Me. The quinquethiophene $\pi$-stacked compound, $s t-\left[\mathbf{M e}-\mathbf{T h}_{\mathbf{5}}-\mathbf{M e}\right]_{\mathbf{2}},\left(\lambda_{\max }=386 \mathrm{~nm}\right)$ is blue shifted in its absorbance by $14 \mathrm{~nm}$ compared to its linear model $\mathbf{M e}-\mathbf{T h}_{\mathbf{5}}-\mathbf{M e}\left(\lambda_{\max }=400 \mathrm{~nm}\right)$, and the fluorescence is red shifted by $16 \mathrm{~nm}\left(\lambda_{\max }=500,526\right.$ shoulder $)$, Figure 4.11 . The Stokes shift for this compound is $140 \mathrm{~nm}$ which is not as large as that of the terthiophene $\pi$-stacked compound. Variable excitation spectra of Me-Th $\mathbf{5}-\mathbf{M e}$ and $s t-\left[\mathbf{M e}-\mathbf{T h}_{\mathbf{5}}-\mathbf{M e}\right]_{\mathbf{2}}$ are illustrated in Figures 4.12 and 4.13.

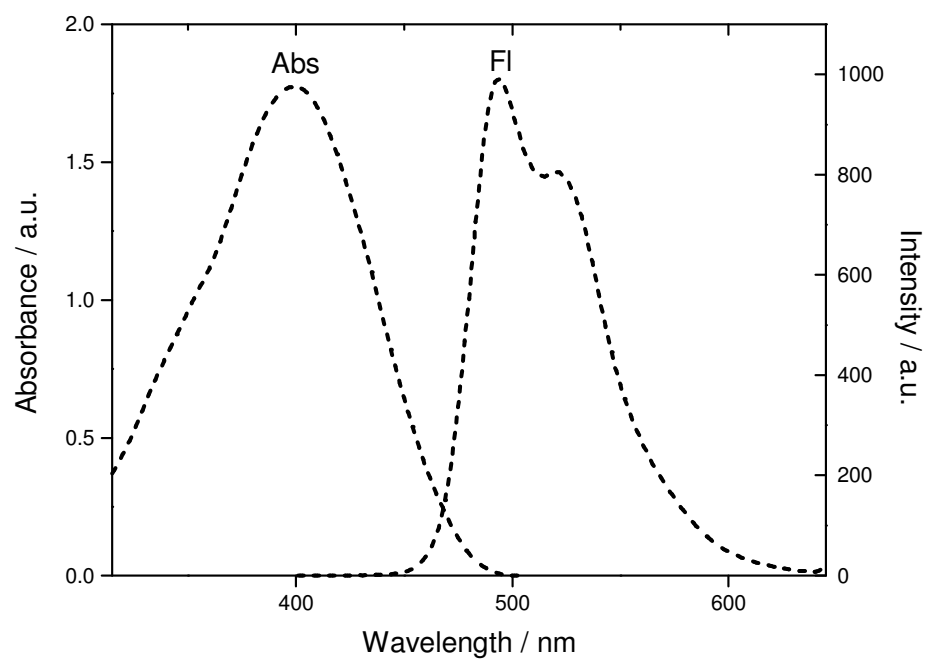

Figure 4.10. Absorbance and fluorescence spectrum of Me-Th5-Me. 


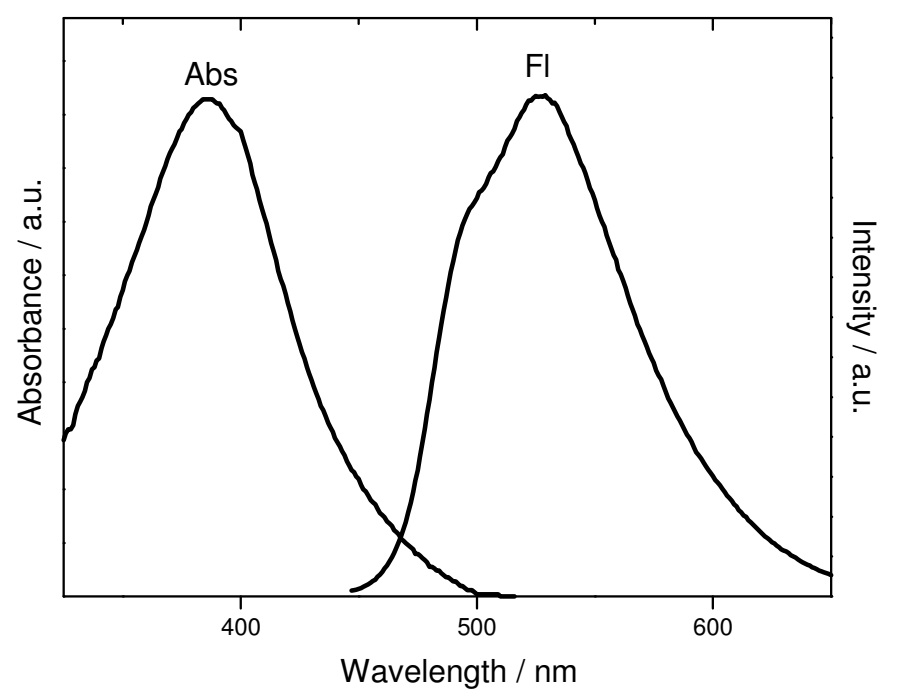

Figure 4.11. Absorbance and fluorescence spectrum of $s t-\left[\mathbf{M e}-\mathbf{T h}_{5}-\mathbf{M e}\right]_{2}$.

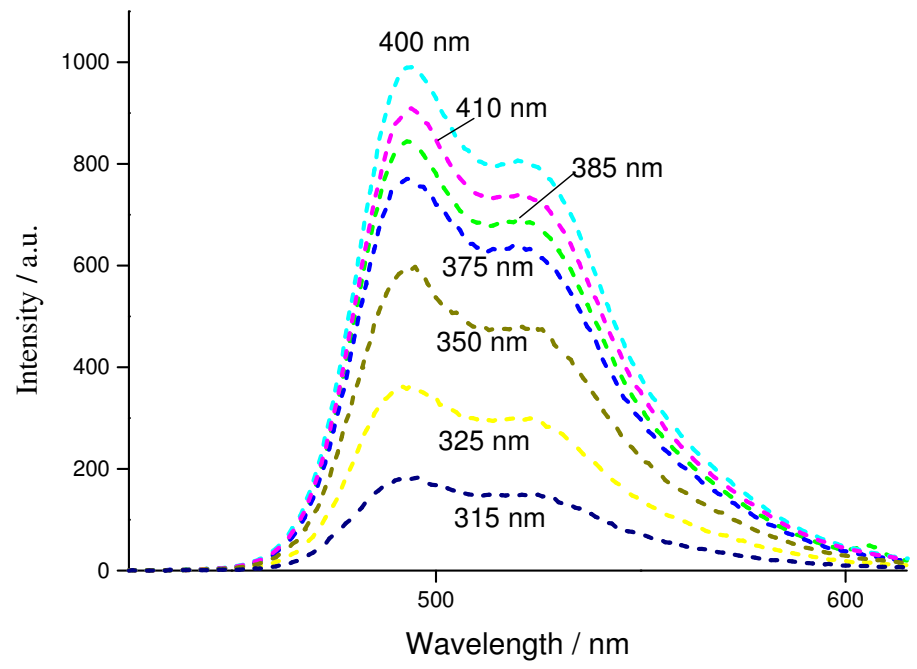

Figure 4.12. Fluorescence spectrum of $\mathbf{M e}-\mathbf{T h}_{5}-\mathbf{M e}$ at variable excitations. 


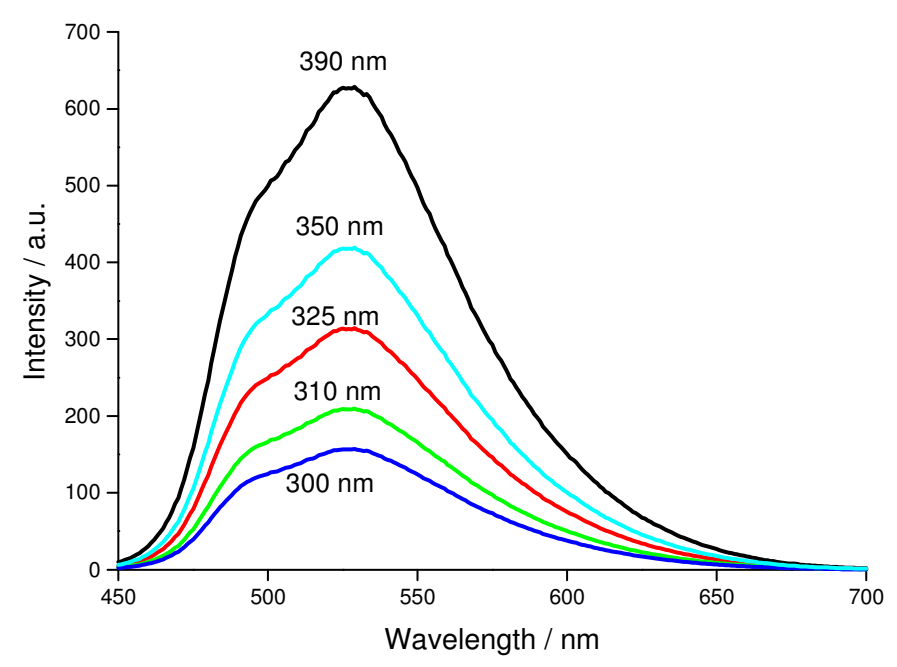

Figure 4.13. Fluorescence spectrum of $s t-\left[\mathbf{M e}-\mathbf{T h}_{\mathbf{5}}-\mathbf{M e}\right]_{2}$ at variable excitations.

A summary of UV-vis and fluorescence data is provided in Table 4.1. The extinction coefficients for the $\pi$-stacked compounds were less than twice the values for their linear analogs. This measurement is related to how well a conjugated material absorbs a photon upon excitation. If the photon penetrates the compound as would be the case in the $\pi$-stacked compounds, the extinction coefficient is lower. Conversely, if the photon hardly penetrates the material as in the linear model compounds and quickly becomes "extinct", the extinction coefficient is higher. However, this is a subtle difference in this series of $\pi$-stacked compounds and can also be attributed to the increased degree of overlap between the two chromophores facilitating the photon to become extinct at a faster rate. 
Table 4.1. Electronic Spectral Data ${ }^{a}$ of Models and Stacked Oligothiophenes

\begin{tabular}{|c|c|c|c|}
\hline & $\begin{array}{c}\text { Absorbance } \\
\lambda_{\max } / \mathrm{nm}\left(\varepsilon^{b}\right)\end{array}$ & $\begin{array}{l}\text { Fluorescence }(\mathrm{nm}) \\
\lambda_{\max }(\text { shoulder })\end{array}$ & $\begin{array}{l}\text { Stokes Shift } \\
(\mathrm{nm})\end{array}$ \\
\hline \multicolumn{4}{|l|}{ Linear Models } \\
\hline $\mathbf{H}-\mathbf{T h}_{\mathbf{1}}-\mathbf{H}^{c}$ & $240\left(7.3 \times 10^{3}\right)$ & 307 & 67 \\
\hline Me-Th $-\mathbf{M e}^{c}$ & $242\left(7.4 \times 10^{3}\right)$ & 308 & 66 \\
\hline H-Th $-\mathbf{H}$ & $333\left(2.1 \times 10^{4}\right)$ & (412) 431 & 98 \\
\hline Me-Th-Me & $345\left(2.2 \times 10^{4}\right)$ & (423) 442 & 97 \\
\hline Me-Th - -Me & $400\left(4.3 \times 10^{4}\right)$ & $492(520)$ & 120 \\
\hline \multicolumn{4}{|l|}{ Stacked Oligomers } \\
\hline$s t-\left[\mathrm{H}-\mathrm{Th}_{\mathbf{1}}-\mathrm{H}\right]_{2}{ }^{c}$ & $238\left(1.2 \times 10^{4}\right)$ & 308 & 70 \\
\hline$s t-\left[\mathbf{M e}-\mathbf{T h}_{\mathbf{1}}-\mathbf{M e}\right]_{2}{ }^{c}$ & $241\left(1.3 \times 10^{4}\right)$ & 310 & 69 \\
\hline$s t-\left[\mathrm{H}-\mathrm{Th}_{3}-\mathrm{H}\right]_{2}$ & $324\left(4.1 \times 10^{4}\right)$ & $421(500)$ & 176 \\
\hline$s t-\left[\mathrm{Me}-\mathrm{Th}_{3}-\mathrm{Me}\right]_{2}$ & $335\left(4.2 \times 10^{4}\right)$ & $444(505)$ & 170 \\
\hline$s t-\left[\mathrm{Me}-\mathrm{Th}_{5}-\mathrm{Me}\right]_{2}$ & $386\left(8.5 \times 10^{4}\right)$ & (500) 526 & 140 \\
\hline
\end{tabular}

${ }^{a}$ Electronic absorption and emission spectra were measured in $\mathrm{CH}_{2} \mathrm{Cl}_{2}, c=10^{-5} \mathrm{M}$. Stacked compounds were half as concentrated for molar absorbance comparisons. ${ }^{b}$ Molar absorptivity coefficients are in parentheses. ${ }^{c}$ Measured in $\mathrm{CHCl}_{3}$.

Stokes shifts are presented graphically as a function of oligomer length in Figure 4.14. The absorbance maxima and emission maxima both increase to lower energy upon extending the conjugation length for the linear model compounds and the Stokes shift increases concomitantly (extending oligomer length stabilizes photon absorption). The larger Stokes shift seen in the three-ring $\pi$-stacked compounds compared to the five ring system $\boldsymbol{s t}$-[Me-Th $\mathbf{5}-\mathbf{M e}]_{2}$ can be attributed to the formation of a "phane state." This state (referred to as an excimer) only forms when one of the dimer components is in an excited state. The wavelength of an excimer's emission is longer than that of the excited monomer's emission, because the excimer is stabilized compared to the excited monomer. Similar behavior has previously been noted by Bazan for styryl-substituted paracyclophanes. ${ }^{8}$ The large Stokes shift can be explained in terms of adsorption by a 
single oligomer acting as the chromophore, followed by energy transfer to a so called "phane state" which is responsible for emission at significantly lower energy. The lower energy associated with the excited state of the longer oligomer st-[Me-Th $5-M e]_{2}$ means that there is less driving force for energy transfer such that a single oligomer is responsible more for both absorption and emission. In the case of the stacked compounds $s t-\left[\mathbf{R}-\mathbf{T h}_{\mathbf{1}}-\mathbf{R}\right]_{\mathbf{2}}$, the Stokes Shift is not as dramatic. This is attributed to the lack of degree of overlap from only one aromatic ring stacked on top itself providing a negligible driving force for photon relaxation.

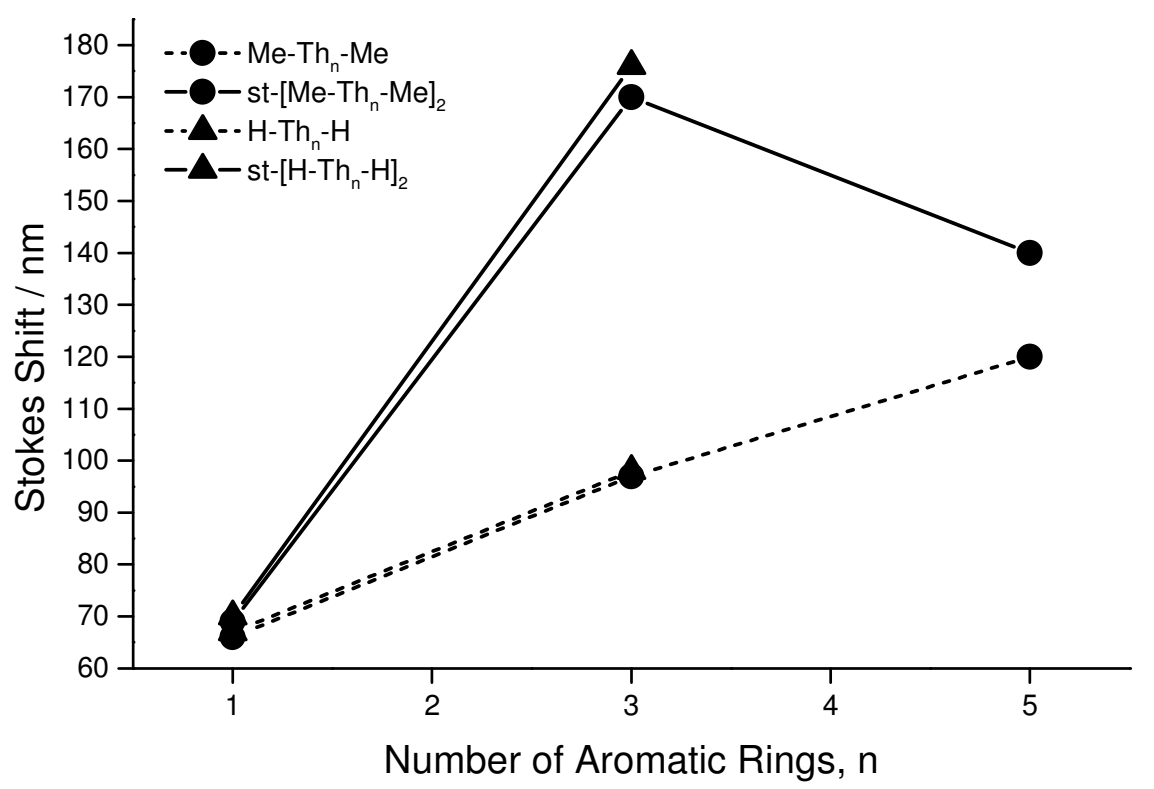

Figure 4.14. Stokes shifts of model and stacked oligothiophenes versus the number of aromatic rings.

The change in vibronic structure for the linear model oligothiophenes is characteristic of the Franck-Condon Principle. ${ }^{9}$ There is a symmetrical carbon-carbon stretching vibration that arises from excitation that is a combination of the single and double bonds; therefore there are two energy peaks present in the emission spectra for 
linear oligothiophenes. As conjugation length increases, the relative intensity of the high energy peak increases. Geometrical relaxation in the excited state takes place on more carbons causing the relative change per bond to diminish. This phenomenon results in the lower energy transition to weaken in intensity upon increasing conjugation length.

\subsubsection{Electrochemistry}

The effect of stacking on the oxidation potential pf conjugated oligomers was determined by electrochemical characterization. Tetramethylthiophene, Me-Th $\mathbf{1}-\mathbf{M e}$, exhibits an irreversible oxidation potential $\left(E_{p}=+1.39 \mathrm{~V}\right)$, Figure 4.15 . On the other hand, the $\pi$-stacked compound $s t-\left[\mathbf{M e}-\mathbf{T h}_{\mathbf{1}}-\mathbf{M e}\right]_{2}$ gives a reversible one-electron oxidation $\left(E_{1 / 2}=+1.09 \mathrm{~V}\right)$, which is significantly lower than the peak of the model compound, Figure 4.16. The mono(radical cation) formed upon one-electron oxidation is stabilized by through-space $\pi-\pi$ interactions of the thiophene core units. Removal of the second electron at $E_{1 / 2}=+1.59 \mathrm{~V}$ to form a dication is an irreversible process. The second oxidation process is $+0.5 \mathrm{~V}$ higher than the first oxidation process, a difference that can be explained by Coulombic destabilization of the highly oxidized species with cationic charge localized on each thiophene ring. The overlaid differential pulse voltammogram (DPV) of Me-Th/ $\mathbf{M}$ Me (dotted line) and $s t-\left[\mathbf{M e}-\mathbf{T h}_{\mathbf{1}}-\mathbf{M e}\right]_{2}$ (solid line), Figure 4.17, illustrate the lowering of the first redox peak for the $\pi$-stacked compound relative to that of the linear model. 


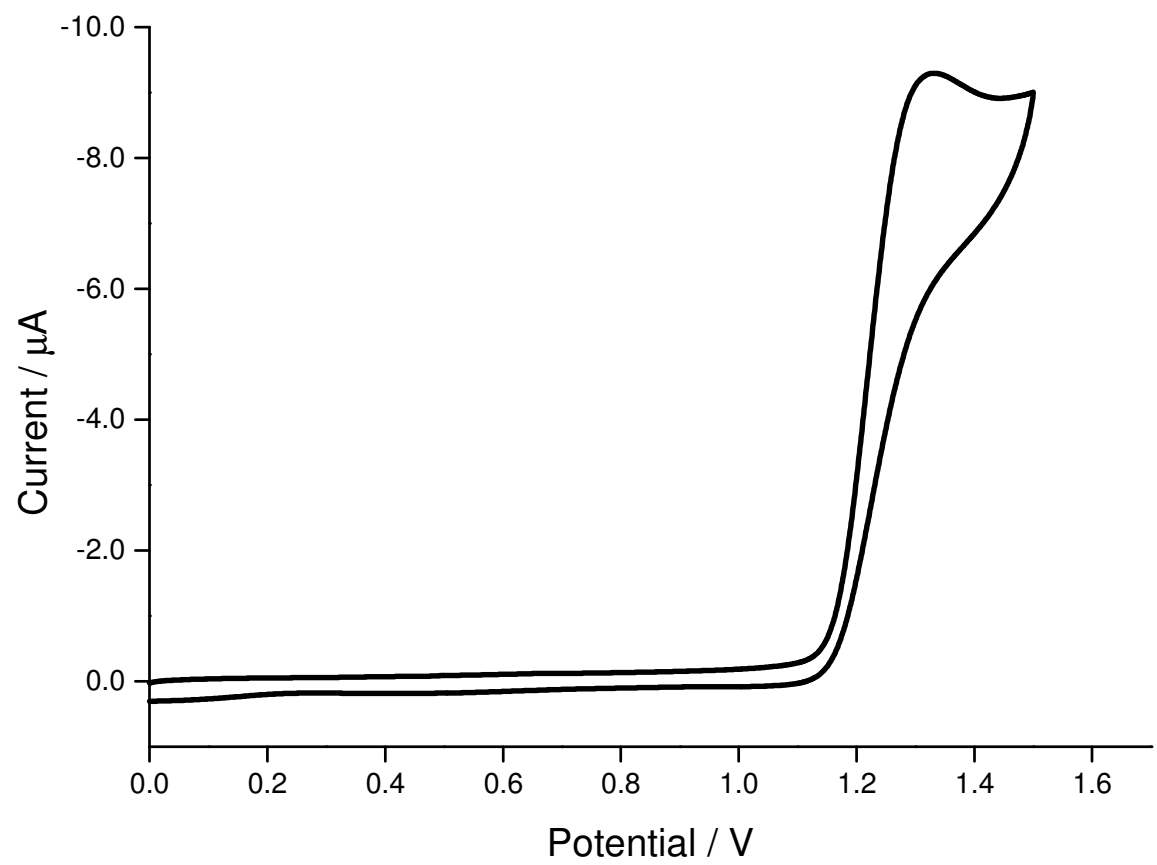

Figure 4.15. $\mathrm{CV}$ of Me-Th-Me. $c=2 \mathrm{mM}$ in $\mathrm{CH}_{2} \mathrm{Cl}_{2} ; 0.1 \mathrm{M} n$ - $\mathrm{BuNPF}_{6} / \mathrm{CH}_{2} \mathrm{Cl}_{2} ; \mathrm{Au}$ working electrode; $\mathrm{Pt}$ auxillary, $\mathrm{Ag} / \mathrm{Ag}^{+}$reference electrode; $v=100 \mathrm{mV} / \mathrm{s}$.

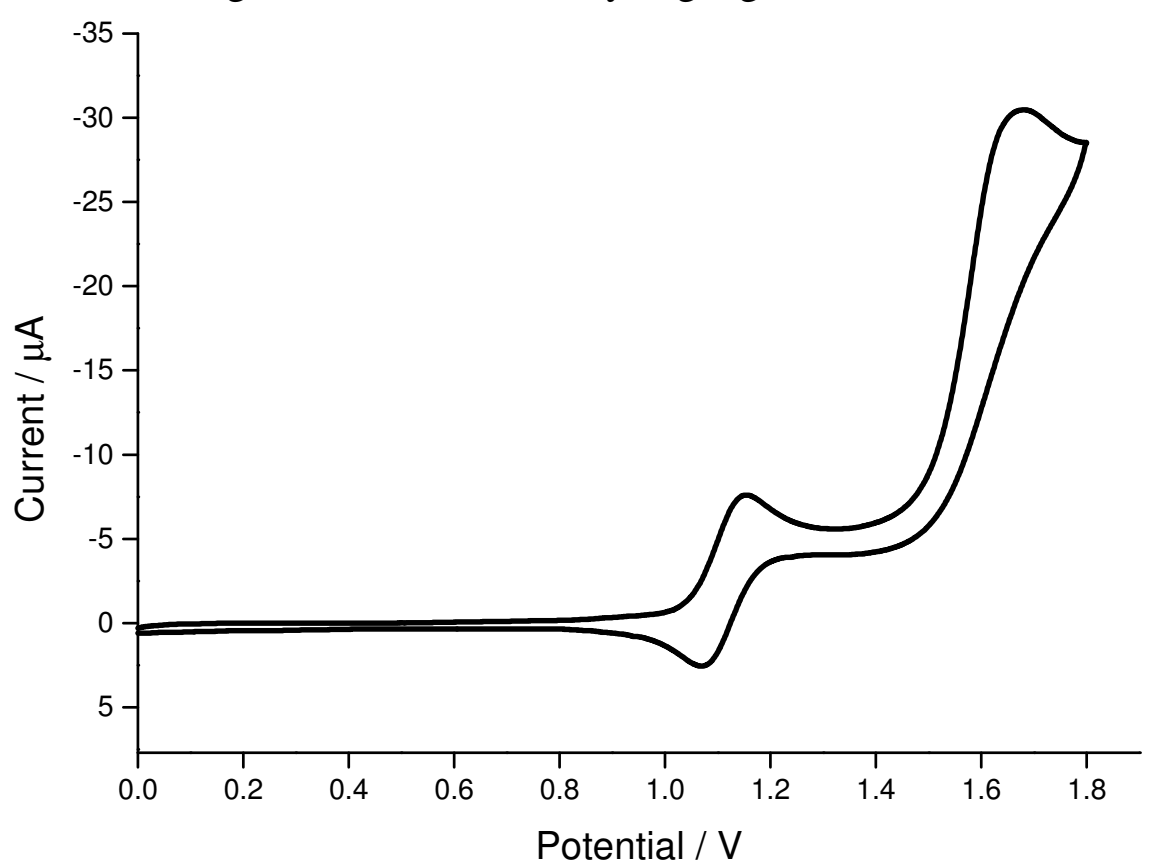

Figure 4.16. $\mathrm{CV}$ of $s t$-[Me-Th $\mathbf{1}-\mathrm{Me}]_{2} . \quad c=2 \mathrm{mM}$ in $\mathrm{CH}_{2} \mathrm{Cl}_{2} ; 0.1 \mathrm{M} n-\mathrm{BuNPF}_{6} / \mathrm{CH}_{2} \mathrm{Cl}_{2}$; $\mathrm{Au}$ working electrode; $\mathrm{Pt}$ auxillary, $\mathrm{Ag} / \mathrm{Ag}^{+}$reference electrode; $v=100$ $\mathrm{mV} / \mathrm{s}$. 


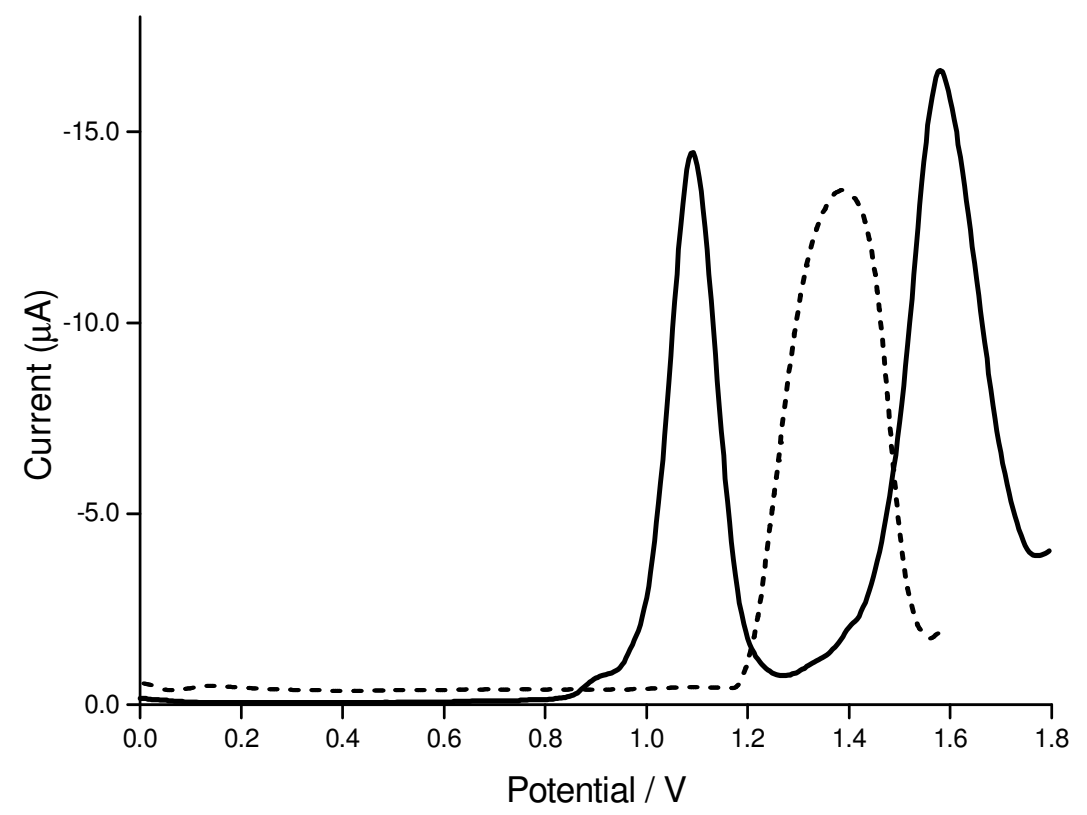

Figure 4.17. DPV of Me-Th $\mathbf{T}$-Me and $s t$-[Me-Th $\left.-\mathbf{T h}_{\mathbf{1}}-\mathbf{M e}\right]_{2} . \quad c=2 \mathrm{mM}$ in $\mathrm{CH}_{2} \mathrm{Cl}_{2} ; 0.1 \mathrm{M}$ $n$ - $\mathrm{BuNPF}_{6} / \mathrm{CH}_{2} \mathrm{Cl}_{2}$; $\mathrm{Au}$ working electrode; $\mathrm{Pt}$ auxillary, $\mathrm{Ag} / \mathrm{Ag}^{+}$reference electrode; $v=100 \mathrm{mV} / \mathrm{s}$.

The terthiophene model $\mathbf{M e}-\mathbf{T h}_{\mathbf{3}}$-Me displays a reversible one-electron wave $\left(E_{1 / 2}\right.$ $=+0.96 \mathrm{~V})$ and an irreversible second oxidation wave $\left(E_{p}=+1.23 \mathrm{~V}\right)$ by cyclic voltammetry, Figure 4.18. The $\pi$-stacked terthiophene analog $s t$-[Me-Th $\mathbf{3}-\mathbf{M e}]_{\mathbf{2}}$ gives two reversible one-electron waves $\left(1 \mathrm{~F} / \mathrm{mol}\right.$ for each wave) at $E_{1 / 2}=+0.70 \mathrm{~V}$ and $E_{1 / 2}=$ $+0.90 \mathrm{~V}$ which are both lower than the first oxidation of the model terthiophene compound Me-Th $\mathbf{T}_{\mathbf{3}}$-Me, Figure 4.19. This splitting of the first oxidation and lowering of the oxidation potentials compared to the terthiophene model is due to increased delocalization of the charged species and stability of the dicationic state. A further $2 \mathrm{~F} / \mathrm{mol}$ oxidation occurs at $E_{1 / 2}=+1.49 \mathrm{~V}$. 


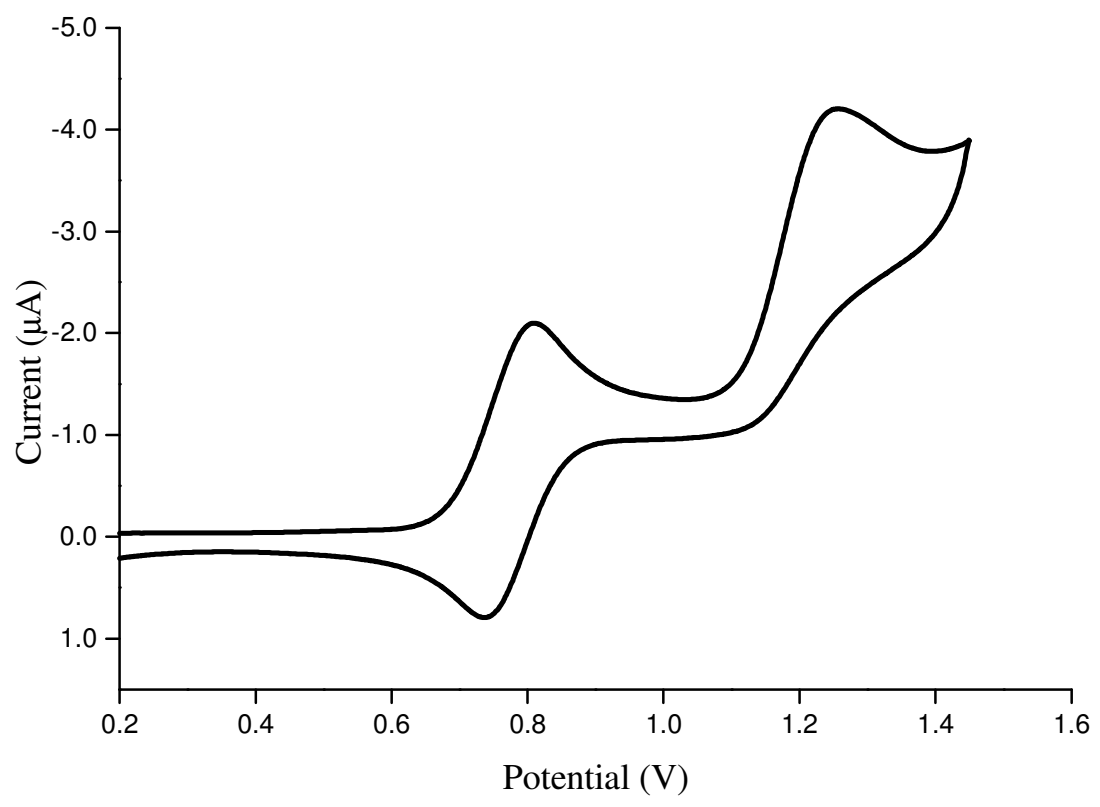

Figure 4.18. $\mathrm{CV}$ of Me-Th -Me. $c=2 \mathrm{mM}$ in $\mathrm{CH}_{2} \mathrm{Cl}_{2} ; 0.1 \mathrm{M} n$ - $\mathrm{BuNPF}_{6} / \mathrm{CH}_{2} \mathrm{Cl}_{2} ; \mathrm{Au}$ working electrode; $\mathrm{Pt}$ auxillary, $\mathrm{Ag} / \mathrm{Ag}^{+}$reference electrode; $v=100 \mathrm{mV} / \mathrm{s}$.

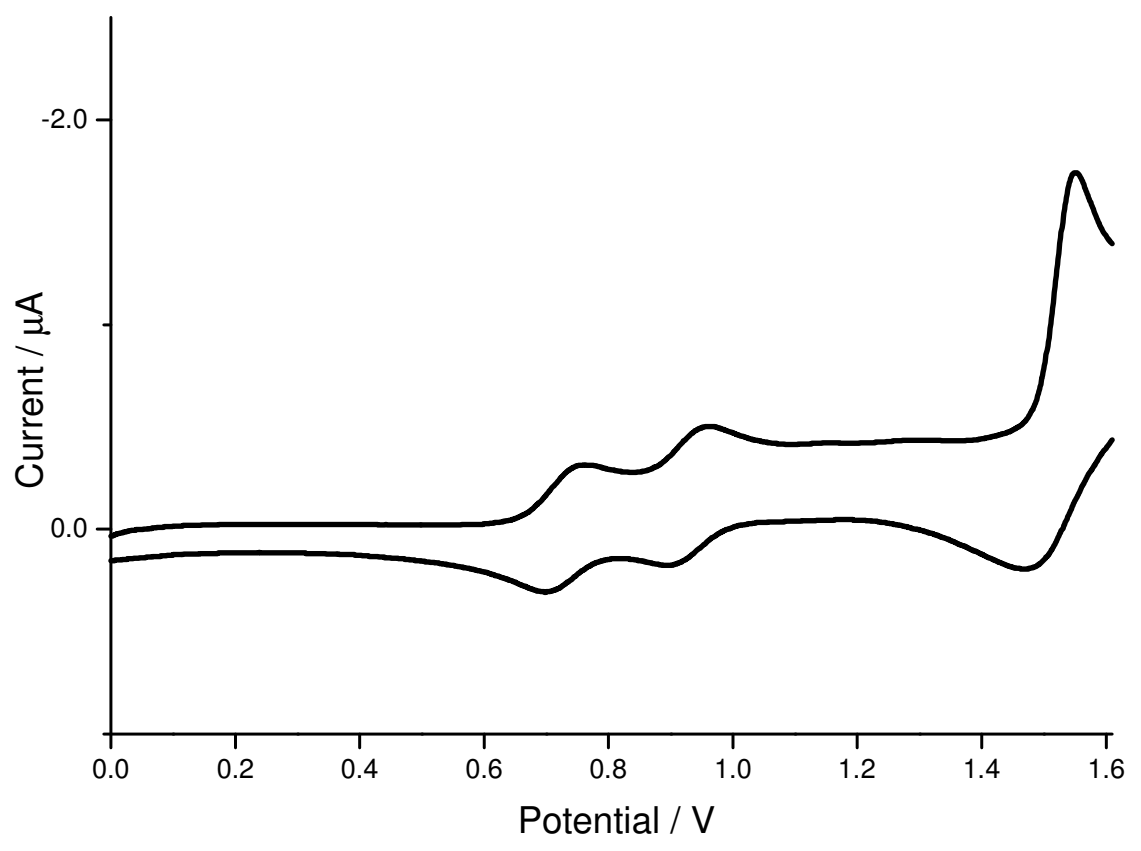

Figure 4.19. $\mathrm{CV}$ of st-[Me-Th/3-Me $]_{2} . \quad c=2 \mathrm{mM}$ in $\mathrm{CH}_{2} \mathrm{Cl}_{2} ; 0.1 \mathrm{M} n-\mathrm{BuNPF}_{6} / \mathrm{CH}_{2} \mathrm{Cl}_{2}$; $\mathrm{Au}$ working electrode; $\mathrm{Pt}$ auxillary, $\mathrm{Ag} / \mathrm{Ag}^{+}$reference electrode; $v=100$ $\mathrm{mV} / \mathrm{s}$. 
Differential pulse voltammetry of the terthiophene model $\mathbf{M e}-\mathbf{T h}_{\mathbf{3}}-\mathbf{M e}$ and $\pi$ stacked compound st-[Me-Th/3-Me $]_{2}$ are shown in Figure 4.20. Well resolved oxidations of the $\pi$-stacked compound take place at lower potentials than the first oxidation of the linear terthiophene, suggesting that both the mono(radical cation) and dication are stabilized by $\pi$-stacking. The lowering of the second oxidation to form the dication to a value lower than the first oxidation of the linear model suggests that the $\pi$-stacked dication is stabilized in such a way that it overcomes the destabilization expected to arise from Coulombic repulsion.

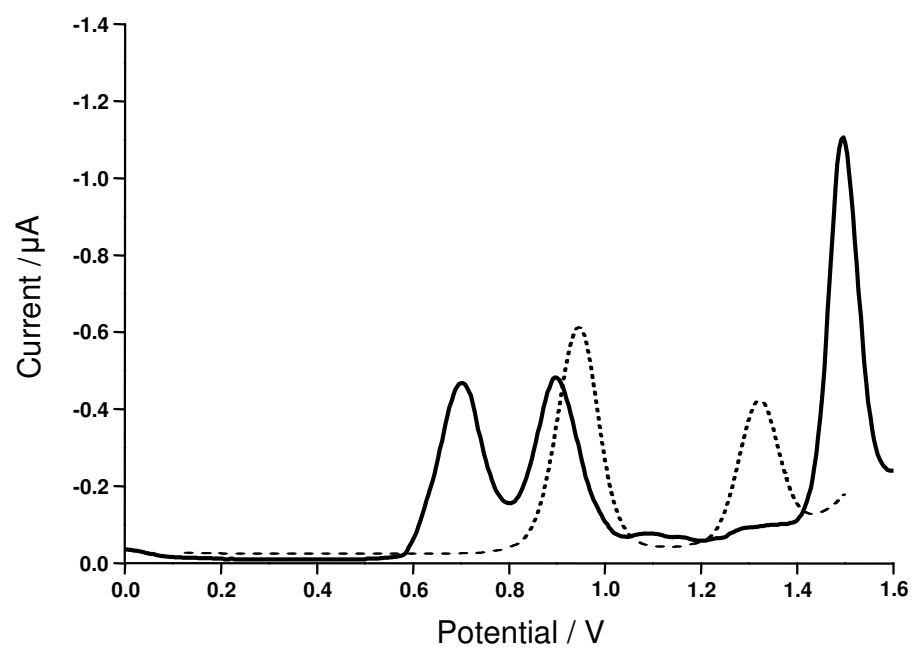

Figure 4.20. DPV of Me-Th $\mathbf{M}_{\mathbf{3}}-\mathbf{M e}$ (dotted line) and st-[Me-Th $\left.\mathbf{T}_{\mathbf{3}}-\mathbf{M e}\right]_{2}$ (solid line). $c=2$ $\mathrm{mM}$ in $\mathrm{CH}_{2} \mathrm{Cl}_{2} ; 0.1 \mathrm{M} n-\mathrm{BuNPF}_{6} / \mathrm{CH}_{2} \mathrm{Cl}_{2} ; \mathrm{Au}$ working electrode; $\mathrm{Pt}$ auxillary, $\mathrm{Ag} / \mathrm{Ag}^{+}$reference electrode; $v=100 \mathrm{mV} / \mathrm{s}$.

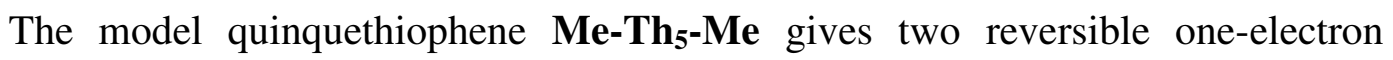
oxidations in the $\mathrm{CV}$ at $E_{1 / 2}=+0.79 \mathrm{~V}$ and $E_{1 / 2}=+1.03 \mathrm{~V}$, Figure 4.21. Two reversible one-electron processes for the stacked analog st-[Me-Th $\mathbf{5}-\mathbf{M e}]_{2}$ at $E_{1 / 2}=+0.67 \mathrm{~V}$ and $\mathrm{E}_{1 / 2}$ $=+0.73 \mathrm{~V}(2 \mathrm{~F} / \mathrm{mol})$ are both lower than the first oxidation of the model compound Me- 
$\mathbf{T h}_{\mathbf{5}}-\mathrm{Me}, \mathrm{CV}$ in Figure 4.22 and DPV in Figure 4.23. A further oxidation (2F/mol) for st[Me-Th $-\mathbf{M e}_{2}$ occurs at $E_{1 / 2}=+1.22 \mathrm{~V}$ to give the tetracation, which is at a higher potential than the second oxidation of the model compound Me-Th5-Me. This higher potential for removal of the third and fourth electrons is due to the stabilization of the $\pi$ stacked dicationic state and the destabilization of the tetracation by Coulombic repulsion.

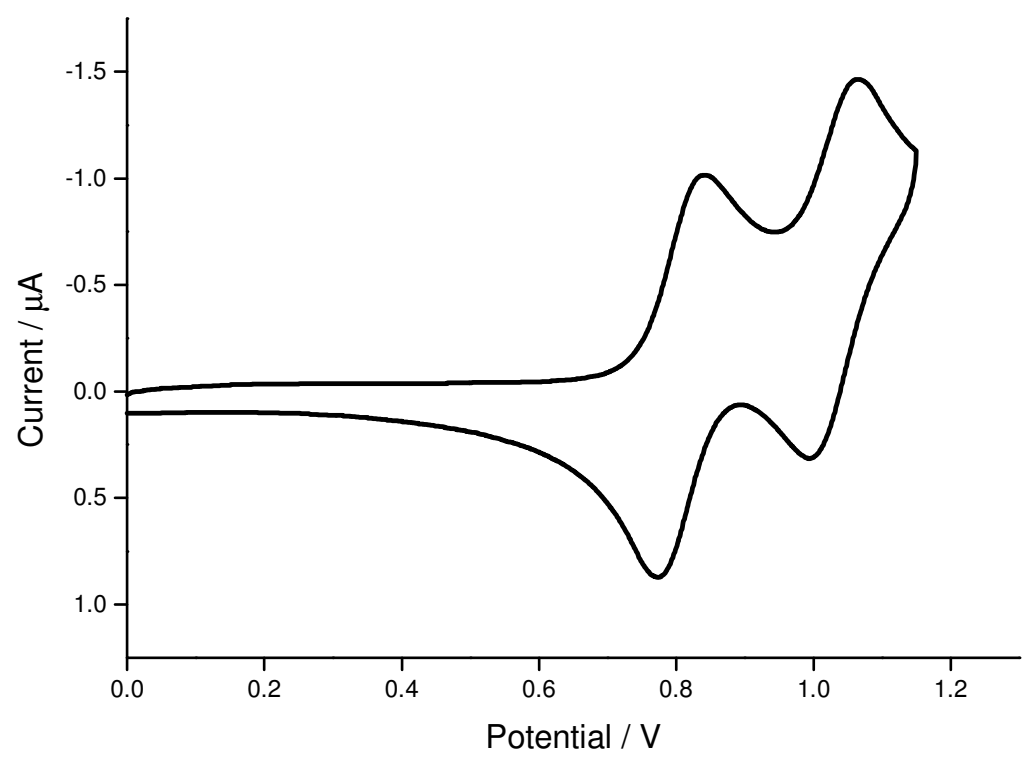

Figure 4.21. $\mathrm{CV}$ of Me-Th -Me. $c=2 \mathrm{mM}$ in $\mathrm{CH}_{2} \mathrm{Cl}_{2} ; 0.1 \mathrm{M} n$ - $\mathrm{BuNPF}_{6} / \mathrm{CH}_{2} \mathrm{Cl}_{2} ; \mathrm{Au}$ working electrode; $\mathrm{Pt}$ auxillary, $\mathrm{Ag} / \mathrm{Ag}^{+}$reference electrode; $v=100 \mathrm{mV} / \mathrm{s}$. 


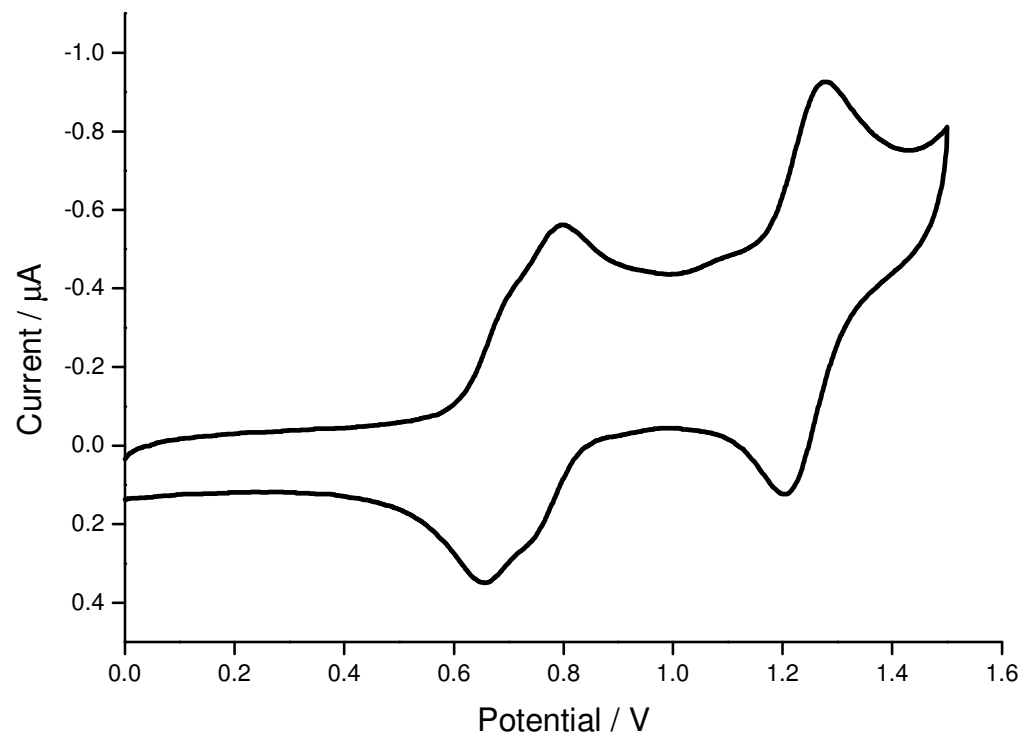

Figure 4.22. $\mathrm{CV}$ of $\boldsymbol{s t}$-[Me-Th$-\mathrm{Me}]_{2} . \quad c=2 \mathrm{mM}$ in $\mathrm{CH}_{2} \mathrm{Cl}_{2} ; 0.1 \mathrm{M} n-\mathrm{BuNPF}_{6} / \mathrm{CH}_{2} \mathrm{Cl}_{2}$; $\mathrm{Au}$ working electrode; $\mathrm{Pt}$ auxillary, $\mathrm{Ag} / \mathrm{Ag}^{+}$reference electrode; $v=100$ $\mathrm{mV} / \mathrm{s}$.

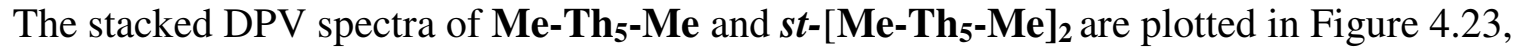
illustrated the splitting previously discussed.

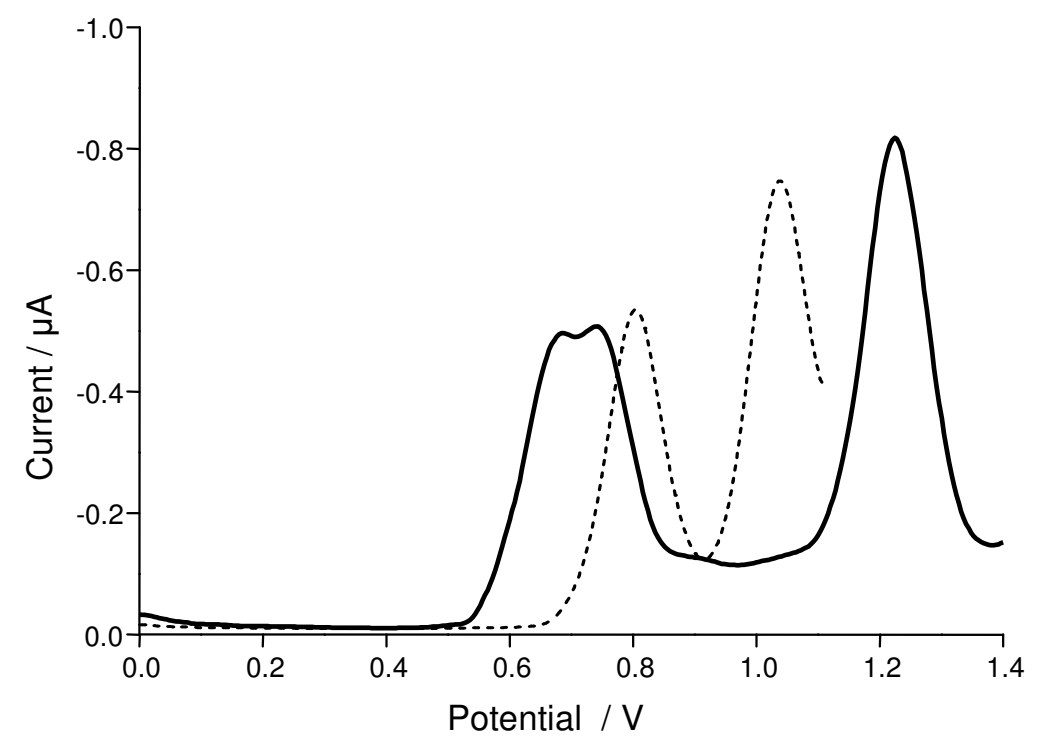

Figure 4.23. DPV of Me-Th $-\mathbf{M e}$ (dotted line) and $s t-\left[\mathbf{M e}-\mathbf{T h}_{\mathbf{5}}-\mathbf{M e}_{2}\right.$ (solid line). $c=2$ $\mathrm{mM}$ in $\mathrm{CH}_{2} \mathrm{Cl}_{2} ; 0.1 \mathrm{M} n$-BuNPF$/ \mathrm{CH}_{2} \mathrm{Cl}_{2} ;$ Au working electrode; $\mathrm{Pt}$ auxillary, $\mathrm{Ag} / \mathrm{Ag}^{+}$reference electrode; $v=100 \mathrm{mV} / \mathrm{s}$. 
The redox potentials of model and $\pi$-stacked oligothiophenes are summarized in Table 4.2. As expected, the ease of oxidation increases upon extending the conjugation length. $\pi$-Stacking of two oligomers also results in a lowering of the oxidation potential and splitting of the potential at which two electrons are removed from the stacked oligomers. The difference between the first and second redox processes in the $\pi$-stacked compounds $\left(\Delta E_{1}\right)$ decreases as oligomer chain length increases $\left(\mathrm{T}_{1}=+0.5 ; \mathrm{T}_{3}=+0.20, \mathrm{~T}_{5}\right.$ $=+0.06 \mathrm{~V})$.

Table 4.2. Oxidation Potentials of Unstacked and Stacked Oligothiophenes

\begin{tabular}{|c|c|c|c|c|}
\hline & $E_{1} / \mathrm{V}\left(\right.$ no $\left.e^{-}\right)$ & $\Delta E_{1} / \mathrm{V}$ & $E_{2} / \mathrm{V}\left(\operatorname{no} e^{-}\right)$ & $\Delta E_{2-1} / \mathrm{V}$ \\
\hline Me-Th - -Me & $1.39(1)^{b}$ & - & - & - \\
\hline$s t-\left[\mathrm{Me}-\mathrm{Th}_{1}-\mathrm{Me}\right]_{2}$ & $1.09(1), 1.59(1)^{b}$ & 0.5 & - & - \\
\hline Me-Th $-\mathrm{Me}$ & $0.96(1)$ & - & $1.23(1)$ & 0.27 \\
\hline$s t-\left[\mathrm{Me}-\mathrm{Th}_{3}-\mathrm{Me}\right]_{2}$ & $0.70(1), 0.90(1)$ & 0.20 & $1.49(2)$ & 0.59 \\
\hline Me-Th 5 -Me & $0.79(1)$ & - & $1.02(1)$ & 0.23 \\
\hline$s t-\left[\mathrm{Me}-\mathrm{Th}_{5}-\mathrm{Me}\right]_{2}$ & $0.67(1), 0.73(1)$ & 0.06 & $1.22(2)$ & 0.49 \\
\hline
\end{tabular}

Plots of the oxidation potentials versus number of aromatic rings (or reciprocal of \# rings) for the series of methyl-capped oligothiophenes illustrates these tendencies, Figure 4.24. The first oxidation potentials of the stacked analogs are all lower than their respective unstacked analogs. This can be attributed to the stacking of monomers upon one another, allowing for better charge stabilization. There is localized Coulombic repulsion upon removal of the second electron $(+1.59 \mathrm{~V})$ from $s t-\left[\mathbf{M e}-\mathbf{T h}_{\mathbf{1}}-\mathbf{M e}\right]_{\mathbf{2}}$, but as oligomer conjugation length increases there is an increase in stability of the dicationic state that overcomes Coulombic repulsion, resulting in particularly lower oxidation potential. The second oxidation for the stacked terthiophene $(+0.90 \mathrm{~V})$ and stacked 
quinquethiophene $(+0.73 \mathrm{~V})$ become lower than the first oxidation of their linear models $(+0.96 \mathrm{~V}$ and $+0.79 \mathrm{~V}$, respectively).
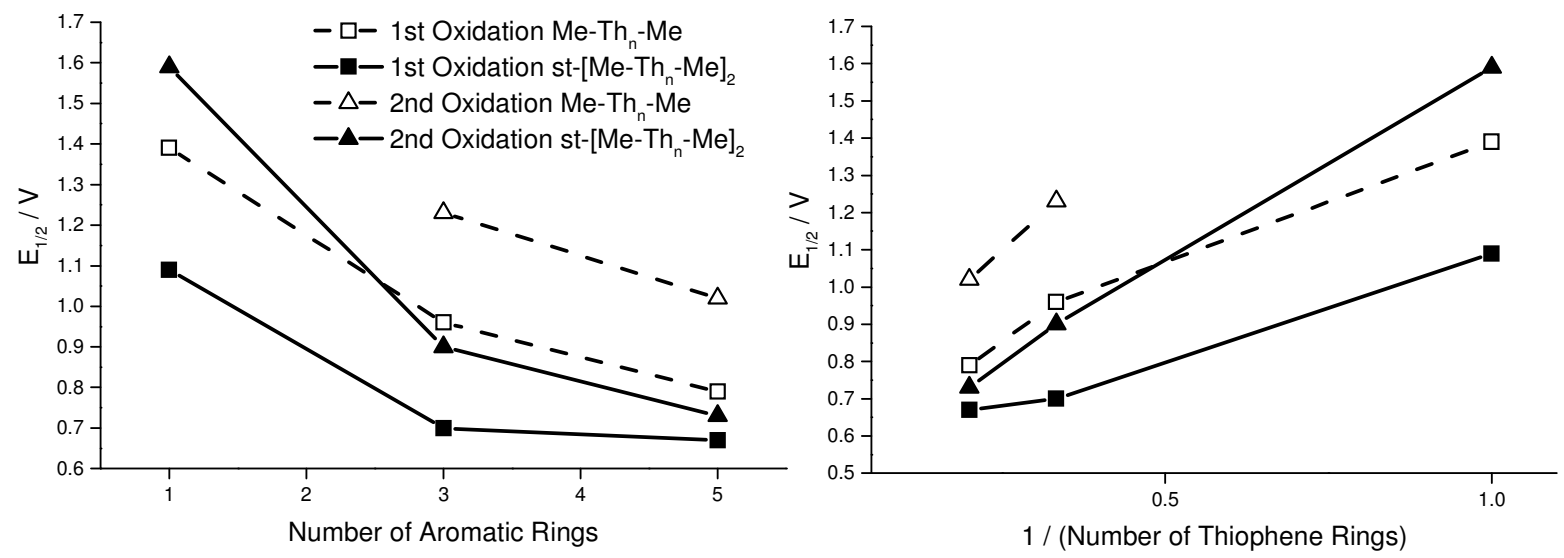

Figure 4.24. Oxidation potentials of oligothiophenes.

\subsubsection{Chemical Oxidation of Neutral Oligothiophenes to Radical Cations}

\section{RADICAL CATIONS}

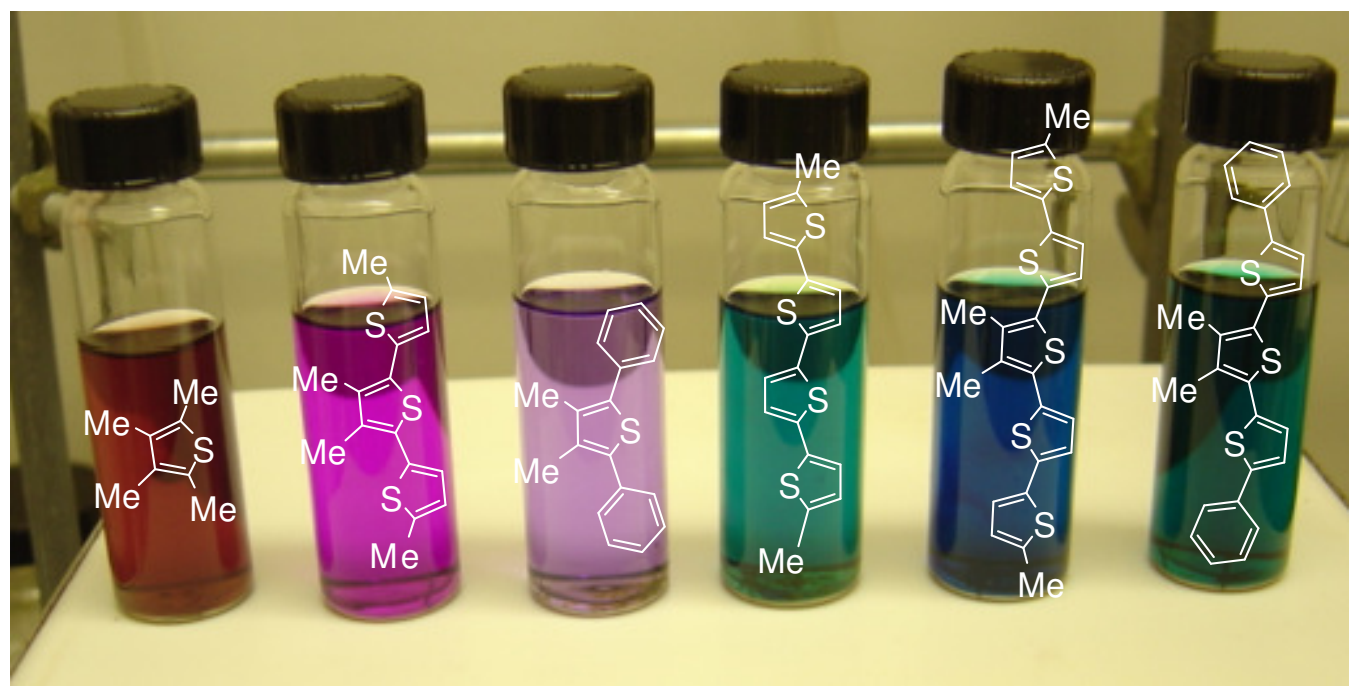

Treatment of oligothiophenes, $\mathrm{Th}_{n}$, with $\mathrm{FeCl}_{3}$ results in chemical oxidation

illustrated in the general equation: 


$$
\mathrm{Th}_{\mathrm{n}}+2 \mathrm{FeCl}_{3} \longrightarrow \mathrm{Th}_{\mathrm{n}}^{+\cdot}+\mathrm{FeCl}_{4}^{-}+\mathrm{FeCl}_{2}
$$

Oxidiation by titration of model terthiophene $\mathbf{M e - T h}$-Me with a stock solution of $\mathrm{FeCl}_{3}$ in $\mathrm{CH}_{2} \mathrm{Cl}_{2}$ of, formed new absorbance bands $\left(\lambda_{\max }=563\right.$ and $\left.884 \mathrm{~nm}\right)$ with two equivalents of $\mathrm{FeCl}_{3}$, Figure 4.25. This is consistent with the formation of a radical cation species. Further addition of $\mathrm{FeCl}_{3}$ (2-4 eq.) does not form the dicationic species due to the high oxidation potential of the cation and instability of the dicationic form.

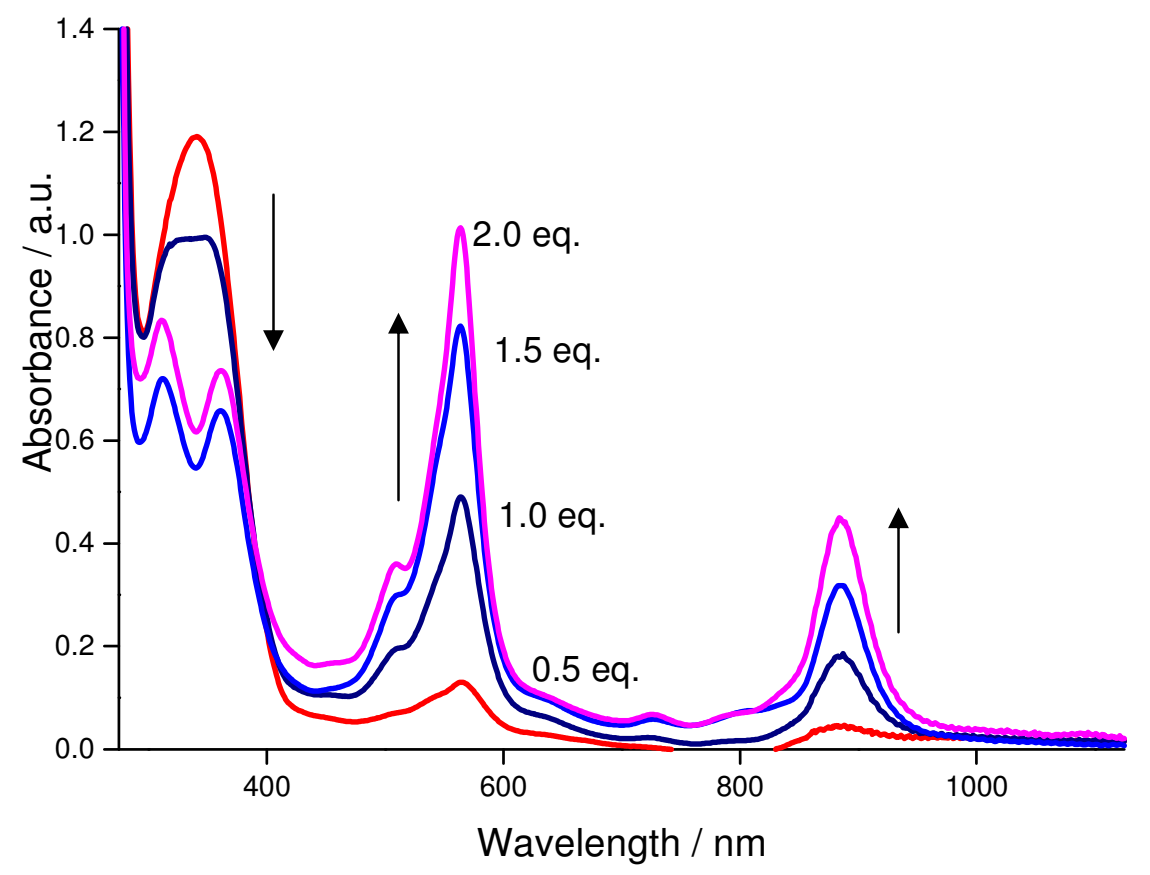

Figure 4.25. UV-vis-NIR spectrum of $\mathbf{M e}^{-} \mathbf{T h}_{3}$-Me doped with $\mathrm{FeCl}_{3}$ (0-2 eq.).

For model quinquethiophene $\mathbf{M e}-\mathbf{T h}_{5}-\mathbf{M e}$ one electron oxidation (2 eq. $\mathrm{FeCl}_{3}$ ) produces two new energy transitions, Figure 4.26 . Peaks at $716 \mathrm{~nm}(1.73 \mathrm{eV})$ and 1322 
$\mathrm{nm}(0.94 \mathrm{eV})$ correspond to a radical cation of $\mathbf{M e}-\mathbf{T h}_{\mathbf{5}}-\mathbf{M e}$. Upon further addition of $\mathrm{FeCl}_{3}$ (up to 4 eq.), the radical cation peaks diminish and a new absorbance grows in at $915 \mathrm{~nm}(1.36 \mathrm{eV})$. This peak is attributed to the dicationic species of this oligomer which is stable at room temperature in $\mathrm{CH}_{2} \mathrm{Cl}_{2}$. A stacked plot of the radical cations of the terthiophene and quinquethiophene models is shown in Figure 4.27.

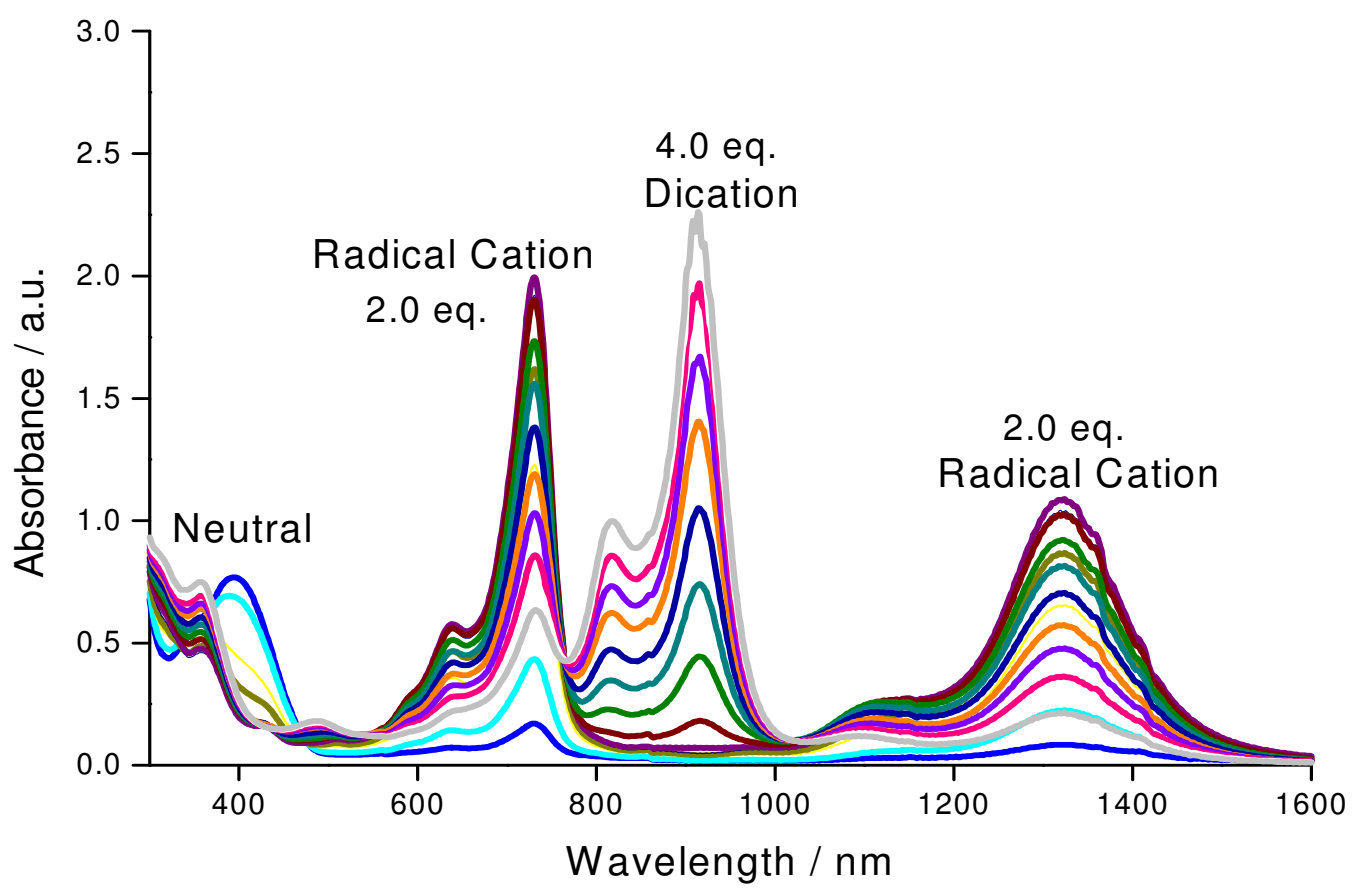

Figure 4.26. UV-vis-NIR spectrum of $\mathbf{M e -} \mathbf{T h}_{\mathbf{5}}-\mathbf{M e}$ doped with $\mathrm{FeCl}_{3}$ (0-4 eq.). 


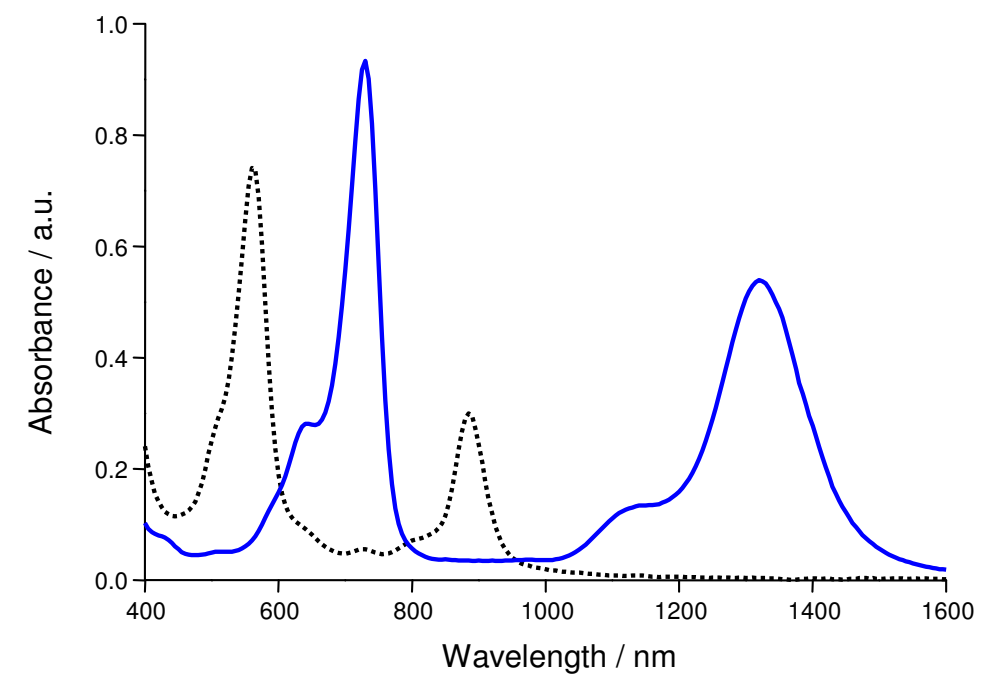

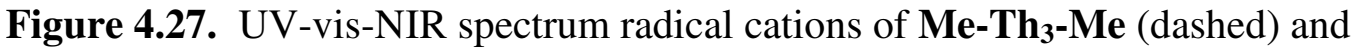
Me-Th5-Me (solid).

The $\pi$-stacked terthiophene $s t-\left[\mathbf{M e}-\mathbf{T h}_{\mathbf{3}}-\mathbf{M e}\right]_{2}$ readily forms the radical cation with two equivalents of $\mathrm{FeCl}_{3}$. The $\pi-\pi *$ transition neutral peak at $335 \mathrm{~nm}$ is red shifted to 362 $\mathrm{nm}$ upon oxidation and three new energy transitions $(437,591$, and $869 \mathrm{~nm})$ appear in Figure 4.28. There is a red shift of peaks for the radical cation of the stacked compound $s t-\left[\mathrm{Me}-\mathrm{Th}_{3}-\mathrm{Me}\right]_{2}$ compared to peaks for the model Me-Th $\mathbf{3}-\mathbf{M e}$. Peaks for the stacked compound appear at 437/591/869 $\mathrm{nm}$ whereas they are at 563/884 $\mathrm{nm}$ for the linear analog.

The $\pi$ - $\pi^{*}$ transition of the $\pi$-stacked $s t-\left[\mathbf{M e}-\mathbf{T h}_{\mathbf{5}}-\mathbf{M e}\right]_{2}$ at $386 \mathrm{~nm}(3.21 \mathrm{eV})$ is red shifted to $440 \mathrm{~nm}(2.82 \mathrm{eV})$ and is weakened upon one-electron oxidation, Figure 4.28. Two new peaks at higher energies $560 \mathrm{~nm}(2.21 \mathrm{eV})$ and $760 \mathrm{~nm}(1.63 \mathrm{eV})$ are similar in intensity and the low energy peak at $1307 \mathrm{~nm}(0.95 \mathrm{eV})$ is broadened. 


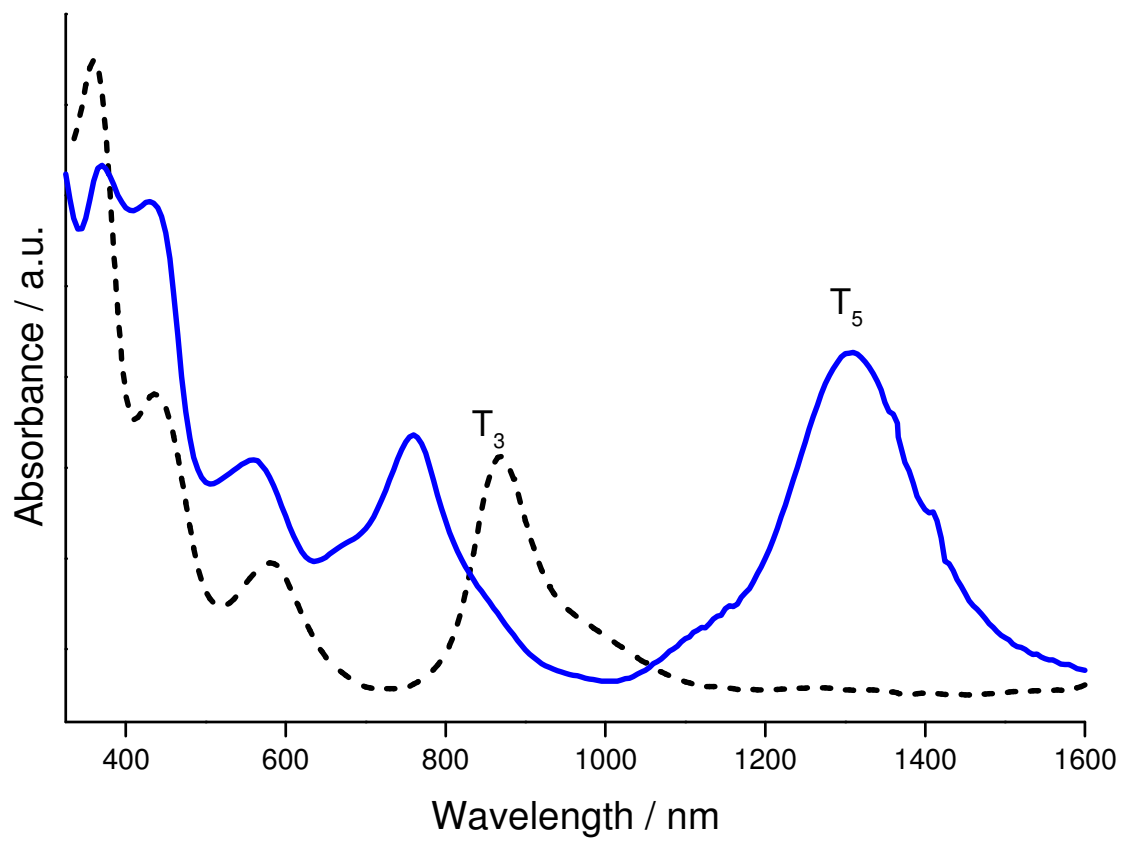

Figure 4.28. UV-vis-NIR spectrum of mono(radical cation) species of $s t$-[Me-Th $\mathbf{M}-\mathbf{M e}]_{2}$ (dashed line), $\boldsymbol{s t}_{\text {- }}\left[\mathbf{M e}-\mathbf{T h}_{\mathbf{5}}-\mathbf{M e}\right]_{2}$ (solid line). Absorbances are normalized for each neutral unit.

\subsubsection{Formation of Dications and $\pi$-Dimers}

$\pi$-Dimer formation by association of linear radical cations. $\pi$-Dimer formation between radical cation is favored at lower temperatures and in more polar solvent such as acetonitrile, which lowers Coulombic repulsion between the two charged species. ${ }^{10}$ Weak absorbance peaks at $460 \mathrm{~nm}(2.58 \mathrm{eV})$ and $725 \mathrm{~nm}(1.64 \mathrm{eV})$ in the spectrum of the

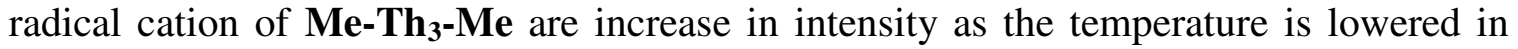
acetonitrile, Figure 4.29 (top). This behavior is consistent with formation of a $\pi$-dimer previously reported. ${ }^{11}$ Similarly, small peaks at $620 \mathrm{~nm}(1.99 \mathrm{eV})$ and $1085 \mathrm{~nm}(1.14$ 
eV) in the spectrum of $\mathbf{M e -} \mathbf{T h}_{\mathbf{5}}-\mathbf{M e}$ become predominant upon cooling the radical cation species in acetonitrile, Figure 4.29 (bottom).
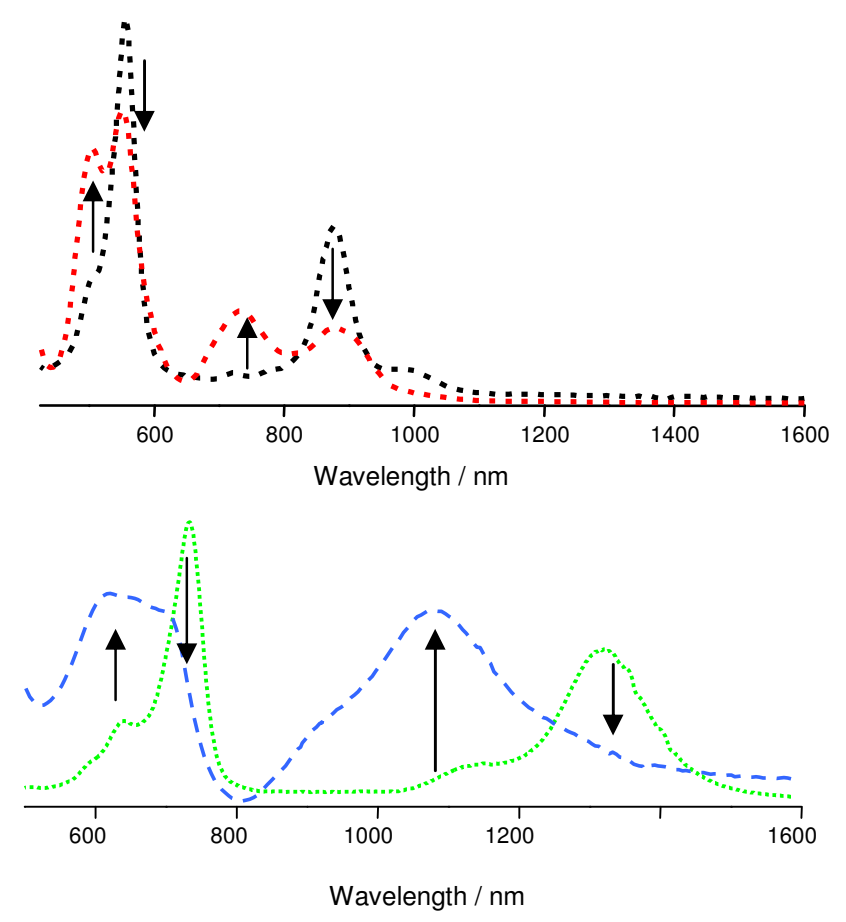

Figure 4.29. UV-vis-NIR spectra of radical cation of Me-Th 3 -Me and $\pi$-dimer formed upon cooling radical cation to $-30{ }^{\circ} \mathrm{C}$ (top). UV-vis-NIR spectra of radical cation of Me-Th 5 -Me and $\pi$-dimer of formed upon cooling radical cation to $-30{ }^{\circ} \mathrm{C}$ (bottom).

Spectral characterization of dications of stacked oligomers. Upon removal of the second electron from $s t$-[Me-Th $\left.{ }_{3}-\mathrm{Me}\right]_{2}$ at room temperature (4 eq. $\mathrm{FeCl}_{3}$ ), new peaks arise at $506 \mathrm{~nm}(2.58 \mathrm{eV}), 778 \mathrm{~nm}(1.53 \mathrm{eV})$, and $970 \mathrm{~nm}(1.22 \mathrm{eV})$, Figure 4.30. These transitions are red shifted compared to the model terthiophene (460 nm abd $725 \mathrm{~nm}$ ), and 
the new $970 \mathrm{~nm}$ absorbance is attributed to a low energy intrachain charge transfer (CT) peak. $^{12}$ Upon formation of the dication of $s t-\left[\mathbf{M e}-\mathbf{T h}_{\mathbf{5}}-\mathbf{M e}\right]_{2}$, new peaks arise at $654 \mathrm{~nm}$ $(1.90 \mathrm{eV})$ and $1123 \mathrm{~nm}(1.10 \mathrm{eV})$ and are assigned to $\pi$-dimer optical transitions. Again, these peaks are red shifted relative to the $\pi$-dimer formed upon association of two linear radical cations.

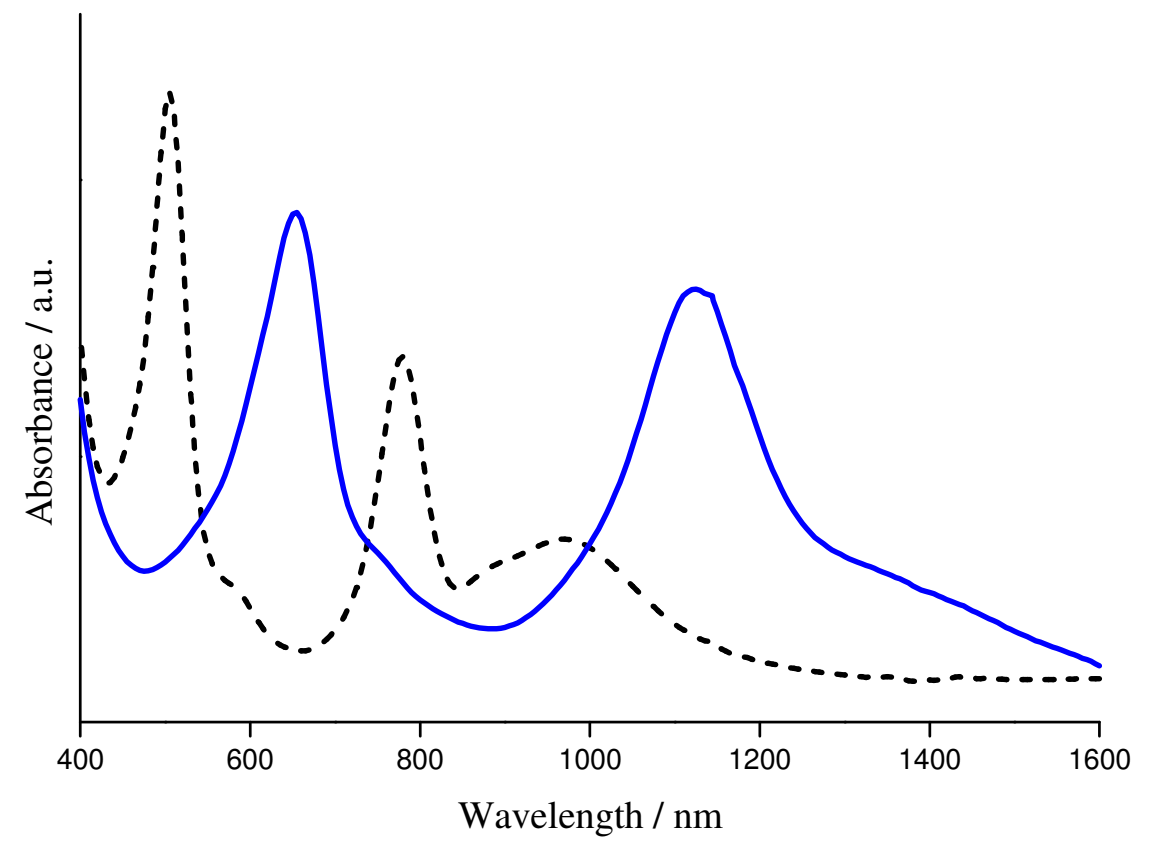

Figure 4.30. Absorbance spectra of dication ( $\pi$-dimer) species of $s t$-[Me-Th/ $-\mathbf{M e}]_{\mathbf{2}}$ (dashed line), $\boldsymbol{s t}$-[Me-Th $\mathbf{5}-\mathbf{M e}]_{2}$ (solid line). Absorbances are normalized for each neutral unit.

A combined spectrum for the neutral, radical cation, and $\pi$-dimer species for linear model compound Me-Th $\mathbf{5}_{\mathbf{5}}$-Me is illustrated in Figure 4.31 (top). The $\pi$-stacked analog $s t$-[Me$\left.\mathbf{T h}_{\mathbf{5}}-\mathbf{M e}\right]_{2}$ is depicted in Figure 4.31 (bottom). 

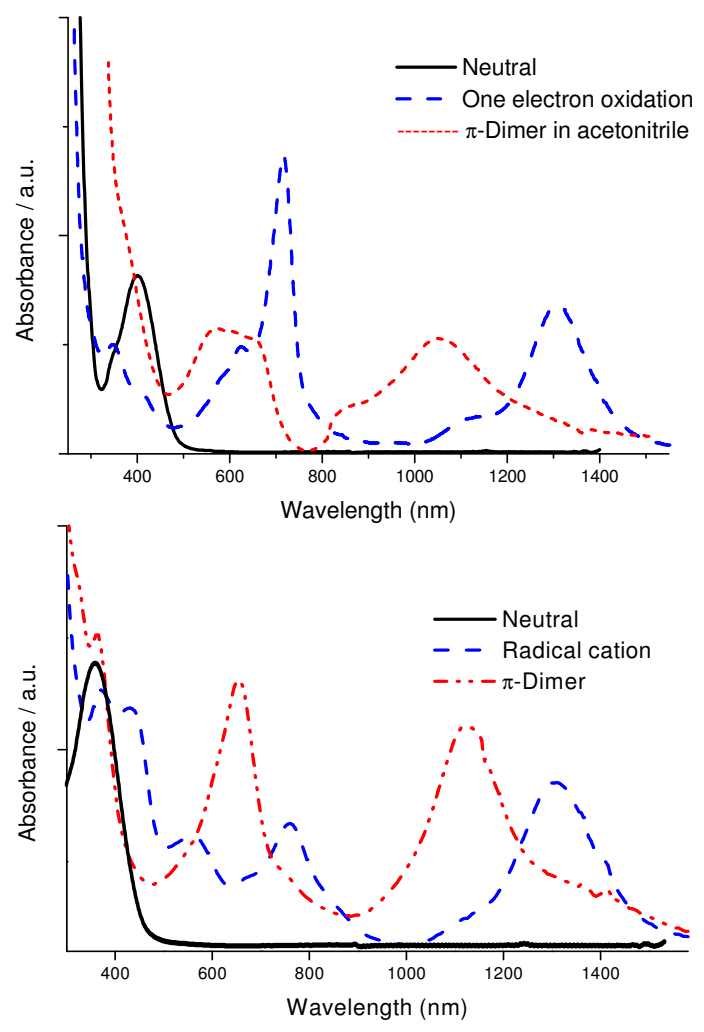

Figure 4.31. Absorbance spectra of neutral, radical dication, and $\pi$-dimer species of Me-Th5-Me (top). Absorbance spectra of neutral, radical dication, and $\pi$ dimer species of $\boldsymbol{s t}$-[Me-Th/5-Me $]_{\mathbf{2}}$ (bottom). Absorbances are normalized for each neutral unit.

The absorbances of the neutral, radical cation, dication, and $\pi$-dimers of the linear model ands $\pi$-analogs is shown in Table 4.3. The relative intensities of the bands are labeled as weak, medium, or strong. In summary, stacking two oligothiophenes together causes a blue shift in the absorbance relative to the unstacked oligomer. Oxidation to form a radical cation takes place at lower potential for the stacked compounds. Removal of a second electron from the stacked oligomer provides a dication which has characteristics of a $\pi$-dimer formed by aggregation of the two linear radical cations formed at low temperature. 
Table 4.3. UV- Vis-NIR Data for Charged Species

\begin{tabular}{|c|c|c|c|c|}
\hline Compound & Neutral & Radical Cation & $\pi$-Dimer & Dication \\
\hline Me-Th-Me & $345(3.59)$ & $\begin{array}{l}563 \mathrm{~s}(2.10) \\
884 \mathrm{~s}(1.40)\end{array}$ & $\begin{array}{c}{ }^{\mathrm{a}} 460(2.70) \\
725(1.71)\end{array}$ & \\
\hline$s t-\left[\mathrm{Me}-\mathrm{Th}_{3}-\mathrm{Me}\right]_{2}$ & $335(3.70)$ & $\begin{array}{c}362 \mathrm{~s}(3.42) \\
437 \mathrm{~m}(2.84) \\
591 \mathrm{~m}(2.10) \\
869 \mathrm{~s}(1.43)\end{array}$ & & $\begin{array}{r}506 \mathrm{~s}(2.45) \\
778 \mathrm{~s}(1.59) \\
970 \mathrm{w}(1.28)^{b}\end{array}$ \\
\hline Me-Th & $400(3.10)$ & $\begin{array}{c}731 \mathrm{~s}(1.69) \\
1322 \mathrm{~s}(0.94)\end{array}$ & $\begin{array}{l}{ }^{\mathrm{a}} 620 \mathrm{~s}(1.99) \\
1085 \mathrm{~s}(1.14)\end{array}$ & $\begin{array}{c}816 \mathrm{w}(1.52) \\
915 \mathrm{~s}(1.36) \\
\mathrm{a} 800 \mathrm{w}(1.55) \\
\mathrm{a} 890 \mathrm{~s}(1.39)\end{array}$ \\
\hline$s t-\left[\mathrm{Me}-\mathrm{Th}_{5}-\mathrm{Me}\right]_{2}$ & $386(3.21)$ & $\begin{array}{l}440 \mathrm{~s}(2.82) \\
560 \mathrm{w}(2.21) \\
760 \mathrm{~m}(1.63) \\
1307 \mathrm{~s}(0.95)\end{array}$ & & $\begin{array}{c}654 \mathrm{~s}(1.90) \\
1123 \mathrm{~s}(1.10)\end{array}$ \\
\hline
\end{tabular}

$\overline{\lambda_{\max }(\mathrm{eV}) . \text { Band intensity: strong, medium, weak }(\mathrm{s}, \mathrm{m}, \mathrm{w}) .{ }^{a} \text { Measured in acetonitrile. }{ }^{b} \text { Charge transfer peak. }}$

\subsubsection{ESR Spectroscopy: Formation of $\pi$-Dimers}

Addition of two equivalents of $\mathrm{FeCl}_{3}$ to $\mathbf{M e}-\mathrm{Th}_{5}-\mathrm{Me}\left(\mathrm{c}=2 \mathrm{mM}\right.$ in $\left.\mathrm{CH}_{2} \mathrm{Cl}_{2}\right)$ forms a mono(radical cation) at room temperature in $\mathrm{CH}_{2} \mathrm{Cl}_{2}$. A strong ESR spectrum corroborates formation of a spin-active species, Figure 4.32. However, upon cooling the solution down, $\pi$-dimer formation is favored especially in acetonitrile. The ESR signal diminishes upon cooling the solution of mono(radical cation), Figure 4.32. This process is reversible, the signal intensified back to the original spin-active spectrum upon warming the solution back to room temperature. Similar, behavior was illustrated with the $\pi$-stacked terthiophene compound, st-[Me-Th $\left.\mathbf{H}_{3}-\mathbf{M e}\right]_{2}$ (not shown). 
Subsequent oxidation with two more equivalents of $\mathrm{FeCl}_{3}$ does form the spinless dicationic species as confirmed by UV-vis-NIR absorbance and disappearance of the ESR signal. We ascribe this behavior to the formation of an intermolecular $\pi$ dimerization with formation of a spin-inactive species.

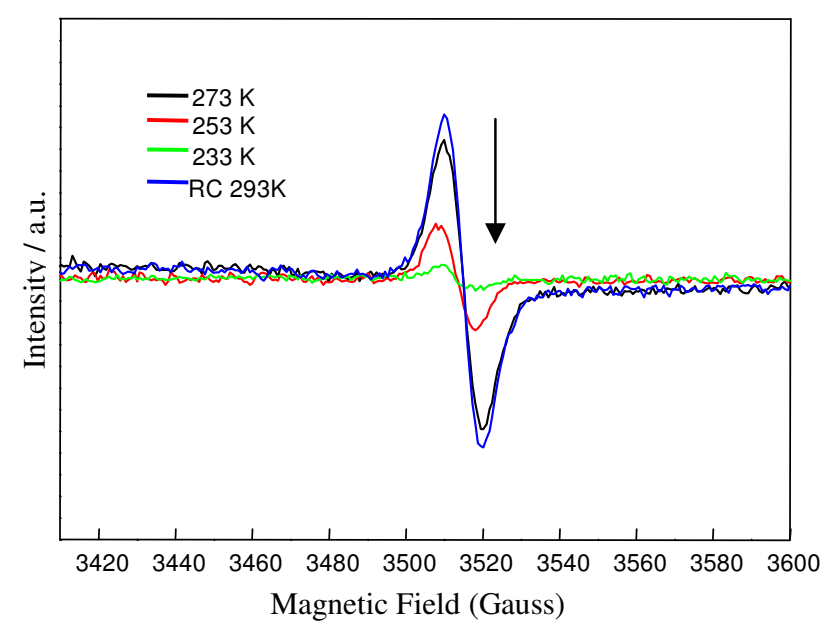

Figure 4.32. ESR spectra of Me-Th $\mathbf{H}_{5}$-Me radical cation formed upon addition of 2 equivalents of $\mathrm{FeCl}_{3}$ then cooling down gradually to form the $\pi$-dimer in acetonitrile.

Upon titration of $s t$-[Me-Th $\left.\mathbf{H}_{5}-\mathbf{M e}\right]_{2}$ with $\mathrm{FeCl}_{3}$, new absorbance bands exhibited in the UV-vis-NIR spectrum are characteristic of a radical cation. The ESR spectrum demonstrates the formation of a spin active mono(radical cation). The signal intensifies to a maximum upon addition of two equivalents of $\mathrm{FeCl}_{3}$, Figure 4.33 (black line). This signal then diminishes upon addition of more $\mathrm{FeCl}_{3}$ with the formation of a spinless dication which possesses the electronic characteristics of a $\pi$-dimer in the UV-vis-NIR spectra, Figure 4.33. The stacked dication $\pi$-dimer is stable at room temperature and low concentrations because the oligomers are held permanently by the undecane framework. 


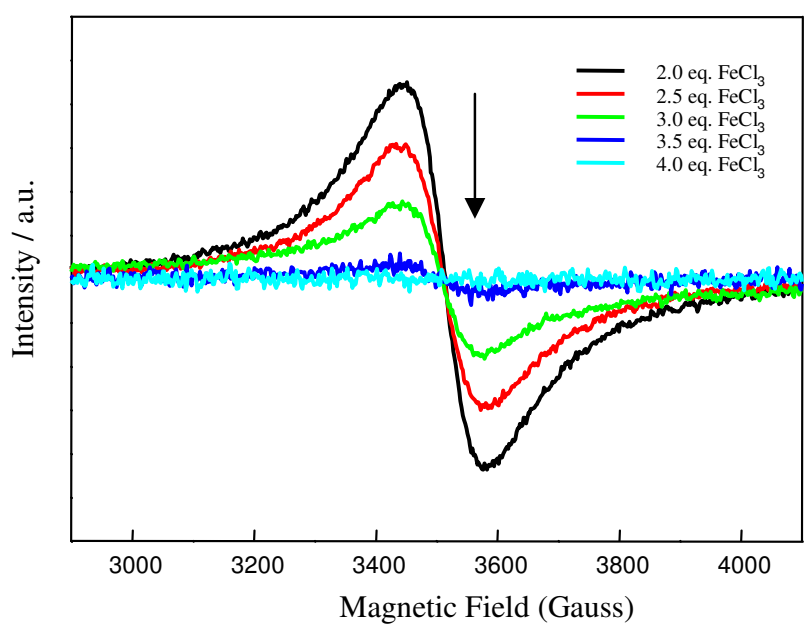

Figure 4.33. ESR spectra of $s t-\left[\mathbf{M e}-\mathbf{T h}_{\mathbf{5}}-\mathbf{M e}\right]_{2}$ radical cation formed upon addition of 2 equivalents of $\mathrm{FeCl}_{3}$ and continued titration up to 4 equivalents total) to form the dicationic $\pi$-dimer.

\subsubsection{Electronic Structure}

Energy diagrams for a linear oligomer in various oxidation states are provided in Figure 4.34 A. Upon oxidation of a linear oligomer, lattice distortion leads to the formation of two new levels in the band gap, labeled P1 and P2 (used from literature ${ }^{13}$ ) corresponding to the SOMO and LUMO levels. Thus, whereas the neutral oligomer has a single high energy optical transition, the radical cation has two absorptions corresponding to HOMO-SOMO (C1) transition and the SOMO-LUMO (C2) transition. Upon oxidation to the dication, the new HOMO and LUMO levels of the bipolaron give rise to a new transition $(\mathrm{C} 4)$. Another possibility for a one-chain radical cation is to associate in solution at low temperature, forming a two-chain aggregate characteristic of a $\pi$-dimer energy diagram, Figure 4.34 A. 


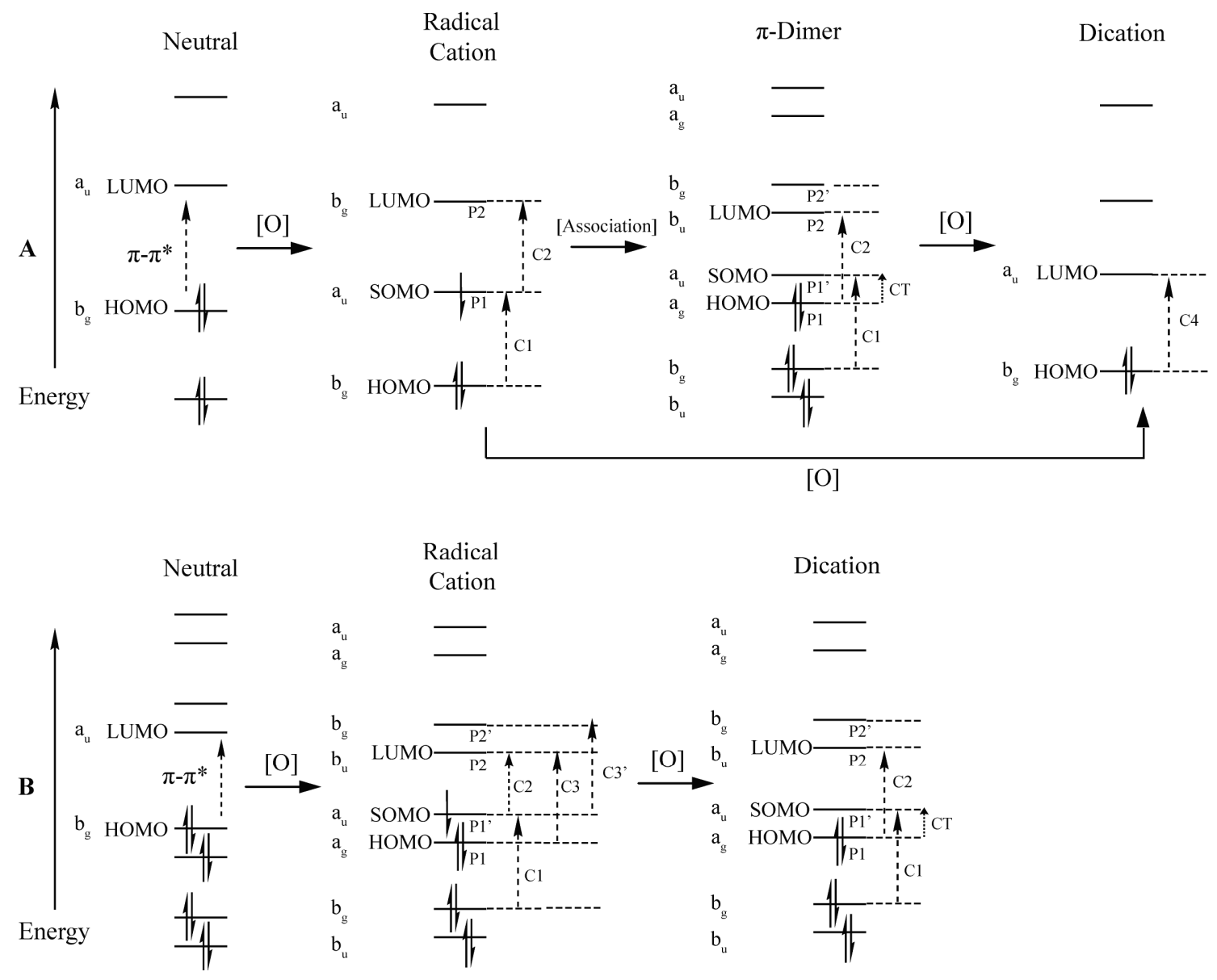

Figure 4.34. Schematic diagram of various redox states of a single chain (A) and two $\pi$-stacked oligomers (B).

The energy diagram for a two oligomers in a stacked arrangement (Figure 4.34 B) displays a splitting of all energy levels into symmetry orbital molecular pairs. For the $\pi$ $\pi^{*}$ transition in the stacked oligomers, the blue shift is attributed to the interaction between transition dipole moments from adjacent chains (known as Davydov $\mathrm{Shift}^{14}$ ). Since the transition dipoles are next to one another, for an intramolecular transition of a two-chain oligomer, the interaction is repulsive. Therefore, the energy required to excite one molecule is blue shifted to higher energy. 
In the case of a single radical cation on two chains, the $\mathrm{C} 1$ transition is allowed from the HOMO to SOMO (P1') but the $\mathrm{C} 2$ transition is now symmetry-forbidden. ${ }^{13}$ Two new transitions $\mathrm{C} 3$ and $\mathrm{C}^{\prime}$ are possible and can form constructive coupling or destructive interference. If the amplitudes of transition dipoles have the same sign (either both positive or both negative), they will add together to form a wave with a larger amplitude, i.e. constructive coupling. If the two amplitudes have opposite signs, they will subtract to form a combined wave with lower amplitude, i.e. destructive interference. Two new $B_{u}$ excited states result from this configuration mixing in a singly charged dimer and can be observed spectroscopically. Upon removal of the second electron, there are three transitions HOMO-LUMO (C1), HOMO-LUMO+1 (C2), and a charge transfer band (P1), Figure 4.31B.

Optical Transitions in Context of Electronic Structure. $\mathrm{FeCl}_{3}$-oxidation of model terthiophene $\mathbf{M e -} \mathbf{T h}_{3}$-Me forms the radical cation species at room temperature with values of $563 \mathrm{~nm}$ and $884 \mathrm{~nm}$. The peak at $563(2.10 \mathrm{eV})$ is due to the C2 transition (P1$\mathrm{P} 2)$ and the lower energy peak at $884(1.40 \mathrm{eV})$ is HOMO-SOMO (C1) excitation. The shoulders at $460 \mathrm{~nm}$ and $725 \mathrm{~nm}$ are consistent with $\pi$-dimer formation which becomes more predominate at high concentrations and low temperature in acetonitrile (and can be assigned to the $\mathrm{C} 3$ and $\mathrm{C} 1$ transitions, respectively. ESR measurements confirm this $\pi$ dimerization at lower temperature with diminishing of the intensity of the signal by $80 \%$. This signal gave back to the original intensity upon warming.

$s t-\left[\mathrm{Me}-\mathbf{T h}_{3}-\mathbf{M e}\right]_{2}$ readily forms the radical cation species with two equivalents of $\mathrm{FeCl}_{3}$. The peak of the radical cation at $362 \mathrm{~nm}(3.42 \mathrm{eV})$ is assigned to the $\pi-\pi^{*}$ transition of a neutral chain being influenced by a radical cation $\pi$-stacked aggregate (C3- 
C3'). The next two peaks at $437 \mathrm{~nm}(2.72 \mathrm{eV})$ and $591 \mathrm{~nm}(2.01 \mathrm{eV})$ are may be due to configuration mixing between electronic states i.e. deconstructive coupling (C3'-C3). There is a larger splitting for this mixed-transition compared to the AM1/FCI calculations performed. ${ }^{13}$ The transition at $869 \mathrm{~nm}(1.43 \mathrm{eV})$ for $s t-\left[\mathbf{M e}-\mathbf{T h}_{3}-\mathbf{M e}\right]_{2}$ is a C1 transition between HOMO-SOMO levels. There are similar $\mathrm{C} 1$ transitions in the $\pi$ stacked compound $s t$-[Me-Th $3-\mathbf{M e}]_{2}$ compared to that of the model terthiophene compound Me-Th $\mathbf{H}_{3}$-Me between respective radical cation peaks (884 $\mathrm{nm}$ to $869 \mathrm{~nm}$ ). The weaker lattice relaxation in the two-chain aggregate polaronic levels, which normally causes a red-shift of the absorption band, is negligible here.

Upon removal of the second electron from $\pi$-stacked compound $s t$-[Me-Th $\left.\mathbf{H}_{3}-\mathbf{M e}\right]_{2}$ new peaks arise at 506, 778, and $970 \mathrm{~nm}$. These are characteristic of $\pi$-dimers in which the electronic structure is a consequence of a combination of the two stacked oligomers, rather than dication-neutral or bis(radical cation) redox states. The $970 \mathrm{~nm}$ peak is a low energy intrachain charge transfer (CT) peak P1-P1'. The higher energy $506 \mathrm{~nm}(2.45 \mathrm{eV})$ peak is a strong optical excitation due to the two chains held together cofacially as a P1P2 transition (C2). The lower energy peak at $778 \mathrm{~nm}(1.59 \mathrm{eV})$ is a HOMO-SOMO' (C1) transition.

As for the terthiophene, one-electron oxidation of the model quinquethiophene Me-Th 5 -Me produces two new energy transitions. The first peak at $716 \mathrm{~nm}(1.73 \mathrm{eV})$ is the $\mathrm{C} 2$ (P1-P2) transition for a single chain radical cation. The lower energy peak at $1322 \mathrm{~nm}(0.94 \mathrm{eV})$ is the $\mathrm{C} 1$ transition between HOMO-SOMO levels. At room temperature this compound more readily forms a $\pi$-dimer in acetonitrile when the corresponding model terthiophene. The shoulder observed at $640 \mathrm{~nm}$ is now 
predominant at $620 \mathrm{~nm}(1.99 \mathrm{eV})$ and is assigned to the $\mathrm{C} 2$ transition of the intermolecular $\pi$-dimer. The low energy peak at $1085 \mathrm{~nm}(1.14 \mathrm{eV})$ is the HOMOSOMO (C1) transition. Further oxidation of the radical cation in $\mathrm{CH}_{2} \mathrm{Cl}_{2}$ produces a new intense band at $915 \mathrm{~nm}(1.36 \mathrm{eV})$ while the radical cation bands are diminished. The two isosbectic points illustrate the change from neutral, radical cation, and dication species. The new band at $915 \mathrm{~nm}(1.36 \mathrm{eV})$ is assigned to the $\mathrm{C} 4$ transition for a dication.

The $\pi-\pi^{*}$ peak at $386 \mathrm{~nm}(3.21 \mathrm{eV})$ for neutral $\pi$-stacked compound $\boldsymbol{s t}$-[Me-Th $\mathbf{5}_{\mathbf{5}}$ $\mathrm{Me}_{2}$ is red shifted to $440 \mathrm{~nm}(2.82 \mathrm{eV})$ and is weakened in intensity upon one electron oxidation. Two new peaks at higher energies $560 \mathrm{~nm}(2.21 \mathrm{eV})$ and $760 \mathrm{~nm}(1.63 \mathrm{eV})$ become apparent. The low energy peak at $1307 \mathrm{~nm}(0.95 \mathrm{eV})$ is assigned to the HOMOSOMO transition (C1) of the mono(radical cation). Upon removal of the second electron, new peaks appear at $654 \mathrm{~nm}(1.90 \mathrm{eV})$ and $1123 \mathrm{~nm}(1.10 \mathrm{eV})$ and are assigned to interoligomer $\pi$-dimer, with a concomitant disappearance the radical cation bands. The higher energy band is assigned to a $\mathrm{C} 3$ transition and $\mathrm{C} 1$ transition for the lower energy band. The $\pi$-dimer bands are red shifted compared to those of the model quinquethiophene, Me-Th5-Me, due to larger $\pi$-stacking interactions in the inherent structure of $\boldsymbol{s t}$-[Me-Th $\mathbf{S}_{\mathbf{5}}$ Me $]_{2}$. Note that the charge transfer band observed for the stacked terthiophene is not observed for the corresponding quinquethiophene due to better delocalization in the longer oligomer.

Combination of data from electrochemistry and electronic spectrea of neutral compounds, Table 4.4, allows us to determine the energy of the HOMOs and LUMOs of the linear models and stacked oligothiophenes, which are illustrated in Figure 4.35. 
Table 4.4. Cyclic Voltammetry and UV-vis Absorption Data

\begin{tabular}{|c|c|c|c|c|c|}
\hline Compound & $\mathrm{E}_{\mathrm{p}}(\mathrm{V})$ & $\begin{array}{l}E^{\text {ox }} \text { onset } \\
(V)^{\mathrm{b}}\end{array}$ & $\begin{array}{c}\lambda_{\text {onset }}(\mathrm{nm})^{\mathrm{c}} \\
(\mathrm{eV})\end{array}$ & $\begin{array}{l}\text { HOMO } \\
(\mathrm{eV})^{\mathrm{d}}\end{array}$ & $\begin{array}{l}\text { LUMO } \\
(\mathrm{eV})^{\mathrm{e}}\end{array}$ \\
\hline$s t-\left[\mathrm{MeTh}_{5}-\mathrm{Me}\right]_{2}$ & $+0.67,+0.73,+1.22^{\mathrm{a}}$ & +0.50 & $\begin{array}{l}486 \\
2.55\end{array}$ & -4.94 & -2.39 \\
\hline Me-Th $-\mathrm{Me}$ & $+0.79,+1.02$ & +0.65 & $\begin{array}{l}500 \\
2.48\end{array}$ & -5.09 & -2.61 \\
\hline$s t-\left[\mathrm{Me}-\mathrm{Th}_{3}-\mathrm{Me}\right]_{2}$ & $+0.70,+0.90,+1.49^{\mathrm{a}}$ & +0.60 & $\begin{array}{l}395 \\
3.14\end{array}$ & -5.04 & -1.90 \\
\hline Me-Th - -Me & $+0.96,+1.23$ & +0.80 & $\begin{array}{l}405 \\
3.06\end{array}$ & -5.24 & -2.18 \\
\hline
\end{tabular}

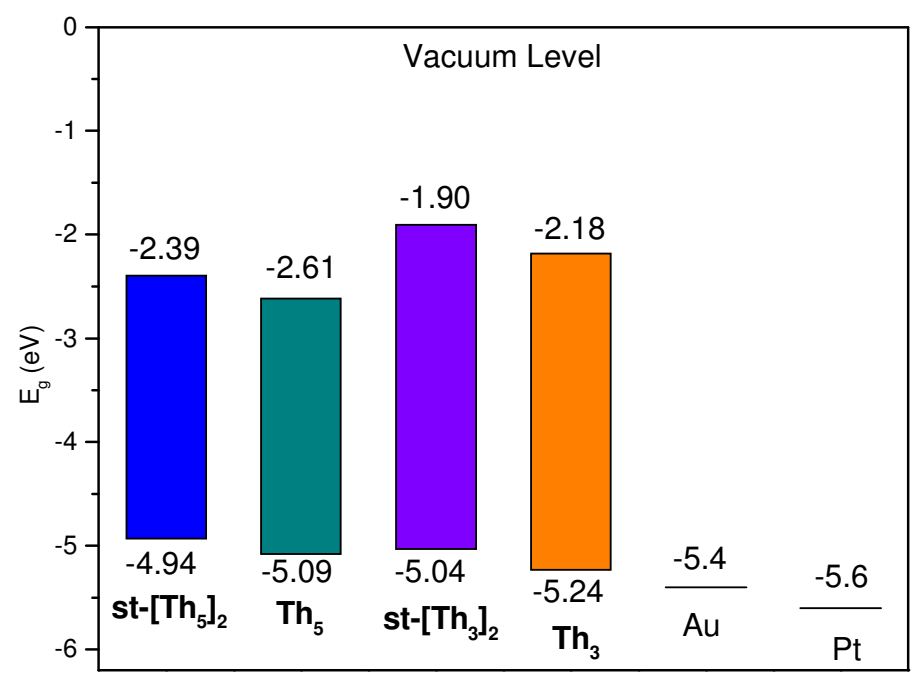

Figure 4.35. HOMO-LUMO energy levels determined by cyclic voltammetry and UV absorption. 
The HOMO energy levels of the $\pi$-stacked compounds are lowered compared to that of the linear model oligomers due to $\pi$-orbital overlap. The extrapolated LUMO levels of the stacked compounds are also lower in energy. As the conjugation length increases, the absolute values of the HOMO levels are lowered and the HOMO-LUMO gap diminishes, in model and $\pi$-stacked compound alike.

\subsection{Conclusion}

Arene-fused bicyclo[4.4.1] undecanes provide a versatile scaffold to explore the effects of $\pi$-stacking on the electronic structure of a variety of conjugated oligomers to provide models for conjugated polymers. Examination of the $\pi$-stacked oligomers and their linear (i.e., unstacked) models by spectroscopy and voltammetry establishes the stabilization of mono- and bis(radical cation)s by interaction of the conjugated oligomeric subunits. The fact that the two le- oxidations of the $\pi$-stacked analogue take place at lower potentials than the le- oxidation of the linear analogue suggests that both the mono(radical cation) and dication are stabilized by the $\pi$-stacking interaction. In particular, lowering of the second 1e- oxidation potential to form the dication suggests that the stacked dication is stabilized in such a way that it overcomes the destabilization that might be expected to arise from Coulombic repulsion.

The linear terthiophene and quinquethiophene undergo a second oxidation to form corresponding dications; the $\pi$-stacked analogues also undergo subsequent oxidation to form tetracations. This latter process takes place without splitting of voltammetric waves and at higher potential than for the linear analogues, which again may be ascribed to 
stabilization of the stacked dication and to destabilization of the tetracation through Coulombic repulsion.

The electronic structure of the stacked dication and origin of this stabilization become apparent from UV-vis-near-IR and ESR spectroscopies. Oxidation of linear model oligomers affords the corresponding radical cation that gives rise to absorptions at low temperatures that are characteristic of the radical cation $\pi$-dimers. The electron oxidation of the stacked analogs provides direct access to a dication with the electronic structure of a $\pi$-dimer. The accessibility and stability of both the mono- and dicationic states of the stacked analogues arise from the stabilizing influence of interchain interactions between conjugated radical cations. Splitting of the first two oxidations of the stacked oligomers gets progressively smaller as the conjugation length increases, consistent with the formation of a spinless charge carrier delocalized over a number of chains in a p-doped polymer film. The stacked mono(radical cation)s and dications serve as better models for polarons and bipolarons, respectively, than linear unstacked oligomers.

\subsection{References}

1. Bredas, J. L.; Street, G. B., "Polarons, bipolarons, and solitons in conducting polymers," Acc. Chem. Res. 1985, 18, 309-315.

2. Cornil, J.; Beljonne, D.; Bredas, J. L., "Nature of optical transitions in conjugated oligomers. II. Theoretical characterization of neutral and doped oligothiophenes," J. Chem. Phys. 1995, 103, 842-849.

3. Beljonne, D.; Cornil, J.; Bredas, J. L.; Friend, R. H., "Theoretical investigation of the lowest singlet and triplet excited states in oligo(phenylene vinylene)s and oligothiophenes," Synth. Met. 1996, 76, 61-65. 
4. Beljonne, D.; Cornil, J.; Friend, R. H.; Janssen, R. A. J.; Bredas, J. L., "Influence of Chain Length and Derivatization on the Lowest Singlet and Triplet States and Intersystem Crossing in Oligothiophenes," J. Am. Chem. Soc. 1996, 118, 64536461.

5. Kaufman, J. H.; Colaneri, N. S., J.C.; Street, G. B., "Evolution of polaron states into bipolarons in polypyrrole," Phys. Rev. Lett. 1984, 53, 1005-1008.

6. Apperloo, J. J.; Janssen, R. A. J.; Malenfant, P. R. L.; Frechet, J. M. J., "Interchain Delocalization of Photoinduced Neutral and Charged States in Nanoaggregates of Lengthy Oligothiophenes," J. Am. Chem. Soc. 2001, 123, 6916-6924.

7. Shimoi, Y.; Abe, S.; Hafigaya, K., Mol. Cryst. Liq. Cryst. 1995, 267, 329.

8. Bartholomew, G. P.; Bazan, G. C., "Bichromophoric Paracyclophanes: Models for Interchromophore Delocalization," Acc. Chem. Res. 2001, 34, 30-39.

9. Pope, M.; Swenberg, C. E., Electronic Processes in Organic Crystals Clarendon Press: Oxford, 1982.

10. Miller, L. L.; Mann, K. R., "p-Dimers and p-Stacks in Solution and in Conducting Polymers," Acc. Chem. Res. 1996, 29, 417-423.

11. Hill, M. G.; Penneau, J. F.; Zinger, B.; Mann, K. R.; Miller, L. L., "Oligothiophene cation radicals. p-Dimers as alternatives to bipolarons in oxidized polythiophenes," Chem. Mater. 1992, 4, 1106-13.

12. Miller, L. L.; Yu, Y., "Synthesis of b-Methoxy, Methyl-Capped aOligothiophenes," J. Org. Chem. 1995, 60, 6813-6819.

13. Beljonne, D.; Cornil, J.; Sirringhaus, H.; Brown, P. J.; Shkunov, M.; Friend, R. H.; Bredas, J.-L., "Optical signature of delocalized polarons in conjugated polymers," Advanced Functional Materials 2001, 11, 229-234.

14. Torrance, J. B.; Scott, B. A.; Welber, B.; Kaufman, F. B.; Seiden, P. E., "Optical properties of the radical cation tetrathiafulvalenium $\left(\mathrm{TTF}^{+}\right)$in its mixed-valence and monovalence halide salts," Phys. Rev. B: Condens. Matter 1979, 19, 730-741. 
15. de Leeuw, D. M.; Simenon, M. M. J.; Brown, A. R.; Einerhand, R. E. F., "Stability of n-type doped conducting polymers and consequences for polymeric microelectronic devices," Synth. Met. 1997, 87, 53-59. 


\section{CHAPTER 5}

\section{PHENYL-CAPPED OLIGOTHIOPHENES:}

\section{SYNTHESIS, STRUCTURAL CHARACTERIZATION, AND PHOTOPHYSICAL/ELECTROCHEMICAL PROPERTIES}

\subsection{Introduction}

Polythiophene and its countless derivatives have continued to attract considerable interest over the past twenty years for potential applications in electronic and opticalelectronic devices. On the basis of such potentially promising aspects of organic semiconducting materials, further development of new high-performance organic materials will increasingly be desired in the near future. Following a simple guiding principle of molecular design, extension of the $\pi$-conjugation in the backbone and substituents can be used to tune a material's properties. While there is great interest in use of oligothiophenes in optical and electronic materials, chemical stability remains a concern because of the reactivity of terminal $\alpha$-positions of the rings. Placing chemically stable substituents at these positions may serve to increase the stability of $\pi$-conjugated materials. Phenyl-capped oligothiophenes ${ }^{1}$ can be synthesized where both ends of a particular thiophene oligomer have well-defined molecular size and a higher chemical stability. 
Studies with linear phenyl-capped oligothiophenes ${ }^{2-5}$ offer insights into the optical and electrochemical properties of conjugated materials. Theoretical investigations of phenyl-substituted EDOT materials ${ }^{6}$ offer explanations to the molecular packing of such materials in the solid state which can be used as a tool to develop new functional materials. Molecular dynamics have been investigated to show the planarity of charge species, ${ }^{7}$ and phenyl groups were shown to contribute to the stabilization of the charged defects by Raman spectroelectrochemical measurements. ${ }^{8}$ This body of literature provides us with knowledge of linear $\pi$-conjugated materials in solution and solid state with little emphasis on the aggregation of oxidized oligomers. Hence, we set out to explore the effects of $\pi$-dimerization of two cofacially held phenyl-capped oligothiophenes.

Although phenyl-capped oligothiophenes are less electron rich than corresponding oligothiophenes, they may serve as suitable models to examine charge migration in new $\pi$-stacked compounds and as potential new organic semiconductors. We can correlate the findings regarding the phenyl-capped compounds to the thiophene analogs and thereby provide greater understanding for the trends in $\pi$-stacked oligomers as it relates to semiconducting materials.

\subsection{Experimental}

\subsubsection{General Procedures}

All reagents and catalysts were purchased from Aldrich, TCI, or Strem Chemicals and used without further purification. NBS was recrystallized from $\mathrm{H}_{2} \mathrm{O}$. THF and diethyl ether were distilled from benzophenone-sodium ketyl. Dichloromethane was distilled 
from calcium hydride and anhydrous DMF was purchased from Aldrich. ${ }^{1} \mathrm{H}$ and ${ }^{13} \mathrm{C}$ NMR spectra were recorded from a 300 or $400 \mathrm{MHz}$ Varian Mercury spectrophotometer. Infrared spectra were recorded on a Nicolet 4700 FTIR. Mass spectra were collected on a VG-70SE instrument. Elemental analyses were obtained from Atlantic Microlabs, Inc. Gravity and flash column chromatographies were carried out with silica gel (32-63 mesh, 60 Å from Sorbent Technologies).

Absorbance and fluorescence measurements were measure on Shimadzu 2401PC UV-vis recording spectrophotometer and RF5301PC spectrofluorophotometer, and a Perkin Elmer Lambda 19 spectrophotometer for doping experiments in the near IR region. Specially designed four sided quartz cuvettes fitted with a 14/20 female joint sealed with a rubber septum were used in order to titrate stock solutions of $\mathrm{FeCl}_{3} / \mathrm{CH}_{2} \mathrm{Cl}_{2}$ via syringe into know concentrations of analyte. Typical titration were performed every 0.25 eq. analyte, which was anywhere between $20 \mu \mathrm{L}-200 \mu \mathrm{L} . \mathrm{FeCl}_{3}$ was dried at $100{ }^{\circ} \mathrm{C}$ under vacuum for 4 prior to dilution in $\mathrm{CH}_{2} \mathrm{Cl}_{2}(1-2 \mathrm{mM}) . \mathrm{CH}_{2} \mathrm{Cl}_{2}$ was distilled from $\mathrm{CaH}_{2}$ onto molecular sieves prior to use.

Electrochemical measurements were carried out under nitrogen and recorded on a BAS 100B Electrochemical Analyzer with a three electrode cell equipped with a $2 \mathrm{~mm}$ gold working electrode, a platinum counter electrode, and a $\mathrm{Ag} / \mathrm{Ag}^{+}$reference electrode with $3 \mathrm{M} \mathrm{NaCl}$ solution end capped with a vycor tip. Substrates $(0.5-2 \mathrm{mM})$ were dissolved in $\mathrm{CH}_{2} \mathrm{Cl}_{2}$ containing $0.1 \mathrm{M} n-\mathrm{Bu}_{4} \mathrm{NPF}_{6}$ or $\left[n-\mathrm{Bu}_{4} \mathrm{~N}\right]\left[\mathrm{B}\left(\mathrm{C}_{6} \mathrm{~F}_{5}\right)_{4}\right]$. The ferrocene/ferrocenium couple appears at $0.45 \mathrm{~V} / 0.47 \mathrm{~V}$ in these electrolyte solutions, respectively. Bulk electrolysis was performed in a specially designed cell enclosing a 
carbon mesh wire as the working electrode. The auxiliary electrode was enclosed in a fritted tube to prevent decomposition of material over typically extended run times.

ESR measurements were recorded on a Bruker EMX EPR with nitrogen temperature controller 4131VT accessory. ESR tubes were purchased from Wilmad. Typical analyte concentrations were $10^{-3}$ to $10^{-4} \mathrm{M}$ and a stock solution of $\mathrm{FeCl}_{3} / \mathrm{CH}_{2} \mathrm{Cl}_{2}$ was titrated into the tube and measured. Typical power was $0.6 \mathrm{~mW}-1 \mathrm{~mW}$ and center fields were 3480-3120 Gauss for $9.849 \mathrm{GHz}$. The modulation phase was set to 260 degrees in all experiments.

\subsubsection{Synthetic Procedures}

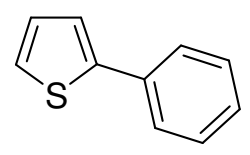

2-Phenylthiophene. A $2.5 \mathrm{M}$ solution of $n$-BuLi in hexanes $(100 \mathrm{~mL}, 0.25 \mathrm{~mol})$ was added dropwise to a solution of thiophene $(0.25 \mathrm{~mol})$ in THF $(200 \mathrm{~mL})$ at $-40{ }^{\circ} \mathrm{C}$. The mixture was stirred for $1 \mathrm{~h}$ at $-30{ }^{\circ} \mathrm{C}$, then cooled at $-40{ }^{\circ} \mathrm{C}$, and a solution of fluorobenzene $(0.125 \mathrm{~mol})$ in THF $(100 \mathrm{~mL})$ was added dropwise over $20 \mathrm{~min}$. The resulting mixture was warmed to room temperature for $30 \mathrm{~min}$ and heated to $60{ }^{\circ} \mathrm{C}$ for 18 h. The reaction mixture was allowed to cool to room temperature and $\mathrm{H}_{2} \mathrm{O}(100 \mathrm{~mL})$ was added. The organic layer was separated, and the aqueous layer was extracted with $\mathrm{Et}_{2} \mathrm{O}(2$ x $100 \mathrm{~mL})$. The organic layers were combined and washed with $\mathrm{H}_{2} \mathrm{O}(2 \times 100 \mathrm{~mL})$, dried over $\mathrm{MgSO}_{4}$, and the solvent was removed under reduced pressure. The residue was purified by flash chromatography on silica gel (100\% hexanes) followed by recrystallization from $\mathrm{MeOH}$ to afford 2-phenylthiophene as a colorless solid, (10.8 $\mathrm{g}$, 
54\%). MP $=36-37^{\circ} \mathrm{C} . \quad{ }^{1} \mathrm{H}$ NMR $\left(300 \mathrm{MHz}, \mathrm{CDCl}_{3}\right): \delta$ 7.70-7.75 (m, 2H, Ph), 7.44-7.75

(m, 2H, Ph), 7.40 (dd, 1H, $J=1,3 \mathrm{~Hz}, \mathrm{Th}-3), 7.34-7.38$ (m, 2H, Ph, Th), 7.16 (dd, 1H, $J$ $=5,3 \mathrm{~Hz}, \mathrm{Th}-4) .{ }^{13} \mathrm{C}$ NMR $\left(75 \mathrm{MHz}, \mathrm{CDCl}_{3}\right): \delta 144.3,134.3,128.8,128.0,127.4,125.9$, 124.7, 123.0. IR (KBr) 3147, 3070, 3036, 1596, 1523, $1486 \mathrm{~cm}^{-1}$. MS (EI): $\mathrm{m} / z(\%)$ $160.1\left(\mathrm{M}^{+}, 100\right)$. HRMS (EI): $\mathrm{m} / z$ Calcd. for $\mathrm{C}_{10} \mathrm{H}_{8} \mathrm{~S}, 160.03367$; found, 160.03467, $\Delta=$ $6.2 \mathrm{ppm}$.

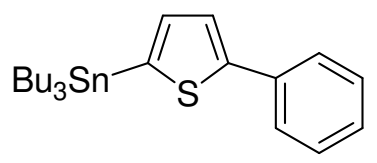

2-Phenyl-5-tri-n-butylstannylthiophene. A solution of $2.5 \mathrm{M} \mathrm{n}$-BuLi in hexanes (75 $\mathrm{mmol}, 30 \mathrm{~mL})$ was added dropwise to solution of 2-phenylthiophene $(11 \mathrm{~g}, 67 \mathrm{mmol})$ in dry $\mathrm{Et}_{2} \mathrm{O}(100 \mathrm{~mL})$ at $0{ }^{\circ} \mathrm{C}$, and the mixture was stirred for $1.5 \mathrm{~h}$. A solution of tri- $n$ butyltin chloride $(24 \mathrm{~g}, 74 \mathrm{mmol})$ in $\operatorname{dry~}_{2} \mathrm{O}(20 \mathrm{~mL})$ was added dropwise over $20 \mathrm{~min}$, and the mixture was stirred for $18 \mathrm{~h}$. A saturated aq. solution of $\mathrm{NaHCO}_{3}(50 \mathrm{~mL})$ was added and stirred for $30 \mathrm{~min}$. The aqueous layer was separated, extracted with $\mathrm{Et}_{2} \mathrm{O}(2 \mathrm{x}$ $50 \mathrm{~mL}$ ), and the combined organic layers were washed with a saturated aq. solution of $\mathrm{NaHCO}_{3}(50 \mathrm{~mL})$ and dried over $\mathrm{MgSO}_{4}$. The solvent was removed under reduce pressure to afford 2-phenyl-5-(tri- $n$-butylstannyl)thiophene as a dark orange oil that was used without further purification (24 g, 80\%). ${ }^{1} \mathrm{H}$ NMR (300 MHz, $\left.\mathrm{CDCl}_{3}\right): \delta 7.61-7.65$ $(\mathrm{m}, 2 \mathrm{H}, J=1.3 \mathrm{~Hz}, 7.1 \mathrm{~Hz}, \mathrm{Ph}), 7.43(\mathrm{~d}, 1 \mathrm{H}, J=3.3 \mathrm{~Hz}, \mathrm{Th}-4), 7.32-7.38(\mathrm{~m}, 2 \mathrm{H}, J=1.3$ $\mathrm{Hz}, 7.7 \mathrm{~Hz}, \mathrm{Ph}), 7.20-7.26$ (m, 1H, $J=7.3 \mathrm{~Hz}, 1.3 \mathrm{~Hz}, \mathrm{Ph}), 7.15$ (d, 1H, $J=3.3 \mathrm{~Hz}, \mathrm{Th}-3)$, 1.54-1.66 (m, 6H, - $\mathrm{CH}_{2} \mathrm{CH}_{2} \mathrm{CH}_{2} \mathrm{CH}_{3}$ ), 1.25-1.41 (m, 6H, - $\mathrm{CH}_{2} \mathrm{CH}_{2} \mathrm{CH}_{2} \mathrm{CH}_{3}$ ), 1.12-1.18 
$\left(\mathrm{m}, 6 \mathrm{H},-\mathrm{CH}_{2} \mathrm{CH}_{2} \mathrm{CH}_{2} \mathrm{CH}_{3}\right), 0.88-0.95\left(\mathrm{~m}, 9 \mathrm{H},-\mathrm{CH}_{2} \mathrm{CH}_{2} \mathrm{CH}_{2} \mathrm{CH}_{3}\right) .{ }^{13} \mathrm{C} \mathrm{NMR}(75 \mathrm{MHz}$, $\left.\mathrm{CDCl}_{3}\right): \delta 145.0,136.7,136.4,134.6,128.8,127.0,125.9,124.2$ (aromatic), 29.0 ($\left.\mathrm{CH}_{2} \mathrm{CH}_{2} \mathrm{CH}_{2} \mathrm{CH}_{3}\right), \quad 27.3 \quad\left(-\mathrm{CH}_{2} \mathrm{CH}_{2} \mathrm{CH}_{2} \mathrm{CH}_{3}\right), \quad 13.7 \quad\left(-\mathrm{CH}_{2} \mathrm{CH}_{2} \mathrm{CH}_{2} \mathrm{CH}_{3}\right), \quad 10.8 \quad$ ($\mathrm{CH}_{2} \mathrm{CH}_{2} \mathrm{CH}_{2} \mathrm{CH}_{3}$ ). IR (KBr) 2953, 2922, 2870, 2852, 1517, 1461, 1413, 1370, 1070, 948, 865, 796, $687 \mathrm{~cm}^{-1}$. MS (EI), $m / z(\%)=450.1\left(\mathrm{M}^{+}, 100\right)$. HRMS (EI): $\mathrm{m} / z$ Calcd. for $\mathrm{C}_{22} \mathrm{H}_{34} \mathrm{SnS}$, 450.14032; found, 450.13702, $\Delta=7.3 \mathrm{ppm}$

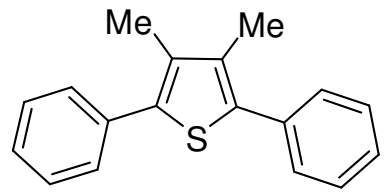

2,5-Diphenyl-3,4-dimethylthiophene. Tri-n-butylphenyltin $(5.8 \mathrm{~g}, 16 \mathrm{mmol})$ was added to a solution of 2,5-dibromo-3,4-dimethylthiophene (1.74 g, $6.5 \mathrm{mmol}), \mathrm{Pd}\left(\mathrm{PPh}_{3}\right)_{4}(750 \mathrm{mg}$, $0.65 \mathrm{mmol})$, and $\mathrm{LiCl}(840 \mathrm{mg}, 20 \mathrm{mmol})$ in dry DMF $(30 \mathrm{~mL})$, and the mixture was heated to $70{ }^{\circ} \mathrm{C}$ for $18 \mathrm{~h}$. The mixture was cooled to room temperature, and a saturated aq. solution of KF (10 mL) was added, and the mixture was stirred for $1 \mathrm{~h}$. The aqueous layer was discarded and the organic layer was eluted though celite and silica with $\mathrm{Et}_{2} \mathrm{O}$ $(150 \mathrm{~mL})$. The solvent was removed under reduced pressure and the residue was subjected to column chromatography (100\% hexanes) followed by recrystallization from methanol to afford 2,5-diphenyl-3,4-dimethylthiophene as a white solid (1.20 g, 70\%). $\mathrm{MP}=162-164{ }^{\circ} \mathrm{C} . \quad{ }^{1} \mathrm{H} \mathrm{NMR}\left(300 \mathrm{MHz}, \mathrm{CDCl}_{3}\right): \delta$ 7.47-7.51 (m, 4H, ortho $\left.\mathrm{Ph}\right), 7.39-$ $7.46(\mathrm{~m}, 4 \mathrm{H}$, meta $\mathrm{Ph}), 7.28-7.36(\mathrm{~m}, 2 \mathrm{H}$, para $\mathrm{Ph}), 2.25\left(\mathrm{~s}, 6 \mathrm{H},-\mathrm{CH}_{3}\right) .{ }^{13} \mathrm{C} \mathrm{NMR}(75$ $\left.\mathrm{MHz}, \mathrm{CDCl}_{3}\right): \delta 136.7,134.9,134.1,129.3,128.4,127.2$ (aromatic), $14.1\left(-\mathrm{CH}_{3}\right) . \quad$ IR (KBr) 3152, 3061, 3022, 2978, 2917, 1383, 1096, 904, $739 \mathrm{~cm}^{-1}$. MS (EI): $\mathrm{m} / z(\%) 264.1$ $\left(\mathrm{M}^{+}, 100\right)$. HRMS (EI): $\mathrm{m} / z$ Calcd. for $\mathrm{C}_{18} \mathrm{H}_{16} \mathrm{~S}, 264.09727$; found, 264.09694, $\Delta=1.2$ 
ppm. Anal. calcd. for $\mathrm{C}_{18} \mathrm{H}_{16} \mathrm{~S}: \mathrm{C}, 81.77 ; \mathrm{H}, 6.10 ; \mathrm{S}, 12.13$. Found: $\mathrm{C}, 81.70 ; \mathrm{H}, 6.27 ; \mathrm{S}$, 12.10 .

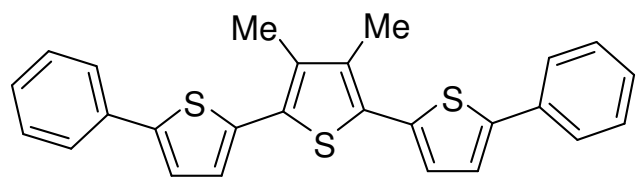

2,5"-Diphenyl-3',4'-dimethyl-5,2':5',2"-terthiophene. 2-Phenyl-5-tri- $n$-butylstannylthiophene (5.8 $\mathrm{g}, 16 \mathrm{mmol})$ was added to a solution of 2,5-dibromo-3,4dimethylthiophene (1.70 g, $6.5 \mathrm{mmol}), \mathrm{Pd}\left(\mathrm{PPh}_{3}\right)_{4}(750 \mathrm{mg}, 0.65 \mathrm{mmol})$, and $\mathrm{LiCl}(840$ $\mathrm{mg}, 20 \mathrm{mmol})$ in dry DMF (30 mL), and the mixture was heated at $60{ }^{\circ} \mathrm{C}$ for $18 \mathrm{~h}$. The mixture was cooled and a saturated sq. solution of $\mathrm{KF}(10 \mathrm{~mL})$ was added, and the mixture was stirred for $1 \mathrm{~h}$ at reflux. The aqueous layer was discarded and mixture was eluted though celite and silica with $\mathrm{CHCl}_{3}(200 \mathrm{~mL})$, and the solvent was removed under reduced pressure. The residue was subjected to column chromatography $(75 \%$ hexanes $/ 25 \%$ dichloromethane) followed by recrystallization from toluene (3 times) to afford 2,5"-diphenyl-3',4'-dimethyl-5,2':5',2"-terthiophene as an orange solid (1.20 g, 70\%). $\mathrm{MP}=228-229{ }^{\circ} \mathrm{C} .{ }^{1} \mathrm{H}$ NMR $\left(300 \mathrm{MHz}, \mathrm{CDCl}_{3}\right): \delta 7.58-7.64(\mathrm{~m}, 4 \mathrm{H}, J=8.2 \mathrm{~Hz}$, $\mathrm{Ph}), 7.33-7.41(\mathrm{~m}, 4 \mathrm{H}, J=7.2 \mathrm{~Hz}, \mathrm{Ph}), 7.23-7.30$ (m, 4H, J = 3.0 Hz, 7.7 Hz, Ph, Th-3), 7.10-7.14 (d, 2H, $J=3.3 \mathrm{~Hz}, \mathrm{Th}-4), 2.39\left(\mathrm{~s}, 6 \mathrm{H},-\mathrm{CH}_{3}\right) .{ }^{13} \mathrm{C} \mathrm{NMR}\left(75 \mathrm{MHz}, \mathrm{CDCl}_{3}\right): \delta$ $144.3,136.0,135.3,134.3,129.9,129.0,127.6,126.9,125.8,123.5$ (aromatic), 14.4 ($\left.\mathrm{CH}_{3}\right) . \mathrm{IR}(\mathrm{KBr}) 3148,2978,2952,2926,2900,2848,1457,1387,2269,1091,1009,908$, $733 \mathrm{~cm}^{-1}$. MS (EI): $\mathrm{m} / z(\%) 428.1\left(\mathrm{M}^{+}, 100\right)$. HRMS (EI): $\mathrm{m} / z$ Calcd. for $\mathrm{C}_{26} \mathrm{H}_{20} \mathrm{~S}_{3}$, 428.07272; Found, 428.07295, $\Delta=0.5$ ppm. Anal. calcd. for $\mathrm{C}_{26} \mathrm{H}_{20} \mathrm{~S}_{3}=\mathrm{C}, 72.86$; $\mathrm{H}$, 4.70; S, 22.44. Found: C, 72.96; H, 4.79; S, 22.54. 


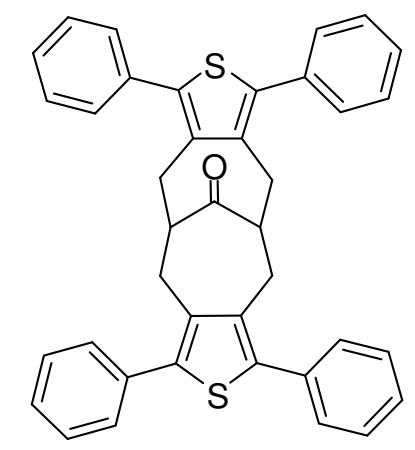

Tetraphenyldithieno[3,4-c:8,9-c']bicyclo[4.4.1]undeca-3,8-diene-11-one. Tri-n-butyl phenyltin $(5.78 \mathrm{~g}, 16 \mathrm{mmol})$ was added to a solution of tetrabromodithieno[3,4-c:8,9c']bicyclo[4.4.1] undeca-3,8-diene-11-one (0.6 g, $1.0 \mathrm{mmol}), \mathrm{Pd}\left(\mathrm{PPh}_{3}\right)_{4}(116 \mathrm{mg}, 100$ $\mu \mathrm{mol})$ and $\mathrm{LiCl}(129 \mathrm{mg}, 2.93 \mathrm{mmol})$ in dry DMF (20 mL), and the mixture was heated to $65^{\circ} \mathrm{C}$ for $36 \mathrm{~h}$. The mixture was cooled and a saturated aq. solution of $\mathrm{KF}(10 \mathrm{~mL})$ was added and stirred for $1 \mathrm{~h}$. The aqueous layer was discarded, the mixture was eluted though celite and silica with $\mathrm{Et}_{2} \mathrm{O}(150 \mathrm{~mL})$, and the solvent was removed under reduced pressure. The residue was subjected to column chromatography $\left(1: 1 \mathrm{CH}_{2} \mathrm{Cl}_{2} /\right.$ hexanes $)$ followed by recrystallization from hexanes/ $\mathrm{CH}_{2} \mathrm{Cl}_{2}(4: 1)$ to afford the title compound as a white solid $(275 \mathrm{mg}, 47 \%) . \quad \mathrm{MP}=265-266{ }^{\circ} \mathrm{C} .{ }^{1} \mathrm{H} \mathrm{NMR}\left(300 \mathrm{MHz}, \mathrm{CDCl}_{3}\right): \delta$ 7.23$7.45(\mathrm{~m}, 20 \mathrm{H}, \mathrm{Ph}), 2.65-3.30\left(\mathrm{~m}, 10 \mathrm{H},-\mathrm{CH}-+-\mathrm{CH}_{2^{-}}\right) .{ }^{13} \mathrm{C} \mathrm{NMR}\left(75 \mathrm{MHz}, \mathrm{CDCl}_{3}\right): \delta$ $215.49(\mathrm{C}=\mathrm{O}), \quad 134.87,134.81,134.077,129.49,128.70,127.75$ (aromatic) 53.92 (bridgehead), 29.02 (- $\left.\mathrm{CH}_{2}-\right)$. IR (KBr) 3156, 3061, 3021, 2983, 2952, 2900, 2843, 1730, 1686, 1596, 1487, 1457, 1439, 1161, 1096, $1048 \mathrm{~cm}^{-1} . \mathrm{MS}(\mathrm{EI}): \mathrm{m} / z(\%) 578.3\left(\mathrm{M}^{+}\right)$, $502.2\left(\mathrm{M}^{+}\right.$- phenyl). HRMS (EI): $\mathrm{m} / z$ Calcd. for $\mathrm{C}_{39} \mathrm{H}_{30} \mathrm{~S}_{2} \mathrm{O}, 578.17381$; Found, $578.17525, \Delta=2.5 \mathrm{ppm}$. 


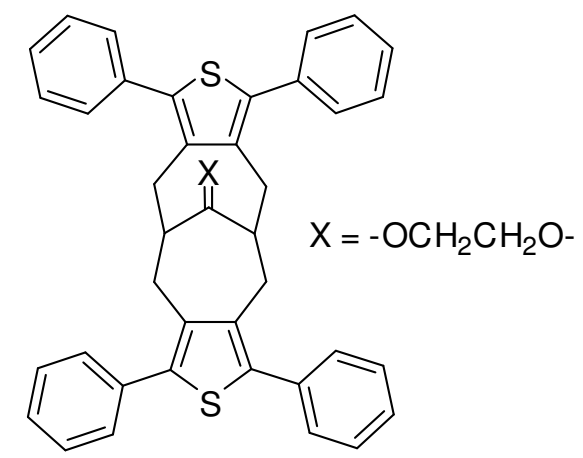

Ethylene acetal of tetraphenyldithieno[3,4-c:8,9-c']bicyclo[4.4.1]undeca-3,8-diene-11one. A solution of tetraphenyldithieno[3,4-c:8,9-c']bicyclo[4.4.1] undeca-3,8-diene-11one (275 mg, $470 \mu \mathrm{mol})$, ethylene glycol (400 mg, $6.50 \mathrm{mmol}$ ), and $p$-toluenesulfonic acid $(6.0 \mathrm{mg}, 32 \mu \mathrm{mol})$ in benzene $(8 \mathrm{ml})$, and the mixture was heated at reflux for $18 \mathrm{~h}$ with a Dean-Stark trap. The solvent was evaporated under reduced pressure, and the residue was subjected to column chromatography on silica gel (40\% ethyl acetate/60\% hexanes) followed by recrystallization from methanol to give the title compound as white crystalline solid $(265 \mathrm{mg}, 92 \%) . \mathrm{MP}=145-146{ }^{\circ} \mathrm{C}$ (decomp). ${ }^{1} \mathrm{H}$ NMR $(300 \mathrm{MHz}$, pyridine- $\left.d_{6}\right): \delta 7.40-7.45(\mathrm{~m}, 8 \mathrm{H}, \mathrm{Ph}), 7.21-7.35(\mathrm{~m}, 12 \mathrm{H}, \mathrm{Ph}), 3.90\left(\mathrm{~s}, 4 \mathrm{H},-\mathrm{OCH}_{2} \mathrm{CH}_{2} \mathrm{O}-\right.$ ), $3.38\left(\mathrm{dd}, 4 \mathrm{H}, J=3.3,15 \mathrm{~Hz},-\mathrm{CH}_{2}-\right), 3.16\left(\mathrm{dd}, 4 \mathrm{H}, J=5,15 \mathrm{~Hz},-\mathrm{CH}_{2}-\right), 2.40-2.45(\mathrm{~m}$, $2 \mathrm{H},-\mathrm{CH}-) .{ }^{13} \mathrm{C}$ NMR $\left(75 \mathrm{MHz}\right.$, pyridine- $\left.d_{6}\right): \delta 137.02,136.78,134.80,129.71,128.26$, 126.88 (aromatic), 113.54 (ketal), $64.42\left(-\mathrm{OCH}_{2} \mathrm{CH}_{2} \mathrm{O}-\right), 43.35$ (bridgehead), 28.26 ($\mathrm{CH}_{2}$-). IR (KBr) 3156, 3052, 3021, 2961, 2900, 1465, 1378, 1261, 1096, 1000, $539 \mathrm{~cm}^{-1}$. MS (EI): $m / z$ (\%) 622.1 HRMS (EI): $m / z$ Calcd. for $\mathrm{C}_{41} \mathrm{H}_{34} \mathrm{O}_{2} \mathrm{~S}_{2}, 622.20002$; found, $622.19559, \Delta=7.4 \mathrm{ppm}$. 


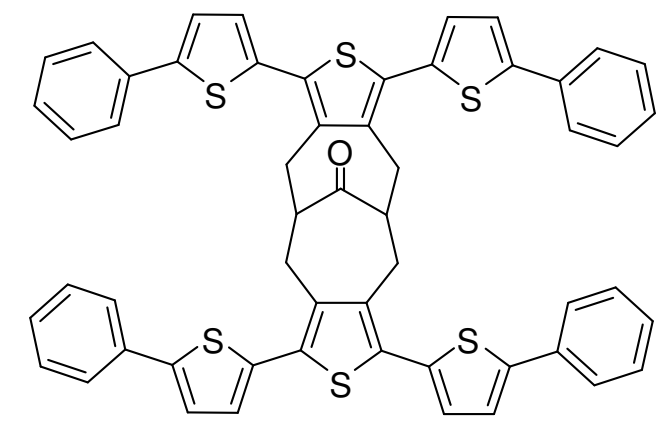

Tetra-(5-phenyl-2-thienyl)-dithieno[3,4-c:8,9-c']bicyclo[4.4.1]undeca-3,8-diene -11-one. A 2.5 M solution of $n$-BuLi in hexanes $(5.0 \mathrm{~mL}, 12.5 \mathrm{mmol})$ was added to a solution of 2phenylthiophene $(2.0 \mathrm{~g}, 12 \mathrm{mmol})$ and TMEDA $(2.0 \mathrm{~mL}, 12 \mathrm{mmol})$ in dry THF $(10 \mathrm{~mL})$ at $0{ }^{\circ} \mathrm{C}$. The mixture was heated at reflux for $2 \mathrm{~h}$ and cooled to room temperature. A 0.5 $\mathrm{M}$ solution of $\mathrm{ZnCl}_{2}$ in THF (25 mL, $12 \mathrm{mmol}$ ) was added, and the mixture was stirred for another $2 \mathrm{~h}$. This mixture was cannulated to a solution of tetrabromo-dithieno[3,4c:8,9-c']bicyclo[4.4.1]undeca-3,8-diene-11-one (0.6 g, $1.0 \mathrm{mmol})$ and $\mathrm{Pd}\left(\mathrm{PPh}_{3}\right)_{4} \quad(300$ $\mathrm{mg}, 260 \mu \mathrm{mol})$ in dry THF $(20 \mathrm{~mL})$ and heated to $60{ }^{\circ} \mathrm{C}$ for $48 \mathrm{~h}$. After the reaction was cooled to room temperature, a $0.5 \mathrm{M}$ solution of $\mathrm{HCl}(40 \mathrm{~mL})$ was added. The organic layer was collected, and the aqueous layer was extracted with methylene chloride $(3 \times 40$ $\mathrm{mL})$. The organic layers were combined and washed with $\mathrm{H}_{2} \mathrm{O}(2 \times 75 \mathrm{~mL})$, and dried over $\mathrm{MgSO}_{4}$. The solvent was removed under reduced pressure, and the residue was subjected to column chromatography $\left(1: 2 \mathrm{CHCl}_{3} /\right.$ hexanes $)$ to afford the title compound as a yellow solid, $(200 \mathrm{mg}, 22 \%) . \mathrm{MP}=293-294{ }^{\circ} \mathrm{C} .{ }^{1} \mathrm{H}$ NMR $\left(300 \mathrm{MHz}, \mathrm{CDCl}_{3}\right): \delta$ 7.23-7.45 (m, 28H, Ar), 2.65-3.30 (m, 10H, -CH- + - $\left.\mathrm{CH}_{2}^{-}\right) . \quad$ IR (KBr) 3055, 3017, 2959, 2913, 2854, 1703, 1599, 1490, 1441, 1254, 1070, 1007, $856 \mathrm{~cm}^{-1}$. MS (MALDI-TOF): $m / z, 907.1(\mathrm{M}+\mathrm{H})$. 


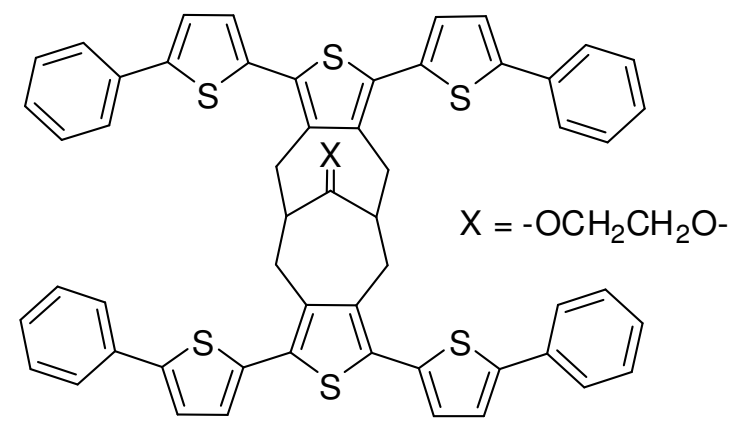

Ethylene acetal of Tetra-(5-phenyl-2-thienyl)-dithieno[3,4-c:8,9-c']bicyclo[4.4.1 undeca3,8-diene-11-one. A solution of tetra-(5-phenyl-2-thienyl)-dithieno[3,4-c:8,9c']bicyclo[4.4.1]undeca-3,8-diene-11-one (200 mg, $220 \mu \mathrm{mol})$, ethylene glycol (250 mg, $5.4 \mathrm{mmol})$, and $p$-toluenesulfonic acid $(5.0 \mathrm{mg}, 26 \mu \mathrm{mol})$ in benzene $(20 \mathrm{~mL})$ was heated at reflux for $48 \mathrm{~h}$ with a Dean-Stark trap. The solvent was evaporated under reduce pressure, and the residue was subjected to column chromatography on silica gel (10\% hexanes/90\% chloroform) followed by triturating from toluene to give the title compound as yellow solid, $(205 \mathrm{mg}, 97 \%) . \quad \mathrm{MP}=305-306{ }^{\circ} \mathrm{C}$ (decomp). ${ }^{1} \mathrm{H}$ NMR $(300 \mathrm{MHz}$, $\left.\mathrm{CDCl}_{3}\right): \delta$ 7.25-7.32 (m, 8H, Ph), 7.11-7.19 (m, 12H, Ph), 7.85-7.89 (d, 4H, J=3.5 Hz, Th), $6.83(\mathrm{~d}, 4 \mathrm{H}, J=3.5 \mathrm{~Hz}, \mathrm{Th}), 4.10\left(\mathrm{~s}, 4 \mathrm{H},-\mathrm{OCH}_{2} \mathrm{CH}_{2} \mathrm{O}-\right), 3.58$ (dd, $4 \mathrm{H}, J=5 \mathrm{~Hz}, 15$ $\left.\mathrm{Hz},-\mathrm{CH}_{2^{-}}\right), 3.16\left(\mathrm{dd}, 4 \mathrm{H}, J=2.2 \mathrm{~Hz}, 15 \mathrm{~Hz},-\mathrm{CH}_{2^{-}}\right), 2.42-2.50$ (m, $2 \mathrm{H}$, bridgehead). ${ }^{13} \mathrm{C}$ NMR $\left(75 \mathrm{MHz}, \mathrm{CDCl}_{3}\right): \delta 143.57,138.03,135.87,133.88,129.85,128.59,127.04$, 126.90, 125.30, 122.86 (aromatic), 113.56 (ketal), $64.83 \quad\left(-\mathrm{OCH}_{2} \mathrm{CH}_{2} \mathrm{O}-\right), 42.54$ (bridgehead), 28.69 (-CH $\left.2^{-}\right)$. IR (KBr) 3056, 3024, 2912, 2848, 1597, 1484, 1444, 1396, 1261, 1095, 1071, 1003, $947 \mathrm{~cm}^{-1}$. MS (MALDI-TOF): $\mathrm{m} / z$ 950.2 [M+H']. HRMS (EI): $m / z$ Calcd. for $\mathrm{C}_{57} \mathrm{H}_{42} \mathrm{O}_{2} \mathrm{~S}_{6}, 950.1509$; found, 950.1389, $\Delta=12.6$ ppm. Anal. calcd. for $\mathrm{C}_{57} \mathrm{H}_{42} \mathrm{~S}_{6} \cdot 2 \mathrm{H}_{2} \mathrm{O}: \mathrm{C}, 69.34 ; \mathrm{H}, 4.70$. Found: C, 69.25; H, 4.85. 


\subsection{Results and Discussion}

\subsubsection{Synthesis}

The phenyl-capped linear model compounds were prepared by coupling 2,5dibromo-3,4-dimethylthiophene to the corresponding stannylated arene. Tri- $n$ butylphenyltin is commercially available and 2-phenyl-5-tri- $n$-butylstannyl-thiophene ${ }^{9}$ was prepared in two steps. Reaction of fluorobenzene with 2-lithiothiophene via a benzyne intermediate afforded 2-phenylthiophene, 5.1, Figure 5.1. Lithiation of $\mathbf{5 . 1}$ followed by quenching with tributylstannyl chloride afforded 2-phenyl-5-tri- $n$ butylstannylthiophene, $\mathbf{5 . 2}$, in $80 \%$ yield.

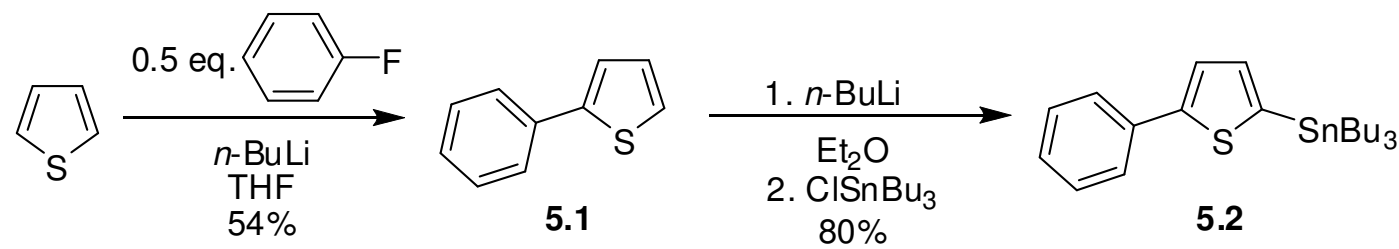

Figure 5.1. Synthesis of 2-phenyl-5-tri- $n$-butylstannylthiophene, 5.2.

Coupling tri- $n$-butyltin benzene to 2,5-dibromo-3,4-dimethylthiophene via Stille reaction afforded 2,5"-diphenyl-3',4'-dimethyl-5,2':5',2"terthiophene, 5.3, as a white crystalline solid (55\% yield), Figure 5.2.

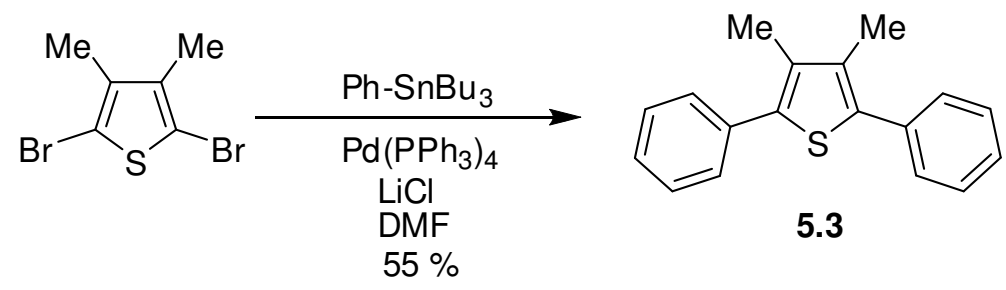

Figure 5.2. Synthesis of model 2,5-diphenyl-3,4-dimethylthiophene, 5.3. 
Coupling $\mathbf{5 . 2}$ to 2,5-dibromo-3,4-dimethylthiophene afforded the extended phenyl-capped oligothiophene 2,5"-diphenyl-3',4'-dimethyl-5,2':5',2"-terthiophene, 5.4, as an orange solid (70\%), after recrystallization several times from toluene, Figure 5.3.
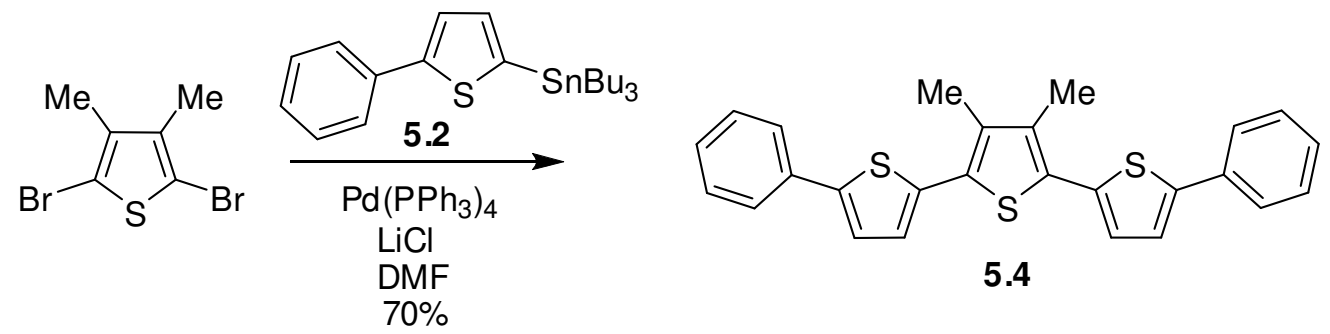

5.4

Figure 5.3. Synthesis of model 2,5"-diphenyl-3',4'-dimethyl-5,2':5',2"-terthiophene, 5.4.

Previously reported tetrabomoketone ${ }^{10} \mathbf{3 . 1}$ (from Chapter 3) was treated with excess tri- $n$-butylphenyl tin using Stille coupling conditions to produce phenyl-capped ketone $\mathbf{5 . 5}$ in a $47 \%$ overall yield, Figure 5.4. Ketalization with ethylene glycol afforded the $\pi$-stacked compound $\mathbf{5 . 6}$ in $92 \%$ yield. Several attempts to couple 2-phenyl-5-tri- $n$ butylstannylthiophene to $\mathbf{3 . 1}$ using Stille conditions were unsuccessful. However, utilization of Negishi coupling conditions by in situ formation of 2-phenyl-5-thienylzinc chloride and coupling it to 3.1, afforded the phenyl-capped ketone $\mathbf{5 . 7}$ in a $22 \%$ yield. Subsequent ketalization with ethylene glycol afforded $\pi$-stacked compound $\mathbf{5 . 8}$ (97\% yield), Figure 5.4. 


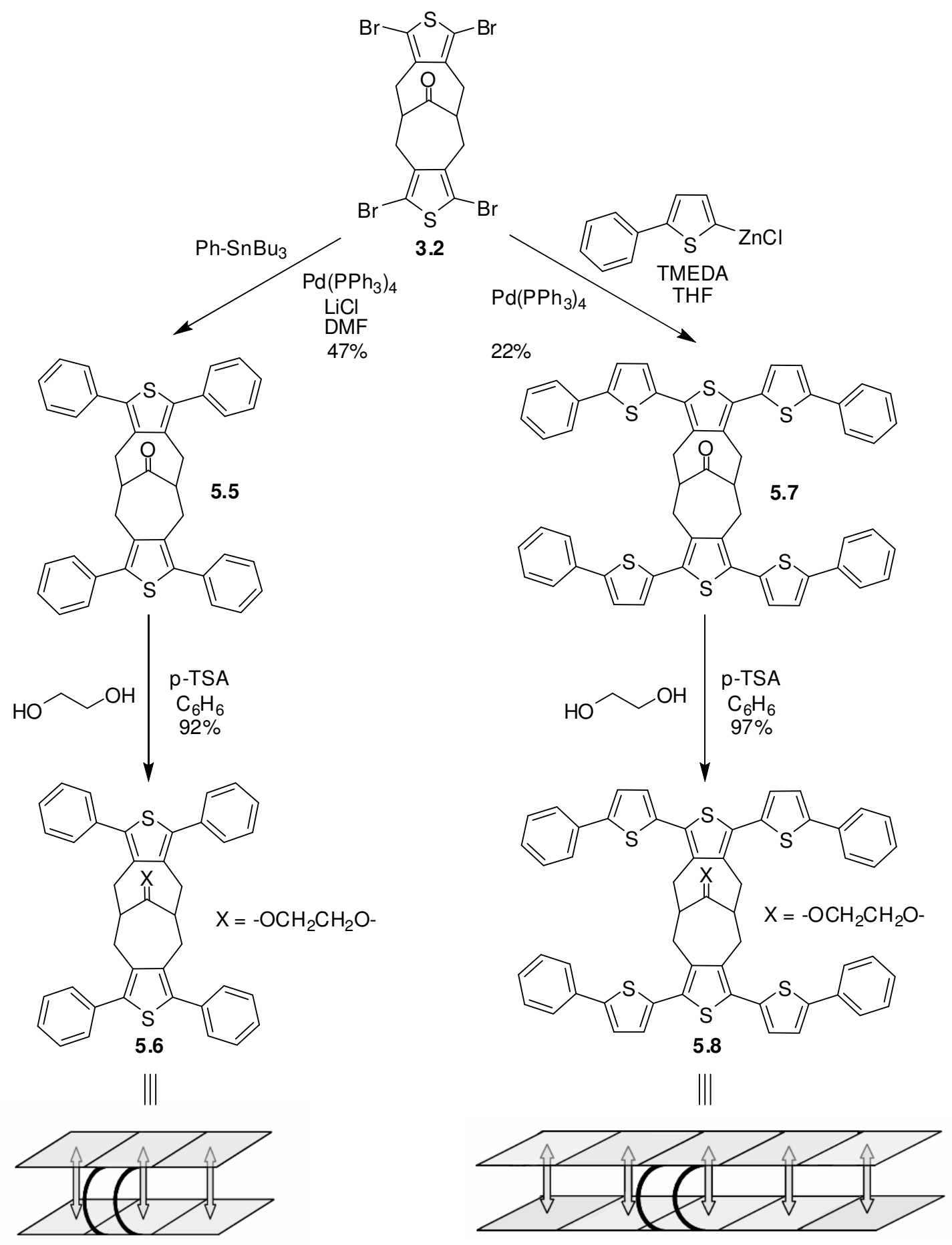

Figure 5.4. Synthesis of phenyl-capped, $\pi$-stacked oligothiophenes, 5.6, and 5.8. 


\subsubsection{Structural Characterization: ${ }^{1} \mathrm{H}$ and ${ }^{13} \mathrm{C}$ NMR Spectroscopy}

The ${ }^{1} \mathrm{H}$ NMR spectrum of 2,5-diphenyl-3,4-dimethylthiophene, 5.3, displays a six proton singlet for the methyl protons $(2.3 \mathrm{ppm})$, Figure 5.5. The aromatic protons of the benzene rings give rise to three distinct multiplets. The downfield signal corresponds to the four ortho protons. The next four proton multiplet corresponds to the meta protons on each benzene ring, while the two para protons give the multiplet signal furthest upfield in the aromatic region.
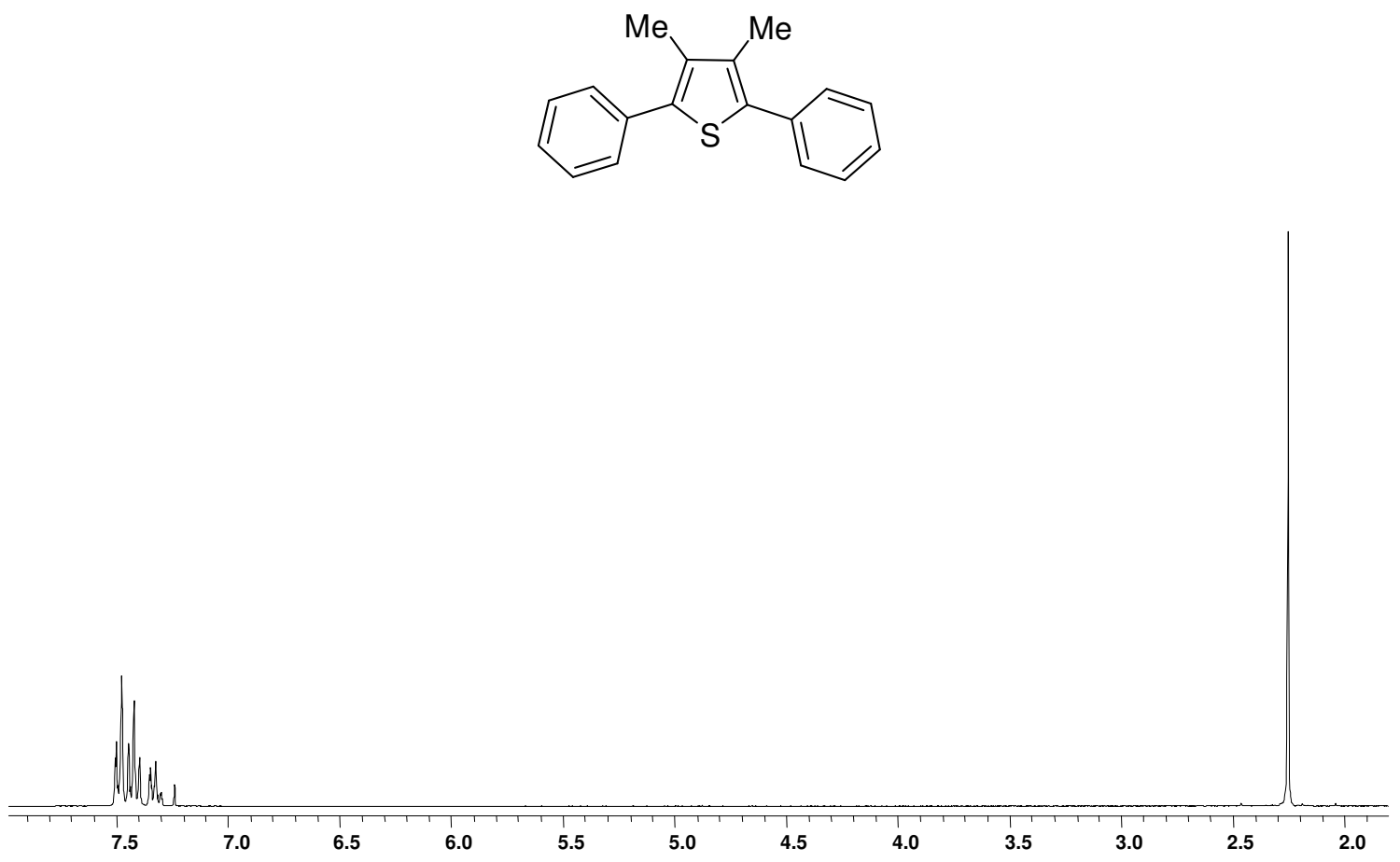

Figure 5.5. ${ }^{1} \mathrm{H}$ NMR $\left(300 \mathrm{MHz}, \mathrm{CDCl}_{3}\right)$ of model $\mathbf{5 . 3}$ at room temperature.

The ${ }^{13} \mathrm{C}$ NMR spectrum of $\mathbf{5 . 3}$ displays six distinct aromatic signals corresponding to four different benzene carbons and two different thiophene carbons, Figure 5.6. There is one carbon signal for the two identical methyl carbons in the alipathic region. 

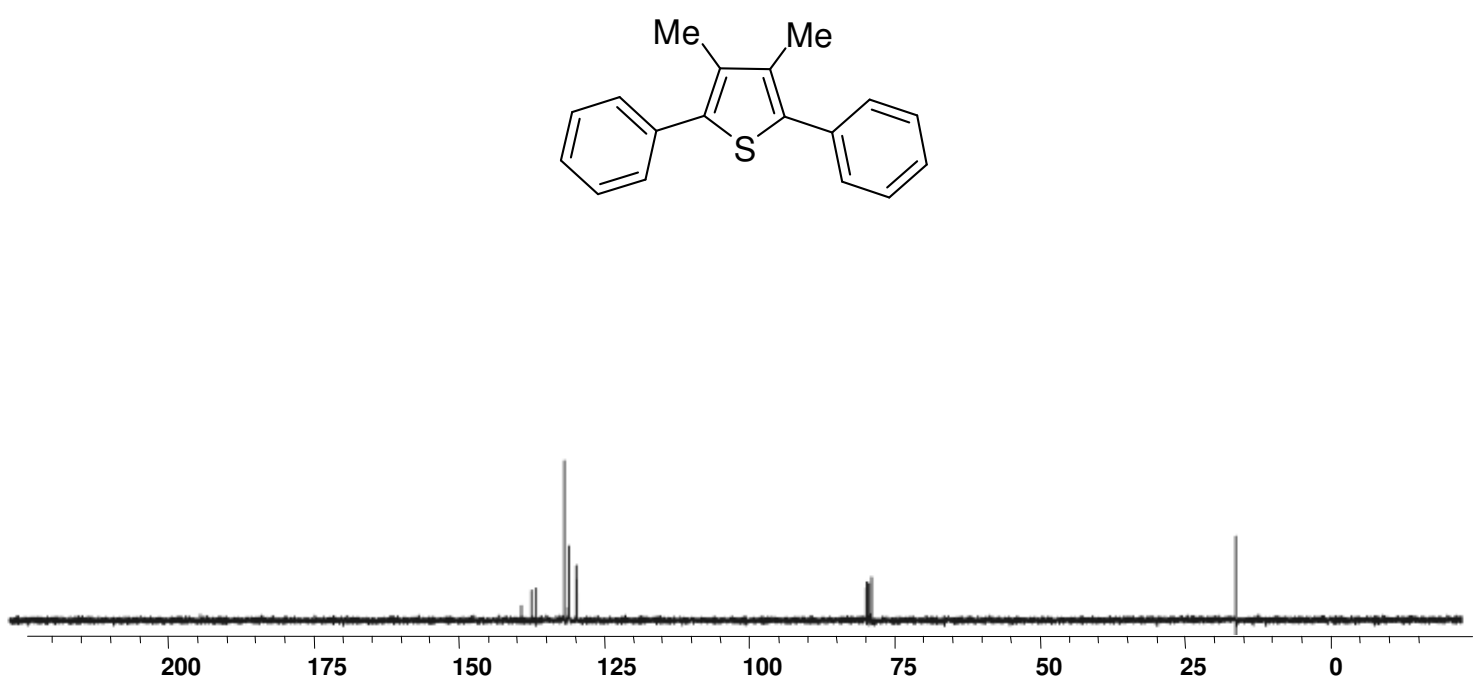

Figure 5.6. ${ }^{13} \mathrm{C}$ NMR $\left(300 \mathrm{MHz}, \mathrm{CDCl}_{3}\right)$ of model 5.3 at room temperature.

Upon ketalization with ethylene glycol to the $\pi$-stacked compound, 5.6, variable temperature ${ }^{1} \mathrm{H}$ NMR illustrated no change in conformation up to $100{ }^{\circ} \mathrm{C}$, indicating the stability of this $\pi$-stacked compound, Figure 5.7. For the aromatic protons, the ortho protons exhibited an eight proton multiplet (7.40-7.45 ppm), while the meta and para protons appear at 7.21-7.35 ppm. There is a small upfield shift in aromatic protons of $\mathbf{5 . 6}$ when compared to the model $\mathbf{5 . 3}$ due to $\pi$-stacking. The bulkier benzene molecules cause less significant magnetic shielding of the aromatic protons in each benzene ring. The ethylene glycol signal appeared at $3.9 \mathrm{ppm}$ as a singlet. As previously seen upon $\pi$ stacking, the chair-chair conformation is confirmed by the appearance of a pair of doublet of doublets for the methylene protons. This is also seen for the phenyl-capped compound, 5.6, with an eight proton pair of doublet of doublets (3.38 and $3.16 \mathrm{ppm})$ with coupling constants consistent with a chair-chair conformation of the bicyclo[4.4.1] undecane framework. The two bridgehead protons appeared furthest upfield in the spectrum as a multplet (2.43 ppm), Figure 5.7. 

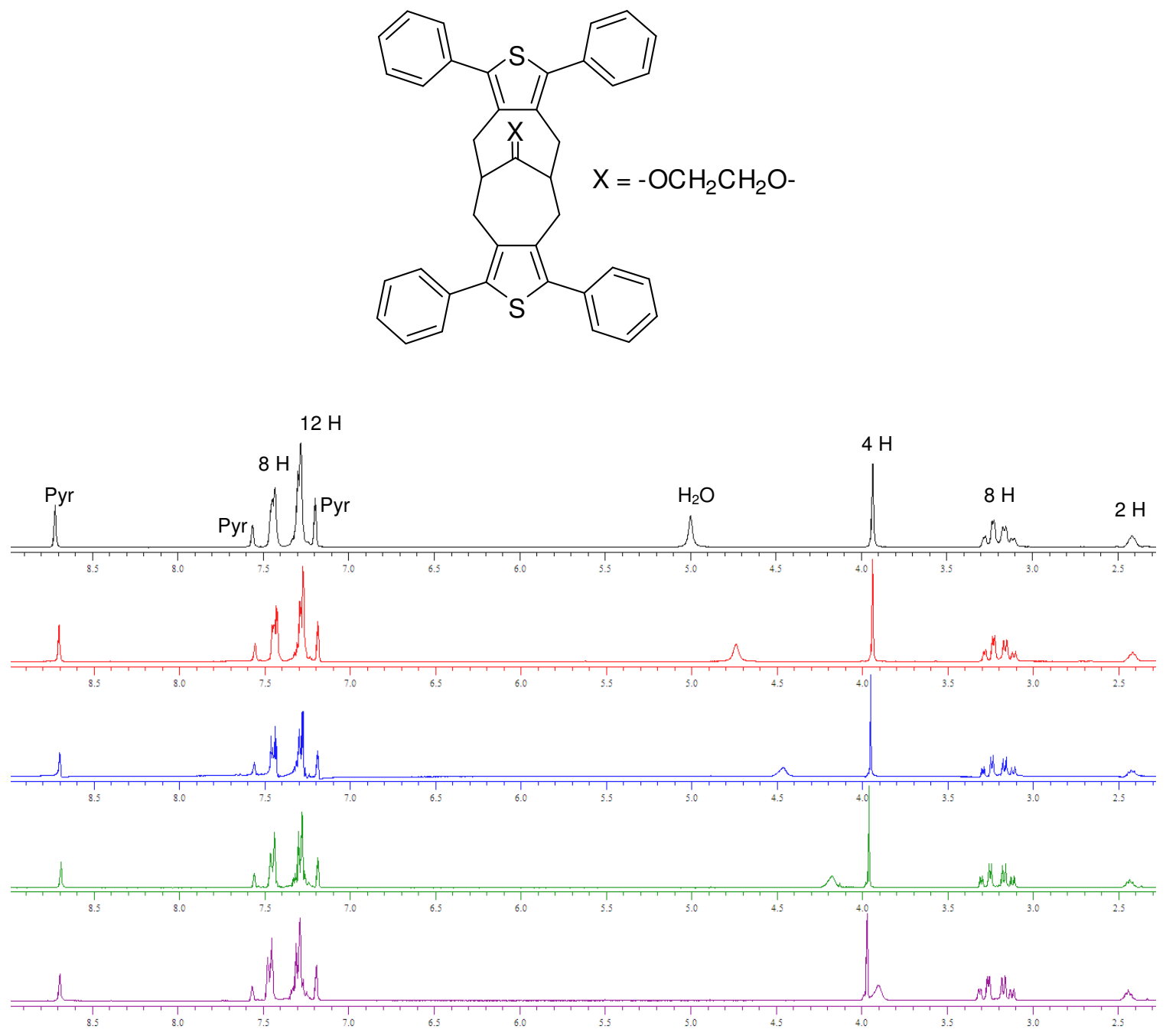

Figure 5.7. Variable temperature ${ }^{1} \mathrm{H}$ NMR (300 MHz, Pyridine-d6) of 5.6. Room temperature (black), $40{ }^{\circ} \mathrm{C}$ (red), $60{ }^{\circ} \mathrm{C}$ (blue), $80{ }^{\circ} \mathrm{C}$ (green), and $100{ }^{\circ} \mathrm{C}$ (purple).

The ${ }^{13} \mathrm{C}$ NMR spectrum of $\pi$-stacked compound $\mathbf{5 . 6}$ confirms the presence of one distinct conformation at room temperature. The aromatic carbons provide six distinct signals: four for the benzene rings and two for the thiophene rings, Figure 5.8. The ketal tertiary carbon is present at $\delta 113 \mathrm{ppm}$. The ethylene glycol, bridgehead, and methylene carbon signals each appear as separate one carbon signals. 

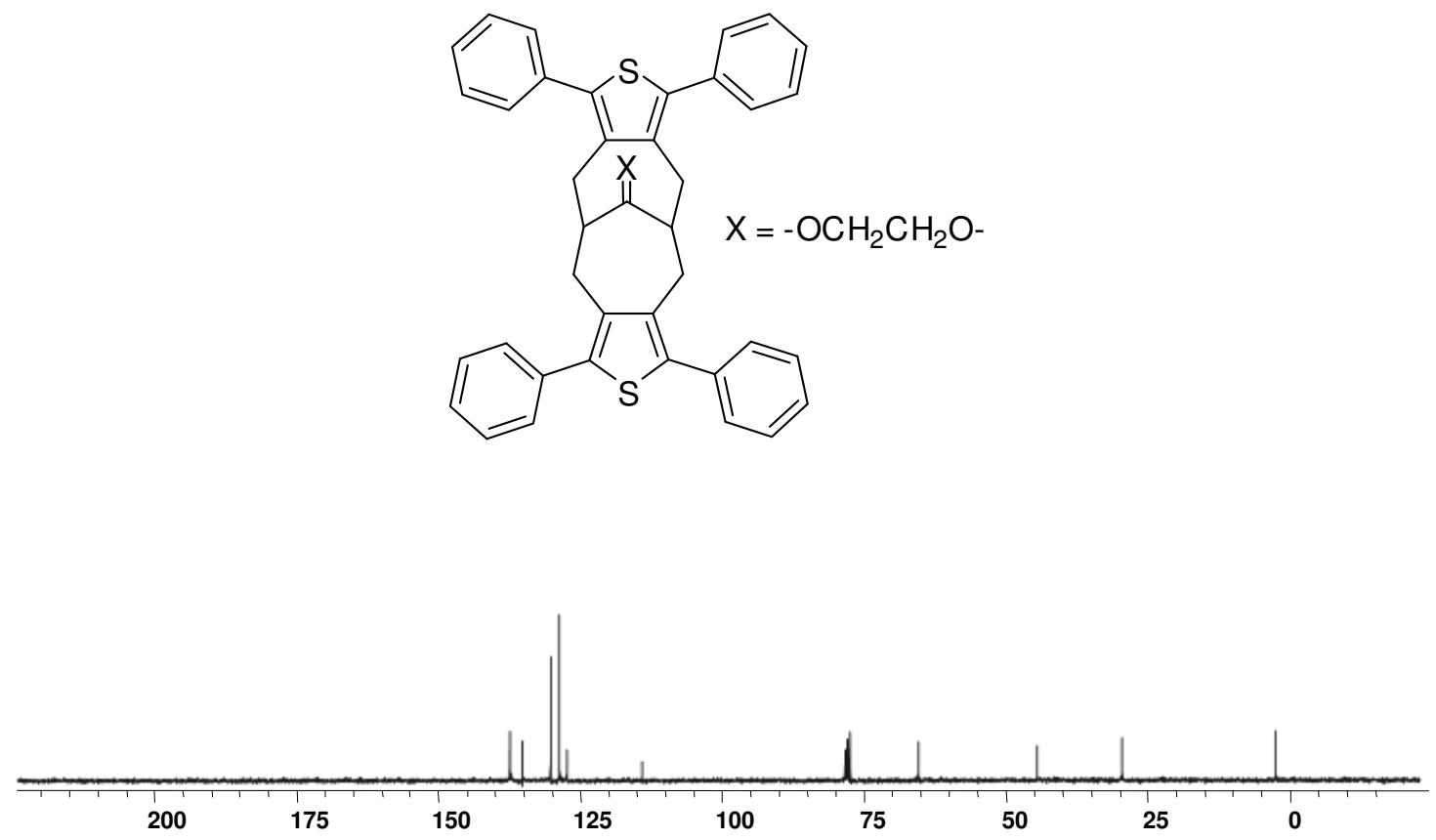

Figure 5.8. ${ }^{13} \mathrm{C} \mathrm{NMR}\left(300 \mathrm{MHz}, \mathrm{CDCl}_{3}\right)$ of $\mathbf{5 . 6}$ at room temperature.

The phenyl-capped terthiophene model compound 5.4 exhibited four distinct signals in the aromatic region for its ${ }^{1} \mathrm{H}$ NMR spectrum. The highest downfield multiplet corresponds to the four ortho protons on the benzene rings. The next multiplet at $7.4 \mathrm{ppm}$ corresponds to the four meta protons on the benzene rings. The multiplet at $7.25 \mathrm{ppm}$ corresponds to the two para protons on the benzene ring and two protons on the thiophene rings. The doublet $(7.1 \mathrm{ppm})$ corresponds to the other thiophene proton signal. The singlet at $\delta 2.35 \mathrm{ppm}$ corresponds to the methyl protons. The ${ }^{13} \mathrm{C}$ NMR spectrum of model $\mathbf{5 . 4}$ at room temperature exhibited ten aromatic carbon proton signals and one methyl carbon signal, Figure 5.10. 

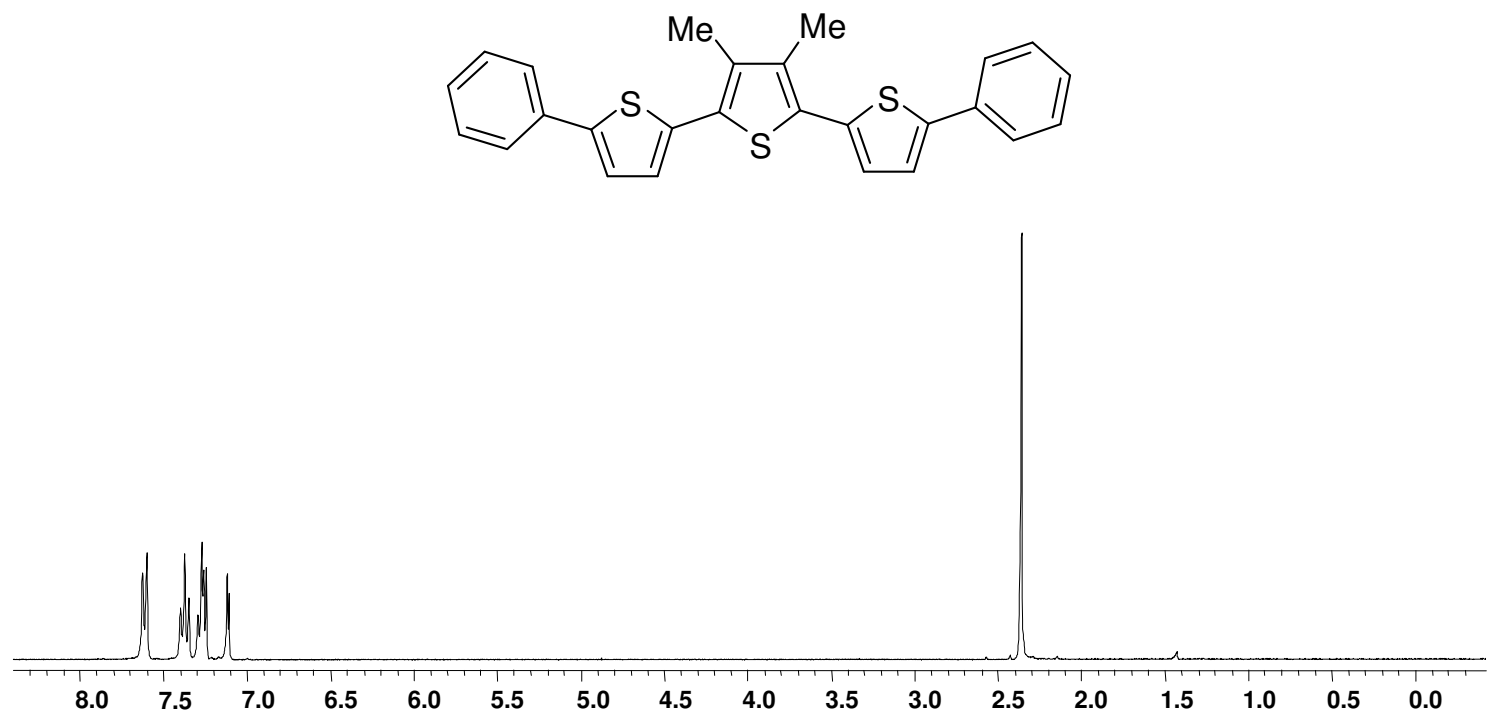

Figure 5.9. ${ }^{1} \mathrm{H} \mathrm{NMR}\left(300 \mathrm{MHz}, \mathrm{CDCl}_{3}\right)$ of $\mathbf{5 . 4}$ at room temperature.

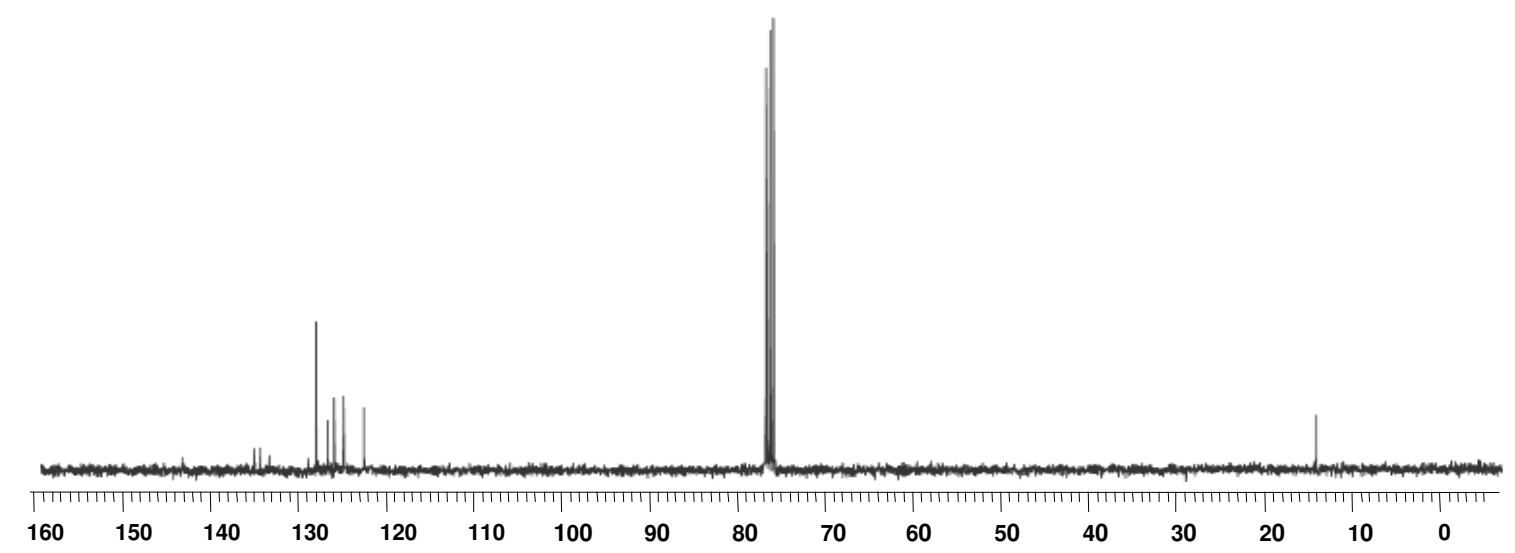

Figure 5.10. ${ }^{13} \mathrm{C}$ NMR $\left(300 \mathrm{MHz}, \mathrm{CDCl}_{3}\right)$ of $\mathbf{5 . 4}$ at room temperature.

The $\pi$-stacked compound $\mathbf{5 . 8}$ exhibits upfield shifts in the aromatic protons compare to that of its model compound, Figure 5.11. The methylene protons exhibit splitting consistent with a chair-chair conformation. The ${ }^{13} \mathrm{C}$ NMR spectrum displays ten aromatic carbons, an ethylene glycol peak, and the other bicyclo[4.4.1]undecane framework signals which have been seen in the other $\pi$-stacked compounds, Figure 5.11. 

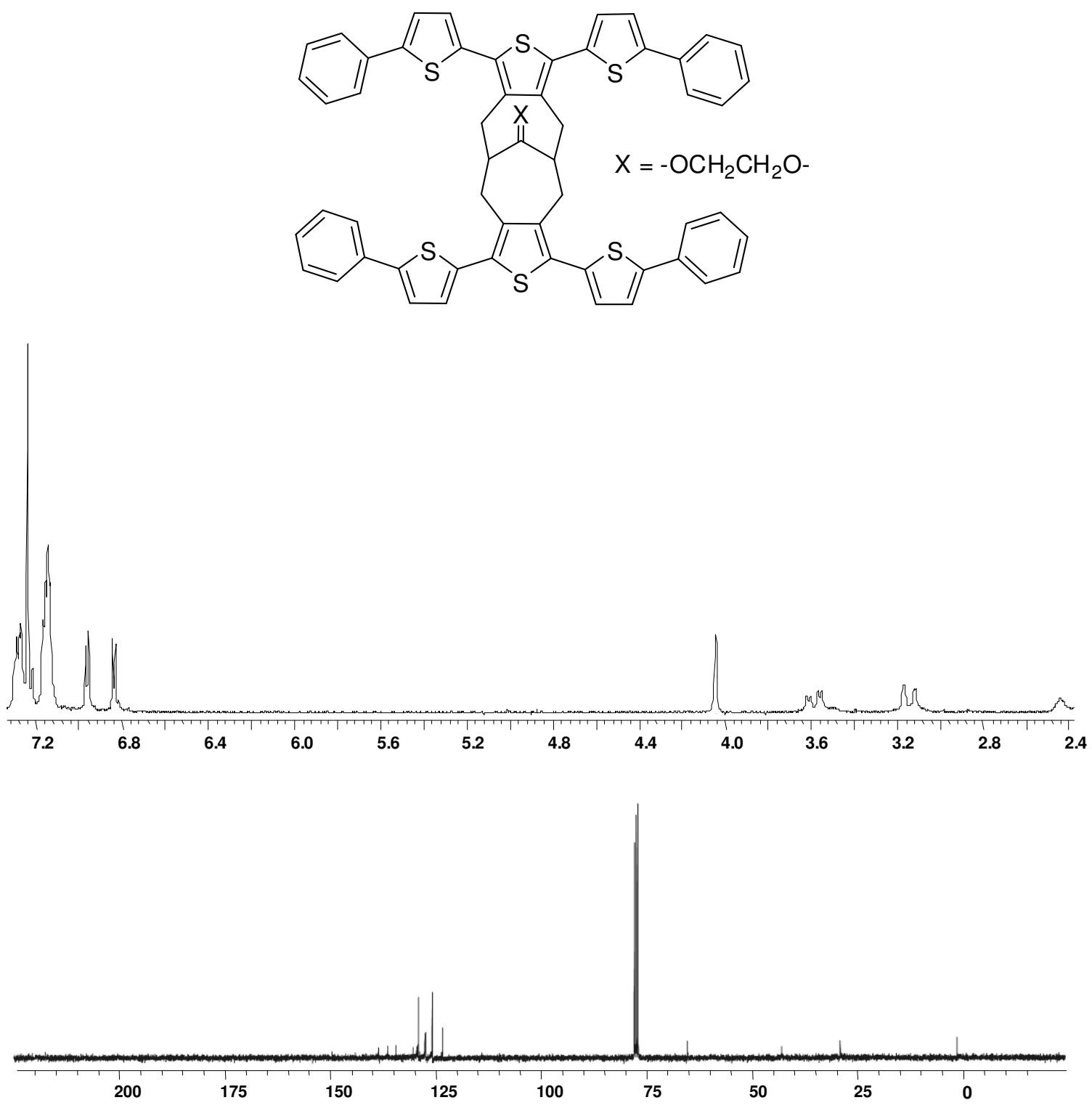

Figure 5.11. ${ }^{1} \mathrm{H}$ NMR $\left(300 \mathrm{MHz}, \mathrm{CDCl}_{3}\right)$ of 5.8 (top). $\left.{ }^{13} \mathrm{C} \mathrm{NMR} \mathrm{(300} \mathrm{MHz}, \mathrm{CDCl}_{3}\right)$ of 5.8 (bottom).

A summary of the influence of $\pi$-stacking aromatic protons for the phenyl-capped model and $\pi$-stacked compounds is shown in Table 5.1. 
Table 5.1. ${ }^{1} \mathrm{H}$ NMR Chemical Shifts $(\delta)$ for aromatic protons of phenyl-capped model and $\pi$-stacked compounds.

\begin{tabular}{|c|c|c|c|c|c|}
\hline Compound & $\mathrm{H}_{1}{ }^{a}$ & $\mathrm{H}_{2}{ }^{a}$ & $\mathrm{H}_{3}{ }^{b}$ & $\mathrm{H}_{4}^{b}$ & $\mathrm{H}_{5}^{b}$ \\
\hline Model 5.3 & & & 7.48 & 7.44 & 7.34 \\
\hline Stack 5.6 & & & 7.45 & 7.27 & 7.27 \\
\hline Model 5.4 & 7.45 & 7.21 & 7.61 & 7.76 & 7.47 \\
\hline Stack 5.8 & 6.91 & 6.82 & 7.18 & 7.29 & 7.29 \\
\hline
\end{tabular}

${ }^{a}$ Thiophene protons. ${ }^{b}$ Benzene protons.

\subsubsection{Structural Characterization: Molecular Modeling}

Molecular modeling was performed on the $\pi$-stacking compound $\mathbf{5 . 6}$ to examine the preferred orientation for the benzene rings. The benzene rings are out of plane from the thiophene rings, because the methylene protons are proximal to one set of ortho protons on the benzene ring. The steric repulsion does not hinder the compound from being in a chair-chair conformation because the benzene rings can adopt a non-planar orientation of each oligomer upon stacking, Figure 5.12.
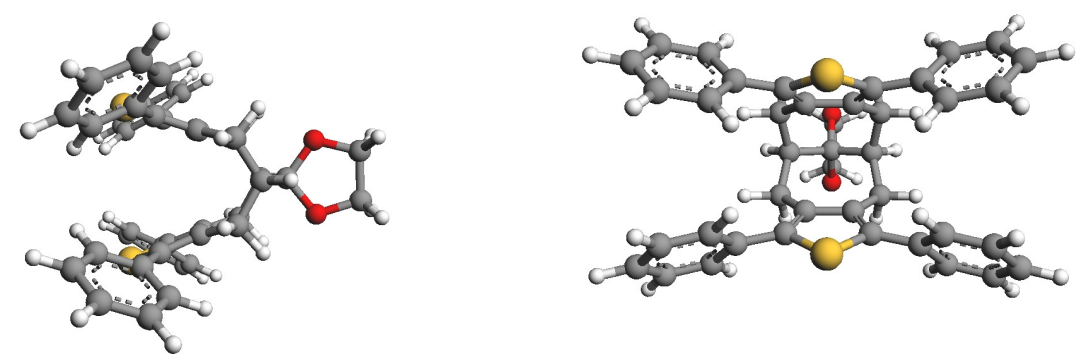

Figure 5.12. Optimized geometry for 5.1 performed at the B3LYP-6-31G* level. 
The HOMO energy orbitals for $\pi$-stacked compound $\mathbf{5 . 6}$ lies mostly on the central thiophene rings and the LUMO level is extended partially on the thiophene-phenyl linkage, Figure 5.13.

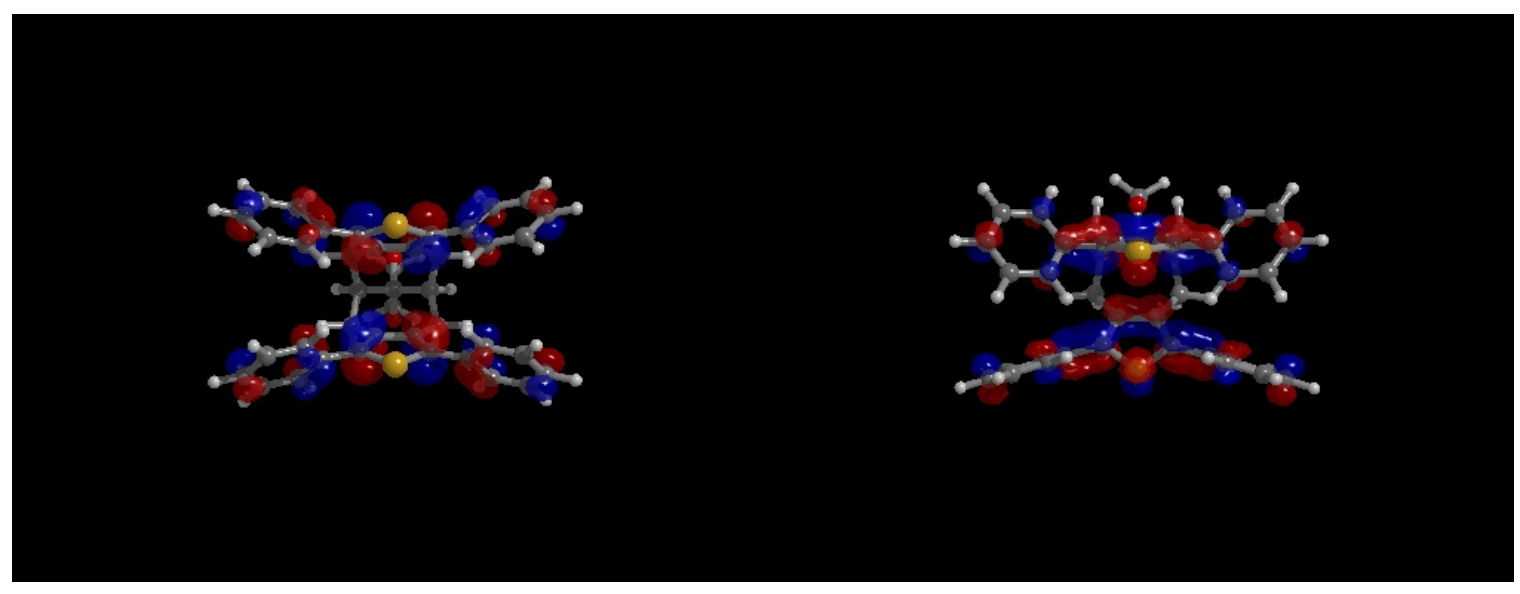

Figure 5.13. HOMO (left) and LUMO (right) levels of 5.6.

\subsubsection{UV-vis and Fluorescence Spectroscopy}

Model compound $\mathbf{5 . 3}$ has an absorbance peak at $\lambda_{\max }=302 \mathrm{~nm}$ and fluorescence peak at $\lambda_{\max }=391 \mathrm{~nm}$, Figure 5.14. The $\pi$-stacked analog $\mathbf{5 . 6}$ shows a slight blue shift in absorbance $\left(\lambda_{\max }=297 \mathrm{~nm}\right)$ and broadened red shift in fluorescence $\left(\lambda_{\max }=396\right.$ and a shoulder at $432 \mathrm{~nm}$ ), Figure 5.14. The broadened fluorescence peak is ascribed to intersystem crossing to a lower energy state, or "phane" state. The extended phenylcapped oligothiophene $\mathbf{5 . 4}$ has a absorbance peak at $\lambda_{\max }=381 \mathrm{~nm}$ and fluorescence peak at $\lambda_{\max }=471 \mathrm{~nm}$ and shoulder peak at $496 \mathrm{~nm}$. The extended $\pi$-stacked analog $\mathbf{5 . 8}$ exhibits a blue shifted neutral absorbance $\left(\lambda_{\max }=376 \mathrm{~nm}\right)$ and broadened, red shifted fluorescence $\left(\lambda_{\max }=501,538 \mathrm{~nm}\right.$ shoulder $)$, Figure 5.14. 

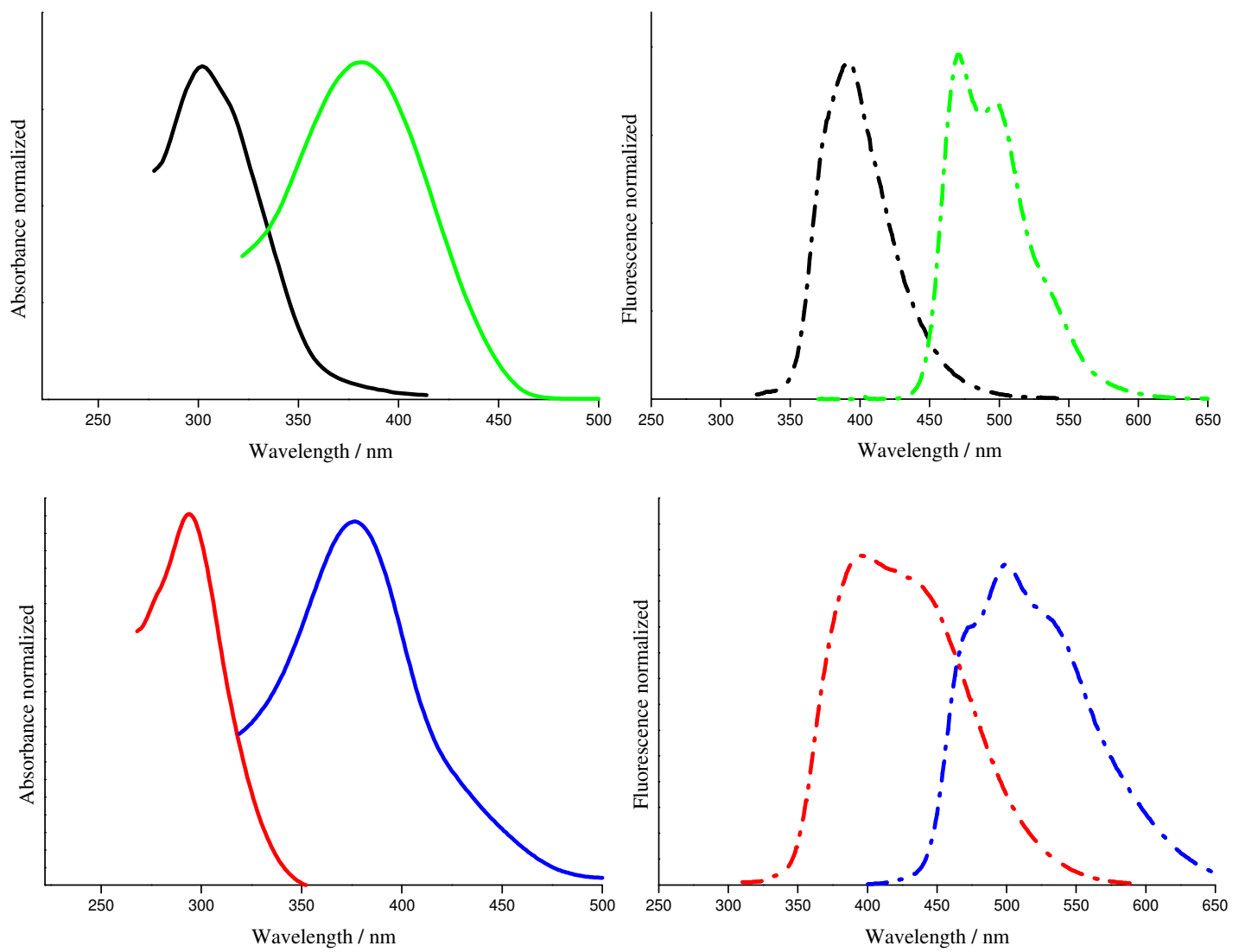

Figure 5.14. Absorbance/Emission Spectra of model 5.3 (black); extended model 5.4 (green); $\pi$-stacked compound $\mathbf{5 . 6}$ (red); extended $\pi$-stacked compound $\mathbf{5 . 8}$ (blue).

Variable excitations of the extended model 5.4 and $\pi$-stacked compound 5.8 illustrated in the emission spectra show contributions from one absorbing species, Figure 5.15. The other compounds $\mathbf{5 . 3 / 5 . 6}$ exhibit similar behavior in emission spectroscopy. 

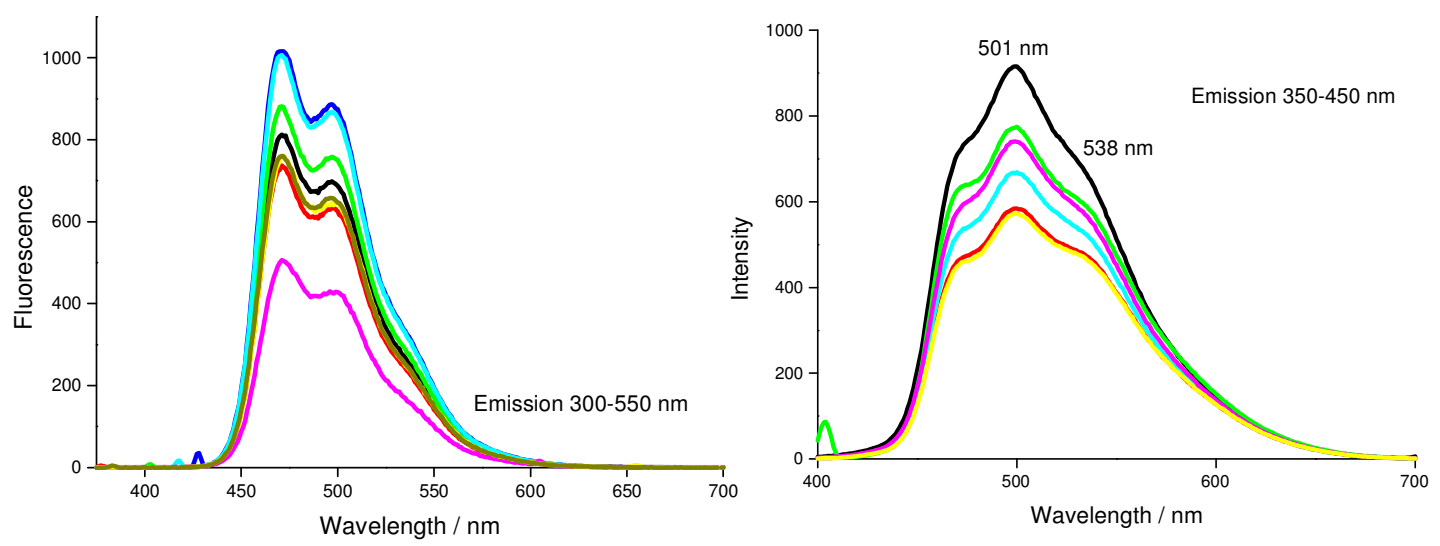

Figure 5.15. Emission spectra of $\mathbf{5 . 4}$ (left) and $\mathbf{5 . 8}$ (right).

A summary of the absorbance and emission peaks is displayed in Table 5.2. As conjugation length increases, the absorbance and fluorescence peaks are red shifted. Upon $\pi$-stacking the general trend, also seen with oligothiophenes, is that there is a blue shift in absorbance when compared to the model compound, and a red shift in fluorescence. The molar absorption values of the $\pi$-stacked compounds are less than two times the value of their model compounds due to nonbonding electronic interactions relating to excimer formation. 
Table 5.2. Electronic Spectral Data ${ }^{a}$ of Models and Stacked Oligothiophenes

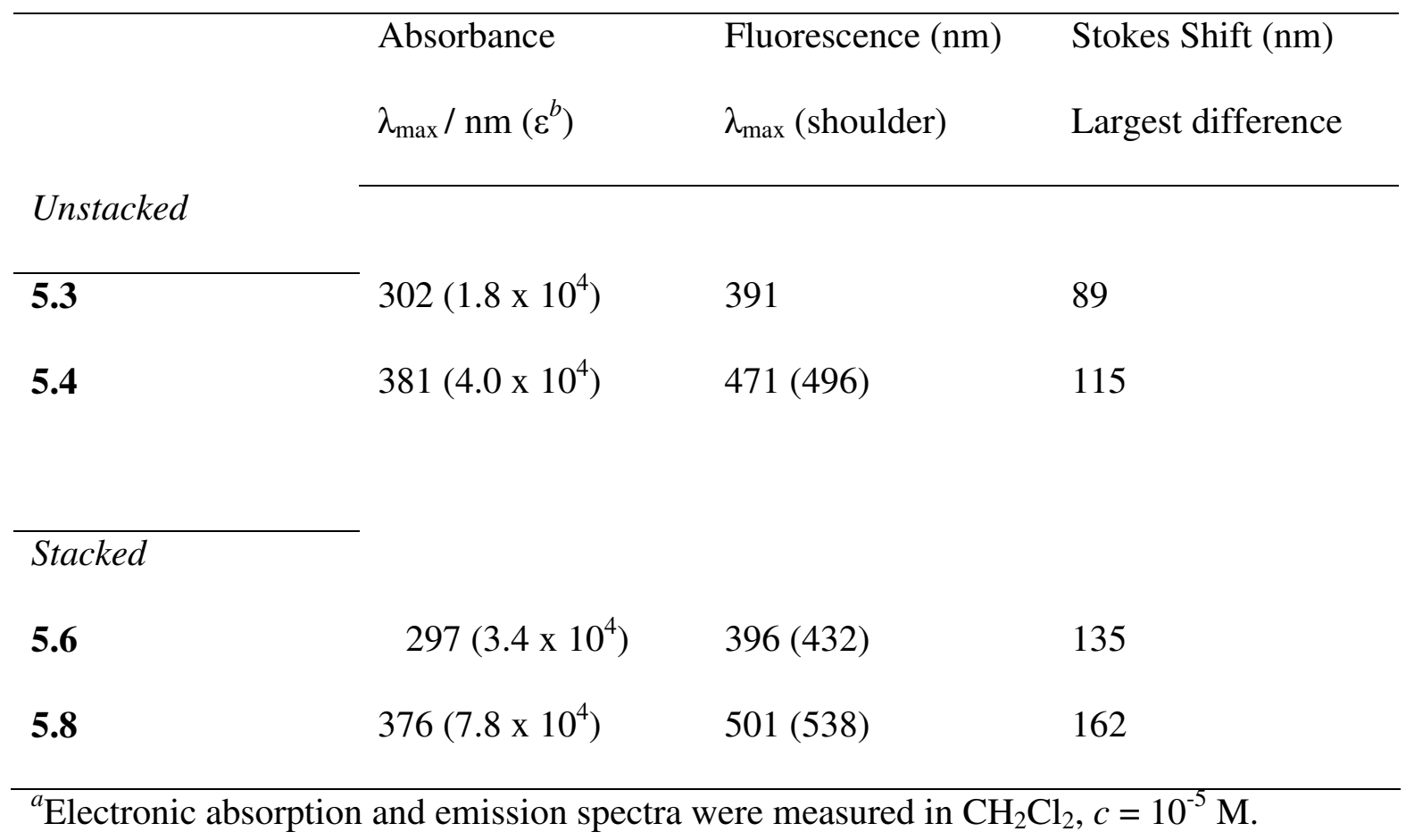

The Stokes shift of the phenyl-capped oligothiophene model and $\pi$-stacked compounds can be compared to the previously discussed compounds in Chapter 4. The $\pi$-stacked compounds exhibit larger Stokes shifts than their model compounds due to increased stability by $\pi$-stacking two oligomers (blue and red lines), Figure 5.16. Interestingly, the $\pi$-stacked three ring system here has more of a similar excited state emission between the absorbing chromophore to the phane state emission. There is not as a much of a driving force for migration of the photon through space to the other chromophore as seen in the $\pi$-stacked terthiophene compound, st-[Me-Th $\mathbf{3}-\mathbf{M e}]_{2}$. Extending the conjugation length to the five ring system promotes a similar driving force for emission from the phane state of the molecule as seen in the shorter stacked 
oligomers. This behavior correlated to the oligothiophene substituted compounds may be attributed to the steric effects of the phenyl group on the excited state characteristics.

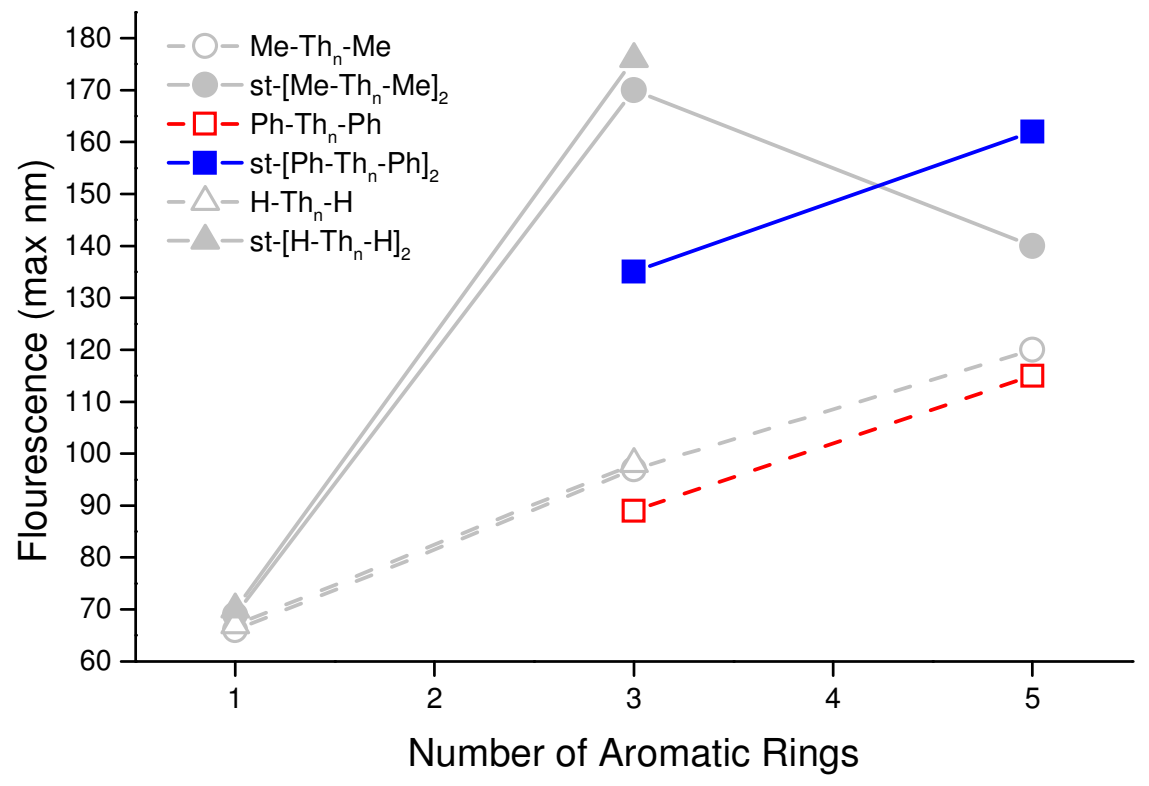

Figure 5.16. Stokes shifts of model and stacked oligothiophenes versus \# of aromatic rings.

\subsubsection{Electrochemistry of Phenyl-Capped Oligothiophenes}

The unstacked phenyl-capped model $\mathbf{5 . 3}$ exhibited a $1 e^{-}$reversible oxidation wave at $E_{1 / 2}=+1.38 \mathrm{~V}$, and the removal of a second electron was not plausible in this electrolyte, $>2.0 \mathrm{~V}$, Figure 5.17. The $\pi$-stacked analog $\mathbf{5 . 6}$ exhibited two sharp reversible oxidation waves (both $1 e^{-}$each) for the oxidation to the radical cation, and then to the dicationic ( $\pi$-dimer) species, at $E_{1 / 2}=+1.19 \mathrm{~V}$ and $E_{1 / 2}=+1.48 \mathrm{~V}$, respectively, Figure 5.17. Further oxidation to the tricationic or tetracationic species was not possible under these conditions. DPV in the same electrolyte also gave two resolved peaks at similar oxidation potentials for the $\pi$-stacked compound and one for the model compound, Figure 5.18. 


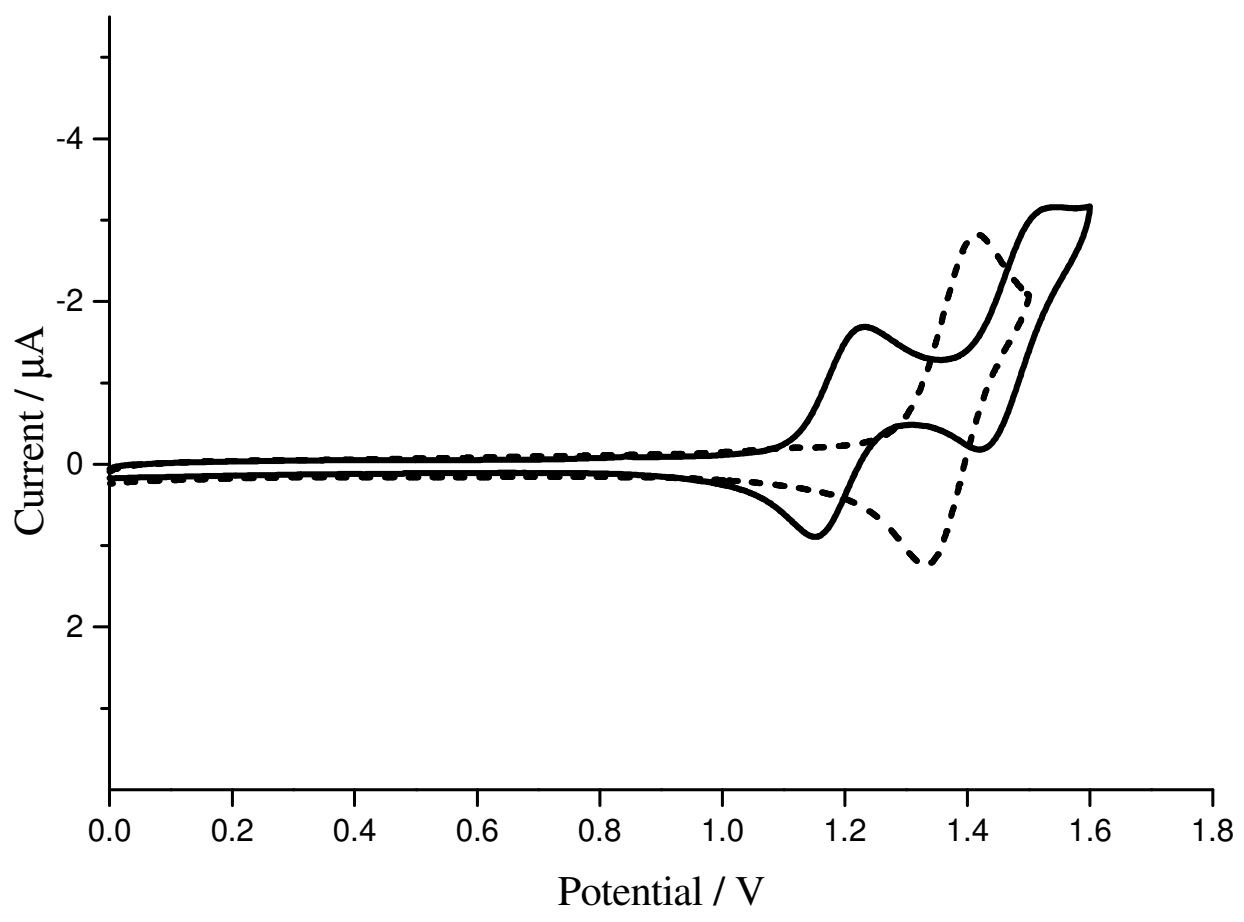

Figure 5.17. $\mathrm{CV}$ of model 5.3 (dashed) and $\pi$-stacked compound $\mathbf{5 . 6}$ (solid). $c=$ $2 \mathrm{mM}$ in $\mathrm{CH}_{2} \mathrm{Cl}_{2} ; 0.1 \mathrm{M} n-\mathrm{Bu}_{4} \mathrm{NPF}_{6} / \mathrm{CH}_{2} \mathrm{Cl}_{2} ; \mathrm{Au}$ working electrode auxiliary, $\mathrm{Ag} / \mathrm{Ag}^{+}$reference electrode; $v=100 \mathrm{mV} / \mathrm{s}$.

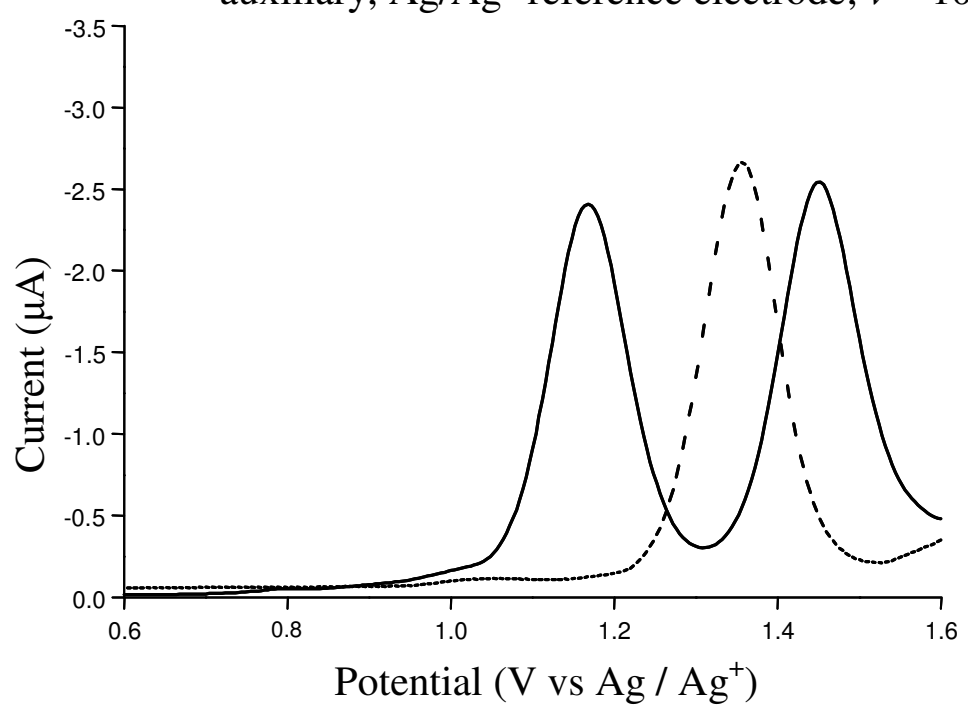

Figure 5.18. DPV of model compound 5.3 (dotted line) and $\pi$-stacked compound 5.6 (solid line). $\quad c=2 \mathrm{mM}$ in $\mathrm{CH}_{2} \mathrm{Cl}_{2} ; 0.1 \mathrm{M} n-\mathrm{BuN}_{4} \mathrm{PF}_{6} / \mathrm{CH}_{2} \mathrm{Cl}_{2} ; \mathrm{Au}$ working electrode; Pt auxillary, $\mathrm{Ag} / \mathrm{Ag}^{+}$reference electrode; $v=100 \mathrm{mV} / \mathrm{s}$. 
The cyclic voltamogram of model compound $\mathbf{5 . 4}$ in the supporting electrolyte $n$ $\mathrm{Bu}_{4} \mathrm{NPF}_{6}$ gave two sharp, reversible $1 e^{-}$oxidation waves for the formation of a radical cation species to the dicationic species $\left(E_{1 / 2}=+0.84 \mathrm{~V}\right.$ and $E_{1 / 2}=+1.20 \mathrm{~V}$, respectively, Figure 5.19. The $\pi$-stacked compound 5.8 exhibited a $1 e^{-}$reversible oxidation for a radical cation stacked ontop a neutral oligomer at $E_{1 / 2}=+0.70 \mathrm{~V}$, followed by another 1 $e^{-} \quad$ reversible oxidation wave to the dicationic species $\left(\pi\right.$-dimer) at $E_{1 / 2}=+0.82 \mathrm{~V}$. At higher oxidation potential, another $2 e^{-}$reversible process occurred concurrently at $E_{1 / 2}=$ $+1.44 \mathrm{~V}$, for the formation of a tetra-cationic species. The DPV of the model $\mathbf{5 . 4}$ and $\pi$ stacked compound $\mathbf{5 . 8}$ more easily illustrate the redox peaks of both compounds, Figure 5.20 .

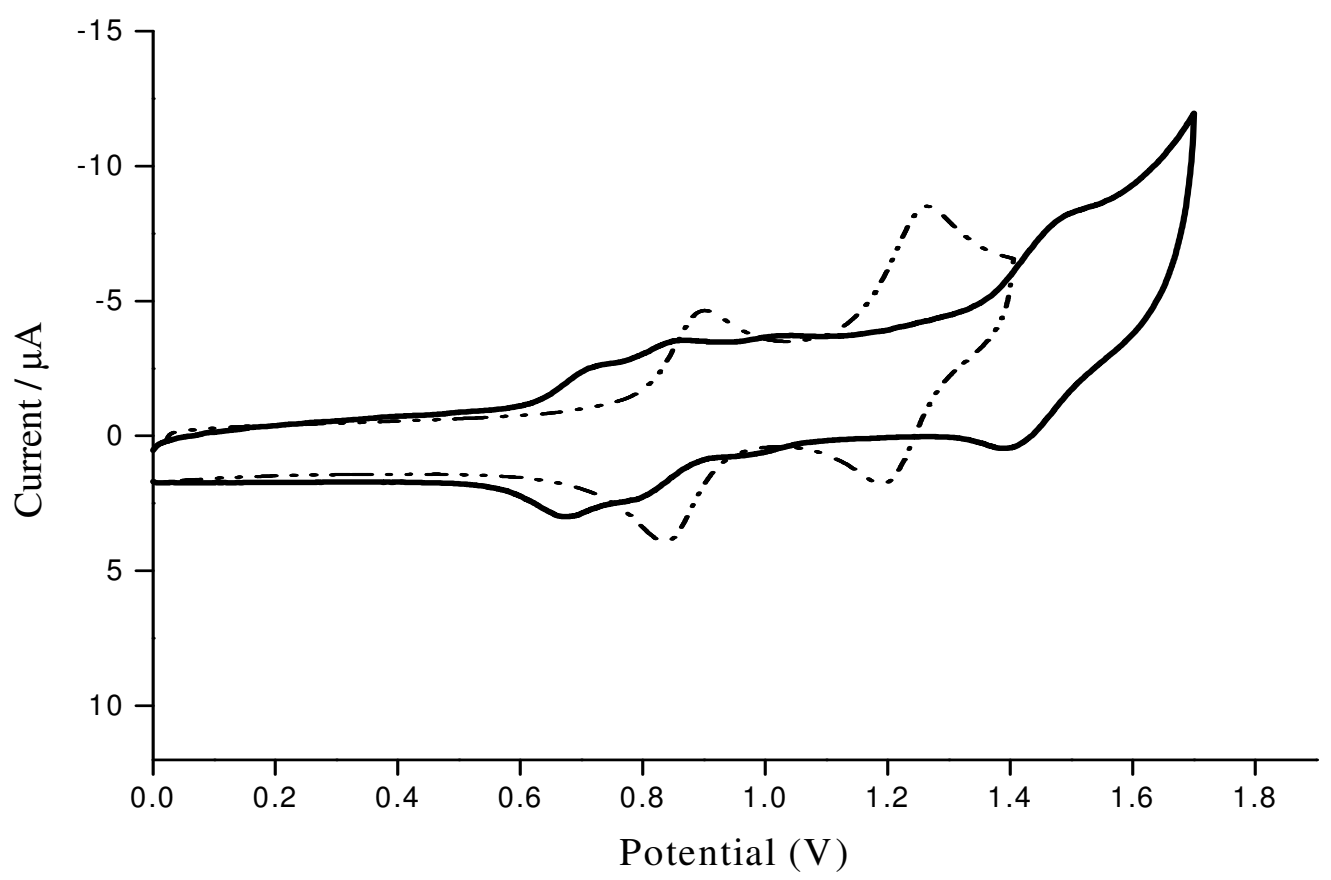

Figure 5.19. $\mathrm{CV}$ of model $\mathbf{5 . 4}$ (dotted line) and $\pi$-stacked compound $\mathbf{5 . 8}$ (solid line). $c$ $=2 \mathrm{mM}$ in $\mathrm{CH}_{2} \mathrm{Cl}_{2} ; 0.1 \mathrm{M} n-\mathrm{BuN}_{4} \mathrm{PF}_{6} / \mathrm{CH}_{2} \mathrm{Cl}_{2}$; Au working electrode; $\mathrm{Pt}$ auxillary, $\mathrm{Ag} / \mathrm{Ag}^{+}$reference electrode; $v=100 \mathrm{mV} / \mathrm{s}$. 


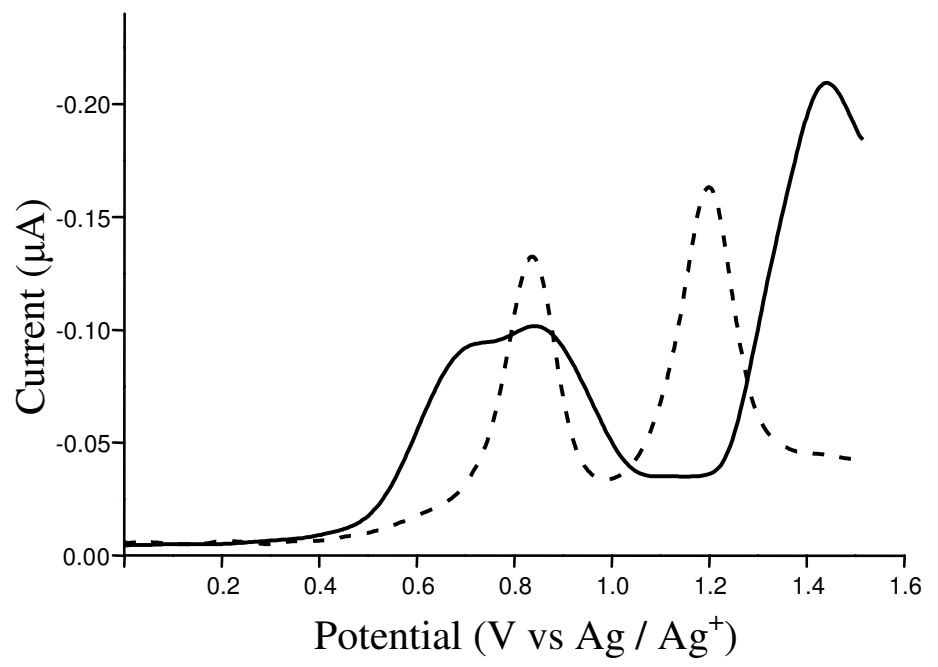

Figure 5.20. DPV of model, 5.4, (dotted line) and $\pi$-stacked compound, 5.8, (black line). $c=2 \mathrm{mM}$ in $\mathrm{CH}_{2} \mathrm{Cl}_{2} ; 0.1 \mathrm{M} n-\mathrm{BuN}_{4} \mathrm{PF}_{6} / \mathrm{CH}_{2} \mathrm{Cl}_{2} ; \mathrm{Au}$ working electrode; Pt auxillary, $\mathrm{Ag} / \mathrm{Ag}^{+}$reference electrode; $v=100 \mathrm{mV} / \mathrm{s}$.

The electronic communication and the nature of the charged species can be influenced by the use of a different supporting electrolyte, such as $\left[n-\mathrm{Bu}_{4} \mathrm{~N}\right]\left[\mathrm{B}\left(\mathrm{C}_{6} \mathrm{~F}_{5}\right)_{4}\right]$ which contains weakly ion-pairing anions This particular electrolyte should decrease Coulombic repulsion and increase the solubility of highly charged cations, allowing the charge to become delocalized more freely over the length conjugated oligomer. Using $\left[\mathrm{Bu}_{4} \mathrm{~N}\right]\left[\mathrm{B}\left(\mathrm{C}_{6} \mathrm{~F}_{5}\right)_{4}\right]$ and focusing on the extended conjugated compounds, the cyclic voltammetry and the DPV of $\mathbf{5 . 4}$ show two reversible redox waves, $E_{1 / 2}=+0.90 \mathrm{~V}$ and $E_{1 / 2}=+1.37 \mathrm{~V}$, Figure 5.21. Compared to the use of the smaller, tightly binding anion $\mathrm{PF}_{6}^{-}$, both oxidation potentials are slightly increased $(+60 \mathrm{mV}$ and $+117 \mathrm{mV}$, respectively). The peak splitting increases by $+110 \mathrm{mV}$ between the two electron oxidation waves in the bulky electrolyte due to the increased solubility of the charged radical cation. 


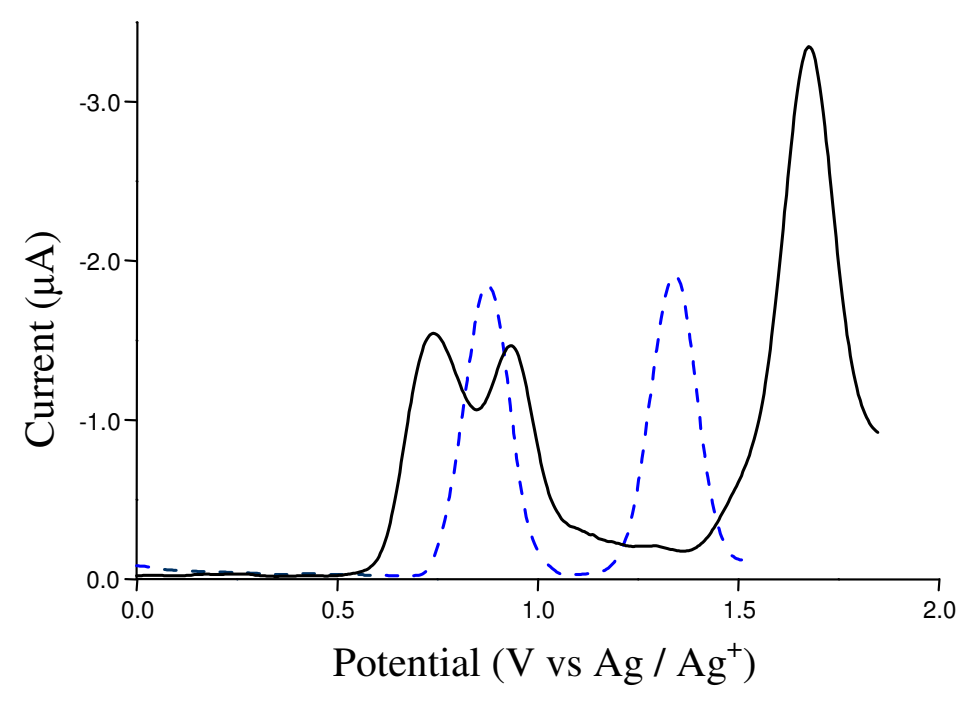

Figure 5.21. DPV of model, 5.4, (blue dotted line) and $\pi$-stacked compound, 5.8, (black line). $\quad c=2 \mathrm{mM}$ in $\mathrm{CH}_{2} \mathrm{Cl}_{2} ; 0.1 \mathrm{M}\left[n-\mathrm{Bu}_{4} \mathrm{~N}\right]\left[\mathrm{B}\left(\mathrm{C}_{6} \mathrm{~F}_{5}\right)_{4}\right] / \mathrm{CH}_{2} \mathrm{Cl}_{2} ; \mathrm{Au}$ working electrode; $\mathrm{Pt}$ auxillary, $\mathrm{Ag} / \mathrm{Ag}^{+}$reference electrode; $v=100 \mathrm{mV} / \mathrm{s}$.

In the $\left[\mathrm{Bu}_{4} \mathrm{~N}\right]\left[\mathrm{B}\left(\mathrm{C}_{6} \mathrm{~F}_{5}\right)_{4}\right]$ electrolyte, the voltamogram of $\mathbf{5 . 8}$ exhibits different oxidation waves to that of $\mathrm{PF}_{6}^{-}$, first oxidation at $E_{1 / 2}=+0.76 \mathrm{~V}$, second oxidation at $E_{1 / 2}$ $=+0.96 \mathrm{~V}$, and simultaneous $3^{\text {rd }}$ and $4^{\text {th }}$ oxidations at $E_{1 / 2}=+1.70 \mathrm{~V}$, Figure 5.21 The oxidation potentials are $+60 \mathrm{mV},+140 \mathrm{mV}$, and $+260 \mathrm{mV}$ higher than in the smaller anion electrolyte. The splitting between the first and second oxidation waves $(+200 \mathrm{mV})$ is larger than the splitting in the $\mathrm{PF}_{6}^{-}(+120 \mathrm{mV})$, due to the increased charge migration. A summary of the electrochemical data is illustrated in Table 5.3. 
Table 5.3. Oxidation Potentials of Unstacked and Stacked Oligothiophenes ${ }^{a}$.

\begin{tabular}{|c|c|c|c|c|}
\hline & $E_{1} / \mathrm{V}\left(\right.$ no $\left.e^{-}\right)$ & $\Delta E_{1} / \mathrm{V}$ & $E_{2} / \mathrm{V}\left(\operatorname{no} e^{-}\right)$ & $\Delta E_{2-1} / \mathrm{V}$ \\
\hline $\mathrm{Me}-\mathrm{Th}_{1}$-Me & $1.39(1)^{b}$ & - & - & - \\
\hline$s t-\left[\mathrm{Me}-\mathrm{Th}_{1}-\mathrm{Me}\right]_{2}$ & $1.09(1), 1.59(1)^{b}$ & 0.5 & & \\
\hline $\mathrm{Me}-\mathrm{Th}_{3}$-Me & 0.96 & - & $1.23(1)$ & 0.27 \\
\hline$s t-\left[\mathrm{Me}-\mathrm{Th}_{3}-\mathrm{Me}\right]_{2}$ & $0.70(1), 0.90(1)$ & 0.20 & $1.49(2)$ & 0.59 \\
\hline Me-Th-Me & 0.79 & - & $1.02(1)$ & 0.23 \\
\hline$s t-\left[\mathrm{Me}-\mathrm{Th}_{5}-\mathrm{Me}\right]_{2}$ & $0.67(1), 0.73(1)$ & 0.06 & $1.22(2)$ & 0.49 \\
\hline 5.3 & $1.38(1)$ & - & $>2$ & - \\
\hline 5.6 & $1.19(1), 1.48(1)$ & 0.29 & $>2$ & - \\
\hline \multirow[t]{2}{*}{5.4} & $0.84(1)$ & - & $1.20(1)$ & 0.36 \\
\hline & $0.90(1)^{c}$ & - & $1.37(1)^{c}$ & 0.47 \\
\hline \multirow[t]{2}{*}{5.8} & $0.70(1), 0.82(1)$ & 0.12 & $1.44(2)$ & 0.62 \\
\hline & $0.76(1), 0.96(1)^{c}$ & 0.20 & $1.70(2)^{c}$ & 0.74 \\
\hline
\end{tabular}

${ }^{a} c=1-2 \mathrm{mM}, 0.1 \mathrm{M} \mathrm{Bu}_{4} \mathrm{NPF}_{6}$ as supporting electrolyte in $\mathrm{CH}_{2} \mathrm{Cl}_{2} v=100 \mathrm{mV} / \mathrm{s} ; \mathrm{Ag} / \mathrm{Ag}^{+}$ reference; $\mathrm{Au}$ working electrode, platinum auxiliary; $\mathrm{Fc} / \mathrm{Fc}^{+}=0.45 \mathrm{~V}{ }^{b}$ irreversible. ${ }^{c}$ Supporting electrolyte $=0.1 \mathrm{M} \mathrm{Bu}_{4} \mathrm{~N}\left[\mathrm{~B}\left(\mathrm{C}_{6} \mathrm{~F}_{5}\right)_{4}\right]$ in $\mathrm{CH}_{2} \mathrm{Cl}_{2} ; \mathrm{Fc} / \mathrm{Fc}^{+}=0.47 \mathrm{~V}$.

$\pi$-Stacked compounds $\mathbf{5 . 6}$ and $\mathbf{5 . 8}$ are permanently held together by the covalent linkage of a bicyclo[4.4.1] undecane core, with an ethylene glycol clipping unit. In the neutral state, each oligomer acts as an electron donor, and lowers the oxidation potential for the first oxidation wave. This is illustrated with $\mathbf{5 . 6}(-190 \mathrm{mV})$ and $\mathbf{5 . 8}(-140 \mathrm{mV})$ when compared to each model compound. In the case of the removal of the second electron for 5.6, $\left(E_{1 / 2}=+1.48 \mathrm{~V}\right)$, there is an energy cost for stable $\pi$-dimer formation, $+100 \mathrm{mV}$ above the first oxidation of model $\mathbf{5 . 3}$, contributed by an electron-withdrawing 
effect of a singly charged oligomer. The highly charged cation of $\mathbf{5 . 6}$ exhibits larger Coulombic repulsion than that of 5.8, due to its decreased conjugation length and more localized charge.

In the case of $\mathbf{5 . 8}$, the removal of the second electron $\left(E_{1 / 2}=+0.82 \mathrm{~V}\right)$ is $-20 \mathrm{mV}$ lower than that of the model 5.4's first oxidation wave. The electron withdrawing effect is substantially diminished due to the increased charge delocalization of the extended oligomer. Thus, the $\pi$-dimer formed upon two electron removal in $\mathbf{5 . 8}$ is readily accessible at room temperature under these conditions. The coincidental third and fourth oxidations at $E_{1 / 2}=+1.44 \mathrm{~V}$ imply that once the $\pi$-dimer is formed, it is stable, and undergoes further oxidation higher than that of its second oxidation wave $(+620 \mathrm{mV})$, causing this two electron process to happen together.

\subsubsection{Chemical Oxidation of Phenyl-Capped Oligothiophenes}

The phenyl-capped model oligothiophene 5.4 undergoes chemical oxidation to the radical cation species with the appearance of new energy transitions at $650 \mathrm{~nm}(1.91 \mathrm{eV})$ and $1095 \mathrm{~nm}(1.13 \mathrm{eV})$ in its UV-vis-NIR spectrum, Figure 5.22. Cooling the solution down to $-30{ }^{\circ} \mathrm{C}$ partially formed the $\pi$-dimer aggregate with new absorbance bands. The radical cation peaks diminished as peaks at $584 \mathrm{~nm}(2.12 \mathrm{eV}), 975 \mathrm{~nm}(1.27 \mathrm{eV}), 1250$ $\mathrm{nm}(0.99 \mathrm{eV})$ increased, Figure 5.22. Further oxidation to the dication at room temperature $\left(4\right.$ eq. $\mathrm{FeCl}_{3}$ ) gave a new peak at $803 \mathrm{~nm}(1.54 \mathrm{eV})$ with the absence of the radical cation peaks. Model $\mathbf{5 . 1 3}$ did not form a radical cation spectrum due to its higher oxidation potential $\left(+160 \mathrm{mV}\right.$ higher than $\left.\mathrm{FeCl}_{3}\right)$. 


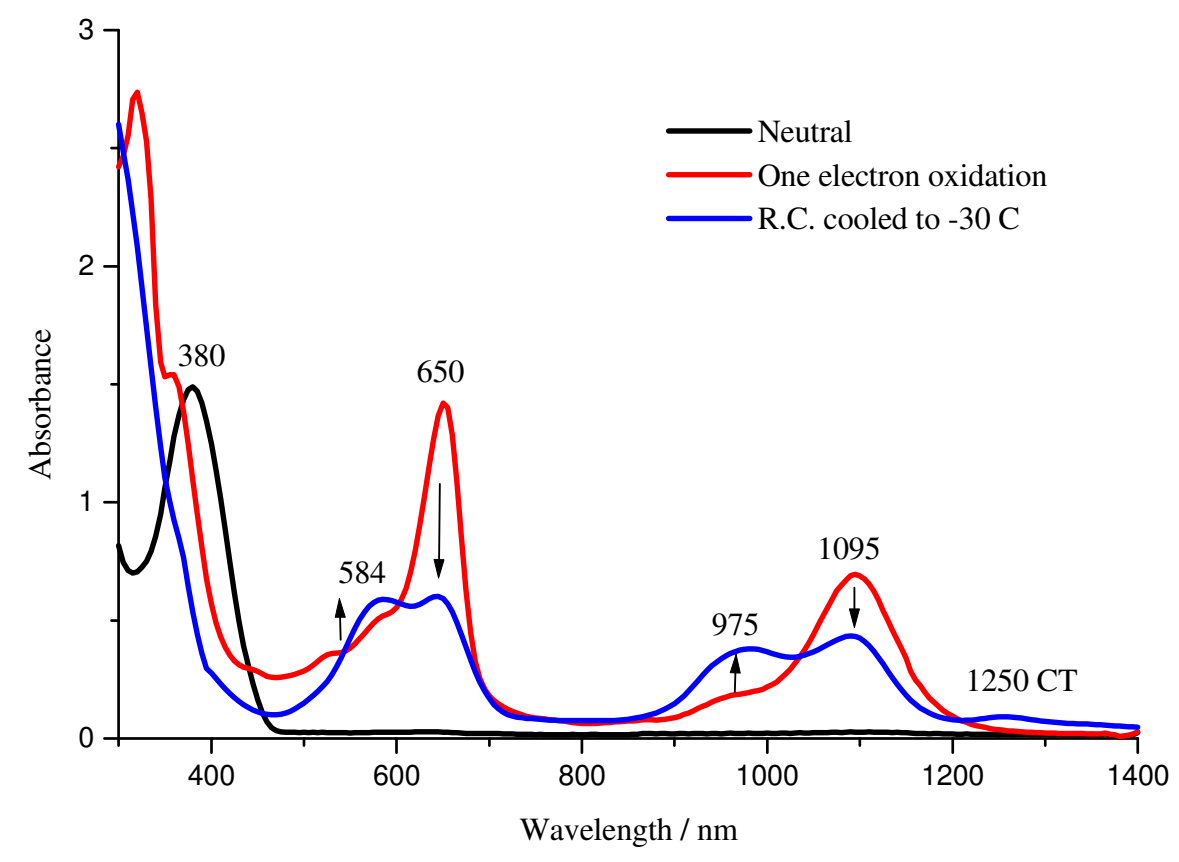

Figure 5.22. Absorbance spectrum of 5.4. Neutral (black line), addition of 2eq. $\mathrm{FeCl}_{3}$ (red line), cooling solution to $-30{ }^{\circ} \mathrm{C}$ (blue line) in acetonitrile.

For the $\pi$-stacked compound $\mathbf{5 . 6}$ the radical cation species can be generated chemically, forming new energy transitions (322 nm (3.85 eV), $443 \mathrm{~nm}(2.80 \mathrm{eV}), 569$ $\mathrm{nm}(2.18 \mathrm{eV})$, and $868 \mathrm{~nm}(1.43 \mathrm{eV})$ similar to the oligothiophenes in Chapter 4. Further oxidation to the $\pi$-dimer species could not be seen with this oxidant. The longer phenylcapped oligothiophene $\mathbf{5 . 8}$ undergoes 1 e- oxidation to the radical cation species with new energy transitions at $400 \mathrm{~nm}(3.10 \mathrm{eV}), 495 \mathrm{~nm}(2.51 \mathrm{eV}), 665 \mathrm{~nm}(1.86 \mathrm{eV})$, and $1105 \mathrm{~nm}(1.12 \mathrm{eV})$, Figure 5.23. The two electron oxidation of $\mathbf{5 . 8}$ forms new peaks at $590 \mathrm{~nm}(2.10 \mathrm{eV}), 965 \mathrm{~nm}(1.28 \mathrm{eV})$, and $1290 \mathrm{~nm}(0.96 \mathrm{eV})$ while the radical cation peaks disappear, Figure 5.23. 


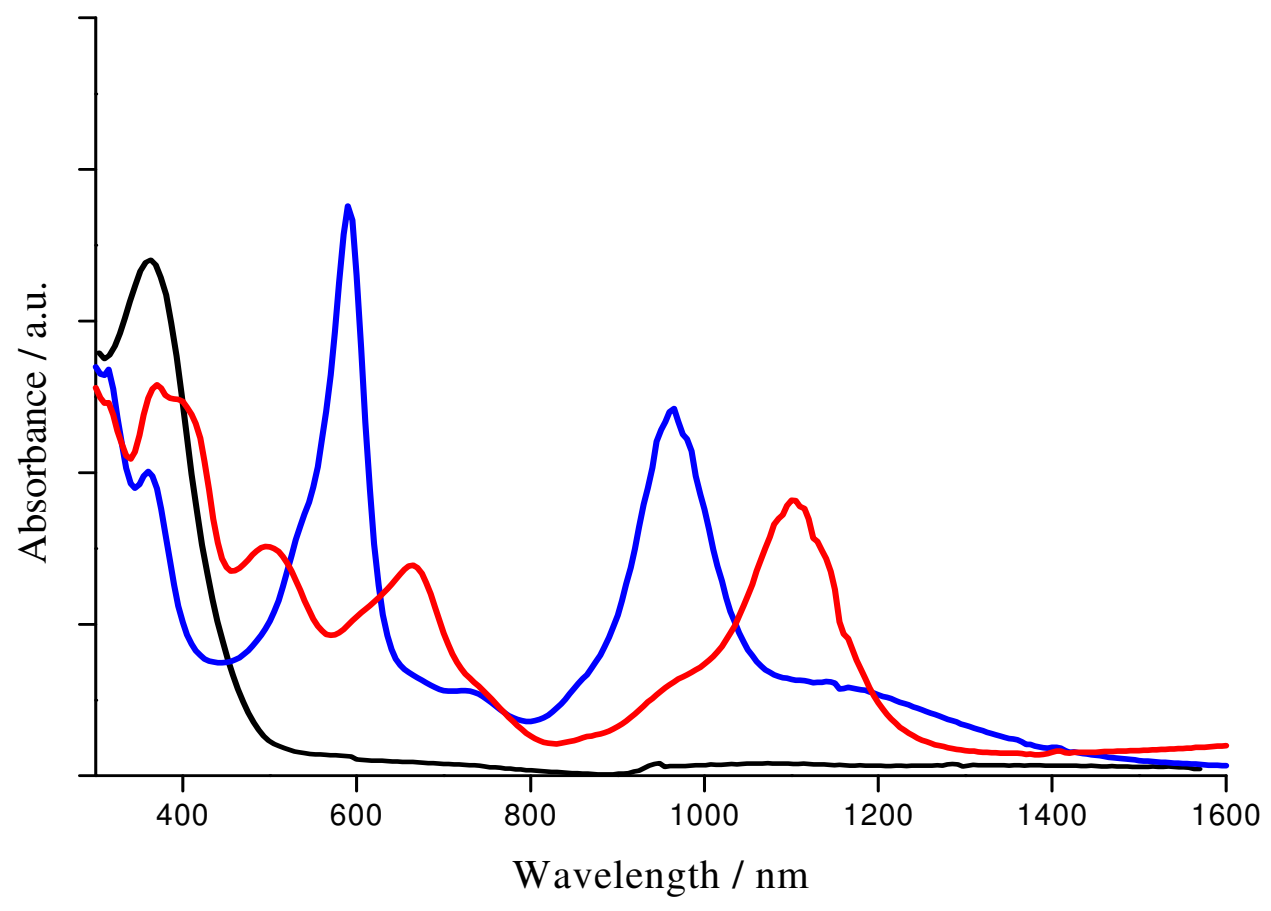

Figure 5.23. Absorbance spectrum of 5.4. Neutral (black line), addition of 2 eq. $\mathrm{FeCl}_{3}$ (red line), addition of 4 eq. $\mathrm{FeCl}_{3}$ (blue line) in dichloromethane at room temperature. Absorbances are normalized for each neutral unit.

The ESR spectrum corroborated the spin active radical cation species or the spinless $\pi$-dimer species. Upon formation of the radical cation species of the model compound 5.4 with two equivalents $\mathrm{FeCl}_{3}$, a large ESR signal forms. Further titration to four eq. forms an ESR inactive signal, Figure 5.24 (top). For the linear model compound 5.4, the spin-active radical cation species diminished upon $\pi$-dimer formation at lower temperature in acetonitrile, Figure 5.24 (bottom). The color changes by visible inspection of the solutions are apparent by formation of the different species. 


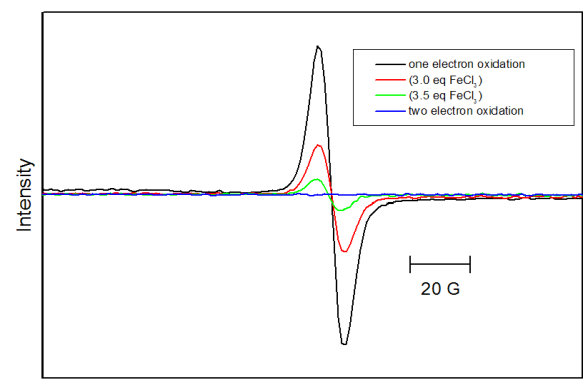

Magnetic Induction

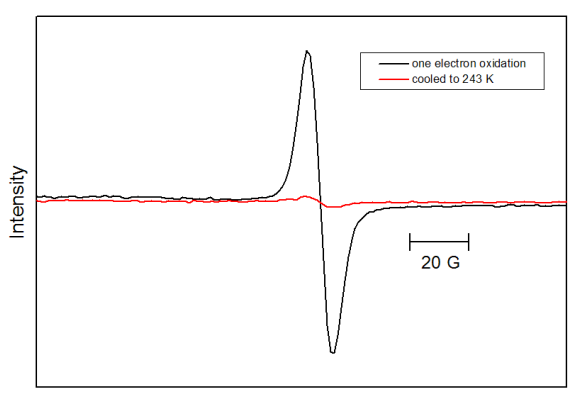

Magnetic Induction

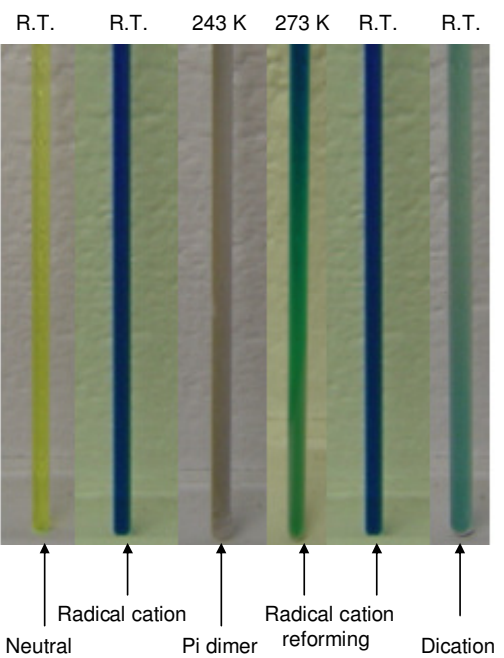

Figure 5.24. ESR spectra of $\mathbf{5 . 4}$ (bottom) and $\mathbf{5 . 8}$ (top).

\subsubsection{Correlations in Electronic Structure}

The onset of oxidation by electrochemical measurements was correlated to the HOMO energy level as calculated by de Leeuw. ${ }^{11}$ The onset of optical absorbances for each molecule was used to determine the energy difference between the HOMO and LUMO levels, Table 5.4. For the phenyl-capped oligothiophenes, band gap estimation to the vacuum level is illustrated for models 5.3/5.4 and $\pi$-stacked compounds $\mathbf{5 . 6 / 5 . 8}$ in Figure 5.25. 
Table 5.4. Cyclic Voltammetry and UV-vis Absorption Data

\begin{tabular}{|c|c|c|c|c|c|}
\hline Compound & $E_{p}(\mathrm{~V})$ & $\begin{array}{l}E^{\text {ox }}{ }_{\text {onset }} \\
(V)^{\mathrm{b}}\end{array}$ & $\begin{array}{c}\lambda_{\text {onset }}(\mathrm{nm})^{\mathrm{c}} \\
(\mathrm{eV})\end{array}$ & $\begin{array}{r}\mathrm{HOMO} \\
(\mathrm{eV})^{\mathrm{d}}\end{array}$ & $\begin{array}{r}\text { LUMO } \\
(\mathrm{eV})^{\mathrm{e}}\end{array}$ \\
\hline 5.8 & $+0.70,+0.82,+1.44^{\mathrm{a}}$ & 0.60 & $\begin{array}{l}477 \\
2.60\end{array}$ & -5.04 & -2.44 \\
\hline 5.4 & $+0.84,+1.20$ & 0.74 & $\begin{array}{l}466 \\
2.66\end{array}$ & -5.18 & -2.52 \\
\hline 5.6 & $+0.19,+1.48$ & 1.06 & $\begin{array}{l}350 \\
3.54\end{array}$ & -5.50 & -1.96 \\
\hline 5.3 & +1.38 & 1.24 & $\begin{array}{l}372 \\
3.33\end{array}$ & -5.68 & -2.35 \\
\hline
\end{tabular}

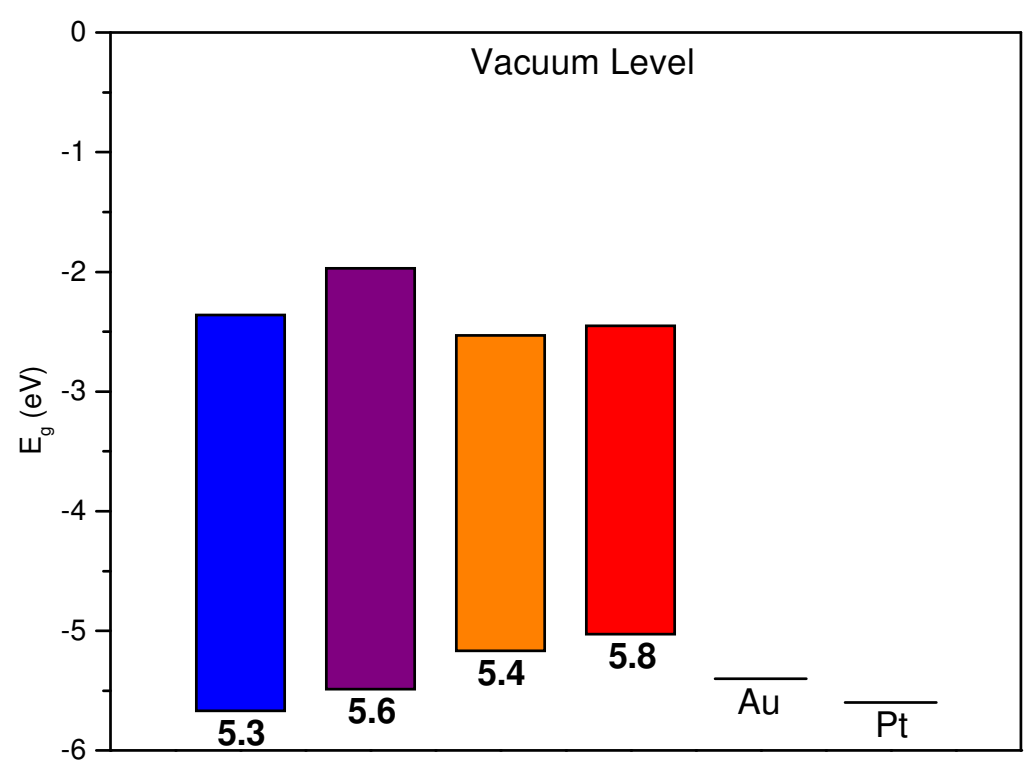

Figure 5.25. HOMO-LUMO energy levels deduced from cyclic voltammetry and UV absorption. 
As two oligomers become cofacially aligned, the HOMO energy level (absolute value) decreases which facilitates ejection of an electron to the LUMO level more easily for the $\pi$-stacked compounds 5.6 and 5.8. Upon extended the conjugation length for the phenyl-capped oligothiophenes, the band gap diminishes imparting more semiconductor

behavior. The $\mathrm{E}_{\mathrm{g}}{ }^{\text {opt }}$ values for model and $\pi$-stacked compounds changes slightly, but of more interest is the ability of the $\pi$-stacked compounds to be oxidized more. The $\pi$ stacked compounds can readily form $\pi$-dimers which stabilize the dicationic species, and subsequent oxidation to the tetra-cationic species is reversible.

\subsection{Conclusion}

Phenyl-capped $\pi$-stacked oligothiophenes have been synthesized and structural characterized by NMR spectroscopy. The neutral absorbance and emission fluorescences of the $\pi$-stacked compounds are characteristic of excimer formation in the excited states, and the larger Stokes shifts and broadened emission spectra are attributed to the intersystem crossing of a photon to a more energetically favored phane state. Electrochemical measurements and $\mathrm{FeCl}_{3}$ doping of this series of phenyl-capped oligothiophenes provides evidence for stable $\pi$-dimer formation of two oligomers held in a cofacial arrangement. 


\subsection{References}

1. Lee, S. A.; Yoshida, Y.; Fukuyama, M.; Hotta, S., "Phenyl-capped oligothiophenes: novel light-emitting materials with different molecular alignments in thin films," Synth. Met. 1999, 106, 39-43.

2. Apperloo, J. J.; Groenendaal, L. B.; Verheyen, H.; Jayakannan, M.; Janssen, R. A. J.; Dkhissi, A.; Beljonne, D.; Lazzaroni, R.; Bredas, J.-L., "Optical and redox properties of a series of 3,4-ethylenedioxythiophene oligomers," Chem. Eur. J. 2002, 8, 2384-2396.

3. Graf, D. D.; Duan, R. G.; Campbell, J. P.; Miller, L. L.; Mann, K. R., "From Monomers to p-Stacks. A Comprehensive Study of the Structure and Properties of Monomeric, p-Dimerized, and p-Stacked Forms of the Cation Radical of 3',4'Dibutyl-2,5"-diphenyl-2,2':5',2"-terthiophene," J. Am. Chem. Soc. 1997, 119, 5888-5899.

4. Graf, D. D.; Campbell, J. P.; Miller, L. L.; Mann, K. R., "Single-Crystal X-ray Structure of the Cation Radical of 3',4'-Dibutyl-2,5"-diphenyl-2,2':5',2"terthiophene: Definitive Evidence for p-Stacked Oxidized Oligothiophenes," $J$. Am. Chem. Soc. 1996, 118, 5480-5481.

5. Hotta, S.; Lee, S. A.; Tamaki, T., "Synthesis of thiophene/phenylene cooligomers. I. Phenyl-capped oligothiophenes," J. Heterocycl. Chem. 2000, 37, 2529.

6. Osikowicz, W.; Denier van der Gon, A. W.; Crispin, X.; de Jong, M. P.; Friedlein, R.; Groenendaal, L.; Fahlman, M.; Beljonne, D.; Lazzaroni, R.; Salaneck, W. R., "A joint theoretical and experimental study on the electronic properties of phenylcapped 3,4-ethylenedioxythiophene oligomers," J. Chem. Phys. 2003, 119, 1041510420.

7. Tachikawa, H.; Kawabata, H.; Ishida, K.; Matsushige, K., "A DFT and direct MO dynamics study on the structures and electronic states of phenyl-capped terthiophene," J. Organomet. Chem. 2005, 690, 2895-2904.

8. Casado, J.; Hernandez, V.; Hotta, S.; Lopez Navarrete, J. T., "Spectroelectrochemical Raman study of a new series of thiophene/phenylene cooligomers," Synth. Met. 2001, 119, 305-306. 
9. Becht, J.-M.; Gissot, A.; Wagner, A.; Mioskowski, C., "Reinvestigation of the noncatalyzed coupling of aryllithium with haloarene: A novel aromatic nucleophilic substitution pathway," Chem. Eur. J. 2003, 9, 3209-3215.

10. Knoblock, K. M.; Silvestri, C. J.; Collard, D. M., "Stacked Conjugated Oligomers as Molecular Models to Examine Interchain Interactions in Conjugated Materials," J. Am. Chem. Soc. 2006, 128, 13680-13681.

11. de Leeuw, D. M.; Simenon, M. M. J.; Brown, A. R.; Einerhand, R. E. F., "Stability of n-type doped conducting polymers and consequences for polymeric microelectronic devices," Synth. Met. 1997, 87, 53-59. 


\section{CHAPTER 6}

\section{FERROCENYL-CAPPED OLIGOTHIOPHENES: SYNTHESIS AND PHYSICAL PROPERTIES}

\subsection{Introduction}

Metallocene and ferrocene substituents when coupled to oligothiophenes are interesting as novel organic-organometallic hybrid compounds, ${ }^{1}$ where applications include sensors, storage devices, and electroluminescent devices. Oligothiophenes facilitate charge delocalization along a $\pi$-conjugated backbone, and attaching a metal center to the system increases charge hopping between metal centers and bridging units, allowing for potential stabilization of the system via another tier. Ferrocene is an ideal candidate for electronic conductivities and magnetic properties, and it can form a 17 electron ferrocenium ion, which has stable mixed valence $\mathrm{Fe}^{\mathrm{II}}$ and $\mathrm{Fe}^{\mathrm{III}}$ oxidation states.

Charge delocalization in linear $\pi$-conjugated model polyenes ${ }^{2,3}$ and poly-ynes ${ }^{4,5}$ has been studied extensively by substitution of the termini of conjugated oligomers with such electroactive groups (binuclear metal complexes). The $\pi$-conjugated chain can mediate electron transfer between the terminal groups with the formation of mixed valence states. Ferrocenyl-substituted polyenes with up to twelve methines display peak separation for oxidation of the two redox centers. ${ }^{6}$ In comparison, complexes with saturated bridges with larger than two carbons show a single voltammetric peak for oxidation of the two iron atoms. These studies have been extended to odd-alternate analogs like $\alpha, \omega-$ diphenylpolymethine anions, ${ }^{7} \alpha, \omega$-bis( $N$-methylpyridinium $)$ polymethine cations, ${ }^{8}$ and 
$\alpha, \omega$-bis(ferrocenyl)-polymethine cations $^{9}$ ) which provide added evidence for charge migration in a one-dimensional conjugated chain. These studies of linear $\pi$-conjugated materials do not, however, address interchain hopping of these charge carriers when in close proximity to one amother.

A recent study of oligomeric ferrocene-phenothiazine compounds ${ }^{10}$ have been shown to adopt an eclipsed conformation by partial intramolecular $\pi$-stacking, as illustrated with splitting in cyclic voltammetry. We can couple ferrocene by Negishi coupling conditions and study the electronic communication in a fully $\pi$-stacked system. The comparison of this end-capped ferrocenyl system can be compared to its synthesized linear, unstacked analog. The effect of $\pi$-stacking on neutral, cofacial oligomers can be monitored by NMR spectroscopy and UV-vis spectroscopy, white the extent and nature of charge migration by delocalization/charge hopping can be measured by cyclic voltammetry.

\subsection{Experimental}

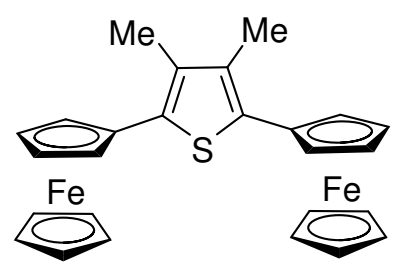

2,5-diferrocenyl-3,4-dimethylthiophene. To a solution of ferrocene (4.0 g, $21.4 \mathrm{mmol})$ and TMEDA $(9.7 \mathrm{~mL}, 64.3 \mathrm{mmol})$ in a mixture of dry THF $(25 \mathrm{~mL})$ and hexanes $(15$ $\mathrm{mL})$ was added $2.5 \mathrm{M} n$-BuLi in hexanes $(8.6 \mathrm{~mL}, 21.4 \mathrm{mmol})$ at $0{ }^{\circ} \mathrm{C}$. The reaction mixture was heated at reflux for $2 \mathrm{~h}$ and cooled to room temperature. A solution of $\mathrm{ZnCl}_{2}$ 
$(8.76 \mathrm{~g}, 64.3 \mathrm{mmol})$ in dry THF $(20 \mathrm{~mL})$ was adde,d and the mixture was stirred for another $2 \mathrm{~h}$. The reaction mixture was cannulated to a solution of 2,5-diiodo-3,4dimethylthiophene $(2.6 \mathrm{~g}, 7.2 \mathrm{mmol})$ and $\mathrm{Pd}\left(\mathrm{PPh}_{3}\right)_{4}(100 \mathrm{mg}, 0.09 \mathrm{mmol})$ in dry THF (20 $\mathrm{mL}$ ) and heated to $50{ }^{\circ} \mathrm{C}$ for $72 \mathrm{~h}$. After the reaction was cooled to room temperature, it was quenched with $0.5 \mathrm{M} \mathrm{HCl}(25 \mathrm{~mL})$. The organic layer was collected, and the aqueous layer was extracted with methylene chloride $(3 \times 50 \mathrm{~mL})$. The organic layers were combined and washed with water $(2 \times 50 \mathrm{~mL})$ and dried over $\mathrm{MgSO}_{4}$. The solvent was removed under reduced pressure to give the crude product as a brownish red solid. The crude material was purified by column chromatography on silica gel (1:1 hexane/ $\left.\mathrm{CH}_{2} \mathrm{Cl}_{2}\right)$ to afford the title compound as an orange solid, $(1.20 \mathrm{~g}, 35 \%)$ after recrystallization from a solution of hexane $/ \mathrm{CH}_{2} \mathrm{Cl}_{2}(3: 1) . \mathrm{MP}=179-180{ }^{\circ} \mathrm{C} .{ }^{1} \mathrm{H} \mathrm{NMR}\left(300 \mathrm{MHz}, \mathrm{CDCl}_{3}\right): \delta$ 4.48-4.52 (t, 4H, $J=1.8 \mathrm{~Hz}), 4.25-4.25(\mathrm{t}, 4 \mathrm{H}, J=1.8 \mathrm{~Hz}), 2.10(\mathrm{~s}, 6 \mathrm{H}) .{ }^{13} \mathrm{C} \mathrm{NMR}$ $\left(75 \mathrm{MHz}, \mathrm{CDCl}_{3}\right): \delta 133.9,133.1,81.9,69.7,68.8,68.0,14.0 . \quad \mathrm{IR}(\mathrm{NaCl})=3148,2983$, 2896, 1817, 1800, 1643, 1470, 1378, 1169, $1091 \mathrm{~cm}^{-1}$. MS (EI): $\mathrm{m} / \mathrm{z}(\%) 479.9\left(\mathrm{M}^{+}\right.$, 100). HRMS (EI): $m / z=$ calc. for $\mathrm{C}_{26} \mathrm{H}_{24} \mathrm{SFe}_{2}, 480.02975$; found, 480.02983. $\Delta=0.17$ ppm. Anal. Calc. for $\mathrm{C}_{26} \mathrm{H}_{24} \mathrm{SFe}_{2} \cdot 0.5 \mathrm{H}_{2} \mathrm{O}: \mathrm{C}, 63.83 ; \mathrm{H}, 5.05 ; \mathrm{S}, 6.55$. Found: C, 63.60; H, 5.09; S, 6.45. 


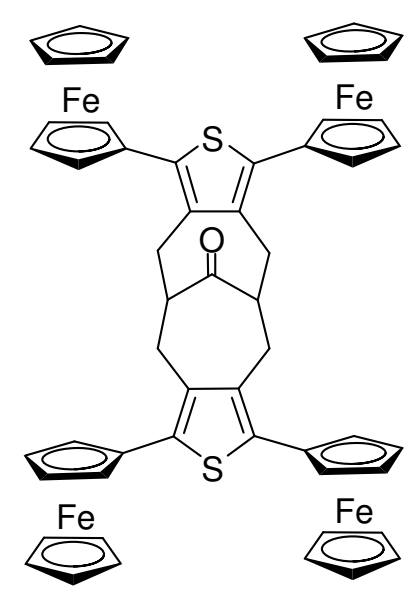

Tetraferrocenyl-dithieno-bicyclo[4.4.1]undecane-11-one. To a solution of ferrocene $(1.31 \mathrm{~g}, 7.05 \mathrm{mmol})$ in dry THF $(10 \mathrm{~mL})$ and hexanes $(10 \mathrm{~mL})$ was dropwise added 1.7 $\mathrm{M} t$-BuLi in pentanes $(5.5 \mathrm{~mL}, 9.4 \mathrm{mmol})$ at $0{ }^{\circ} \mathrm{C}$ over $10 \mathrm{~min}$. The reaction mixture was heated at reflux for $2 \mathrm{~h}$ and cooled to room temperature. A $0.5 \mathrm{M}$ solution of $\mathrm{ZnCl}_{2}$ in THF (18.8 mL, $9.4 \mathrm{mmol})$ was added, and the mixture was stirred for another $2 \mathrm{~h}$. The reaction mixture was cannulated to a solution of $3.2(0.52 \mathrm{~g}, 0.89 \mathrm{mmol})$ and $\mathrm{Pd}\left(\mathrm{PPh}_{3}\right)_{4}$ (400 mg, $0.35 \mathrm{mmol})$ in dry THF $\left(20 \mathrm{~mL}\right.$ ) and heated to $50{ }^{\circ} \mathrm{C}$ for $72 \mathrm{~h}$. After the reaction was cooled to room temperature, it was quenched with $0.5 \mathrm{M} \mathrm{HCl}(25 \mathrm{~mL})$. The organic layer was collected, and the aqueous layer was extracted with methylene chloride $(3 \times 50 \mathrm{~mL})$. The organic layers were combined and washed with water $(2 \times 50 \mathrm{~mL})$ and dried over $\mathrm{MgSO}_{4}$. The solvent was removed under reduced pressure to afford the crude material as a brownish red solid. The crude material was purified by column chromatography on silica gel (10\% ethyl acetate/hexanes) to afford the title compound as an orange powder, $(250 \mathrm{mg}, 28 \%)$ after recystallization from a solution of hexane/ $\mathrm{CH}_{2} \mathrm{Cl}_{2}$ (3:1). $\mathrm{MP}=210-212{ }^{\circ} \mathrm{C} . \quad{ }^{1} \mathrm{H}$ NMR $\left(300 \mathrm{MHz}, \mathrm{CDCl}_{3}\right): \delta$ 4.44-4.48 (m, 4H, Cp), 4.384.44 (m, 4H, Cp), 4.23-4.34 (m, 8H, Cp), 4.18-4.22 (s, 20H, Cp), 2.4-2.8 (m, 10H, 
methylene/bridgehead). IR $(\mathrm{NaCl})=3140,2975,2875,1690,1465,1372,1270,1165$, $1091,908,735 \mathrm{~cm}^{-1}$.

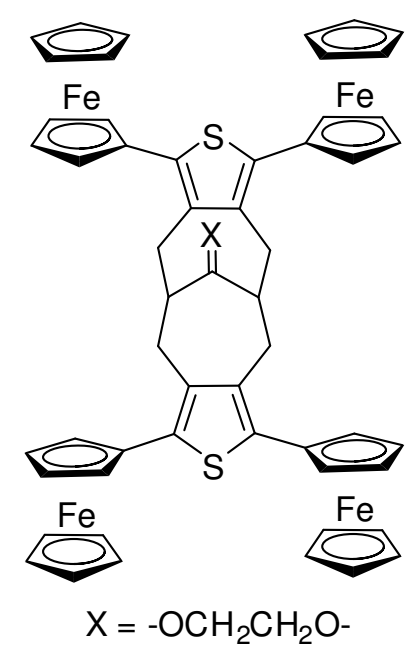

Tetraferrocenyl-dithieno[c,h]bicyclo[4.4.1]undecan-11-ethylene glycol. A solution of the tetraferrocennyl ketone $(275 \mathrm{mg}, 0.47 \mathrm{mmol})$, ethylene glycol (400 mg, $6.5 \mathrm{mmol})$, and p-toluene sulfonic acid $(6 \mathrm{mg})$ in benzene $(15 \mathrm{~mL})$ was heated at reflux for $48 \mathrm{~h}$ with a Dean-stark trap. The solvent was evaporated under reduce pressure, and the residue was subjected to column chromatography on silica gel (25\% dichloromethane/75\% hexanes) to give the title compound as orange solid, $(160 \mathrm{mg}, 32 \%)$. MP $=235-237{ }^{\circ} \mathrm{C}$ decomp. ${ }^{1} \mathrm{H}$ NMR (300 MHz, $\left.\mathrm{CDCl}_{3}\right): \delta 4.00-4.32(\mathrm{~m}, 20 \mathrm{H}, \mathrm{Cp}), 4.32-4.40(\mathrm{~m}, 4 \mathrm{H}, \mathrm{Cp})$, 4.40-4.48 (m, 4H, Cp), 3.88-3.90 (s, 4H, ethylene), 2.86-3.02 (dd, $J=5 \mathrm{~Hz}, \mathrm{~J}=15 \mathrm{~Hz}$, $4 \mathrm{H}$, methylene), 2.66-2.80 (dd, $J=6 \mathrm{~Hz}, J=15 \mathrm{~Hz}, 4 \mathrm{H}$, methylene), 2.12-2.28 (m, $2 \mathrm{H}$, bridgehead). ${ }^{13} \mathrm{C}$ NMR $\left(75 \mathrm{MHz}, \mathrm{CDCl}_{3}\right): \delta \quad 137.32,133.22,113.38,81.17,69.60$, 68.88, 67.95, 67.88, 64.03, 42.83, 28.10. IR (KBr): 3156, 3052, 3021, 2961, 2900, 1465, 1378, 1261, 1096, 1000, $539 \mathrm{~cm}^{-1}$. MS (MALDI-TOF): $\mathrm{m} / z(\%)=1054.0\left(\mathrm{M}^{+}, 100\right)$. HRMS (EI): $m / z=$ calc. for $\mathrm{C}_{57} \mathrm{H}_{50} \mathrm{O}_{2} \mathrm{~S}_{2} \mathrm{Fe}_{4}, 1054.06498$; found, 1054.07010. $\Delta=4.8$ 
ppm. Anal. Calc. for $\mathrm{C}_{57} \mathrm{H}_{50} \mathrm{O}_{2} \mathrm{~S}_{2} \mathrm{Fe}_{4} \cdot 1.5 \mathrm{H}_{2} \mathrm{O}: \mathrm{C}, 63.32 ; \mathrm{H}, 4.80 ; \mathrm{S}, 5.93$ : found: $\mathrm{C}, 63.22$; H, 4.75; S, 6.03 .

\subsection{Results and Discussion}

\subsubsection{Synthesis of Ferrocenyl Compounds}

Iodination of 3,4-dimethylthiophene with mercurous oxide, molecular iodine, and benzene provided 3,4-diiodo-3,4-dimethylthiophene in good yield (95\%), Figure 6.1. The synthesis of the model 2,5-diferrocenyl-3,4-diemethyl-thiophene was attempted by the Palladium catalyzed Stille and Suzuki reactions using the appropriate reagents, but these attempts were unsuccessful. The Negishi coupling with zinc-chloro-ferrocene was successful which provided 6.1 as an orange solid (75\%) after purification, Figure 6.1.
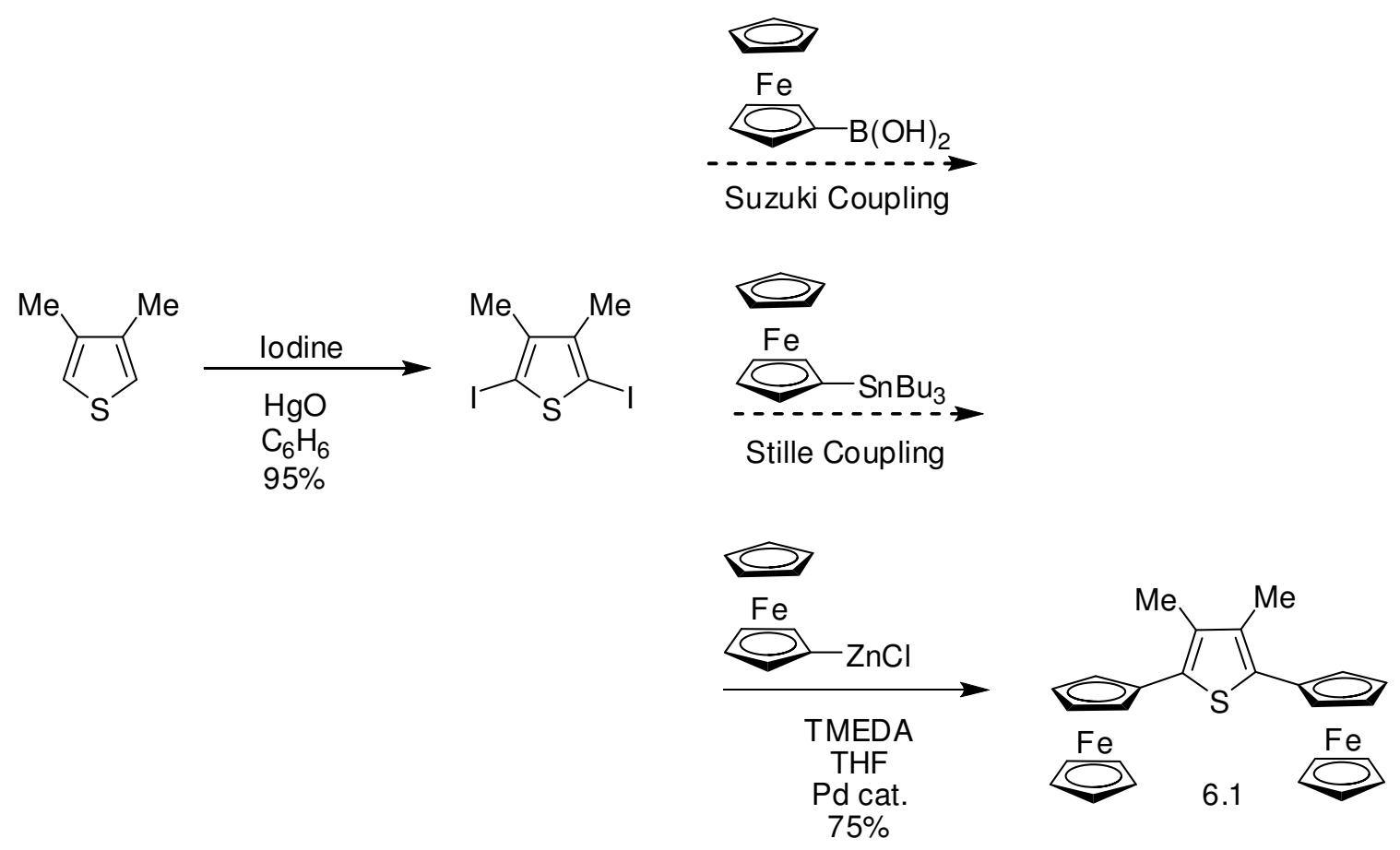

Figure 6.1. Synthesis of model 2,5-diferrocennyl-3,4-dimethylthiophene, 6.1.

The synthesis of the $\pi$-stacked anolog, 6.2, was synthesized in two steps from previously synthesized tetrabromo-ketone 3.2. The reaction of ketone 3.2 in THF and 
$\mathrm{Pd}\left(\mathrm{PPh}_{3}\right)_{4}$ with excess zinc-chloro- ferrocene formed in situ afforded the tetra-substituted ferrocennyl ketone in good yield (66\%), Figure 6.2. Ketalization of this intermediate compound with ethylene glycol in benzene with p-TSA afforded the $\pi$-stacked compound, 6.2, in a good yield (90\%) as an orange solid after purification, Figure 6.2.

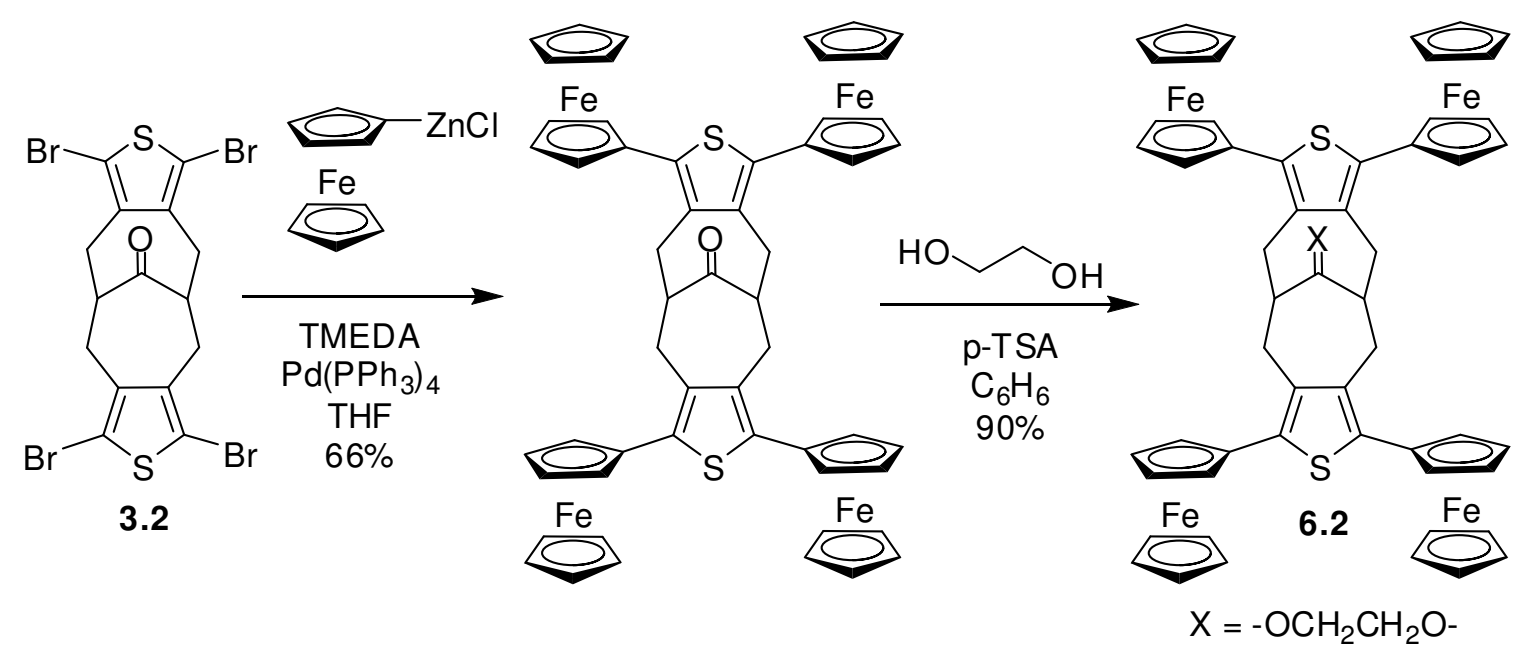

Figure 6.2. Synthesis of tetra-ferrocennyl-capped $\pi$-stacked compound $\mathbf{6 . 2}$.

\subsubsection{Structural Characterization: ${ }^{1} \mathrm{H}$ and ${ }^{13} \mathrm{C}$ NMR Spectroscopy}

The ${ }^{1} \mathrm{H}$ NMR spectrum of model compound $\mathbf{6 . 1}$ illustrated three distinct proton cyclopentadienyl signals, Figure 6.3. Two multiplets (four protons each) corresponding to the two different types of protons on the cyclopentadienyl ring adjacent to the thiophene ring were seen $(\delta 4.35$ and $4.5 \mathrm{ppm})$. The other ten protons on the bottom cyclopentadienyl ring correspond to a singlet at $4.2 \mathrm{ppm}$. The six methyl protons on the thiophene ring correspond to a singlet at $\delta 2.1 \mathrm{ppm}$. The ${ }^{13} \mathrm{C}$ NMR spectrum of $\mathbf{6 . 1}$ exhibited two types of aromatic carbon signals for the thiophene ring, Figure 6.4. The next four carbon signals upfield correspond to the four types of cyclopentadienyl carbon 
signals (three from the top ring and one from the bottom ring). The methyl carbon was consistent with one carbon signal further upfield in the alipathic region.

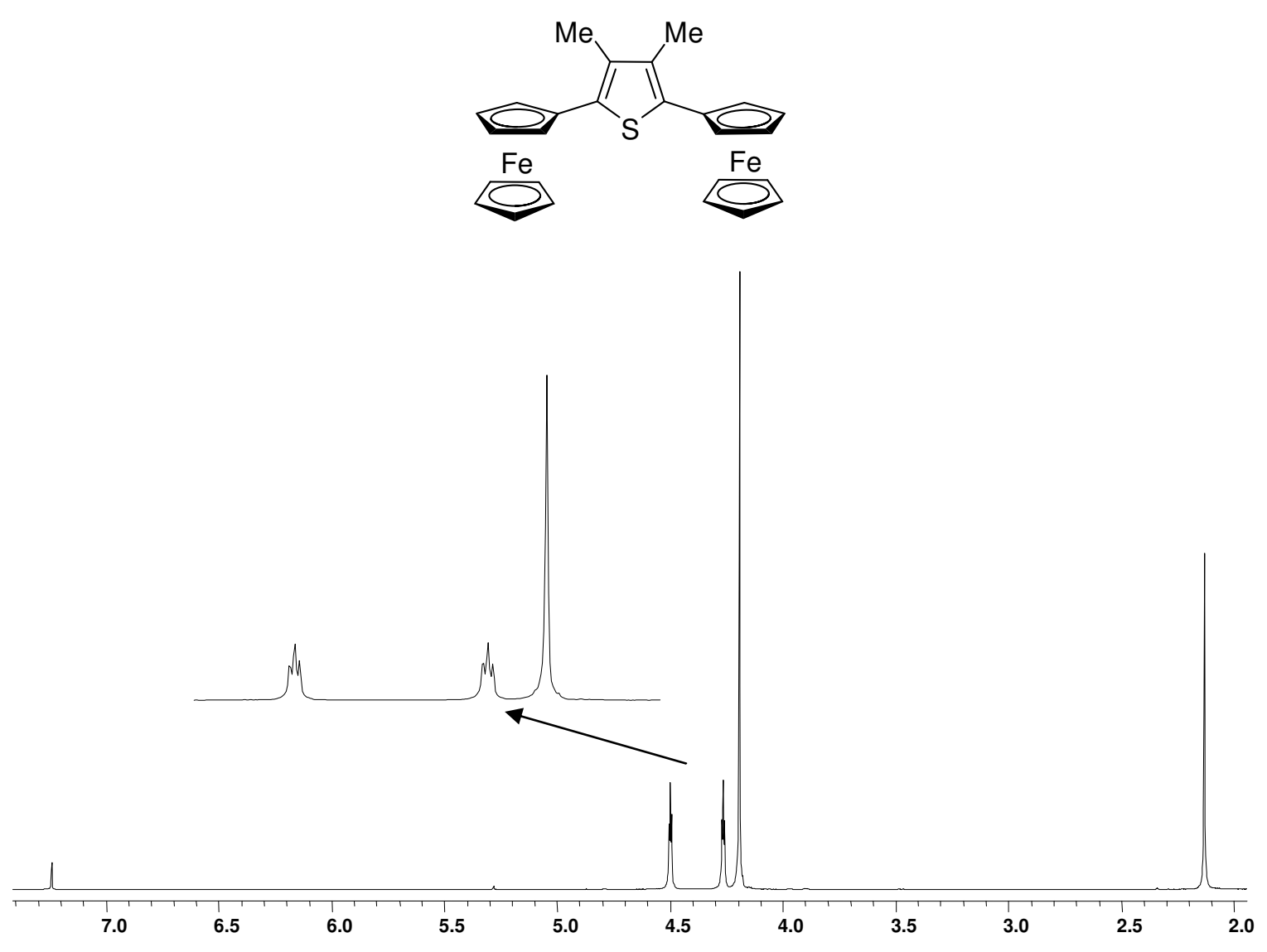

Figure 6.3. ${ }^{1} \mathrm{H} \mathrm{NMR}\left(300 \mathrm{MHz}, \mathrm{CDCl}_{3}\right)$ of model 6.1 at room temperature. 

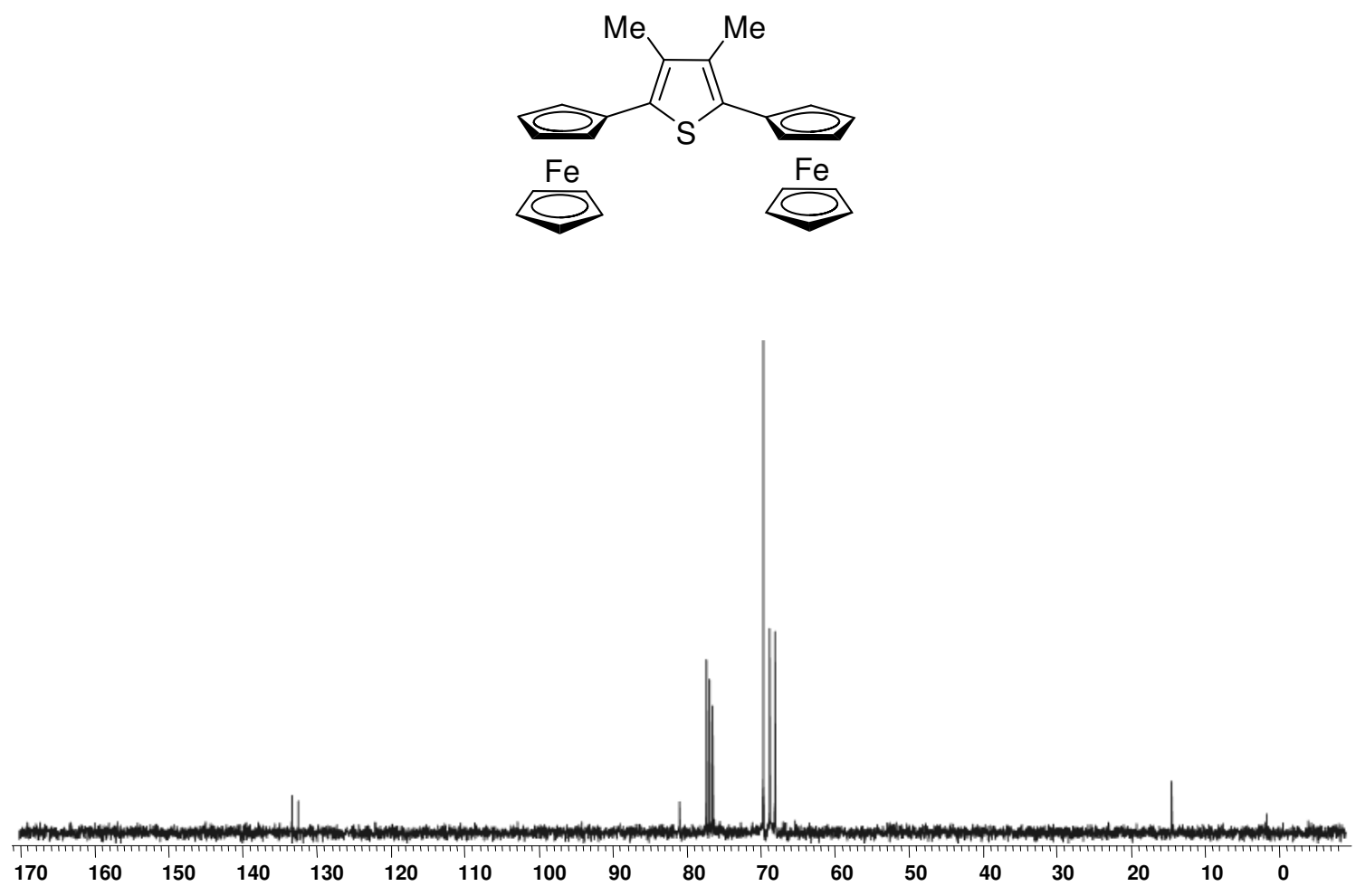

Figure 6.4. ${ }^{13} \mathrm{C} \mathrm{NMR}\left(300 \mathrm{MHz}, \mathrm{CDCl}_{3}\right)$ of model 6.1 at room termperature.

The ${ }^{1} \mathrm{H}$ NMR spectrum of $\pi$-stacked compound, 6.2, is illustrated in Figure 6.5. The cyclopentadienyl rings attached directly to the thiophene ring exhibited two multiplet signals ( $\delta 4.44$ and $4.36 \mathrm{ppm})$. One set of protons is distinctly more upfield than the corresponding linear compounds, 6.1, due to the effect of $\pi$-stacking the ferrocene compounds on top one another. The large singlet for the twenty protons of the cyclopentadienyl rings not attached to the thiophene rings is broadened due to the proximity of ethylene glycol unit to the top rings of ferrocene, and small shoulder peaks ( $\delta$ 4.0-4.2 $\mathrm{ppm}$ ) may be attributed to the spatial arrangement of protons next to the ethylene glycol clipping unit. The next peak upfield is attributed to the ethylene glycol signal (singlet at $\delta 3.9 \mathrm{ppm}$ ). The methylene protons for the bicyclo[4.4.1]undecane core ( $\delta 2.7$ and $2.9 \mathrm{ppm}$ ) is consistent with a chair-chair conformation displaying two sets of 
doublet of doublets, Figure 6.5. The two bridgehead protons upfield are a multiplet $(\delta$ $2.2 \mathrm{ppm})$ as previously seen in other $\pi$-stacked analogs.
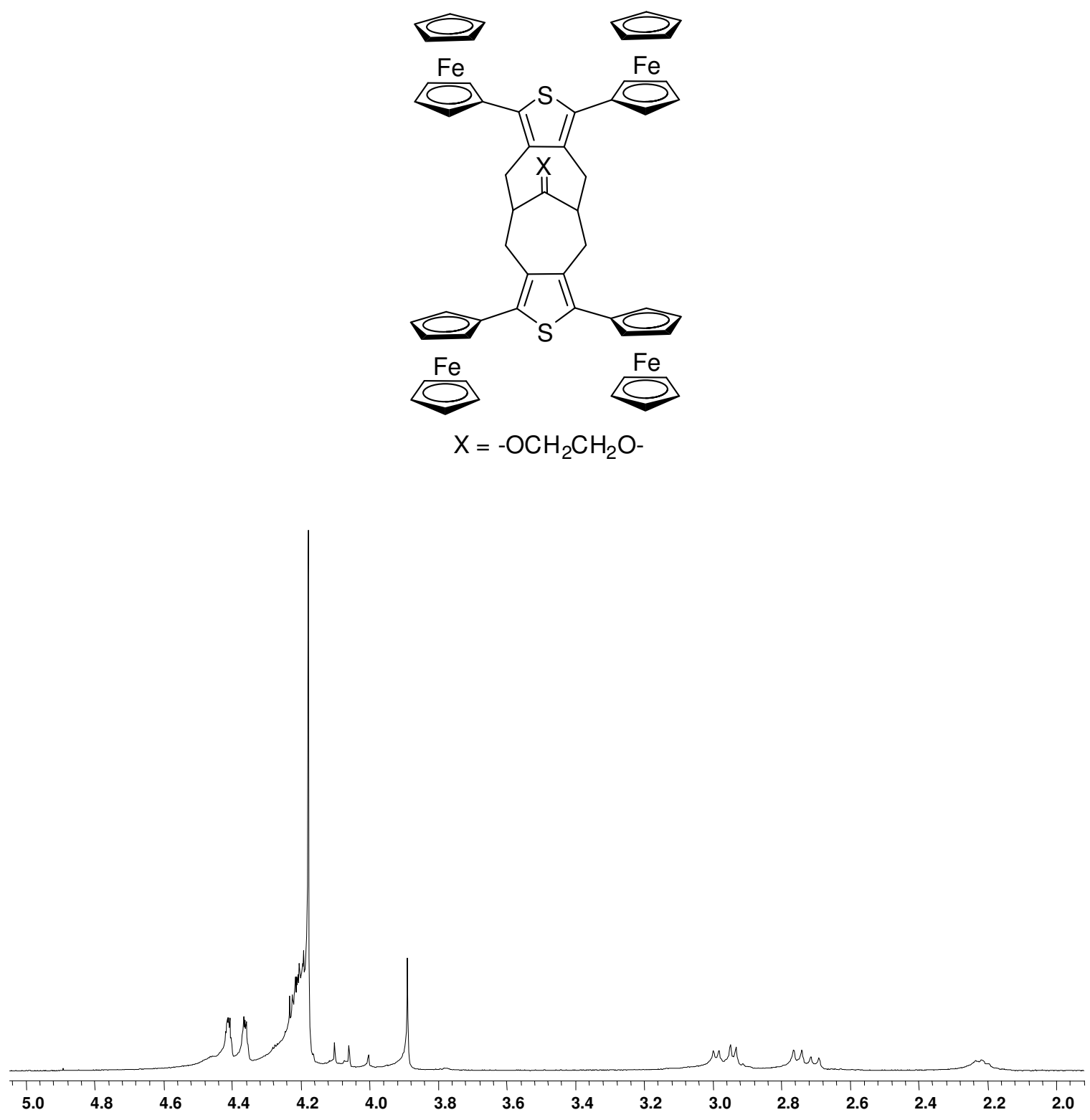

Figure 6.5. ${ }^{1} \mathrm{H} \mathrm{NMR}\left(300 \mathrm{MHz}, \mathrm{CDCl}_{3}\right)$ of $\pi$-stacked compound 6.2 at room temperature. 
The ${ }^{13} \mathrm{C}$ NMR spectrum of $\pi$-stacked compound, 6.2, is illustrated in Figure 6.6. The aromatic carbons consistent for one thiophene ring conformation, and the bicyclo[4.4.1] undecane framework carbons are consistent with a chair-chair conformation. The cyclopentadienyl carbons show up as four different signals (three from the ring attached to thiophene and one for the other ring).
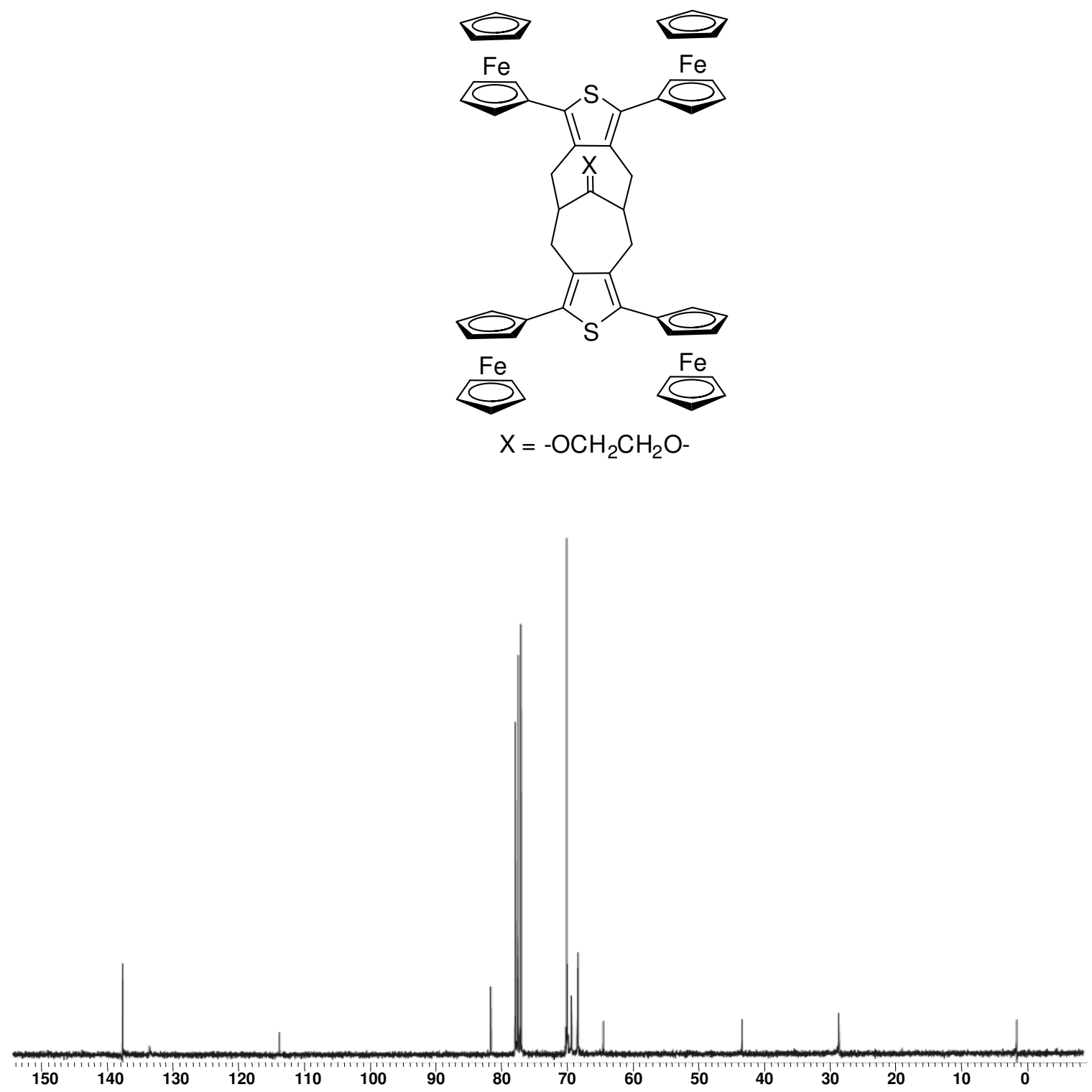

Figure 6.6. ${ }^{13} \mathrm{C} \mathrm{NMR}\left(300 \mathrm{MHz}, \mathrm{CDCl}_{3}\right)$ of 6.2. 


\subsubsection{UV-vis Spectroscopy of Ferrecene Substituted Compounds}

The model compound, 6.1, exhibited a $\pi-\pi^{*}$ absorbance band at $\lambda_{\max }=323 \mathrm{~nm}(\varepsilon$ $\left.=2.1 \times 10^{4} \mathrm{M}^{-1} \mathrm{~cm}^{-1}\right)$ and $\mathrm{Fe}^{\mathrm{II}} \mathrm{d}-\mathrm{d}$ transition absorbance band at $\lambda=452 \mathrm{~nm}\left(1.8 \times 10^{3} \mathrm{M}\right.$ ${ }^{-1} \mathrm{~cm}^{-1}$ ) in $\mathrm{CH}_{2} \mathrm{Cl}_{2}$, Figure 6.7.

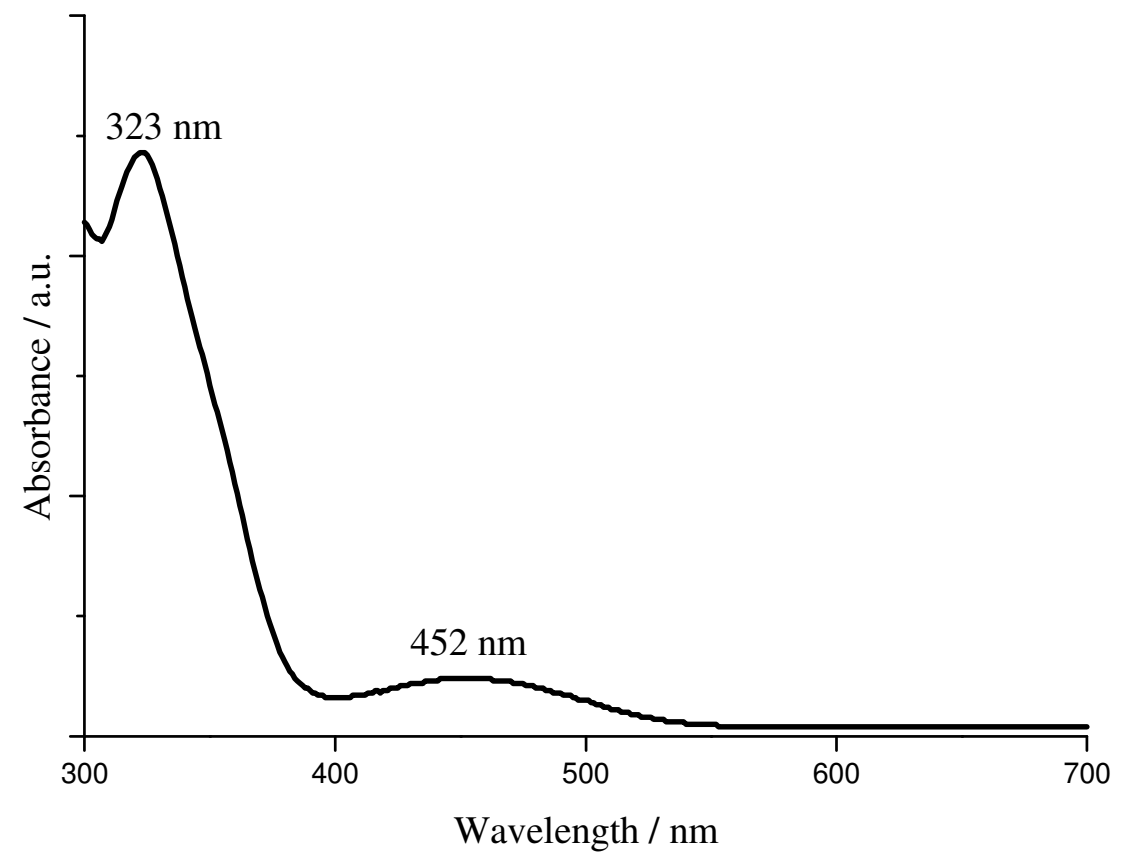

Figure 6.7. UV-vis spectrum of model compound 6.1. $c=8.12 \times 10^{-5} \mathrm{M}^{-1} \mathrm{CH}_{2} \mathrm{Cl}_{2}$; $323 \mathrm{~nm}, \varepsilon=2.1 \times 10^{4} \mathrm{M}^{-1} \mathrm{~cm}^{-1} ; 452 \mathrm{~nm}, \varepsilon=1.8 \times 10^{3} \mathrm{M}^{-1} \mathrm{~cm}^{-1}$.

Upon $\pi$-stacking the oligomer, there is a slight blue shift $(3 \mathrm{~nm})$ for the $\pi$ - $\pi^{*}$ absorbance band at $\lambda_{\max }=320 \mathrm{~nm}\left(\varepsilon=1.8 \times 10^{4} \mathrm{M}^{-1} \mathrm{~cm}^{-1}\right)$, and the $\mathrm{Fe}{ }^{\mathrm{II}} \mathrm{d}-\mathrm{d}$ transition absorbance band at $\lambda=452 \mathrm{~nm}\left(1.7 \times 10^{3} \mathrm{M}^{-1} \mathrm{~cm}^{-1}\right)$ is similar, Figure 6.8. The molar absorptivity is slightly lower in the $\pi$-stacked compound due to excimer formation, as seen in other compounds. 


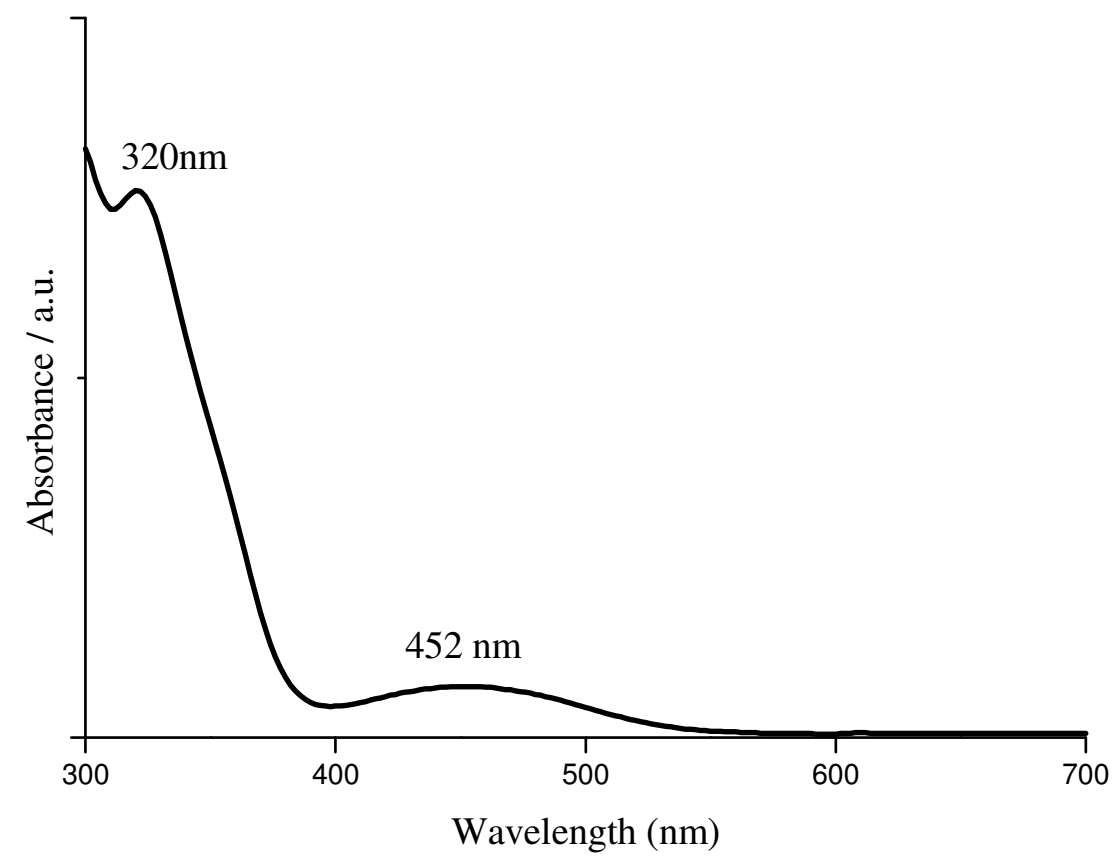

Figure 6.8. UV-vis spectrum of $\pi$-stacked compound 6.2. $c=4.17 \times 10^{-5} \mathrm{M}$ in $\mathrm{CH}_{2} \mathrm{Cl}_{2} ; 320 \mathrm{~nm}, \varepsilon=1.8 \times 10^{4} \mathrm{M}^{-1} \mathrm{~cm}^{-1} ; 452 \mathrm{~nm}, \varepsilon=1.7 \times 10^{3} \mathrm{M}^{-1} \mathrm{~cm}^{-1}$.

\subsubsection{Electrochemistry}

The cyclic voltammogram of model compound $\mathbf{6 . 1}$ and ferrocene was performed with the supporting electrolyte $0.1 \mathrm{M} n-\mathrm{BuNPF}_{6} / \mathrm{CH}_{2} \mathrm{Cl}_{2}$, Figure 6.9. Ferrocene exhibits a $1 e^{-}$reversible redox wave at $E_{1 / 2}=0.45 \mathrm{~V}$, while model 6.1 exhibits two $1 e^{-}$reversible redox waves at $E_{1 / 2}=0.35 \mathrm{~V}$ and $E_{1 / 2}=0.50 \mathrm{~V}$. The DPV of model compound, 6.1, is depicted where the peak difference between radical cation and dication potentials in this electrolye is $\Delta E=150 \mathrm{mV}$, Figure 6.1 . 


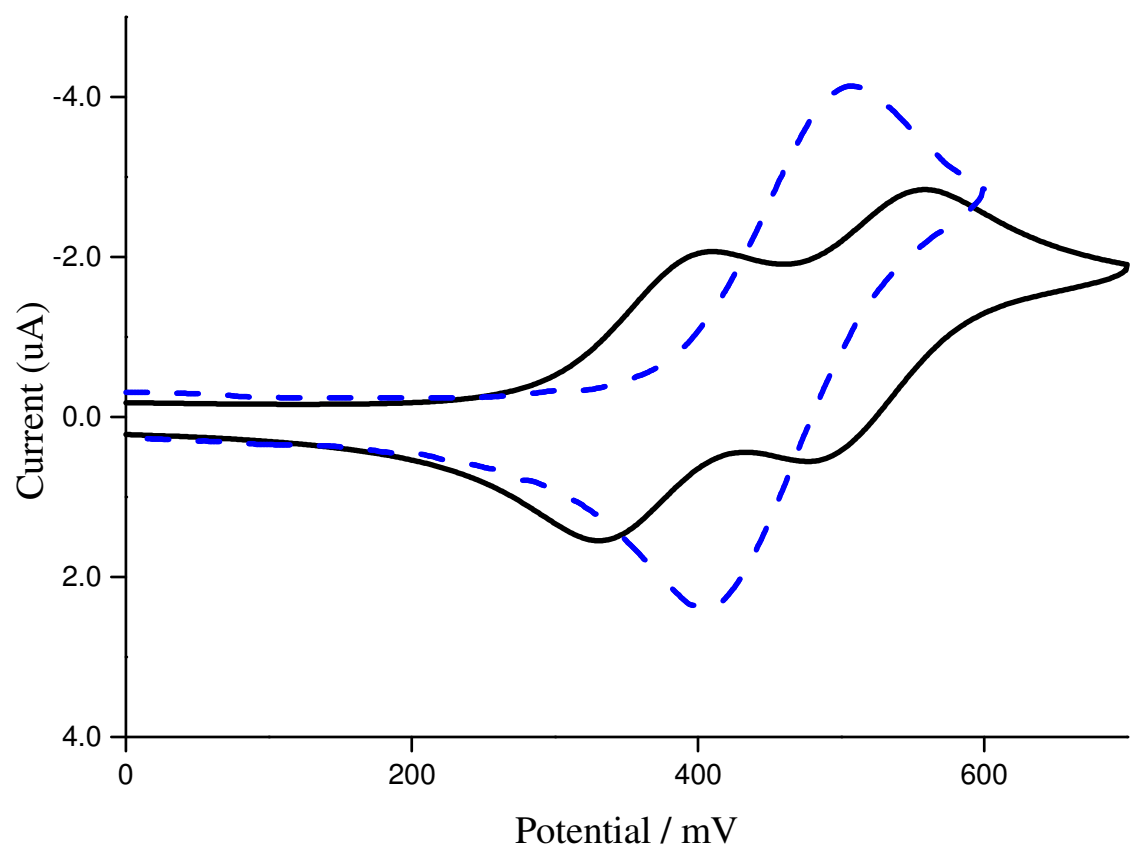

Figure 6.9. $\mathrm{CV}$ of model compound 6.1 (solid line) and ferrocene (dashed line). $c=1$ $\mathrm{mM}$ in $\mathrm{CH}_{2} \mathrm{Cl}_{2} ; 0.1 \mathrm{M} n-\mathrm{BuNPF}_{6} / \mathrm{CH}_{2} \mathrm{Cl}_{2} ; \mathrm{Au}$ working electrode; $\mathrm{Pt}$ auxillary, $\mathrm{Ag} / \mathrm{Ag}^{+}$reference electrode; $v=100 \mathrm{mV} / \mathrm{s}$.

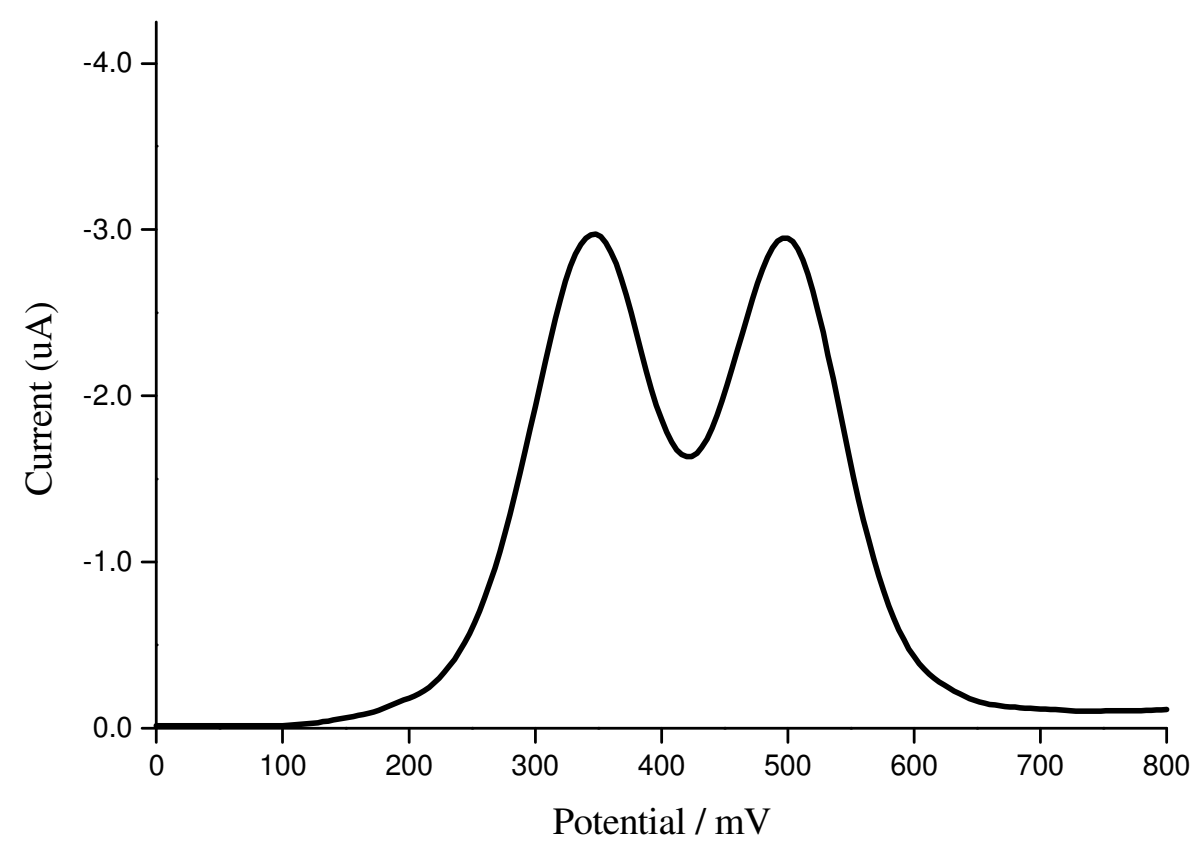

Figure 6.10. DPV of model compound 6.1. $c=1 \mathrm{mM}$ in $\mathrm{CH}_{2} \mathrm{Cl}_{2} ; 0.1 \mathrm{M} n-\mathrm{BuNPF}_{6} /$ $\mathrm{CH}_{2} \mathrm{Cl}_{2}$; Au working electrode; $\mathrm{Pt}$ auxiliary, $\mathrm{Ag} / \mathrm{Ag}^{+}$reference electrode; $v=100 \mathrm{mV} / \mathrm{s}$. 
A bulky electrolyte solution of $0.1 \mathrm{M}[n-\mathrm{BuN}]\left[\mathrm{B}\left(\mathrm{C}_{6} \mathrm{~F}_{5}\right)_{4} / \mathrm{CH}_{2} \mathrm{Cl}_{2}\right.$ was used to examine the redox behavior of model compound, 6.1. ${ }^{11}$ The removal of $1 e^{-}$occurred higher $(+70 \mathrm{mV})$ at $E_{1 / 2}=0.42 \mathrm{~V}$, while the removal of a second electron was $+170 \mathrm{mV}$ higher at $E_{1 / 2}=0.67 \mathrm{~V}$, both of which were reversible processes, Figure 6.11. The peak separation of the two processes illustrated by DPV was larger $(+250 \mathrm{mV})$ due to the better solubility of the charge species in a bulky, weakly anion binding electrolyte, Figure 6.12. The different scan rated used helped determine that the redox process was not diffusion controlled due to the linearity in the slope when plotting oxidation potential versus $1 / \mathrm{n}$ (not shown).

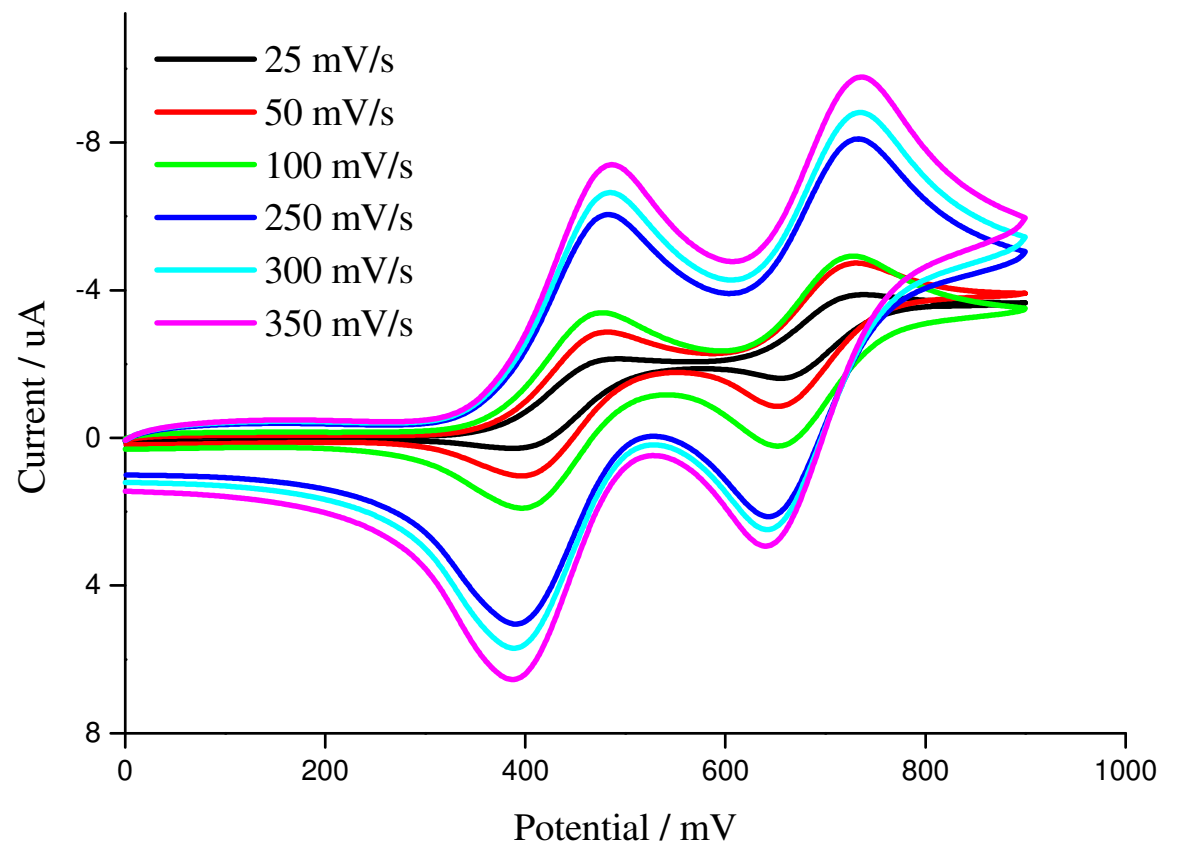

Figure 6.11. $\mathrm{CV}$ of model compound, 6.1. $c=1 \mathrm{mM}$ in $\mathrm{CH}_{2} \mathrm{Cl}_{2}$; bulky electrolyte: $0.1 \mathrm{M}[n-\mathrm{BuN}]\left[\mathrm{B}\left(\mathrm{C}_{6} \mathrm{~F}_{5}\right)_{4}\right] / \mathrm{CH}_{2} \mathrm{Cl}_{2} ;$ Au working electrode; Pt auxiliary, $\mathrm{Ag} / \mathrm{Ag}^{+}$reference electrode; $v=25-350 \mathrm{mV} / \mathrm{s}$. 


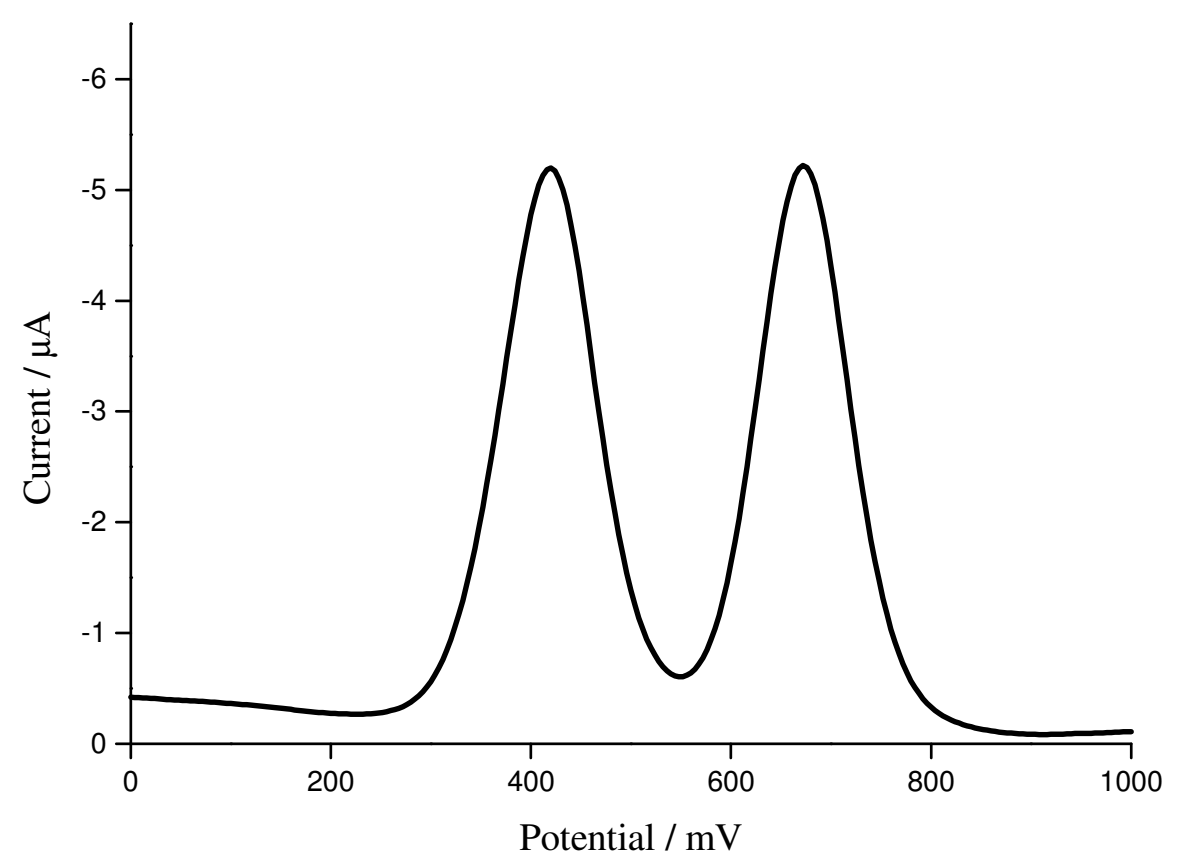

Figure 6.12. $\mathrm{CV}$ of model compound, 6.1. $c=1 \mathrm{mM}$ in $\mathrm{CH}_{2} \mathrm{Cl}_{2}$; bulky electrolyte: $0.1 \mathrm{M}[n-\mathrm{BuN}]\left[\mathrm{B}\left(\mathrm{C}_{6} \mathrm{~F}_{5}\right)_{4}\right] / \mathrm{CH}_{2} \mathrm{Cl}_{2} ;$ Au working electrode; $\mathrm{Pt}$ auxiliary, $\mathrm{Ag} / \mathrm{Ag}^{+}$reference electrode; $v=100 \mathrm{mV} / \mathrm{s}$.

The $\pi$-stacked compound, 6.2, exhibited two reversible redox waves in the smaller electrolyte solution. Each wave corresponded to two electrons each, therefore the effects of $\pi$-stacking were hard to distinguish due to the destabilized charge migration in a tightly anion binding electrolyte. In the bulkier electrolyte solution, the charge stability was greatly enhanced and splitting was observed. The first $1 e^{-}$process to form radical cation occurred at $E_{1 / 2}=0.38 \mathrm{~V}$, and the bis(radical cation) species formed upon removal of a second electron at $E_{1 / 2}=0.47 \mathrm{~V}$, bothe of which were reversible, Figure 6.13. The first electron in the $\pi$-stacked compound, 6.2, was lower than that of its model, 6.1, by $-40 \mathrm{mV}$ due to the effect of $\pi$-stacking. The second electron process was stabilized by the bulkier 
electrolyte solution and at higher potential. Therefore, $\pi$-dimerization was slightly impeded by the charge delocalization of the charged species to the extended cyclopentadienyl tiers in the ferrocene moieties. Further redox processes at higher potential was also exhibited in the $\pi$-stacked compound, 6.2. A $2 e^{-}$reversible wave at $E_{1 / 2}=0.75 \mathrm{~V}$ corresponded to the formation of the tetra-cationic species. The larger splitting between the second oxidation process and the coincidental two electron process is due to the stabilization of the $\pi$-dimer formed in this electrolyte solution and Coulombic repulsion of the unstable tricationic species to form a less destabilized tetracationic species.

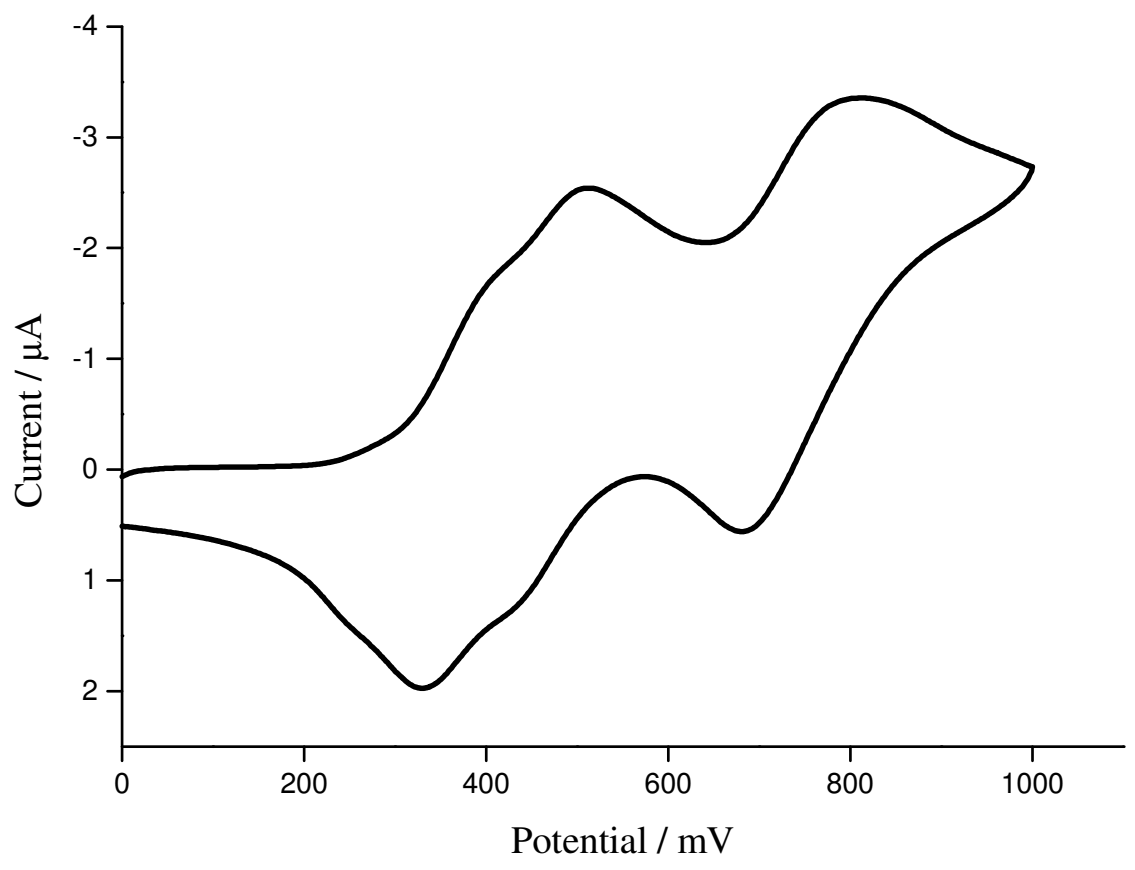

Figure 6.13. $\mathrm{CV}$ of $\pi$-stacked compound, 6.2. $c=1 \mathrm{mM}$ in $\mathrm{CH}_{2} \mathrm{Cl}_{2}$; bulky electrolyte: $0.1 \mathrm{M}[n-\mathrm{BuN}]\left[\mathrm{B}\left(\mathrm{C}_{6} \mathrm{~F}_{5}\right)_{4}\right] / \mathrm{CH}_{2} \mathrm{Cl}_{2} ; \mathrm{Au}$ working electrode; $\mathrm{Pt}$ auxiliary, $\mathrm{Ag} / \mathrm{Ag}^{+}$reference electrode; $v=100 \mathrm{mV} / \mathrm{s}$. 
The splitting of redox waves and influence of $\pi$-stacking oligothiophene-ferrocene compounds can be illustrated also in the DPV voltammogram of 6.2, Figure 6.14. The peak difference between the first two peaks is $+90 \mathrm{mV}$ and between the second and third peaks is $+280 \mathrm{mV}$. The $\pi$-stacked oligothiophene $\left.\mathbf{5 . 8}(\boldsymbol{s t} \text {-[Ph-Th} \mathbf{3}-\mathbf{P h}]_{2}\right)$, exhibited splitting between its similar peaks of $+200 \mathrm{mV}$ and $+740 \mathrm{mV}$. The demonstrates the facile conversion of the ferrocene $\pi$-stacked compound to form a $\pi$-dimer due to the inceased delocalization/hopping though the compound. The splitting for the tetracationic species is less than 2.6 times than that of the phenyl-capped $\pi$-stacked compound also explaining how the addition of another tier increases the stability of the entire charge compound.

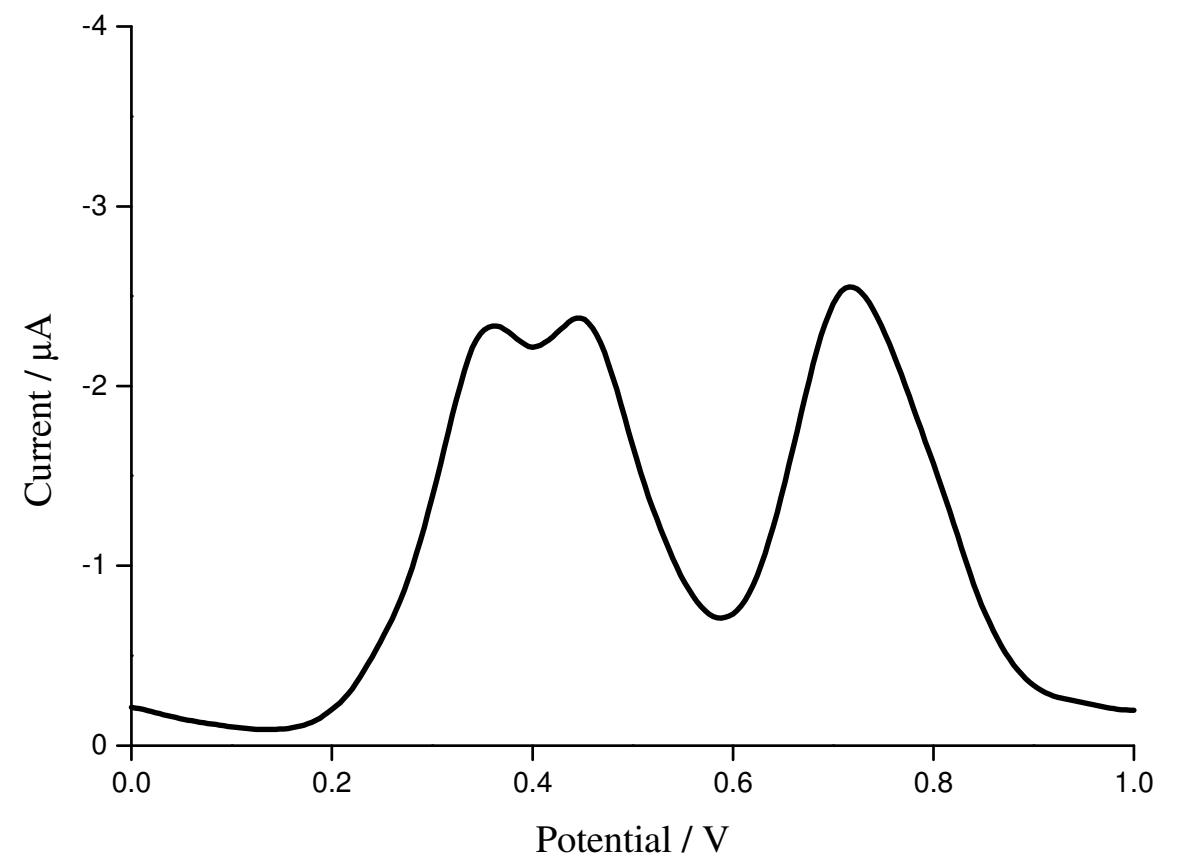

Figure 6.14. DPV of $\pi$-stacked compound, 6.2. $c=1 \mathrm{mM}$ in $\mathrm{CH}_{2} \mathrm{Cl}_{2}$; bulky electrolyte: $0.1 \mathrm{M}[n-\mathrm{BuN}]\left[\mathrm{B}\left(\mathrm{C}_{6} \mathrm{~F}_{5}\right)_{4}\right] / \mathrm{CH}_{2} \mathrm{Cl}_{2} ;$ Au working electrode; $\mathrm{Pt}$ auxiliary, $\mathrm{Ag} / \mathrm{Ag}^{+}$reference electrode; $v=100 \mathrm{mV} / \mathrm{s}$. 


\subsection{Conclusion}

In conclusion, a ferrocene substituted, hybrid $\pi$-stacked compound was synthesized and characterized by NMR and UV-vis spectroscopy of the neutral material and electrochemistry for its redox behavior. The stability of the doped material was enhanced in a bulky electrolyte, where the influence of $\pi$-stacking and charge transfer in metal centers could be ascertained. Further synthesis of extended oligothiophenes capped with ferrocene or other metal centers like $\mathrm{Ru}$, Os, or Mn may potentially be synthesized and explored for their role as molecular wires, sensors, or other devices.

\subsection{References}

1. Nakamura, E., "Bucky ferrocene. Hybrid of ferrocene and fullerene.," Pure Appl. Chem. 2003, 75, 427-434.

2. Ribou, A. C.; Launay, J.-P.; Takahashi, K.; Nihira, T.; Tarutani, S.; Spangler, C. W., "Intervalence electron transfer in pentaammineruthenium complexes of dipyridylpolyenes, dipyridylthiophene, and dipyridylfuran," Inorg. Chem. 1994, $1325-1329$.

3. Bonvoisin, J.; Launay, J.-P.; Rovira, C.; Veciana, J., "Nanometer-size, purely organic molecules with different degrees of oxidation at the ends and long-range electron transfer - Synthesis and optical and ESR studies of the radical anion of a bis(triarylmethyl) diradical," Angew. Chem, Int. Ed. Engl. 1994, 33, 2106-2109.

4. Chawdhury, N.; Kohler, A.; Friend, R. H.; Younus, M.; Long, N. J.; Raithby, P. R.; Lewis, J., "Synthesis and electronic structure of platinum-containing polyynes with aromatic and heteroaromatic rings," Macromolecules 1998, 31, 722727.

5. Weng, W.; Bartik, T.; Gladysz, J. A., "On the way to coupling of single metals to one-dimensional carbon wires: charge transfer between terminal rhenium and manganese centers in C5-cumulene," Angew. Chem., Int. Ed. Engl. 1994, 33, 2199-2202. 
6. Ribou, A.-C.; Launay, J. P.; Sachtleben, M. L.; Li, H.; Spangler, C. W., "Intervalence electron transfer in mixed valence diferrocenylpolyenes. decay law of the metal-metal coupling with distance," Inorg. Chem. 1996, 35, 3735-3740.

7. Tolbert, L. M.; Ogle, M. E., "Carbon-13 NMR spectroscopy of a, $\omega-$ diphenylpolyenyl anions. Confirmation of charge localization in soliton model compounds," J. Am. Chem. Soc. 1989, 111, 5958-5959.

8. Tolbert, L. M.; Zhao, X., "Extended cyanine dyes," Synth. Met. 1993, 55-57, 4788-4795.

9. Tolbert, L. M.; Zhao, X.; Ding, Y.; Bottomley, L. A., "Bis(ferrocenyl)polymethine cations. A prototype molecular wire with redoxactive end groups," J. Am. Chem. Soc. 1995, 117, 12891-12892.

10. Sailer, M.; Rominger, F.; Muller, T., "Ferrocennyl oligophenothiazines as organic-organometallic hybrid electrophores- Synthesis, structure, and electronic properties," J. Organomet. Chem. 2006, 691, 299-308.

11. LeSuer, R. J.; Geiger, W. E., "Improved electrochemistry in low-polarity media using tetrakis(pentafluorophenyl)-borate salts as supporting electrolytes," Angew. Chem. 2000, 39, 248-250. 


\section{CHAPTER 7}

\section{FUTURE WORK}

\subsection{Future Directions in Research}

Designing new $\pi$-conjugated materials for uses in electrical devices can be further developed through new synthetic routes systematically modified with the intermediate compound 3.1 previously synthesized. The detailed experiments performed in this thesis have demonstrated the tendencies of charge migration and delocalization in $\pi$-stacked oligothiophenes, specifically stable $\pi$-dimer formation being a key for bis(radical cation) stability at room temperature, low concentration, and a moderately polar solvent like dichloromethane. The p-dopable, cofacial oligomers oriented in a $\pi$-stacked conformation were in a fully stacked oriention for each thiophene ring (each position of the thiophene rings on the undecane core were substitued with the same group). A continuation of thiophene $\pi$-stacked oligomers would be to vary the degree of overlap for each tier. Initial attempts to synthesize cis/trans terthiophene $\pi$-stacked compounds $\mathbf{7 . 1}$ and 7.2 were unsuccessful, Figure 7.1. Bromination of $\mathbf{3 . 2}$ with two equivalents of NBS in DMF at low temperature produced an inseperable byproduct which was thought to not be formed. Bromination at one thiophene position deactivated the ring but, in this case, the purification could not be attained for the cis/trans dibrominated materials. Subsequent palladium catayzed Negishi coupling to the ketone followed by ketalization with ethylene glycol should be straight forward. 


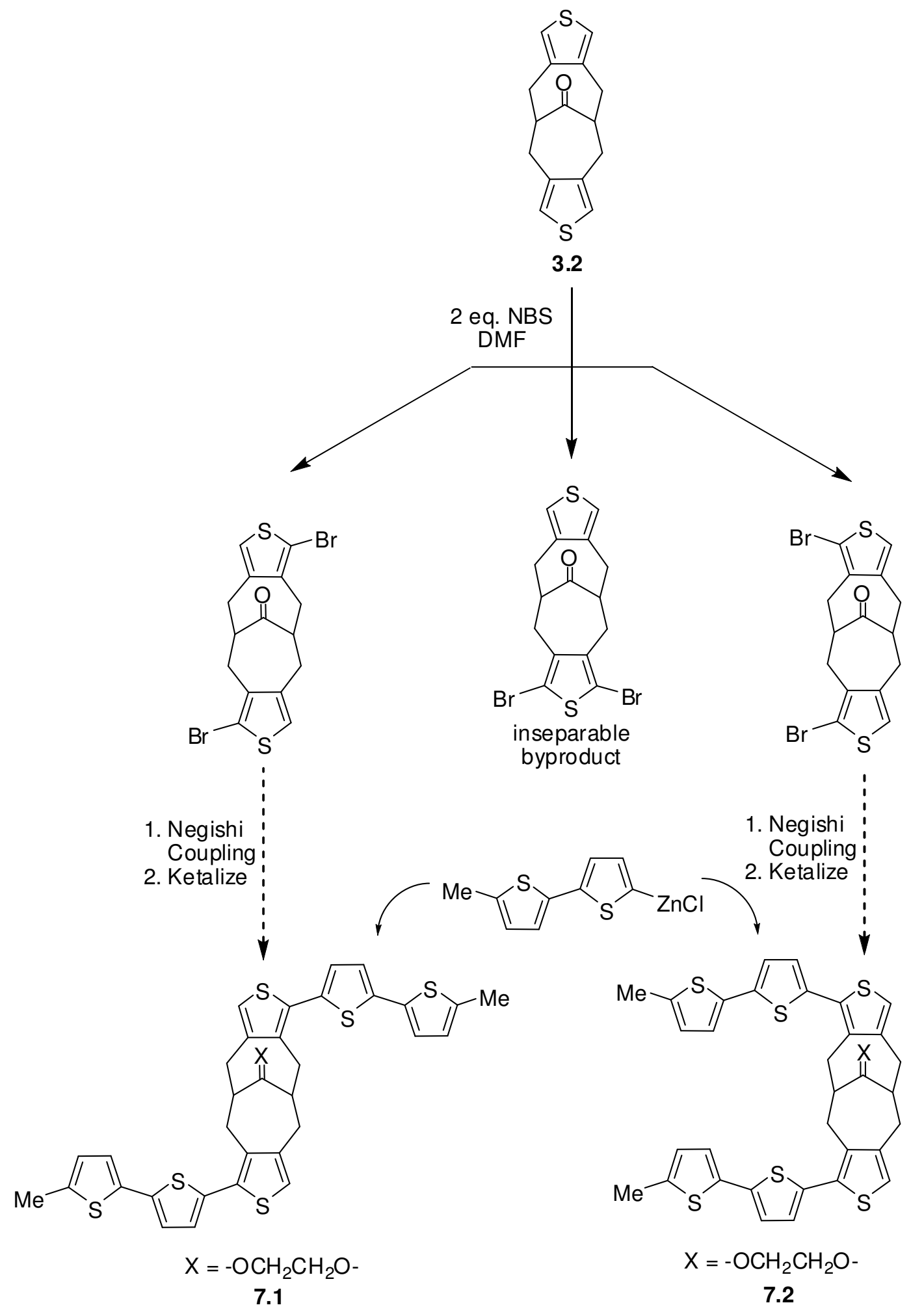

Figure 7.1. Synthesis of terthiophene $\pi$-stacked compounds 7.1 and 7.2. 
Synthesis of a model terthiophene compound, 7.3, was achieved by the bromination of 3,4-dimethylthiophene with one equivalent of NBS followed by the Stille coupling of 2-methyl-5'-tri- $n$-butylstannyl-5:2'-bithiophene to produce $\mathbf{7 . 3}$ in a $75 \%$ overall yield, Figure 7.2. This compound is important for its neutral state properties when compared to the $\pi$-stacked compounds, i.e. NMR, UV-vis, and emission spectra.

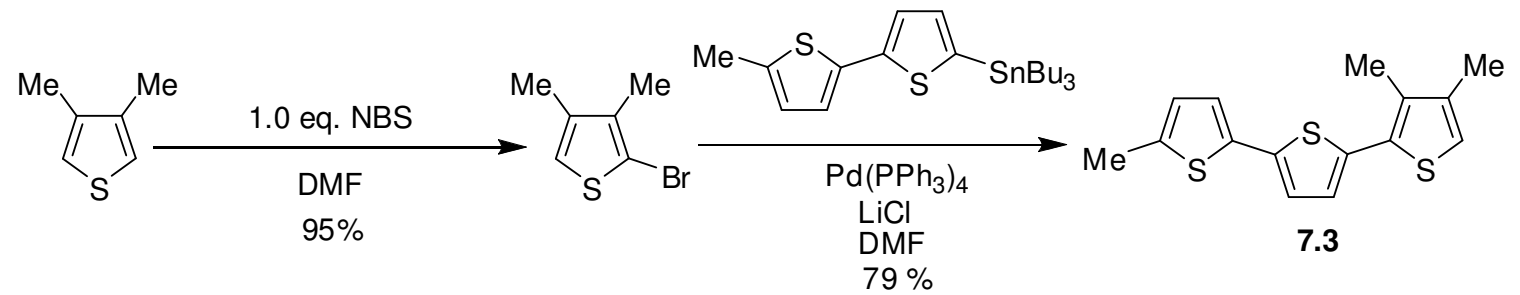

Figure 7.2. Synthesis of model terthiophene 7.3.

However, the unblocked $\alpha$-position on one thiophene ring will dimerize with another molecule upon doping to the radical cation species forming a sexithiophene compound. To circumvent this homo-coupling process, the $\alpha$-position was methylcapped in two steps: bromination with NBS followed by a Kumada coupling with methylmagnesium bromide in a 75\% overall yield to produce model compound, 7.4.<smiles>Cc1ccc(-c2ccc(-c3scc(C)c3C)s2)s1</smiles>

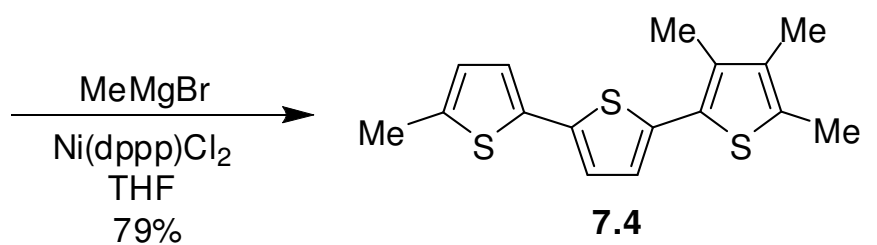

Figure 7.3. Synthesis of model methyl-capped terthiophene 7.4. 
A large body of work focuses on the study of alkyne spacers in conjugated materials. ${ }^{1-8}$ Recent work devoted to synthesis of interlocking $\pi$-conjugated macrocycles with terminal acetylene spacers ${ }^{9}$ provides comparisons to the studying of larger extended compounds, which is plausible with our intermediate compounds. Uncomplexed bis(alkynyl)oligothiophenes with transition metals ${ }^{10}$ has been extensively studied for their electronic communication by electrochemistry, and we can correlate some of these results with new one undiscovered yet. Another extension to study the effects of charge migration in our conjugated materials might be to couple ethynyl aromatic compounds to the brominated ketone, 3.2, via Sonogashira reaction conditions to form 7.5 after ketalization, Figure 7.4.

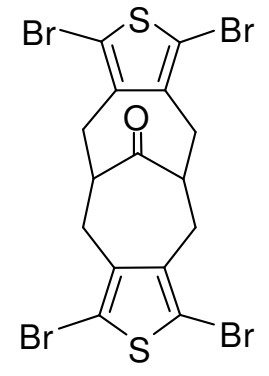

3.2

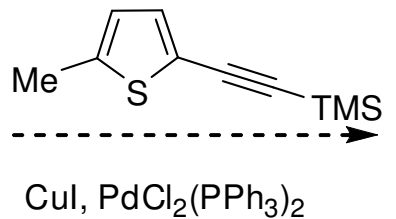

Piperidine $\mathrm{K}_{2} \mathrm{CO}_{3}, \mathrm{MeOH}$
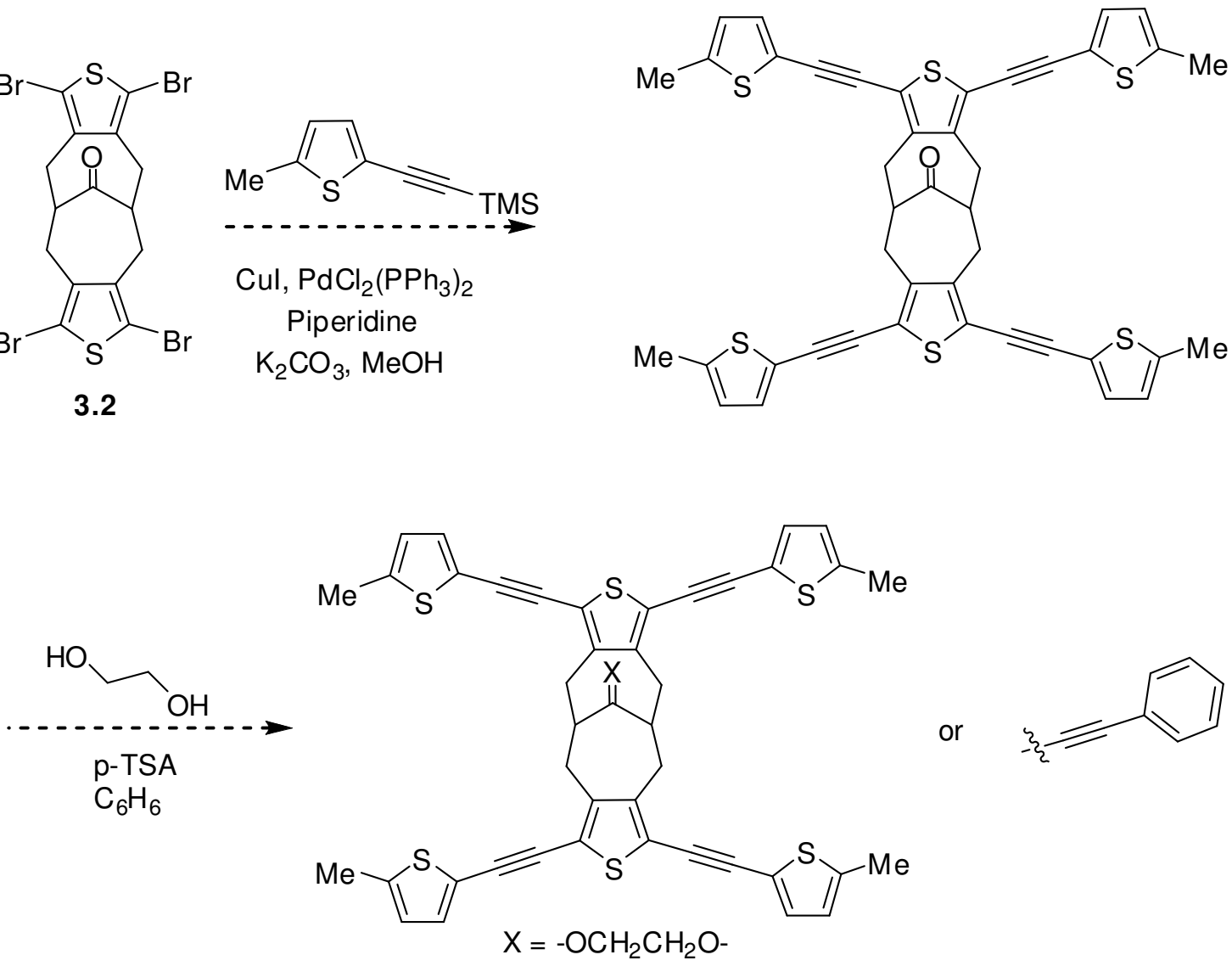

7.5

Figure 7.4. Synthesis of alkyne spacer in terthiophene $\pi$-stacked compound 7.5. 
The alkyne spacers in between the terthiophene oligomers may facilitate charge delocalization better in the $\pi$-stacked compound and should be further studied. The analogous model terthiophene, 7.6, was synthesized in two steps from 3,4dimethylthiophene. Iodination of the 2,5-positions with molecular iodine with the oxidant potassium periodate followed by the Sonogashira coupling with a TMS acetylated thiophene formed the terthiophene model compound, 7.6, in a 57\% overall yield, Figure 7.5. Other compounds can be coupled in similar fashion to study the effects of $\pi$-stacking the $\pi$-conjugated oligomers.

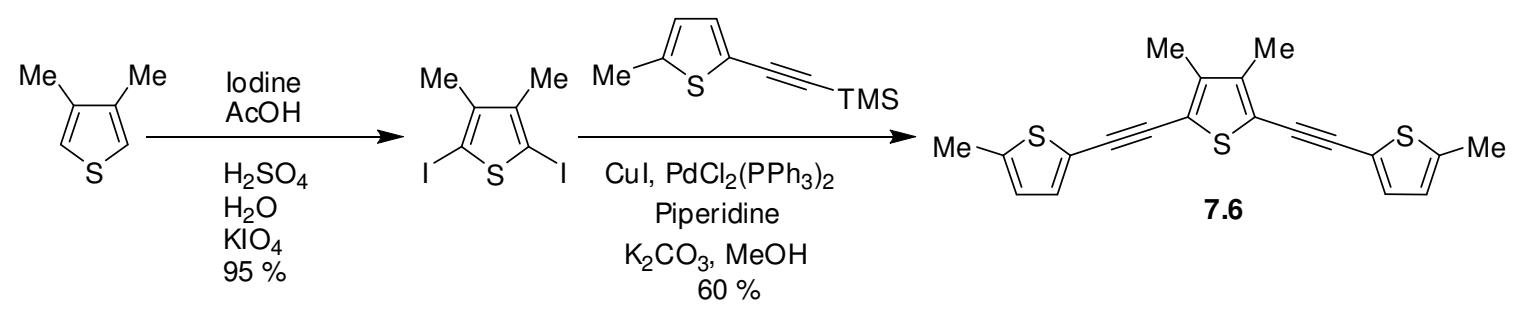

Figure 7.5. Synthesis of alkyne substituted model compound 7.6.

Another branch of research in $\pi$-conjugated materials focuses on the synthesis and characterization of new functional materials containing Poly $(3,4-$ ethylenedioxythiophenes), of PEDOT materials. ${ }^{11-16}$ One characteristic that can be beneficial for our studies would be to attached this p-dopable compound to the bicyclo[4.4.1] undecane core in order to increase the ease of oxidation of the material. Terthiophene EDOT and quinquethiophene EDOT $\pi$-stacked compounds $\mathbf{7 . 7}$ and $\mathbf{7 . 8}$ can be envisioned by coupling the corresponding thiophene or bithiophene EDOT to ketone 3.2, followed by ketalization with ethylene glycol Figure 7.6. 


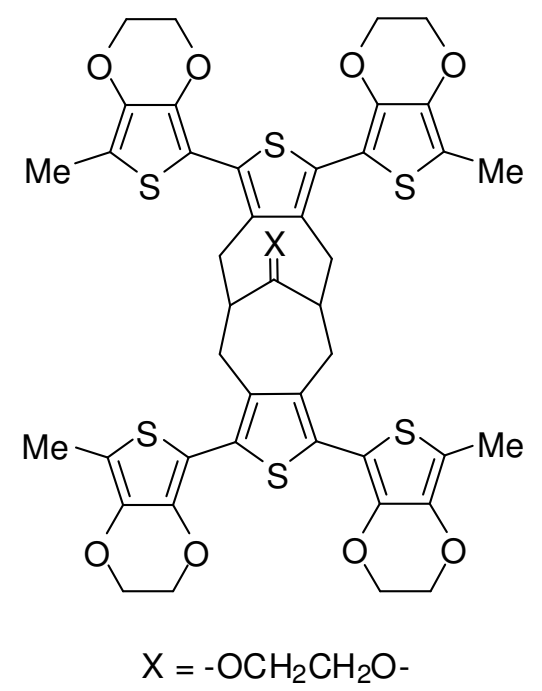

7.7

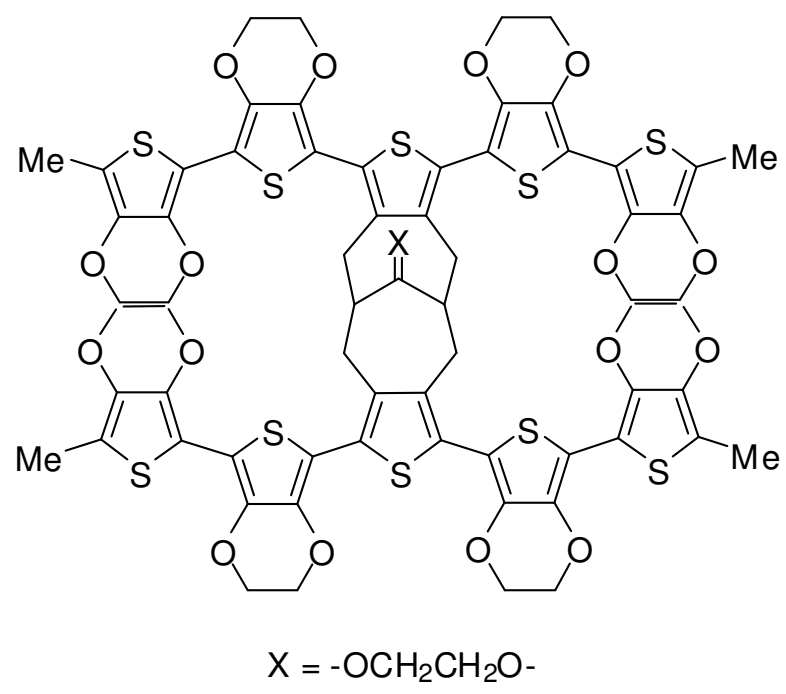

7.8

Figure 7.6. Ethylenedioxy-substituted terthiophene 7.7 and quinquethiophene 7.8 .

One concern with this approach that should be addressed is the steric strain that may be imposed upon stacking the EDOT terthiophene or quinquethiophene together. Synthesis, structural characterization, and electrochemical investigations will provide evidence for or against the effective $\pi$-stacking of such compounds. Modification of the clipping unit to neopentyl glycol may facilitate the $\pi$-stacking better if the ethylene glycol unit is not sufficient enough.

A broad spectrum of studies has been performed on thiazoles ${ }^{17-21}$ which are ndopable materials, an this $\pi$-stacking motif can facilitate the design of such compounds. It can be envisioned to couple a 5-methyl-thiazole or bithiazole with an appropriate palladium catalyzed reaction to ketone 3.2 to afford $\pi$-stacked compounds $\mathbf{7 . 9}$ and 7.10 after ketalization with ethylene glycol, Figure 7.7. 


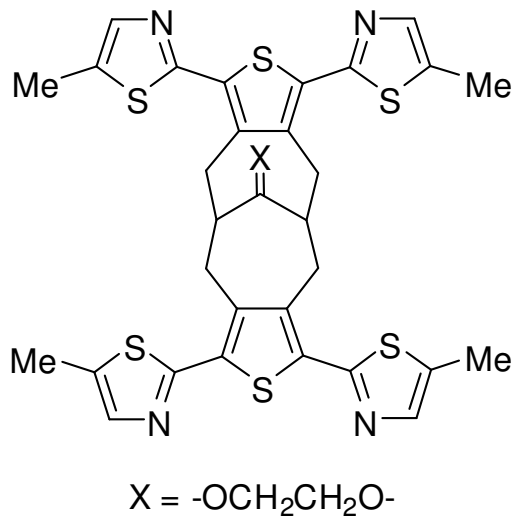

7.9

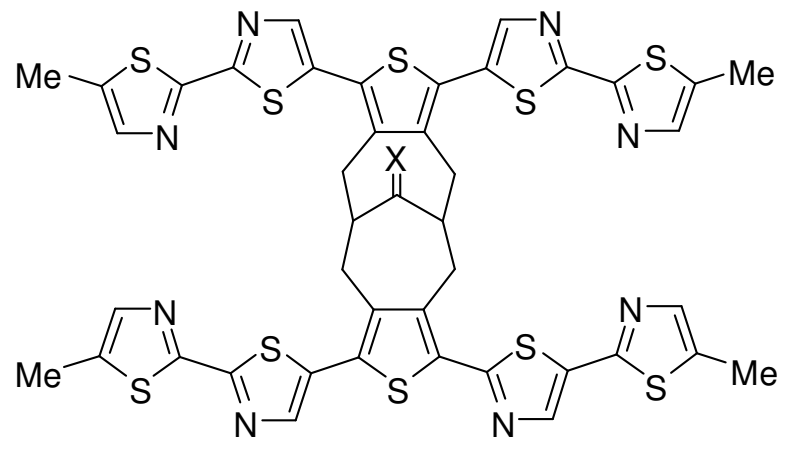

$\mathrm{X}=-\mathrm{OCH}_{2} \mathrm{CH}_{2} \mathrm{O}-$

7.10

Figure 7.7. Thiazole-substituted $\pi$-stacked compounds 7.9 and 7.10.

Raman spectroscopy, not explored, can be another useful technique for studying the electronic and vibrational states of self-localized excitations for doped poly(pphenylenevinylene $)^{22}$ and poly(p-phenylene). ${ }^{23}$ Similarly, $\mathrm{SbF}_{6}{ }^{-}$radical cation salt formation of these compounds can be a useful technique to determining the solid state structure of doped $\pi$-conjugated oligomers.

\subsection{References}

1. Adachi, C.; Oyamada, T.; Hiyama, T.; Shimizu, M.; Ejiri, E.; Yahiro, M.; Akiyama, S. 2,5-bis[(thiophen-2-yl)aryl-1-ethynyl]thiophenes and organic transistors using them. 2004-380140; 2006182730, 2006.

2. Goeb, S.; De Nicola, A.; Ziessel, R.; Sabatini, C.; Barbieri, A.; Barigelletti, F., "Energy Transfer in Hybrids Based on a Thiophene-Substituted Ethynylbipyridine Dimer Decorated with Re(I), Ru(II), and Os(II) Units," Inorg. Chem. 2006, 45, 1173-1183. 
3. Goeb, S.; De Nicola, A.; Ziessel, R., "Stepwise synthesis of conjugatively bridged bipyridine ligands from thiophene and alkyne linkages," Synthesis 2005, 11691177.

4. Roue, S.; Lapinte, C., "Iron(II) and iron(III) complexes containing ethynyl thiophene fragments," J. Organomet. Chem. 2005, 690, 594-604.

5. Rodriguez, J. G.; Lafuente, A.; Rubio, L., "Synthesis of conjugated 2-arylethynyl and 2-arylethenyl thiophene structures with optical properties," Tetrahedron Lett. 2004, 45, 5685-5688.

6. Liu, S.; Schanze, K. S., "Solvent tuned excited state configuration mixing in a pconjugated metal-organic oligomer," Chemical Communications (Cambridge, United Kingdom) 2004, 1510-1511.

7. Roue, S.; Le Stang, S.; Toupet, L.; Lapinte, C., "Magnetic communication between two [(h5-C5Me5)(h2-dppe)Fe(III)] units mediated by the 2,5bis(ethynyl)thiophene spacer," Comptes Rendus Chimie 2003, 6, 353-366.

8. Iucci, G.; Polzonetti, G.; Altamura, P.; Paolucci, G.; Goldoni, A.; Russo, M. V., "X-ray photoelectron spectroscopy studies of novel P-conjugated ethynyl thiophene containing Pd(II) complexes and of their interaction with chromium," $J$. Vac. Sci. Technol., A 2000, 18, 248-256.

9. Ammann, M.; Rang, A.; Schalley, C. A.; Baeuerle, P., "A synthetic approach towards interlocked p-conjugated macrocycles," European Journal of Organic Chemistry 2006, 1940-1948.

10. Jung, T. S.; Kim, J. H.; Jang, E. K.; Kim, D. H.; Shim, Y. B.; Park, B.; Shin, S. C., "Synthesis and physical properties of a,w-bis[Co2(CO)6 $\{\mathrm{m}-\mathrm{h} 2: \mathrm{h} 2-$ C(R).tplbond.C \}] oligothiophenes," J. Organomet. Chem. 2000, 599, 232-237.

11. Segura, J. L.; Gomez, R.; Blanco, R.; Reinold, E.; Baeuerle, P., "Synthesis and Electronic Properties of Anthraquinone-, Tetracyanoanthraquinodimethane-, and Perylenetetracarboxylic Diimide-Functionalized Poly $(3,4-$ ethylenedioxythiophenes)," Chem. Mater. 2006, 18, 2834-2847.

12. Cutler, C. A.; Bouguettaya, M.; Kang, T.-S.; Reynolds, J. R., "AlkoxysulfonateFunctionalized PEDOT Polyelectrolyte Multilayer Films: Electrochromic and Hole Transport Materials," Macromolecules 2005, 38, 3068-3074. 
13. Caras-Quintero, D.; Baeuerle, P., "Synthesis of the first enantiomerically pure and chiral, disubstituted 3,4-ethylenedioxythiophenes (EDOTs) and corresponding stereo- and regioregular PEDOTs," Chemical Communications (Cambridge, United Kingdom) 2004, 926-927.

14. Saito, Y.; Fukuri, N.; Senadeera, R.; Kitamura, T.; Wada, Y.; Yanagida, S., "Solid state dye sensitized solar cells using in situ polymerized PEDOTs as hole conductor," Electrochem. Commun. 2004, 6, 71-74.

15. Stromberg, C.; Tsakova, V.; Schultze, J. W., "Composition of the microemulsion and its influence on the polymerisation and redox activation of PEDOT," $J$. Electroanal. Chem. 2003, 547, 125-133.

16. Caras-Quintero, D.; Bauerle, P., "Synthesis of the first enantiomerically pure and chiral, disubstituted 3,4-ethylenedioxythiophenes (EDOTs) and corresponding stereo- and regioregular PEDOTs," Chemical communications (Cambridge, England) 2004, 926-7.

17. Kobayashi, K.; Mohamed Ahmed, M. S.; Mori, A., "Introduction of ethynylene and thienylene spacers into 2,5-diarylthiazole and 2,5-diarylthiophene," Tetrahedron 2006, 62, 9548-9553.

18. Ando, S.; Murakami, R.; Nishida, J.-I.; Tada, H.; Inoue, Y.; Tokito, S.; Yamashita, Y., "n-Type Organic Field-Effect Transistors with Very High Electron Mobility Based on Thiazole Oligomers with Trifluoromethylphenyl Groups," $J$. Am. Chem. Soc. 2005, 127, 14996-14997.

19. Abdel-Gawad, S., "Utility of 2-[4-benzo[d]furan-1,3-thiazol-2-yl] ethane-nitrile in synthesis of thiazole, coumarin, thiophene, and thiadiazoline derivatives," Phosphorus, Sulfur Silicon Relat. Elem. 2005, 180, 2303-2314.

20. Breitung, E. M.; Shu, C.-F.; McMahon, R. J., "Thiazole and Thiophene Analogues of Donor-Acceptor Stilbenes: Molecular Hyperpolarizabilities and Structure-Property Relationships," J. Am. Chem. Soc. 2000, 122, 1154-1160.

21. Mataka, S.; Takahashi, K.; Tashiro, M., "Ring transformation of 3-hydroxy-1,2,5and -1,2,4-thiadiazoles and -isothiazoles into isothiazole, thiazole and thiophene derivatives," J. Heterocycl. Chem. 1985, 22, 1497-1502. 
22. Sakamoto, A.; Furukawa, Y.; Tasumi, M., "Resonance raman characterization of polarons and bipolarons in sodium-doped poly(p-phenylenevinylene)," J. Phys. Chem. 1992, 96, 3870-3874.

23. Furukawa, Y.; Ohtsuka, H.; Tasumi, M., "Raman studies of polarons and bipolarons in sodium-doped poly-p-phenylene " Synth. Met. 1993, 55, 516-523. 


\section{APPENDIX A}

\section{X-RAY STRUCTURAL ANALYSIS}

A suitable crystal of $s t-\left[\mathbf{H}-\mathbf{T h} \mathbf{h}_{\mathbf{1}}-\mathbf{H}\right]_{\mathbf{2}}$ was coated with Paratone $\mathrm{N}$ oil, suspended in a small fiber loop and placed in a cooled nitrogen gas stream at $173 \mathrm{~K}$ on a Bruker D8 SMART APEX CCD sealed tube diffractometer with graphite monochromated MoK $\alpha$ $(0.71073 \AA)$ radiation. Data was measured using a series of combinations of phi and omega scans with $10 \mathrm{~s}$ frame exposures and $0.3^{\circ}$ frame widths. Data collection, indexing and initial cell refinements were all carried out using SMART $^{1}$ software. Frame integration and final cell refinements were done using $\mathrm{SAINT}^{2}$ software. The final cell parameters were determined from least-squares refinement on 3398 reflections. The $\mathrm{SADABS}^{3}$ program was used to carry out absorption corrections.

The structure was solved using Direct methods and difference Fourier techniques (SHELXTL, V6.12). ${ }^{4}$ Hydrogen atoms were placed in their expected chemical positions using the HFIX command and were included in the final cycles of least-squares with isotropic Uij's related to the riding atom. The $\mathrm{C}-\mathrm{H}$ distances were fixed at $0.93 \AA$ (aromatic and amide), 0.98 (methine), $0.97 \AA$ (methylene), or $0.96 \AA$ (methyl). All nonhydrogen atoms were refined anisotropically. Scattering factors and anomalous dispersion corrections are taken from the International Tables for X-ray Crystallography. ${ }^{5}$ Structure solution, refinement, graphics and generation of publication materials were performed using SHELXTL, V6.12 software. Additional details of data collection and structure refinement are given in Tables A.1-A.6. 
The crystals were all intimately twinned to some degree so data was collected on one clean sample that contained approximately equal contributions of the two components. The unit cells for each component were determined by using a beta test program written by George Sheldrick called Cell_Now. The reflection data was processed with SAINT, taking into account the overlapping of reflections from the two components and were corrected for absorption effects S9 by using TWINABS, a version of SADABS. The structure was solved using only the data that was generated by component 1; however the final refinements used all the data and included the contributions from both components. 
Table A.1. Crystal data and structure refinement for $s t-\left[\mathbf{H}-\mathbf{T h}_{\mathbf{1}}-\mathbf{H}\right]_{\mathbf{2}}$.

Empirical formula

Formula weight

Temperature

Wavelength

Crystal system

Space group

Unit cell dimensions

Volume

Z

Density (calculated)

Absorption coefficient

$\mathrm{F}(000)$

Crystal size

Theta range for data collection

Index ranges

Reflections collected

Independent reflections

Completeness to theta $=28.36^{\circ}$

Absorption correction

Max. and min. transmission

Refinement method

Data / restraints / parameters

Goodness-of-fit on $\mathrm{F}^{2}$

Final $\mathrm{R}$ indices [I $>2$ sigma(I)]

$\mathrm{R}$ indices (all data)

Largest diff. peak and hole
C17 H18 O2 S2

318.43

173(2) K

$0.71073 \AA$

Monoclinic

$\mathrm{P} 2(1) / \mathrm{c}$

$$
\begin{aligned}
& \mathrm{a}=7.537(1) \AA \quad \alpha=90^{\circ} \text {. } \\
& \mathrm{b}=15.690(2) \AA \quad \beta=100.987(3)^{\circ} . \\
& \mathrm{c}=12.4552(16) \AA \quad \gamma=90^{\circ} \text {. }
\end{aligned}
$$

1445.9(3) $\AA^{3}$

4

$1.463 \mathrm{Mg} / \mathrm{m}^{3}$

$0.370 \mathrm{~mm}^{-1}$

672

$0.80 \times 0.35 \times 0.11 \mathrm{~mm}^{3}$

2.11 to $28.36^{\circ}$.

$-10<=\mathrm{h}<=9,0<=\mathrm{k}<=20,0<=\mathrm{l}<=16$

7109

$7134[\mathrm{R}($ int $)=0.0000]$

$99.4 \%$

Semi-empirical from equivalents

0.9605 and 0.7565

Full-matrix least-squares on $\mathrm{F}^{2}$

7134 / 0 / 190

1.034

$\mathrm{R} 1=0.0638, \mathrm{wR} 2=0.1320$

$\mathrm{R} 1=0.0844, \mathrm{wR} 2=0.1411$

0.496 and -0.281 e. $\AA^{-3}$ 
Table A.2. Atomic coordinates ( $\mathrm{x} 10^{4}$ ) and equivalent isotropic displacement parameters $\left(\AA^{2} \times 1^{3}\right)$ for $s t-\left[\mathbf{H}-\mathbf{T h}_{\mathbf{1}}-\mathbf{H}\right]_{2} . \quad \mathrm{U}(\mathrm{eq})$ is defined as one third of the trace of the orthogonalized Uij tensor.

\begin{tabular}{|c|c|c|c|c|}
\hline & $\mathrm{x}$ & $\mathrm{y}$ & $\mathrm{z}$ & $\mathrm{U}(\mathrm{eq})$ \\
\hline$S(1)$ & $4470(1)$ & $5804(1)$ & $7618(1)$ & $27(1)$ \\
\hline$S(2)$ & $3490(1)$ & $3718(1)$ & $5358(1)$ & $28(1)$ \\
\hline $\mathrm{O}(1)$ & $-1419(2)$ & $3987(1)$ & $9430(1)$ & $21(1)$ \\
\hline $\mathrm{O}(2)$ & $-2041(2)$ & $2835(1)$ & $8291(1)$ & $22(1)$ \\
\hline $\mathrm{C}(1)$ & $-904(3)$ & $3583(1)$ & $8503(2)$ & $18(1)$ \\
\hline$C(2)$ & $-1423(3)$ & 4191(1) & $7538(2)$ & $18(1)$ \\
\hline$C(3)$ & $-603(3)$ & $5085(1)$ & $7761(2)$ & $19(1)$ \\
\hline$C(4)$ & $1409(3)$ & $5183(1)$ & $7838(2)$ & $17(1)$ \\
\hline$C(5)$ & $2152(3)$ & $5800(1)$ & $7296(2)$ & $21(1)$ \\
\hline$C(6)$ & $4460(3)$ & $4962(1)$ & $8494(2)$ & $21(1)$ \\
\hline$C(7)$ & $2766(3)$ & $4687(1)$ & $8535(2)$ & $18(1)$ \\
\hline $\mathrm{C}(8)$ & $2378(3)$ & $3988(1)$ & $9290(2)$ & $20(1)$ \\
\hline$C(9)$ & 1061(3) & $3274(1)$ & $8811(2)$ & $17(1)$ \\
\hline$C(10)$ & $1666(3)$ & $2721(1)$ & $7924(2)$ & $20(1)$ \\
\hline$C(11)$ & 1996(3) & $3172(1)$ & $6909(2)$ & $19(1)$ \\
\hline$C(12)$ & $3586(3)$ & $3138(2)$ & $6537(2)$ & $23(1)$ \\
\hline $\mathrm{C}(13)$ & $1269(3)$ & 3992(1) & $5348(2)$ & $23(1)$ \\
\hline$C(14)$ & $662(3)$ & $3671(1)$ & $6218(2)$ & $20(1)$ \\
\hline$C(15)$ & $-1222(3)$ & $3807(1)$ & $6429(2)$ & $20(1)$ \\
\hline$C(16)$ & $-2066(3)$ & $3329(1)$ & $10052(2)$ & $23(1)$ \\
\hline $\mathrm{C}(17)$ & $-2971(3)$ & $2728(2)$ & $9166(2)$ & $30(1)$ \\
\hline
\end{tabular}


Table A.3. Bond lengths $[\AA]$ and angles $\left[{ }^{\circ}\right]$ for $s t-\left[\mathbf{H}-\mathbf{T h}_{\mathbf{1}}-\mathbf{H}\right]_{2}$.

\begin{tabular}{|c|c|c|c|}
\hline$S(1)-C(6)$ & $1.713(2)$ & $\mathrm{C}(13)-\mathrm{H}(13)$ & 0.9500 \\
\hline$S(1)-C(5)$ & $1.716(2)$ & $C(14)-C(15)$ & $1.507(3)$ \\
\hline $\mathrm{S}(2)-\mathrm{C}(12)$ & $1.717(2)$ & $\mathrm{C}(15)-\mathrm{H}(15 \mathrm{~A})$ & 0.9900 \\
\hline$S(2)-C(13)$ & $1.727(2)$ & $\mathrm{C}(15)-\mathrm{H}(15 \mathrm{~B})$ & 0.9900 \\
\hline $\mathrm{O}(1)-\mathrm{C}(16)$ & $1.431(3)$ & C(16)-C(17) & $1.512(3)$ \\
\hline $\mathrm{O}(1)-\mathrm{C}(1)$ & $1.433(2)$ & $\mathrm{C}(16)-\mathrm{H}(16 \mathrm{~A})$ & 0.9900 \\
\hline $\mathrm{O}(2)-\mathrm{C}(17)$ & $1.413(3)$ & $\mathrm{C}(16)-\mathrm{H}(16 \mathrm{~B})$ & 0.9900 \\
\hline $\mathrm{O}(2)-\mathrm{C}(1)$ & $1.447(2)$ & $\mathrm{C}(17)-\mathrm{H}(17 \mathrm{~A})$ & 0.9900 \\
\hline $\mathrm{C}(1)-\mathrm{C}(2)$ & $1.526(3)$ & $\mathrm{C}(17)-\mathrm{H}(17 \mathrm{~B})$ & 0.9900 \\
\hline $\mathrm{C}(1)-\mathrm{C}(9)$ & $1.536(3)$ & $C(6)-S(1)-C(5)$ & $91.05(11)$ \\
\hline $\mathrm{C}(2)-\mathrm{C}(3)$ & $1.538(3)$ & $\mathrm{C}(12)-\mathrm{S}(2)-\mathrm{C}(13)$ & $91.21(11)$ \\
\hline$C(2)-C(15)$ & $1.540(3)$ & $\mathrm{C}(16)-\mathrm{O}(1)-\mathrm{C}(1)$ & $106.78(15)$ \\
\hline $\mathrm{C}(2)-\mathrm{H}(2)$ & 1.0000 & $\mathrm{C}(17)-\mathrm{O}(2)-\mathrm{C}(1)$ & $108.59(15)$ \\
\hline$C(3)-C(4)$ & $1.509(3)$ & $\mathrm{O}(1)-\mathrm{C}(1)-\mathrm{O}(2)$ & $105.34(15)$ \\
\hline $\mathrm{C}(3)-\mathrm{H}(3 \mathrm{~A})$ & 0.9900 & $\mathrm{O}(1)-\mathrm{C}(1)-\mathrm{C}(2)$ & $106.83(16)$ \\
\hline $\mathrm{C}(3)-\mathrm{H}(3 \mathrm{~B})$ & 0.9900 & $\mathrm{O}(2)-\mathrm{C}(1)-\mathrm{C}(2)$ & $107.99(16)$ \\
\hline$C(4)-C(5)$ & $1.360(3)$ & $\mathrm{O}(1)-\mathrm{C}(1)-\mathrm{C}(9)$ & $109.54(16)$ \\
\hline $\mathrm{C}(4)-\mathrm{C}(7)$ & $1.437(3)$ & $\mathrm{O}(2)-\mathrm{C}(1)-\mathrm{C}(9)$ & $107.44(16)$ \\
\hline $\mathrm{C}(5)-\mathrm{H}(5)$ & 0.9500 & $\mathrm{C}(2)-\mathrm{C}(1)-\mathrm{C}(9)$ & $118.91(17)$ \\
\hline$C(6)-C(7)$ & $1.359(3)$ & $C(1)-C(2)-C(3)$ & $113.23(16)$ \\
\hline $\mathrm{C}(6)-\mathrm{H}(6)$ & 0.9500 & $\mathrm{C}(1)-\mathrm{C}(2)-\mathrm{C}(15)$ & $114.11(17)$ \\
\hline$C(7)-C(8)$ & $1.509(3)$ & $C(3)-C(2)-C(15)$ & $114.44(17)$ \\
\hline $\mathrm{C}(8)-\mathrm{C}(9)$ & $1.540(3)$ & $\mathrm{C}(1)-\mathrm{C}(2)-\mathrm{H}(2)$ & 104.5 \\
\hline $\mathrm{C}(8)-\mathrm{H}(8 \mathrm{~A})$ & 0.9900 & $\mathrm{C}(3)-\mathrm{C}(2)-\mathrm{H}(2)$ & 104.5 \\
\hline $\mathrm{C}(8)-\mathrm{H}(8 \mathrm{~B})$ & 0.9900 & $\mathrm{C}(15)-\mathrm{C}(2)-\mathrm{H}(2)$ & 104.5 \\
\hline C(9)-C(10) & $1.541(3)$ & $C(4)-C(3)-C(2)$ & $117.95(17)$ \\
\hline $\mathrm{C}(9)-\mathrm{H}(9)$ & 1.0000 & $\mathrm{C}(4)-\mathrm{C}(3)-\mathrm{H}(3 \mathrm{~A})$ & 107.8 \\
\hline $\mathrm{C}(10)-\mathrm{C}(11)$ & $1.509(3)$ & $\mathrm{C}(2)-\mathrm{C}(3)-\mathrm{H}(3 \mathrm{~A})$ & 107.8 \\
\hline $\mathrm{C}(10)-\mathrm{H}(10 \mathrm{~A})$ & 0.9900 & $\mathrm{C}(4)-\mathrm{C}(3)-\mathrm{H}(3 \mathrm{~B})$ & 107.8 \\
\hline $\mathrm{C}(10)-\mathrm{H}(10 \mathrm{~B})$ & 0.9900 & $\mathrm{C}(2)-\mathrm{C}(3)-\mathrm{H}(3 \mathrm{~B})$ & 107.8 \\
\hline$C(11)-C(12)$ & $1.367(3)$ & $\mathrm{H}(3 \mathrm{~A})-\mathrm{C}(3)-\mathrm{H}(3 \mathrm{~B})$ & 107.2 \\
\hline $\mathrm{C}(11)-\mathrm{C}(14)$ & $1.427(3)$ & $C(5)-C(4)-C(7)$ & $111.86(19)$ \\
\hline C(12)-H(12) & 0.9500 & $C(5)-C(4)-C(3)$ & 123.02(19) \\
\hline$C(13)-C(14)$ & $1.352(3)$ & $C(7)-C(4)-C(3)$ & $125.00(18)$ \\
\hline
\end{tabular}




\begin{tabular}{|c|c|c|c|}
\hline$C(4)-C(5)-S(1)$ & $112.58(17)$ & $C(13)-C(14)-C(11)$ & $112.4(2)$ \\
\hline $\mathrm{C}(4)-\mathrm{C}(5)-\mathrm{H}(5)$ & 123.7 & $C(13)-C(14)-C(15)$ & 124.1(2) \\
\hline $\mathrm{S}(1)-\mathrm{C}(5)-\mathrm{H}(5)$ & 123.7 & $\mathrm{C}(11)-\mathrm{C}(14)-\mathrm{C}(15)$ & $123.47(18)$ \\
\hline$C(7)-C(6)-S(1)$ & $112.77(17)$ & $C(14)-C(15)-C(2)$ & $117.94(17)$ \\
\hline $\mathrm{C}(7)-\mathrm{C}(6)-\mathrm{H}(6)$ & 123.6 & $\mathrm{C}(14)-\mathrm{C}(15)-\mathrm{H}(15 \mathrm{~A})$ & 107.8 \\
\hline $\mathrm{S}(1)-\mathrm{C}(6)-\mathrm{H}(6)$ & 123.6 & $\mathrm{C}(2)-\mathrm{C}(15)-\mathrm{H}(15 \mathrm{~A})$ & 107.8 \\
\hline$C(6)-C(7)-C(4)$ & $111.75(19)$ & $\mathrm{C}(14)-\mathrm{C}(15)-\mathrm{H}(15 \mathrm{~B})$ & 107.8 \\
\hline$C(6)-C(7)-C(8)$ & $123.34(19)$ & $\mathrm{C}(2)-\mathrm{C}(15)-\mathrm{H}(15 \mathrm{~B})$ & 107.8 \\
\hline $\mathrm{C}(4)-\mathrm{C}(7)-\mathrm{C}(8)$ & $124.77(19)$ & $\mathrm{H}(15 \mathrm{~A})-\mathrm{C}(15)-\mathrm{H}(15 \mathrm{~B})$ & 107.2 \\
\hline $\mathrm{C}(7)-\mathrm{C}(8)-\mathrm{C}(9)$ & $118.32(18)$ & $\mathrm{O}(1)-\mathrm{C}(16)-\mathrm{C}(17)$ & 101.97(17) \\
\hline $\mathrm{C}(7)-\mathrm{C}(8)-\mathrm{H}(8 \mathrm{~A})$ & 107.7 & $\mathrm{O}(1)-\mathrm{C}(16)-\mathrm{H}(16 \mathrm{~A})$ & 111.4 \\
\hline $\mathrm{C}(9)-\mathrm{C}(8)-\mathrm{H}(8 \mathrm{~A})$ & 107.7 & $\mathrm{C}(17)-\mathrm{C}(16)-\mathrm{H}(16 \mathrm{~A})$ & 111.4 \\
\hline $\mathrm{C}(7)-\mathrm{C}(8)-\mathrm{H}(8 \mathrm{~B})$ & 107.7 & $\mathrm{O}(1)-\mathrm{C}(16)-\mathrm{H}(16 \mathrm{~B})$ & 111.4 \\
\hline $\mathrm{C}(9)-\mathrm{C}(8)-\mathrm{H}(8 \mathrm{~B})$ & 107.7 & $\mathrm{C}(17)-\mathrm{C}(16)-\mathrm{H}(16 \mathrm{~B})$ & 111.4 \\
\hline $\mathrm{H}(8 \mathrm{~A})-\mathrm{C}(8)-\mathrm{H}(8 \mathrm{~B})$ & 107.1 & $\mathrm{H}(16 \mathrm{~A})-\mathrm{C}(16)-\mathrm{H}(16 \mathrm{~B})$ & 109.2 \\
\hline $\mathrm{C}(1)-\mathrm{C}(9)-\mathrm{C}(8)$ & $112.81(16)$ & $\mathrm{O}(2)-\mathrm{C}(17)-\mathrm{C}(16)$ & $105.53(18)$ \\
\hline $\mathrm{C}(1)-\mathrm{C}(9)-\mathrm{C}(10)$ & $113.69(17)$ & $\mathrm{O}(2)-\mathrm{C}(17)-\mathrm{H}(17 \mathrm{~A})$ & 110.6 \\
\hline $\mathrm{C}(8)-\mathrm{C}(9)-\mathrm{C}(10)$ & $115.46(17)$ & $\mathrm{C}(16)-\mathrm{C}(17)-\mathrm{H}(17 \mathrm{~A})$ & 110.6 \\
\hline $\mathrm{C}(1)-\mathrm{C}(9)-\mathrm{H}(9)$ & 104.5 & $\mathrm{O}(2)-\mathrm{C}(17)-\mathrm{H}(17 \mathrm{~B})$ & 110.6 \\
\hline $\mathrm{C}(8)-\mathrm{C}(9)-\mathrm{H}(9)$ & 104.5 & $\mathrm{C}(16)-\mathrm{C}(17)-\mathrm{H}(17 \mathrm{~B})$ & 110.6 \\
\hline $\mathrm{C}(10)-\mathrm{C}(9)-\mathrm{H}(9)$ & 104.5 & $\mathrm{H}(17 \mathrm{~A})-\mathrm{C}(17)-\mathrm{H}(17 \mathrm{~B})$ & 108.8 \\
\hline $\mathrm{C}(11)-\mathrm{C}(10)-\mathrm{C}(9)$ & $117.08(17)$ & & \\
\hline $\mathrm{C}(11)-\mathrm{C}(10)-\mathrm{H}(10 \mathrm{~A})$ & 108.0 & & \\
\hline $\mathrm{C}(9)-\mathrm{C}(10)-\mathrm{H}(10 \mathrm{~A})$ & 108.0 & & \\
\hline $\mathrm{C}(11)-\mathrm{C}(10)-\mathrm{H}(10 \mathrm{~B})$ & 108.0 & & \\
\hline $\mathrm{C}(9)-\mathrm{C}(10)-\mathrm{H}(10 \mathrm{~B})$ & 108.0 & & \\
\hline $\mathrm{H}(10 \mathrm{~A})-\mathrm{C}(10)-\mathrm{H}(10 \mathrm{~B})$ & 107.3 & & \\
\hline $\mathrm{C}(12)-\mathrm{C}(11)-\mathrm{C}(14)$ & $112.29(19)$ & & \\
\hline $\mathrm{C}(12)-\mathrm{C}(11)-\mathrm{C}(10)$ & $124.1(2)$ & & \\
\hline $\mathrm{C}(14)-\mathrm{C}(11)-\mathrm{C}(10)$ & $123.57(19)$ & & \\
\hline C(11)-C(12)-S(2) & $111.92(17)$ & & \\
\hline $\mathrm{C}(11)-\mathrm{C}(12)-\mathrm{H}(12)$ & 124.0 & & \\
\hline $\mathrm{S}(2)-\mathrm{C}(12)-\mathrm{H}(12)$ & 124.0 & & \\
\hline C(14)-C(13)-S(2) & $112.15(17)$ & & \\
\hline $\mathrm{C}(14)-\mathrm{C}(13)-\mathrm{H}(13)$ & 123.9 & & \\
\hline $\mathrm{S}(2)-\mathrm{C}(13)-\mathrm{H}(13)$ & 123.9 & & \\
\hline
\end{tabular}


Table A.4. Anisotropic displacement parameters $\left(\AA^{2} \times 10^{3}\right)$ for $s t-\left[\mathbf{H}-\mathbf{T h}_{\mathbf{1}}-\mathbf{H}\right]_{\mathbf{2}}$. The anisotropic displacement factor exponent takes the form: $-2 \pi^{2}\left[h^{2} a^{* 2} U^{11}\right.$ $\left.+\ldots+2 \mathrm{~h} \mathrm{k} \mathrm{a}^{*} \mathrm{~b}^{*} \mathrm{U}^{12}\right]$

\begin{tabular}{|c|c|c|c|c|c|c|}
\hline & $\mathrm{U}^{11}$ & $\mathrm{U}^{22}$ & $\mathrm{U}^{33}$ & $\mathrm{U}^{23}$ & $\mathrm{U}^{13}$ & $\mathrm{U}^{12}$ \\
\hline$S(1)$ & $25(1)$ & $25(1)$ & $32(1)$ & $1(1)$ & $10(1)$ & $-6(1)$ \\
\hline $\mathrm{S}(2)$ & $29(1)$ & $35(1)$ & $24(1)$ & $-2(1)$ & $13(1)$ & $-1(1)$ \\
\hline $\mathrm{O}(1)$ & $26(1)$ & $19(1)$ & $19(1)$ & $-3(1)$ & $9(1)$ & $-2(1)$ \\
\hline $\mathrm{O}(2)$ & $24(1)$ & $21(1)$ & $23(1)$ & $-6(1)$ & $8(1)$ & $-6(1)$ \\
\hline $\mathrm{C}(1)$ & $20(1)$ & $16(1)$ & $18(1)$ & $-3(1)$ & $5(1)$ & $-2(1)$ \\
\hline$C(2)$ & $13(1)$ & $20(1)$ & $20(1)$ & $-3(1)$ & $3(1)$ & $0(1)$ \\
\hline $\mathrm{C}(3)$ & $20(1)$ & $18(1)$ & $19(1)$ & 1(1) & $3(1)$ & $3(1)$ \\
\hline$C(4)$ & $22(1)$ & $15(1)$ & $15(1)$ & $-4(1)$ & $4(1)$ & $0(1)$ \\
\hline$C(5)$ & $24(1)$ & $19(1)$ & $20(1)$ & $0(1)$ & $2(1)$ & $-1(1)$ \\
\hline$C(6)$ & $20(1)$ & $19(1)$ & $23(1)$ & $-2(1)$ & $3(1)$ & $0(1)$ \\
\hline$C(7)$ & $22(1)$ & $16(1)$ & $17(1)$ & $-4(1)$ & $4(1)$ & $-2(1)$ \\
\hline$C(8)$ & $19(1)$ & $21(1)$ & $19(1)$ & $0(1)$ & $0(1)$ & $1(1)$ \\
\hline $\mathrm{C}(9)$ & $21(1)$ & $14(1)$ & $17(1)$ & 1(1) & $5(1)$ & $-1(1)$ \\
\hline$C(10)$ & $19(1)$ & $18(1)$ & $22(1)$ & $2(1)$ & $4(1)$ & $4(1)$ \\
\hline $\mathrm{C}(11)$ & $22(1)$ & $17(1)$ & $18(1)$ & $-6(1)$ & $4(1)$ & $-1(1)$ \\
\hline$C(12)$ & $21(1)$ & $29(1)$ & $21(1)$ & $-2(1)$ & $3(1)$ & $2(1)$ \\
\hline $\mathrm{C}(13)$ & $28(1)$ & $23(1)$ & $19(1)$ & $-3(1)$ & $5(1)$ & $4(1)$ \\
\hline$C(14)$ & $24(1)$ & $17(1)$ & $18(1)$ & $-7(1)$ & $4(1)$ & $-2(1)$ \\
\hline$C(15)$ & $21(1)$ & $23(1)$ & $16(1)$ & $-2(1)$ & $1(1)$ & $0(1)$ \\
\hline$C(16)$ & $26(1)$ & $23(1)$ & $20(1)$ & $1(1)$ & $7(1)$ & $-2(1)$ \\
\hline $\mathrm{C}(17)$ & $36(1)$ & $31(1)$ & $27(1)$ & $-5(1)$ & $17(1)$ & $-11(1)$ \\
\hline
\end{tabular}


Table A.5. Hydrogen coordinates ( $\mathrm{x} 10^{4}$ ) and isotropic displacement parameters $\left(\AA^{2} \mathrm{x}\right.$ $\left.10^{3}\right)$ for $s t-\left[\mathbf{H}-\mathbf{T h}_{\mathbf{1}}-\mathbf{H}\right]_{2}$.

\begin{tabular}{|c|c|c|c|c|}
\hline & $\mathrm{x}$ & $\mathrm{y}$ & $\mathrm{z}$ & $\mathrm{U}(\mathrm{eq})$ \\
\hline $\mathrm{H}(2)$ & -2753 & 4278 & 7474 & 21 \\
\hline $\mathrm{H}(3 \mathrm{~A})$ & -1214 & 5468 & 7174 & 23 \\
\hline $\mathrm{H}(3 \mathrm{~B})$ & -903 & 5292 & 8456 & 23 \\
\hline $\mathrm{H}(5)$ & 1464 & 6186 & 6795 & 26 \\
\hline $\mathrm{H}(6)$ & 5526 & 4715 & 8906 & 25 \\
\hline $\mathrm{H}(8 \mathrm{~A})$ & 1900 & 4258 & 9895 & 24 \\
\hline $\mathrm{H}(8 \mathrm{~B})$ & 3544 & 3718 & 9616 & 24 \\
\hline $\mathrm{H}(9)$ & 1062 & 2874 & 9437 & 20 \\
\hline $\mathrm{H}(10 \mathrm{~A})$ & 2795 & 2424 & 8260 & 24 \\
\hline $\mathrm{H}(10 \mathrm{~B})$ & 734 & 2279 & 7696 & 24 \\
\hline $\mathrm{H}(12)$ & 4622 & 2831 & 6888 & 28 \\
\hline $\mathrm{H}(13)$ & 556 & 4330 & 4795 & 28 \\
\hline $\mathrm{H}(15 \mathrm{~A})$ & -1850 & 3250 & 6350 & 24 \\
\hline $\mathrm{H}(15 \mathrm{~B})$ & -1869 & 4184 & 5845 & 24 \\
\hline $\mathrm{H}(16 \mathrm{~A})$ & -2939 & 3555 & 10482 & 27 \\
\hline $\mathrm{H}(16 \mathrm{~B})$ & -1059 & 3046 & 10551 & 27 \\
\hline $\mathrm{H}(17 \mathrm{~A})$ & -2874 & 2132 & 9430 & 36 \\
\hline $\mathrm{H}(17 \mathrm{~B})$ & -4265 & 2874 & 8933 & 36 \\
\hline
\end{tabular}


Table A.6. Torsion angles $\left[{ }^{\circ}\right]$ for $s t-\left[\mathbf{H}-\mathbf{T h} \mathbf{h}_{\mathbf{1}}-\mathbf{H}\right]_{2}$.

\begin{tabular}{|c|c|}
\hline $\mathrm{C}(16)-\mathrm{O}(1)-\mathrm{C}(1)-\mathrm{O}(2)$ & $28.3(2)$ \\
\hline $\mathrm{C}(16)-\mathrm{O}(1)-\mathrm{C}(1)-\mathrm{C}(2)$ & $142.96(17)$ \\
\hline $\mathrm{C}(16)-\mathrm{O}(1)-\mathrm{C}(1)-\mathrm{C}(9)$ & $-87.01(19)$ \\
\hline $\mathrm{C}(17)-\mathrm{O}(2)-\mathrm{C}(1)-\mathrm{O}(1)$ & $-9.3(2)$ \\
\hline $\mathrm{C}(17)-\mathrm{O}(2)-\mathrm{C}(1)-\mathrm{C}(2)$ & $-123.17(18)$ \\
\hline $\mathrm{C}(17)-\mathrm{O}(2)-\mathrm{C}(1)-\mathrm{C}(9)$ & $107.43(19)$ \\
\hline $\mathrm{O}(1)-\mathrm{C}(1)-\mathrm{C}(2)-\mathrm{C}(3)$ & $55.1(2)$ \\
\hline $\mathrm{O}(2)-\mathrm{C}(1)-\mathrm{C}(2)-\mathrm{C}(3)$ & $167.99(16)$ \\
\hline $\mathrm{C}(9)-\mathrm{C}(1)-\mathrm{C}(2)-\mathrm{C}(3)$ & $-69.4(2)$ \\
\hline $\mathrm{O}(1)-\mathrm{C}(1)-\mathrm{C}(2)-\mathrm{C}(15)$ & $-171.63(16)$ \\
\hline $\mathrm{O}(2)-\mathrm{C}(1)-\mathrm{C}(2)-\mathrm{C}(15)$ & $-58.8(2)$ \\
\hline$C(9)-C(1)-C(2)-C(15)$ & $63.9(2)$ \\
\hline $\mathrm{C}(1)-\mathrm{C}(2)-\mathrm{C}(3)-\mathrm{C}(4)$ & $70.3(2)$ \\
\hline $\mathrm{C}(15)-\mathrm{C}(2)-\mathrm{C}(3)-\mathrm{C}(4)$ & $-62.9(2)$ \\
\hline $\mathrm{C}(2)-\mathrm{C}(3)-\mathrm{C}(4)-\mathrm{C}(5)$ & $131.8(2)$ \\
\hline$C(2)-C(3)-C(4)-C(7)$ & $-52.7(3)$ \\
\hline$C(7)-C(4)-C(5)-S(1)$ & $-0.5(2)$ \\
\hline$C(3)-C(4)-C(5)-S(1)$ & $175.51(15)$ \\
\hline $\mathrm{C}(6)-\mathrm{S}(1)-\mathrm{C}(5)-\mathrm{C}(4)$ & $0.12(17)$ \\
\hline$C(5)-S(1)-C(6)-C(7)$ & $0.33(17)$ \\
\hline$S(1)-C(6)-C(7)-C(4)$ & $-0.7(2)$ \\
\hline$S(1)-C(6)-C(7)-C(8)$ & $-176.43(16)$ \\
\hline$C(5)-C(4)-C(7)-C(6)$ & $0.8(3)$ \\
\hline$C(3)-C(4)-C(7)-C(6)$ & $-175.16(19)$ \\
\hline$C(5)-C(4)-C(7)-C(8)$ & $176.45(19)$ \\
\hline $\mathrm{C}(3)-\mathrm{C}(4)-\mathrm{C}(7)-\mathrm{C}(8)$ & $0.5(3)$ \\
\hline$C(6)-C(7)-C(8)-C(9)$ & $-132.6(2)$ \\
\hline$C(4)-C(7)-C(8)-C(9)$ & $52.2(3)$ \\
\hline $\mathrm{O}(1)-\mathrm{C}(1)-\mathrm{C}(9)-\mathrm{C}(8)$ & $-54.0(2)$ \\
\hline $\mathrm{O}(2)-\mathrm{C}(1)-\mathrm{C}(9)-\mathrm{C}(8)$ & $-167.96(16)$ \\
\hline$C(2)-C(1)-C(9)-C(8)$ & $69.1(2)$ \\
\hline $\mathrm{O}(1)-\mathrm{C}(1)-\mathrm{C}(9)-\mathrm{C}(10)$ & $172.05(16)$ \\
\hline $\mathrm{O}(2)-\mathrm{C}(1)-\mathrm{C}(9)-\mathrm{C}(10)$ & $58.1(2)$ \\
\hline $\mathrm{C}(2)-\mathrm{C}(1)-\mathrm{C}(9)-\mathrm{C}(10)$ & $-64.8(2)$ \\
\hline
\end{tabular}




$\begin{array}{lc}\mathrm{C}(7)-\mathrm{C}(8)-\mathrm{C}(9)-\mathrm{C}(1) & -70.1(2) \\ \mathrm{C}(7)-\mathrm{C}(8)-\mathrm{C}(9)-\mathrm{C}(10) & 63.0(2) \\ \mathrm{C}(1)-\mathrm{C}(9)-\mathrm{C}(10)-\mathrm{C}(11) & 73.3(2) \\ \mathrm{C}(8)-\mathrm{C}(9)-\mathrm{C}(10)-\mathrm{C}(11) & -59.4(2) \\ \mathrm{C}(9)-\mathrm{C}(10)-\mathrm{C}(11)-\mathrm{C}(12) & 123.7(2) \\ \mathrm{C}(9)-\mathrm{C}(10)-\mathrm{C}(11)-\mathrm{C}(14) & -57.5(3) \\ \mathrm{C}(14)-\mathrm{C}(11)-\mathrm{C}(12)-\mathrm{S}(2) & 0.6(2) \\ \mathrm{C}(10)-\mathrm{C}(11)-\mathrm{C}(12)-\mathrm{S}(2) & 179.56(16) \\ \mathrm{C}(13)-\mathrm{S}(2)-\mathrm{C}(12)-\mathrm{C}(11) & -1.15(18) \\ \mathrm{C}(12)-\mathrm{S}(2)-\mathrm{C}(13)-\mathrm{C}(14) & 1.41(18) \\ \mathrm{S}(2)-\mathrm{C}(13)-\mathrm{C}(14)-\mathrm{C}(11) & -1.3(2) \\ \mathrm{S}(2)-\mathrm{C}(13)-\mathrm{C}(14)-\mathrm{C}(15) & 179.82(16) \\ \mathrm{C}(12)-\mathrm{C}(11)-\mathrm{C}(14)-\mathrm{C}(13) & 0.4(3) \\ \mathrm{C}(10)-\mathrm{C}(11)-\mathrm{C}(14)-\mathrm{C}(13) & -178.5(2) \\ \mathrm{C}(12)-\mathrm{C}(11)-\mathrm{C}(14)-\mathrm{C}(15) & 179.32(19) \\ \mathrm{C}(10)-\mathrm{C}(11)-\mathrm{C}(14)-\mathrm{C}(15) & 0.4(3) \\ \mathrm{C}(13)-\mathrm{C}(14)-\mathrm{C}(15)-\mathrm{C}(2) & -124.8(2) \\ \mathrm{C}(11)-\mathrm{C}(14)-\mathrm{C}(15)-\mathrm{C}(2) & 56.5(3) \\ \mathrm{C}(1)-\mathrm{C}(2)-\mathrm{C}(15)-\mathrm{C}(14) & -71.9(2) \\ \mathrm{C}(3)-\mathrm{C}(2)-\mathrm{C}(15)-\mathrm{C}(14) & 60.8(2) \\ \mathrm{C}(1)-\mathrm{O}(1)-\mathrm{C}(16)-\mathrm{C}(17) & -34.7(2) \\ \mathrm{C}(1)-\mathrm{O}(2)-\mathrm{C}(17)-\mathrm{C}(16) & -11.9(2) \\ \mathrm{O}(1)-\mathrm{C}(16)-\mathrm{C}(17)-\mathrm{O}(2) & 28.4(2)\end{array}$

Symmetry transformations used to generate equivalent atoms: 
A suitable crystal of $\mathbf{3 . 5}$ was coated with Paratone $\mathbf{N}$ oil, suspended in a small fiber loop and placed in a cooled nitrogen gas stream at $173 \mathrm{~K}$ on a Bruker D8 SMART APEX CCD sealed tube diffractometer with graphite monochromated MoK $\alpha(0.71073 \AA)$ radiation. Data was measured using a series of combinations of phi and omega scans with $10 \mathrm{~s}$ frame exposures and $0.3^{\circ}$ frame widths. Data collection, indexing and initial cell refinements were all carried out using $\mathrm{SMART}^{1}$ software. Frame integration and final cell refinements were done using $\mathrm{SAINT}^{2}$ software. The final cell parameters were determined from least-squares refinement on 6168 reflections.

The structure was solved using Direct methods and difference Fourier techniques (SHELXTL, V6.12). ${ }^{4}$ Hydrogen atoms were placed in their expected chemical positions using the HFIX command and were included in the final cycles of least-squares with isotropic Uij's related to the riding atom. The $\mathrm{C}-\mathrm{H}$ distances were fixed at $0.93 \AA$ (aromatic and amide), 0.98 (methine), $0.97 \AA$ (methylene), or $0.96 \AA$ (methyl). All nonhydrogen atoms were refined anisotropically. Scattering factors and anomalous dispersion corrections are taken from the International Tables for X-ray Crystallography. ${ }^{5}$ Structure solution, refinement, graphics and generation of publication materials were performed using SHELXTL, V6.12 software. Additional details of data collection and structure refinement are given in Tables A.7-A.12. 
Table A.7. Crystal data and structure refinement for 3.5.

\begin{tabular}{|c|c|c|}
\hline Empirical formula & \multicolumn{2}{|l|}{ C35 H30 O S6 } \\
\hline Formula weight & \multicolumn{2}{|l|}{658.95} \\
\hline Temperature & \multicolumn{2}{|l|}{$173(2) \mathrm{K}$} \\
\hline Wavelength & \multicolumn{2}{|l|}{$0.71073 \AA$} \\
\hline Crystal system & \multicolumn{2}{|l|}{ Monoclinic } \\
\hline Space group & \multicolumn{2}{|l|}{$\mathrm{P} 2(1) / \mathrm{n}$} \\
\hline \multirow[t]{3}{*}{ Unit cell dimensions } & $a=13.8734(12) \AA$ & $\alpha=90^{\circ}$ \\
\hline & $\mathrm{b}=12.6812(11) \AA$ & $\beta=98.282(2)^{\circ}$. \\
\hline & $c=17.7401(15) \AA$ & $\gamma=90^{\circ}$ \\
\hline Volume & \multicolumn{2}{|l|}{$3088.5(5) \AA^{3}$} \\
\hline $\mathrm{Z}$ & \multicolumn{2}{|l|}{4} \\
\hline Density (calculated) & \multicolumn{2}{|l|}{$1.417 \mathrm{Mg} / \mathrm{m}^{3}$} \\
\hline Absorption coefficient & \multicolumn{2}{|l|}{$0.472 \mathrm{~mm}^{-1}$} \\
\hline $\mathrm{F}(000)$ & \multicolumn{2}{|l|}{1376} \\
\hline Crystal size & \multicolumn{2}{|c|}{$0.36 \times 0.35 \times 0.16 \mathrm{~mm}^{3}$} \\
\hline Theta range for data collection & \multicolumn{2}{|l|}{1.75 to $28.32^{\circ}$. } \\
\hline Index ranges & \multicolumn{2}{|c|}{$-18<=\mathrm{h}<=18,-16<=\mathrm{k}<=16,-23<=\mathrm{l}<=21$} \\
\hline Reflections collected & \multicolumn{2}{|l|}{29539} \\
\hline Independent reflections & \multicolumn{2}{|c|}{$7658[\mathrm{R}($ int $)=0.0493]$} \\
\hline Completeness to theta $=28.32^{\circ}$ & \multicolumn{2}{|l|}{$99.6 \%$} \\
\hline Absorption correction & \multicolumn{2}{|l|}{ None } \\
\hline Refinement method & \multicolumn{2}{|c|}{ Full-matrix least-squares on $\mathrm{F}^{2}$} \\
\hline Data / restraints / parameters & \multicolumn{2}{|c|}{$7658 / 0 / 383$} \\
\hline Goodness-of-fit on $\mathrm{F}^{2}$ & \multicolumn{2}{|l|}{1.030} \\
\hline Final $R$ indices $[\mathrm{I}>2 \operatorname{sigma}(\mathrm{I})]$ & \multicolumn{2}{|c|}{$\mathrm{R} 1=0.0462, \mathrm{wR} 2=0.0983$} \\
\hline $\mathrm{R}$ indices (all data) & \multicolumn{2}{|c|}{$\mathrm{R} 1=0.0658, \mathrm{wR} 2=0.1033$} \\
\hline Largest diff. peak and hole & \multicolumn{2}{|c|}{0.487 and -0.254 e. $\AA^{-3}$} \\
\hline
\end{tabular}


Table A.8. Atomic coordinates (x 104) and equivalent isotropic displacement parameters $\left(\AA^{2} \times 10^{3}\right)$ for 3.5 . U(eq) is defined as one third of the trace of the orthogonalized $\mathrm{U}^{\mathrm{ij}}$ tensor.

\begin{tabular}{|c|c|c|c|c|}
\hline & $\mathrm{X}$ & $\mathrm{y}$ & $\mathrm{z}$ & $\mathrm{U}(\mathrm{eq})$ \\
\hline $\mathrm{C}(1)$ & $9538(1)$ & $1423(2)$ & $8784(1)$ & $22(1)$ \\
\hline$C(2)$ & $9560(1)$ & $1932(2)$ & $8014(1)$ & $21(1)$ \\
\hline$C(3)$ & $9850(1)$ & $3105(2)$ & $8062(1)$ & $23(1)$ \\
\hline$C(4)$ & $10507(1)$ & $3398(2)$ & $8779(1)$ & $23(1)$ \\
\hline$C(5)$ & 10143(1) & $3407(2)$ & $9499(1)$ & $21(1)$ \\
\hline$C(6)$ & 9107(1) & $3067(2)$ & $9522(1)$ & $24(1)$ \\
\hline$C(7)$ & 8911(1) & 1890(2) & $9336(1)$ & $22(1)$ \\
\hline $\mathrm{C}(8)$ & $7818(1)$ & $1673(2)$ & $9034(1)$ & $22(1)$ \\
\hline $\mathrm{C}(9)$ & $7382(1)$ & 2391(2) & 8399(1) & $20(1)$ \\
\hline$C(10)$ & $7746(1)$ & $2446(2)$ & $7680(1)$ & $20(1)$ \\
\hline$C(11)$ & 8566(1) & 1761(2) & $7502(1)$ & $22(1)$ \\
\hline$C(12)$ & 10807(1) & $3794(2)$ & $10080(1)$ & $23(1)$ \\
\hline $\mathrm{C}(13)$ & $10768(1)$ & $3983(2)$ & 10890(1) & $23(1)$ \\
\hline$C(14)$ & $11497(2)$ & $4372(2)$ & $11418(1)$ & $27(1)$ \\
\hline$C(15)$ & $11238(2)$ & $4457(2)$ & $12158(1)$ & $29(1)$ \\
\hline$C(16)$ & $10317(2)$ & $4142(2)$ & $12208(1)$ & $28(1)$ \\
\hline$C(17)$ & $9784(2)$ & $4155(2)$ & 12881(1) & $42(1)$ \\
\hline$C(18)$ & $11446(1)$ & $3767(2)$ & 8832(1) & $25(1)$ \\
\hline$C(19)$ & $12035(1)$ & $3987(2)$ & $8234(1)$ & $27(1)$ \\
\hline$C(20)$ & $12564(2)$ & $4880(2)$ & $8144(1)$ & $35(1)$ \\
\hline$C(21)$ & $13035(2)$ & $4856(2)$ & $7484(1)$ & $38(1)$ \\
\hline $\mathrm{C}(22)$ & $12883(2)$ & $3965(2)$ & $7076(1)$ & $32(1)$ \\
\hline$C(23)$ & $13235(2)$ & $3678(2)$ & $6343(1)$ & $45(1)$ \\
\hline$C(24)$ & $6586(1)$ & $3031(2)$ & $8417(1)$ & $22(1)$ \\
\hline$C(25)$ & $5957(2)$ & $3205(2)$ & $9003(1)$ & $26(1)$ \\
\hline$C(26)$ & $4973(2)$ & $3367(2)$ & $8892(1)$ & $36(1)$ \\
\hline$C(27)$ & $4591(2)$ & $3563(2)$ & $9576(2)$ & $41(1)$ \\
\hline$C(28)$ & $5262(2)$ & $3565(2)$ & 10204(1) & $33(1)$ \\
\hline$C(29)$ & $5117(2)$ & $3747(2)$ & $11010(1)$ & $47(1)$ \\
\hline $\mathrm{C}(30)$ & $7234(1)$ & $3132(2)$ & 7177(1) & $21(1)$ \\
\hline
\end{tabular}




$\begin{array}{lrrrr}\mathrm{C}(31) & 7344(2) & 3422(2) & 6395(1) & 23(1) \\ \mathrm{C}(32) & 6628(2) & 3648(2) & 5807(1) & 30(1) \\ \mathrm{C}(33) & 6990(2) & 3943(2) & 5127(1) & 36(1) \\ \mathrm{C}(34) & 7972(2) & 3950(2) & 5190(1) & 35(1) \\ \mathrm{C}(35) & 8604(2) & 4210(2) & 4599(2) & 59(1) \\ \mathrm{O}(1) & 9980(1) & 609(1) & 8940(1) & 32(1) \\ \mathrm{S}(1) & 9753(1) & 3728(1) & 11326(1) & 33(1) \\ \mathrm{S}(2) & 11887(1) & 4129(1) & 9756(1) & 29(1) \\ \mathrm{S}(3) & 12150(1) & 3116(1) & 7503(1) & 38(1) \\ \mathrm{S}(4) & 8475(1) & 3606(1) & 6104(1) & 38(1) \\ \mathrm{S}(5) & 6286(1) & 3706(1) & 7566(1) & 25(1) \\ \mathrm{S}(6) & 6400(1) & 3320(1) & 9960(1) & 37(1) \\ \end{array}$


Table A.9. Bond lengths $[\AA]$ and angles $\left[{ }^{\circ}\right]$ for 3.5 .

\begin{tabular}{|c|c|c|c|}
\hline $\mathrm{C}(1)-\mathrm{O}(1)$ & $1.212(2)$ & $C(15)-C(16)$ & 1.354(3) \\
\hline$C(1)-C(2)$ & $1.516(3)$ & $\mathrm{C}(15)-\mathrm{H}(15)$ & 0.9500 \\
\hline $\mathrm{C}(1)-\mathrm{C}(7)$ & $1.520(3)$ & $C(16)-C(17)$ & $1.493(3)$ \\
\hline$C(2)-C(3)$ & $1.540(3)$ & $C(16)-S(1)$ & $1.727(2)$ \\
\hline $\mathrm{C}(2)-\mathrm{C}(11)$ & $1.553(3)$ & $\mathrm{C}(17)-\mathrm{H}(17 \mathrm{~A})$ & 0.9800 \\
\hline $\mathrm{C}(2)-\mathrm{H}(2)$ & 1.0000 & $\mathrm{C}(17)-\mathrm{H}(17 \mathrm{~B})$ & 0.9800 \\
\hline $\mathrm{C}(3)-\mathrm{C}(4)$ & $1.500(3)$ & $\mathrm{C}(17)-\mathrm{H}(17 \mathrm{C})$ & 0.9800 \\
\hline $\mathrm{C}(3)-\mathrm{H}(3 \mathrm{~A})$ & 0.9900 & $\mathrm{C}(18)-\mathrm{C}(19)$ & $1.456(3)$ \\
\hline $\mathrm{C}(3)-\mathrm{H}(3 \mathrm{~B})$ & 0.9900 & $C(18)-S(2)$ & $1.726(2)$ \\
\hline $\mathrm{C}(4)-\mathrm{C}(18)$ & $1.375(3)$ & $C(19)-C(20)$ & $1.371(3)$ \\
\hline $\mathrm{C}(4)-\mathrm{C}(5)$ & 1.439(3) & C(19)-S(3) & $1.728(2)$ \\
\hline$C(5)-C(12)$ & $1.370(3)$ & $C(20)-C(21)$ & $1.422(3)$ \\
\hline$C(5)-C(6)$ & $1.507(3)$ & $\mathrm{C}(20)-\mathrm{H}(20)$ & 0.9500 \\
\hline $\mathrm{C}(6)-\mathrm{C}(7)$ & $1.544(3)$ & $C(21)-C(22)$ & $1.342(3)$ \\
\hline $\mathrm{C}(6)-\mathrm{H}(6 \mathrm{~A})$ & 0.9900 & $\mathrm{C}(21)-\mathrm{H}(21)$ & 0.9500 \\
\hline $\mathrm{C}(6)-\mathrm{H}(6 \mathrm{~B})$ & 0.9900 & $C(22)-C(23)$ & $1.498(3)$ \\
\hline $\mathrm{C}(7)-\mathrm{C}(8)$ & $1.558(3)$ & $C(22)-S(3)$ & $1.729(2)$ \\
\hline $\mathrm{C}(7)-\mathrm{H}(7)$ & 1.0000 & $\mathrm{C}(23)-\mathrm{H}(23 \mathrm{~A})$ & 0.9800 \\
\hline $\mathrm{C}(8)-\mathrm{C}(9)$ & $1.505(3)$ & $\mathrm{C}(23)-\mathrm{H}(23 \mathrm{~B})$ & 0.9800 \\
\hline $\mathrm{C}(8)-\mathrm{H}(8 \mathrm{~A})$ & 0.9900 & $\mathrm{C}(23)-\mathrm{H}(23 \mathrm{C})$ & 0.9800 \\
\hline $\mathrm{C}(8)-\mathrm{H}(8 \mathrm{~B})$ & 0.9900 & $\mathrm{C}(24)-\mathrm{C}(25)$ & $1.468(3)$ \\
\hline $\mathrm{C}(9)-\mathrm{C}(24)$ & $1.375(3)$ & $C(24)-S(5)$ & $1.732(2)$ \\
\hline $\mathrm{C}(9)-\mathrm{C}(10)$ & $1.439(3)$ & $C(25)-C(26)$ & $1.366(3)$ \\
\hline C(10)-C(30) & $1.370(3)$ & $C(25)-S(6)$ & $1.728(2)$ \\
\hline $\mathrm{C}(10)-\mathrm{C}(11)$ & $1.501(3)$ & $C(26)-C(27)$ & $1.415(3)$ \\
\hline $\mathrm{C}(11)-\mathrm{H}(11 \mathrm{~A})$ & 0.9900 & $\mathrm{C}(26)-\mathrm{H}(26)$ & 0.9500 \\
\hline $\mathrm{C}(11)-\mathrm{H}(11 \mathrm{~B})$ & 0.9900 & $\mathrm{C}(27)-\mathrm{C}(28)$ & $1.345(3)$ \\
\hline $\mathrm{C}(12)-\mathrm{C}(13)$ & $1.466(3)$ & $\mathrm{C}(27)-\mathrm{H}(27)$ & 0.9500 \\
\hline $\mathrm{C}(12)-\mathrm{S}(2)$ & $1.733(2)$ & $\mathrm{C}(28)-\mathrm{C}(29)$ & $1.490(3)$ \\
\hline$C(13)-C(14)$ & $1.367(3)$ & $\mathrm{C}(28)-\mathrm{S}(6)$ & $1.725(2)$ \\
\hline C(13)-S(1) & $1.732(2)$ & $\mathrm{C}(29)-\mathrm{H}(29 \mathrm{~A})$ & 0.9800 \\
\hline$C(14)-C(15)$ & $1.414(3)$ & $\mathrm{C}(29)-\mathrm{H}(29 \mathrm{~B})$ & 0.9800 \\
\hline C(14)-H(14) & 0.9500 & C(29)-H(29C) & 0.9800 \\
\hline
\end{tabular}




\begin{tabular}{|c|c|c|c|}
\hline $\mathrm{C}(30)-\mathrm{C}(31)$ & $1.463(3)$ & $\mathrm{C}(5)-\mathrm{C}(6)-\mathrm{H}(6 \mathrm{~A})$ & 108.7 \\
\hline $\mathrm{C}(30)-\mathrm{S}(5)$ & $1.732(2)$ & $\mathrm{C}(7)-\mathrm{C}(6)-\mathrm{H}(6 \mathrm{~A})$ & 108.7 \\
\hline $\mathrm{C}(31)-\mathrm{C}(32)$ & $1.364(3)$ & $\mathrm{C}(5)-\mathrm{C}(6)-\mathrm{H}(6 \mathrm{~B})$ & 108.7 \\
\hline $\mathrm{C}(31)-\mathrm{S}(4)$ & $1.737(2)$ & $\mathrm{C}(7)-\mathrm{C}(6)-\mathrm{H}(6 \mathrm{~B})$ & 108.7 \\
\hline $\mathrm{C}(32)-\mathrm{C}(33)$ & $1.422(3)$ & $\mathrm{H}(6 \mathrm{~A})-\mathrm{C}(6)-\mathrm{H}(6 \mathrm{~B})$ & 107.6 \\
\hline $\mathrm{C}(32)-\mathrm{H}(32)$ & 0.9500 & $C(1)-C(7)-C(6)$ & $114.51(16)$ \\
\hline $\mathrm{C}(33)-\mathrm{C}(34)$ & $1.350(3)$ & $\mathrm{C}(1)-\mathrm{C}(7)-\mathrm{C}(8)$ & $109.15(16)$ \\
\hline $\mathrm{C}(33)-\mathrm{H}(33)$ & 0.9500 & $\mathrm{C}(6)-\mathrm{C}(7)-\mathrm{C}(8)$ & $112.12(16)$ \\
\hline $\mathrm{C}(34)-\mathrm{C}(35)$ & $1.499(3)$ & $\mathrm{C}(1)-\mathrm{C}(7)-\mathrm{H}(7)$ & 106.9 \\
\hline $\mathrm{C}(34)-\mathrm{S}(4)$ & $1.726(2)$ & $\mathrm{C}(6)-\mathrm{C}(7)-\mathrm{H}(7)$ & 106.9 \\
\hline $\mathrm{C}(35)-\mathrm{H}(35 \mathrm{~A})$ & 0.9800 & $\mathrm{C}(8)-\mathrm{C}(7)-\mathrm{H}(7)$ & 106.9 \\
\hline $\mathrm{C}(35)-\mathrm{H}(35 \mathrm{~B})$ & 0.9800 & $\mathrm{C}(9)-\mathrm{C}(8)-\mathrm{C}(7)$ & $114.64(16)$ \\
\hline \multirow[t]{2}{*}{$\mathrm{C}(35)-\mathrm{H}(35 \mathrm{C})$} & 0.9800 & $\mathrm{C}(9)-\mathrm{C}(8)-\mathrm{H}(8 \mathrm{~A})$ & 108.6 \\
\hline & & $\mathrm{C}(7)-\mathrm{C}(8)-\mathrm{H}(8 \mathrm{~A})$ & 108.6 \\
\hline $\mathrm{O}(1)-\mathrm{C}(1)-\mathrm{C}(2)$ & $119.50(18)$ & $\mathrm{C}(9)-\mathrm{C}(8)-\mathrm{H}(8 \mathrm{~B})$ & 108.6 \\
\hline $\mathrm{O}(1)-\mathrm{C}(1)-\mathrm{C}(7)$ & $120.22(18)$ & $\mathrm{C}(7)-\mathrm{C}(8)-\mathrm{H}(8 \mathrm{~B})$ & 108.6 \\
\hline $\mathrm{C}(2)-\mathrm{C}(1)-\mathrm{C}(7)$ & $120.16(17)$ & $\mathrm{H}(8 \mathrm{~A})-\mathrm{C}(8)-\mathrm{H}(8 \mathrm{~B})$ & 107.6 \\
\hline $\mathrm{C}(1)-\mathrm{C}(2)-\mathrm{C}(3)$ & $113.59(16)$ & $\mathrm{C}(24)-\mathrm{C}(9)-\mathrm{C}(10)$ & $112.16(18)$ \\
\hline $\mathrm{C}(1)-\mathrm{C}(2)-\mathrm{C}(11)$ & 109.67(16) & $\mathrm{C}(24)-\mathrm{C}(9)-\mathrm{C}(8)$ & $125.29(18)$ \\
\hline$C(3)-C(2)-C(11)$ & $111.69(16)$ & $\mathrm{C}(10)-\mathrm{C}(9)-\mathrm{C}(8)$ & $122.50(17)$ \\
\hline $\mathrm{C}(1)-\mathrm{C}(2)-\mathrm{H}(2)$ & 107.2 & $\mathrm{C}(30)-\mathrm{C}(10)-\mathrm{C}(9)$ & $113.15(17)$ \\
\hline $\mathrm{C}(3)-\mathrm{C}(2)-\mathrm{H}(2)$ & 107.2 & $\mathrm{C}(30)-\mathrm{C}(10)-\mathrm{C}(11)$ & $124.59(18)$ \\
\hline $\mathrm{C}(11)-\mathrm{C}(2)-\mathrm{H}(2)$ & 107.2 & $\mathrm{C}(9)-\mathrm{C}(10)-\mathrm{C}(11)$ & $122.16(17)$ \\
\hline $\mathrm{C}(4)-\mathrm{C}(3)-\mathrm{C}(2)$ & $114.08(16)$ & $\mathrm{C}(10)-\mathrm{C}(11)-\mathrm{C}(2)$ & $115.57(16)$ \\
\hline $\mathrm{C}(4)-\mathrm{C}(3)-\mathrm{H}(3 \mathrm{~A})$ & 108.7 & $\mathrm{C}(10)-\mathrm{C}(11)-\mathrm{H}(11 \mathrm{~A})$ & 108.4 \\
\hline $\mathrm{C}(2)-\mathrm{C}(3)-\mathrm{H}(3 \mathrm{~A})$ & 108.7 & $\mathrm{C}(2)-\mathrm{C}(11)-\mathrm{H}(11 \mathrm{~A})$ & 108.4 \\
\hline $\mathrm{C}(4)-\mathrm{C}(3)-\mathrm{H}(3 \mathrm{~B})$ & 108.7 & $\mathrm{C}(10)-\mathrm{C}(11)-\mathrm{H}(11 \mathrm{~B})$ & 108.4 \\
\hline $\mathrm{C}(2)-\mathrm{C}(3)-\mathrm{H}(3 \mathrm{~B})$ & 108.7 & $\mathrm{C}(2)-\mathrm{C}(11)-\mathrm{H}(11 \mathrm{~B})$ & 108.4 \\
\hline $\mathrm{H}(3 \mathrm{~A})-\mathrm{C}(3)-\mathrm{H}(3 \mathrm{~B})$ & 107.6 & $\mathrm{H}(11 \mathrm{~A})-\mathrm{C}(11)-\mathrm{H}(11 \mathrm{~B})$ & 107.4 \\
\hline $\mathrm{C}(18)-\mathrm{C}(4)-\mathrm{C}(5)$ & $112.66(18)$ & $C(5)-C(12)-C(13)$ & 132.91(19) \\
\hline $\mathrm{C}(18)-\mathrm{C}(4)-\mathrm{C}(3)$ & $126.68(19)$ & $C(5)-C(12)-S(2)$ & $110.94(15)$ \\
\hline $\mathrm{C}(5)-\mathrm{C}(4)-\mathrm{C}(3)$ & $120.39(17)$ & $\mathrm{C}(13)-\mathrm{C}(12)-\mathrm{S}(2)$ & $116.14(15)$ \\
\hline$C(12)-C(5)-C(4)$ & $112.78(17)$ & $\mathrm{C}(14)-\mathrm{C}(13)-\mathrm{C}(12)$ & $127.04(19)$ \\
\hline$C(12)-C(5)-C(6)$ & $128.48(18)$ & $\mathrm{C}(14)-\mathrm{C}(13)-\mathrm{S}(1)$ & $109.30(16)$ \\
\hline$C(4)-C(5)-C(6)$ & $118.64(18)$ & $C(12)-C(13)-S(1)$ & $123.65(15)$ \\
\hline$C(5)-C(6)-C(7)$ & $114.22(16)$ & $\mathrm{C}(13)-\mathrm{C}(14)-\mathrm{C}(15)$ & $113.66(19)$ \\
\hline
\end{tabular}




\begin{tabular}{|c|c|c|c|}
\hline $\mathrm{C}(13)-\mathrm{C}(14)-\mathrm{H}(14)$ & 123.2 & $\mathrm{C}(9)-\mathrm{C}(24)-\mathrm{S}(5)$ & $111.40(15)$ \\
\hline $\mathrm{C}(15)-\mathrm{C}(14)-\mathrm{H}(14)$ & 123.2 & $\mathrm{C}(25)-\mathrm{C}(24)-\mathrm{S}(5)$ & $116.77(15)$ \\
\hline$C(16)-C(15)-C(14)$ & $114.0(2)$ & $\mathrm{C}(26)-\mathrm{C}(25)-\mathrm{C}(24)$ & $127.2(2)$ \\
\hline $\mathrm{C}(16)-\mathrm{C}(15)-\mathrm{H}(15)$ & 123.0 & $C(26)-C(25)-S(6)$ & $109.60(17)$ \\
\hline $\mathrm{C}(14)-\mathrm{C}(15)-\mathrm{H}(15)$ & 123.0 & $\mathrm{C}(24)-\mathrm{C}(25)-\mathrm{S}(6)$ & $123.05(15)$ \\
\hline $\mathrm{C}(15)-\mathrm{C}(16)-\mathrm{C}(17)$ & $129.1(2)$ & $\mathrm{C}(25)-\mathrm{C}(26)-\mathrm{C}(27)$ & $113.2(2)$ \\
\hline $\mathrm{C}(15)-\mathrm{C}(16)-\mathrm{S}(1)$ & $109.82(17)$ & $\mathrm{C}(25)-\mathrm{C}(26)-\mathrm{H}(26)$ & 123.4 \\
\hline $\mathrm{C}(17)-\mathrm{C}(16)-\mathrm{S}(1)$ & $121.06(17)$ & $\mathrm{C}(27)-\mathrm{C}(26)-\mathrm{H}(26)$ & 123.4 \\
\hline $\mathrm{C}(16)-\mathrm{C}(17)-\mathrm{H}(17 \mathrm{~A})$ & 109.5 & $\mathrm{C}(28)-\mathrm{C}(27)-\mathrm{C}(26)$ & $114.2(2)$ \\
\hline $\mathrm{C}(16)-\mathrm{C}(17)-\mathrm{H}(17 \mathrm{~B})$ & 109.5 & $\mathrm{C}(28)-\mathrm{C}(27)-\mathrm{H}(27)$ & 122.9 \\
\hline $\mathrm{H}(17 \mathrm{~A})-\mathrm{C}(17)-\mathrm{H}(17 \mathrm{~B})$ & 109.5 & $\mathrm{C}(26)-\mathrm{C}(27)-\mathrm{H}(27)$ & 122.9 \\
\hline C(16)-C(17)-H(17C) & 109.5 & $\mathrm{C}(27)-\mathrm{C}(28)-\mathrm{C}(29)$ & $128.5(2)$ \\
\hline $\mathrm{H}(17 \mathrm{~A})-\mathrm{C}(17)-\mathrm{H}(17 \mathrm{C})$ & 109.5 & $\mathrm{C}(27)-\mathrm{C}(28)-\mathrm{S}(6)$ & $109.99(17)$ \\
\hline $\mathrm{H}(17 \mathrm{~B})-\mathrm{C}(17)-\mathrm{H}(17 \mathrm{C})$ & 109.5 & $\mathrm{C}(29)-\mathrm{C}(28)-\mathrm{S}(6)$ & $121.56(19)$ \\
\hline $\mathrm{C}(4)-\mathrm{C}(18)-\mathrm{C}(19)$ & $129.8(2)$ & $\mathrm{C}(28)-\mathrm{C}(29)-\mathrm{H}(29 \mathrm{~A})$ & 109.5 \\
\hline $\mathrm{C}(4)-\mathrm{C}(18)-\mathrm{S}(2)$ & $111.04(16)$ & $\mathrm{C}(28)-\mathrm{C}(29)-\mathrm{H}(29 \mathrm{~B})$ & 109.5 \\
\hline $\mathrm{C}(19)-\mathrm{C}(18)-\mathrm{S}(2)$ & $118.78(15)$ & $\mathrm{H}(29 \mathrm{~A})-\mathrm{C}(29)-\mathrm{H}(29 \mathrm{~B})$ & 109.5 \\
\hline $\mathrm{C}(20)-\mathrm{C}(19)-\mathrm{C}(18)$ & $127.5(2)$ & $\mathrm{C}(28)-\mathrm{C}(29)-\mathrm{H}(29 \mathrm{C})$ & 109.5 \\
\hline$C(20)-C(19)-S(3)$ & $109.35(16)$ & $H(29 A)-C(29)-H(29 C)$ & 109.5 \\
\hline C(18)-C(19)-S(3) & $123.13(16)$ & $\mathrm{H}(29 B)-\mathrm{C}(29)-\mathrm{H}(29 \mathrm{C})$ & 109.5 \\
\hline$C(19)-C(20)-C(21)$ & $113.3(2)$ & $C(10)-C(30)-C(31)$ & $131.46(18)$ \\
\hline $\mathrm{C}(19)-\mathrm{C}(20)-\mathrm{H}(20)$ & 123.3 & $C(10)-C(30)-S(5)$ & $111.05(15)$ \\
\hline $\mathrm{C}(21)-\mathrm{C}(20)-\mathrm{H}(20)$ & 123.3 & $\mathrm{C}(31)-\mathrm{C}(30)-\mathrm{S}(5)$ & $117.47(15)$ \\
\hline$C(22)-C(21)-C(20)$ & $114.0(2)$ & $\mathrm{C}(32)-\mathrm{C}(31)-\mathrm{C}(30)$ & $127.87(19)$ \\
\hline $\mathrm{C}(22)-\mathrm{C}(21)-\mathrm{H}(21)$ & 123.0 & $\mathrm{C}(32)-\mathrm{C}(31)-\mathrm{S}(4)$ & $109.48(16)$ \\
\hline $\mathrm{C}(20)-\mathrm{C}(21)-\mathrm{H}(21)$ & 123.0 & $\mathrm{C}(30)-\mathrm{C}(31)-\mathrm{S}(4)$ & $122.54(15)$ \\
\hline $\mathrm{C}(21)-\mathrm{C}(22)-\mathrm{C}(23)$ & $128.8(2)$ & $\mathrm{C}(31)-\mathrm{C}(32)-\mathrm{C}(33)$ & $113.4(2)$ \\
\hline $\mathrm{C}(21)-\mathrm{C}(22)-\mathrm{S}(3)$ & $110.15(17)$ & $\mathrm{C}(31)-\mathrm{C}(32)-\mathrm{H}(32)$ & 123.3 \\
\hline $\mathrm{C}(23)-\mathrm{C}(22)-\mathrm{S}(3)$ & $121.04(18)$ & $\mathrm{C}(33)-\mathrm{C}(32)-\mathrm{H}(32)$ & 123.3 \\
\hline $\mathrm{C}(22)-\mathrm{C}(23)-\mathrm{H}(23 \mathrm{~A})$ & 109.5 & $\mathrm{C}(34)-\mathrm{C}(33)-\mathrm{C}(32)$ & $113.9(2)$ \\
\hline $\mathrm{C}(22)-\mathrm{C}(23)-\mathrm{H}(23 \mathrm{~B})$ & 109.5 & $\mathrm{C}(34)-\mathrm{C}(33)-\mathrm{H}(33)$ & 123.0 \\
\hline $\mathrm{H}(23 \mathrm{~A})-\mathrm{C}(23)-\mathrm{H}(23 \mathrm{~B})$ & 109.5 & $\mathrm{C}(32)-\mathrm{C}(33)-\mathrm{H}(33)$ & 123.0 \\
\hline $\mathrm{C}(22)-\mathrm{C}(23)-\mathrm{H}(23 \mathrm{C})$ & 109.5 & $\mathrm{C}(33)-\mathrm{C}(34)-\mathrm{C}(35)$ & $128.9(2)$ \\
\hline $\mathrm{H}(23 \mathrm{~A})-\mathrm{C}(23)-\mathrm{H}(23 \mathrm{C})$ & 109.5 & $\mathrm{C}(33)-\mathrm{C}(34)-\mathrm{S}(4)$ & $110.10(17)$ \\
\hline $\mathrm{H}(23 \mathrm{~B})-\mathrm{C}(23)-\mathrm{H}(23 \mathrm{C})$ & 109.5 & $\mathrm{C}(35)-\mathrm{C}(34)-\mathrm{S}(4)$ & $120.96(19)$ \\
\hline $\mathrm{C}(9)-\mathrm{C}(24)-\mathrm{C}(25)$ & $131.80(19)$ & $\mathrm{C}(34)-\mathrm{C}(35)-\mathrm{H}(35 \mathrm{~A})$ & 109.5 \\
\hline
\end{tabular}




$\begin{array}{ll}\mathrm{C}(34)-\mathrm{C}(35)-\mathrm{H}(35 \mathrm{~B}) & 109.5 \\ \mathrm{H}(35 \mathrm{~A})-\mathrm{C}(35)-\mathrm{H}(35 \mathrm{~B}) & 109.5 \\ \mathrm{C}(34)-\mathrm{C}(35)-\mathrm{H}(35 \mathrm{C}) & 109.5 \\ \mathrm{H}(35 \mathrm{~A})-\mathrm{C}(35)-\mathrm{H}(35 \mathrm{C}) & 109.5 \\ \mathrm{H}(35 \mathrm{~B})-\mathrm{C}(35)-\mathrm{H}(35 \mathrm{C}) & 109.5 \\ \mathrm{C}(16)-\mathrm{S}(1)-\mathrm{C}(13) & 93.22(10) \\ \mathrm{C}(18)-\mathrm{S}(2)-\mathrm{C}(12) & 92.56(10) \\ \mathrm{C}(19)-\mathrm{S}(3)-\mathrm{C}(22) & 93.15(11) \\ \mathrm{C}(34)-\mathrm{S}(4)-\mathrm{C}(31) & 93.02(11) \\ \mathrm{C}(30)-\mathrm{S}(5)-\mathrm{C}(24) & 92.23(10) \\ \mathrm{C}(28)-\mathrm{S}(6)-\mathrm{C}(25) & 92.99(11)\end{array}$

Symmetry transformations used to generate equivalent atoms: 
Table A.10. Anisotropic displacement parameters $\left(\AA^{2} \times 10^{3}\right)$ for 3.5. The anisotropic displacement factor exponent takes the form: $-2 \square^{2}\left[h^{2} a^{* 2} U^{11}+\ldots+2 h\right.$ $k a^{*} b^{*} U^{12}$ ]

\begin{tabular}{|c|c|c|c|c|c|c|}
\hline & U11 & $\mathrm{U}^{22}$ & $\mathrm{U}^{33}$ & $\mathrm{U}^{23}$ & $\mathrm{U}^{13}$ & $\mathrm{U}^{12}$ \\
\hline $\mathrm{C}(1)$ & $16(1)$ & $23(1)$ & $25(1)$ & $-1(1)$ & $-2(1)$ & $-4(1)$ \\
\hline $\mathrm{C}(2)$ & $17(1)$ & $25(1)$ & $21(1)$ & $-3(1)$ & $3(1)$ & $3(1)$ \\
\hline$C(3)$ & $19(1)$ & $27(1)$ & $22(1)$ & $0(1)$ & 1(1) & $-2(1)$ \\
\hline $\mathrm{C}(4)$ & $21(1)$ & $22(1)$ & $24(1)$ & $1(1)$ & $1(1)$ & $0(1)$ \\
\hline$C(5)$ & $20(1)$ & $22(1)$ & $22(1)$ & $0(1)$ & $1(1)$ & $1(1)$ \\
\hline$C(6)$ & $20(1)$ & $29(1)$ & $23(1)$ & $-3(1)$ & $3(1)$ & $-1(1)$ \\
\hline$C(7)$ & $21(1)$ & $26(1)$ & $19(1)$ & $6(1)$ & $2(1)$ & $1(1)$ \\
\hline$C(8)$ & $22(1)$ & $23(1)$ & $22(1)$ & $-1(1)$ & $4(1)$ & $-2(1)$ \\
\hline $\mathrm{C}(9)$ & $18(1)$ & $22(1)$ & $21(1)$ & $-2(1)$ & $0(1)$ & $-3(1)$ \\
\hline$C(10)$ & $19(1)$ & $22(1)$ & $19(1)$ & $-4(1)$ & $2(1)$ & $-2(1)$ \\
\hline$C(11)$ & $22(1)$ & $23(1)$ & $20(1)$ & $-2(1)$ & $1(1)$ & $2(1)$ \\
\hline$C(12)$ & $20(1)$ & $23(1)$ & $24(1)$ & $1(1)$ & $3(1)$ & $1(1)$ \\
\hline$C(13)$ & $24(1)$ & $22(1)$ & $24(1)$ & 1(1) & $2(1)$ & $2(1)$ \\
\hline $\mathrm{C}(14)$ & $23(1)$ & $28(1)$ & $29(1)$ & $-1(1)$ & $-1(1)$ & $3(1)$ \\
\hline$C(15)$ & $32(1)$ & $29(1)$ & $23(1)$ & $-3(1)$ & $-6(1)$ & $8(1)$ \\
\hline$C(16)$ & $37(1)$ & $26(1)$ & $20(1)$ & 1(1) & $0(1)$ & $4(1)$ \\
\hline $\mathrm{C}(17)$ & $49(2)$ & $49(2)$ & $29(1)$ & $2(1)$ & $8(1)$ & $0(1)$ \\
\hline$C(18)$ & $23(1)$ & $29(1)$ & $23(1)$ & $2(1)$ & $3(1)$ & $-1(1)$ \\
\hline C(19) & $20(1)$ & $35(1)$ & $25(1)$ & $1(1)$ & $1(1)$ & $-2(1)$ \\
\hline$C(20)$ & $34(1)$ & $39(1)$ & $33(1)$ & $-5(1)$ & $8(1)$ & $-12(1)$ \\
\hline $\mathrm{C}(21)$ & $35(1)$ & $40(1)$ & $40(2)$ & $2(1)$ & $11(1)$ & $-13(1)$ \\
\hline$C(22)$ & $28(1)$ & $37(1)$ & $31(1)$ & $7(1)$ & $9(1)$ & $1(1)$ \\
\hline $\mathrm{C}(23)$ & $52(2)$ & $47(2)$ & $42(2)$ & $2(1)$ & $23(1)$ & $4(1)$ \\
\hline$C(24)$ & $18(1)$ & $26(1)$ & $21(1)$ & $-3(1)$ & $1(1)$ & $-2(1)$ \\
\hline$C(25)$ & $23(1)$ & $27(1)$ & $27(1)$ & $-2(1)$ & $6(1)$ & $-2(1)$ \\
\hline$C(26)$ & $26(1)$ & $50(2)$ & $33(1)$ & $-2(1)$ & $4(1)$ & $5(1)$ \\
\hline $\mathrm{C}(27)$ & $26(1)$ & $52(2)$ & $48(2)$ & $-3(1)$ & $15(1)$ & $6(1)$ \\
\hline $\mathrm{C}(28)$ & $31(1)$ & $34(1)$ & $37(1)$ & $-5(1)$ & $16(1)$ & $-5(1)$ \\
\hline $\mathrm{C}(29)$ & $54(2)$ & $54(2)$ & $40(2)$ & $-9(1)$ & $28(1)$ & $-10(1)$ \\
\hline$C(30)$ & $17(1)$ & $23(1)$ & $23(1)$ & $-3(1)$ & $1(1)$ & $-3(1)$ \\
\hline
\end{tabular}




$\begin{array}{lllllll}\mathrm{C}(31) & 24(1) & 22(1) & 23(1) & -1(1) & 1(1) & 0(1) \\ \mathrm{C}(32) & 27(1) & 30(1) & 32(1) & 5(1) & -4(1) & -4(1) \\ \mathrm{C}(33) & 47(2) & 35(1) & 22(1) & 5(1) & -8(1) & -5(1) \\ \mathrm{C}(34) & 46(1) & 38(1) & 22(1) & 3(1) & 5(1) & 6(1) \\ \mathrm{C}(35) & 69(2) & 77(2) & 37(2) & 19(2) & 23(2) & 17(2) \\ \mathrm{O}(1) & 31(1) & 29(1) & 36(1) & 6(1) & 1(1) & 9(1) \\ \mathrm{S}(1) & 32(1) & 42(1) & 26(1) & -3(1) & 6(1) & -9(1) \\ \mathrm{S}(2) & 20(1) & 40(1) & 26(1) & -2(1) & 1(1) & -6(1) \\ \mathrm{S}(3) & 45(1) & 32(1) & 42(1) & -4(1) & 20(1) & -7(1) \\ \mathrm{S}(4) & 27(1) & 60(1) & 27(1) & 12(1) & 5(1) & 7(1) \\ \mathrm{S}(5) & 21(1) & 26(1) & 27(1) & 1(1) & 2(1) & 4(1) \\ \mathrm{S}(6) & 26(1) & 58(1) & 27(1) & -8(1) & 7(1) & -3(1)\end{array}$


Table A.11. Hydrogen coordinates ( x 104) and isotropic displacement parameters $\left(\AA^{2} \times 10^{3}\right)$ for $\mathbf{3 . 5}$.

\begin{tabular}{|c|c|c|c|c|}
\hline & $\mathrm{x}$ & $\mathrm{y}$ & $\mathrm{z}$ & $\mathrm{U}(\mathrm{eq})$ \\
\hline $\mathrm{H}(2)$ & 10065 & 1553 & 7768 & 25 \\
\hline $\mathrm{H}(3 \mathrm{~A})$ & 10180 & 3282 & 7620 & 27 \\
\hline $\mathrm{H}(3 \mathrm{~B})$ & 9250 & 3537 & 8026 & 27 \\
\hline $\mathrm{H}(6 \mathrm{~A})$ & 8669 & 3498 & 9153 & 29 \\
\hline $\mathrm{H}(6 \mathrm{~B})$ & 8941 & 3213 & 10036 & 29 \\
\hline $\mathrm{H}(7)$ & 9068 & 1494 & 9826 & 27 \\
\hline $\mathrm{H}(8 \mathrm{~A})$ & 7752 & 935 & 8851 & 27 \\
\hline $\mathrm{H}(8 \mathrm{~B})$ & 7438 & 1744 & 9462 & 27 \\
\hline $\mathrm{H}(11 \mathrm{~A})$ & 8657 & 1885 & 6965 & 26 \\
\hline $\mathrm{H}(11 \mathrm{~B})$ & 8373 & 1014 & 7545 & 26 \\
\hline $\mathrm{H}(14)$ & 12119 & 4567 & 11299 & 33 \\
\hline $\mathrm{H}(15)$ & 11672 & 4712 & 12582 & 35 \\
\hline $\mathrm{H}(17 \mathrm{~A})$ & 10254 & 4159 & 13350 & 63 \\
\hline $\mathrm{H}(17 \mathrm{~B})$ & 9372 & 3525 & 12873 & 63 \\
\hline $\mathrm{H}(17 \mathrm{C})$ & 9376 & 4787 & 12863 & 63 \\
\hline $\mathrm{H}(20)$ & 12611 & 5457 & 8489 & 42 \\
\hline $\mathrm{H}(21)$ & 13423 & 5420 & 7344 & 45 \\
\hline $\mathrm{H}(23 \mathrm{~A})$ & 13775 & 4143 & 6262 & 68 \\
\hline $\mathrm{H}(23 \mathrm{~B})$ & 12701 & 3760 & 5920 & 68 \\
\hline $\mathrm{H}(23 \mathrm{C})$ & 13459 & 2944 & 6367 & 68 \\
\hline $\mathrm{H}(26)$ & 4585 & 3351 & 8405 & 44 \\
\hline $\mathrm{H}(27)$ & 3917 & 3683 & 9591 & 49 \\
\hline $\mathrm{H}(29 \mathrm{~A})$ & 4437 & 3940 & 11028 & 71 \\
\hline H(29B) & 5544 & 4320 & 11227 & 71 \\
\hline $\mathrm{H}(29 \mathrm{C})$ & 5275 & 3102 & 11306 & 71 \\
\hline $\mathrm{H}(32)$ & 5954 & 3612 & 5847 & 36 \\
\hline $\mathrm{H}(33)$ & 6578 & 4120 & 4669 & 43 \\
\hline $\mathrm{H}(35 \mathrm{~A})$ & 8212 & 4198 & 4093 & 89 \\
\hline $\mathrm{H}(35 \mathrm{~B})$ & 9129 & 3689 & 4618 & 89 \\
\hline $\mathrm{H}(35 \mathrm{C})$ & 8886 & 4914 & 4698 & 89 \\
\hline
\end{tabular}


Table A.12. Torsion angles $\left[^{\circ}\right]$ for 3.5 .

$\begin{array}{lc}\mathrm{O}(1)-\mathrm{C}(1)-\mathrm{C}(2)-\mathrm{C}(3) & -128.27(19) \\ \mathrm{C}(7)-\mathrm{C}(1)-\mathrm{C}(2)-\mathrm{C}(3) & 55.9(2) \\ \mathrm{O}(1)-\mathrm{C}(1)-\mathrm{C}(2)-\mathrm{C}(11) & 106.0(2) \\ \mathrm{C}(7)-\mathrm{C}(1)-\mathrm{C}(2)-\mathrm{C}(11) & -69.9(2) \\ \mathrm{C}(1)-\mathrm{C}(2)-\mathrm{C}(3)-\mathrm{C}(4) & 28.9(2) \\ \mathrm{C}(11)-\mathrm{C}(2)-\mathrm{C}(3)-\mathrm{C}(4) & 153.53(16) \\ \mathrm{C}(2)-\mathrm{C}(3)-\mathrm{C}(4)-\mathrm{C}(18) & 116.5(2) \\ \mathrm{C}(2)-\mathrm{C}(3)-\mathrm{C}(4)-\mathrm{C}(5) & -69.9(2) \\ \mathrm{C}(18)-\mathrm{C}(4)-\mathrm{C}(5)-\mathrm{C}(12) & 0.7(3) \\ \mathrm{C}(3)-\mathrm{C}(4)-\mathrm{C}(5)-\mathrm{C}(12) & -173.75(18) \\ \mathrm{C}(18)-\mathrm{C}(4)-\mathrm{C}(5)-\mathrm{C}(6) & 177.43(18) \\ \mathrm{C}(3)-\mathrm{C}(4)-\mathrm{C}(5)-\mathrm{C}(6) & 2.9(3) \\ \mathrm{C}(12)-\mathrm{C}(5)-\mathrm{C}(6)-\mathrm{C}(7) & -117.5(2) \\ \mathrm{C}(4)-\mathrm{C}(5)-\mathrm{C}(6)-\mathrm{C}(7) & 66.4(2) \\ \mathrm{O}(1)-\mathrm{C}(1)-\mathrm{C}(7)-\mathrm{C}(6) & 129.4(2) \\ \mathrm{C}(2)-\mathrm{C}(1)-\mathrm{C}(7)-\mathrm{C}(6) & -54.8(2) \\ \mathrm{O}(1)-\mathrm{C}(1)-\mathrm{C}(7)-\mathrm{C}(8) & -104.0(2) \\ \mathrm{C}(2)-\mathrm{C}(1)-\mathrm{C}(7)-\mathrm{C}(8) & 71.8(2) \\ \mathrm{C}(5)-\mathrm{C}(6)-\mathrm{C}(7)-\mathrm{C}(1) & -30.9(2) \\ \mathrm{C}(5)-\mathrm{C}(6)-\mathrm{C}(7)-\mathrm{C}(8) & -155.91(17) \\ \mathrm{C}(1)-\mathrm{C}(7)-\mathrm{C}(8)-\mathrm{C}(9) & -78.1(2) \\ \mathrm{C}(6)-\mathrm{C}(7)-\mathrm{C}(8)-\mathrm{C}(9) & 49.9(2) \\ \mathrm{C}(7)-\mathrm{C}(8)-\mathrm{C}(9)-\mathrm{C}(24) & -121.9(2) \\ \mathrm{C}(7)-\mathrm{C}(8)-\mathrm{C}(9)-\mathrm{C}(10) & 60.6(2) \\ \mathrm{C}(24)-\mathrm{C}(9)-\mathrm{C}(10)-\mathrm{C}(30) & 1.0(2) \\ \mathrm{C}(8)-\mathrm{C}(9)-\mathrm{C}(10)-\mathrm{C}(30) & 178.68(18) \\ \mathrm{C}(24)-\mathrm{C}(9)-\mathrm{C}(10)-\mathrm{C}(11) & -175.49(17) \\ \mathrm{C}(8)-\mathrm{C}(9)-\mathrm{C}(10)-\mathrm{C}(11) & 2.2(3) \\ \mathrm{C}(30)-\mathrm{C}(10)-\mathrm{C}(11)-\mathrm{C}(2) & 120.9(2) \\ \mathrm{C}(9)-\mathrm{C}(10)-\mathrm{C}(11)-\mathrm{C}(2) & -63.0(2) \\ \mathrm{C}(1)-\mathrm{C}(2)-\mathrm{C}(11)-\mathrm{C}(10) & 76.1(2) \\ \mathrm{C}(3)-\mathrm{C}(2)-\mathrm{C}(11)-\mathrm{C}(10) & -50.7(2) \\ \mathrm{C}(4)-\mathrm{C}(5)-\mathrm{C}(12)-\mathrm{C}(13) & 178.1(2) \\ & \\ & \\ & \end{array}$




\begin{tabular}{|c|c|}
\hline$C(6)-C(5)-C(12)-C(13)$ & $1.8(4)$ \\
\hline$C(4)-C(5)-C(12)-S(2)$ & $-1.0(2)$ \\
\hline$C(6)-C(5)-C(12)-S(2)$ & $-177.30(17)$ \\
\hline $\mathrm{C}(5)-\mathrm{C}(12)-\mathrm{C}(13)-\mathrm{C}(14)$ & $179.5(2)$ \\
\hline$S(2)-C(12)-C(13)-C(14)$ & $-1.5(3)$ \\
\hline $\mathrm{C}(5)-\mathrm{C}(12)-\mathrm{C}(13)-\mathrm{S}(1)$ & $-0.2(3)$ \\
\hline$S(2)-C(12)-C(13)-S(1)$ & $178.78(11)$ \\
\hline $\mathrm{C}(12)-\mathrm{C}(13)-\mathrm{C}(14)-\mathrm{C}(15)$ & $-179.57(19)$ \\
\hline $\mathrm{S}(1)-\mathrm{C}(13)-\mathrm{C}(14)-\mathrm{C}(15)$ & $0.2(2)$ \\
\hline$C(13)-C(14)-C(15)-C(16)$ & $-0.2(3)$ \\
\hline $\mathrm{C}(14)-\mathrm{C}(15)-\mathrm{C}(16)-\mathrm{C}(17)$ & $-177.6(2)$ \\
\hline $\mathrm{C}(14)-\mathrm{C}(15)-\mathrm{C}(16)-\mathrm{S}(1)$ & $0.1(2)$ \\
\hline C(5)-C(4)-C(18)-C(19) & $-172.9(2)$ \\
\hline $\mathrm{C}(3)-\mathrm{C}(4)-\mathrm{C}(18)-\mathrm{C}(19)$ & $1.2(4)$ \\
\hline $\mathrm{C}(5)-\mathrm{C}(4)-\mathrm{C}(18)-\mathrm{S}(2)$ & $-0.1(2)$ \\
\hline $\mathrm{C}(3)-\mathrm{C}(4)-\mathrm{C}(18)-\mathrm{S}(2)$ & $173.95(16)$ \\
\hline $\mathrm{C}(4)-\mathrm{C}(18)-\mathrm{C}(19)-\mathrm{C}(20)$ & 131.2(3) \\
\hline$S(2)-C(18)-C(19)-C(20)$ & $-41.1(3)$ \\
\hline $\mathrm{C}(4)-\mathrm{C}(18)-\mathrm{C}(19)-\mathrm{S}(3)$ & $-47.9(3)$ \\
\hline$S(2)-C(18)-C(19)-S(3)$ & $139.78(14)$ \\
\hline $\mathrm{C}(18)-\mathrm{C}(19)-\mathrm{C}(20)-\mathrm{C}(21)$ & $-178.1(2)$ \\
\hline$S(3)-C(19)-C(20)-C(21)$ & $1.1(3)$ \\
\hline$C(19)-C(20)-C(21)-C(22)$ & $-0.5(3)$ \\
\hline $\mathrm{C}(20)-\mathrm{C}(21)-\mathrm{C}(22)-\mathrm{C}(23)$ & $178.0(2)$ \\
\hline$C(20)-C(21)-C(22)-S(3)$ & $-0.3(3)$ \\
\hline $\mathrm{C}(10)-\mathrm{C}(9)-\mathrm{C}(24)-\mathrm{C}(25)$ & $177.4(2)$ \\
\hline $\mathrm{C}(8)-\mathrm{C}(9)-\mathrm{C}(24)-\mathrm{C}(25)$ & $-0.3(3)$ \\
\hline$C(10)-C(9)-C(24)-S(5)$ & $-0.5(2)$ \\
\hline$C(8)-C(9)-C(24)-S(5)$ & $-178.16(15)$ \\
\hline$C(9)-C(24)-C(25)-C(26)$ & $-142.7(2)$ \\
\hline$S(5)-C(24)-C(25)-C(26)$ & $35.1(3)$ \\
\hline $\mathrm{C}(9)-\mathrm{C}(24)-\mathrm{C}(25)-\mathrm{S}(6)$ & $41.9(3)$ \\
\hline$S(5)-C(24)-C(25)-S(6)$ & $-140.28(14)$ \\
\hline$C(24)-C(25)-C(26)-C(27)$ & $-176.9(2)$ \\
\hline $\mathrm{S}(6)-\mathrm{C}(25)-\mathrm{C}(26)-\mathrm{C}(27)$ & $-1.0(3)$ \\
\hline$C(25)-C(26)-C(27)-C(28)$ & $0.7(3)$ \\
\hline
\end{tabular}




\begin{tabular}{|c|c|}
\hline $\mathrm{C}(26)-\mathrm{C}(27)-\mathrm{C}(28)-\mathrm{C}(29)$ & $179.7(2)$ \\
\hline $\mathrm{C}(26)-\mathrm{C}(27)-\mathrm{C}(28)-\mathrm{S}(6)$ & $-0.1(3)$ \\
\hline$C(9)-C(10)-C(30)-C(31)$ & $-179.50(19)$ \\
\hline $\mathrm{C}(11)-\mathrm{C}(10)-\mathrm{C}(30)-\mathrm{C}(31)$ & $-3.1(3)$ \\
\hline $\mathrm{C}(9)-\mathrm{C}(10)-\mathrm{C}(30)-\mathrm{S}(5)$ & $-1.0(2)$ \\
\hline$C(11)-C(10)-C(30)-S(5)$ & $175.40(15)$ \\
\hline$C(10)-C(30)-C(31)-C(32)$ & $144.0(2)$ \\
\hline$S(5)-C(30)-C(31)-C(32)$ & $-34.5(3)$ \\
\hline $\mathrm{C}(10)-\mathrm{C}(30)-\mathrm{C}(31)-\mathrm{S}(4)$ & $-40.1(3)$ \\
\hline$S(5)-C(30)-C(31)-S(4)$ & $141.41(13)$ \\
\hline $\mathrm{C}(30)-\mathrm{C}(31)-\mathrm{C}(32)-\mathrm{C}(33)$ & $177.6(2)$ \\
\hline $\mathrm{S}(4)-\mathrm{C}(31)-\mathrm{C}(32)-\mathrm{C}(33)$ & $1.3(2)$ \\
\hline $\mathrm{C}(31)-\mathrm{C}(32)-\mathrm{C}(33)-\mathrm{C}(34)$ & $-0.3(3)$ \\
\hline $\mathrm{C}(32)-\mathrm{C}(33)-\mathrm{C}(34)-\mathrm{C}(35)$ & $179.6(2)$ \\
\hline $\mathrm{C}(32)-\mathrm{C}(33)-\mathrm{C}(34)-\mathrm{S}(4)$ & $-0.9(3)$ \\
\hline $\mathrm{C}(15)-\mathrm{C}(16)-\mathrm{S}(1)-\mathrm{C}(13)$ & $-0.02(17)$ \\
\hline $\mathrm{C}(17)-\mathrm{C}(16)-\mathrm{S}(1)-\mathrm{C}(13)$ & 177.96(19) \\
\hline $\mathrm{C}(14)-\mathrm{C}(13)-\mathrm{S}(1)-\mathrm{C}(16)$ & $-0.11(16)$ \\
\hline $\mathrm{C}(12)-\mathrm{C}(13)-\mathrm{S}(1)-\mathrm{C}(16)$ & $179.68(18)$ \\
\hline$C(4)-C(18)-S(2)-C(12)$ & $-0.38(17)$ \\
\hline $\mathrm{C}(19)-\mathrm{C}(18)-\mathrm{S}(2)-\mathrm{C}(12)$ & $173.28(17)$ \\
\hline$C(5)-C(12)-S(2)-C(18)$ & $0.80(16)$ \\
\hline $\mathrm{C}(13)-\mathrm{C}(12)-\mathrm{S}(2)-\mathrm{C}(18)$ & $-178.43(16)$ \\
\hline $\mathrm{C}(20)-\mathrm{C}(19)-\mathrm{S}(3)-\mathrm{C}(22)$ & $-1.09(18)$ \\
\hline $\mathrm{C}(18)-\mathrm{C}(19)-\mathrm{S}(3)-\mathrm{C}(22)$ & $178.17(18)$ \\
\hline $\mathrm{C}(21)-\mathrm{C}(22)-\mathrm{S}(3)-\mathrm{C}(19)$ & $0.81(19)$ \\
\hline $\mathrm{C}(23)-\mathrm{C}(22)-\mathrm{S}(3)-\mathrm{C}(19)$ & $-177.7(2)$ \\
\hline $\mathrm{C}(33)-\mathrm{C}(34)-\mathrm{S}(4)-\mathrm{C}(31)$ & $1.34(19)$ \\
\hline $\mathrm{C}(35)-\mathrm{C}(34)-\mathrm{S}(4)-\mathrm{C}(31)$ & $-179.1(2)$ \\
\hline $\mathrm{C}(32)-\mathrm{C}(31)-\mathrm{S}(4)-\mathrm{C}(34)$ & $-1.49(17)$ \\
\hline $\mathrm{C}(30)-\mathrm{C}(31)-\mathrm{S}(4)-\mathrm{C}(34)$ & $-178.03(17)$ \\
\hline $\mathrm{C}(10)-\mathrm{C}(30)-\mathrm{S}(5)-\mathrm{C}(24)$ & $0.56(16)$ \\
\hline $\mathrm{C}(31)-\mathrm{C}(30)-\mathrm{S}(5)-\mathrm{C}(24)$ & 179.34(16) \\
\hline$C(9)-C(24)-S(5)-C(30)$ & $-0.02(16)$ \\
\hline $\mathrm{C}(25)-\mathrm{C}(24)-\mathrm{S}(5)-\mathrm{C}(30)$ & $-178.26(16)$ \\
\hline $\mathrm{C}(27)-\mathrm{C}(28)-\mathrm{S}(6)-\mathrm{C}(25)$ & $-0.46(19)$ \\
\hline
\end{tabular}


$\mathrm{C}(29)-\mathrm{C}(28)-\mathrm{S}(6)-\mathrm{C}(25)$

$179.7(2)$

$\mathrm{C}(26)-\mathrm{C}(25)-\mathrm{S}(6)-\mathrm{C}(28)$

$0.86(18)$

$\mathrm{C}(24)-\mathrm{C}(25)-\mathrm{S}(6)-\mathrm{C}(28)$

$176.96(18)$

Symmetry transformations used to generate equivalent atoms: 
A suitable crystal of $s t-\left[\mathbf{H}-\mathbf{T h} \mathbf{h}_{\mathbf{3}}-\mathbf{H}\right]_{\mathbf{2}}$ was coated with Paratone $\mathrm{N}$ oil, suspended in a small fiber loop and placed in a cooled nitrogen gas stream at $173 \mathrm{~K}$ on a Bruker D8 SMART $1000 \mathrm{CCD}$ sealed tube diffractometer with graphite monochromated $\mathrm{CuK} \alpha$ $(1.54178 \AA)$ radiation. Data was measured using a series of combinations of phi and omega scans with $10 \mathrm{~s}$ frame exposures and $0.3^{\circ}$ frame widths. Data collection, indexing and initial cell refinements were all carried out using SMART $^{1}$ software. Frame integration and final cell refinements were done using $\mathrm{SAINT}^{2}$ software. The final cell parameters were determined from least-squares refinement on 3846 reflections. The $\mathrm{SADABS}^{3}$ program was used to carry out absorption corrections.

The structure was solved using Direct methods and difference Fourier techniques (SHELXTL, V6.12). ${ }^{4}$ Hydrogen atoms were placed in their expected chemical positions using the HFIX command and were included in the final cycles of least-squares with isotropic Uij's related to the riding atom. The $\mathrm{C}-\mathrm{H}$ distances were fixed at $0.93 \AA$ (aromatic and amide), 0.98 (methine), $0.97 \AA$ (methylene), or $0.96 \AA$ (methyl). All nonhydrogen atoms were refined anisotropically. Scattering factors and anomalous dispersion corrections are taken from the International Tables for X-ray Crystallography. ${ }^{5}$ Structure solution, refinement, graphics and generation of publication materials were performed using SHELXTL, V6.12 software. Additional details of data collection and structure refinement are given in Tables A.13-A.17. 
Table A.13. Crystal data and structure refinement for $s t-\left[\mathbf{H}-\mathbf{T h} \mathbf{h}_{3}-\mathbf{H}\right]_{2}$.

Empirical formula

Formula weight

Temperature

Wavelength

Crystal system

Space group

Unit cell dimensions

Volume

$\mathrm{Z}$

Density (calculated)

Absorption coefficient

$\mathrm{F}(000)$

Crystal size

Theta range for data collection

Index ranges

Reflections collected

Independent reflections

Completeness to theta $=66.78^{\circ}$

Absorption correction

Max. and min. transmission

Refinement method

Data / restraints / parameters

Goodness-of-fit on $\mathrm{F}^{2}$

Final $\mathrm{R}$ indices [I $>2 \operatorname{sigma}(\mathrm{I})]$

$\mathrm{R}$ indices (all data)

Largest diff. peak and hole

\begin{tabular}{|c|c|}
\hline C33 H26 O2 S6 & \\
\hline 646.90 & \\
\hline $173(2) \mathrm{K}$ & \\
\hline $1.54178 \AA$ & \\
\hline Triclinic & \\
\hline P-1 & \\
\hline$a=8.7052(6) \AA$ & $\alpha=78.705(3)^{\circ}$. \\
\hline $\mathrm{b}=11.1163(7) \AA$ & $\beta=85.048(3)^{\circ}$. \\
\hline$c=15.8390(8) \AA$ & $\gamma=70.247(3)^{\circ}$. \\
\hline
\end{tabular}

1414.27(15) $\AA^{3}$

2

$1.519 \mathrm{Mg} / \mathrm{m}^{3}$

$4.725 \mathrm{~mm}^{-1}$

672

$0.38 \times 0.33 \times 0.12 \mathrm{~mm}^{3}$

2.85 to $66.78^{\circ}$.

$-7<=\mathrm{h}<=9,-9<=\mathrm{k}<=11,-17<=\mathrm{l}<=16$

5174

$3220[\mathrm{R}(\mathrm{int})=0.0329]$

$64.0 \%$

Semi-empirical from equivalents

1.00 and 0.557226

Full-matrix least-squares on $\mathrm{F}^{2}$

3220 / 0 / 370

1.040

$\mathrm{R} 1=0.0513, \mathrm{wR} 2=0.1396$

$\mathrm{R} 1=0.0558, \mathrm{wR} 2=0.1438$

0.484 and -0.478 e. $\AA^{-3}$ 
Table A.14. Atomic coordinates ( x 104) and equivalent isotropic displacement parameters $\left(\AA^{2} \times 10^{3}\right)$ for $\boldsymbol{s t}$-[H-Th $\left.\mathbf{3}-\mathbf{H}\right]_{2}$. U(eq) is defined as one third of the trace of the orthogonalized $\mathrm{U}^{\mathrm{ij}}$ tensor.

\begin{tabular}{|c|c|c|c|c|}
\hline & $\mathrm{x}$ & $\mathrm{y}$ & $\mathrm{z}$ & $\mathrm{U}(\mathrm{eq})$ \\
\hline $\mathrm{C}(1)$ & $7362(5)$ & $3402(4)$ & $2611(2)$ & $26(1)$ \\
\hline $\mathrm{C}(2)$ & $6408(7)$ & $1918(5)$ & $2176(3)$ & $47(1)$ \\
\hline$C(3)$ & $7711(8)$ & $1220(5)$ & $2775(5)$ & $76(2)$ \\
\hline$C(4)$ & $8360(5)$ & $3995(4)$ & $1910(2)$ & $24(1)$ \\
\hline$C(5)$ & $7334(5)$ & $5287(4)$ & $1365(2)$ & $26(1)$ \\
\hline$C(6)$ & $6592(5)$ & $6488(4)$ & $1770(2)$ & $23(1)$ \\
\hline$C(7)$ & $6645(5)$ & $7685(4)$ & $1365(2)$ & $25(1)$ \\
\hline$C(8)$ & $5012(5)$ & $7775(4)$ & $2730(2)$ & $23(1)$ \\
\hline $\mathrm{C}(9)$ & $5642(5)$ & $6542(4)$ & $2551(2)$ & $22(1)$ \\
\hline$C(10)$ & $5224(5)$ & $5400(4)$ & $3073(3)$ & $25(1)$ \\
\hline $\mathrm{C}(11)$ & $6651(5)$ & $4144(4)$ & $3349(2)$ & $24(1)$ \\
\hline$C(12)$ & $7939(5)$ & $4316(4)$ & 3891(3) & $27(1)$ \\
\hline $\mathrm{C}(13)$ & $8809(5)$ & $5258(4)$ & $3491(2)$ & $25(1)$ \\
\hline$C(14)$ & $8803(5)$ & $6314(4)$ & $3829(2)$ & $27(1)$ \\
\hline$C(15)$ & $10444(5)$ & 6091(4) & $2449(2)$ & $24(1)$ \\
\hline$C(16)$ & $9751(5)$ & $5135(4)$ & $2712(2)$ & $25(1)$ \\
\hline $\mathrm{C}(17)$ & $9935(5)$ & $4025(4)$ & $2254(3)$ & $26(1)$ \\
\hline $\mathrm{C}(18)$ & $7345(5)$ & $8074(4)$ & $528(3)$ & $28(1)$ \\
\hline C(19) & $7160(5)$ & $7727(4)$ & $-285(2)$ & $21(1)$ \\
\hline$C(20)$ & $7999(6)$ & $8354(5)$ & $-945(3)$ & $40(1)$ \\
\hline $\mathrm{C}(21)$ & $8680(7)$ & $9133(5)$ & $-677(3)$ & $50(1)$ \\
\hline$C(22)$ & $3829(5)$ & $8286(4)$ & $3391(2)$ & $24(1)$ \\
\hline $\mathrm{C}(23)$ & $3751(5)$ & $7812(4)$ & $4269(2)$ & $26(1)$ \\
\hline$C(24)$ & $2350(6)$ & $8596(4)$ & $4672(3)$ & $30(1)$ \\
\hline$C(25)$ & $1408(6)$ & $9623(4)$ & $4126(3)$ & $30(1)$ \\
\hline$C(26)$ & $8016(5)$ & $6802(4)$ & $4599(3)$ & $27(1)$ \\
\hline $\mathrm{C}(27)$ & $7709(5)$ & $6136(4)$ & $5404(2)$ & $27(1)$ \\
\hline$C(28)$ & $6919(6)$ & $7009(5)$ & $5984(3)$ & $35(1)$ \\
\hline C(29) & $6639(6)$ & $8268(5)$ & $5633(3)$ & $39(1)$ \\
\hline$C(30)$ & $11446(5)$ & $6387(4)$ & $1696(2)$ & $25(1)$ \\
\hline
\end{tabular}




\begin{tabular}{lrrrr}
$\mathrm{C}(31)$ & $12147(6)$ & $7336(4)$ & $1554(3)$ & $32(1)$ \\
$\mathrm{C}(32)$ & $13003(6)$ & $7430(5)$ & $761(3)$ & $33(1)$ \\
$\mathrm{C}(33)$ & $12951(7)$ & $6552(5)$ & $294(3)$ & $42(1)$ \\
$\mathrm{O}(1)$ & $6031(3)$ & $3245(3)$ & $2212(2)$ & $28(1)$ \\
$\mathrm{O}(2)$ & $8375(4)$ & $2112(3)$ & $2964(2)$ & $29(1)$ \\
$\mathrm{S}(1)$ & $5562(1)$ & $8886(1)$ & $1945(1)$ & $26(1)$ \\
$\mathrm{S}(2)$ & $9968(1)$ & $7150(1)$ & $3186(1)$ & $28(1)$ \\
$\mathrm{S}(3)$ & $8409(2)$ & $9138(1)$ & $390(1)$ & $53(1)$ \\
$\mathrm{S}(4)$ & $2168(1)$ & $9674(1)$ & $3101(1)$ & $29(1)$ \\
$\mathrm{S}(5)$ & $7324(2)$ & $8463(1)$ & $4590(1)$ & $39(1)$ \\
$\mathrm{S}(6)$ & $11827(2)$ & $5615(1)$ & $814(1)$ & $53(1)$ \\
\hline
\end{tabular}


Table A.15. Bond lengths $[\AA]$ and angles $\left[^{\circ}\right]$ for $s t-\left[\mathbf{H}-\mathbf{T h}_{3}-\mathbf{H}\right]_{2}$.

\begin{tabular}{|c|c|c|c|}
\hline $\mathrm{C}(1)-\mathrm{O}(2)$ & $1.437(5)$ & $C(13)-C(16)$ & $1.425(6)$ \\
\hline $\mathrm{C}(1)-\mathrm{O}(1)$ & $1.442(5)$ & $C(14)-C(26)$ & $1.454(6)$ \\
\hline $\mathrm{C}(1)-\mathrm{C}(11)$ & $1.528(6)$ & $\mathrm{C}(14)-\mathrm{S}(2)$ & $1.737(4)$ \\
\hline $\mathrm{C}(1)-\mathrm{C}(4)$ & $1.535(6)$ & $C(15)-C(16)$ & $1.372(6)$ \\
\hline $\mathrm{C}(2)-\mathrm{O}(1)$ & $1.410(6)$ & $\mathrm{C}(15)-\mathrm{C}(30)$ & $1.467(6)$ \\
\hline$C(2)-C(3)$ & $1.446(7)$ & $C(15)-S(2)$ & $1.745(4)$ \\
\hline $\mathrm{C}(2)-\mathrm{H}(2 \mathrm{~A})$ & 0.9900 & $C(16)-C(17)$ & $1.507(6)$ \\
\hline $\mathrm{C}(2)-\mathrm{H}(2 \mathrm{~B})$ & 0.9900 & $\mathrm{C}(17)-\mathrm{H}(17 \mathrm{~A})$ & 0.9900 \\
\hline $\mathrm{C}(3)-\mathrm{O}(2)$ & $1.392(6)$ & $\mathrm{C}(17)-\mathrm{H}(17 \mathrm{~B})$ & 0.9900 \\
\hline $\mathrm{C}(3)-\mathrm{H}(3 \mathrm{~A})$ & 0.9900 & $\mathrm{C}(18)-\mathrm{C}(19)$ & $1.451(6)$ \\
\hline $\mathrm{C}(3)-\mathrm{H}(3 \mathrm{~B})$ & 0.9900 & $\mathrm{C}(18)-\mathrm{S}(3)$ & $1.706(4)$ \\
\hline C(4)-C(17) & $1.532(6)$ & $C(19)-C(20)$ & $1.428(6)$ \\
\hline$C(4)-C(5)$ & $1.545(5)$ & $\mathrm{C}(19)-\mathrm{H}(19)$ & 0.9500 \\
\hline $\mathrm{C}(4)-\mathrm{H}(4)$ & 1.0000 & $\mathrm{C}(20)-\mathrm{C}(21)$ & $1.348(7)$ \\
\hline $\mathrm{C}(5)-\mathrm{C}(6)$ & $1.514(6)$ & $\mathrm{C}(20)-\mathrm{H}(20)$ & 0.9500 \\
\hline $\mathrm{C}(5)-\mathrm{H}(5 \mathrm{~A})$ & 0.9900 & $\mathrm{C}(21)-\mathrm{S}(3)$ & $1.687(5)$ \\
\hline $\mathrm{C}(5)-\mathrm{H}(5 \mathrm{~B})$ & 0.9900 & $\mathrm{C}(21)-\mathrm{H}(21)$ & 0.9500 \\
\hline$C(6)-C(7)$ & $1.373(6)$ & $C(22)-C(23)$ & $1.391(5)$ \\
\hline$C(6)-C(9)$ & $1.428(6)$ & $\mathrm{C}(22)-\mathrm{S}(4)$ & $1.736(4)$ \\
\hline $\mathrm{C}(7)-\mathrm{C}(18)$ & $1.459(6)$ & $\mathrm{C}(23)-\mathrm{C}(24)$ & $1.421(6)$ \\
\hline$C(7)-S(1)$ & $1.731(4)$ & $\mathrm{C}(23)-\mathrm{H}(23)$ & 0.9500 \\
\hline $\mathrm{C}(8)-\mathrm{C}(9)$ & $1.370(6)$ & $\mathrm{C}(24)-\mathrm{C}(25)$ & $1.352(6)$ \\
\hline $\mathrm{C}(8)-\mathrm{C}(22)$ & $1.460(6)$ & $\mathrm{C}(24)-\mathrm{H}(24)$ & 0.9500 \\
\hline$C(8)-S(1)$ & $1.730(4)$ & $C(25)-S(4)$ & $1.697(4)$ \\
\hline $\mathrm{C}(9)-\mathrm{C}(10)$ & $1.509(5)$ & $\mathrm{C}(25)-\mathrm{H}(25)$ & 0.9500 \\
\hline $\mathrm{C}(10)-\mathrm{C}(11)$ & $1.538(6)$ & $C(26)-C(27)$ & $1.396(6)$ \\
\hline $\mathrm{C}(10)-\mathrm{H}(10 \mathrm{~A})$ & 0.9900 & $\mathrm{C}(26)-\mathrm{S}(5)$ & $1.735(4)$ \\
\hline $\mathrm{C}(10)-\mathrm{H}(10 \mathrm{~B})$ & 0.9900 & $\mathrm{C}(27)-\mathrm{C}(28)$ & $1.431(7)$ \\
\hline $\mathrm{C}(11)-\mathrm{C}(12)$ & $1.551(5)$ & $\mathrm{C}(27)-\mathrm{H}(27)$ & 0.9500 \\
\hline $\mathrm{C}(11)-\mathrm{H}(11)$ & 1.0000 & $\mathrm{C}(28)-\mathrm{C}(29)$ & $1.348(7)$ \\
\hline$C(12)-C(13)$ & $1.505(6)$ & $\mathrm{C}(28)-\mathrm{H}(28)$ & 0.9500 \\
\hline $\mathrm{C}(12)-\mathrm{H}(12 \mathrm{~A})$ & 0.9900 & $\mathrm{C}(29)-\mathrm{S}(5)$ & $1.706(5)$ \\
\hline $\mathrm{C}(12)-\mathrm{H}(12 \mathrm{~B})$ & 0.9900 & $\mathrm{C}(29)-\mathrm{H}(29)$ & 0.9500 \\
\hline$C(13)-C(14)$ & $1.381(6)$ & $\mathrm{C}(30)-\mathrm{C}(31)$ & $1.361(6)$ \\
\hline
\end{tabular}




\begin{tabular}{|c|c|c|c|}
\hline$C(30)-S(6)$ & $1.731(4)$ & $\mathrm{C}(4)-\mathrm{C}(5)-\mathrm{H}(5 \mathrm{~B})$ & 107.3 \\
\hline $\mathrm{C}(31)-\mathrm{C}(32)$ & $1.408(6)$ & $\mathrm{H}(5 \mathrm{~A})-\mathrm{C}(5)-\mathrm{H}(5 \mathrm{~B})$ & 106.9 \\
\hline $\mathrm{C}(31)-\mathrm{H}(31)$ & 0.9500 & $\mathrm{C}(7)-\mathrm{C}(6)-\mathrm{C}(9)$ & $112.7(4)$ \\
\hline $\mathrm{C}(32)-\mathrm{C}(33)$ & $1.350(6)$ & $C(7)-C(6)-C(5)$ & $122.0(4)$ \\
\hline $\mathrm{C}(32)-\mathrm{H}(32)$ & 0.9500 & $\mathrm{C}(9)-\mathrm{C}(6)-\mathrm{C}(5)$ & $124.9(3)$ \\
\hline C(33)-S(6) & $1.713(5)$ & $\mathrm{C}(6)-\mathrm{C}(7)-\mathrm{C}(18)$ & $130.3(4)$ \\
\hline \multirow[t]{2}{*}{$\mathrm{C}(33)-\mathrm{H}(33)$} & 0.9500 & $\mathrm{C}(6)-\mathrm{C}(7)-\mathrm{S}(1)$ & $111.4(3)$ \\
\hline & & $\mathrm{C}(18)-\mathrm{C}(7)-\mathrm{S}(1)$ & $118.1(3)$ \\
\hline $\mathrm{O}(2)-\mathrm{C}(1)-\mathrm{O}(1)$ & $105.7(3)$ & $\mathrm{C}(9)-\mathrm{C}(8)-\mathrm{C}(22)$ & $130.3(4)$ \\
\hline $\mathrm{O}(2)-\mathrm{C}(1)-\mathrm{C}(11)$ & $108.9(3)$ & $\mathrm{C}(9)-\mathrm{C}(8)-\mathrm{S}(1)$ & $111.7(3)$ \\
\hline $\mathrm{O}(1)-\mathrm{C}(1)-\mathrm{C}(11)$ & $107.9(3)$ & $\mathrm{C}(22)-\mathrm{C}(8)-\mathrm{S}(1)$ & $117.4(3)$ \\
\hline $\mathrm{O}(2)-\mathrm{C}(1)-\mathrm{C}(4)$ & $108.0(3)$ & $\mathrm{C}(8)-\mathrm{C}(9)-\mathrm{C}(6)$ & $112.5(3)$ \\
\hline $\mathrm{O}(1)-\mathrm{C}(1)-\mathrm{C}(4)$ & $108.7(3)$ & $\mathrm{C}(8)-\mathrm{C}(9)-\mathrm{C}(10)$ & $123.4(4)$ \\
\hline $\mathrm{C}(11)-\mathrm{C}(1)-\mathrm{C}(4)$ & 117.1(3) & $\mathrm{C}(6)-\mathrm{C}(9)-\mathrm{C}(10)$ & $123.8(4)$ \\
\hline $\mathrm{O}(1)-\mathrm{C}(2)-\mathrm{C}(3)$ & $106.1(4)$ & $\mathrm{C}(9)-\mathrm{C}(10)-\mathrm{C}(11)$ & $117.2(4)$ \\
\hline $\mathrm{O}(1)-\mathrm{C}(2)-\mathrm{H}(2 \mathrm{~A})$ & 110.5 & $\mathrm{C}(9)-\mathrm{C}(10)-\mathrm{H}(10 \mathrm{~A})$ & 108.0 \\
\hline $\mathrm{C}(3)-\mathrm{C}(2)-\mathrm{H}(2 \mathrm{~A})$ & 110.5 & $\mathrm{C}(11)-\mathrm{C}(10)-\mathrm{H}(10 \mathrm{~A})$ & 108.0 \\
\hline $\mathrm{O}(1)-\mathrm{C}(2)-\mathrm{H}(2 \mathrm{~B})$ & 110.5 & $\mathrm{C}(9)-\mathrm{C}(10)-\mathrm{H}(10 \mathrm{~B})$ & 108.0 \\
\hline $\mathrm{C}(3)-\mathrm{C}(2)-\mathrm{H}(2 \mathrm{~B})$ & 110.5 & $\mathrm{C}(11)-\mathrm{C}(10)-\mathrm{H}(10 \mathrm{~B})$ & 108.0 \\
\hline $\mathrm{H}(2 \mathrm{~A})-\mathrm{C}(2)-\mathrm{H}(2 \mathrm{~B})$ & 108.7 & $\mathrm{H}(10 \mathrm{~A})-\mathrm{C}(10)-\mathrm{H}(10 \mathrm{~B})$ & 107.2 \\
\hline $\mathrm{O}(2)-\mathrm{C}(3)-\mathrm{C}(2)$ & $107.8(4)$ & $\mathrm{C}(1)-\mathrm{C}(11)-\mathrm{C}(10)$ & $113.0(3)$ \\
\hline $\mathrm{O}(2)-\mathrm{C}(3)-\mathrm{H}(3 \mathrm{~A})$ & 110.2 & $C(1)-C(11)-C(12)$ & $114.6(4)$ \\
\hline $\mathrm{C}(2)-\mathrm{C}(3)-\mathrm{H}(3 \mathrm{~A})$ & 110.2 & $\mathrm{C}(10)-\mathrm{C}(11)-\mathrm{C}(12)$ & $113.9(3)$ \\
\hline $\mathrm{O}(2)-\mathrm{C}(3)-\mathrm{H}(3 \mathrm{~B})$ & 110.2 & $\mathrm{C}(1)-\mathrm{C}(11)-\mathrm{H}(11)$ & 104.6 \\
\hline $\mathrm{C}(2)-\mathrm{C}(3)-\mathrm{H}(3 \mathrm{~B})$ & 110.2 & $\mathrm{C}(10)-\mathrm{C}(11)-\mathrm{H}(11)$ & 104.6 \\
\hline $\mathrm{H}(3 \mathrm{~A})-\mathrm{C}(3)-\mathrm{H}(3 \mathrm{~B})$ & 108.5 & $\mathrm{C}(12)-\mathrm{C}(11)-\mathrm{H}(11)$ & 104.6 \\
\hline $\mathrm{C}(17)-\mathrm{C}(4)-\mathrm{C}(1)$ & $112.4(3)$ & $\mathrm{C}(13)-\mathrm{C}(12)-\mathrm{C}(11)$ & $118.1(3)$ \\
\hline$C(17)-C(4)-C(5)$ & $114.7(3)$ & $\mathrm{C}(13)-\mathrm{C}(12)-\mathrm{H}(12 \mathrm{~A})$ & 107.8 \\
\hline$C(1)-C(4)-C(5)$ & $113.6(4)$ & $\mathrm{C}(11)-\mathrm{C}(12)-\mathrm{H}(12 \mathrm{~A})$ & 107.8 \\
\hline $\mathrm{C}(17)-\mathrm{C}(4)-\mathrm{H}(4)$ & 105.0 & $\mathrm{C}(13)-\mathrm{C}(12)-\mathrm{H}(12 \mathrm{~B})$ & 107.8 \\
\hline $\mathrm{C}(1)-\mathrm{C}(4)-\mathrm{H}(4)$ & 105.0 & $\mathrm{C}(11)-\mathrm{C}(12)-\mathrm{H}(12 \mathrm{~B})$ & 107.8 \\
\hline $\mathrm{C}(5)-\mathrm{C}(4)-\mathrm{H}(4)$ & 105.0 & $\mathrm{H}(12 \mathrm{~A})-\mathrm{C}(12)-\mathrm{H}(12 \mathrm{~B})$ & 107.1 \\
\hline$C(6)-C(5)-C(4)$ & $120.2(3)$ & $\mathrm{C}(14)-\mathrm{C}(13)-\mathrm{C}(16)$ & $112.7(4)$ \\
\hline $\mathrm{C}(6)-\mathrm{C}(5)-\mathrm{H}(5 \mathrm{~A})$ & 107.3 & $\mathrm{C}(14)-\mathrm{C}(13)-\mathrm{C}(12)$ & $124.8(4)$ \\
\hline $\mathrm{C}(4)-\mathrm{C}(5)-\mathrm{H}(5 \mathrm{~A})$ & 107.3 & $C(16)-C(13)-C(12)$ & $122.5(4)$ \\
\hline $\mathrm{C}(6)-\mathrm{C}(5)-\mathrm{H}(5 \mathrm{~B})$ & 107.3 & $\mathrm{C}(13)-\mathrm{C}(14)-\mathrm{C}(26)$ & $131.3(4)$ \\
\hline
\end{tabular}




\begin{tabular}{|c|c|c|c|}
\hline$C(13)-C(14)-S(2)$ & $110.8(3)$ & $\mathrm{C}(24)-\mathrm{C}(25)-\mathrm{H}(25)$ & 124.0 \\
\hline$C(26)-C(14)-S(2)$ & $117.9(3)$ & $\mathrm{S}(4)-\mathrm{C}(25)-\mathrm{H}(25)$ & 124.0 \\
\hline $\mathrm{C}(16)-\mathrm{C}(15)-\mathrm{C}(30)$ & $133.5(4)$ & $\mathrm{C}(27)-\mathrm{C}(26)-\mathrm{C}(14)$ & $130.3(4)$ \\
\hline C(16)-C(15)-S(2) & $110.2(3)$ & $\mathrm{C}(27)-\mathrm{C}(26)-\mathrm{S}(5)$ & $110.4(3)$ \\
\hline$C(30)-C(15)-S(2)$ & $116.3(3)$ & $C(14)-C(26)-S(5)$ & $119.3(3)$ \\
\hline $\mathrm{C}(15)-\mathrm{C}(16)-\mathrm{C}(13)$ & $113.9(4)$ & $C(26)-C(27)-C(28)$ & $111.5(4)$ \\
\hline $\mathrm{C}(15)-\mathrm{C}(16)-\mathrm{C}(17)$ & $125.4(4)$ & $\mathrm{C}(26)-\mathrm{C}(27)-\mathrm{H}(27)$ & 124.2 \\
\hline $\mathrm{C}(13)-\mathrm{C}(16)-\mathrm{C}(17)$ & $120.7(4)$ & $\mathrm{C}(28)-\mathrm{C}(27)-\mathrm{H}(27)$ & 124.2 \\
\hline C(16)-C(17)-C(4) & $115.7(4)$ & $\mathrm{C}(29)-\mathrm{C}(28)-\mathrm{C}(27)$ & $113.6(4)$ \\
\hline $\mathrm{C}(16)-\mathrm{C}(17)-\mathrm{H}(17 \mathrm{~A})$ & 108.3 & $\mathrm{C}(29)-\mathrm{C}(28)-\mathrm{H}(28)$ & 123.2 \\
\hline $\mathrm{C}(4)-\mathrm{C}(17)-\mathrm{H}(17 \mathrm{~A})$ & 108.3 & $\mathrm{C}(27)-\mathrm{C}(28)-\mathrm{H}(28)$ & 123.2 \\
\hline $\mathrm{C}(16)-\mathrm{C}(17)-\mathrm{H}(17 \mathrm{~B})$ & 108.3 & $\mathrm{C}(28)-\mathrm{C}(29)-\mathrm{S}(5)$ & $112.2(4)$ \\
\hline $\mathrm{C}(4)-\mathrm{C}(17)-\mathrm{H}(17 \mathrm{~B})$ & 108.3 & $\mathrm{C}(28)-\mathrm{C}(29)-\mathrm{H}(29)$ & 123.9 \\
\hline $\mathrm{H}(17 \mathrm{~A})-\mathrm{C}(17)-\mathrm{H}(17 \mathrm{~B})$ & 107.4 & $\mathrm{~S}(5)-\mathrm{C}(29)-\mathrm{H}(29)$ & 123.9 \\
\hline $\mathrm{C}(19)-\mathrm{C}(18)-\mathrm{C}(7)$ & $127.2(4)$ & $\mathrm{C}(31)-\mathrm{C}(30)-\mathrm{C}(15)$ & $126.5(4)$ \\
\hline C(19)-C(18)-S(3) & 111.1(3) & $\mathrm{C}(31)-\mathrm{C}(30)-\mathrm{S}(6)$ & 109.3(3) \\
\hline C(7)-C(18)-S(3) & $121.5(3)$ & $C(15)-C(30)-S(6)$ & $124.2(3)$ \\
\hline$C(20)-C(19)-C(18)$ & $108.6(4)$ & $\mathrm{C}(30)-\mathrm{C}(31)-\mathrm{C}(32)$ & $114.4(4)$ \\
\hline $\mathrm{C}(20)-\mathrm{C}(19)-\mathrm{H}(19)$ & 125.7 & $\mathrm{C}(30)-\mathrm{C}(31)-\mathrm{H}(31)$ & 122.8 \\
\hline $\mathrm{C}(18)-\mathrm{C}(19)-\mathrm{H}(19)$ & 125.7 & $\mathrm{C}(32)-\mathrm{C}(31)-\mathrm{H}(31)$ & 122.8 \\
\hline $\mathrm{C}(21)-\mathrm{C}(20)-\mathrm{C}(19)$ & $114.6(4)$ & $\mathrm{C}(33)-\mathrm{C}(32)-\mathrm{C}(31)$ & $112.5(4)$ \\
\hline $\mathrm{C}(21)-\mathrm{C}(20)-\mathrm{H}(20)$ & 122.7 & $\mathrm{C}(33)-\mathrm{C}(32)-\mathrm{H}(32)$ & 123.7 \\
\hline $\mathrm{C}(19)-\mathrm{C}(20)-\mathrm{H}(20)$ & 122.7 & $\mathrm{C}(31)-\mathrm{C}(32)-\mathrm{H}(32)$ & 123.7 \\
\hline $\mathrm{C}(20)-\mathrm{C}(21)-\mathrm{S}(3)$ & $112.7(4)$ & $\mathrm{C}(32)-\mathrm{C}(33)-\mathrm{S}(6)$ & $111.4(4)$ \\
\hline $\mathrm{C}(20)-\mathrm{C}(21)-\mathrm{H}(21)$ & 123.6 & $\mathrm{C}(32)-\mathrm{C}(33)-\mathrm{H}(33)$ & 124.3 \\
\hline $\mathrm{S}(3)-\mathrm{C}(21)-\mathrm{H}(21)$ & 123.6 & $\mathrm{~S}(6)-\mathrm{C}(33)-\mathrm{H}(33)$ & 124.3 \\
\hline $\mathrm{C}(23)-\mathrm{C}(22)-\mathrm{C}(8)$ & $130.3(4)$ & $\mathrm{C}(2)-\mathrm{O}(1)-\mathrm{C}(1)$ & $108.5(3)$ \\
\hline C(23)-C(22)-S(4) & $110.2(3)$ & $\mathrm{C}(3)-\mathrm{O}(2)-\mathrm{C}(1)$ & 109.1(3) \\
\hline $\mathrm{C}(8)-\mathrm{C}(22)-\mathrm{S}(4)$ & $119.4(3)$ & $\mathrm{C}(7)-\mathrm{S}(1)-\mathrm{C}(8)$ & $91.7(2)$ \\
\hline $\mathrm{C}(22)-\mathrm{C}(23)-\mathrm{C}(24)$ & 111.7(4) & $C(14)-S(2)-C(15)$ & $92.4(2)$ \\
\hline $\mathrm{C}(22)-\mathrm{C}(23)-\mathrm{H}(23)$ & 124.2 & $C(21)-S(3)-C(18)$ & $92.9(2)$ \\
\hline $\mathrm{C}(24)-\mathrm{C}(23)-\mathrm{H}(23)$ & 124.2 & $C(25)-S(4)-C(22)$ & $92.4(2)$ \\
\hline $\mathrm{C}(25)-\mathrm{C}(24)-\mathrm{C}(23)$ & $113.7(4)$ & $C(29)-S(5)-C(26)$ & $92.3(2)$ \\
\hline $\mathrm{C}(25)-\mathrm{C}(24)-\mathrm{H}(24)$ & 123.2 & $C(33)-S(6)-C(30)$ & $92.4(2)$ \\
\hline $\mathrm{C}(23)-\mathrm{C}(24)-\mathrm{H}(24)$ & 123.2 & & \\
\hline C(24)-C(25)-S(4) & $112.0(4)$ & & \\
\hline
\end{tabular}


Table A.16. Anisotropic displacement parameters $\left(\AA^{2} \times 10^{3}\right)$ for $\boldsymbol{s t}$ - $\left[\mathbf{H}-\mathbf{T h}_{\mathbf{3}}-\mathbf{H}\right]_{2}$. The anisotropic displacement factor exponent takes the form: $-2 \pi^{2}\left[h^{2} a^{* 2} U^{11}\right.$ $+\ldots+2 \mathrm{hk} \mathrm{a}^{*} \mathrm{~b}^{*} \mathrm{U}^{12}$ ]

\begin{tabular}{lllllll}
\hline & $\mathrm{U}^{11}$ & $\mathrm{U}^{22}$ & $\mathrm{U}^{33}$ & $\mathrm{U}^{23}$ & $\mathrm{U}^{13}$ & $\mathrm{U}$ \\
\hline $\mathrm{C}(1)$ & $29(3)$ & $20(2)$ & $27(2)$ & $-1(2)$ & $-6(2)$ & $-8(2)$ \\
$\mathrm{C}(2)$ & $61(4)$ & $25(3)$ & $59(3)$ & $-13(2)$ & $-17(3)$ & $-13(2)$ \\
$\mathrm{C}(3)$ & $90(5)$ & $24(3)$ & $123(5)$ & $-2(3)$ & $-61(4)$ & $-21(3)$ \\
$\mathrm{C}(4)$ & $31(3)$ & $18(2)$ & $23(2)$ & $-7(2)$ & $0(2)$ & $-7(2)$ \\
$\mathrm{C}(5)$ & $36(3)$ & $23(3)$ & $19(2)$ & $-1(2)$ & $-2(2)$ & $-10(2)$ \\
$\mathrm{C}(6)$ & $25(3)$ & $21(3)$ & $20(2)$ & $-1(2)$ & $-4(2)$ & $-5(2)$ \\
$\mathrm{C}(7)$ & $30(3)$ & $26(3)$ & $19(2)$ & $-4(2)$ & $-1(2)$ & $-8(2)$ \\
$\mathrm{C}(8)$ & $24(3)$ & $30(3)$ & $14(2)$ & $-2(2)$ & $2(2)$ & $-9(2)$ \\
$\mathrm{C}(9)$ & $24(3)$ & $22(2)$ & $17(2)$ & $-3(2)$ & $-2(2)$ & $-5(2)$ \\
$\mathrm{C}(10)$ & $27(3)$ & $25(3)$ & $24(2)$ & $-4(2)$ & $6(2)$ & $-9(2)$ \\
$\mathrm{C}(11)$ & $31(3)$ & $25(2)$ & $19(2)$ & $0(2)$ & $0(2)$ & $-14(2)$ \\
$\mathrm{C}(12)$ & $34(3)$ & $28(3)$ & $22(2)$ & $-2(2)$ & $-3(2)$ & $-15(2)$ \\
$\mathrm{C}(13)$ & $25(3)$ & $24(3)$ & $24(2)$ & $-3(2)$ & $-6(2)$ & $-6(2)$ \\
$\mathrm{C}(14)$ & $28(3)$ & $30(3)$ & $23(2)$ & $-3(2)$ & $-2(2)$ & $-10(2)$ \\
$\mathrm{C}(15)$ & $21(3)$ & $27(3)$ & $24(2)$ & $-8(2)$ & $-1(2)$ & $-5(2)$ \\
$\mathrm{C}(16)$ & $28(3)$ & $22(3)$ & $25(2)$ & $-4(2)$ & $-4(2)$ & $-9(2)$ \\
$\mathrm{C}(17)$ & $26(3)$ & $21(2)$ & $27(2)$ & $-5(2)$ & $5(2)$ & $-6(2)$ \\
$\mathrm{C}(18)$ & $33(3)$ & $18(2)$ & $30(2)$ & $0(2)$ & $1(2)$ & $-5(2)$ \\
$\mathrm{C}(19)$ & $30(3)$ & $14(2)$ & $13(2)$ & $-1(2)$ & $10(2)$ & $-2(2)$ \\
$\mathrm{C}(20)$ & $53(4)$ & $31(3)$ & $25(2)$ & $0(2)$ & $6(2)$ & $-2(2)$ \\
$\mathrm{C}(21)$ & $50(4)$ & $45(3)$ & $48(3)$ & $8(2)$ & $10(3)$ & $-19(3)$ \\
$\mathrm{C}(22)$ & $28(3)$ & $21(2)$ & $24(2)$ & $-4(2)$ & $-2(2)$ & $-7(2)$ \\
$\mathrm{C}(23)$ & $26(3)$ & $30(3)$ & $19(2)$ & $-8(2)$ & $2(2)$ & $-2(2)$ \\
$\mathrm{C}(24)$ & $36(3)$ & $34(3)$ & $19(2)$ & $-3(2)$ & $4(2)$ & $-11(2)$ \\
$\mathrm{C}(25)$ & $33(3)$ & $27(3)$ & $26(2)$ & $-9(2)$ & $6(2)$ & $-6(2)$ \\
$\mathrm{C}(26)$ & $25(3)$ & $30(3)$ & $27(2)$ & $-8(2)$ & $-2(2)$ & $-10(2)$ \\
$\mathrm{C}(27)$ & $22(3)$ & $33(3)$ & $24(2)$ & $-7(2)$ & $-7(2)$ & $-7(2)$ \\
$\mathrm{C}(28)$ & $35(3)$ & $49(3)$ & $28(2)$ & $-7(2)$ & $-4(2)$ & $-21(2)$ \\
$\mathrm{C}(29)$ & $48(3)$ & $41(3)$ & $38(3)$ & $-20(2)$ & $9(2)$ & $-21(2)$ \\
& & & & & & \\
& & & & \\
\\
\end{tabular}




$\begin{array}{lllllll}\mathrm{C}(30) & 26(3) & 27(3) & 22(2) & -6(2) & -2(2) & -7(2) \\ \mathrm{C}(31) & 39(3) & 37(3) & 27(2) & -12(2) & -1(2) & -19(2) \\ \mathrm{C}(32) & 35(3) & 39(3) & 30(2) & -4(2) & -2(2) & -20(2) \\ \mathrm{C}(33) & 55(4) & 47(3) & 31(3) & -12(2) & 13(2) & -25(3) \\ \mathrm{O}(1) & 32(2) & 25(2) & 32(2) & -6(1) & -8(1) & -12(1) \\ \mathrm{O}(2) & 36(2) & 18(2) & 33(2) & 1(1) & -9(1) & -9(1) \\ \mathrm{S}(1) & 35(1) & 20(1) & 22(1) & -3(1) & 2(1) & -8(1) \\ \mathrm{S}(2) & 35(1) & 27(1) & 27(1) & -8(1) & 2(1) & -14(1) \\ \mathrm{S}(3) & 68(1) & 58(1) & 41(1) & 4(1) & -4(1) & -38(1) \\ \mathrm{S}(4) & 35(1) & 26(1) & 20(1) & -3(1) & -1(1) & -4(1) \\ \mathrm{S}(5) & 53(1) & 32(1) & 37(1) & -12(1) & 10(1) & -19(1) \\ \mathrm{S}(6) & 86(1) & 56(1) & 39(1) & -26(1) & 25(1) & -47(1)\end{array}$


Table A.17. Hydrogen coordinates ( x 104) and isotropic displacement parameters $\left(\AA^{2} \times 10^{3}\right)$ for $s t-\left[\mathbf{H}-\mathbf{T h}_{\mathbf{3}}-\mathbf{H}\right]_{2}$.

\begin{tabular}{|c|c|c|c|c|}
\hline & $\mathrm{x}$ & $\mathrm{y}$ & $\mathrm{z}$ & $\mathrm{U}(\mathrm{eq})$ \\
\hline $\mathrm{H}(2 \mathrm{~A})$ & 6766 & 1756 & 1586 & 56 \\
\hline $\mathrm{H}(2 \mathrm{~B})$ & 5442 & 1639 & 2344 & 56 \\
\hline $\mathrm{H}(3 \mathrm{~A})$ & 7281 & 800 & 3308 & 92 \\
\hline $\mathrm{H}(3 \mathrm{~B})$ & 8559 & 538 & 2515 & 92 \\
\hline $\mathrm{H}(4)$ & 8729 & 3368 & 1500 & 29 \\
\hline $\mathrm{H}(5 \mathrm{~A})$ & 8032 & 5504 & 873 & 32 \\
\hline $\mathrm{H}(5 \mathrm{~B})$ & 6428 & 5120 & 1124 & 32 \\
\hline $\mathrm{H}(10 \mathrm{~A})$ & 4472 & 5193 & 2734 & 31 \\
\hline $\mathrm{H}(10 \mathrm{~B})$ & 4620 & 5673 & 3600 & 31 \\
\hline $\mathrm{H}(11)$ & 6144 & 3567 & 3755 & 29 \\
\hline $\mathrm{H}(12 \mathrm{~A})$ & 7390 & 4589 & 4429 & 32 \\
\hline $\mathrm{H}(12 \mathrm{~B})$ & 8776 & 3454 & 4055 & 32 \\
\hline $\mathrm{H}(17 \mathrm{~A})$ & 10421 & 3200 & 2656 & 31 \\
\hline $\mathrm{H}(17 \mathrm{~B})$ & 10717 & 4060 & 1765 & 31 \\
\hline $\mathrm{H}(19)$ & 6578 & 7174 & -365 & 25 \\
\hline $\mathrm{H}(20)$ & 8071 & 8232 & -1526 & 48 \\
\hline $\mathrm{H}(21)$ & 9252 & 9627 & -1049 & 60 \\
\hline $\mathrm{H}(23)$ & 4537 & 7057 & 4562 & 32 \\
\hline $\mathrm{H}(24)$ & 2100 & 8415 & 5270 & 36 \\
\hline $\mathrm{H}(25)$ & 436 & 10242 & 4296 & 35 \\
\hline $\mathrm{H}(27)$ & 7988 & 5218 & 5548 & 32 \\
\hline $\mathrm{H}(28)$ & 6621 & 6727 & 6561 & 42 \\
\hline $\mathrm{H}(29)$ & 6120 & 8967 & 5932 & 47 \\
\hline $\mathrm{H}(31)$ & 12066 & 7888 & 1955 & 38 \\
\hline $\mathrm{H}(32)$ & 13556 & 8043 & 575 & 39 \\
\hline $\mathrm{H}(33)$ & 13472 & 6464 & -254 & 51 \\
\hline
\end{tabular}


A suitable crystal of $s t-\left[\mathbf{M e}-\mathbf{T h}_{\mathbf{3}}-\mathbf{M e}\right]_{2}$ was coated with Paratone $\mathrm{N}$ oil, suspended in a small fiber loop and placed in a cooled nitrogen gas stream at $173 \mathrm{~K}$ on a Bruker D8 SMART 1000 CCD sealed tube diffractometer with graphite monochromated CuK $\alpha$ $(1.54178 \AA)$ radiation. Data was measured using a series of combinations of phi and omega scans with $10 \mathrm{~s}$ frame exposures and $0.3^{\circ}$ frame widths. Data collection, indexing and initial cell refinements were all carried out using SMART $^{1}$ software. Frame integration and final cell refinements were done using $\mathrm{SAINT}^{2}$ software. The final cell parameters were determined from least-squares refinement on 3996 reflections. The $\mathrm{SADABS}^{3}$ program was used to carry out absorption corrections.

The structure was solved using Direct methods and difference Fourier techniques (SHELXTL, V6.12). ${ }^{4}$ Hydrogen atoms were placed in their expected chemical positions using the HFIX command and were included in the final cycles of least-squares with isotropic Uij's related to the riding atom. The $\mathrm{C}-\mathrm{H}$ distances were fixed at $0.93 \AA$ (aromatic and amide), 0.98 (methine), $0.97 \AA$ (methylene), or $0.96 \AA$ (methyl). Only the $\mathrm{S}$ and $\mathrm{O}$ atoms were refined anisotropically. Scattering factors and anomalous dispersion corrections are taken from the International Tables for X-ray Crystallography. ${ }^{5}$ Structure solution, refinement, graphics and generation of publication materials were performed using SHELXTL, V6.12 software. Additional details of data collection and structure refinement are given in Tables A.18-A.22. 
Table A.18. Crystal data and structure refinement for $s t-\left[\mathbf{M e}-\mathbf{T h}_{3}-\mathbf{M e}\right]_{2}$.

Empirical formula

Formula weight

Temperature

Wavelength

Crystal system

Space group

Unit cell dimensions

Volume

Z

Density (calculated)

Absorption coefficient

$\mathrm{F}(000)$

Crystal size

Theta range for data collection

Index ranges

Reflections collected

Independent reflections

Completeness to theta $=58.93^{\circ}$

Absorption correction

Max. and min. transmission

Refinement method

Data / restraints / parameters

Goodness-of-fit on $\mathrm{F}^{2}$

Final $\mathrm{R}$ indices [I $>2 \operatorname{sigma}(\mathrm{I})]$

$\mathrm{R}$ indices (all data)

Largest diff. peak and hole
C37 H34 O2 S6

703.00

173(2) $\mathrm{K}$

$1.54178 \AA$

Triclinic

P-1

$\mathrm{a}=13.4911(11) \AA \quad \alpha=105.859(4)^{\circ}$.

$\mathrm{b}=15.5222(11) \AA \quad \beta=91.158(4)^{\circ}$.

$\mathrm{c}=16.5506(13) \AA \quad \gamma=96.297(4)^{\circ}$.

3309.3(4) $\AA^{3}$

4

$1.411 \mathrm{Mg} / \mathrm{m}^{3}$

$4.083 \mathrm{~mm}^{-1}$

1472

$0.28 \times 0.23 \times 0.02 \mathrm{~mm}^{3}$

2.78 to $58.93^{\circ}$.

$-14<=\mathrm{h}<=13,-16<=\mathrm{k}<=17,-18<=\mathrm{l}<=15$

15680

$8373[\mathrm{R}($ int $)=0.1144]$

$88.1 \%$

Semi-empirical from equivalents

1.00 and 0.566295

Full-matrix least-squares on $\mathrm{F}^{2}$

8373 / 0 / 466

1.048

$\mathrm{R} 1=0.1510, \mathrm{wR} 2=0.3341$

$\mathrm{R} 1=0.1877, \mathrm{wR} 2=0.3594$

1.290 and -0.687 e. $\AA^{-3}$ 
Table A.19. Atomic coordinates $\left(\times 10^{4}\right.$ ) and equivalent isotropic displacement parameters $\left(\AA^{2} \mathrm{x} 10^{3}\right)$ for $s t$-[Me-Th $\left.\mathbf{T}_{3}-\mathbf{M e}\right]_{2}$. U(eq) is defined as one third of the trace of the orthogonalized $\mathrm{U}^{\mathrm{ij}}$ tensor.

\begin{tabular}{|c|c|c|c|c|}
\hline & $\mathrm{X}$ & $\mathrm{y}$ & $\mathrm{z}$ & $\mathrm{U}(\mathrm{eq})$ \\
\hline $\mathrm{C}(1)$ & $3866(7)$ & $6235(6)$ & $1110(6)$ & $18(2)$ \\
\hline$C(2)$ & $3544(12)$ & $7345(10)$ & $517(9)$ & $65(4)$ \\
\hline$C(3)$ & $4234(10)$ & $6803(8)$ & $-15(8)$ & $51(3)$ \\
\hline$C(4)$ & $3119(7)$ & $5437(6)$ & $1177(6)$ & $20(2)$ \\
\hline$C(5)$ & $3527(8)$ & $4525(6)$ & $895(6)$ & $23(2)$ \\
\hline$C(6)$ & $4254(7)$ & $4334(6)$ & $1489(6)$ & $17(2)$ \\
\hline$C(7)$ & $4158(7)$ & $3538(6)$ & $1734(6)$ & $21(2)$ \\
\hline $\mathrm{C}(8)$ & $5751(7)$ & $4533(6)$ & $2285(6)$ & $19(2)$ \\
\hline $\mathrm{C}(9)$ & $5163(7)$ & $4886(6)$ & $1809(5)$ & $13(2)$ \\
\hline$C(10)$ & $5493(8)$ & $5769(6)$ & $1618(6)$ & $23(2)$ \\
\hline$C(11)$ & $4760(7)$ & $6496(6)$ & $1712(6)$ & $21(2)$ \\
\hline$C(12)$ & $4504(8)$ & $6911(6)$ & $2626(6)$ & $24(2)$ \\
\hline $\mathrm{C}(13)$ & $4107(7)$ & $6257(6)$ & $3114(6)$ & $17(2)$ \\
\hline$C(14)$ & $4515(7)$ & $6204(6)$ & $3848(6)$ & $22(2)$ \\
\hline$C(15)$ & 2974(8) & $5119(7)$ & $3343(6)$ & $25(2)$ \\
\hline$C(16)$ & $3207(7)$ & $5640(6)$ & $2810(6)$ & $22(2)$ \\
\hline$C(17)$ & $2607(8)$ & $5613(7)$ & $2037(6)$ & $24(2)$ \\
\hline $\mathrm{C}(18)$ & $6720(7)$ & $4852(6)$ & $2710(6)$ & $19(2)$ \\
\hline $\mathrm{C}(19)$ & $7583(8)$ & $5254(7)$ & $2429(7)$ & $29(3)$ \\
\hline$C(20)$ & 8392(9) & $5450(7)$ & $3015(6)$ & $32(3)$ \\
\hline$C(21)$ & $8216(8)$ & $5191(7)$ & $3720(7)$ & $32(3)$ \\
\hline $\mathrm{C}(22)$ & $3395(7)$ & $2745(6)$ & $1507(6)$ & $20(2)$ \\
\hline$C(23)$ & $2375(8)$ & $2699(7)$ & $1538(6)$ & $32(3)$ \\
\hline$C(24)$ & 1921(9) & $1778(7)$ & $1325(6)$ & $32(3)$ \\
\hline$C(25)$ & $2560(8)$ & 1171(7) & $1175(7)$ & $32(3)$ \\
\hline$C(26)$ & $5313(8)$ & $6768(7)$ & $4389(6)$ & $29(3)$ \\
\hline$C(27)$ & $6267(8)$ & $7061(7)$ & $4232(7)$ & $33(3)$ \\
\hline $\mathrm{C}(28)$ & $6810(10)$ & $7668(8)$ & $4967(7)$ & $42(3)$ \\
\hline $\mathrm{C}(29)$ & $6275(8)$ & $7819(7)$ & $5662(7)$ & $32(3)$ \\
\hline $\mathrm{C}(30)$ & $2151(8)$ & $4410(7)$ & $3312(6)$ & $26(2)$ \\
\hline
\end{tabular}




\begin{tabular}{|c|c|c|c|c|}
\hline $\mathrm{C}(31)$ & 2221(9) & $3626(7)$ & $3550(7)$ & $39(3)$ \\
\hline$C(32)$ & 1263(9) & 3093(8) & $3464(7)$ & $39(3)$ \\
\hline$C(33)$ & $516(9)$ & $3436(8)$ & $3176(7)$ & $39(3)$ \\
\hline $\mathrm{C}(34)$ & $-547(11)$ & $3081(10)$ & $3015(9)$ & $63(4)$ \\
\hline$C(35)$ & $6587(10)$ & $8432(8)$ & $6533(7)$ & $49(3)$ \\
\hline$C(36)$ & $2356(10)$ & 154(9) & $990(8)$ & $55(4)$ \\
\hline $\mathrm{C}(37)$ & $8910(10)$ & 5309(9) & $4480(8)$ & $50(3)$ \\
\hline $\mathrm{O}(1)$ & $3345(5)$ & $6993(4)$ & $1195(4)$ & $26(2)$ \\
\hline $\mathrm{O}(2)$ & $4180(5)$ & $6010(4)$ & $257(4)$ & $26(2)$ \\
\hline$S(1)$ & 6991(2) & $4720(2)$ & $3689(2)$ & $36(1)$ \\
\hline$S(2)$ & $5171(2)$ & $3494(2)$ & $2363(2)$ & $23(1)$ \\
\hline$S(3)$ & $3769(2)$ & $1686(2)$ & $1225(2)$ & $31(1)$ \\
\hline$S(4)$ & $5107(2)$ & $7226(2)$ & $5457(2)$ & $42(1)$ \\
\hline$S(5)$ & $3830(2)$ & $5367(2)$ & $4197(2)$ & $27(1)$ \\
\hline$S(6)$ & $945(2)$ & $4473(2)$ & $3007(2)$ & $36(1)$ \\
\hline $\mathrm{C}(1 \mathrm{~B})$ & 10107(9) & $7025(8)$ & $376(7)$ & $38(3)$ \\
\hline $\mathrm{C}(2 \mathrm{~B})$ & $10725(16)$ & $6636(14)$ & $-914(13)$ & $111(7)$ \\
\hline $\mathrm{C}(3 \mathrm{~B})$ & $10313(12)$ & $5795(10)$ & $-732(9)$ & $67(4)$ \\
\hline $\mathrm{C}(4 \mathrm{~B})$ & $9258(8)$ & $7579(7)$ & 419(7) & $35(3)$ \\
\hline $\mathrm{C}(5 \mathrm{~B})$ & $8336(9)$ & $7233(8)$ & $868(7)$ & $40(3)$ \\
\hline$C(6 B)$ & $8449(9)$ & $7559(7)$ & $1799(7)$ & $37(3)$ \\
\hline $\mathrm{C}(7 \mathrm{~B})$ & $7856(8)$ & $8114(7)$ & $2316(6)$ & $29(3)$ \\
\hline$C(8 B)$ & $9273(8)$ & $7721(7)$ & $3113(6)$ & $29(3)$ \\
\hline $\mathrm{C}(9 \mathrm{~B})$ & $9258(8)$ & $7323(7)$ & $2261(6)$ & $26(2)$ \\
\hline $\mathrm{C}(10 \mathrm{~B})$ & $9969(8)$ & $6693(7)$ & $1808(6)$ & $29(3)$ \\
\hline$C(11 B)$ & $10664(8)$ & $7046(7)$ & $1200(7)$ & $34(3)$ \\
\hline $\mathrm{C}(12 \mathrm{~B})$ & 11307(8) & $7937(7)$ & $1599(7)$ & $29(3)$ \\
\hline$C(13 B)$ & $10826(8)$ & $8766(7)$ & 1994(6) & $26(2)$ \\
\hline$C(14 B)$ & 11121(8) & $9342(7)$ & $2759(6)$ & $26(2)$ \\
\hline $\mathrm{C}(15 \mathrm{~B})$ & $9733(8)$ & $9857(6)$ & $2081(6)$ & $23(2)$ \\
\hline$C(16 B)$ & $10016(8)$ & $9058(6)$ & 1591(6) & $22(2)$ \\
\hline $\mathrm{C}(17 \mathrm{~B})$ & $9574(9)$ & $8612(7)$ & $723(7)$ & $36(3)$ \\
\hline $\mathrm{C}(18 \mathrm{~B})$ & $6984(9)$ & $8506(8)$ & $2131(7)$ & $38(3)$ \\
\hline$C(19 B)$ & $6274(10)$ & $8800(8)$ & $2684(8)$ & $51(3)$ \\
\hline$C(20 B)$ & $5569(12)$ & $9247(10)$ & $2322(10)$ & $71(4)$ \\
\hline$C(21 B)$ & $5725(11)$ & $9257(10)$ & 1539(9) & $62(4)$ \\
\hline
\end{tabular}




\begin{tabular}{|c|c|c|c|c|}
\hline $\mathrm{C}(22 \mathrm{~B})$ & $9934(7)$ & $7675(6)$ & $3806(6)$ & $22(2)$ \\
\hline$C(23 B)$ & $9830(9)$ & $8075(8)$ & $4643(7)$ & $41(3)$ \\
\hline$C(24 B)$ & $10613(9)$ & $7948(8)$ & $5162(8)$ & $42(3)$ \\
\hline$C(25 B)$ & 11313(9) & $7475(7)$ & $4754(7)$ & $35(3)$ \\
\hline$C(26 B)$ & 11913(10) & $9304(8)$ & $3351(8)$ & $43(3)$ \\
\hline $\mathrm{C}(30 \mathrm{~B})$ & $8950(8)$ & 10387(7) & $1925(6)$ & $32(3)$ \\
\hline$C(31 B)$ & $8768(6)$ & $10729(5)$ & $1240(5)$ & $10(2)$ \\
\hline $\mathrm{C}(32 \mathrm{~B})$ & 7998(11) & $11209(10)$ & $1330(10)$ & $68(4)$ \\
\hline$C(33 B)$ & $7546(11)$ & $11274(10)$ & $2025(9)$ & $63(4)$ \\
\hline$C(34 B)$ & $6689(14)$ & $11789(13)$ & $2369(11)$ & $100(6)$ \\
\hline$C(36 B)$ & $5144(13)$ & $9685(12)$ & $998(11)$ & $89(5)$ \\
\hline$C(37 B)$ & $12269(10)$ & 7241(9) & $5084(8)$ & $49(3)$ \\
\hline $\mathrm{O}(1 \mathrm{~B})$ & $10855(7)$ & $7304(5)$ & $-154(4)$ & $49(2)$ \\
\hline $\mathrm{O}(2 \mathrm{~B})$ & $9719(7)$ & $6106(5)$ & $-53(4)$ & $50(2)$ \\
\hline$S(1 B)$ & $8298(2)$ & $8374(2)$ & $3357(2)$ & $34(1)$ \\
\hline $\mathrm{S}(2 \mathrm{~B})$ & $11017(2)$ & $7172(2)$ & $3684(2)$ & $32(1)$ \\
\hline $\mathrm{S}(3 \mathrm{~B})$ & $6755(2)$ & $8746(2)$ & 1193(2) & $52(1)$ \\
\hline $\mathrm{S}(4 \mathrm{~B})$ & $8106(3)$ & $10722(2)$ & $2643(2)$ & $52(1)$ \\
\hline$S(5 B)$ & $10447(2)$ & $10251(2)$ & $3015(2)$ & $32(1)$ \\
\hline$S(6 B)$ & $12970(20)$ & $8988(16)$ & $3220(20)$ & $39(3)$ \\
\hline $\mathrm{C}(27 \mathrm{~B})$ & $11750(60)$ & $9630(50)$ & $4260(40)$ & $110(30)$ \\
\hline $\mathrm{C}(28 \mathrm{~B})$ & $12580(20)$ & $9573(15)$ & 4773(17) & $35(6)$ \\
\hline$C(29 B)$ & $13370(20)$ & $9196(17)$ & $4328(19)$ & $29(7)$ \\
\hline $\mathrm{C}(35 \mathrm{~B})$ & $14340(20)$ & $8960(20)$ & $4588(18)$ & $67(8)$ \\
\hline$S(6 X)$ & 11917(9) & $9699(6)$ & $4341(5)$ & $27(2)$ \\
\hline$C(27 X)$ & $12980(80)$ & $8900(60)$ & $3220(70)$ & 20 \\
\hline$C(28 X)$ & $13510(20)$ & $9044(15)$ & $3824(19)$ & $38(6)$ \\
\hline$C(29 X)$ & $13050(30)$ & $9440(20)$ & 4538(19) & $37(7)$ \\
\hline$C(35 X)$ & $13630(30)$ & $9670(20)$ & $5420(20)$ & $87(10)$ \\
\hline
\end{tabular}


Table A.20. Bond lengths $[\AA]$ and angles $\left[^{\circ}\right]$ for $s t-\left[\mathbf{M e}-\mathbf{T h}_{3}-\mathbf{M e}\right]_{2}$.

\begin{tabular}{|c|c|c|c|}
\hline $\mathrm{C}(1)-\mathrm{O}(1)$ & $1.412(11)$ & $\mathrm{C}(13)-\mathrm{C}(16)$ & $1.450(13)$ \\
\hline $\mathrm{C}(1)-\mathrm{O}(2)$ & $1.442(11)$ & $C(14)-C(26)$ & $1.433(14)$ \\
\hline $\mathrm{C}(1)-\mathrm{C}(11)$ & $1.495(13)$ & $\mathrm{C}(14)-\mathrm{S}(5)$ & $1.744(10)$ \\
\hline $\mathrm{C}(1)-\mathrm{C}(4)$ & $1.540(13)$ & $C(15)-C(16)$ & $1.371(14)$ \\
\hline $\mathrm{C}(2)-\mathrm{O}(1)$ & $1.393(16)$ & $C(15)-C(30)$ & $1.464(14)$ \\
\hline$C(2)-C(3)$ & $1.465(17)$ & $\mathrm{C}(15)-\mathrm{S}(5)$ & $1.736(11)$ \\
\hline $\mathrm{C}(2)-\mathrm{H}(2 \mathrm{~A})$ & 0.9900 & $C(16)-C(17)$ & $1.488(13)$ \\
\hline $\mathrm{C}(2)-\mathrm{H}(2 \mathrm{~B})$ & 0.9900 & $\mathrm{C}(17)-\mathrm{H}(17 \mathrm{~A})$ & 0.9900 \\
\hline $\mathrm{C}(3)-\mathrm{O}(2)$ & $1.417(14)$ & $\mathrm{C}(17)-\mathrm{H}(17 \mathrm{~B})$ & 0.9900 \\
\hline $\mathrm{C}(3)-\mathrm{H}(3 \mathrm{~A})$ & 0.9900 & $\mathrm{C}(18)-\mathrm{C}(19)$ & $1.408(14)$ \\
\hline $\mathrm{C}(3)-\mathrm{H}(3 \mathrm{~B})$ & 0.9900 & $\mathrm{C}(18)-\mathrm{S}(1)$ & $1.725(10)$ \\
\hline$C(4)-C(5)$ & $1.532(12)$ & $\mathrm{C}(19)-\mathrm{C}(20)$ & $1.396(14)$ \\
\hline $\mathrm{C}(4)-\mathrm{C}(17)$ & $1.563(13)$ & $\mathrm{C}(19)-\mathrm{H}(19)$ & 0.9500 \\
\hline $\mathrm{C}(4)-\mathrm{H}(4)$ & 1.0000 & $\mathrm{C}(20)-\mathrm{C}(21)$ & $1.352(15)$ \\
\hline$C(5)-C(6)$ & $1.484(13)$ & $\mathrm{C}(20)-\mathrm{H}(20)$ & 0.9500 \\
\hline $\mathrm{C}(5)-\mathrm{H}(5 \mathrm{~A})$ & 0.9900 & $\mathrm{C}(21)-\mathrm{C}(37)$ & $1.511(16)$ \\
\hline $\mathrm{C}(5)-\mathrm{H}(5 \mathrm{~B})$ & 0.9900 & $\mathrm{C}(21)-\mathrm{S}(1)$ & $1.727(12)$ \\
\hline$C(6)-C(7)$ & $1.394(13)$ & $\mathrm{C}(22)-\mathrm{C}(23)$ & $1.373(14)$ \\
\hline$C(6)-C(9)$ & $1.419(13)$ & $\mathrm{C}(22)-\mathrm{S}(3)$ & $1.717(9)$ \\
\hline $\mathrm{C}(7)-\mathrm{C}(22)$ & $1.473(13)$ & $\mathrm{C}(23)-\mathrm{C}(24)$ & $1.438(15)$ \\
\hline$C(7)-S(2)$ & $1.721(10)$ & $\mathrm{C}(23)-\mathrm{H}(23)$ & 0.9500 \\
\hline $\mathrm{C}(8)-\mathrm{C}(9)$ & $1.364(13)$ & $\mathrm{C}(24)-\mathrm{C}(25)$ & $1.325(14)$ \\
\hline $\mathrm{C}(8)-\mathrm{C}(18)$ & $1.442(13)$ & $\mathrm{C}(24)-\mathrm{H}(24)$ & 0.9500 \\
\hline $\mathrm{C}(8)-\mathrm{S}(2)$ & $1.752(10)$ & $C(25)-C(36)$ & $1.515(16)$ \\
\hline C(9)-C(10) & $1.513(13)$ & $\mathrm{C}(25)-\mathrm{S}(3)$ & $1.727(11)$ \\
\hline $\mathrm{C}(10)-\mathrm{C}(11)$ & $1.558(13)$ & $C(26)-C(27)$ & $1.371(15)$ \\
\hline $\mathrm{C}(10)-\mathrm{H}(10 \mathrm{~A})$ & 0.9900 & $\mathrm{C}(26)-\mathrm{S}(4)$ & $1.757(10)$ \\
\hline $\mathrm{C}(10)-\mathrm{H}(10 \mathrm{~B})$ & 0.9900 & $\mathrm{C}(27)-\mathrm{C}(28)$ & $1.445(16)$ \\
\hline $\mathrm{C}(11)-\mathrm{C}(12)$ & $1.537(13)$ & $\mathrm{C}(27)-\mathrm{H}(27)$ & 0.9500 \\
\hline $\mathrm{C}(11)-\mathrm{H}(11)$ & 1.0000 & $\mathrm{C}(28)-\mathrm{C}(29)$ & $1.351(15)$ \\
\hline $\mathrm{C}(12)-\mathrm{C}(13)$ & $1.522(14)$ & $\mathrm{C}(28)-\mathrm{H}(28)$ & 0.9500 \\
\hline $\mathrm{C}(12)-\mathrm{H}(12 \mathrm{~A})$ & 0.9900 & $C(29)-C(35)$ & $1.515(15)$ \\
\hline $\mathrm{C}(12)-\mathrm{H}(12 \mathrm{~B})$ & 0.9900 & $\mathrm{C}(29)-\mathrm{S}(4)$ & $1.713(12)$ \\
\hline $\mathrm{C}(13)-\mathrm{C}(14)$ & $1.350(13)$ & $C(30)-C(31)$ & $1.389(15)$ \\
\hline
\end{tabular}




\begin{tabular}{|c|c|c|c|}
\hline$C(30)-S(6)$ & $1.715(11)$ & $\mathrm{C}(6 \mathrm{~B})-\mathrm{C}(7 \mathrm{~B})$ & $1.375(15)$ \\
\hline $\mathrm{C}(31)-\mathrm{C}(32)$ & $1.438(16)$ & $\mathrm{C}(6 \mathrm{~B})-\mathrm{C}(9 \mathrm{~B})$ & $1.456(15)$ \\
\hline $\mathrm{C}(31)-\mathrm{H}(31)$ & 0.9500 & $C(7 B)-C(18 B)$ & $1.447(15)$ \\
\hline C(32)-C(33) & $1.329(16)$ & $\mathrm{C}(7 \mathrm{~B})-\mathrm{S}(1 \mathrm{~B})$ & $1.736(11)$ \\
\hline $\mathrm{C}(32)-\mathrm{H}(32)$ & 0.9500 & $\mathrm{C}(8 \mathrm{~B})-\mathrm{C}(9 \mathrm{~B})$ & $1.375(14)$ \\
\hline $\mathrm{C}(33)-\mathrm{C}(34)$ & $1.470(18)$ & $\mathrm{C}(8 \mathrm{~B})-\mathrm{C}(22 \mathrm{~B})$ & $1.460(14)$ \\
\hline$C(33)-S(6)$ & $1.746(12)$ & $\mathrm{C}(8 \mathrm{~B})-\mathrm{S}(1 \mathrm{~B})$ & $1.735(11)$ \\
\hline $\mathrm{C}(34)-\mathrm{H}(34 \mathrm{~A})$ & 0.9800 & $\mathrm{C}(9 \mathrm{~B})-\mathrm{C}(10 \mathrm{~B})$ & $1.507(13)$ \\
\hline $\mathrm{C}(34)-\mathrm{H}(34 \mathrm{~B})$ & 0.9800 & $\mathrm{C}(10 \mathrm{~B})-\mathrm{C}(11 \mathrm{~B})$ & $1.556(15)$ \\
\hline C(34)-H(34C) & 0.9800 & $\mathrm{C}(10 \mathrm{~B})-\mathrm{H}(10 \mathrm{C})$ & 0.9900 \\
\hline $\mathrm{C}(35)-\mathrm{H}(35 \mathrm{~A})$ & 0.9800 & $\mathrm{C}(10 \mathrm{~B})-\mathrm{H}(10 \mathrm{D})$ & 0.9900 \\
\hline $\mathrm{C}(35)-\mathrm{H}(35 \mathrm{~B})$ & 0.9800 & $\mathrm{C}(11 \mathrm{~B})-\mathrm{C}(12 \mathrm{~B})$ & $1.521(15)$ \\
\hline $\mathrm{C}(35)-\mathrm{H}(35 \mathrm{C})$ & 0.9800 & $\mathrm{C}(11 \mathrm{~B})-\mathrm{H}(11 \mathrm{~B})$ & 1.0000 \\
\hline $\mathrm{C}(36)-\mathrm{H}(36 \mathrm{~A})$ & 0.9800 & $\mathrm{C}(12 \mathrm{~B})-\mathrm{C}(13 \mathrm{~B})$ & $1.499(13)$ \\
\hline $\mathrm{C}(36)-\mathrm{H}(36 \mathrm{~B})$ & 0.9800 & $\mathrm{C}(12 \mathrm{~B})-\mathrm{H}(12 \mathrm{C})$ & 0.9900 \\
\hline $\mathrm{C}(36)-\mathrm{H}(36 \mathrm{C})$ & 0.9800 & $\mathrm{C}(12 \mathrm{~B})-\mathrm{H}(12 \mathrm{D})$ & 0.9900 \\
\hline $\mathrm{C}(37)-\mathrm{H}(37 \mathrm{~A})$ & 0.9800 & $\mathrm{C}(13 \mathrm{~B})-\mathrm{C}(14 \mathrm{~B})$ & $1.358(13)$ \\
\hline $\mathrm{C}(37)-\mathrm{H}(37 \mathrm{~B})$ & 0.9800 & $\mathrm{C}(13 \mathrm{~B})-\mathrm{C}(16 \mathrm{~B})$ & $1.445(14)$ \\
\hline $\mathrm{C}(37)-\mathrm{H}(37 \mathrm{C})$ & 0.9800 & $C(14 B)-C(26 B)$ & $1.453(16)$ \\
\hline $\mathrm{C}(1 \mathrm{~B})-\mathrm{O}(2 \mathrm{~B})$ & $1.443(13)$ & $C(14 B)-S(5 B)$ & $1.722(10)$ \\
\hline $\mathrm{C}(1 \mathrm{~B})-\mathrm{O}(1 \mathrm{~B})$ & $1.456(14)$ & $\mathrm{C}(15 \mathrm{~B})-\mathrm{C}(16 \mathrm{~B})$ & $1.381(13)$ \\
\hline$C(1 B)-C(4 B)$ & $1.497(15)$ & $\mathrm{C}(15 \mathrm{~B})-\mathrm{C}(30 \mathrm{~B})$ & $1.469(14)$ \\
\hline$C(1 B)-C(11 B)$ & $1.534(16)$ & $C(15 B)-S(5 B)$ & $1.727(10)$ \\
\hline $\mathrm{C}(2 \mathrm{~B})-\mathrm{O}(1 \mathrm{~B})$ & $1.39(2)$ & $\mathrm{C}(16 \mathrm{~B})-\mathrm{C}(17 \mathrm{~B})$ & $1.493(14)$ \\
\hline $\mathrm{C}(2 \mathrm{~B})-\mathrm{C}(3 \mathrm{~B})$ & $1.47(2)$ & $\mathrm{C}(17 \mathrm{~B})-\mathrm{H}(17 \mathrm{C})$ & 0.9900 \\
\hline $\mathrm{C}(2 \mathrm{~B})-\mathrm{H}(2 \mathrm{~B} 1)$ & 0.9900 & $\mathrm{C}(17 \mathrm{~B})-\mathrm{H}(17 \mathrm{D})$ & 0.9900 \\
\hline $\mathrm{C}(2 \mathrm{~B})-\mathrm{H}(2 \mathrm{~B} 2)$ & 0.9900 & $\mathrm{C}(18 \mathrm{~B})-\mathrm{C}(19 \mathrm{~B})$ & $1.366(16)$ \\
\hline $\mathrm{C}(3 \mathrm{~B})-\mathrm{O}(2 \mathrm{~B})$ & $1.401(15)$ & $\mathrm{C}(18 \mathrm{~B})-\mathrm{S}(3 \mathrm{~B})$ & $1.721(12)$ \\
\hline $\mathrm{C}(3 \mathrm{~B})-\mathrm{H}(3 \mathrm{~B} 1)$ & 0.9900 & $\mathrm{C}(19 \mathrm{~B})-\mathrm{C}(20 \mathrm{~B})$ & $1.448(19)$ \\
\hline $\mathrm{C}(3 \mathrm{~B})-\mathrm{H}(3 \mathrm{~B} 2)$ & 0.9900 & $\mathrm{C}(19 \mathrm{~B})-\mathrm{H}(19 \mathrm{~B})$ & 0.9500 \\
\hline $\mathrm{C}(4 \mathrm{~B})-\mathrm{C}(17 \mathrm{~B})$ & $1.551(15)$ & $\mathrm{C}(20 \mathrm{~B})-\mathrm{C}(21 \mathrm{~B})$ & $1.321(19)$ \\
\hline$C(4 B)-C(5 B)$ & $1.581(16)$ & $\mathrm{C}(20 \mathrm{~B})-\mathrm{H}(20 \mathrm{~B})$ & 0.9500 \\
\hline $\mathrm{C}(4 \mathrm{~B})-\mathrm{H}(4 \mathrm{~B})$ & 1.0000 & $\mathrm{C}(21 \mathrm{~B})-\mathrm{C}(36 \mathrm{~B})$ & $1.50(2)$ \\
\hline $\mathrm{C}(5 \mathrm{~B})-\mathrm{C}(6 \mathrm{~B})$ & $1.484(15)$ & $\mathrm{C}(21 \mathrm{~B})-\mathrm{S}(3 \mathrm{~B})$ & $1.708(15)$ \\
\hline $\mathrm{C}(5 \mathrm{~B})-\mathrm{H}(5 \mathrm{~B} 1)$ & 0.9900 & $\mathrm{C}(22 \mathrm{~B})-\mathrm{C}(23 \mathrm{~B})$ & $1.372(14)$ \\
\hline $\mathrm{C}(5 \mathrm{~B})-\mathrm{H}(5 \mathrm{~B} 2)$ & 0.9900 & $\mathrm{C}(22 \mathrm{~B})-\mathrm{S}(2 \mathrm{~B})$ & $1.721(10)$ \\
\hline
\end{tabular}




\begin{tabular}{|c|c|c|c|}
\hline $\mathrm{C}(23 \mathrm{~B})-\mathrm{C}(24 \mathrm{~B})$ & $1.413(16)$ & $S(6 X)-C(29 X)$ & $1.68(4)$ \\
\hline $\mathrm{C}(23 \mathrm{~B})-\mathrm{H}(23 \mathrm{~B})$ & 0.9500 & $\mathrm{C}(27 \mathrm{X})-\mathrm{C}(28 \mathrm{X})$ & $1.17(12)$ \\
\hline $\mathrm{C}(24 \mathrm{~B})-\mathrm{C}(25 \mathrm{~B})$ & $1.338(15)$ & $\mathrm{C}(27 \mathrm{X})-\mathrm{H}(27 \mathrm{X})$ & 0.9500 \\
\hline $\mathrm{C}(24 \mathrm{~B})-\mathrm{H}(24 \mathrm{~B})$ & 0.9500 & $C(28 X)-C(29 X)$ & $1.37(4)$ \\
\hline$C(25 B)-C(37 B)$ & $1.509(16)$ & $\mathrm{C}(28 \mathrm{X})-\mathrm{H}(28 \mathrm{X})$ & 0.9500 \\
\hline $\mathrm{C}(25 \mathrm{~B})-\mathrm{S}(2 \mathrm{~B})$ & $1.731(11)$ & $C(29 X)-C(35 X)$ & $1.57(4)$ \\
\hline$C(26 B)-C(27 B)$ & $1.49(7)$ & $\mathrm{C}(35 \mathrm{X})-\mathrm{H}(35 \mathrm{D})$ & 1.4458 \\
\hline$C(26 B)-S(6 B)$ & $1.56(3)$ & $\mathrm{C}(35 \mathrm{X})-\mathrm{H}(35 \mathrm{G})$ & 0.9800 \\
\hline$C(26 B)-S(6 X)$ & $1.585(15)$ & $\mathrm{C}(35 \mathrm{X})-\mathrm{H}(35 \mathrm{H})$ & 0.9800 \\
\hline$C(26 B)-C(27 X)$ & $1.63(10)$ & $\mathrm{C}(35 \mathrm{X})-\mathrm{H}(35 \mathrm{I})$ & 0.9800 \\
\hline$C(30 B)-C(31 B)$ & $1.404(13)$ & & \\
\hline$C(30 B)-S(4 B)$ & $1.682(11)$ & $\mathrm{O}(1)-\mathrm{C}(1)-\mathrm{O}(2)$ & $105.5(7)$ \\
\hline $\mathrm{C}(31 \mathrm{~B})-\mathrm{C}(32 \mathrm{~B})$ & $1.332(16)$ & $\mathrm{O}(1)-\mathrm{C}(1)-\mathrm{C}(11)$ & $108.8(7)$ \\
\hline $\mathrm{C}(31 \mathrm{~B})-\mathrm{H}(31 \mathrm{~B})$ & 0.9500 & $\mathrm{O}(2)-\mathrm{C}(1)-\mathrm{C}(11)$ & $109.9(8)$ \\
\hline $\mathrm{C}(32 \mathrm{~B})-\mathrm{C}(33 \mathrm{~B})$ & $1.297(19)$ & $\mathrm{O}(1)-\mathrm{C}(1)-\mathrm{C}(4)$ & $108.3(7)$ \\
\hline $\mathrm{C}(32 \mathrm{~B})-\mathrm{H}(32 \mathrm{~B})$ & 0.9500 & $\mathrm{O}(2)-\mathrm{C}(1)-\mathrm{C}(4)$ & $106.5(7)$ \\
\hline $\mathrm{C}(33 \mathrm{~B})-\mathrm{C}(34 \mathrm{~B})$ & $1.51(2)$ & $C(11)-C(1)-C(4)$ & $117.3(8)$ \\
\hline$C(33 B)-S(4 B)$ & $1.713(15)$ & $\mathrm{O}(1)-\mathrm{C}(2)-\mathrm{C}(3)$ & $108.5(11)$ \\
\hline $\mathrm{C}(34 \mathrm{~B})-\mathrm{H}(34 \mathrm{D})$ & 0.9800 & $\mathrm{O}(1)-\mathrm{C}(2)-\mathrm{H}(2 \mathrm{~A})$ & 110.0 \\
\hline $\mathrm{C}(34 \mathrm{~B})-\mathrm{H}(34 \mathrm{E})$ & 0.9800 & $\mathrm{C}(3)-\mathrm{C}(2)-\mathrm{H}(2 \mathrm{~A})$ & 110.0 \\
\hline $\mathrm{C}(34 \mathrm{~B})-\mathrm{H}(34 \mathrm{~F})$ & 0.9800 & $\mathrm{O}(1)-\mathrm{C}(2)-\mathrm{H}(2 \mathrm{~B})$ & 110.0 \\
\hline $\mathrm{C}(36 \mathrm{~B})-\mathrm{H}(36 \mathrm{D})$ & 0.9800 & $\mathrm{C}(3)-\mathrm{C}(2)-\mathrm{H}(2 \mathrm{~B})$ & 110.0 \\
\hline $\mathrm{C}(36 \mathrm{~B})-\mathrm{H}(36 \mathrm{E})$ & 0.9800 & $\mathrm{H}(2 \mathrm{~A})-\mathrm{C}(2)-\mathrm{H}(2 \mathrm{~B})$ & 108.4 \\
\hline $\mathrm{C}(36 \mathrm{~B})-\mathrm{H}(36 \mathrm{~F})$ & 0.9800 & $\mathrm{O}(2)-\mathrm{C}(3)-\mathrm{C}(2)$ & $103.6(11)$ \\
\hline $\mathrm{C}(37 \mathrm{~B})-\mathrm{H}(37 \mathrm{D})$ & 0.9800 & $\mathrm{O}(2)-\mathrm{C}(3)-\mathrm{H}(3 \mathrm{~A})$ & 111.0 \\
\hline $\mathrm{C}(37 \mathrm{~B})-\mathrm{H}(37 \mathrm{E})$ & 0.9800 & $\mathrm{C}(2)-\mathrm{C}(3)-\mathrm{H}(3 \mathrm{~A})$ & 111.0 \\
\hline $\mathrm{C}(37 \mathrm{~B})-\mathrm{H}(37 \mathrm{~F})$ & 0.9800 & $\mathrm{O}(2)-\mathrm{C}(3)-\mathrm{H}(3 \mathrm{~B})$ & 111.0 \\
\hline$S(6 B)-C(29 B)$ & $1.83(5)$ & $\mathrm{C}(2)-\mathrm{C}(3)-\mathrm{H}(3 \mathrm{~B})$ & 111.0 \\
\hline $\mathrm{C}(27 \mathrm{~B})-\mathrm{C}(28 \mathrm{~B})$ & $1.42(7)$ & $\mathrm{H}(3 \mathrm{~A})-\mathrm{C}(3)-\mathrm{H}(3 \mathrm{~B})$ & 109.0 \\
\hline $\mathrm{C}(27 \mathrm{~B})-\mathrm{H}(27 \mathrm{~B})$ & 0.9500 & $\mathrm{C}(5)-\mathrm{C}(4)-\mathrm{C}(1)$ & $113.4(8)$ \\
\hline $\mathrm{C}(28 \mathrm{~B})-\mathrm{C}(29 \mathrm{~B})$ & $1.39(4)$ & $\mathrm{C}(5)-\mathrm{C}(4)-\mathrm{C}(17)$ & $114.5(8)$ \\
\hline $\mathrm{C}(28 \mathrm{~B})-\mathrm{H}(28 \mathrm{~B})$ & 0.9500 & $\mathrm{C}(1)-\mathrm{C}(4)-\mathrm{C}(17)$ & $113.4(7)$ \\
\hline$C(29 B)-C(35 B)$ & $1.49(4)$ & $\mathrm{C}(5)-\mathrm{C}(4)-\mathrm{H}(4)$ & 104.7 \\
\hline $\mathrm{C}(35 \mathrm{~B})-\mathrm{H}(35 \mathrm{D})$ & 0.9800 & $\mathrm{C}(1)-\mathrm{C}(4)-\mathrm{H}(4)$ & 104.7 \\
\hline $\mathrm{C}(35 \mathrm{~B})-\mathrm{H}(35 \mathrm{E})$ & 0.9800 & $\mathrm{C}(17)-\mathrm{C}(4)-\mathrm{H}(4)$ & 104.7 \\
\hline $\mathrm{C}(35 \mathrm{~B})-\mathrm{H}(35 \mathrm{~F})$ & 0.9800 & $C(6)-C(5)-C(4)$ & $116.5(8)$ \\
\hline
\end{tabular}




\begin{tabular}{|c|c|c|c|}
\hline $\mathrm{C}(6)-\mathrm{C}(5)-\mathrm{H}(5 \mathrm{~A})$ & 108.2 & $\mathrm{C}(14)-\mathrm{C}(13)-\mathrm{C}(12)$ & $125.3(9)$ \\
\hline $\mathrm{C}(4)-\mathrm{C}(5)-\mathrm{H}(5 \mathrm{~A})$ & 108.2 & $C(16)-C(13)-C(12)$ & $120.2(8)$ \\
\hline $\mathrm{C}(6)-\mathrm{C}(5)-\mathrm{H}(5 \mathrm{~B})$ & 108.2 & $C(13)-C(14)-C(26)$ & $130.5(10)$ \\
\hline $\mathrm{C}(4)-\mathrm{C}(5)-\mathrm{H}(5 \mathrm{~B})$ & 108.2 & $C(13)-C(14)-S(5)$ & $110.6(8)$ \\
\hline $\mathrm{H}(5 \mathrm{~A})-\mathrm{C}(5)-\mathrm{H}(5 \mathrm{~B})$ & 107.3 & $C(26)-C(14)-S(5)$ & $118.5(8)$ \\
\hline $\mathrm{C}(7)-\mathrm{C}(6)-\mathrm{C}(9)$ & 112.3(9) & $C(16)-C(15)-C(30)$ & $131.5(10)$ \\
\hline$C(7)-C(6)-C(5)$ & $122.9(9)$ & $C(16)-C(15)-S(5)$ & $112.1(8)$ \\
\hline$C(9)-C(6)-C(5)$ & $124.5(9)$ & $C(30)-C(15)-S(5)$ & $116.4(8)$ \\
\hline$C(6)-C(7)-C(22)$ & 131.5(9) & $\mathrm{C}(15)-\mathrm{C}(16)-\mathrm{C}(13)$ & $110.9(9)$ \\
\hline$C(6)-C(7)-S(2)$ & 111.1(7) & $C(15)-C(16)-C(17)$ & $125.4(9)$ \\
\hline$C(22)-C(7)-S(2)$ & 117.3(7) & $\mathrm{C}(13)-\mathrm{C}(16)-\mathrm{C}(17)$ & $123.7(9)$ \\
\hline $\mathrm{C}(9)-\mathrm{C}(8)-\mathrm{C}(18)$ & $132.3(9)$ & $\mathrm{C}(16)-\mathrm{C}(17)-\mathrm{C}(4)$ & 119.2(8) \\
\hline $\mathrm{C}(9)-\mathrm{C}(8)-\mathrm{S}(2)$ & $110.4(7)$ & $\mathrm{C}(16)-\mathrm{C}(17)-\mathrm{H}(17 \mathrm{~A})$ & 107.5 \\
\hline $\mathrm{C}(18)-\mathrm{C}(8)-\mathrm{S}(2)$ & 117.3(7) & $\mathrm{C}(4)-\mathrm{C}(17)-\mathrm{H}(17 \mathrm{~A})$ & 107.5 \\
\hline $\mathrm{C}(8)-\mathrm{C}(9)-\mathrm{C}(6)$ & $114.0(8)$ & $\mathrm{C}(16)-\mathrm{C}(17)-\mathrm{H}(17 \mathrm{~B})$ & 107.5 \\
\hline$C(8)-C(9)-C(10)$ & 121.7(9) & $\mathrm{C}(4)-\mathrm{C}(17)-\mathrm{H}(17 \mathrm{~B})$ & 107.5 \\
\hline C(6)-C(9)-C(10) & $124.2(8)$ & $\mathrm{H}(17 \mathrm{~A})-\mathrm{C}(17)-\mathrm{H}(17 \mathrm{~B})$ & 107.0 \\
\hline$C(9)-C(10)-C(11)$ & $120.1(8)$ & $C(19)-C(18)-C(8)$ & $129.5(9)$ \\
\hline $\mathrm{C}(9)-\mathrm{C}(10)-\mathrm{H}(10 \mathrm{~A})$ & 107.3 & $\mathrm{C}(19)-\mathrm{C}(18)-\mathrm{S}(1)$ & $109.1(8)$ \\
\hline $\mathrm{C}(11)-\mathrm{C}(10)-\mathrm{H}(10 \mathrm{~A})$ & 107.3 & $\mathrm{C}(8)-\mathrm{C}(18)-\mathrm{S}(1)$ & $121.4(7)$ \\
\hline $\mathrm{C}(9)-\mathrm{C}(10)-\mathrm{H}(10 \mathrm{~B})$ & 107.3 & $\mathrm{C}(20)-\mathrm{C}(19)-\mathrm{C}(18)$ & $112.7(10)$ \\
\hline $\mathrm{C}(11)-\mathrm{C}(10)-\mathrm{H}(10 \mathrm{~B})$ & 107.3 & $\mathrm{C}(20)-\mathrm{C}(19)-\mathrm{H}(19)$ & 123.7 \\
\hline $\mathrm{H}(10 \mathrm{~A})-\mathrm{C}(10)-\mathrm{H}(10 \mathrm{~B})$ & 106.9 & C(18)-C(19)-H(19) & 123.7 \\
\hline $\mathrm{C}(1)-\mathrm{C}(11)-\mathrm{C}(12)$ & 113.3(8) & $\mathrm{C}(21)-\mathrm{C}(20)-\mathrm{C}(19)$ & $114.9(10)$ \\
\hline$C(1)-C(11)-C(10)$ & $115.3(7)$ & $\mathrm{C}(21)-\mathrm{C}(20)-\mathrm{H}(20)$ & 122.6 \\
\hline $\mathrm{C}(12)-\mathrm{C}(11)-\mathrm{C}(10)$ & $113.5(8)$ & $\mathrm{C}(19)-\mathrm{C}(20)-\mathrm{H}(20)$ & 122.6 \\
\hline $\mathrm{C}(1)-\mathrm{C}(11)-\mathrm{H}(11)$ & 104.4 & $\mathrm{C}(20)-\mathrm{C}(21)-\mathrm{C}(37)$ & $128.9(11)$ \\
\hline $\mathrm{C}(12)-\mathrm{C}(11)-\mathrm{H}(11)$ & 104.4 & $C(20)-C(21)-S(1)$ & $110.1(9)$ \\
\hline $\mathrm{C}(10)-\mathrm{C}(11)-\mathrm{H}(11)$ & 104.4 & $\mathrm{C}(37)-\mathrm{C}(21)-\mathrm{S}(1)$ & $120.9(9)$ \\
\hline$C(13)-C(12)-C(11)$ & $116.7(8)$ & $C(23)-C(22)-C(7)$ & 129.7(9) \\
\hline $\mathrm{C}(13)-\mathrm{C}(12)-\mathrm{H}(12 \mathrm{~A})$ & 108.1 & $C(23)-C(22)-S(3)$ & $111.0(8)$ \\
\hline $\mathrm{C}(11)-\mathrm{C}(12)-\mathrm{H}(12 \mathrm{~A})$ & 108.1 & $C(7)-C(22)-S(3)$ & 119.1(7) \\
\hline $\mathrm{C}(13)-\mathrm{C}(12)-\mathrm{H}(12 \mathrm{~B})$ & 108.1 & $\mathrm{C}(22)-\mathrm{C}(23)-\mathrm{C}(24)$ & 111.1(10) \\
\hline $\mathrm{C}(11)-\mathrm{C}(12)-\mathrm{H}(12 \mathrm{~B})$ & 108.1 & $\mathrm{C}(22)-\mathrm{C}(23)-\mathrm{H}(23)$ & 124.4 \\
\hline $\mathrm{H}(12 \mathrm{~A})-\mathrm{C}(12)-\mathrm{H}(12 \mathrm{~B})$ & 107.3 & $\mathrm{C}(24)-\mathrm{C}(23)-\mathrm{H}(23)$ & 124.4 \\
\hline$C(14)-C(13)-C(16)$ & $114.5(9)$ & $\mathrm{C}(25)-\mathrm{C}(24)-\mathrm{C}(23)$ & $114.7(11)$ \\
\hline
\end{tabular}




\begin{tabular}{|c|c|c|c|}
\hline $\mathrm{C}(25)-\mathrm{C}(24)-\mathrm{H}(24)$ & 122.7 & $\mathrm{C}(29)-\mathrm{C}(35)-\mathrm{H}(35 \mathrm{~B})$ & 109.5 \\
\hline $\mathrm{C}(23)-\mathrm{C}(24)-\mathrm{H}(24)$ & 122.7 & $\mathrm{H}(35 \mathrm{~A})-\mathrm{C}(35)-\mathrm{H}(35 \mathrm{~B})$ & 109.5 \\
\hline$C(24)-C(25)-C(36)$ & $129.1(11)$ & $\mathrm{C}(29)-\mathrm{C}(35)-\mathrm{H}(35 \mathrm{C})$ & 109.5 \\
\hline $\mathrm{C}(24)-\mathrm{C}(25)-\mathrm{S}(3)$ & $110.6(8)$ & $\mathrm{H}(35 \mathrm{~A})-\mathrm{C}(35)-\mathrm{H}(35 \mathrm{C})$ & 109.5 \\
\hline$C(36)-C(25)-S(3)$ & $120.2(9)$ & $\mathrm{H}(35 \mathrm{~B})-\mathrm{C}(35)-\mathrm{H}(35 \mathrm{C})$ & 109.5 \\
\hline$C(27)-C(26)-C(14)$ & $131.7(10)$ & $\mathrm{C}(25)-\mathrm{C}(36)-\mathrm{H}(36 \mathrm{~A})$ & 109.5 \\
\hline $\mathrm{C}(27)-\mathrm{C}(26)-\mathrm{S}(4)$ & $109.3(8)$ & $\mathrm{C}(25)-\mathrm{C}(36)-\mathrm{H}(36 \mathrm{~B})$ & 109.5 \\
\hline$C(14)-C(26)-S(4)$ & $119.0(8)$ & $\mathrm{H}(36 \mathrm{~A})-\mathrm{C}(36)-\mathrm{H}(36 \mathrm{~B})$ & 109.5 \\
\hline$C(26)-C(27)-C(28)$ & $113.0(10)$ & $\mathrm{C}(25)-\mathrm{C}(36)-\mathrm{H}(36 \mathrm{C})$ & 109.5 \\
\hline $\mathrm{C}(26)-\mathrm{C}(27)-\mathrm{H}(27)$ & 123.5 & $\mathrm{H}(36 \mathrm{~A})-\mathrm{C}(36)-\mathrm{H}(36 \mathrm{C})$ & 109.5 \\
\hline $\mathrm{C}(28)-\mathrm{C}(27)-\mathrm{H}(27)$ & 123.5 & $\mathrm{H}(36 \mathrm{~B})-\mathrm{C}(36)-\mathrm{H}(36 \mathrm{C})$ & 109.5 \\
\hline $\mathrm{C}(29)-\mathrm{C}(28)-\mathrm{C}(27)$ & $113.4(11)$ & $\mathrm{C}(21)-\mathrm{C}(37)-\mathrm{H}(37 \mathrm{~A})$ & 109.5 \\
\hline $\mathrm{C}(29)-\mathrm{C}(28)-\mathrm{H}(28)$ & 123.3 & $\mathrm{C}(21)-\mathrm{C}(37)-\mathrm{H}(37 \mathrm{~B})$ & 109.5 \\
\hline $\mathrm{C}(27)-\mathrm{C}(28)-\mathrm{H}(28)$ & 123.3 & $\mathrm{H}(37 \mathrm{~A})-\mathrm{C}(37)-\mathrm{H}(37 \mathrm{~B})$ & 109.5 \\
\hline $\mathrm{C}(28)-\mathrm{C}(29)-\mathrm{C}(35)$ & $128.0(11)$ & $\mathrm{C}(21)-\mathrm{C}(37)-\mathrm{H}(37 \mathrm{C})$ & 109.5 \\
\hline $\mathrm{C}(28)-\mathrm{C}(29)-\mathrm{S}(4)$ & 111.3(9) & $\mathrm{H}(37 \mathrm{~A})-\mathrm{C}(37)-\mathrm{H}(37 \mathrm{C})$ & 109.5 \\
\hline$C(35)-C(29)-S(4)$ & $120.6(8)$ & $\mathrm{H}(37 \mathrm{~B})-\mathrm{C}(37)-\mathrm{H}(37 \mathrm{C})$ & 109.5 \\
\hline$C(31)-C(30)-C(15)$ & $125.7(10)$ & $\mathrm{C}(2)-\mathrm{O}(1)-\mathrm{C}(1)$ & $108.5(8)$ \\
\hline$C(31)-C(30)-S(6)$ & $111.0(8)$ & $\mathrm{C}(3)-\mathrm{O}(2)-\mathrm{C}(1)$ & $107.7(7)$ \\
\hline$C(15)-C(30)-S(6)$ & $123.2(8)$ & $\mathrm{C}(18)-\mathrm{S}(1)-\mathrm{C}(21)$ & $93.2(5)$ \\
\hline$C(30)-C(31)-C(32)$ & $111.0(11)$ & $\mathrm{C}(7)-\mathrm{S}(2)-\mathrm{C}(8)$ & $92.2(5)$ \\
\hline $\mathrm{C}(30)-\mathrm{C}(31)-\mathrm{H}(31)$ & 124.5 & $\mathrm{C}(22)-\mathrm{S}(3)-\mathrm{C}(25)$ & $92.5(5)$ \\
\hline $\mathrm{C}(32)-\mathrm{C}(31)-\mathrm{H}(31)$ & 124.5 & $\mathrm{C}(29)-\mathrm{S}(4)-\mathrm{C}(26)$ & $93.0(5)$ \\
\hline $\mathrm{C}(33)-\mathrm{C}(32)-\mathrm{C}(31)$ & $115.1(12)$ & $C(15)-S(5)-C(14)$ & $91.9(5)$ \\
\hline $\mathrm{C}(33)-\mathrm{C}(32)-\mathrm{H}(32)$ & 122.4 & $\mathrm{C}(30)-\mathrm{S}(6)-\mathrm{C}(33)$ & $92.6(5)$ \\
\hline $\mathrm{C}(31)-\mathrm{C}(32)-\mathrm{H}(32)$ & 122.4 & $\mathrm{O}(2 \mathrm{~B})-\mathrm{C}(1 \mathrm{~B})-\mathrm{O}(1 \mathrm{~B})$ & $106.4(8)$ \\
\hline $\mathrm{C}(32)-\mathrm{C}(33)-\mathrm{C}(34)$ & $129.8(12)$ & $\mathrm{O}(2 \mathrm{~B})-\mathrm{C}(1 \mathrm{~B})-\mathrm{C}(4 \mathrm{~B})$ & $106.9(9)$ \\
\hline$C(32)-C(33)-S(6)$ & $110.2(10)$ & $\mathrm{O}(1 \mathrm{~B})-\mathrm{C}(1 \mathrm{~B})-\mathrm{C}(4 \mathrm{~B})$ & $109.0(9)$ \\
\hline $\mathrm{C}(34)-\mathrm{C}(33)-\mathrm{S}(6)$ & $120.0(10)$ & $\mathrm{O}(2 \mathrm{~B})-\mathrm{C}(1 \mathrm{~B})-\mathrm{C}(11 \mathrm{~B})$ & 109.1(9) \\
\hline $\mathrm{C}(33)-\mathrm{C}(34)-\mathrm{H}(34 \mathrm{~A})$ & 109.4 & $\mathrm{O}(1 \mathrm{~B})-\mathrm{C}(1 \mathrm{~B})-\mathrm{C}(11 \mathrm{~B})$ & $106.4(9)$ \\
\hline $\mathrm{C}(33)-\mathrm{C}(34)-\mathrm{H}(34 \mathrm{~B})$ & 109.5 & $\mathrm{C}(4 \mathrm{~B})-\mathrm{C}(1 \mathrm{~B})-\mathrm{C}(11 \mathrm{~B})$ & 118.4(9) \\
\hline $\mathrm{H}(34 \mathrm{~A})-\mathrm{C}(34)-\mathrm{H}(34 \mathrm{~B})$ & 109.5 & $\mathrm{O}(1 \mathrm{~B})-\mathrm{C}(2 \mathrm{~B})-\mathrm{C}(3 \mathrm{~B})$ & $107.3(15)$ \\
\hline $\mathrm{C}(33)-\mathrm{C}(34)-\mathrm{H}(34 \mathrm{C})$ & 109.5 & $\mathrm{O}(1 \mathrm{~B})-\mathrm{C}(2 \mathrm{~B})-\mathrm{H}(2 \mathrm{~B} 1)$ & 110.3 \\
\hline $\mathrm{H}(34 \mathrm{~A})-\mathrm{C}(34)-\mathrm{H}(34 \mathrm{C})$ & 109.5 & $\mathrm{C}(3 \mathrm{~B})-\mathrm{C}(2 \mathrm{~B})-\mathrm{H}(2 \mathrm{~B} 1)$ & 110.3 \\
\hline $\mathrm{H}(34 \mathrm{~B})-\mathrm{C}(34)-\mathrm{H}(34 \mathrm{C})$ & 109.5 & $\mathrm{O}(1 \mathrm{~B})-\mathrm{C}(2 \mathrm{~B})-\mathrm{H}(2 \mathrm{~B} 2)$ & 110.3 \\
\hline $\mathrm{C}(29)-\mathrm{C}(35)-\mathrm{H}(35 \mathrm{~A})$ & 109.5 & $\mathrm{C}(3 \mathrm{~B})-\mathrm{C}(2 \mathrm{~B})-\mathrm{H}(2 \mathrm{~B} 2)$ & 110.3 \\
\hline
\end{tabular}




\begin{tabular}{|c|c|c|c|}
\hline $\mathrm{H}(2 \mathrm{~B} 1)-\mathrm{C}(2 \mathrm{~B})-\mathrm{H}(2 \mathrm{~B} 2)$ & 108.5 & $\mathrm{H}(10 \mathrm{C})-\mathrm{C}(10 \mathrm{~B})-\mathrm{H}(10 \mathrm{D})$ & 107.4 \\
\hline $\mathrm{O}(2 \mathrm{~B})-\mathrm{C}(3 \mathrm{~B})-\mathrm{C}(2 \mathrm{~B})$ & $102.5(13)$ & $C(12 B)-C(11 B)-C(1 B)$ & $113.4(9)$ \\
\hline $\mathrm{O}(2 \mathrm{~B})-\mathrm{C}(3 \mathrm{~B})-\mathrm{H}(3 \mathrm{~B} 1)$ & 111.3 & $\mathrm{C}(12 \mathrm{~B})-\mathrm{C}(11 \mathrm{~B})-\mathrm{C}(10 \mathrm{~B})$ & $115.0(9)$ \\
\hline $\mathrm{C}(2 \mathrm{~B})-\mathrm{C}(3 \mathrm{~B})-\mathrm{H}(3 \mathrm{~B} 1)$ & 111.3 & $\mathrm{C}(1 \mathrm{~B})-\mathrm{C}(11 \mathrm{~B})-\mathrm{C}(10 \mathrm{~B})$ & $112.3(9)$ \\
\hline $\mathrm{O}(2 \mathrm{~B})-\mathrm{C}(3 \mathrm{~B})-\mathrm{H}(3 \mathrm{~B} 2)$ & 111.3 & $\mathrm{C}(12 \mathrm{~B})-\mathrm{C}(11 \mathrm{~B})-\mathrm{H}(11 \mathrm{~B})$ & 105.0 \\
\hline $\mathrm{C}(2 \mathrm{~B})-\mathrm{C}(3 \mathrm{~B})-\mathrm{H}(3 \mathrm{~B} 2)$ & 111.3 & $\mathrm{C}(1 \mathrm{~B})-\mathrm{C}(11 \mathrm{~B})-\mathrm{H}(11 \mathrm{~B})$ & 105.0 \\
\hline $\mathrm{H}(3 \mathrm{~B} 1)-\mathrm{C}(3 \mathrm{~B})-\mathrm{H}(3 \mathrm{~B} 2)$ & 109.2 & $\mathrm{C}(10 \mathrm{~B})-\mathrm{C}(11 \mathrm{~B})-\mathrm{H}(11 \mathrm{~B})$ & 105.0 \\
\hline$C(1 B)-C(4 B)-C(17 B)$ & 114.1(10) & $\mathrm{C}(13 \mathrm{~B})-\mathrm{C}(12 \mathrm{~B})-\mathrm{C}(11 \mathrm{~B})$ & $120.0(9)$ \\
\hline$C(1 B)-C(4 B)-C(5 B)$ & $112.9(10)$ & $\mathrm{C}(13 \mathrm{~B})-\mathrm{C}(12 \mathrm{~B})-\mathrm{H}(12 \mathrm{C})$ & 107.3 \\
\hline$C(17 B)-C(4 B)-C(5 B)$ & $114.5(9)$ & $\mathrm{C}(11 \mathrm{~B})-\mathrm{C}(12 \mathrm{~B})-\mathrm{H}(12 \mathrm{C})$ & 107.3 \\
\hline $\mathrm{C}(1 \mathrm{~B})-\mathrm{C}(4 \mathrm{~B})-\mathrm{H}(4 \mathrm{~B})$ & 104.6 & $\mathrm{C}(13 \mathrm{~B})-\mathrm{C}(12 \mathrm{~B})-\mathrm{H}(12 \mathrm{D})$ & 107.3 \\
\hline $\mathrm{C}(17 \mathrm{~B})-\mathrm{C}(4 \mathrm{~B})-\mathrm{H}(4 \mathrm{~B})$ & 104.6 & $\mathrm{C}(11 \mathrm{~B})-\mathrm{C}(12 \mathrm{~B})-\mathrm{H}(12 \mathrm{D})$ & 107.3 \\
\hline $\mathrm{C}(5 \mathrm{~B})-\mathrm{C}(4 \mathrm{~B})-\mathrm{H}(4 \mathrm{~B})$ & 104.6 & $\mathrm{H}(12 \mathrm{C})-\mathrm{C}(12 \mathrm{~B})-\mathrm{H}(12 \mathrm{D})$ & 106.9 \\
\hline$C(6 B)-C(5 B)-C(4 B)$ & $113.1(10)$ & $C(14 B)-C(13 B)-C(16 B)$ & $112.4(9)$ \\
\hline $\mathrm{C}(6 \mathrm{~B})-\mathrm{C}(5 \mathrm{~B})-\mathrm{H}(5 \mathrm{~B} 1)$ & 109.0 & $\mathrm{C}(14 \mathrm{~B})-\mathrm{C}(13 \mathrm{~B})-\mathrm{C}(12 \mathrm{~B})$ & $123.9(10)$ \\
\hline $\mathrm{C}(4 \mathrm{~B})-\mathrm{C}(5 \mathrm{~B})-\mathrm{H}(5 \mathrm{~B} 1)$ & 109.0 & $\mathrm{C}(16 \mathrm{~B})-\mathrm{C}(13 \mathrm{~B})-\mathrm{C}(12 \mathrm{~B})$ & $123.7(9)$ \\
\hline $\mathrm{C}(6 \mathrm{~B})-\mathrm{C}(5 \mathrm{~B})-\mathrm{H}(5 \mathrm{~B} 2)$ & 109.0 & $C(13 B)-C(14 B)-C(26 B)$ & $129.6(10)$ \\
\hline $\mathrm{C}(4 \mathrm{~B})-\mathrm{C}(5 \mathrm{~B})-\mathrm{H}(5 \mathrm{~B} 2)$ & 109.0 & $C(13 B)-C(14 B)-S(5 B)$ & $112.4(8)$ \\
\hline $\mathrm{H}(5 \mathrm{~B} 1)-\mathrm{C}(5 \mathrm{~B})-\mathrm{H}(5 \mathrm{~B} 2)$ & 107.8 & $C(26 B)-C(14 B)-S(5 B)$ & $118.0(8)$ \\
\hline $\mathrm{C}(7 \mathrm{~B})-\mathrm{C}(6 \mathrm{~B})-\mathrm{C}(9 \mathrm{~B})$ & $112.6(10)$ & $\mathrm{C}(16 \mathrm{~B})-\mathrm{C}(15 \mathrm{~B})-\mathrm{C}(30 \mathrm{~B})$ & 130.3(9) \\
\hline$C(7 B)-C(6 B)-C(5 B)$ & $126.2(11)$ & $C(16 B)-C(15 B)-S(5 B)$ & $111.6(8)$ \\
\hline $\mathrm{C}(9 \mathrm{~B})-\mathrm{C}(6 \mathrm{~B})-\mathrm{C}(5 \mathrm{~B})$ & $121.2(10)$ & $C(30 B)-C(15 B)-S(5 B)$ & $118.1(7)$ \\
\hline $\mathrm{C}(6 \mathrm{~B})-\mathrm{C}(7 \mathrm{~B})-\mathrm{C}(18 \mathrm{~B})$ & 131.3(10) & $\mathrm{C}(15 \mathrm{~B})-\mathrm{C}(16 \mathrm{~B})-\mathrm{C}(13 \mathrm{~B})$ & $111.9(9)$ \\
\hline$C(6 B)-C(7 B)-S(1 B)$ & $110.7(9)$ & $C(15 B)-C(16 B)-C(17 B)$ & $122.4(9)$ \\
\hline $\mathrm{C}(18 \mathrm{~B})-\mathrm{C}(7 \mathrm{~B})-\mathrm{S}(1 \mathrm{~B})$ & $118.0(8)$ & $C(13 B)-C(16 B)-C(17 B)$ & $125.5(9)$ \\
\hline $\mathrm{C}(9 \mathrm{~B})-\mathrm{C}(8 \mathrm{~B})-\mathrm{C}(22 \mathrm{~B})$ & $131.8(10)$ & $C(16 B)-C(17 B)-C(4 B)$ & $121.5(10)$ \\
\hline$C(9 B)-C(8 B)-S(1 B)$ & $110.5(8)$ & $\mathrm{C}(16 \mathrm{~B})-\mathrm{C}(17 \mathrm{~B})-\mathrm{H}(17 \mathrm{C})$ & 107.0 \\
\hline $\mathrm{C}(22 \mathrm{~B})-\mathrm{C}(8 \mathrm{~B})-\mathrm{S}(1 \mathrm{~B})$ & $117.7(7)$ & $\mathrm{C}(4 \mathrm{~B})-\mathrm{C}(17 \mathrm{~B})-\mathrm{H}(17 \mathrm{C})$ & 107.0 \\
\hline $\mathrm{C}(8 \mathrm{~B})-\mathrm{C}(9 \mathrm{~B})-\mathrm{C}(6 \mathrm{~B})$ & $113.0(9)$ & $\mathrm{C}(16 \mathrm{~B})-\mathrm{C}(17 \mathrm{~B})-\mathrm{H}(17 \mathrm{D})$ & 107.0 \\
\hline $\mathrm{C}(8 \mathrm{~B})-\mathrm{C}(9 \mathrm{~B})-\mathrm{C}(10 \mathrm{~B})$ & $126.4(10)$ & $\mathrm{C}(4 \mathrm{~B})-\mathrm{C}(17 \mathrm{~B})-\mathrm{H}(17 \mathrm{D})$ & 107.0 \\
\hline$C(6 B)-C(9 B)-C(10 B)$ & $120.6(9)$ & $\mathrm{H}(17 \mathrm{C})-\mathrm{C}(17 \mathrm{~B})-\mathrm{H}(17 \mathrm{D})$ & 106.7 \\
\hline $\mathrm{C}(9 \mathrm{~B})-\mathrm{C}(10 \mathrm{~B})-\mathrm{C}(11 \mathrm{~B})$ & 116.2(9) & $C(19 B)-C(18 B)-C(7 B)$ & $125.5(11)$ \\
\hline $\mathrm{C}(9 \mathrm{~B})-\mathrm{C}(10 \mathrm{~B})-\mathrm{H}(10 \mathrm{C})$ & 108.2 & $C(19 B)-C(18 B)-S(3 B)$ & $110.5(10)$ \\
\hline $\mathrm{C}(11 \mathrm{~B})-\mathrm{C}(10 \mathrm{~B})-\mathrm{H}(10 \mathrm{C})$ & 108.2 & $\mathrm{C}(7 \mathrm{~B})-\mathrm{C}(18 \mathrm{~B})-\mathrm{S}(3 \mathrm{~B})$ & $123.8(8)$ \\
\hline $\mathrm{C}(9 \mathrm{~B})-\mathrm{C}(10 \mathrm{~B})-\mathrm{H}(10 \mathrm{D})$ & 108.2 & $C(18 B)-C(19 B)-C(20 B)$ & $111.0(12)$ \\
\hline$C(11 B)-C(10 B)-H(10 D)$ & 108.2 & $\mathrm{C}(18 \mathrm{~B})-\mathrm{C}(19 \mathrm{~B})-\mathrm{H}(19 \mathrm{~B})$ & 124.5 \\
\hline
\end{tabular}




\begin{tabular}{|c|c|c|c|}
\hline $\mathrm{C}(20 \mathrm{~B})-\mathrm{C}(19 \mathrm{~B})-\mathrm{H}(19 \mathrm{~B})$ & 124.5 & $\mathrm{C}(33 \mathrm{~B})-\mathrm{C}(32 \mathrm{~B})-\mathrm{H}(32 \mathrm{~B})$ & 122.5 \\
\hline$C(21 B)-C(20 B)-C(19 B)$ & $114.7(14)$ & $\mathrm{C}(31 \mathrm{~B})-\mathrm{C}(32 \mathrm{~B})-\mathrm{H}(32 \mathrm{~B})$ & 122.5 \\
\hline$C(21 B)-C(20 B)-H(20 B)$ & 122.7 & $\mathrm{C}(32 \mathrm{~B})-\mathrm{C}(33 \mathrm{~B})-\mathrm{C}(34 \mathrm{~B})$ & $130.5(15)$ \\
\hline$C(19 B)-C(20 B)-H(20 B)$ & 122.7 & $\mathrm{C}(32 \mathrm{~B})-\mathrm{C}(33 \mathrm{~B})-\mathrm{S}(4 \mathrm{~B})$ & $111.1(12)$ \\
\hline $\mathrm{C}(20 \mathrm{~B})-\mathrm{C}(21 \mathrm{~B})-\mathrm{C}(36 \mathrm{~B})$ & $127.6(14)$ & $C(34 B)-C(33 B)-S(4 B)$ & $118.3(12)$ \\
\hline $\mathrm{C}(20 \mathrm{~B})-\mathrm{C}(21 \mathrm{~B})-\mathrm{S}(3 \mathrm{~B})$ & $110.7(12)$ & $\mathrm{C}(33 \mathrm{~B})-\mathrm{C}(34 \mathrm{~B})-\mathrm{H}(34 \mathrm{D})$ & 109.5 \\
\hline$C(36 B)-C(21 B)-S(3 B)$ & $121.6(11)$ & $\mathrm{C}(33 \mathrm{~B})-\mathrm{C}(34 \mathrm{~B})-\mathrm{H}(34 \mathrm{E})$ & 109.5 \\
\hline $\mathrm{C}(23 \mathrm{~B})-\mathrm{C}(22 \mathrm{~B})-\mathrm{C}(8 \mathrm{~B})$ & $125.7(10)$ & $\mathrm{H}(34 \mathrm{D})-\mathrm{C}(34 \mathrm{~B})-\mathrm{H}(34 \mathrm{E})$ & 109.5 \\
\hline $\mathrm{C}(23 \mathrm{~B})-\mathrm{C}(22 \mathrm{~B})-\mathrm{S}(2 \mathrm{~B})$ & 109.6(8) & $\mathrm{C}(33 \mathrm{~B})-\mathrm{C}(34 \mathrm{~B})-\mathrm{H}(34 \mathrm{~F})$ & 109.5 \\
\hline $\mathrm{C}(8 \mathrm{~B})-\mathrm{C}(22 \mathrm{~B})-\mathrm{S}(2 \mathrm{~B})$ & $124.5(7)$ & $\mathrm{H}(34 \mathrm{D})-\mathrm{C}(34 \mathrm{~B})-\mathrm{H}(34 \mathrm{~F})$ & 109.5 \\
\hline $\mathrm{C}(22 \mathrm{~B})-\mathrm{C}(23 \mathrm{~B})-\mathrm{C}(24 \mathrm{~B})$ & $112.7(11)$ & $\mathrm{H}(34 \mathrm{E})-\mathrm{C}(34 \mathrm{~B})-\mathrm{H}(34 \mathrm{~F})$ & 109.5 \\
\hline $\mathrm{C}(22 \mathrm{~B})-\mathrm{C}(23 \mathrm{~B})-\mathrm{H}(23 \mathrm{~B})$ & 123.7 & $\mathrm{C}(21 \mathrm{~B})-\mathrm{C}(36 \mathrm{~B})-\mathrm{H}(36 \mathrm{D})$ & 109.5 \\
\hline $\mathrm{C}(24 \mathrm{~B})-\mathrm{C}(23 \mathrm{~B})-\mathrm{H}(23 \mathrm{~B})$ & 123.7 & $\mathrm{C}(21 \mathrm{~B})-\mathrm{C}(36 \mathrm{~B})-\mathrm{H}(36 \mathrm{E})$ & 109.4 \\
\hline $\mathrm{C}(25 \mathrm{~B})-\mathrm{C}(24 \mathrm{~B})-\mathrm{C}(23 \mathrm{~B})$ & $115.1(11)$ & $\mathrm{H}(36 \mathrm{D})-\mathrm{C}(36 \mathrm{~B})-\mathrm{H}(36 \mathrm{E})$ & 109.5 \\
\hline $\mathrm{C}(25 \mathrm{~B})-\mathrm{C}(24 \mathrm{~B})-\mathrm{H}(24 \mathrm{~B})$ & 122.5 & $\mathrm{C}(21 \mathrm{~B})-\mathrm{C}(36 \mathrm{~B})-\mathrm{H}(36 \mathrm{~F})$ & 109.5 \\
\hline $\mathrm{C}(23 \mathrm{~B})-\mathrm{C}(24 \mathrm{~B})-\mathrm{H}(24 \mathrm{~B})$ & 122.5 & $\mathrm{H}(36 \mathrm{D})-\mathrm{C}(36 \mathrm{~B})-\mathrm{H}(36 \mathrm{~F})$ & 109.5 \\
\hline $\mathrm{C}(24 \mathrm{~B})-\mathrm{C}(25 \mathrm{~B})-\mathrm{C}(37 \mathrm{~B})$ & $130.3(11)$ & $\mathrm{H}(36 \mathrm{E})-\mathrm{C}(36 \mathrm{~B})-\mathrm{H}(36 \mathrm{~F})$ & 109.5 \\
\hline$C(24 B)-C(25 B)-S(2 B)$ & 109.4(9) & $\mathrm{C}(25 \mathrm{~B})-\mathrm{C}(37 \mathrm{~B})-\mathrm{H}(37 \mathrm{D})$ & 109.5 \\
\hline $\mathrm{C}(37 \mathrm{~B})-\mathrm{C}(25 \mathrm{~B})-\mathrm{S}(2 \mathrm{~B})$ & $120.2(8)$ & $\mathrm{C}(25 \mathrm{~B})-\mathrm{C}(37 \mathrm{~B})-\mathrm{H}(37 \mathrm{E})$ & 109.5 \\
\hline$C(14 B)-C(26 B)-C(27 B)$ & $118(3)$ & $\mathrm{H}(37 \mathrm{D})-\mathrm{C}(37 \mathrm{~B})-\mathrm{H}(37 \mathrm{E})$ & 109.5 \\
\hline$C(14 B)-C(26 B)-S(6 B)$ & $131.9(16)$ & $\mathrm{C}(25 \mathrm{~B})-\mathrm{C}(37 \mathrm{~B})-\mathrm{H}(37 \mathrm{~F})$ & 109.5 \\
\hline$C(27 B)-C(26 B)-S(6 B)$ & $110(4)$ & $\mathrm{H}(37 \mathrm{D})-\mathrm{C}(37 \mathrm{~B})-\mathrm{H}(37 \mathrm{~F})$ & 109.5 \\
\hline$C(14 B)-C(26 B)-S(6 X)$ & $125.3(10)$ & $\mathrm{H}(37 \mathrm{E})-\mathrm{C}(37 \mathrm{~B})-\mathrm{H}(37 \mathrm{~F})$ & 109.5 \\
\hline$C(27 B)-C(26 B)-S(6 X)$ & $9(4)$ & $\mathrm{C}(2 \mathrm{~B})-\mathrm{O}(1 \mathrm{~B})-\mathrm{C}(1 \mathrm{~B})$ & $105.0(12)$ \\
\hline$S(6 B)-C(26 B)-S(6 X)$ & $102.6(15)$ & $\mathrm{C}(3 \mathrm{~B})-\mathrm{O}(2 \mathrm{~B})-\mathrm{C}(1 \mathrm{~B})$ & $108.3(10)$ \\
\hline $\mathrm{C}(14 \mathrm{~B})-\mathrm{C}(26 \mathrm{~B})-\mathrm{C}(27 \mathrm{X})$ & $132(4)$ & $\mathrm{C}(8 \mathrm{~B})-\mathrm{S}(1 \mathrm{~B})-\mathrm{C}(7 \mathrm{~B})$ & $93.2(5)$ \\
\hline $\mathrm{C}(27 \mathrm{~B})-\mathrm{C}(26 \mathrm{~B})-\mathrm{C}(27 \mathrm{X})$ & $110(5)$ & $C(22 B)-S(2 B)-C(25 B)$ & $93.2(5)$ \\
\hline$S(6 B)-C(26 B)-C(27 X)$ & $5(5)$ & $\mathrm{C}(21 \mathrm{~B})-\mathrm{S}(3 \mathrm{~B})-\mathrm{C}(18 \mathrm{~B})$ & $93.1(7)$ \\
\hline$S(6 X)-C(26 B)-C(27 X)$ & 102(4) & $C(30 B)-S(4 B)-C(33 B)$ & $92.0(6)$ \\
\hline $\mathrm{C}(31 \mathrm{~B})-\mathrm{C}(30 \mathrm{~B})-\mathrm{C}(15 \mathrm{~B})$ & $130.5(9)$ & $C(14 B)-S(5 B)-C(15 B)$ & $91.7(5)$ \\
\hline$C(31 B)-C(30 B)-S(4 B)$ & $108.3(8)$ & $C(26 B)-S(6 B)-C(29 B)$ & $98(2)$ \\
\hline$C(15 B)-C(30 B)-S(4 B)$ & $121.1(8)$ & $\mathrm{C}(28 \mathrm{~B})-\mathrm{C}(27 \mathrm{~B})-\mathrm{C}(26 \mathrm{~B})$ & $112(6)$ \\
\hline $\mathrm{C}(32 \mathrm{~B})-\mathrm{C}(31 \mathrm{~B})-\mathrm{C}(30 \mathrm{~B})$ & 113.6(10) & $\mathrm{C}(28 \mathrm{~B})-\mathrm{C}(27 \mathrm{~B})-\mathrm{H}(27 \mathrm{~B})$ & 123.9 \\
\hline $\mathrm{C}(32 \mathrm{~B})-\mathrm{C}(31 \mathrm{~B})-\mathrm{H}(31 \mathrm{~B})$ & 123.2 & $\mathrm{C}(26 \mathrm{~B})-\mathrm{C}(27 \mathrm{~B})-\mathrm{H}(27 \mathrm{~B})$ & 123.9 \\
\hline $\mathrm{C}(30 \mathrm{~B})-\mathrm{C}(31 \mathrm{~B})-\mathrm{H}(31 \mathrm{~B})$ & 123.2 & $\mathrm{C}(29 \mathrm{~B})-\mathrm{C}(28 \mathrm{~B})-\mathrm{C}(27 \mathrm{~B})$ & $115(4)$ \\
\hline $\mathrm{C}(33 \mathrm{~B})-\mathrm{C}(32 \mathrm{~B})-\mathrm{C}(31 \mathrm{~B})$ & $114.9(14)$ & $\mathrm{C}(29 \mathrm{~B})-\mathrm{C}(28 \mathrm{~B})-\mathrm{H}(28 \mathrm{~B})$ & 122.7 \\
\hline
\end{tabular}




$$
\begin{array}{ll}
\mathrm{C}(27 \mathrm{~B})-\mathrm{C}(28 \mathrm{~B})-\mathrm{H}(28 \mathrm{~B}) & 122.7 \\
\mathrm{C}(28 \mathrm{~B})-\mathrm{C}(29 \mathrm{~B})-\mathrm{C}(35 \mathrm{~B}) & 133(3) \\
\mathrm{C}(28 \mathrm{~B})-\mathrm{C}(29 \mathrm{~B})-\mathrm{S}(6 \mathrm{~B}) & 105(2) \\
\mathrm{C}(35 \mathrm{~B})-\mathrm{C}(29 \mathrm{~B})-\mathrm{S}(6 \mathrm{~B}) & 122(2) \\
\mathrm{C}(29 \mathrm{~B})-\mathrm{C}(35 \mathrm{~B})-\mathrm{H}(35 \mathrm{D}) & 109.3 \\
\mathrm{C}(29 \mathrm{~B})-\mathrm{C}(35 \mathrm{~B})-\mathrm{H}(35 \mathrm{E}) & 109.6 \\
\mathrm{H}(35 \mathrm{D})-\mathrm{C}(35 \mathrm{~B})-\mathrm{H}(35 \mathrm{E}) & 109.5 \\
\mathrm{C}(29 \mathrm{~B})-\mathrm{C}(35 \mathrm{~B})-\mathrm{H}(35 \mathrm{~F}) & 109.5 \\
\mathrm{H}(35 \mathrm{D})-\mathrm{C}(35 \mathrm{~B})-\mathrm{H}(35 \mathrm{~F}) & 109.5 \\
\mathrm{H}(35 \mathrm{E})-\mathrm{C}(35 \mathrm{~B})-\mathrm{H}(35 \mathrm{~F}) & 109.5 \\
\mathrm{C}(26 \mathrm{~B})-\mathrm{S}(6 \mathrm{X})-\mathrm{C}(29 X) & 95.7(13) \\
\mathrm{C}(28 \mathrm{X})-\mathrm{C}(27 \mathrm{X})-\mathrm{C}(26 \mathrm{~B}) & 116(8) \\
\mathrm{C}(28 \mathrm{X})-\mathrm{C}(27 \mathrm{X})-\mathrm{H}(27 \mathrm{X}) & 121.8 \\
\mathrm{C}(26 \mathrm{~B})-\mathrm{C}(27 \mathrm{X})-\mathrm{H}(27 \mathrm{X}) & 121.8 \\
\mathrm{C}(27 \mathrm{X})-\mathrm{C}(28 \mathrm{X})-\mathrm{C}(29 \mathrm{X}) & 112(6) \\
\mathrm{C}(27 \mathrm{X})-\mathrm{C}(28 \mathrm{X})-\mathrm{H}(28 \mathrm{X}) & 124.0 \\
\mathrm{C}(29 \mathrm{X})-\mathrm{C}(28 \mathrm{X})-\mathrm{H}(28 \mathrm{X}) & 124.0 \\
\mathrm{C}(28 \mathrm{X})-\mathrm{C}(29 \mathrm{X})-\mathrm{C}(35 \mathrm{X}) & 120(3) \\
\mathrm{C}(28 \mathrm{X})-\mathrm{C}(29 \mathrm{X})-\mathrm{S}(6 \mathrm{X}) & 113(2) \\
\mathrm{C}(35 \mathrm{X})-\mathrm{C}(29 \mathrm{X})-\mathrm{S}(6 \mathrm{X}) & 127(3) \\
\mathrm{C}(29 \mathrm{X})-\mathrm{C}(35 \mathrm{X})-\mathrm{H}(35 \mathrm{D}) & 99.0 \\
\mathrm{C}(29 \mathrm{X})-\mathrm{C}(35 \mathrm{X})-\mathrm{H}(35 \mathrm{G}) & 109.6 \\
\mathrm{H}(35 \mathrm{D})-\mathrm{C}(35 \mathrm{X})-\mathrm{H}(35 \mathrm{G}) & 67.8 \\
\mathrm{C}(29 \mathrm{X})-\mathrm{C}(35 \mathrm{X})-\mathrm{H}(35 \mathrm{H}) & 109.3 \\
\mathrm{H}(35 \mathrm{D})-\mathrm{C}(35 \mathrm{X})-\mathrm{H}(35 \mathrm{H}) & 150.3 \\
\mathrm{H}(35 \mathrm{G})-\mathrm{C}(35 \mathrm{X})-\mathrm{H}(35 \mathrm{H}) & 109.5 \\
\mathrm{C}(29 \mathrm{X})-\mathrm{C}(35 \mathrm{X})-\mathrm{H}(35 \mathrm{I}) & 109.5 \\
\mathrm{H}(35 \mathrm{D})-\mathrm{C}(35 \mathrm{X})-\mathrm{H}(35 \mathrm{I}) & 50.0 \\
\mathrm{H}(35 \mathrm{G})-\mathrm{C}(35 \mathrm{X})-\mathrm{H}(35 \mathrm{I}) & 109.5 \\
\mathrm{H}(35 \mathrm{H})-\mathrm{C}(35 \mathrm{X})-\mathrm{H}(35 \mathrm{I}) & 109.5 \\
&
\end{array}
$$

Symmetry transformations used to generate equivalent atoms: 
Table A.21. Anisotropic displacement parameters $\left(\AA^{2} \times 10^{3}\right)$ for $s t-\left[\mathbf{M e}-\mathbf{T h}_{\mathbf{3}}-\mathbf{M e}\right]_{2}$. The anisotropic displacement factor exponent takes the form: $-2 \pi^{2}\left[h^{2}\right.$ $\left.\mathrm{a}^{* 2} \mathrm{U}^{11}+\ldots+2 \mathrm{~h} \mathrm{k} \mathrm{a}^{*} \mathrm{~b}^{*} \mathrm{U}^{12}\right]$

\begin{tabular}{lcccccc}
\hline & $\mathrm{U}^{11}$ & $\mathrm{U}^{22}$ & $\mathrm{U}^{33}$ & $\mathrm{U}^{23}$ & $\mathrm{U}^{13}$ & $\mathrm{U} 12$ \\
\hline $\mathrm{O}(1)$ & $32(5)$ & $25(4)$ & $28(4)$ & $16(3)$ & $10(3)$ & $11(3)$ \\
$\mathrm{O}(2)$ & $31(5)$ & $24(4)$ & $28(4)$ & $12(3)$ & $7(3)$ & $13(3)$ \\
$\mathrm{S}(1)$ & $28(2)$ & $54(2)$ & $30(2)$ & $22(1)$ & $-2(1)$ & $-2(1)$ \\
$\mathrm{S}(2)$ & $19(2)$ & $25(1)$ & $30(2)$ & $16(1)$ & $-1(1)$ & $2(1)$ \\
$\mathrm{S}(3)$ & $29(2)$ & $23(1)$ & $42(2)$ & $13(1)$ & $5(1)$ & $3(1)$ \\
$\mathrm{S}(4)$ & $40(2)$ & $52(2)$ & $25(2)$ & $2(1)$ & $5(1)$ & $-6(2)$ \\
$\mathrm{S}(5)$ & $30(2)$ & $31(2)$ & $24(2)$ & $13(1)$ & $3(1)$ & $-2(1)$ \\
$\mathrm{S}(6)$ & $27(2)$ & $33(2)$ & $50(2)$ & $20(1)$ & $5(1)$ & $-3(1)$ \\
$\mathrm{O}(1 \mathrm{~B})$ & $80(7)$ & $41(5)$ & $23(4)$ & $1(4)$ & $-1(4)$ & $19(5)$ \\
$\mathrm{O}(2 \mathrm{~B})$ & $101(8)$ & $20(4)$ & $26(4)$ & $-1(3)$ & $-5(4)$ & $16(4)$ \\
$\mathrm{S}(1 \mathrm{~B})$ & $22(2)$ & $40(2)$ & $48(2)$ & $23(1)$ & $8(1)$ & $6(1)$ \\
$\mathrm{S}(2 \mathrm{~B})$ & $32(2)$ & $34(2)$ & $32(2)$ & $10(1)$ & $2(1)$ & $11(1)$ \\
$\mathrm{S}(3 \mathrm{~B})$ & $33(2)$ & $51(2)$ & $81(2)$ & $38(2)$ & $-15(2)$ & $1(2)$ \\
$\mathrm{S}(4 \mathrm{~B})$ & $38(2)$ & $44(2)$ & $70(2)$ & $11(2)$ & $4(2)$ & $8(2)$ \\
$\mathrm{S}(5 \mathrm{~B})$ & $29(2)$ & $21(1)$ & $44(2)$ & $5(1)$ & $-7(1)$ & $3(1)$ \\
$\mathrm{S}(6 \mathrm{~B})$ & $29(4)$ & $30(8)$ & $58(4)$ & $9(5)$ & $7(3)$ & $9(5)$ \\
$\mathrm{S}(6 \mathrm{X})$ & $31(4)$ & $27(3)$ & $22(4)$ & $2(2)$ & $-3(3)$ & $5(3)$ \\
& & & & & & \\
\hline
\end{tabular}


Table A.22. Hydrogen coordinates ( $\times 10^{4}$ ) and isotropic displacement parameters $\left(\AA^{2} \mathrm{x} 10^{3}\right)$ for $s t-\left[\mathrm{Me}-\mathrm{Th}_{3}-\mathrm{Me}\right]_{2}$.

\begin{tabular}{|c|c|c|c|c|}
\hline & $\mathrm{x}$ & $\mathrm{y}$ & $\mathrm{z}$ & $\mathrm{U}(\mathrm{eq})$ \\
\hline $\mathrm{H}(2 \mathrm{~A})$ & 3848 & 7981 & 723 & 78 \\
\hline $\mathrm{H}(2 \mathrm{~B})$ & 2917 & 7325 & 189 & 78 \\
\hline $\mathrm{H}(3 \mathrm{~A})$ & 4019 & 6661 & -617 & 61 \\
\hline $\mathrm{H}(3 \mathrm{~B})$ & 4921 & 7122 & 72 & 61 \\
\hline $\mathrm{H}(4)$ & 2566 & 5399 & 752 & 24 \\
\hline $\mathrm{H}(5 \mathrm{~A})$ & 2955 & 4043 & 782 & 27 \\
\hline $\mathrm{H}(5 \mathrm{~B})$ & 3851 & 4487 & 357 & 27 \\
\hline $\mathrm{H}(10 \mathrm{~A})$ & 5704 & 5623 & 1032 & 28 \\
\hline $\mathrm{H}(10 \mathrm{~B})$ & 6096 & 6055 & 1985 & 28 \\
\hline $\mathrm{H}(11)$ & 5151 & 7004 & 1551 & 25 \\
\hline $\mathrm{H}(12 \mathrm{~A})$ & 5112 & 7277 & 2935 & 29 \\
\hline $\mathrm{H}(12 \mathrm{~B})$ & 4000 & 7329 & 2623 & 29 \\
\hline $\mathrm{H}(17 \mathrm{~A})$ & 2332 & 6196 & 2136 & 29 \\
\hline $\mathrm{H}(17 \mathrm{~B})$ & 2033 & 5140 & 1973 & 29 \\
\hline $\mathrm{H}(19)$ & 7611 & 5377 & 1898 & 35 \\
\hline $\mathrm{H}(20)$ & 9019 & 5744 & 2925 & 38 \\
\hline $\mathrm{H}(23)$ & 2017 & 3209 & 1681 & 38 \\
\hline $\mathrm{H}(24)$ & 1218 & 1619 & 1295 & 39 \\
\hline $\mathrm{H}(27)$ & 6543 & 6883 & 3696 & 40 \\
\hline $\mathrm{H}(28)$ & 7477 & 7936 & 4961 & 50 \\
\hline $\mathrm{H}(31)$ & 2822 & 3464 & 3744 & 47 \\
\hline $\mathrm{H}(32)$ & 1172 & 2536 & 3603 & 47 \\
\hline $\mathrm{H}(34 \mathrm{~A})$ & -612 & 2424 & 2786 & 95 \\
\hline $\mathrm{H}(34 \mathrm{~B})$ & -848 & 3346 & 2609 & 95 \\
\hline $\mathrm{H}(34 \mathrm{C})$ & -890 & 3237 & 3542 & 95 \\
\hline $\mathrm{H}(35 \mathrm{~A})$ & 7299 & 8652 & 6555 & 74 \\
\hline $\mathrm{H}(35 \mathrm{~B})$ & 6467 & 8094 & 6950 & 74 \\
\hline $\mathrm{H}(35 \mathrm{C})$ & 6197 & 8945 & 6656 & 74 \\
\hline $\mathrm{H}(36 \mathrm{~A})$ & 2684 & -40 & 1433 & 83 \\
\hline $\mathrm{H}(36 \mathrm{~B})$ & 2618 & -130 & 446 & 83 \\
\hline $\mathrm{H}(36 \mathrm{C})$ & 1635 & -25 & 972 & 83 \\
\hline
\end{tabular}




\begin{tabular}{|c|c|c|c|}
\hline $\mathrm{H}(37 \mathrm{~A})$ & 9514 & 5706 & 4445 \\
\hline $\mathrm{H}(37 \mathrm{~B})$ & 9092 & 4719 & 4497 \\
\hline $\mathrm{H}(37 \mathrm{C})$ & 8574 & 5576 & 4992 \\
\hline $\mathrm{H}(2 \mathrm{~B} 1)$ & 11372 & 6561 & -1181 \\
\hline $\mathrm{H}(2 \mathrm{~B} 2)$ & 10260 & 6800 & -1302 \\
\hline $\mathrm{H}(3 \mathrm{~B} 1)$ & 9908 & 5386 & -1221 \\
\hline $\mathrm{H}(3 \mathrm{~B} 2)$ & 10850 & 5476 & -575 \\
\hline $\mathrm{H}(4 \mathrm{~B})$ & 9012 & 7463 & -180 \\
\hline $\mathrm{H}(5 \mathrm{~B} 1)$ & 7725 & 7437 & 676 \\
\hline $\mathrm{H}(5 \mathrm{~B} 2)$ & 8247 & 6565 & 696 \\
\hline $\mathrm{H}(10 \mathrm{C})$ & 9572 & 6124 & 1482 \\
\hline $\mathrm{H}(10 \mathrm{D})$ & 10393 & 6544 & 2235 \\
\hline $\mathrm{H}(11 \mathrm{~B})$ & 11147 & 6593 & 1033 \\
\hline $\mathrm{H}(12 \mathrm{C})$ & 11757 & 7837 & 2036 \\
\hline $\mathrm{H}(12 \mathrm{D})$ & 11734 & 8073 & 1160 \\
\hline $\mathrm{H}(17 \mathrm{C})$ & 10061 & 8761 & 328 \\
\hline $\mathrm{H}(17 \mathrm{D})$ & 8975 & 8907 & 654 \\
\hline $\mathrm{H}(19 \mathrm{~B})$ & 6247 & 8721 & 3232 \\
\hline $\mathrm{H}(20 \mathrm{~B})$ & 5036 & 9513 & 2623 \\
\hline $\mathrm{H}(23 \mathrm{~B})$ & 9290 & 8402 & 4851 \\
\hline $\mathrm{H}(24 \mathrm{~B})$ & 10642 & 8181 & 5757 \\
\hline $\mathrm{H}(31 \mathrm{~B})$ & 9157 & 10627 & 759 \\
\hline $\mathrm{H}(32 \mathrm{~B})$ & 7794 & 11484 & 917 \\
\hline $\mathrm{H}(34 \mathrm{D})$ & 6941 & 12323 & 2826 \\
\hline $\mathrm{H}(34 \mathrm{E})$ & 6202 & 11400 & 2584 \\
\hline $\mathrm{H}(34 \mathrm{~F})$ & 6367 & 11977 & 1920 \\
\hline$H(36 D)$ & 5068 & 9291 & 421 \\
\hline $\mathrm{H}(36 \mathrm{E})$ & 5504 & 10270 & 1002 \\
\hline $\mathrm{H}(36 \mathrm{~F})$ & 4484 & 9772 & 1220 \\
\hline H(37D) & 12428 & 7617 & 5662 \\
\hline $\mathrm{H}(37 \mathrm{E})$ & 12813 & 7350 & 4728 \\
\hline $\mathrm{H}(37 \mathrm{~F})$ & 12186 & 6603 & 5076 \\
\hline $\mathrm{H}(27 \mathrm{~B})$ & 11152 & 9859 & 4480 \\
\hline $\mathrm{H}(28 \mathrm{~B})$ & 12605 & 9774 & 5370 \\
\hline $\mathrm{H}(35 \mathrm{D})$ & 14563 & 9349 & 5149 \\
\hline $\mathrm{H}(35 \mathrm{E})$ & 14844 & 9044 & 4186 \\
\hline
\end{tabular}




\begin{tabular}{lrrrr}
$\mathrm{H}(35 \mathrm{~F})$ & 14268 & 8327 & 4600 & 100 \\
$\mathrm{H}(27 \mathrm{X})$ & 13164 & 8555 & 2690 & 24 \\
$\mathrm{H}(28 \mathrm{X})$ & 14180 & 8907 & 3818 & 45 \\
$\mathrm{H}(35 \mathrm{G})$ & 13718 & 9116 & 5564 & 130 \\
$\mathrm{H}(35 \mathrm{H})$ & 13236 & 10044 & 5843 & 130 \\
$\mathrm{H}(35 \mathrm{I})$ & 14279 & 10010 & 5398 & 130 \\
\hline
\end{tabular}

\section{References}

1. SMART Version 5.628, 2003, Bruker AXS, Inc., Analytical X-ray Systems, 5465 East Cheryl Parkway, Madison WI 53711-5373.

2. SIANT Version 6.36A, 2002, Bruker AXS, Inc., Analytical X-ray Systems, 5465 East Cheryl Parkway, Madison WI 53711-5373.

3. SADABS Version 2.08, George Sheldrick, University of Göttingen, 1993.

4. SHELXTL Version 6.12, 2002, Bruker AXS, Inc., Analytical X-ray Systems, 5465 East Cheryl Parkway, Madison WI 53711-5373.

5. A.J.C. Wilson (ed), International Tables for X-ray Crystallography, Volume C. Kynoch, Academic Publishers, Dordrecht, 1992, Tables 6.1.1.1 (pp.500-502) and 4.2.6.8 (pp. 219-222). 


\section{VITA}

\section{Kurt M. Knoblock}

Kurt Knoblock was born in New Orleans, Louisiana. He attended public school in Baton Rouge, Louisiana, where he received a B.S. in Biochemistry from Louisiana State University. In 2001, he attended Georgia Institute of Technology pursuing a doctorate degree in organic chemistry. His research was concentrated on the synthesis and characterization of $\pi$-stacked oligothiophenes as models for excitons and $\pi$-dimers in conductive materials. He defended his thesis in November 2006. In his spare time, he enjoys spending time with his beautiful wife, Dawson, and his three dogs, Freddie, Fancy, and Missy. 